\title{
LOW VELOCITY IMPACT ASSESSMENT OF FLAX AND KEVLAR-FLAX FIBRE REINFORCED POLYMER LAMINATES USING EXPERIMENTAL AND NUMERICAL METHODS
}

\author{
by \\ Benedict Lawrence Sy \\ Bachelor of Engineering, Ryerson University (2012)

\begin{abstract}
A thesis
in partial fulfillment of the

requirements for the degree of

Master of Applied Science

in the program of

Aerospace Engineering
\end{abstract} \\ presented to Ryerson University
}

Toronto, Ontario, Canada, 2017

CC Benedict Lawrence Sy, 2017 


\section{AUTHOR'S DECLARATION FOR ELECTRONIC SUBMISSION OF A THESIS}

I hereby declare that I am the sole author of this thesis. This is the true copy of the thesis, including any required final versions, as accepted by my examiners.

I authorize Ryerson University to lend this thesis to other institutions or individuals for scholarly research.

I further authorize Ryerson University to reproduce this thesis by photocopying or by other means, in total or in part, at the request of other institutions or individuals for scholarly research.

I understand that my thesis may be made electronically available to the public. 


\title{
Low VELOCITy IMPACT ASSESSMENT OF FLAX AND KEVLAR-FLAX FibRE REINFORCED Polymer Laminates USing Experimental and Numerical Methods
}

\author{
Benedict Lawrence Sy \\ Master of Applied Science, Aerospace Engineering, Ryerson University, Toronto (2017)
}

\begin{abstract}
Flax/epoxy composite laminates were tested under low velocity impact loading, using passive Infra-Red thermography to monitor the damage evolution during the impact event. Two configurations were tested: unidirectional $\left(\left[0_{8 \mathrm{~F}}\right]_{\mathrm{S}}\right)$ and cross-ply $\left(\left[(0 / 90)_{4 \mathrm{~F}}\right]_{\mathrm{S}}\right)$. The unidirectional laminate exhibited poor and brittle impact response. Conversely, the cross-ply laminate showed better impact performance with its energy penetration threshold three times higher than the unidirectional. Its impact toughness was also 2.5 times higher. Additional tests were conducted to evaluate the effect of hybridization with Kevlar@49. Test results showed significant improvement on the impact performance of the unidirectional flax/epoxy laminate. Hybridization increased its energy penetration threshold three times and impact toughness five times. Conversely, it reduced the penetration threshold of the cross-ply flax/epoxy laminate by $10 \%$; however, it more than doubled the impact toughness. The impact toughness the Kevlar-Flax/epoxy laminates were slightly higher than those of aluminum and CFRP's, making them sustainable alternatives for impact applications.
\end{abstract}




\section{ACKNOWLEDGEMENTS}

Firstly, I would like to thank my thesis supervisors Dr. Zouheir Fawaz of the Department of Aerospace Engineering and Dr. Habiba Bougherara of the Department of Mechanical and Industrial Engineering at Ryerson University. Their guidance and support helped me advance my knowledge and understanding in the field of Advanced Composite Materials. Their constant feedbacks have been very valuable in steering my research work towards the right direction. I would also like to thank Dr. Fawaz for giving me the opportunity to take part and present my research work in the CANCOM 2017 conference in Ottawa. This opportunity enabled me to learn from the industry and the academia about the latest innovations on composite materials.

Besides my thesis supervisors, I would like to thank the members of the review committee: Dr. Bo Tan, Dr. Cheung Poon and Dr. Joon Chung for reviewing my thesis and their valuable feedback.

My sincere thanks to Dr. Hamid Ghaemi for his input in the design of my impact apparatus, and Dr. David Naylor of the Department of Mechanical Engineering for the use of his high-speed camera, which was a vital tool for the experiments.

I thank my fellow graduate students Ahmed Sarwar, Zainab Al-Hajaj, Saeed Manteghi and Zia Mahboob for helping me with the manufacture and testing of the composite plates as well as the assistance they provided whenever needed. I likewise thank Karim Masri, Anton Ibrahim, Herman Woo and Parthkumar Patel for their contribution during the manufacturing and testing phases of my research work.

I would like to acknowledge Mr. Anthony Rossi and Kavya Roy for their support in the numerical analysis part of my research. Anthony's expertise, constant guidance and feedback was instrumental to the success of my impact modelling of composites using LS Dyna. In addition, I would like to thank Mr. Chris Galbraith from metal Forming Analysis Corp. for providing us with the additional licence to use LS-Dyna free of charge. 
Likewise, I would like to acknowledge Huntsman Corporation (Huntsman Advanced Materials, The Woodlands, TX) for their complimentary supply of epoxy resin and hardener and for shipping it free of charge as needed.

I would also like to thank UTC Aerospace Systems for their Employee Scholarship program and my work supervisors Nicholas Chronopoulos, Brian Lau and Bhuwan Jain for the flexibility to effectively balance my work and studies. I would also like to thank the Chief Engineering group (Paul Vanderpol and Brad Baird) for allowing me time off work to attend the CANCOM 2017 conference in Ottawa.

Finally, I would like to thank my family for their understanding, support and encouragement throughout this journey. A special thanks to my brother Michael Sy for his patience and significant contribution in the design and experimental aspects of my research work. 


\section{TABle of Contents}

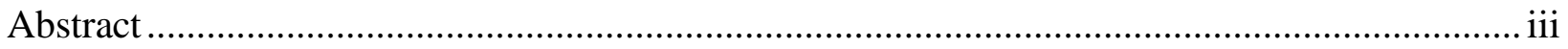

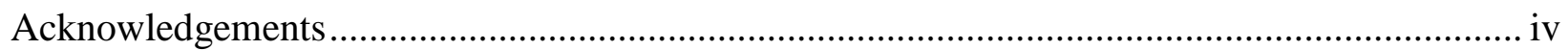

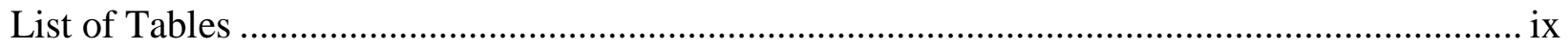

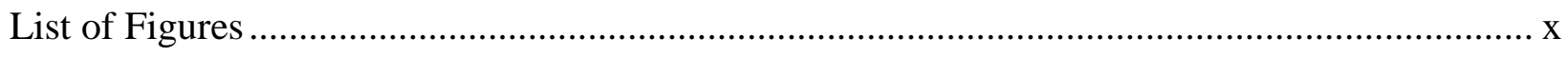

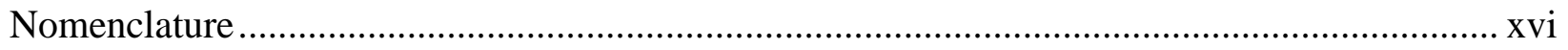

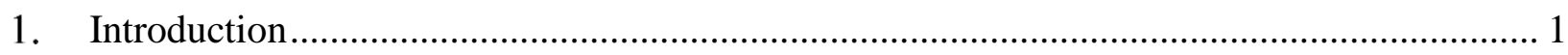

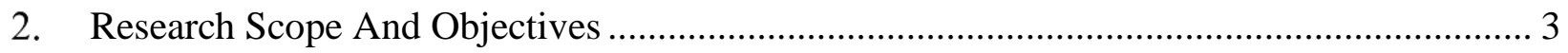

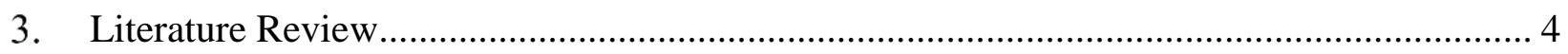

3.1. Overview of Composite Materials …………………............................................... 4

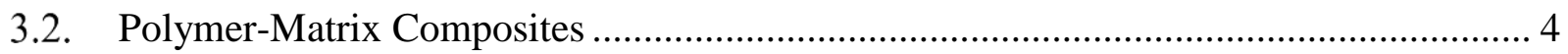

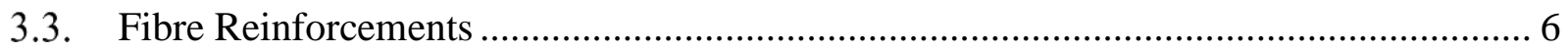

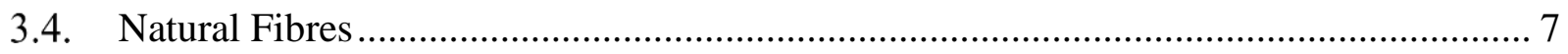

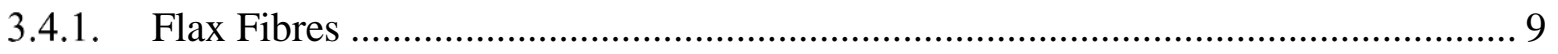

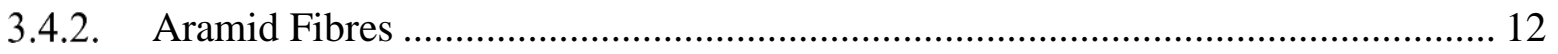

3.5. Laminating Resin System: Polymer Matrix ……………………………................. 13

3.6. Impact Optimized Composites ................................................................................ 15

3.7. Theory of Composite Impact and Failure modes ........................................................ 20

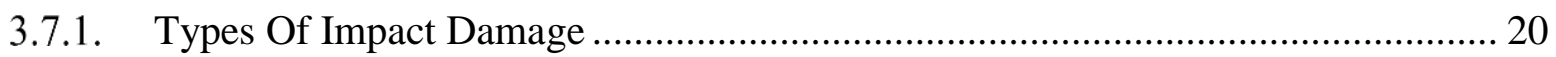

3.8. Impact Testing of Composite Laminates …………...................................................... 23

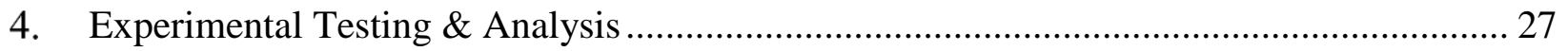

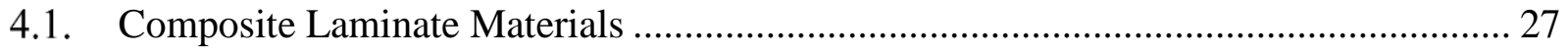

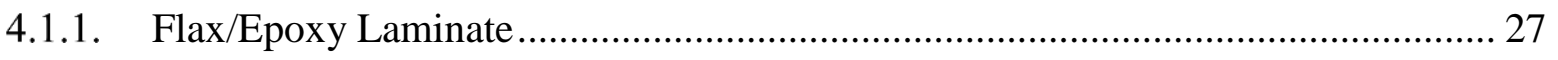

4.1.2. Aramid-Flax/Epoxy Hybrid Laminate .................................................................... 29 


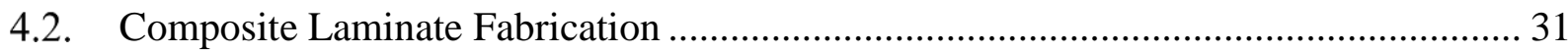

4.3. Mechanical Properties Characterization.......................................................................... 38

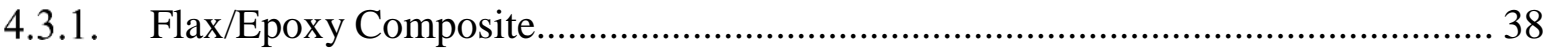

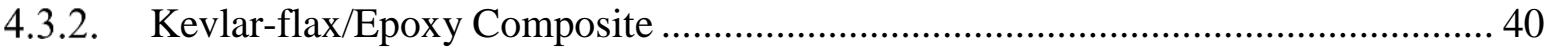

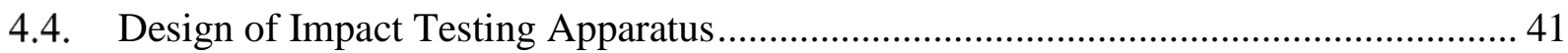

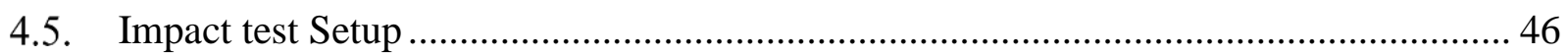

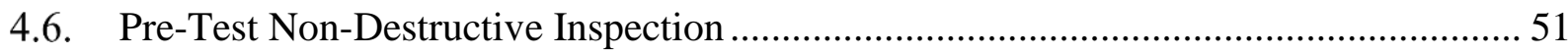

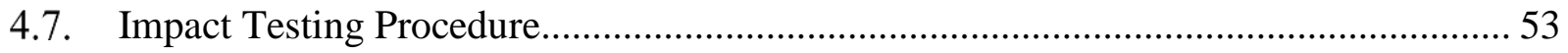

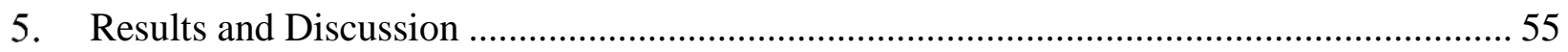

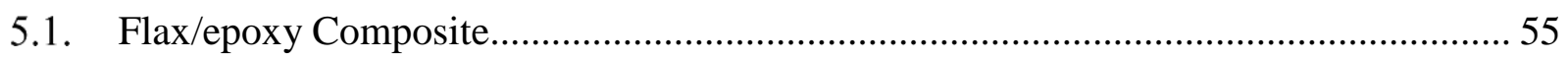

5.1.1. General Impact Response …………….......................................................... 55

5.1.2. Post-Impact Damage Characterization ................................................................... 59

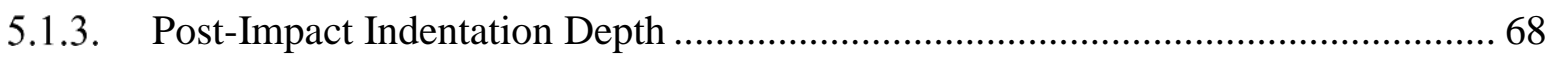

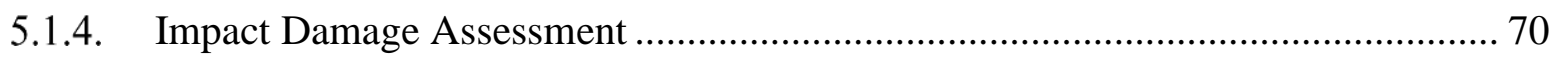

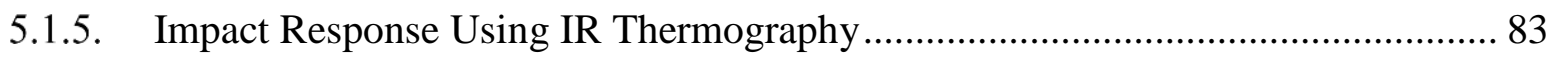

5.1.6. Impact Damage Characterization Using IR Thermography ................................... 96

5.1.7. Summary of Low Velocity Impact Response ………………………………........ 98

5.2. Effect of Hybridization with Kevlar 49...................................................................... 100

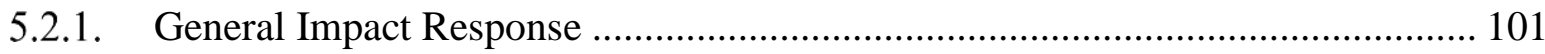

5.2.2. Post-Impact Damage Characterization .............................................................. 104

5.2.3. Impact Damage Assessment Using IR Thermography ....................................... 115

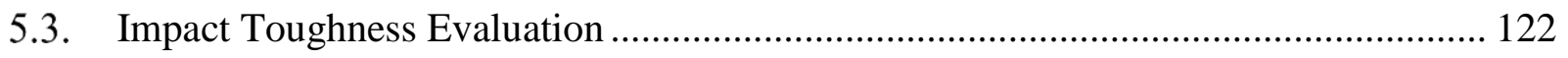

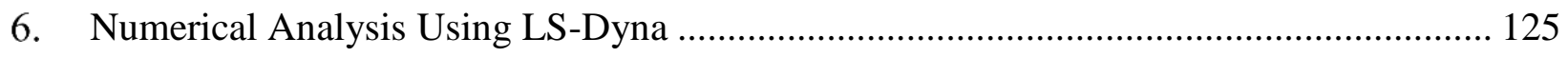

6.1. Composite FE Model ........................................................................................... 130

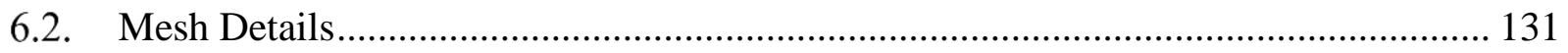




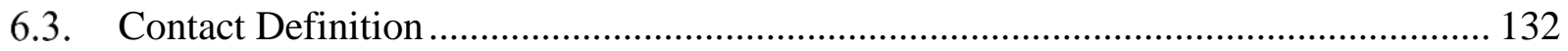

6.4. Material Definition ............................................................................................... 133

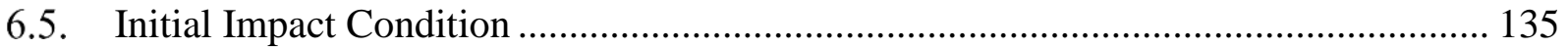

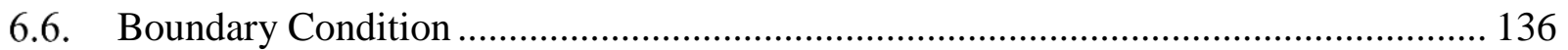

6.7. Time Step and Termination Time ……………………………………………….... 137

6.8. Mesh Convergence Study .................................................................................... 137

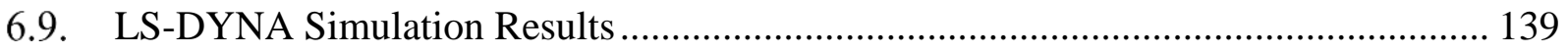

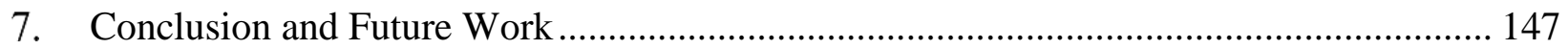

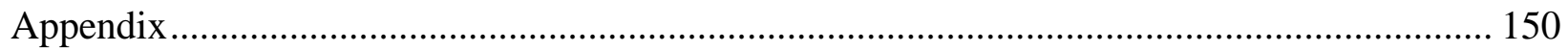

A1 Raw Experimental Data .............................................................................. 150

A2 LS-DYNA Input Files ……………………………........................................ 154

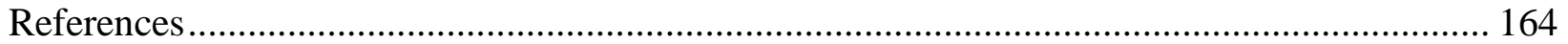




\section{LIST OF TABLES}

Table 1: Mechanical Properties of select synthetic and natural fibre composites [4] [17] [19] ..... 8

Table 2: Properties of some commercially available synthetic fibres [12] ................................... 13

Table 3: Basic Physical Properties of Lineo FlaxPly UD150 [53] ............................................... 27

Table 4: Physical and Mechanical Properties of the Resin System per supplier [54] .................. 28

Table 5: Physical and Mechanical Properties of the Resin System from test [11] ....................... 28

Table 6: Basic Physical Properties of Kevlar 49 Woven Fabric [55] [56] ……………............... 29

Table 7: Basic Mechanical Properties of 17 x 17 Plain Weave Kevlar 49 [57] [55]..................... 30

Table 8: Basic Mechanical Properties of 13 x 13 Plain Weave Kevlar 49 .................................... 30

Table 9: Mechanical Properties of 16-layer Flax/Epoxy Composite in Tension [11] .................. 38

Table 10: Mechanical Properties of 16-layer Flax/Epoxy Composite in Compression [11] ....... 39

Table 11: Mechanical Properties of Kevlar-Flax/Epoxy Composite ............................................ 40

Table 12: Mechanical Properties of 16-layer Flax/Epoxy Composite in Compression [11] ....... 45

Table 13: Impact Toughness of Flax/Epoxy Composite......................................................... 122

Table 14: Impact Toughness of Kevlar-Flax/Epoxy Composite ……………………………... 123

Table 15: MAT54/55 Required Composite Mechanical Properties ............................................ 128

Table 16: MAT54/55 Damage Factors Input..................................................................... 128

Table 17: MAT55 Material properties for unidirectional Flax/Epoxy lamina [11] .................... 134

Table 18: MAT54/55 Damage Factors Input for Flax/Epoxy Lamina …………….................... 135

Table 19: Impact Velocity vs. Impact Energy for the Pendulum Impact Apparatus .................. 136

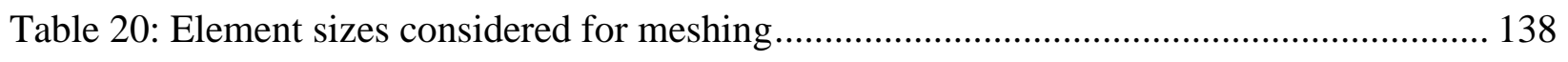

Table 21: Experimental vs. numerical results for absorbed energy for $\left[0_{8 \mathrm{~F}}\right] \mathrm{s}$............................ 144

Table 22: Experimental vs. numerical results for absorbed energy for $\left[(0 / 90)_{4 \mathrm{~F}}\right]_{\mathrm{s}}$.................... 145

Table 23: Experimental data and results for the $\left[0_{8 \mathrm{~F}}\right] \mathrm{s}$ composite ............................................ 150

Table 24: Experimental data and results for the $\left[(0 / 90)_{4 \mathrm{~F}}\right] \mathrm{s}$ composite ....................................... 151

Table 25: Experimental data and results for the $\left[0_{2 \mathrm{~K}} / 0_{6 \mathrm{~F}}\right]_{\mathrm{S}}$ composite..................................... 152

Table 26: Experimental data and results for the $\left[0_{2 K} /(0 / 90)_{3 \mathrm{~F}}\right] \mathrm{s}$ composite ................................ 153 


\section{LiST OF Figures}

Figure 1: Typical stress-strain curve for fibre, resin and PMC................................................ 5

Figure 2: Different Types and Sources of Natural Fibres [4] ................................................. 7

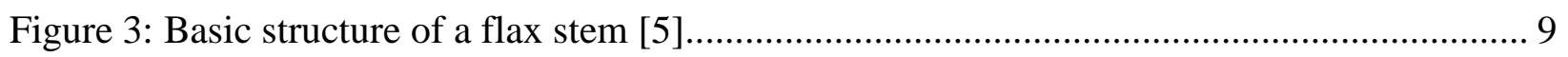

Figure 4: Stress-strain curve of different flax fibres in tension [5].................................... 10

Figure 5: Impact properties of various composite and metallic materials [30] ........................ 17

Figure 6: Impact properties of various composite and metallic materials [43] ........................ 18

Figure 7: Relative compression after impact strengths of CFRPs [41] .................................. 19

Figure 8: Charpy/Izod impact test setup [49] ................................................................. 23

Figure 9: Drop weight impact test setup for composite plates [49] [50] ................................. 24

Figure 10: (a) Drop weight impact test fixture per ASTM D7136 [51].................................. 25

Figure 11: (a) Load and energy vs. time [49]; (b) load-deflection curves [52] ......................... 26

Figure 12: Carver Auto Series Compression Moulding Machine at Ryerson University ........... 31

Figure 13: Moulding plate wrapped in HT plastic membrane ................................................ 32

Figure 14: Application of high temperature sealant tape to form the mould cavity .................. 33

Figure 15: Peel ply and flax fibre wet lay-up process ..................................................... 34

Figure 16: Peel ply application (left) before closing the mould with the top plate (right) ......... 34

Figure 17: HT membrane bagging (left); Compression moulding machine installation (right).. 34

Figure 18: Closing of the protective glass (left) and start of compression (right) .................... 35

Figure 19: Optical Microscopic images of the Kevlar-flax/epoxy laminate cross section .......... 35

Figure 20: 16-layer Flax/epoxy laminate fabrication assembly............................................. 36

Figure 21: Kevlar-flax/epoxy laminate fabrication assembly ............................................. 36

Figure 22: Curing temperature cycle for the flax and Kevlar-Flax/epoxy composite ................ 37

Figure 23: Curing pressure cycle for the flax and Kevlar-Flax/epoxy composite..................... 37

Figure 24: Modified Charpy pendulum impact testing apparatus .......................................... 41

Figure 25: Standard Charpy and Izod Impact Test Loading Mechanism ............................... 42

Figure 26: Drop Weight Impact Test vs. Modified Charpy Impact Test Loading Mechanism ... 43

Figure 27: Modified Charpy Pendulum Impact Test Schematics .......................................... 44

Figure 28. Low Velocity Pendulum Impact Test Setup...................................................... 46

Figure 29. Position of FLIR SC5000 IR Camera............................................................. 47 
Figure 30. MotionPro X3 High Speed Camera Setup................................................................ 48

Figure 31. Angle Measurement using Iconico Screen Protractor Software.................................. 48

Figure 32. Light gate setup for impact velocity measurement..................................................... 49

Figure 33. Theoretical vs. actual velocity of the impact test apparatus .......................................... 50

Figure 34. Defect-free vs. defective composite plate (with delamination damage) ...................... 51

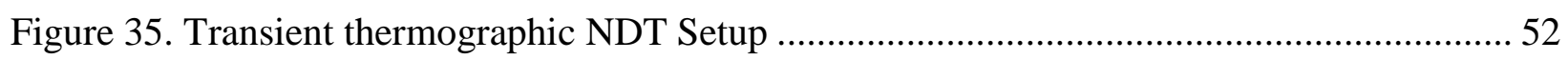

Figure 36. Heating up of the samples during the transient thermographic NDT.......................... 52

Figure 37. Absorbed energy versus impact energy for flax/epoxy composite ............................. 55

Figure 38. Absorbed energy versus impact energy for $\left[0_{8 \mathrm{~F}}\right]_{\mathrm{S}}$ flax/epoxy composite ..................... 56

Figure 39. Absorbed energy versus impact energy for [(0/90) $\left.)_{4}\right] \mathrm{s}$ flax/epoxy composite............. 56

Figure 40. Percent absorbed energy versus impact energy for $\left[0_{8 \mathrm{~F}}\right] \mathrm{s}$ laminate ………..................5 58

Figure 41. Percent absorbed energy versus impact energy for $\left[(0 / 90)_{4 \mathrm{~F}}\right]_{\mathrm{s}}$ laminate...................... 58

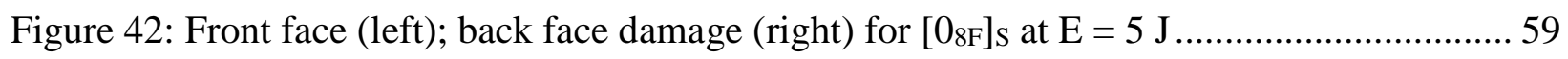

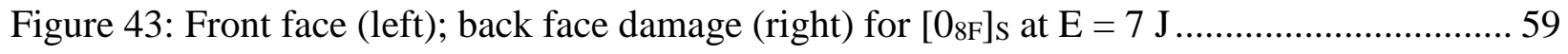

Figure 44: Front face (left); back face damage (right) for $\left[0_{8 \mathrm{~F}}\right] \mathrm{s}$ at $\mathrm{E}=8 \mathrm{~J} \ldots \ldots \ldots \ldots \ldots \ldots \ldots \ldots \ldots \ldots . . . . . . . . . . . . . . .60$

Figure 45: Front face (left); back face damage (right) for $\left[0_{8 \mathrm{~F}}\right]_{\mathrm{S}}$ at $\mathrm{E}=9 \mathrm{~J} \ldots \ldots \ldots \ldots \ldots \ldots \ldots \ldots \ldots \ldots . . . . . . . . . . . . . . . .60$

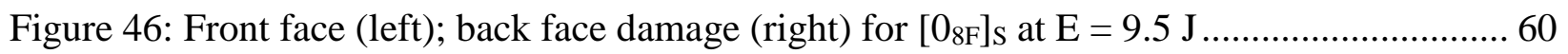

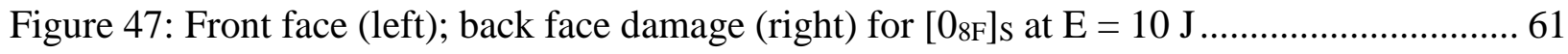

Figure 48: Typical front (left) and back (right) face damage to the $\left[0_{8 \mathrm{~F}}\right]_{\mathrm{s}}$ composite .................... 61

Figure 49. Longitudinal crack lengths versus impact energy for the $\left[0_{8 \mathrm{~F}}\right]_{\mathrm{s}}$ laminate..................... 62

Figure 50: Front face (left); back face damage (right) for $\left[(0 / 90)_{4 \mathrm{~F}}\right] \mathrm{s}$ at $\mathrm{E}=5 \mathrm{~J} \ldots \ldots \ldots \ldots \ldots \ldots \ldots \ldots \ldots . . . . . . . . . . .63$

Figure 51: Front face (left); back face damage (right) for $\left[(0 / 90)_{4 \mathrm{~F}}\right] \mathrm{s}$ at $\mathrm{E}=10 \mathrm{~J}$........................ 63

Figure 52: Front face (left); back face damage (right) for $\left[(0 / 90)_{4 \mathrm{~F}}\right] \mathrm{s}$ at $\mathrm{E}=15 \mathrm{~J}$........................ 64

Figure 53: Front face (left); back face damage (right) for $\left[(0 / 90)_{4 \mathrm{~F}}\right] \mathrm{s}$ at $\mathrm{E}=20 \mathrm{~J}$........................ 64

Figure 54: Front face (left); back face damage (right) for $\left[(0 / 90)_{4}\right] \mathrm{s}$ at $\mathrm{E}=25 \mathrm{~J}$.......................... 64

Figure 55: Front face (left); back face damage (right) for $\left[(0 / 90)_{4 \mathrm{~F}}\right]_{\mathrm{S}}$ at $\mathrm{E}=27 \mathrm{~J}$........................ 65

Figure 56: Front face (left); back face damage (right) for $\left[(0 / 90)_{4 \mathrm{~F}}\right]_{\mathrm{S}}$ at $\mathrm{E}=30 \mathrm{~J}$......................... 65

Figure 57: Typical front (left) and rear (left) face damage on a cross-ply flax/epoxy composite 66

Figure 58: Front face delamination zone area versus impact energy for $\left[(0 / 90)_{4 \mathrm{~F}}\right] \mathrm{s} \ldots \ldots \ldots \ldots \ldots \ldots \ldots . . . . . .67$

Figure 59: Longitudinal and transverse crack lengths versus impact energy for $\left[(0 / 90)_{4 \mathrm{~F}}\right]_{\mathrm{s}} \ldots \ldots . .67$

Figure 60: Indentation depth measurement using a digital height indicator................................. 68 
Figure 61: Front face indentation depth versus impact energy for the flax/epoxy composites ... 68

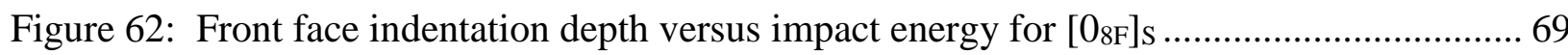

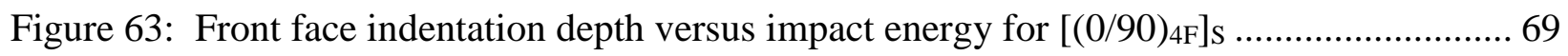

Figure 64: Section cuts on $\left[0_{8 \mathrm{~F}}\right]_{\mathrm{S}}(\mathrm{A}-\mathrm{A})$ and $\left[(0 / 90)_{4 \mathrm{~F}}\right]_{\mathrm{s}}(\mathrm{B}-\mathrm{B})$ flax/epoxy composites ................ 70

Figure 65: Schematic of typical cross section damage on unidirectional flax/epoxy ................... 71

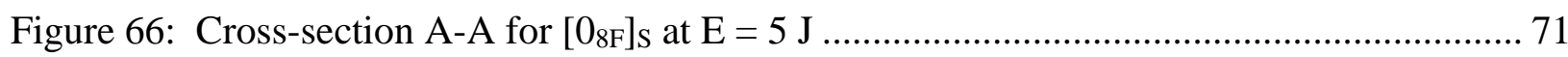

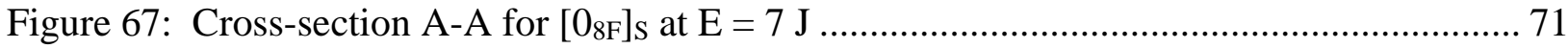

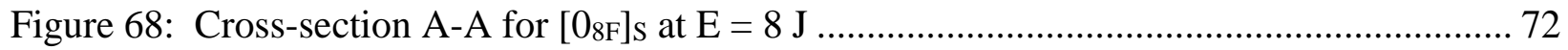

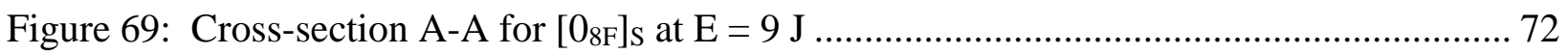

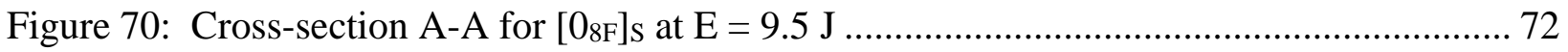

Figure 71: Matrix cracking at the primary (left) and secondary (right) crack origin .................. 73

Figure 72: Fibre damage (pull-out and breakage) along the primary crack path.......................... 73

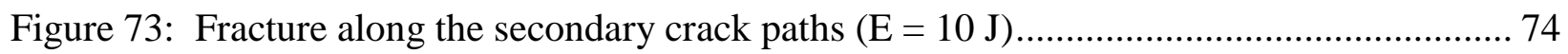

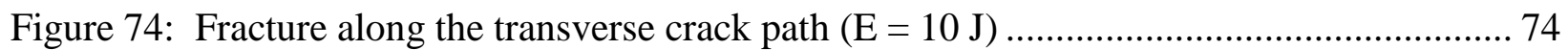

Figure 75: Schematic of typical cross section damage on cross-ply flax/epoxy .......................... 75

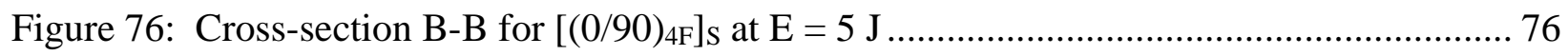

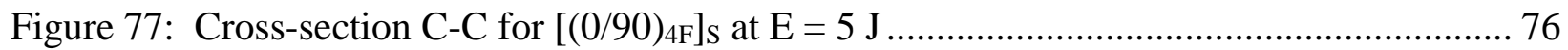

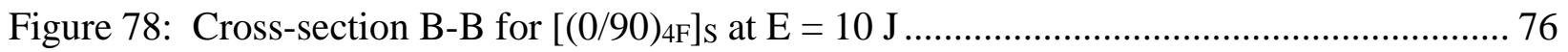

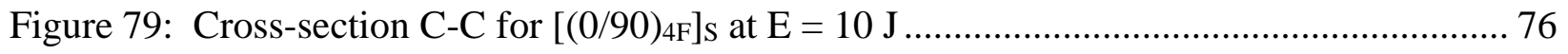

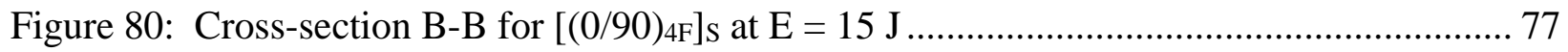

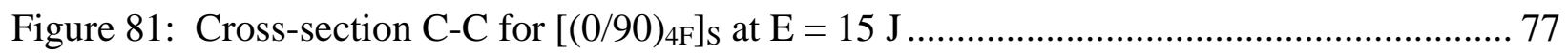

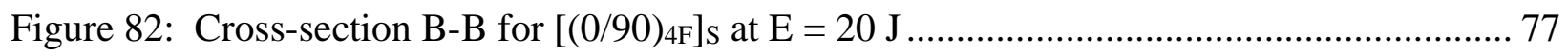

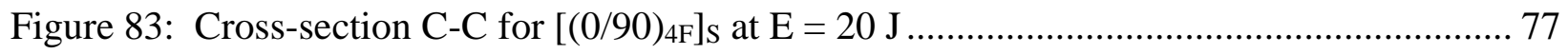

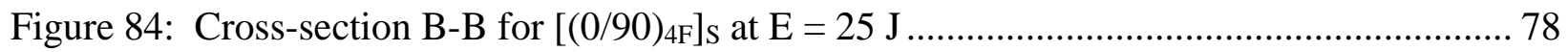

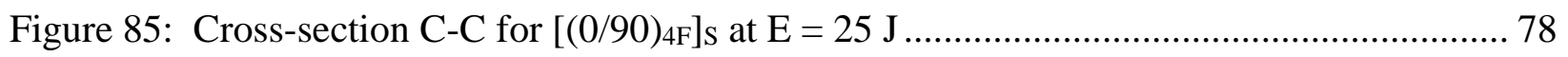

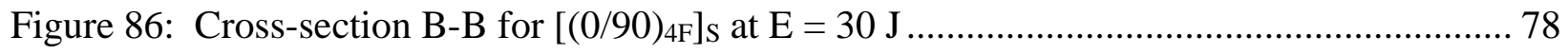

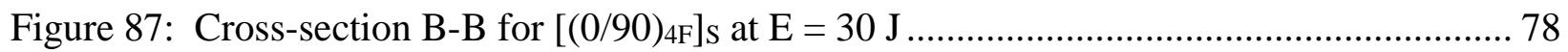

Figure 88: Microscopic images of the crack damage at $\mathrm{E}=5 \mathrm{~J}$ for $\left[(0 / 90)_{4 \mathrm{~F}}\right] \mathrm{s} \ldots \ldots \ldots \ldots \ldots \ldots \ldots \ldots \ldots . . . . . . . . . . . .79$

Figure 89: Microscopy of delamination zone near the crack tip of $\left[(0 / 90)_{4 \mathrm{~F}}\right] \mathrm{s}$ at $\mathrm{E}=15 \mathrm{~J} \ldots \ldots \ldots . . .80$

Figure 90: Microscopy of the middle delamination zone of $\left[(0 / 90)_{4 \mathrm{~F}}\right] \mathrm{s}$ at $\mathrm{E}=15 \mathrm{~J} \ldots \ldots \ldots \ldots \ldots \ldots \ldots . . . . . . . . .80$

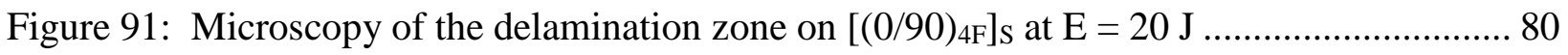


Figure 92: Matrix cracking at the delaminated layer of $\left[(0 / 90)_{4 \mathrm{~F}}\right]_{\mathrm{S}}$ at $\mathrm{E}=20 \mathrm{~J} \ldots \ldots \ldots \ldots \ldots \ldots \ldots . \ldots 1$

Figure 93: Fibre breakage and pull-out the crack path of the $\left[(0 / 90)_{4 \mathrm{~F}}\right]_{\mathrm{S}}$ at $\mathrm{E}=25 \mathrm{~J} \ldots \ldots \ldots \ldots \ldots . . . . .81$

Figure 94: Matrix crack at the back face (left) and through-the-thickness (right) at E = $25 \mathrm{~J} \ldots .82$

Figure 95: Microscopic image of the delamination interface of the $\left[(0 / 90)_{4 \mathrm{~F}}\right]_{\mathrm{S}}$ at $\mathrm{E}=25 \mathrm{~J} \ldots \ldots . .82$

Figure 96: Microscopic image of the delamination interface of the $\left[(0 / 90)_{4 \mathrm{~F}}\right]_{\mathrm{S}}$ at $\mathrm{E}=30 \mathrm{~J} \ldots \ldots . .82$

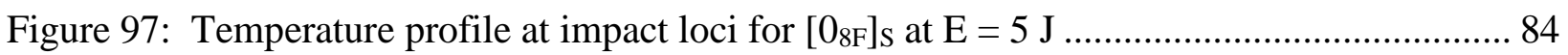

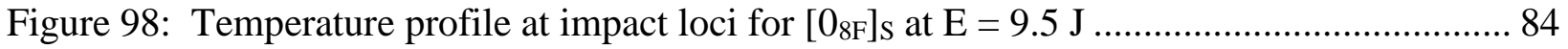

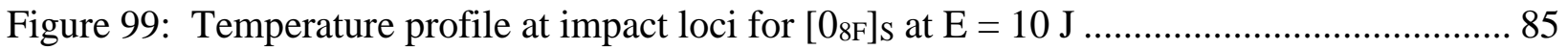

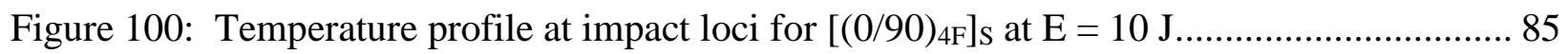

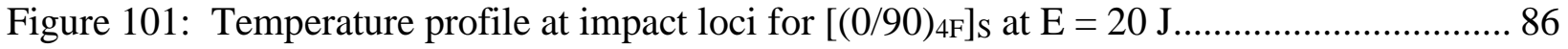

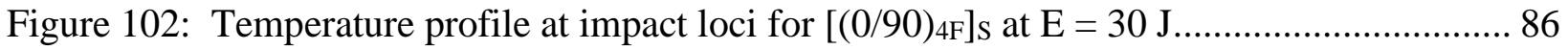

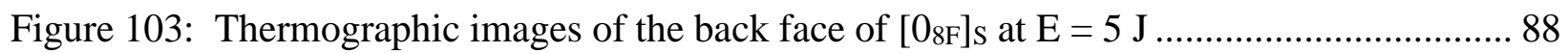

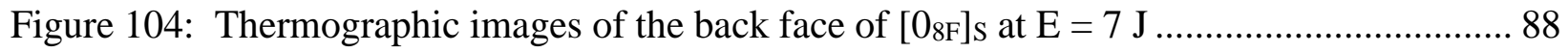

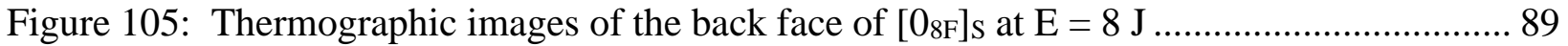

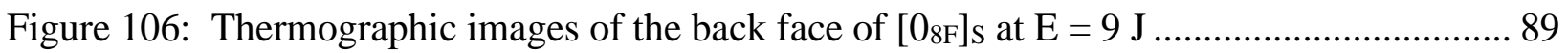

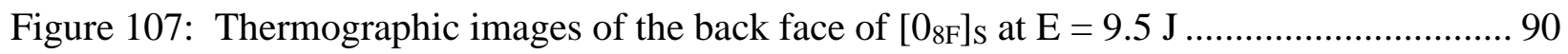

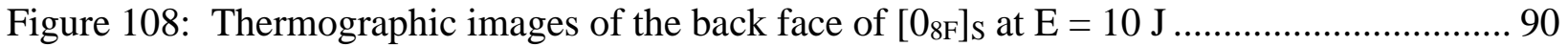

Figure 109: Thermographic images of the back face of $\left[(0 / 90)_{4 \mathrm{~F}}\right]_{\mathrm{S}}$ at $\mathrm{E}=5 \mathrm{~J} \ldots \ldots \ldots \ldots \ldots \ldots \ldots . . \ldots 1$

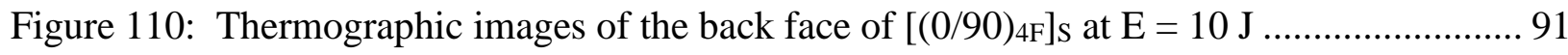

Figure 111: Thermographic images of the back face of $\left[(0 / 90)_{4 \mathrm{~F}}\right]_{\mathrm{S}}$ at $\mathrm{E}=15 \mathrm{~J} \ldots \ldots \ldots \ldots \ldots \ldots \ldots . . . . . . . . . .22$

Figure 112: Thermographic images of the back face of $\left[(0 / 90)_{4 \mathrm{~F}}\right]_{\mathrm{s}}$ at $\mathrm{E}=20 \mathrm{~J} \ldots \ldots \ldots \ldots \ldots \ldots \ldots . . . . . . . . . .92$

Figure 113: Thermographic images of the back face of $\left[(0 / 90)_{4 \mathrm{~F}}\right]_{\mathrm{S}}$ at $\mathrm{E}=25 \mathrm{~J} \ldots \ldots \ldots \ldots \ldots \ldots \ldots \ldots . . . . . . . . . . .33$

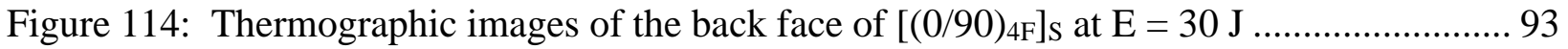

Figure 115: $\Delta \mathrm{T}$ versus impact energy for flax/epoxy composite .......................................... 94

Figure 116: Absorbed energy versus $\Delta \mathrm{T}$ for flax/epoxy composite …................................... 95

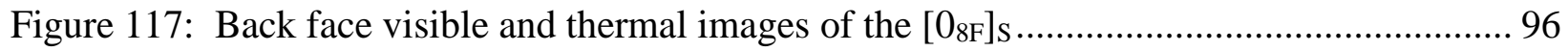

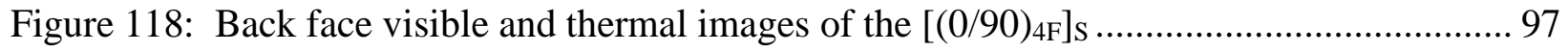

Figure 119: Absorbed energy versus impact energy for Kevlar-flax/Epoxy composite ........... 101

Figure 120: Absorbed vs. impact energy for flax/epoxy and Kevlar-flax/epoxy composite..... 102

Figure 121: Percent absorbed energy versus impact energy for Kevlar-flax/Epoxy composite 103 
Figure 122: Front face (left); back face damage (right) for $\left[0_{2 \mathrm{~K}} / 0_{6 \mathrm{~F}}\right]_{\mathrm{S}}$ at $\mathrm{E}=5 \mathrm{~J} \ldots \ldots \ldots \ldots \ldots \ldots \ldots . \ldots \ldots$

Figure 123: Front face (left); back face damage (right) for $\left[0_{2 \mathrm{~K}} / 0_{6 \mathrm{~F}}\right]_{\mathrm{S}}$ at $\mathrm{E}=10 \mathrm{~J} \ldots \ldots \ldots \ldots \ldots \ldots . . . . . . .104$

Figure 124: Front face (left); back face damage (right) for $\left[0_{2 \mathrm{~K}} / 0_{6 \mathrm{~F}}\right]_{\mathrm{S}}$ at $\mathrm{E}=15 \mathrm{~J} \ldots \ldots \ldots \ldots \ldots \ldots \ldots . . . . . .105$

Figure 125: Front face (left); back face damage (right) for $\left[0_{2 \mathrm{~K}} / 0_{6 \mathrm{~F}}\right]_{\mathrm{S}}$ at $\mathrm{E}=20 \mathrm{~J} \ldots \ldots \ldots \ldots \ldots \ldots \ldots . . . . . . .105$

Figure 126: Front face (left); back face damage (right) for $\left[0_{2 \mathrm{~K}} / 0_{6 \mathrm{~F}}\right]_{\mathrm{S}}$ at $\mathrm{E}=25 \mathrm{~J} \ldots \ldots \ldots \ldots \ldots \ldots \ldots . \ldots \ldots$

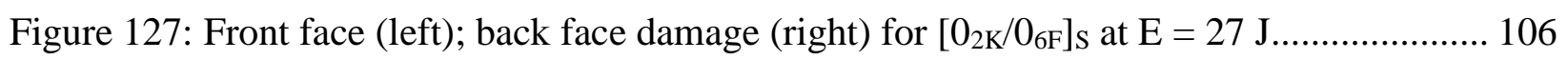

Figure 128: Front face (left); back face damage (right) for $\left[0_{2 \mathrm{~K}} / 0_{6 \mathrm{~F}}\right]_{\mathrm{S}}$ at $\mathrm{E}=30 \mathrm{~J} \ldots \ldots \ldots \ldots \ldots \ldots \ldots$

Figure 129: Front face (left); back face damage (right) for $\left[0_{2 \mathrm{~K}} /(0 / 90)_{3 \mathrm{~F}}\right]_{\mathrm{S}}$ at $\mathrm{E}=5 \mathrm{~J} \ldots \ldots \ldots \ldots \ldots . . . . .107$

Figure 130: Front face (left); back face damage (right) for $\left[0_{2 \mathrm{~K}} /(0 / 90)_{3 \mathrm{~F}}\right]_{\mathrm{S}}$ at $\mathrm{E}=10 \mathrm{~J} \ldots \ldots \ldots \ldots 108$

Figure 131: Front face (left); back face damage (right) for $\left[0_{2 \mathrm{~K}} /(0 / 90)_{3 \mathrm{~F}}\right]_{\mathrm{S}}$ at $\mathrm{E}=15 \mathrm{~J} \ldots \ldots \ldots \ldots . . .108$

Figure 132: Front face (left); back face damage (right) for $\left[0_{2 \mathrm{~K}} /(0 / 90)_{3 \mathrm{~F}}\right]_{\mathrm{S}}$ at $\mathrm{E}=20 \mathrm{~J} \ldots \ldots \ldots \ldots . . . .108$

Figure 133: Front face (left); back face damage (right) for $\left[0_{2 \mathrm{~K}} /(0 / 90)_{3 \mathrm{~F}}\right]_{\mathrm{S}}$ at $\mathrm{E}=25 \mathrm{~J} \ldots \ldots \ldots \ldots . . . .109$

Figure 134: Front face (left); back face damage (right) for $\left[0_{2 \mathrm{~K}} /(0 / 90)_{3 \mathrm{~F}}\right]_{\mathrm{S}}$ at $\mathrm{E}=27 \mathrm{~J} \ldots \ldots \ldots \ldots . . . .109$

Figure 135: Front face (left); back face damage (right) for $\left[0_{2 \mathrm{~K}} /(0 / 90)_{3 \mathrm{~F}}\right]_{\mathrm{S}}$ at $\mathrm{E}=30 \mathrm{~J} \ldots \ldots \ldots \ldots . . . .109$

Figure 136: Image $\mathrm{J}$ thresholding for $\left[0_{2 \mathrm{~K}} / 0_{6 \mathrm{~F}}\right]_{\mathrm{S}}$ impacted at $\mathrm{E}=5 \mathrm{~J}, 10 \mathrm{~J}$ and $15 \mathrm{~J} \ldots \ldots \ldots \ldots \ldots . . . . . .110$

Figure 137: Image $\mathrm{J}$ thresholding for $\left[0_{2 \mathrm{~K}} / 0_{6} \mathrm{~F}\right]_{\mathrm{S}}$ impacted at $\mathrm{E}=20 \mathrm{~J}, 25 \mathrm{~J}$ and $27 \mathrm{~J} \ldots \ldots \ldots \ldots \ldots . . . . .111$

Figure 138: Image J thresholding for $\left[0_{2 \mathrm{~K}} /(0 / 90)_{3 \mathrm{~F}}\right]_{\mathrm{S}}$ impacted at $\mathrm{E}=10 \mathrm{~J}, 15 \mathrm{~J}$ and $20 \mathrm{~J} \ldots \ldots \ldots 111$

Figure 139: Image $\mathrm{J}$ thresholding for $\left[0_{2 \mathrm{~K}} /(0 / 90)_{3 \mathrm{~F}}\right]_{\mathrm{s}}$ impacted at $\mathrm{E}=25 \mathrm{~J}, 27 \mathrm{~J}$ and $30 \mathrm{~J} \ldots \ldots \ldots .111$

Figure 140: Back-face damage area vs. impact energy for the Kevlar-flax/epoxy composite ... 112

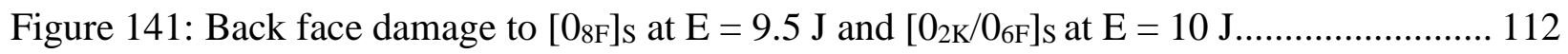

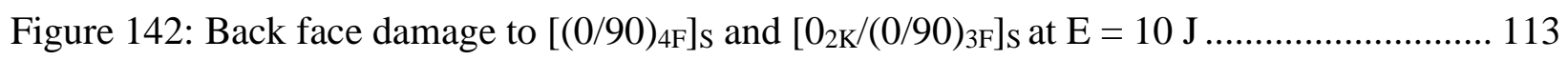

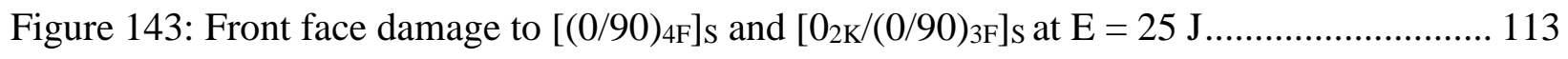

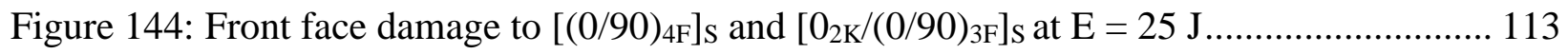

Figure 145: Dent Depth versus impact energy for the Flax/Epoxy and Kevlar-flax/epoxy ....... 114

Figure 146: Visible back face damage (left) and IR image for $\left[0_{2 \mathrm{~K}} / 0_{6 \mathrm{~F}}\right]_{\mathrm{S}}$ at $\mathrm{E}=5 \mathrm{~J} \ldots \ldots \ldots \ldots \ldots . \ldots \ldots$

Figure 147: Visible back face damage (left) and IR image for $\left[0_{2 \mathrm{~K}} / 0_{6 \mathrm{~F}}\right]_{\mathrm{S}}$ at $\mathrm{E}=10 \mathrm{~J} \ldots \ldots \ldots \ldots \ldots 115$

Figure 148: Visible back face damage (left) and IR image for $\left[0_{2 \mathrm{~K}} / 0_{6 \mathrm{~F}}\right]_{\mathrm{S}}$ at $\mathrm{E}=15 \mathrm{~J} \ldots \ldots \ldots \ldots \ldots . . . .116$

Figure 149: Visible back face damage (left) and IR image for $\left[0_{2 \mathrm{~K}} / 0_{6 \mathrm{~F}}\right]_{\mathrm{S}}$ at $\mathrm{E}=20 \mathrm{~J} \ldots \ldots \ldots \ldots \ldots$

Figure 150: Visible back face damage (left) and IR image for $\left[0_{2 \mathrm{~K}} / 0_{6 \mathrm{~F}}\right]_{\mathrm{S}}$ at $\mathrm{E}=25 \mathrm{~J} \ldots \ldots \ldots \ldots \ldots$

Figure 151: Visible back face damage (left) and IR image for $\left[0_{2 \mathrm{~K}} / 0_{6 \mathrm{~F}}\right]_{\mathrm{S}}$ at $\mathrm{E}=27 \mathrm{~J} \ldots \ldots \ldots \ldots \ldots 117$

Figure 152: Visible back face damage (left) and IR image for $\left[0_{2 \mathrm{~K}} /(0 / 90)_{3 \mathrm{~F}}\right]_{\mathrm{S}}$ at $\mathrm{E}=5 \mathrm{~J} \ldots \ldots \ldots 117$ 
Figure 153: Visible back face damage (left) and IR image for $\left[0_{2 \mathrm{~K}} /(0 / 90)_{3 \mathrm{~F}}\right]_{\mathrm{S}}$ at $\mathrm{E}=10 \mathrm{~J} \ldots \ldots . .117$

Figure 154: Visible back face damage (left) and IR image for $\left[0_{2 \mathrm{~K}} /(0 / 90)_{3 \mathrm{~F}}\right]_{\mathrm{S}}$ at $\mathrm{E}=15 \mathrm{~J} \ldots \ldots . .118$

Figure 155: Visible back face damage (left) and IR image for $\left[0_{2 \mathrm{~K}} /(0 / 90)_{3 \mathrm{~F}}\right]_{\mathrm{S}}$ at $\mathrm{E}=20 \mathrm{~J} \ldots \ldots . .118$

Figure 156: Visible back face damage (left) and IR image for $\left[0_{2 \mathrm{~K}} /(0 / 90)_{3 \mathrm{~F}}\right]_{\mathrm{S}}$ at $\mathrm{E}=25 \mathrm{~J} \ldots \ldots . .118$

Figure 157: Visible back face damage (left) and IR image for $\left[0_{2 \mathrm{~K}} /(0 / 90)_{3 \mathrm{~F}}\right]_{\mathrm{S}}$ at $\mathrm{E}=27 \mathrm{~J} \ldots \ldots . .119$

Figure 158: Visible back face damage (left) and IR image for $\left[0_{2 \mathrm{~K}} /(0 / 90)_{3 \mathrm{~F}}\right]_{\mathrm{S}}$ at $\mathrm{E}=30 \mathrm{~J} \ldots \ldots . .119$

Figure 159: $\Delta \mathrm{T}$ versus impact energy for Kevlar/flax/epoxy composite ................................ 120

Figure 160: $\Delta \mathrm{T}$ versus impact energy for flax/epoxy and Kevlar/flax/epoxy composite .......... 121

Figure 161: Impact properties of various composite and metallic materials [30] [43]............. 124

Figure 162: Strength versus impact toughness of various materials [70] ............................. 124

Figure 163: LS-DYNA Flax/Epoxy Composite Impact Assembly Model .............................. 130

Figure 164: *PART_COMPOSITE shell layer of unidirectional flax/epoxy .......................... 131

Figure 165: PART_COMPOSITE shell layer of cross-ply flax/epoxy (above symmetry line) . 131

Figure 166: PART_COMPOSITE shell layer of cross-ply flax/epoxy (below symmetry line) . 131

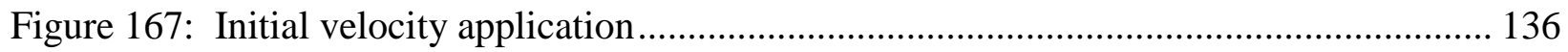

Figure 168: SPC boundary condition on the composite model .......................................... 137

Figure 169: Element sizes considered in the mesh convergence study ................................. 138

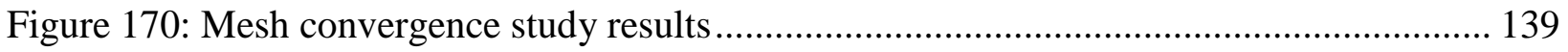

Figure 171: Force-deflection curves for composites subjected to low velocity impact [52]..... 140

Figure 172: Contact force-time history plot for unidirectional flax/epoxy composite ............. 141

Figure 173: Contact force vs. time for cross-ply flax/epoxy composite ............................... 141

Figure 174: Deflection vs. time for unidirectional flax/epoxy composite ............................. 142

Figure 175: Deflection vs. time for cross-ply flax/epoxy composite ................................... 142

Figure 176: Contact force versus deflection for unidirectional flax/epoxy composite............. 143

Figure 177: Contact force versus deflection for cross-ply flax/epoxy composite ................... 144

Figure 178: Typical Von-Mises stress plot of the impacted unidirectional flax/epoxy............ 146

Figure 179: Typical Von-Mises stress plot of the impacted cross-ply flax/epoxy ................... 146 


\section{NOMENCLATURE}

\begin{tabular}{|c|c|c|c|}
\hline$V_{f}$ & Fibre volume fraction & $\varepsilon_{22}{ }^{\mathrm{TU}}$ & Transverse tensile fail strain \\
\hline $\mathrm{V}_{\mathrm{m}}$ & Matrix volume fraction & $\gamma_{22}^{\mathrm{U}}$ & In-plane shear strain \\
\hline $\mathrm{E}_{\mathrm{f}}$ & Elastic modulus of fibre & $\varepsilon_{11}{ }^{\mathrm{CU}}$ & Long. compressive fail strain \\
\hline $\mathrm{E}_{\mathrm{m}}$ & Elastic modulus of matrix & $\varepsilon_{22}{ }^{\mathrm{CU}}$ & Trans. compressive fail strain \\
\hline $\mathrm{E}_{\mathrm{c}}$ & Elastic modulus of composite & $\mathrm{u}$ & Energy per unit area \\
\hline $\mathrm{E}_{11}{ }^{\mathrm{T}}$ & Long. elastic modulus (tension) & $\mathrm{U}$ & Delamination energy \\
\hline $\mathrm{E}_{11}{ }^{\mathrm{C}}$ & Long. elastic modulus (compress.) & $\mathrm{P}_{\mathrm{C}}$ & Delamination threshold force \\
\hline $\mathrm{E}_{22}{ }^{\mathrm{T}}$ & Trans. elastic modulus (tension) & $\mathrm{t}$ & Laminate thickness \\
\hline $\mathrm{E}_{22}{ }^{\mathrm{C}}$ & Trans. elastic modulus (compress.) & $\rho$ & Density \\
\hline $\mathrm{G}_{12}$ & In-plane shear modulus & $E_{\text {absorbed }}$ & Energy absorbed \\
\hline$v$ & Poisson's ratio & E $_{\text {rebound }}$ & Rebound energy \\
\hline$v_{12}, v_{\mathrm{AB}}$ & Major Poisson's ratio & E, Eimpact & Impact Energy \\
\hline$v_{21}, v_{\mathrm{BA}}$ & Minor Poisson's ratio & $\mathrm{E}_{\mathrm{m}}$ & Membrane energy \\
\hline$\sigma_{\mathrm{f}}, \sigma_{\mathrm{fu}}$ & Tensile strength of fibre & $\mathrm{E}_{\mathrm{b}}$ & Bending energy \\
\hline$\sigma_{\mathrm{m},} \sigma_{\mathrm{mu}}$ & Tensile strength of matrix & $\mathrm{E}_{\mathrm{d}}$ & Damage energy \\
\hline$\sigma_{\mathrm{c},} \sigma_{\mathrm{cu}}$ & Composite tensile strength & $\mathrm{m}$ & Pendulum mass \\
\hline$\sigma_{11}{ }^{\mathrm{TU}}, \mathrm{S}_{1}$ & Longitudinal tensile strength & $\mathrm{h}_{0}, \mathrm{H}_{1}$ & Initial pendulum height \\
\hline$\sigma_{11}^{\mathrm{CU}}, \mathrm{C}_{1}$ & Long. compressive strength & $\mathrm{h}_{\mathrm{f}}, \mathrm{H}_{2}$ & Final/rebound pendulum height \\
\hline$\sigma_{22}{ }^{\mathrm{TU}}, \mathrm{S}_{2}$ & Transverse tensile strength & $\alpha$ & Pendulum initial drop angle \\
\hline$\sigma_{22}{ }^{\mathrm{CU}}, \mathrm{C}_{2}$ & Transverse compressive strength & $\theta$ & Pendulum rebound angle \\
\hline$\tau_{12}, S_{12}$ & In-plane shear strength & $\mathrm{L}$ & Pendulum arm length \\
\hline$\varepsilon_{11}{ }^{\mathrm{TU}}$ & Longitudinal tensile fail strain & $\mathrm{E}_{\mathrm{t}}$ & Total energy \\
\hline
\end{tabular}




$\begin{array}{llll}\mathrm{E}_{\mathrm{i}} & \text { Initiation energy } & \mathrm{a} & \text { Average crack length } \\ \mathrm{E}_{\mathrm{p}} & \text { Propagation energy } & \mathrm{X}_{\mathrm{T}} & \text { Tensile strength in fibre direction } \\ \mathrm{v}_{\mathrm{i}} & \text { Impact velocity } & \mathrm{Y}_{\mathrm{T}} & \text { Tensile strength in matrix direction } \\ \mathrm{g} & \text { Acceleration due to gravity } & \mathrm{X}_{\mathrm{C}} & \text { Compress. strength (fibre direction) } \\ \Delta \mathrm{T} & \text { Change in temperature } & \mathrm{Y}_{\mathrm{C}} & \text { Compress. strength (matrix direction) } \\ \mathrm{G}_{\text {impact }} & \text { Impact toughness } & \mathrm{S}_{\mathrm{C}} & \text { In-plane shear strength }\end{array}$

DFAILM Maximum strain for matrix failure

DFAILS Maximum in-plane shear strain

DFAILT Maximum strain for fibre tension

DFAILC Maximum strain for fibre compression

FBRT Reduction factor for fibre tensile strength

YCFAC Reduction factor for fibre compressive strength

SOFT Softening reduction factor for material strength in crash front elements

ALPH Shear stress parameter for nonlinear term in matrix stress equation

BETA Weighting factor for shear term in tensile fibre mode 


\section{INTRODUCTION}

The use of lignocellulosic natural fibre as reinforcement in composite structures is not new. In fact, history has shown that this has been used by multiple civilizations to enhance the stiffness and strength of a material or structure. Nowadays, a renewed interest in natural fibres has emerged as an alternative to conventional reinforcement materials such as glass or carbon fibre. Government and environmental groups have put strong emphasis on sustainability and recyclability, which pushed the composite industry to find alternative and ecofriendly materials to produce compatible composites [1] [2].

Natural fibres have attracted the interest of both scientists and manufacturers because of their sustainability, biodegradability, abundance, cost savings and lower specific gravity in contrast to synthetic fibres like glass and carbon [1] [3]. Although their strengths are relatively lower than synthetic fibres, they have comparable specific properties (i.e. specific strength and specific stiffness) [4], and acceptable mechanical properties such as elongation, flexural strength, impact resistance, non-abrasiveness and acoustic absorption [3]. In fact, natural fibres are now widely used in the automotive industry, with an annual growth rate of above 20\% [4].

Despite their great benefits, there are still major drawbacks which restrict the usage of natural fibres in many engineering applications. Compared to synthetic fibres, natural fibres have high moisture absorption, which makes them incompatible to hydrophobic matrices. They also have low degradation temperatures, typically below $200^{\circ} \mathrm{C}$, which makes them incompatible to high-temperature curing thermosets [3] [5]. They also exhibit poor fire resistance, susceptibility to microbe infection [3] [4], large variability of mechanical properties [5] and poor resistance to weathering [3]. In terms of geometry, natural fibres are not uniform monofilament cylinders unlike carbon and glass fibres. Instead, natural fibres have irregular cross sections which contain voids and defects [6].

Among all natural fibres, flax is one of the most widely utilized because it offers the best combination of low cost, light weight and high strength and stiffness for structural applications [5]. In fact, it widely used in the European automotive industry [7] as thermoplastic composite 
reinforcement to cars' internal structures [8]. To name a few, BMW and Mercedes Bens have used a blend flax and sisal fibres to build their car door panels for increased strength and impact resistance [4] [9]. Flax is a cost-effective material which has the potential to replace glass fibres for similar applications [6]. Moreover, compared to glass fibres, flax/epoxy composites exhibit non-linear stress-strain behaviour [10] [11]. This non-linearity results in energy dissipation, which improves the damping ability of the material [10]. This is a desirable property especially in sports equipment where vibrational damping is often required [10].

A major drawback of flax fibres is the variability in their properties when exposed to different environmental conditions. Like most lignocellulosic fibres, flax fibres are hydrophilic. Not only does this make them incompatible with hydrophobic matrices, but it also makes them susceptible to tensile properties degradation with increasing relative humidity [5] [6]. Treating the flax fibres with suitable coupling agents such as alkali or silane will reduce their moisture absorption and improve fibre-matrix adhesion [5] [6] [8] [11]. It will also enhance their mechanical and flexural properties [5,6]. All these treatments, however, are at the expense of a reduction in their impact performance [6] [11].

A common approach to increasing the mechanical and impact performance of natural fibres is through hybridization with stronger, stiffer and tougher synthetic fibres such as aramid fibres. The advantage of using a hybrid composite is that one type of fibre can compensate for the disadvantages of the other fibre [10]. In this research, hybrid flax-aramid (Kevlar 49) fibrereinforced polymer composite is developed and tested. Aramid fibres have high tensile strength and stiffness, low density, good impact resistance and damage tolerance [13]. The hybridization of both fibres could potentially create a material with excellent specific strength, stiffness and damping ability, while also offering improved impact strength and toughness. This will be beneficial in aerospace, automotive and sports equipment applications, where such properties are desirable. 


\section{RESEARCH SCOPE AND OBJECTIVES}

The main objective of this research is to advance the knowledge in flax composites and their hybrids. Specifically, our aim is to characterize the impact performance of flax-fibre and hybrid Kevlar-flax fibre-reinforced polymer composites under low velocity/low energy impact loading. The first part of the study consists of a series experimental impact tests. The impact tests will first be performed on flax-fibre/epoxy composites to establish the baseline characteristics of the composite under low velocity impact loading. This is followed by the impact testing of the hybrid Kevlar-flax-fibre/epoxy composites to evaluate the effectiveness of hybridization to the impact performance of the flax/epoxy composite. The impact performance of the composite laminates is evaluated based on its energy absorbing capacity, damage size, indentation depth, damage mechanism/failure mode, internal damage and impact toughness.

The impact tests are performed using an in-house designed pendulum-type impact apparatus. Moreover, an infrared (IR) camera is used to monitor the thermal response of the material during the impact event. It is a non-destructive technique (NDT), which offers valuable information on the damage experienced by the laminate during an impact event. A few studies [14,15,16,17] have shown that the usage of IR thermography can provide information regarding the initiation and propagation of impact damage, since the energy released from any form of damage (e.g. matrix cracking, delamination, fibre breakage, etc.) is dissipated as heat. This heat dissipation will be captured by the IR camera as a hot spot on the material surface [14].

The second part of this research is to simulate the impact tests using LS-DYNA and to correlate the experimental results with those obtained from the simulations. The objective to the numerical (FE) analysis is to establish the basic modelling parameters required to be able to reproduce the results of the experiment. The goal is to be able to analytically evaluate the impact performance of different lay-up configurations without conducting further experiments. 


\section{LiTERATURE REVIEW}

\subsection{OVERVIEW OF COMPOSITE MATERIALS}

A composite material is defined as a combination of two or more constituent materials with distinct macroscopic phases. When combined, they produce a material with characteristics different from the individual constituents. The constituent materials consist of a reinforcement and a matrix. The reinforcement is a material that is embedded into a matrix to improve its mechanical properties such as strength and stiffness. It is the load-carrying constituent of the composite, which could take the form of fibres, whiskers or particulates. The matrix on the other hand binds the fibres together and protects them from environmental damages. It also acts to transfer and distribute the load into the reinforcement material. Typical materials for a matrix include polymer, metal, ceramic and graphite.

In general, a composite material can be sub-divided into three main categories depending on the type of matrix used: (1) Polymer-matrix composite (PMCs); (2) Metal-matrix composite (MMCs); and (3) Ceramic-matrix composites (CMCs). PMCs are the most common type of composite used in aerospace, automotive and biomedical applications. It consists of a fibre reinforcement and a polymer-based matrix. In this report, only PMCs will be discussed because of its relevance to the type of composite being investigated in this research.

\subsection{POLYMer-Matrix COMPOSITES}

Fibre-reinforced polymer-matrix composites (PMCs) consist of a fibrous reinforcement material bound together by an organic polymer matrix. PMCs are often classified based on the type of the reinforcement fibres. Typical materials for the fibres are E-glass (which forms E-glass fibre-reinforced polymer or E-GFRP), S-glass (S-GFRP), carbon/graphite (CFRP) and aramid (AFRP). The polymer used for the resin matrix can be classified as thermoplastics or thermosets, depending on their structure and behaviour when exposed to heat. Thermoplastics can undergo reversible melting and solidification; therefore, they can be reformed under heat and pressure. Examples of thermoplastics are polyethylene and polyether ether ketone (PEEK). Thermosets on the other hand cannot be re-melted. They rather decompose when re-exposed to heat. 
The fibres used in PMCs generally have high strength and stiffness; however, they are not readily used on their own in structural applications because of their small cross-sectional properties [12]. Polymer-based matrices on the other hand can be formed into random complex shapes; however, they have very low mechanical properties that limits their structural use on their own. The combination of fibre and matrix into single composite results in a material that combines the individual properties of each constituent materials, which would not have been useful in structural engineering applications if used on their own. Compared to metals, fibre-reinforced PMCs generally have superior properties such as high specific strength and stiffness, durability, corrosion resistance, electrical resistance, fatigue and design flexibility. The following figure shows the typical stress strain curve of an FRP composite and its individual constituents.

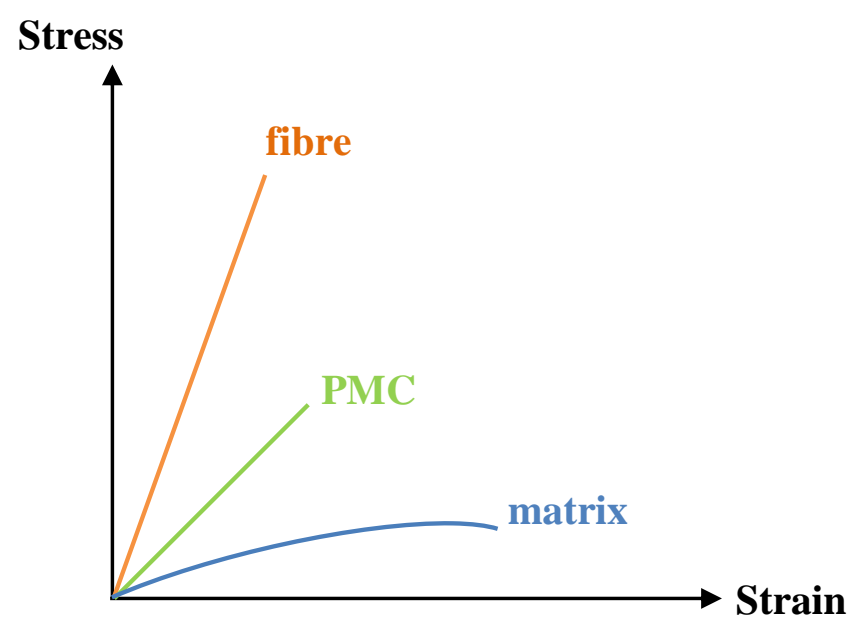

Figure 1: Typical stress-strain curve for fibre, resin and PMC

The strength and stiffness of a fibre-reinforced polymer composite are dependent on the volume fraction $(V)$ of the fibre and matrix constituents and can be expressed using the following equations (assuming void content is negligible):

$$
\begin{aligned}
& E_{c}=E_{f} V_{f}+E_{m} V_{m} \\
& \sigma_{c}=\sigma_{f} V_{f}+\sigma_{m} V_{m}
\end{aligned}
$$




\subsection{FIBRE REINFORCEMENTS}

Fibre selection is an extremely important part of the material selection process since the fibres account for most of the strength of the composite. They provide the required strength, stiffness and other structural properties, while the matrix binds the fibres together and transfer the applied load to the fibres. The fibres take most of the applied load on the structure, therefore, it is important to select the proper material and form of the fibre to maximize the benefits for the intended application.

In the fibre selection process, the engineer must consider both the physical and mechanical properties of the fibre because this will affect the overall structural performance of the composite. Other fibre selection considerations include thermal properties, ply thickness, tow size, ply flexibility, part curvature, sizing, surface treatments for matrix bonding and wetting, cost, lead time and supply [13].

A rather unique criterion for fibre selection has recently emerged due to emphasis on environmental preservation. Recent push for sustainability and recyclability have pushed industries to find alternative and ecofriendly materials to produce compatible composites [1]. Synthetic fibres such as carbon and glass have allowed different industries to produce light-weight and high-performance composite structures; however, the downside of synthetic-fibre PMCs in the long term is that they are not easily recyclable [14]. CFRPs for instance are energy intensive materials [14] and the production of carbon fibres contributes to increased greenhouse gas emissions. Natural fibres are getting attention from both scientists and industries due to their ecofriendly nature and sustainability. They also have lower cost and lower specific gravity compared to conventional synthetic fibres [1]. Furthermore, natural fibres have comparable specific properties and acceptable mechanical characteristics such as elongation, flexural strength, impact resistance, non-abrasiveness and acoustic absorption [3]. These factors have in fact been the main driver of this research, with the hopes of developing a material that is both sustainable, light-weight and has a good combination of physical, mechanical and impact properties. 


\subsection{NATURAL FibRES}

Natural fibres are those derived from natural resources, which include plants, animals and minerals. Fibres from plants are obtained from either their leaf, bast, straw, seed, fruit or wood. Animal fibres are obtained from silk, wool, hair or feathers of animals. Mineral fibres are obtained from natural minerals such as asbestos. Among these natural fibres, plant-based fibres are the most frequently used in commercial composite applications [15].

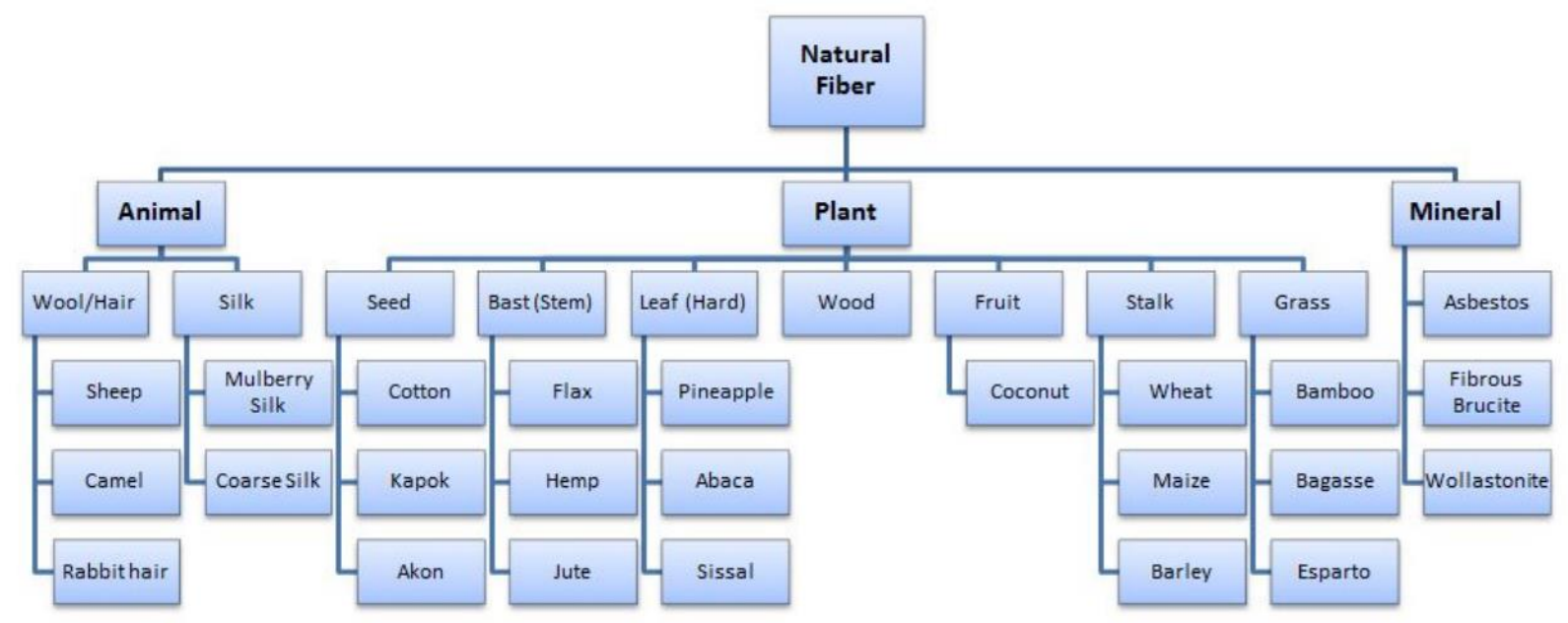

Figure 2: Different Types and Sources of Natural Fibres [4]

Plants are considered lignocellulosic structures [16]. They contain cellulose, hemicellulose and lignin, which are the three major organic constituents of plant cell walls [17]. A plant is essentially a naturally-occurring composite with the lignocellulose fibril as reinforcement, which is embedded in a lignin matrix [18]. Other chemical compositions include wax, ash and pectin, which vary with various natural fibres [18].

The strength and stiffness of the fibres are provided by hydrogen bonds and other linkages in the cellulose [15]. Thus, the amount of cellulose in each fibre determines the fibre's strength and stiffness. In addition, the microfibrillar angle of the fibres determines their stiffness [4]. If the microfibrils have a spiral orientation with respect to the fibre axis, then they are more ductile; and 
if the microfibrils are parallel to the fibre axis, then they are rigid, inflexible but have higher tensile strength [4]. The amount of hemicellulose controls moisture absorption, biodegradation, and the thermal degradation of the plant fibres. Lignin on the other hand is responsible for the degradation of the fibres under ultraviolet (UV) radiation [15]. The following table shows the physical and mechanical properties of different plant-based and synthetic fibre composites:

Table 1: Mechanical Properties of select synthetic and natural fibre composites [4] [17] [19]

\begin{tabular}{|ccccccc|}
\hline $\begin{array}{c}\text { Fiber } \\
\text { Name }\end{array}$ & $\begin{array}{c}\text { Density } \\
{\left[\mathrm{g} / \mathbf{c m}^{\mathbf{3}}\right]}\end{array}$ & $\begin{array}{c}\text { Tensile } \\
\text { Strength } \\
{[\mathrm{MPa}]}\end{array}$ & $\begin{array}{c}\text { Specific } \\
\text { Strength } \\
{[\mathbf{S} / \mathbf{\rho}]}\end{array}$ & $\begin{array}{c}\text { Tensile } \\
\text { Modulus } \\
{[\mathrm{GPA}]}\end{array}$ & $\begin{array}{c}\text { Specific } \\
\text { Modulus } \\
{[\mathrm{E} / \mathbf{\rho}]}\end{array}$ & $\begin{array}{c}\text { Elongation } \\
\text { at Break } \\
{[\%]}\end{array}$ \\
\hline Cotton & 1.5 & $287-597$ & $191-398$ & $5.5-12.6$ & $4-8$ & $7-8$ \\
\hline Jute & 1.46 & $393-773$ & $302-595$ & $10-30$ & $7-21$ & $1.5-1.8$ \\
\hline Flax & 1.5 & $345-1035$ & $230-690$ & $27.6-80$ & $18-53$ & $2.7-3.2$ \\
\hline Hemp & 1.5 & 690 & 460 & 70 & 47 & 1.6 \\
\hline Sisal & 1.5 & $511-635$ & $341-423$ & $9.4-22$ & 6 & $2-2.5$ \\
\hline Coir & 1.2 & 175 & 146 & $4-6$ & $3-4$ & 30 \\
\hline Ramie & 1.5 & $400-938$ & 267 & $61.4-128$ & $41-85$ & 3.6 .3 .8 \\
\hline E-glass & 2.55 & 3400 & 1333 & 73 & 29 & 3.4 \\
\hline S-glass & 2.5 & 4580 & 1832 & 85 & 34 & 4.6 \\
\hline Aramid & 1.44 & 3000 & 1917 & 124 & 86 & 2.5 \\
\hline HS Carbon & 1.82 & 2550 & 1401 & 200 & 110 & 1.3 \\
\hline
\end{tabular}

One of the main problems with natural fibres is their high moisture absorption, which poses a problem not only with the fibre-matrix adhesion, but also with the material degradation after prolonged exposure to moisture and humidity. This is one of the reasons why natural fibres are not widely used in structural applications. Surface chemical treatments such as alkali treatment, silane treatment, acetylation, benoylation and acrylation are usually performed on natural fibres to overcome this problem [4]. These chemical treatments remove moisture from the fibres and roughen their surface to increase the fibre-matrix contact area [18]. These processes also help improve the composite strength. 


\subsubsection{FlaX FibRES}

Flax is the most widely utilized natural fibre, with Canada being the world's largest producer and exporter since 1994 [5]. Prior to being used as reinforcement in PMCs, its seeds were used as source of oil for the basal component of paints and polymers. Its fibres on the other hand were used in the textile and paper industries [20]. The flax fibres used for PMC applications are harvested from the stem of flax plants.

The stem of a flax plant exhibits a complex, hierarchical and multi-component structure [21]. From a macroscopic level, the stem consists of a bark, phloem, xylem and a central void. The phloem and xylem are vascular tissues in plants that transports water from the root and food from the leaves. From a mesoscopic level, the stem consists of bundles of fibres held together by pectin. From a microscopic level, an elementary fibre consists of layers of concentric walls, with a small central opening called a lumen [5] [21]. The lumen contributes to the water uptake of the flax fibres [5] and is therefore responsible for the hydrophilic nature of flax.

Each layer of cell wall in the elementary fibre consists of cellulosic microfibrils, which runs parallel to one another and form a microfibrillar angle with the fibre axis [5]. The microfibrils are responsible for the strength of the flax fibres. Specifically, the S2 layer in Figure 3 is the thickest cell wall with the least microfibrillar angle of $10^{\circ}$. It provides the flax fibres its high tensile strength [5].

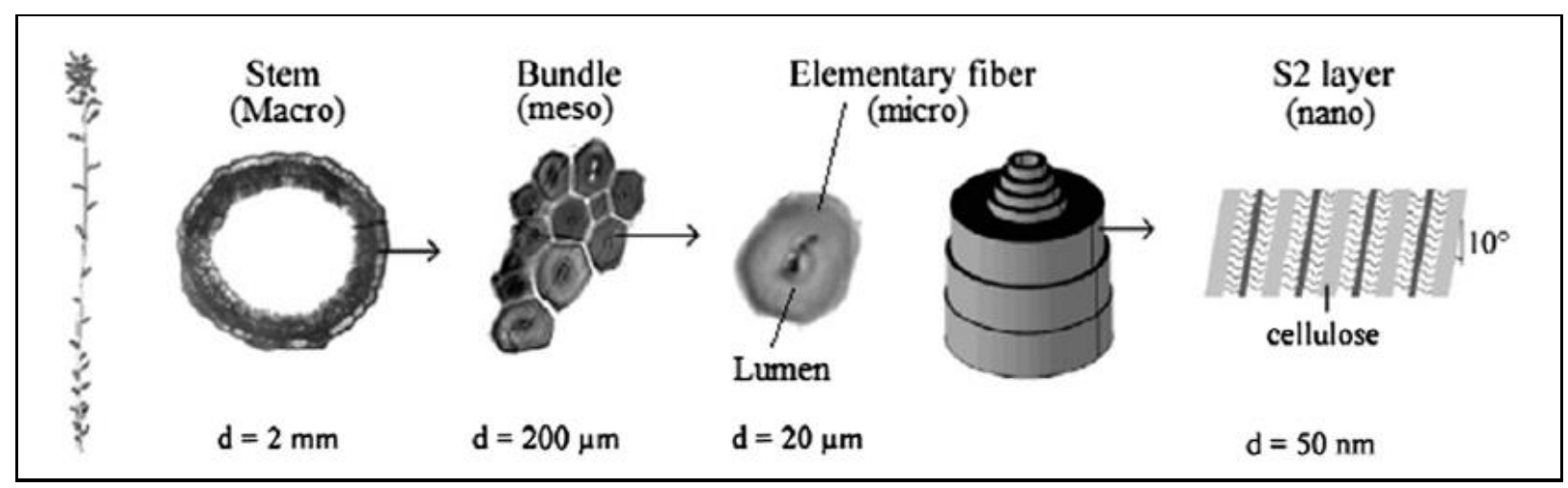

Figure 3: Basic structure of a flax stem [5] 
The primary constituents of an elementary flax fibre are cellulose, hemicellulose, wax, lignin and pectin. Essentially, the flax fibre by itself is a natural-occurring cellulosic polymer composite with the cellulosic fibrils as reinforcements, and lignin and pectin as matrix. Although the flax fibre is a cellulosic polymer, its structure is more crystalline making the fibre strong and stiff. The strength and ductility of the flax fibres depend on the microfibrillar angle. The fibre is more ductile if the microfibrils have a spiral orientation with respect to the fibre axis [5].

The time and location of harvest affect the internal structure (i.e. microfibril orientation) of the elementary flax fibre [5]. Therefore, the tensile properties of flax fibres will depend on when and where they are harvested. When loaded in tension, the microfibrils tend to re-orient and straighten towards the loading direction [11]. Depending on the initial microfibrillar angle, the resulting stiffness of the flax fibres will vary under tensile loading. This explains the high variability in their mechanical properties [11]. For instance, the longitudinal tensile modulus of an elementary fibre varies between 27-91 GPa and its tensile strength also vary between 300-1300 MPa [11]. It is also worth noting that the mechanical properties of the flax fibre also depend on the gauge length and the diameter of the fibre tested.

In tension, flax fibres exhibit non-linearity in its stress-strain behaviour unlike conventional synthetic fibres, where their stress-strain curve tend to be linear. The typical stress-strain curves for flax fibres harvested at different locations are given in Figure 4 below.

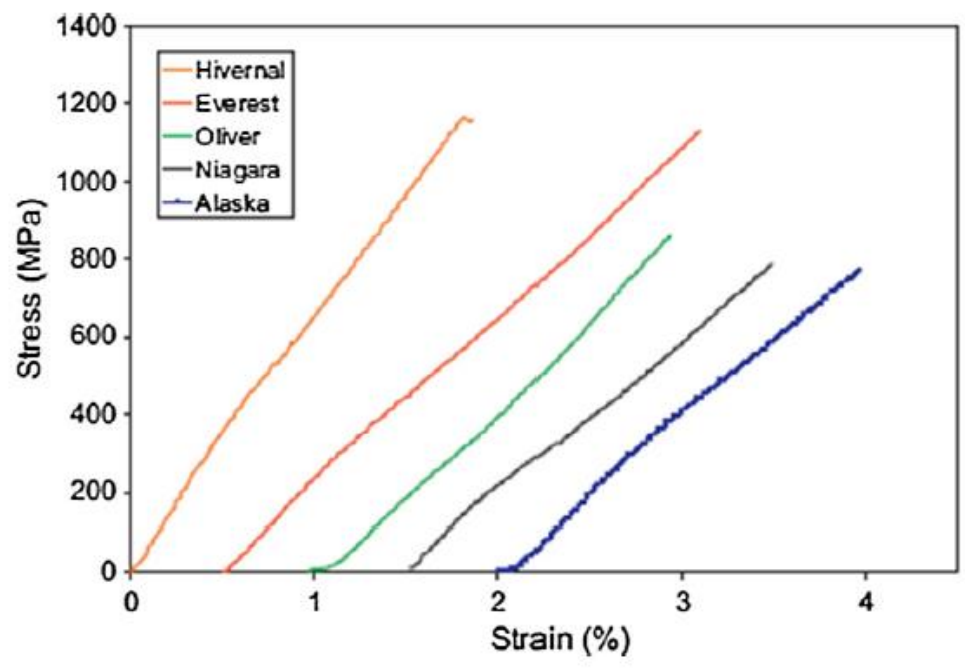

Figure 4: Stress-strain curve of different flax fibres in tension [5] 
The first part of the stress-strain curve tends to be linear because of the deformation associated with the global loading of the fibre through the deformation of each cell wall [5]. The second part of the curve shows non-linear behaviour because of the elasto-visco-plastic deformation of the fibre [5]. The angle of the cellulosic microfibrils with respect to the fibre axis results in the re-arrangement of the amorphous part of the cell walls [5]. The curve then increases linearly to rupture. This linearity is attributed to the elastic response of the straightened microfibrils to the applied tensile strain [5]. The non-linearity in the stress-strain behaviour is what gives the flax fibres good damping properties. Non-linearity in the stress-strain curve creates a hysteresis loop during the loading-unloading process, which translates to energy dissipation. The higher the hysteresis, the greater the energy dissipation and the damping capacity of the material.

A major drawback of flax fibres is the variability in their mechanical properties. As mentioned previously, the tensile properties of flax are sensitive to dimensional parameters such as gauge length and fibre diameter. In addition, they are also sensitive to environmental effects such as humidity. This often degrades the tensile properties of the fibres [5]. Like most lignocellulosic fibres, they are also hydrophilic, which make them incompatible with hydrophobic matrices. Treating the flax fibres with suitable coupling agents such as an alkali or silane will reduce their moisture absorption capacity and improve fibre-matrix adhesion [5] [6] [8] [11]. It will also enhance their mechanical and flexural properties [5,6]; however, at the expense of a reduction in impact performance [6] [11].

The density of flax fibres is $1.45 \mathrm{~g} / \mathrm{cm}^{3}$, which makes them significantly lighter than glass and carbon. Flax fibres for composite applications often come in different forms such as a unidirectional flax tape, prepreg, fabric, yarns and roving. They are compatible with different manufacturing techniques such as pultrusion, filament winding, vacuum infusion, RTM and compression molding [22].

Currently, flax fibre composites are widely used in the European automotive industry. It is used by Mercedes-Benz to fabricate car door panels [23] and exterior components like the front bumpers [24]. In the sports industry, they are used to manufacture tennis racquets, bio-boards, paddle boards and bicycle frames due to their good mechanical and damping characteristics. 


\subsubsection{ARAMID FibRES}

Aramid (Kevlar $®)$ fibres are made of carbon, hydrogen, oxygen and nitrogen [25]. They have high tensile strength and stiffness, low density, low cost and resistance to high temperatures. They also have excellent impact resistance and damage tolerance [26]. Hence, they are predominantly used in low and high-speed impact applications such as bullet proof vests. A disadvantage of Kevlar fibres is the fact that they are poor in compression, sensitive to UV light and prone to corrosion damage from moisture.

There are two main types of aramid fibres, namely Kevlar 29 and Kevlar 49. Both fibres have similar density but Kevlar 49 has higher tensile strength and stiffness than Kevlar 29. Kevlar 29 is used in the manufacturing of body armors, ropes and cables, while Kevlar 49 is used in highperformance applications such as in the aircraft industry [25]. An improvement to the Kevlar 29 and Kevlar 49 fibres are the Kevlar 129 and Kevlar 149, respectively. Kevlar 129 has the same density but higher strength and stiffness than Kevlar 29 [27], but lower than those of Kevlar 49 and Kevlar 149. Kevlar 149 is a high-performance, aerospace grade fibre with the highest modulus of all Kevlar fibres [28]. It has a slightly higher density and strength than Kevlar 49, but has lower moisture regain value (i.e. better moisture resistance) than other Kevlar fibres [29].

Aramid fibres are produced by making solutions of different polymers and acids, which are then extruded into hot cylinders at $392^{\circ} \mathrm{F}$, washed and then dried on spools [25]. The fibres are then stretched and drawn to increase its tensile strength and stiffness [25]. The fibre properties can be varied by using solvent additives, modifying spinning conditions and posts-pinning heat treatments [12].

A major disadvantage of aramid fibres is that their compression strength is low [30], with their compressive strength being only one-eighth of their tensile strength [12]. Under compression, they undergo linear deformation at strain levels of approximately $0.5 \%$ through the formation of kink bands in the fibre [30]. This is due to the anisotropic nature of the aramid fibres [12]. Another disadvantage is their poor interfacial strengths in thermosetting resins, which is about half as strong as compared to that of graphite-epoxy [31]. Silane treatments are often performed to improve adhesion. 
The following table shows the basic physical and mechanical properties of aramid fibres in comparison with other synthetic fibres. The values in the table are general values obtained from a single source [12] and may vary depending on factors such as fibre type, denier size and supplier.

Table 2: Properties of some commercially available synthetic fibres [12]

\begin{tabular}{|l|c|c|c|}
\hline \multicolumn{1}{|c|}{ Fibre Type } & $\begin{array}{c}\text { Density } \\
\left(\mathrm{g} / \mathrm{cm}^{3}\right)\end{array}$ & $\begin{array}{c}\text { Elastic Modulus } \\
(\mathbf{G P a})\end{array}$ & $\begin{array}{c}\text { Tensile Strength } \\
(\mathbf{M P a})\end{array}$ \\
\hline E-glass & 2.54 & 72.4 & 3448 \\
\hline S-glass & 2.49 & 85.5 & 4585 \\
\hline Carbon Fibre (PAN) & $1.77-1.96$ & $230-595$ & $1925-6200$ \\
\hline Kevlar 29 & 1.44 & 62 & 2760 \\
\hline Kevlar 49 & 1.44 & 124 & 3620 \\
\hline Kevlar 129 & 1.44 & 96 & 3380 \\
\hline Kevlar 149 & 1.44 & 186 & 3440 \\
\hline
\end{tabular}

\subsection{LAminating ReSin System: Polymer Matrix}

Matrix in the form of resin is the second component which constitutes a composite. The resin holds the fibres together, transfers the loads to the fibres, and protects them from environmental degradation and handling damage. The matrix affects the overall mechanical properties of the composite laminate such as its transverse strength, transverse modulus, shear and compression properties. It also limits the service temperature of the composite [12].

In a PMC, polymer is the matrix material. Polymers are long chains of molecules of hydrogen and carbon, held together by primary and covalent bonds. This is the most common type of resin used in fibre-reinforced composites because of its low cost, low density, good chemical resistance and ease of processibility [12]. The properties of a polymer matrix are determined by the molecular arrangement and intermolecular bonds. Based on their molecular structure and behavior, polymers can be classified into three categories namely thermoplastics, thermosets and elastomers. 
Thermoplastics soften or melt when heated above the glass temperature. As such, the melting and solidification of the polymer is reversible. This type of polymer consists of linear or branched molecules having strong intramolecular but weak intermolecular bonds [12]. This structure provides thermoplastics with desirable properties such as high ductility, fracture toughness, impact resistance and higher operating temperature [32]. In aircraft applications, thermoplastics are often used in cockpit windows and canopies due to their high-impact resistance. Some examples of thermoplastics are polyethylene, nylon, polycarbonate, acrylic plastics and polyether-ether ketone (PEEK) and polyetherimide (PEI).

On the other hand, thermosets become hard and permanent when heated above their glass transition temperature. When initially heated, they soften and flow for processing. Once the glass transition temperature is reached, a chemical reaction ensues and permanently sets the material into a solid. This is because the chemical reaction that occurs during the curing process results in the cross-linking of the molecules, which changes the overall molecular structure of the polymer. Strong covalent bonds are created between molecules, which makes the process irreversible. This cross-linking is what provides thermosets with their high elastic modulus and tensile strength, compared to thermoplastics [32]; however, they are more brittle and have lower impact toughness. Some common examples of thermosets are epoxies, polyester and polyimides. In aircraft structural applications, epoxy resin is the most commonly used polymer matrix. This is because of its low shrinkage, low release of volatiles during curing, high strength and good durability in hot and moist environments [32].

The last category of polymers are elastomers. Elastomers bridge the gap between thermoplastics and thermosets. These are lightly linked polymer systems that have properties which lie between those of thermosets and thermoplastics [33]. Examples of elastomers are natural and synthetic rubber. Elastomers are not typically used as matrix in composite applications; however, these are often co-polymerized with naturally brittle matrices such as epoxies to improve their ductility [34]. 


\subsection{IMPACT OPTIMIZED COMPOSITES}

In many engineering applications, impact events are unavoidable. In the aircraft industry for instance, many parts are susceptible to impact damage coming from runway and engine debris, burst rubber tire fragments, hail strikes, or even tool drops during maintenance. Unlike metals, composite materials are less resilient to impact. Metals are ductile and can absorb a large amount of energy through yielding and plastic deformation. On the other hand, most composite structures are brittle in nature and can only absorb impact energy elastically and through damage mechanisms [35]. An impact loading in a composite structure can result in severe structural damage ranging from deformation, delamination to fibre breakage.

An impact event can be categorized as low or high velocity (ballistic) impact. There is no clear transition between the two types of impact events since different authors provide varying and conflicting definitions in literature. According to Sjoblom et. al. [36], a low velocity impact can be defined as an impact event where the velocity is low enough to cause a quasi-static type of response, with impact speeds ranging from one to tens of $\mathrm{m} / \mathrm{s}$ depending on the target stiffness. The contact duration is long enough for the composite structure to respond to the impact, thus more energy is absorbed elastically [36] [35]. Cantwell and Morton [37] categorize a low velocity impact as an event that can be simulated by drop-weight impact tests (e.g. Charpy and Izod), with velocities up to $10 \mathrm{~m} / \mathrm{s}$, while Abrate [38] considers impact speeds of up to $100 \mathrm{~m} / \mathrm{s}$ as low velocity impact.

Other authors classify a low velocity impact event based on the damage incurred by the composite. According to Liu et. al. [39], the main damage mode for a low velocity impact is delamination accompanied by matrix cracking. If the damage results in penetration-induced fibre breakage, then it is classified as a high velocity impact event [39]. A high velocity impact event is also one that is dominated by stress wave propagation though the material in which the structure does not have the time to respond resulting in a localized damage [35] [36].

When a composite plate is subjected to impact loading, the evolution of material damage can be separated into three stages: deformation, delamination and fibre failure. Upon impact, a portion of the incident energy is spent on the elastic deformation of the material while the 
remaining energy is dissipated through material damage mechanisms that include delamination and fibre shear-out [40]. The total energy required to penetrate the laminate is the sum of the elastic deformation, delamination and fibre shear-out energy [40].

The impact response of a composite laminate can be separated into two cases, depending on the intended application and impact energy level involved. In structural engineering applications (e.g. aerospace), one looks at the residual load bearing capacity (i.e. compression after impact or CAI) of the structure after impact. This is mostly found in the case of a low velocity impact event. A low velocity impact may often leave little indication of damage on the surface (i.e. barely visible impact damage or BVID); however, the matrix damage may be significant [41]. Thus, the ability of the matrix to stabilize the fibres in compression is seriously degraded, affecting the CAI strength of the composite. On the other hand, one may also evaluate the overall energy absorption capacity of the laminate, without any concern for its residual strength [40]. Such is the case for high velocity impact such as found in military ballistic applications. Thus, to optimize the design of a composite laminate under impact loading, one needs to have a clear understanding of the different damage mechanisms involved during an impact event.

Most often, improving the composite's tensile properties will degrade its impact performance. This is because a material with a high elastic modulus is often brittle and absorbs energy less elastically compared to the one with low modulus. For example, the tensile and fatigue properties of glass/epoxy composites are inferior to those of carbon/epoxy composites; however, the former has better impact toughness [30]. Glass fibres, especially when produced in a woven form, offer sufficient impact resistance at low material cost when compared to carbon fibres. This is what makes them attractive in many structural applications [42].

Different material and design parameters affect the impact properties of the composite. These include the type of fibre, matrix, fibre-matrix interface, product form, laminate thickness, manufacturing methods and environmental conditions [35]. The fibre form also affects to some degree the impact toughness of the resulting laminate. Woven fabrics for example, have better impact resistance than unidirectional tapes [41]. Moreover, the stacking sequence and lay-up configuration can also affect impact resistance of the composite laminate. For instance, 
unidirectional laminates are highly susceptible to transverse impact loads resulting in significant damages such as matrix cracking, delamination and fibre fracture [35].

The choice of the material will affect the overall stiffness of the laminate and will thus have a significant effect on the dynamic response of the structure [35]. The properties of the material constituents control the initiation and growth of the impact damage [35]. Thus, careful selection of these materials must be exercised to achieve an impact resistant structure.

The type of fibre, matrix and material product form can also affect the impact response of composite laminates [8]. In general, PMCs are known to be highly susceptible to internal damage caused by transverse impact loads even at low velocities. A proper selection of material, however, can help improve the impact resistance of a PMC structure. For instance, in Figure 6 the Sglass/epoxy, E-glass/epoxy and Kevlar/epoxy composites are good material choices for impact applications due to their high impact energy absorption capacity. The S-glass/epoxy composites are approximately seven times more impact resistant than HS carbon/epoxy and about 35 times more impact resistant and HM carbon/epoxy. This is because carbon fibre/epoxy composites are stiff and brittle, which makes them absorb impact loads less elastically but through a brittle fracture process.

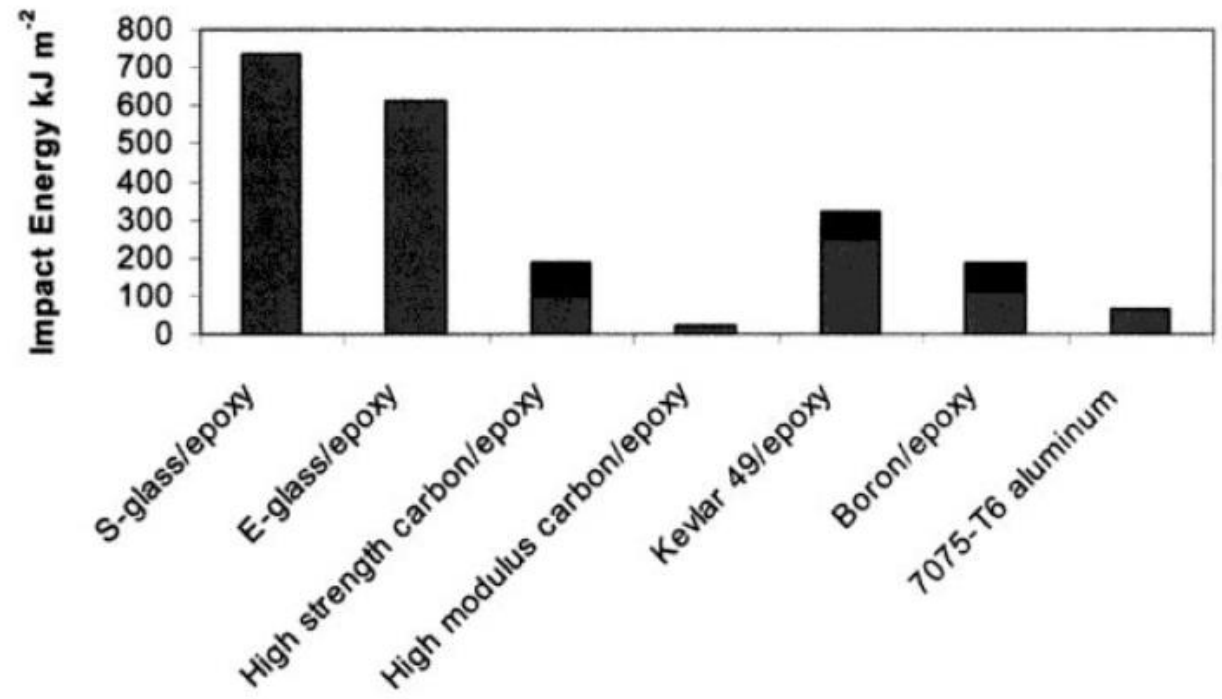

Figure 5: Impact properties of various composite and metallic materials [30] 


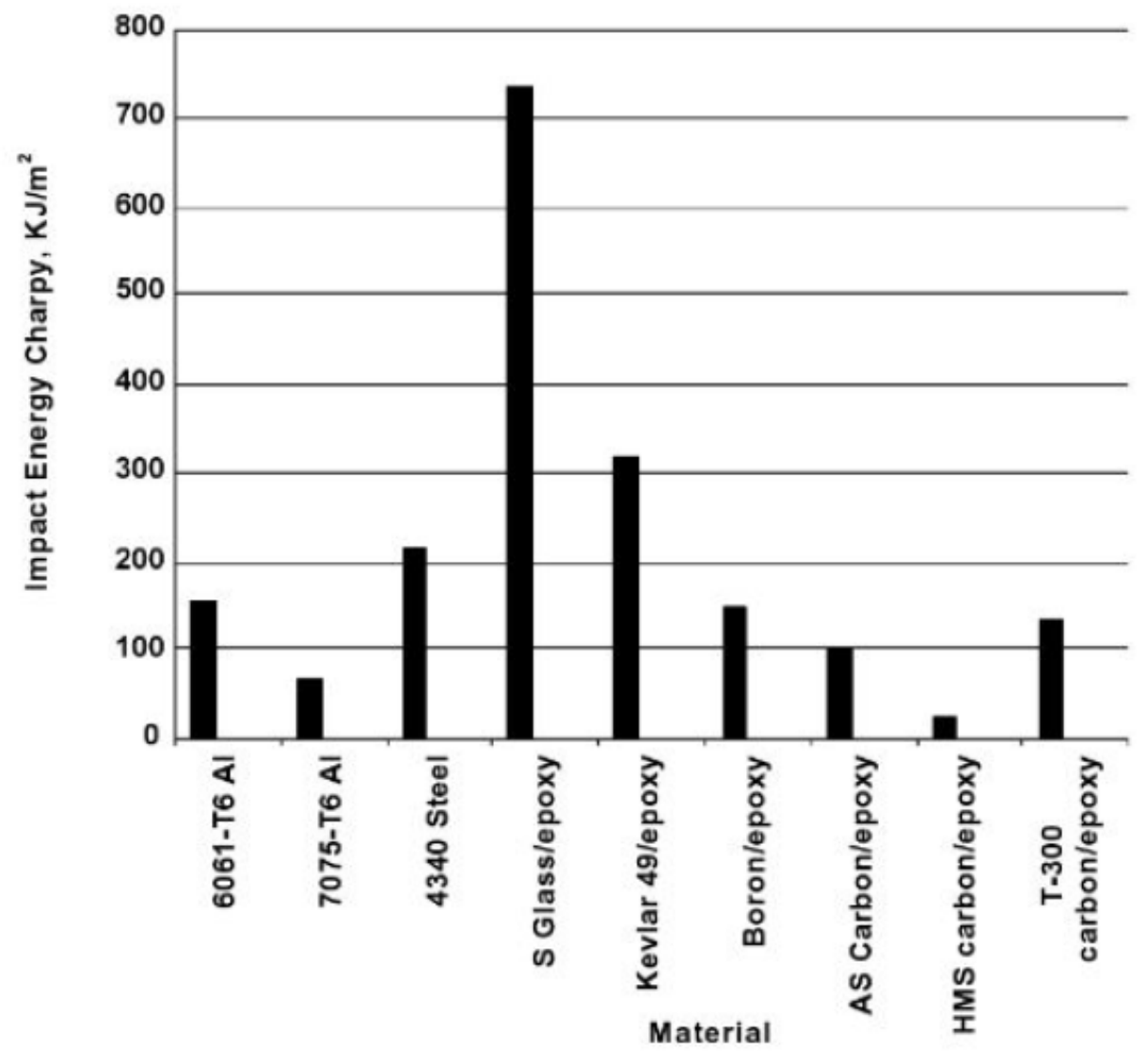

Figure 6: Impact properties of various composite and metallic materials [43]

The impact behavior of a composite laminate is also dependent on the type of matrix used. Thermosets such as epoxies are highly brittle because of the high cross-linking of molecules during the curing process. When subjected to an impact load, the material absorbs the impact energy through matrix cracking. Matrix cracking can seriously degrade the ability of the matrix to stabilize the fibres in compression and it will reduce the compression after impact (CAI) strength of the composite. On the other hand, thermoplastics have high impact resistance and toughness. The use of toughened resins or thermoplastics can help reduce the matrix dominated damage [35], especially in the case of low velocity impact loading. Thus, a proper selection of matrix will improve the impact resistance of a composite laminate. Figure 7 in the following page shows a comparison of the relative CAI strengths of CFRPs using different types of resins. 


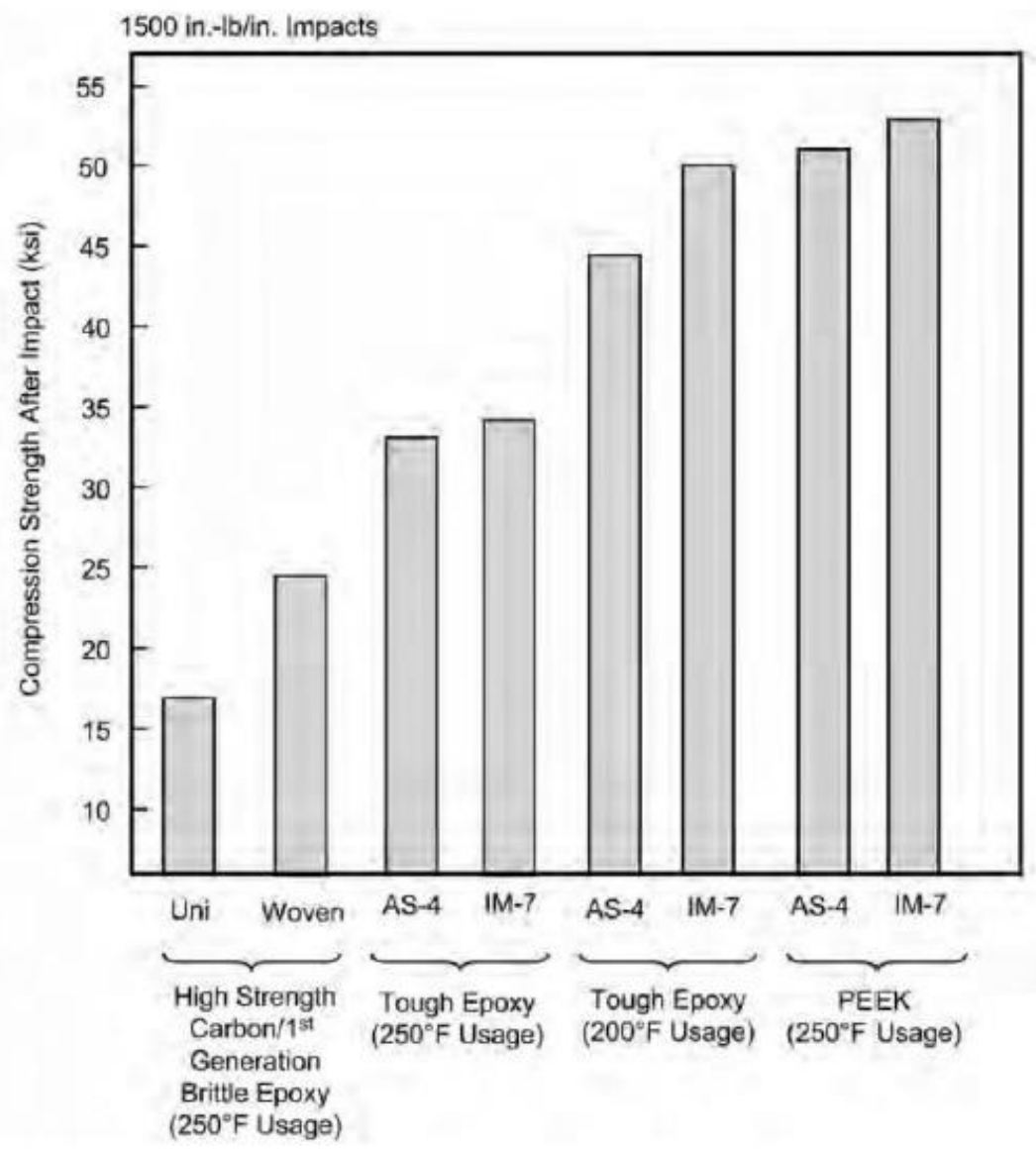

Figure 7: Relative compression after impact strengths of CFRPs [41]

There are several ways of optimizing the mechanical and impact characteristics of a composite laminate. One of the common methods employed in the industry is hybridization. The impact performance of a stiff composite such as a CFRP can be improved by replacing a few of the outer layers with low modulus and high toughness fibre such as glass or Kevlar [12]. 


\subsection{THEORY OF COMPOSITE IMPACT AND FAILURE MODES}

When a laminated composite is subjected to impact loading, the impact energy is absorbed through material deformation and the creation of new surfaces by different damage mechanisms. The damage evolution in a composite material is a complex process because it involves different types of damages such as matrix cracking, delamination, fibre breakage, fibre splitting, debonding and fibre pull-out, which usually interact with each other under a low velocity impact event [4].

\subsubsection{TyPES OF IMPACT DAMAGE}

The major types of impact damage in a composite material includes fibre breakage, matrix deformation and cracking, fibre debonding, fibre pull-out and delamination cracks. Each of these damage types will be discussed briefly as follows.

\subsubsection{FIBRE BREAKAGE}

Fibre breakage occurs when a crack propagates in the direction normal to the fibres. This occurs when the composite strain exceeds the failure strain of the fibres. Under impact loading, fibre breakage often occurs at the back face of the composite where the tensile bending stresses are the highest. Brittle fibres such as carbon have low fracture strain and undergo fibre breakage at low impact energies. Hence, the energy absorption capacity or toughness of carbon fibres is low. Aramid fibres on the other hand are ductile and can sustain higher stain levels (2-3\%) before fibre failure. The energy per unit area required for fibre breakage in tension can be expressed using the following equation.

$$
u=\frac{V_{f} \sigma_{f u}^{2} l}{6 E_{f}}
$$

where $V_{f}$ is the volume fraction, $\sigma_{f u}$ is the ultimate fibre strength, 1 is the fibre length and $E_{f}$ is the fibre tensile modulus [12]. It is worth noting that fibre breakage alone accounts for only a very small fraction of the energy absorbed by the composite material under impact loading [12]. 


\subsubsection{MATRIX DEFORMATION AND CRACKING}

When subjected to impact, the matrix constituent undergoes some deformation prior to matrix cracking. For thermosetting resins such as epoxy, this deformation is often very small due to the brittle nature of the matrix material. In fact, matrix cracking occurs at a stress level much lower than the proportional limit of the composite material [44]. Once the matrix failure strain is reached, matrix cracking occurs. The energy required to initiate matrix fracture per unit area of composite is given by the following equation.

$$
u=\frac{\left(1-V_{f}\right)^{2}}{V_{f}} \frac{\sigma_{m u} d}{4 \tau} U_{m}
$$

where $\mathrm{U}_{\mathrm{m}}$ is work done in matrix deformation to rupture per unit volume, $\sigma_{\mathrm{mu}}$ is the matrix tensile strength, $d$ is the fibre diameter and $\tau$ is the interfacial shear stress. For brittle matrices such as epoxy, the energy required for matrix deformation is small. For matrix cracking, the energy absorbed is the product of the surface energy and new area produced by the crack [12]. Thus, when a crack propagates in one direction, the new surface area produced is small resulting in small energy absorbed. For cracks branching off in multiple directions, the energy absorbed by the secondary crack is much larger than the primary crack. Secondary cracks occur when a matrix crack encounters a strong fibre placed perpendicular to the crack propagation [12]. This is the reason why cross-ply and angle-ply composites exhibit higher energy absorption capacity than unidirectional laminates [45] [46].

\subsubsection{FIBRE DEBONDING}

Fibre debonding occurs when the fibres become separated from the matrix by cracks running parallel to the fibres. This occurs when the fibres are strong and the fibre-matrix interface is weak [12]. This produces a new surface in the composite. The energy absorbed by fibre debonding depends on the size and extent of the new surface produced. A composite with weak fibre-to-matrix interface strength will absorb more impact energy through fibre debonding. Fibre debonding is also often regarded as a secondary matrix crack branching off from the primary matrix crack direction [12] 


\subsubsection{FIBRE PULLOUT}

Fibre pullout occurs when the fibres fracture at their weak cross section, not necessarily in the plane of composite fracture. This failure mode is typically seen when brittle fibres are embedded in a tough matrix material [12]. A crack initiated at a fibre break is unable to propagate into a tough matrix because the stress concentration generated by the fibre break is relieved by matrix yielding [12]. Moreover, fibre pullout also occurs when a fibre bridges the gap created due to matrix cracking. For the matrix crack to propagate, the fibres either must be loaded up to their fracture strength (fibre breakage), or be pulled out of the tough matrix (fibre pullout). The energy per unit area required for fibre pullout in a continuous fibre composite is approximated by the following equation, where $1_{c}$ is the fibre length [12].

$$
u=\frac{V_{f} \sigma_{f u} l_{c}}{12}
$$

\subsubsection{DELAMINATION CRACKS}

Delamination is the most common type of impact damage [47]. It involves the initiation and propagation of cracks running in the interlaminar region between two adjacent laminae in the composite. When a matrix crack propagates through the adjacent plies, it may get arrested by the fibres in the adjacent ply. Due to the high shear stress developed in the matrix near the crack tip, this crack may branch off in the direction parallel to the plane of the lamina [12]. This generates high interlaminar shear stresses in between plies, causing the delamination cracks. In terms of energy, this type of damage is responsible for a large amount of fracture energy absorbed during impact. The energy $U$ required to produce delamination damage based on a force-driven model was derived by Davies and Zhang [48] as follows:

$$
U=\frac{9 P_{C}^{2}\left(1-v^{2}\right)}{8 \pi^{2} t^{3} G_{C}}
$$

where $\mathrm{P}_{\mathrm{C}}$ is the threshold force for the onset of delamination (obtained from the load-time history plot), $\mathrm{E}$ is the elastic modulus, $v$ is the Poisson's ratio, $t$ is the laminate thickness and $\mathrm{G}_{\mathrm{C}}$ is the mode II critical inter-laminar energy release rate of the composite material. 


\subsection{IMPACT TESTING OF COMPOSITE LAMINATES}

There are several testing methods used to evaluate the mechanical and damage response of a composite plate under low velocity impact loading. One of the most common method is the Charpy impact test. This test method is used to evaluate the toughness of a material by measuring the energy required to fracture a specimen. In this method, a rectangular V-notched specimen is simply supported on both ends and a swinging anvil impacts the specimen directly opposite the notch.

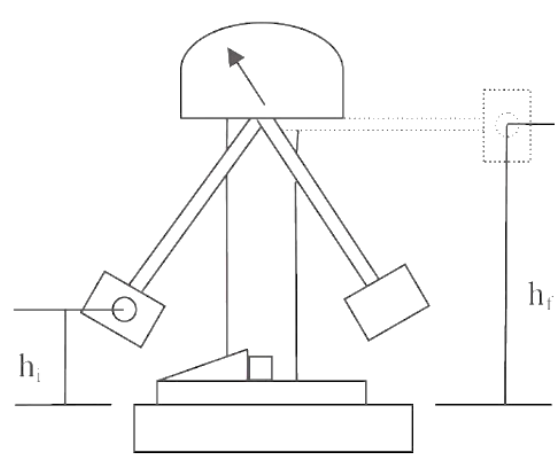

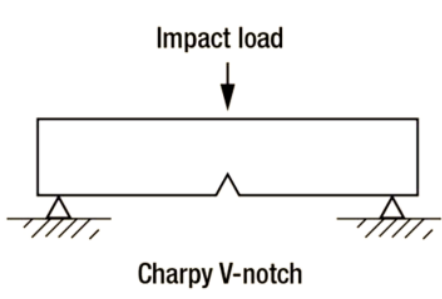

a)

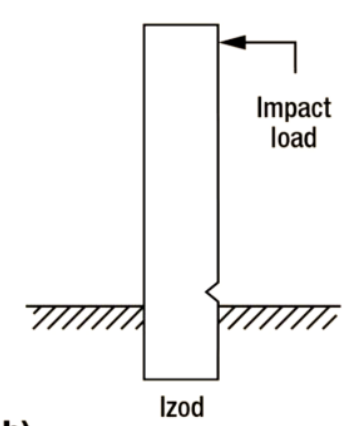

b)

Figure 8: Charpy/Izod impact test setup [49]

This test is based on the principle of the conservation of energy, in which the difference in the potential energies before and after striking the specimen amounts to the energy absorbed by the specimen.

$$
E_{\text {absorbed }}=m g\left(h_{0}-h_{f}\right)
$$

where $\mathrm{m}$ is the mass, $\mathrm{g}$ is the acceleration due to gravity, $\mathrm{h}_{0}$ is the initial height and $\mathrm{h}_{\mathrm{f}}$ is the final height. This test was originally developed for metallic materials (ASTM E23-16B) but was later also applied to plastic (ASTM D6110-10) and composite materials. A similar test method is the Izod impact test. This method uses the same impact pendulum apparatus, except that the test specimen is held as a cantilever and the impact load is applied at the free end of the cantilever. In both tests, the specimen is broken in flexure by the single blow of the swinging pendulum. 
Both the Charpy and Izod test methods are suitable for isotropic materials such as metals, where the failure mode is tensile at the notch root. Fibre-reinforced composite material on the other hand are anisotropic, and the failure mode under impact loading is often complex and typically involves a combination of multiple failure modes such as fibre breakage, matrix cracking, delamination, fibre pullout and debonding. The mode of fracture of the composite material depends on several parameters such as fibre orientation, specimen geometry, impact velocity and other test variables [12]. Thus, a basic Charpy or Izod impact test will not provide significant information about the energy absorbed and the damage mechanisms involved during a material failure in impact [12]. Advances in technology have led to instrumentation of Charpy impact test apparatus with force transducers [49] to record the load history during the impact event; however, test parameters such as impact velocity and available energy are usually held constant. This limitation of the Charpy impact test resulted in the development of other types of impact test systems [12].

The more common method for the low velocity impact testing of FRP composite materials is the drop weight impact test. In this testing method, the composite plate is placed on rigid supports and a known mass with a striker tip is dropped from a certain height to impact the specimen. The mass and drop height of the falling weight can be adjusted to achieve the desired impact velocity and energy.
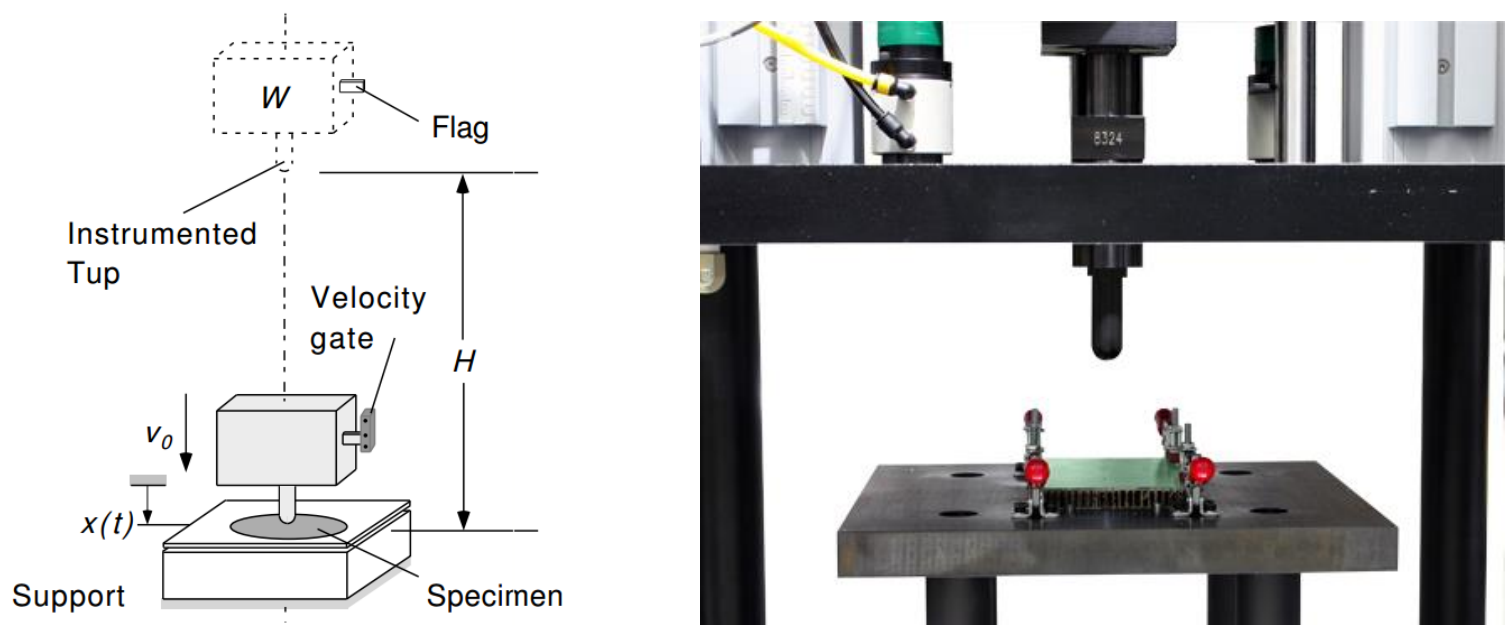

Figure 9: Drop weight impact test setup for composite plates [49] [50] 
The standard procedure for conducting low velocity drop weight impact testing of FRP composites is defined in ASTM D7136/D7136M-15. A typical drop-weight impact testing apparatus consists of a drop tower with a rigid base, a drop weight impactor, a rebound catcher and a guide mechanism. The base of the tower consists of a support fixture that rigidly restrains the test specimen during impact. The standard specimen used is a 6 in. $\times 4$ in. $(150 \mathrm{~mm} \times 100 \mathrm{~mm})$ rectangular plate rigidly clamped onto a fixture base with a 5 in. $\times 3$ in. $(125 \mathrm{~mm} \times 75 \mathrm{~mm})$ window cut-out. The impactor used in the test is a $5.5 \mathrm{~kg}$ mass with a 16-mm diameter smooth hemispherical tip. If the desired energy cannot be achieved using the standard impactor mass dropped from a height of at least $12 \mathrm{in.}(300 \mathrm{~mm})$, an impactor mass of $2.0 \mathrm{~kg}$ can be used. [51]
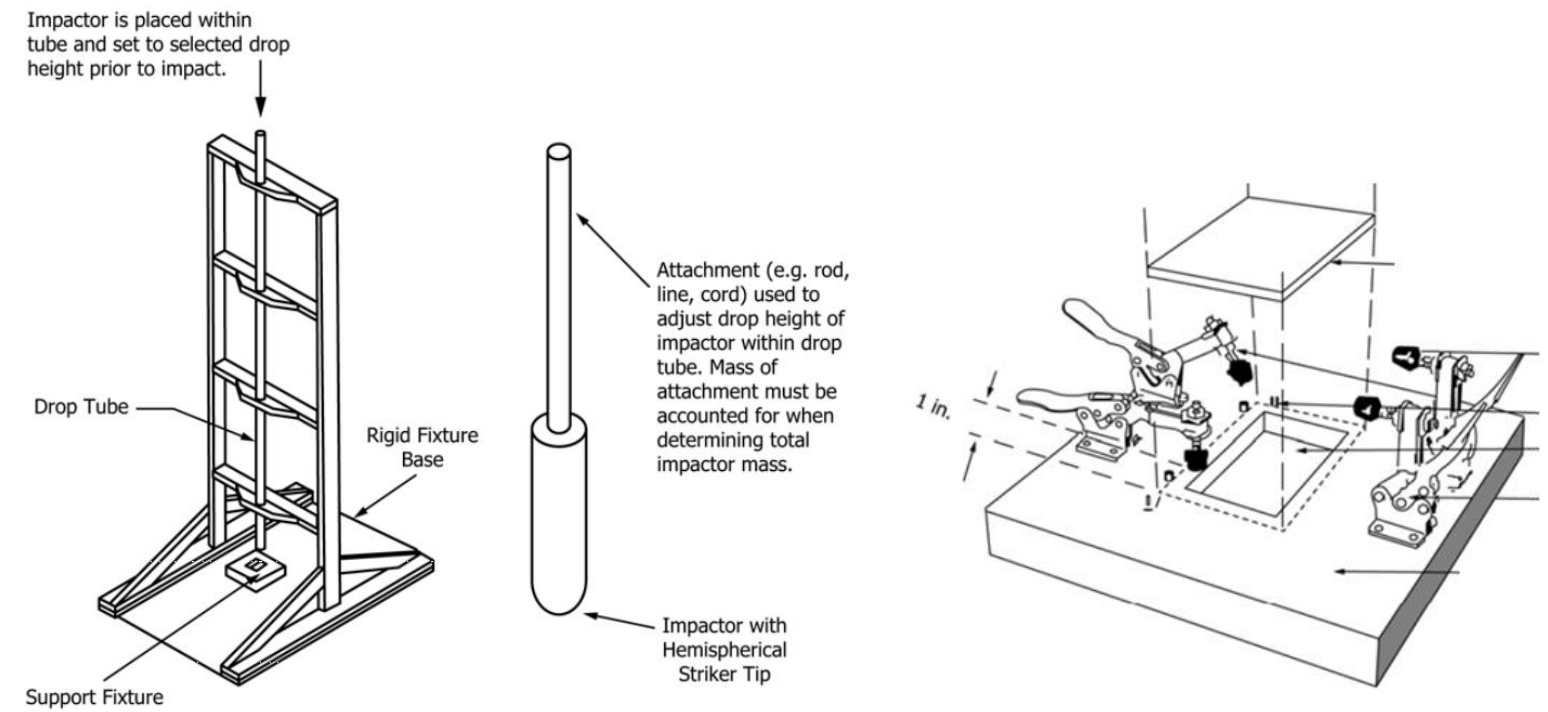

Figure 10: (a) Drop weight impact test fixture per ASTM D7136 [51]

In a drop weight impact test, the support fixture or the striker is typically instrumented to record the load and strain history during the impact event. This allows the data acquisition software to generate force-time, energy-time, deflection-time and load-deflection curves such as shown in Figure 11 (next page). These curves provide valuable information regarding the material behaviour during an impact event. 


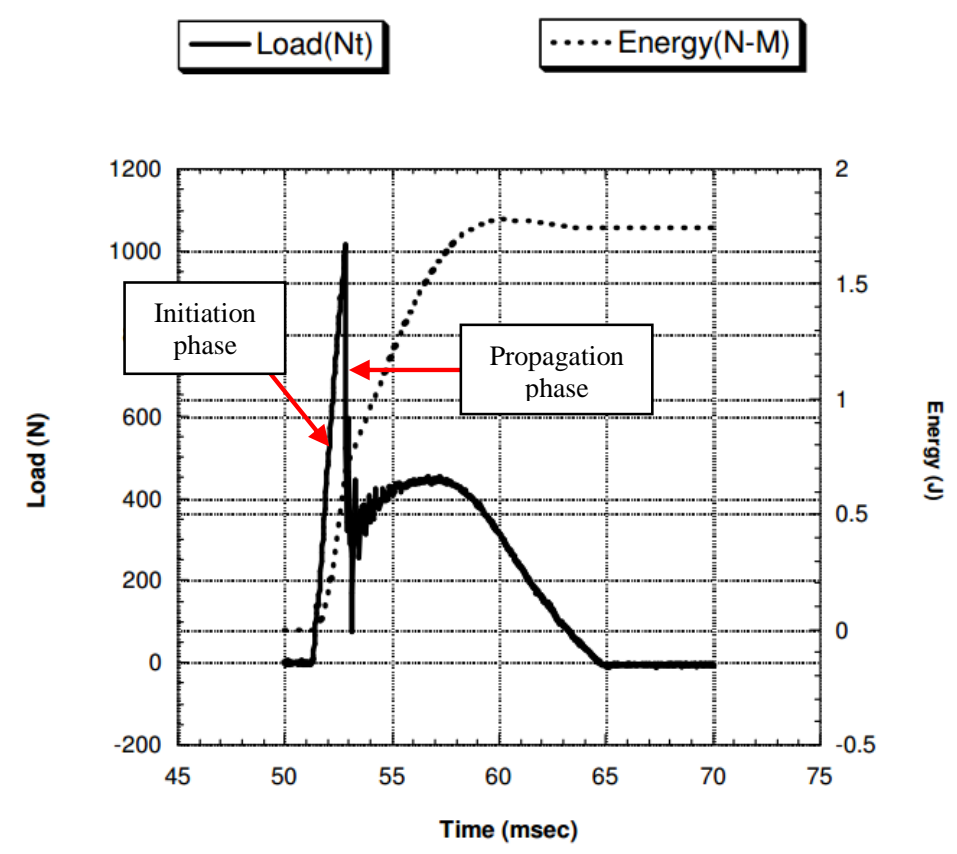

(a)
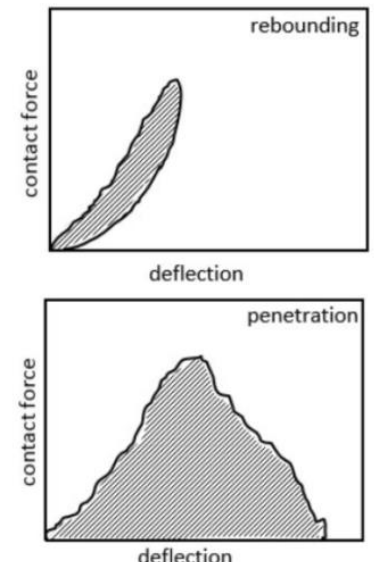

deflection

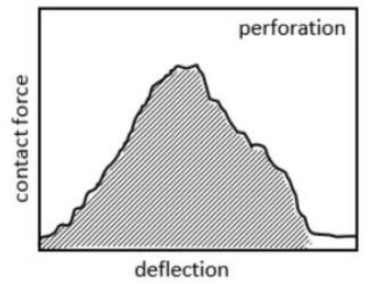

(b)

Figure 11: (a) Load and energy vs. time [49]; (b) load-deflection curves [52]

From the load vs. time curve shown in Figure 11a, one can distinguish the damage initiation phase as indicated by the steady increase in load, which is then followed by a sudden load drop during the damage propagation phase leading to fracture. The slope of the damage initiation phase indicates whether the fracture propagates in a brittle or progressive manner [12]. Integrating the load vs. time curve will give the total energy absorbed $E_{t}$ by the specimen, which is the sum of the initiation energy $E_{i}$ and the propagation energy $E_{p}$.

$$
E_{t}=v \int P d t=E_{i}+E_{p}
$$

A brittle material will have higher $E_{i}$ but lower $E_{p}$, while a ductile material will have lower $E_{i}$ but higher $E_{p}$ [12]. In addition, the load-deflection curves in Figure $11 \mathrm{~b}$ indicate whether the impactor is rebounding, penetrating or perforating the specimen [52]. 


\section{Experimental Testing \& ANAlysis}

The experimental aspect of this study is divided into two parts. The first part of the experiment is the low velocity impact testing of 16-layer pure flax fibre/epoxy composite laminate. The purpose of this experiment is to characterize the impact and damage response of the composite under such loading. The second part of the experiment is the low velocity impact testing of a hybridized aramid-flax fibre/epoxy composite. Twelve layers of flax fibre/epoxy plies are sandwiched in between two top and bottom layers of woven Kevlar 49/epoxy plies. The purpose of this study is to determine and quantify the improvement in the impact properties of the flax fibre/epoxy laminate by replacing the top and bottom two layers with a tougher fibre-reinforcement material.

\subsection{Composite Laminate Materials}

\subsubsection{FLAX/EPOXY LAMINATE}

The flax fibre/epoxy composite laminate is manufactured from 16 layers of commercially available dry FlaxPly® UD150 fabric (Lineo NV, Belgium). The fabric architecture consists of twisted fibre bundles predominantly in the warp $\left(0^{\circ}\right)$ direction, held together by periodic crossweave $\left(90^{\circ}\right)$ [11]. Microscopic observations of the composite cross section indicate that the fibre bundles measure between 150-250 $\mu \mathrm{m}$ in diameter, with individual flax fibres of 10-30 $\mu \mathrm{m}$ in diameter [11]. The physical properties of the fibre per supplier's specifications are as follows:

Table 3: Basic Physical Properties of Lineo FlaxPly UD150 [53]

\begin{tabular}{|ccc|}
\hline Property & Unit & Value \\
\hline Density & $\mathrm{g} / \mathrm{cm}^{3}$ & 1.45 \\
\hline Areal Weight & $\mathrm{g} / \mathrm{m}^{2}$ & 154 \\
\hline Areal Volume & $\mathrm{mm}^{3} / \mathrm{mm}^{2}$ & 0.106 \\
\hline Thickness & $\mathrm{mm}$ & 0.165 \\
\hline Weave Style & --- & ribs $4 / 4$ \\
\hline Yarns/cm & (warp) & 52 \\
\hline Picks/cm & (weft yarns) & 3 \\
\hline
\end{tabular}


For the matrix, the Araldite ${ }^{2}$ LY 1564 (epoxy) + Aradur ${ }^{\circledR} 22962$ (hardener) thermosetting resin system is used. Araldite LY 1564 is a low viscosity resin and Aradur 22962 is a cycloaliphatic polyamine hardener [54]. This resin system was selected because it has a maximum curing temperature of $150^{\circ} \mathrm{C}$, which is below the degradation temperature of the flax fibres. An epoxyto-hardener ratio of 100:25 parts by weight was used as per supplier's recommendation. The following table shows the physical and mechanical properties of the resin per supplier's specifications:

Table 4: Physical and Mechanical Properties of the Resin System per supplier [54]

\begin{tabular}{|lcc|}
\multicolumn{1}{|c}{ Property } & Unit & Value \\
\hline Density at $\mathbf{2 5}^{\circ} \mathbf{C}$ (Araldite LY 1564) & $\mathrm{g} / \mathrm{cm}^{3}$ & $1.10-1.20$ \\
\hline Density at $\mathbf{2 5}^{\circ} \mathbf{C}$ (Aradur 22962) & $\mathrm{g} / \mathrm{cm}^{3}$ & $0.89-0.90$ \\
\hline Density of resin (100:25) - Calculated & $\mathrm{g} / \mathrm{cm}^{3}$ & $1.06-1.14$ \\
\hline Young's Modulus & $\mathrm{GPa}$ & $2.8-3.3$ \\
\hline Tensile Strength & $\mathrm{MPa}$ & $75-80$ \\
\hline Tensile Fail strain & $\%$ & $3.5-8.0$ \\
\hline
\end{tabular}

A previous study [11] conducted tensile test on the same resin system and the resulting physical and mechanical properties are shown in the table below:

Table 5: Physical and Mechanical Properties of the Resin System from test [11]

\begin{tabular}{|lcc|}
\multicolumn{1}{|c}{ Property } & Unit & Value \\
\hline Density of resin (100:25) & $\mathrm{g} / \mathrm{cm}^{3}$ & $1.15 \pm 0.04$ \\
\hline Young's Modulus (Tension) & $\mathrm{GPa}$ & $3.03 \pm 0.46$ \\
\hline Young's Modulus (Compression) & $\mathrm{GPa}$ & $3.57 \pm 0.38$ \\
\hline Poisson's Ratio (Tension) & & $0.403 \pm 0.007$ \\
\hline Strength (Tension) & $\mathrm{MPa}$ & $67.17 \pm 2.45$ \\
\hline Strength (Compression) & $\mathrm{MPa}$ & $73.99 \pm 4.64$ \\
\hline Fail strain (Tension) & $\%$ & $3.61 \pm 0.23$ \\
\hline Fail strain (Compression) & $\%$ & $3.72 \pm 0.95$ \\
\hline
\end{tabular}


Two laminate configurations were manufactured based on laminate stack-up sequence:

(1) 16-layer unidirectional composite laminate with laminate code [0] $]_{85}$;

(2) 16-layer cross-ply laminate with laminate code $[0 / 90]_{4 \mathrm{~s}}$.

The resulting flax/epoxy laminate thickness is approximately $3.7 \mathrm{~mm}$.

\subsubsection{ARAMid-Flax/EPOXy Hybrid Laminate}

The hybrid aramid-flax/epoxy composite laminate is manufactured from 12 layers commercially available dry UD FlaxPly® fabric, sandwiched in between four layers of plain weave Kevlar® 49 (BGF Industries - Style 5500) fabric. The following table shows the physical and mechanical characteristics of the specific fabric used:

Table 6: Basic Physical Properties of Kevlar 49 Woven Fabric [55] [56]

\begin{tabular}{|ccc|}
\hline Property & Unit & Value \\
\hline Density & $\mathrm{g} / \mathrm{cm}^{3}$ & 1.44 \\
\hline Denier & --- & 1420 \\
\hline Thickness & $\mathrm{mm}$ & 0.254 \\
\hline Areal weight & $\mathrm{g} / \mathrm{m}^{2}$ & 169.5 \\
\hline Count & $($ Ends $\times$ picks)/inch & $13 \times 13$ \\
\hline Breaking strength (warp) & $\mathrm{lb} / \mathrm{in}$ & 650 \\
& $\mathrm{~N} / \mathrm{mm}$ & 113.8 \\
\hline Breaking strength (fill) & $\mathrm{lb} / \mathrm{in}$ & 650 \\
& $\mathrm{~N} / \mathrm{mm}$ & 113.8 \\
\hline
\end{tabular}

The Kevlar manufacturer (BFG Industries, Greensboro, NC, USA) does not have the tensile stiffness and strength data of this specific type of fabric. In the literature, there are some data available on unidirectional aramid yarns but very little on woven fabrics. There is one study [57] that performed mechanical characterization of plain weave Kevlar 49 fabric, but it is for a 17 $\times 17$ yarns per inch weave pattern. Their test result shows the following fabric mechanical properties: 
Table 7: Basic Mechanical Properties of 17 x 17 Plain Weave Kevlar 49 [57] [55]

\begin{tabular}{|ccc|}
\hline Property & Unit & Value \\
\hline Elastic Modulus & $\mathrm{GPa}$ & 117 \\
\hline Tensile Strength & $\mathrm{MPa}$ & 1800 (average value) \\
\hline Ultimate Strain & $\mathrm{mm} / \mathrm{mm}$ & 0.020 \\
\hline Poisson's Ratio & --- & $0.35-0.63$ \\
\hline Breaking strength (warp) & $\mathrm{lb} / \mathrm{in}$ & 500 \\
\hline Breaking strength (fill) & $\mathrm{lb} / \mathrm{in}$ & 500 \\
\hline
\end{tabular}

The Kevlar fabric used in this research is a 13 x 13 yarns/inch plain weave Kevlar 49. Per manufacturer's specifications, the breaking strength of the fabric is $650 \mathrm{lb} / \mathrm{in}$ in both the warp and fill directions. The elastic modulus should not change significantly based on the weave pattern; however, the tensile strength and fail strain will change. By factoring the tensile strength and strain in Table 9 by the ratio of breaking strengths, the tensile strength and strain for the $13 \times 13$ plain weave fabric can be approximated.

Table 8: Basic Mechanical Properties of 13 x 13 Plain Weave Kevlar 49

\begin{tabular}{|ccc|}
\hline Property & Unit & Value \\
\hline Elastic Modulus & $\mathrm{GPa}$ & 117 \\
\hline Tensile Strength & $\mathrm{MPa}$ & 2340 (factored) \\
\hline Ultimate Strain & $\mathrm{mm} / \mathrm{mm}$ & 0.026 \\
\hline Poisson's Ratio & --- & $0.35-0.63$ \\
\hline Breaking strength (warp) & $\mathrm{lb} / \mathrm{in}$ & 650 \\
\hline Breaking strength (fill) & $\mathrm{lb} / \mathrm{in}$ & 650 \\
\hline
\end{tabular}

Two laminate configurations were manufactured based on fibre orientation and laminate stack-up sequence: F stands for flax and K for Kevlar.

(1) 16-layer unidirectional composite laminate with laminate code $\left[0_{2 \mathrm{~K}} / 0_{6 \mathrm{~F}}\right] \mathrm{s}$;

(2) 16-layer cross-ply laminate with laminate code $\left[0_{2 \mathrm{~K}} /(0 / 90)_{3 \mathrm{~F}}\right]_{\mathrm{s}}$.

where F stands for flax and $\mathrm{K}$ for Kevlar. The laminate thickness for both is about $3.4 \mathrm{~mm}$. 


\subsection{COMPOSITE LAMinate FABRication}

The composite laminate manufacturing process at Ryerson University uses a customized procedure, which combines hand lay-up and compression moulding processes. The laboratory in the Department of Mechanical Engineering has a compression moulding machine (Carver Auto Series Press), which is a hydraulic press consisting of a 15 in. x 15 in. heated platens, capable of providing up to 30 tons of clamping force. It has a built-in control panel which allows the user to control the temperature and clamping force at each segment of the composite curing cycle. A photograph of the machine is shown below:

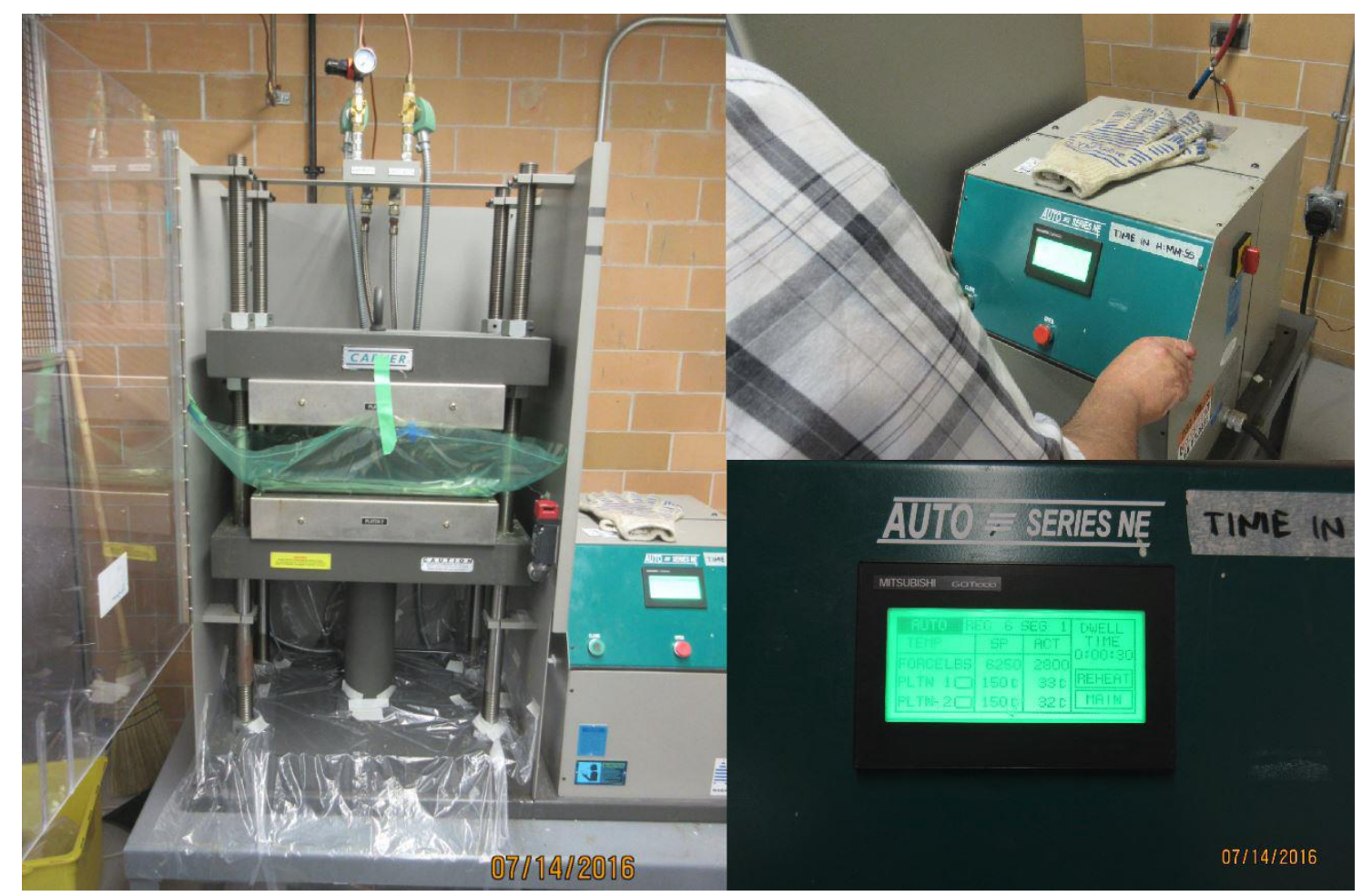

Figure 12: Carver Auto Series Compression Moulding Machine at Ryerson University

The laminates were fabricated using a wet hand lay-up process followed by compression moulding process. Two metallic steel plates were used as the moulding tool. The layers of lamina were stacked up and sandwiched in between the plates and then compression moulded to cure the resin. The following procedure details the steps involved in the manufacturing of the laminate. 


\section{Step 1: Mould Preparation}

The first step is the moulding tool preparation. In this process, the at moulding plates were first covered in high-temperature (HT) plastic membrane to protect the plates from resin leakage and contamination. This protective membrane is a high temperature plastic that can withstand temperatures up to $400^{\circ} \mathrm{F}$. This is well above the curing temperature of most thermosetting resins. As a result, the resin will not leak out of the plastic membrane as it cures under high temperature. Care was taken that the plastic membrane was tightly wrapped around the mould so that the laminate remained flat and even after being assembled.

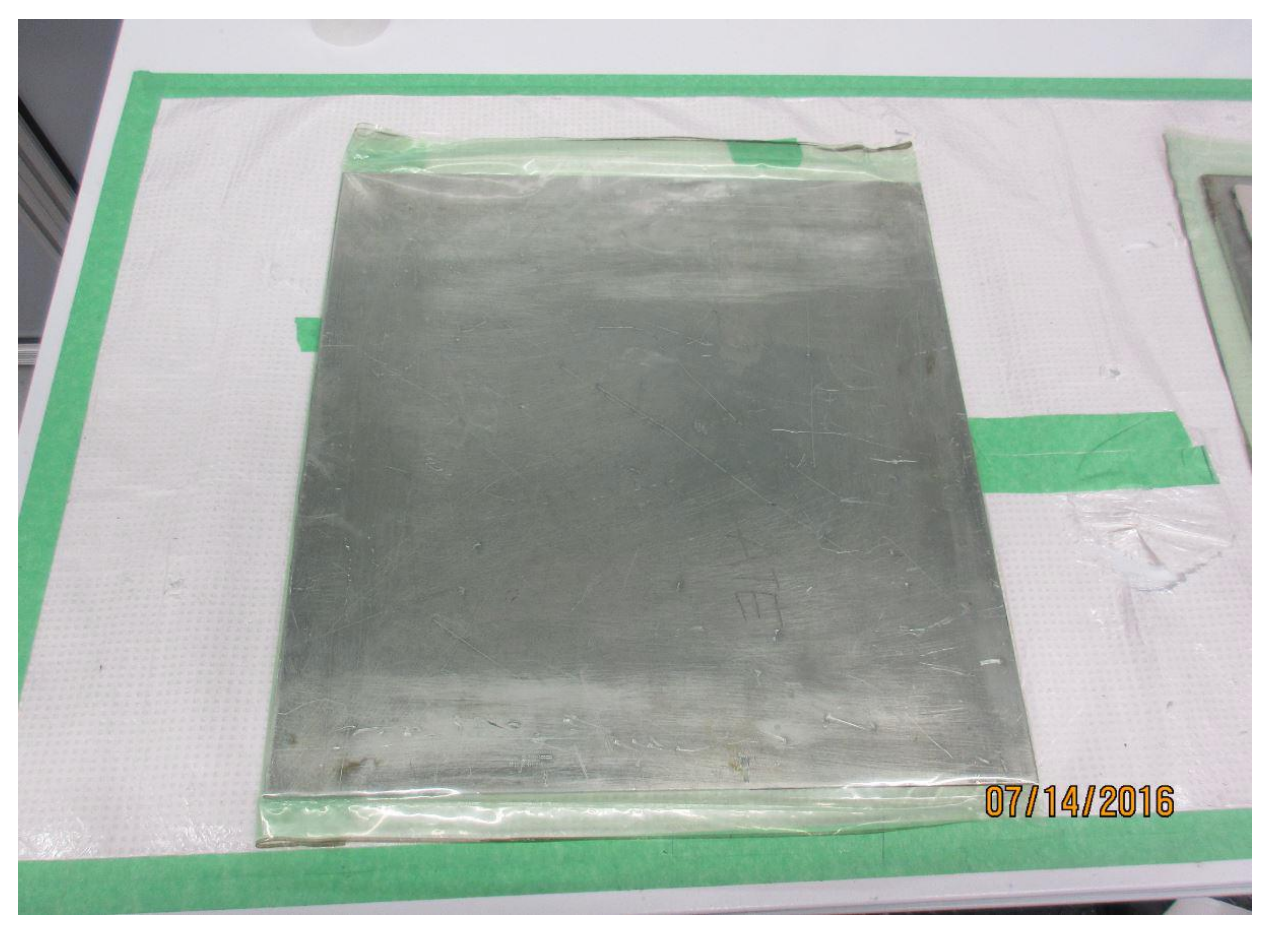

Figure 13: Moulding plate wrapped in HT plastic membrane

After wrapping the plates with HT plastic membrane, two layers of high temperature sealant tape were placed at the center of the lower plate, outlining the perimeter of the laminate. The purpose of the sealant tape was to prevent lamina slippage during compression moulding. The sealant tape also acted as cushion, preventing the laminate from being fully compressed, and the resin from fully squeezing out of the mould. 


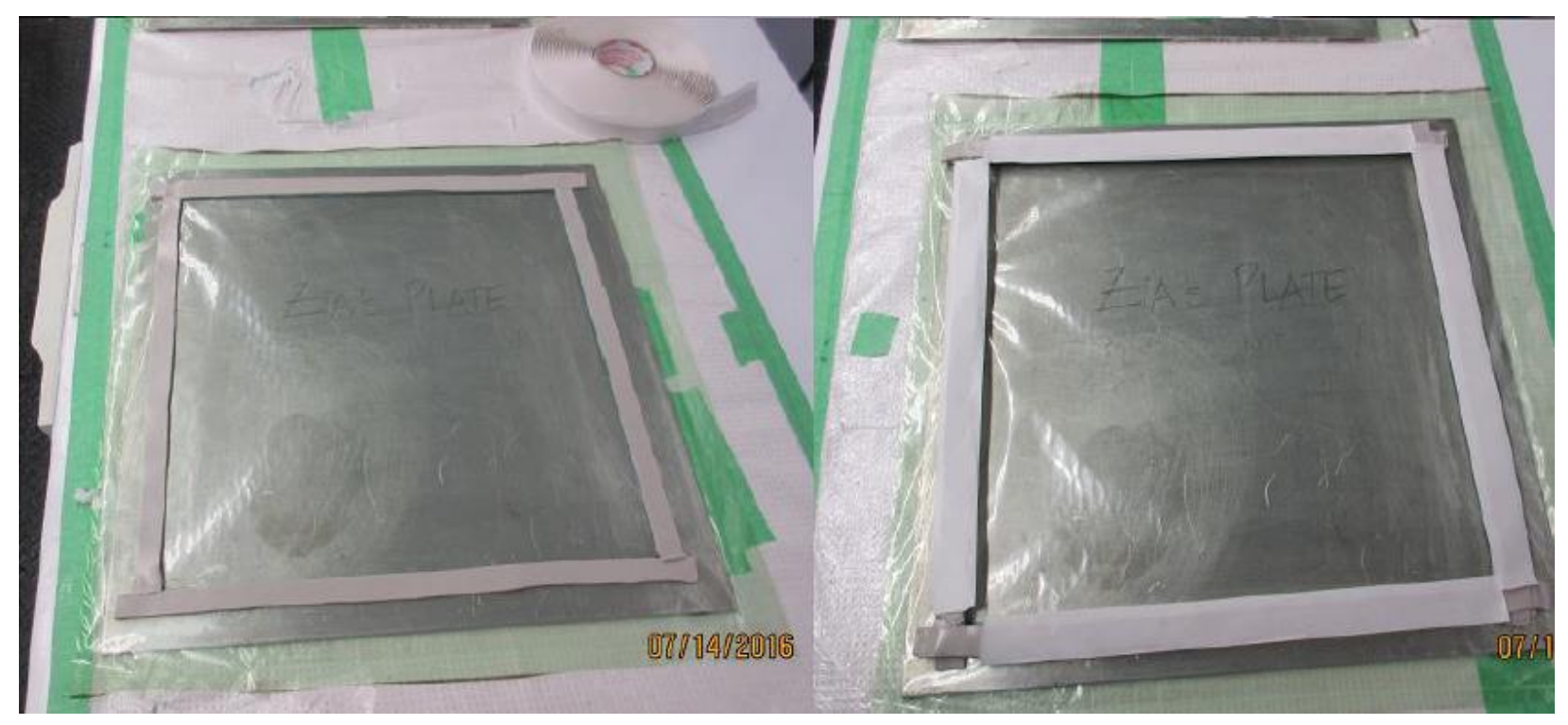

Figure 14: Application of high temperature sealant tape to form the mould cavity

\section{Step 2: Hand Lay-up}

A layer of peel ply was first applied at the bottom of the mould. The peel ply is a nylonbased fabric that prevented the laminate from sticking into the mould. Although it is a tightly woven fabric, it still allowed excess resin and air to flow through, thus eliminating voids in the laminate. After the peel ply was laid, a portion of the resin mixture was added. The resin was evenly spread throughout the entire area of the peel ply using a paint brush. Thereafter, a serrated roller was used to eliminate air pockets entrapped underneath the fabric.

Following the application of the peel ply and resin, successive layers of the reinforcement fibre and resin were applied. At each layer, the resin was evenly spread on the fabric using a paint brush. Serrated rollers were then used to rid the laminate of air pockets trapped in-between layers of the lamina.

After all the layers of lamina have been stacked, a final layer of peel ply was placed. The mould was then closed, bagged and sealed inside a high temperature plastic membrane to prevent the excess resin from dripping while the assembly was being compressed. The assembly was then placed inside the compression moulding machine. For even distribution of force and temperature during compression, the mould assembly was centrally aligned on the machine's platen. 


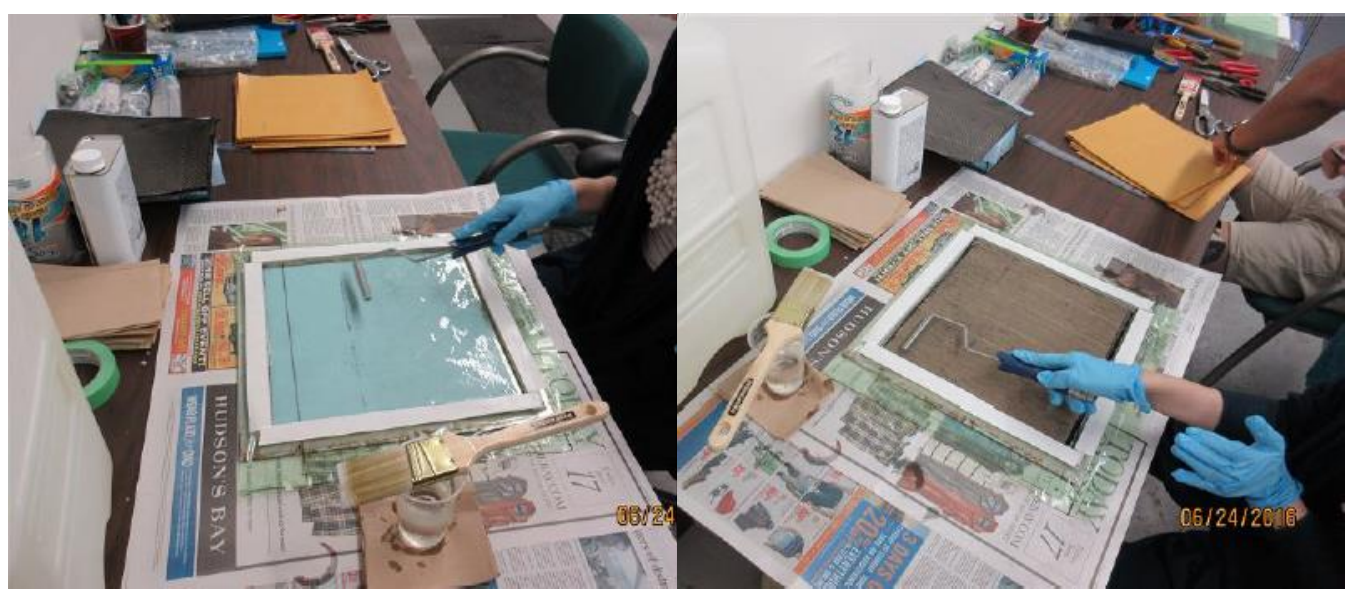

Figure 15: Peel ply and flax fibre wet lay-up process

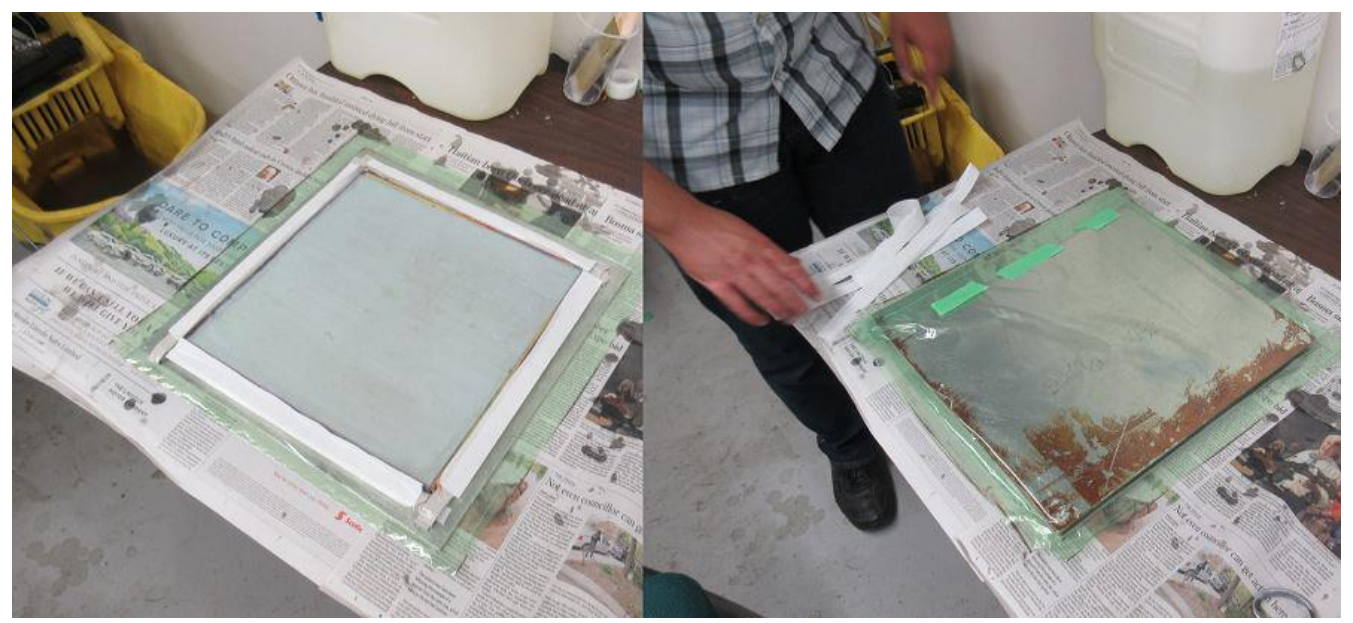

Figure 16: Peel ply application (left) before closing the mould with the top plate (right)

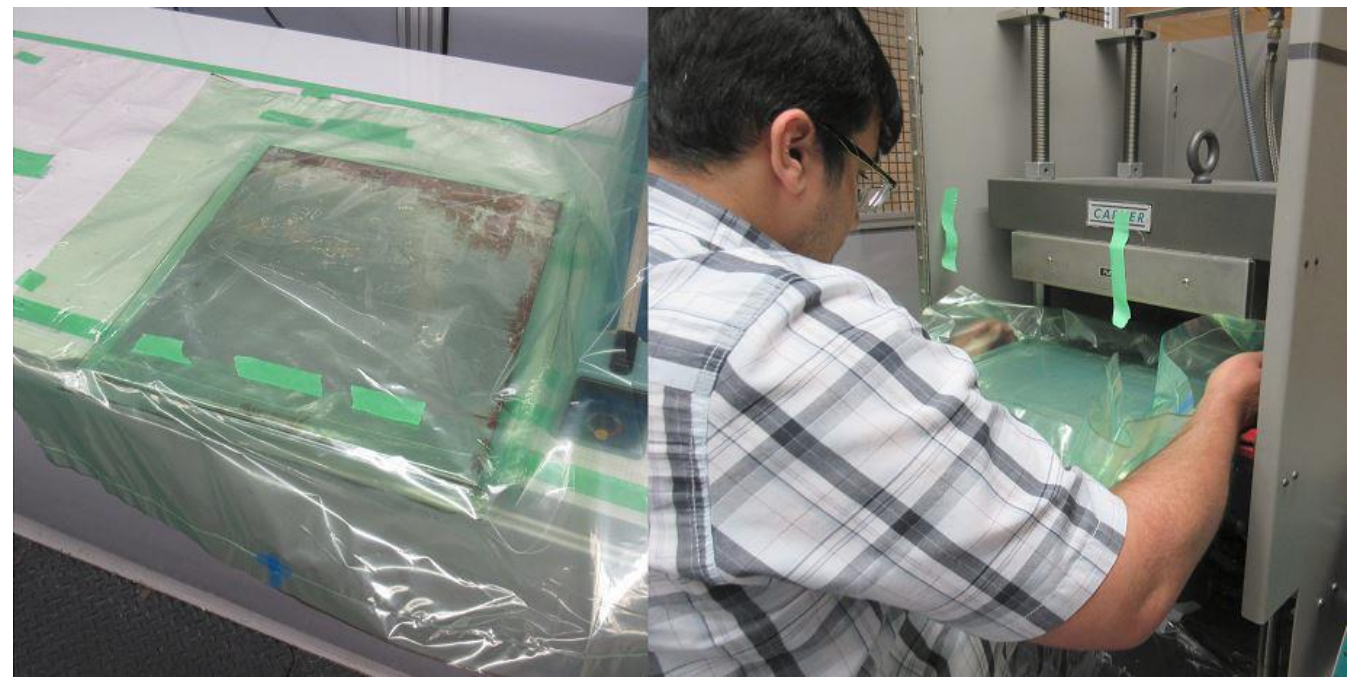

Figure 17: HT membrane bagging (left); Compression moulding machine installation (right) 


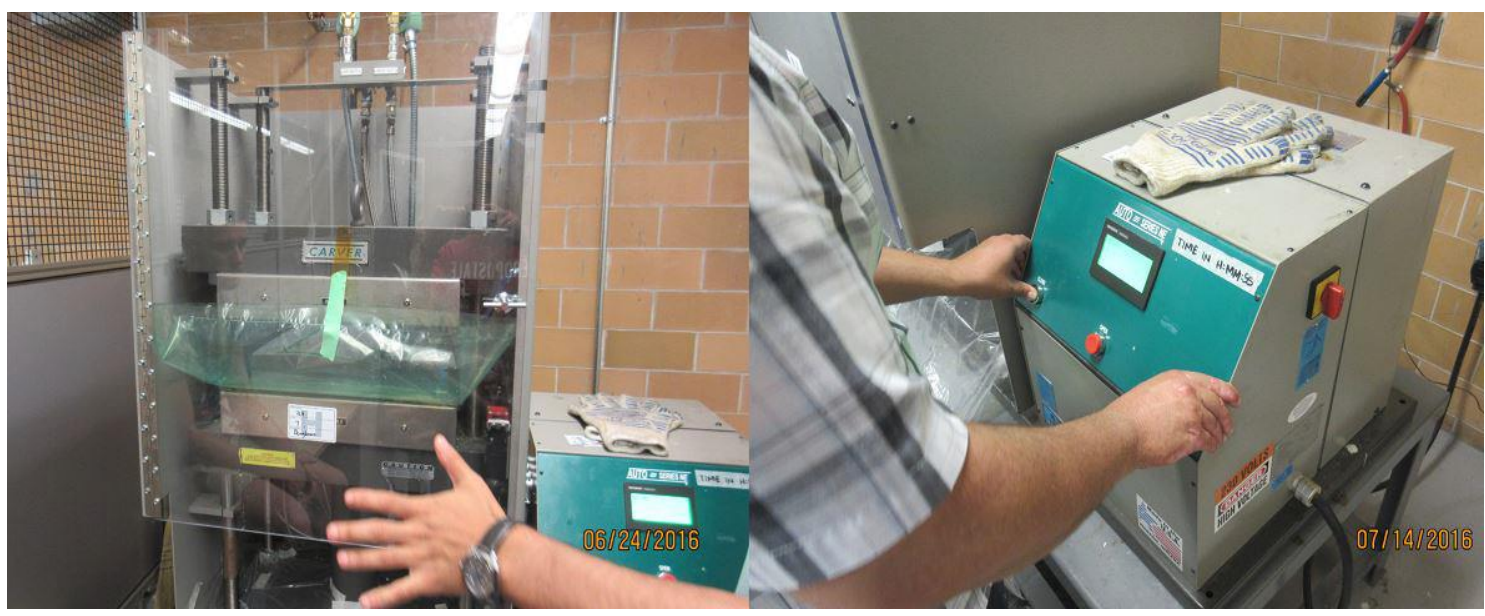

Figure 18: Closing of the protective glass (left) and start of compression (right)

\section{Step 4: Curing Process}

For the curing cycle, the plates were initially heated from room temperature to $150^{\circ} \mathrm{C}$ at 2.5 bars pressure for $0.5 \mathrm{~h}$. This was followed by a steady curing stage for $2.5 \mathrm{~h}$ at $150^{\circ} \mathrm{C} / 5 \mathrm{bars}$, and a cooling stage from $150^{\circ} \mathrm{C}$ to room temperature for another $1 \mathrm{~h}$ while maintaining 5 bars pressure. This curing cycle was selected based on a previous works [58] [11] utilizing similar fibre and resin constituents, and the same number of plies. Based on several trials and errors in changing the manufacturing parameters (time, pressure and temperature), this curing cycle produced a laminate with a fibre volume fraction of $50-60 \%$ and an acceptable void content of $\leq 3 \%$ [58]. Figure 19 shows optical microscopic images of the Kevlar-flax/epoxy laminate cross section.

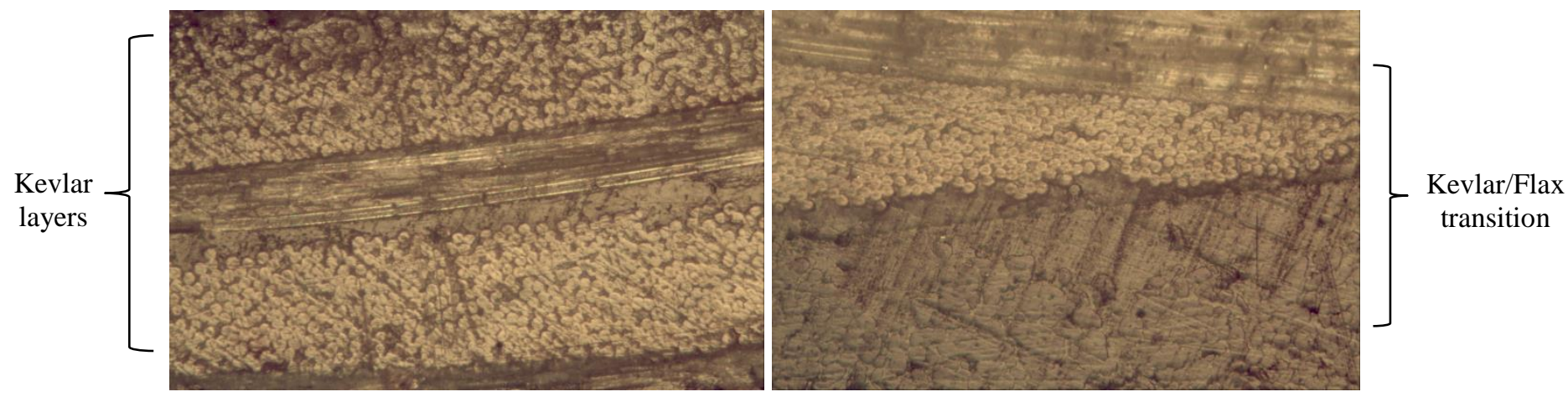

Figure 19: Optical Microscopic images of the Kevlar-flax/epoxy laminate cross section 
An exploded assembly of the different tools and materials used to fabricate the 16-layer flax/epoxy composite laminate is shown in Figure 20 below.

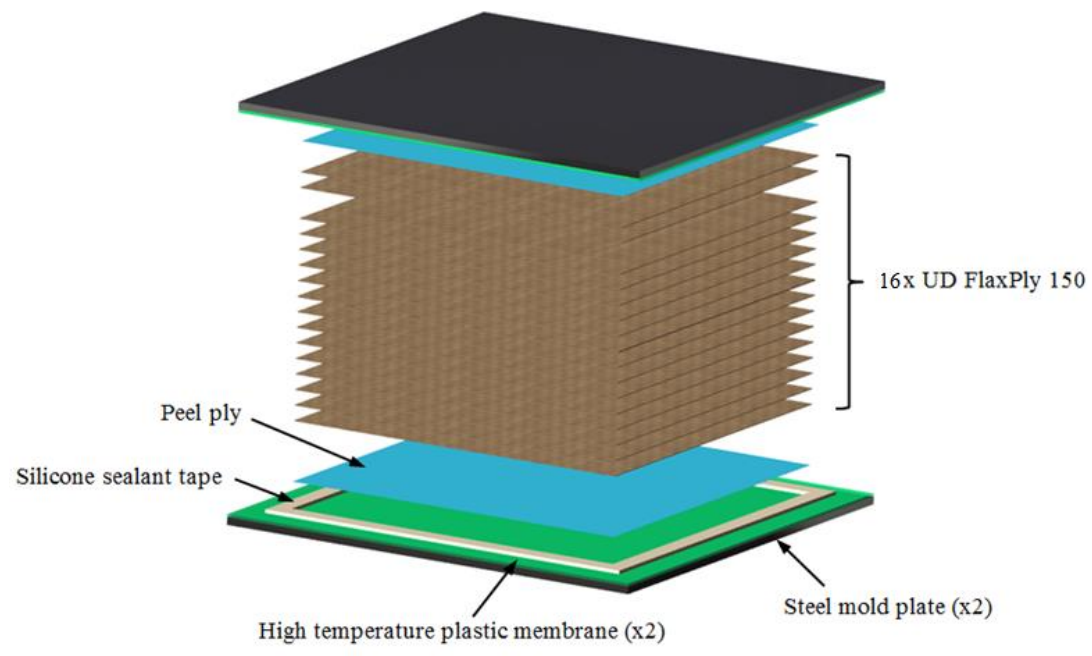

Figure 20: 16-layer Flax/epoxy laminate fabrication assembly

For the Kevlar-flax/epoxy composite laminate fabrication, a similar exploded assembly is shown in Figure 21. The assembly is essentially the same as that of Figure 20, except that the top and bottom two layers of flax fabric were replaced with woven Kevlar 49 fabrics.

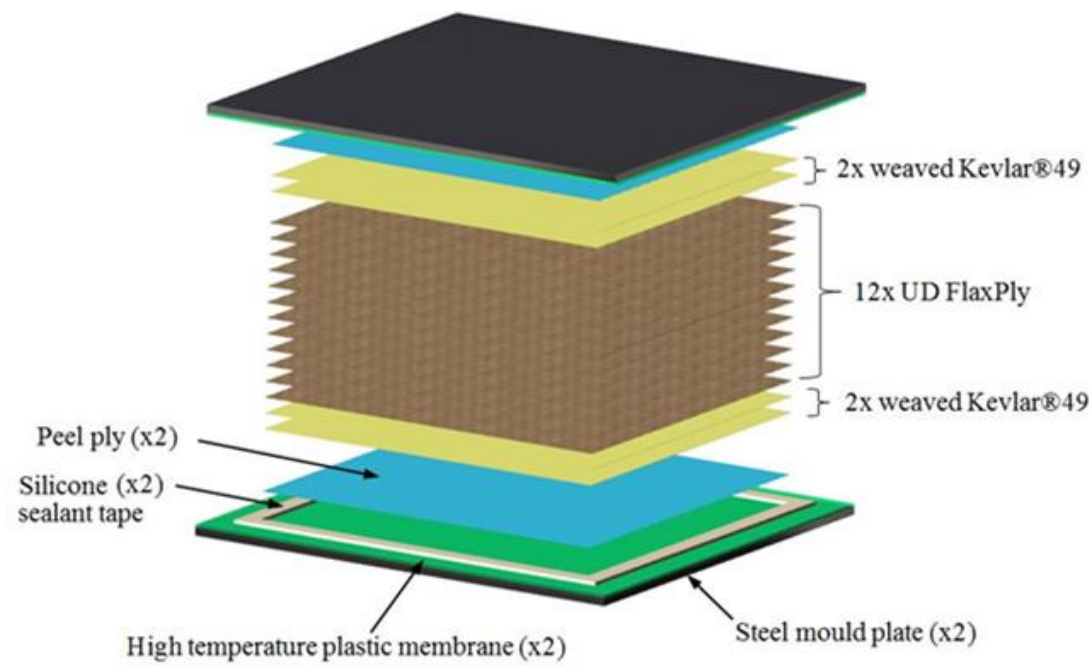

Figure 21: Kevlar-flax/epoxy laminate fabrication assembly 
The curing temperature and pressure cycles used during the compression molding of the composite laminates are graphically shown in Figure 22 and Figure 23, respectively.

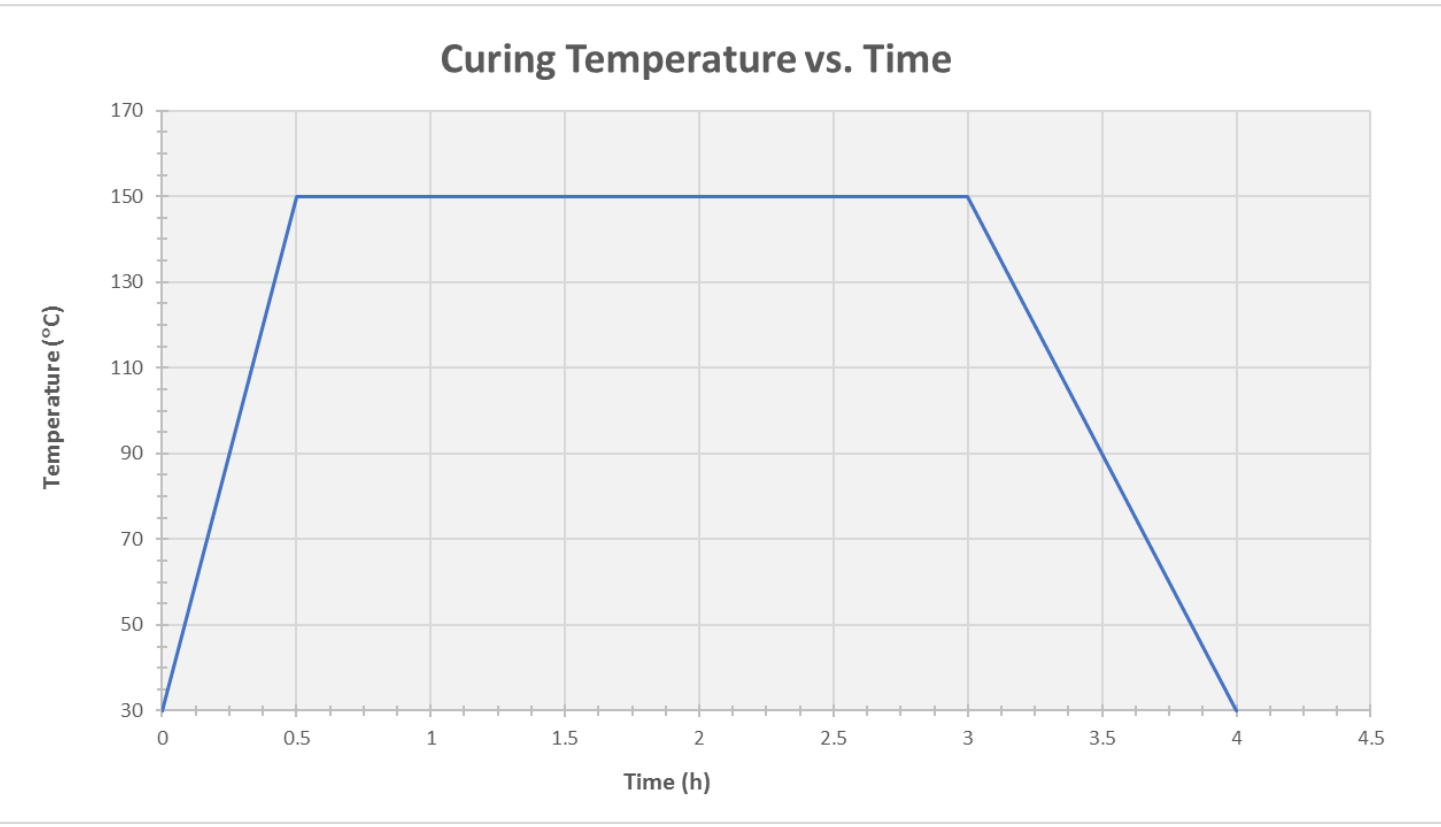

Figure 22: Curing temperature cycle for the flax and Kevlar-Flax/epoxy composite

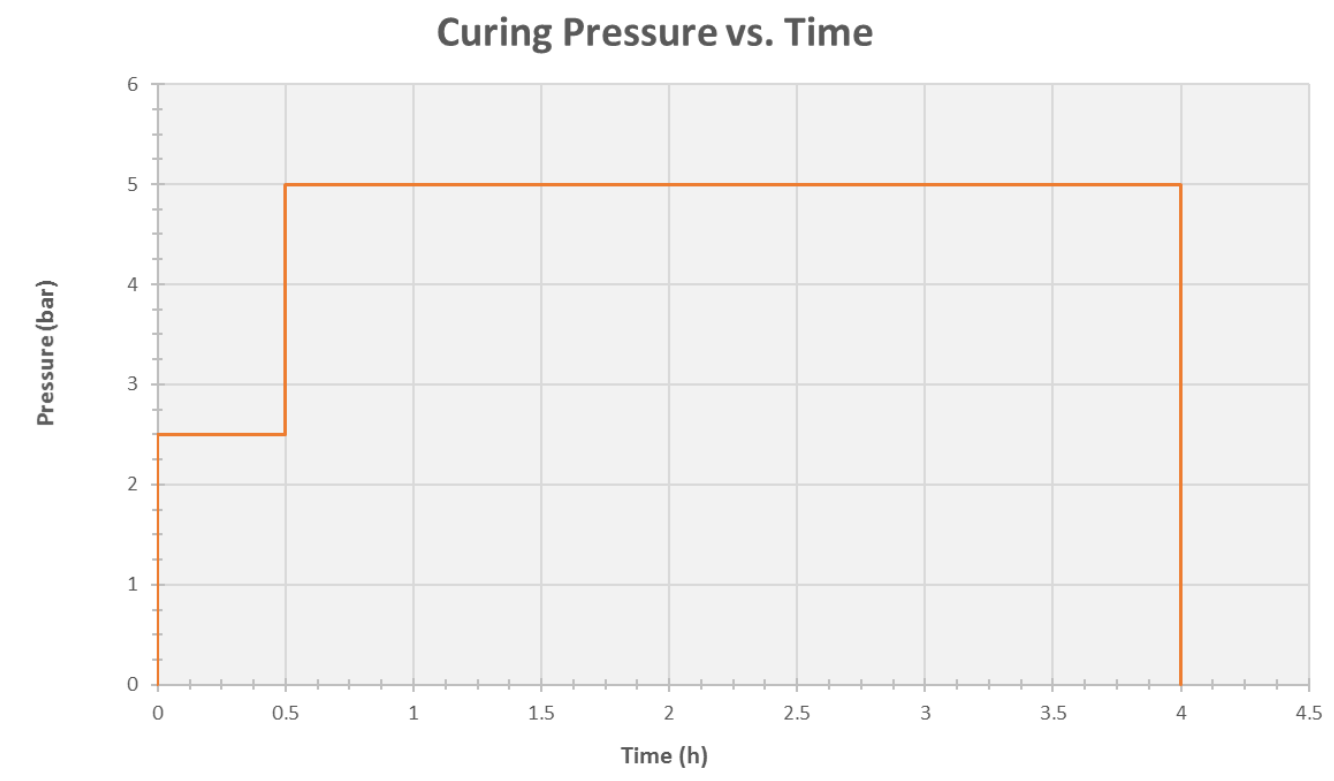

Figure 23: Curing pressure cycle for the flax and Kevlar-Flax/epoxy composite 


\subsection{Mechanical Properties Characterization}

\subsubsection{FlaX/EPOXY COMPOSITE}

The basic mechanical properties of the flax/epoxy composite were taken from [11]. The mechanical properties were obtained using the mechanical testing methods per ASTM D3039 (tensile) and ASTM D3518 (in-plane shear). The 16-layer flax/epoxy composite laminates characterized in [11] were manufactured using the same material and fabrication method as the ones used in this current study. Therefore, the mechanical properties were equivalent.

Table 9: Mechanical Properties of 16-layer Flax/Epoxy Composite in Tension [11]

\begin{tabular}{|c|c|c|c|c|}
\hline Property & Symbol & Units & Unidirectional & Cross-ply \\
\hline \multirow{3}{*}{ Modulus } & $E_{11}$ & GPa & $31.42 \pm 1.47$ & $16.69 \pm 0.72$ \\
\hline & $\mathrm{E}_{22}$ & GPa & $5.58 \pm 0.5$ & $16.69 \pm 0.72$ \\
\hline & $\mathrm{G}_{12}$ & $\mathrm{GPa}$ & $2.07 \pm 0.13$ & $6.42 \pm 0.41$ \\
\hline \multirow{2}{*}{ Poisson's Ratio } & $v_{12}$ & --- & $0.353 \pm 0.011$ & $0.111 \pm 0.027$ \\
\hline & $v_{21}$ & --- & $0.067 \pm 0.003$ & $0.111 \pm 0.027$ \\
\hline \multirow{3}{*}{$\begin{array}{l}\text { Ultimate } \\
\text { Strength }\end{array}$} & $\sigma_{11}^{\mathrm{TU}}$ & $\mathrm{MPa}$ & $286.70 \pm 13.30$ & $155.78 \pm 9.56$ \\
\hline & $\sigma_{22}{ }^{\mathrm{TU}}$ & $\mathrm{MPa}$ & $33.86 \pm 1.35$ & $155.78 \pm 9.56$ \\
\hline & $\tau_{12}{ }^{\mathrm{U}}$ & $\mathrm{MPa}$ & $37.35 \pm 1.78$ & $74.28 \pm 3.56$ \\
\hline \multirow{3}{*}{$\begin{array}{c}\text { Ultimate Fail } \\
\text { Strain }\end{array}$} & $\varepsilon_{11}{ }^{\mathrm{TU}}$ & $\%$ & $1.53 \pm 0.07$ & $1.57 \pm 0.08$ \\
\hline & $\varepsilon_{22}{ }^{\mathrm{TU}}$ & $\%$ & $1.36 \pm 0.18$ & $1.57 \pm 0.08$ \\
\hline & $\gamma_{12}{ }^{\mathrm{TU}}$ & $\%$ & $14.92 \pm 2.57$ & $11.04 \pm 0.40$ \\
\hline Density & $\rho$ & $\mathrm{g} / \mathrm{cm}^{3}$ & 1.31 & 1.31 \\
\hline Thickness & $\mathrm{t}$ & $\mathrm{mm}$ & 3.7 & 3.7 \\
\hline
\end{tabular}


Table 10: Mechanical Properties of 16-layer Flax/Epoxy Composite in Compression [11]

\begin{tabular}{|c|c|c|c|c|}
\hline Property & Symbol & Units & Unidirectional & Cross-ply \\
\hline \multirow{3}{*}{ Modulus } & $\mathrm{E}_{11}^{\mathrm{C}}$ & $\mathrm{GPa}$ & $30.32 \pm 3.04$ & $17.40 \pm 1.68$ \\
\hline & $\mathrm{E}_{22}{ }^{\mathrm{C}}$ & $\mathrm{GPa}$ & $5.70 \pm 0.71$ & $17.40 \pm 1.68$ \\
\hline & $\mathrm{G}_{12}{ }^{\mathrm{C}}$ & $\mathrm{GPa}$ & $1.63 \pm 0.25$ & $6.01 \pm 1.03$ \\
\hline \multirow{2}{*}{ Poisson's Ratio } & $v_{12}{ }^{C}$ & --- & $0.396 \pm 0.046$ & $0.095 \pm 0.008$ \\
\hline & $\mathrm{v}_{21}{ }^{\mathrm{C}}$ & --- & $0.066 \pm 0.010$ & $0.095 \pm 0.008$ \\
\hline \multirow{3}{*}{$\begin{array}{l}\text { Ultimate } \\
\text { Strength }\end{array}$} & $\sigma_{11} \mathrm{CU}$ & $\mathrm{MPa}$ & $127.11 \pm 5.08$ & $96.89 \pm 3.75$ \\
\hline & $\sigma_{22} \mathrm{CU}$ & $\mathrm{MPa}$ & $79.94 \pm 9.95$ & $96.89 \pm 3.75$ \\
\hline & $\tau_{12}{ }^{\mathrm{CU}}$ & $\mathrm{MPa}$ & $43.24 \pm 0.52$ & $86.47 \pm 1.05$ \\
\hline \multirow{3}{*}{$\begin{array}{c}\text { Ultimate Fail } \\
\text { Strain }\end{array}$} & $\varepsilon_{11}{ }^{\mathrm{CU}}$ & $\%$ & $1.60 \pm 0.29$ & $2.84 \pm 0.28$ \\
\hline & $\varepsilon_{22}{ }^{\mathrm{CU}}$ & $\%$ & $2.61 \pm 0.53$ & $2.84 \pm 0.28$ \\
\hline & $\gamma_{12}{ }^{\mathrm{CU}}$ & $\%$ & $9.76 \pm 2.63$ & $6.23 \pm 1.80$ \\
\hline Density & $\rho$ & $\mathrm{g} / \mathrm{cm}^{3}$ & 1.31 & 1.31 \\
\hline Thickness & $\mathrm{t}$ & $\mathrm{mm}$ & 3.7 & 3.7 \\
\hline
\end{tabular}




\subsubsection{KEVLAR-FLAX/EPOXY COMPOSITE}

The mechanical properties of the Kevlar-flax/epoxy composite were obtained by another MASc. student researcher (Mr. Ahmed Sarwar) from the Department of Mechanical and Industrial Engineering. These properties are tabulated below:

Table 11: Mechanical Properties of Kevlar-Flax/Epoxy Composite

\begin{tabular}{|c|c|c|c|c|}
\hline Property & Symbol & Units & Unidirectional & Cross-ply \\
\hline \multirow{2}{*}{ Modulus } & $\mathrm{E}_{11}$ & GPa & 31 & \multirow{2}{*}{22} \\
\hline & $E_{22}$ & $\mathrm{GPa}$ & 12 & \\
\hline Poisson's Ratio & $v_{12}$ & --- & 0.12 & 0.05 \\
\hline \multirow{4}{*}{$\begin{array}{l}\text { Ultimate } \\
\text { Strength }\end{array}$} & $\sigma_{11}^{\mathrm{TU}}$ & $\mathrm{MPa}$ & 340 & \multirow{2}{*}{240} \\
\hline & $\sigma_{22}{ }^{\mathrm{TU}}$ & $\mathrm{MPa}$ & 130 & \\
\hline & $\sigma_{11} \mathrm{CU}$ & $\mathrm{MPa}$ & 120 & \multirow{2}{*}{85} \\
\hline & $\sigma_{22} \mathrm{CU}$ & $\mathrm{MPa}$ & 75 & \\
\hline \multirow{4}{*}{$\begin{array}{c}\text { Ultimate Fail } \\
\text { Strain }\end{array}$} & $\varepsilon_{11}{ }^{\mathrm{TU}}$ & $\%$ & 1.6 & 1.33 \\
\hline & $\varepsilon_{22}{ }^{\mathrm{TU}}$ & $\%$ & 1.6 & 1.33 \\
\hline & $\varepsilon_{11} \mathrm{CU}$ & $\%$ & 0.5 & 1.2 \\
\hline & $\varepsilon_{22}{ }^{\mathrm{CU}}$ & $\%$ & 1.5 & 1.2 \\
\hline
\end{tabular}




\subsection{DESIGN OF IMPACT Testing APPARATUS}

The standard method for testing a composite laminate under low velocity impact loading is using an instrumented drop weight impact test per ASTM-D7136, which was earlier described in §3.8. However, the university does not have access to such apparatus and to procure such apparatus is expensive. As an alternative, a least-expensive impact testing apparatus was designed and manufactured to perform similar low velocity impact tests on composite plates.

The impact apparatus designed for this experiment is a pendulum-type impact apparatus, much like a Charpy impact testing machine but with some modifications to the impact support fixture, striker tip and specimen geometry. This concept was inspired by few studies [59] [60], which used a similar approach in testing composite laminates under low velocity/low energy impact loading. The layout of the test apparatus is shown in Figure 24.

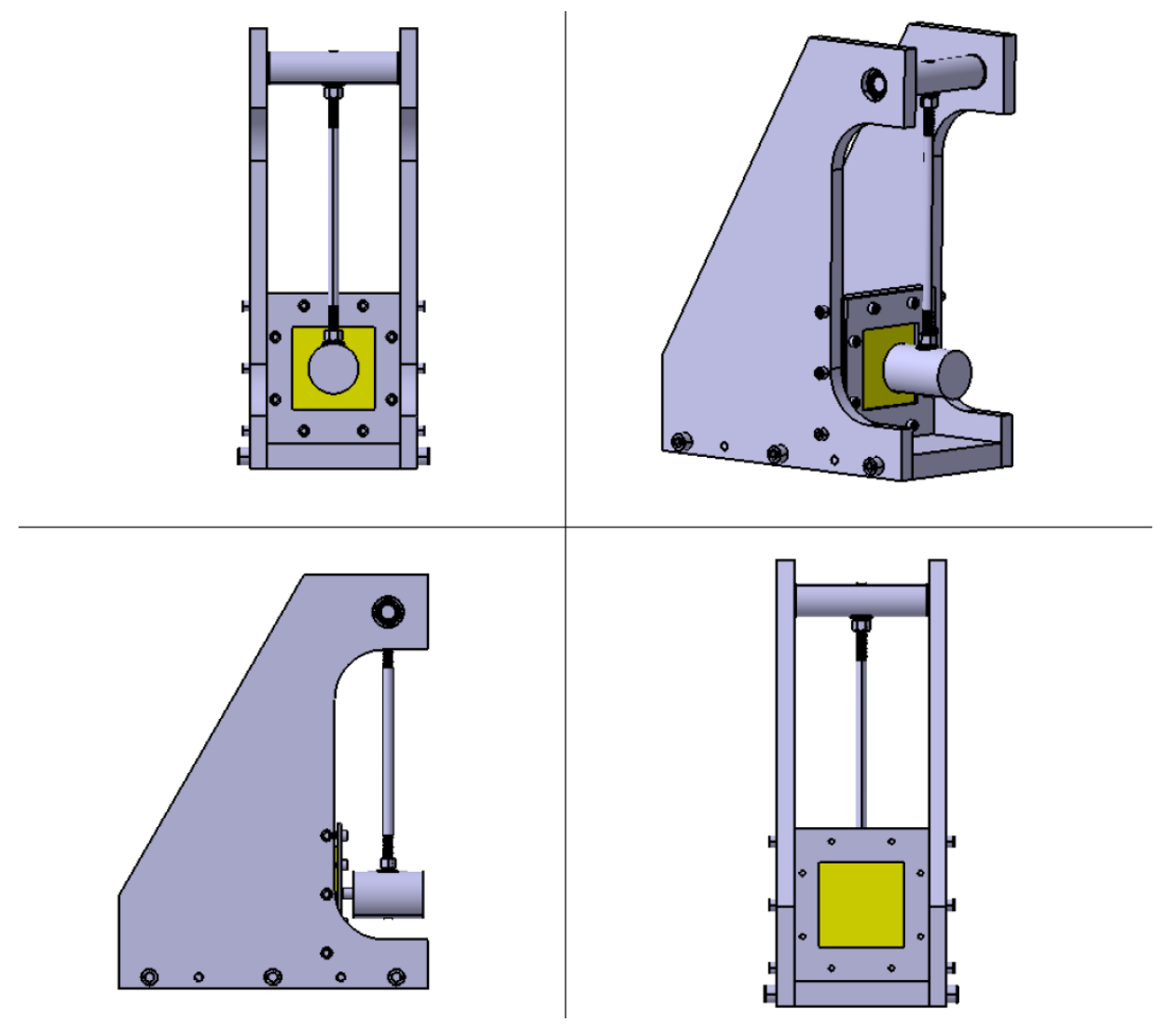

Figure 24: Modified Charpy pendulum impact testing apparatus 
This test apparatus is a simple machine designed to perform low-energy/low-velocity impact test on plastic or composite plate specimens. The machine allows one to evaluate the impact properties of a certain material such as the energy absorbed during impact. The apparatus works on the pendulum and energy conservation principle, in which a mass attached to a pendulum arm is raised at a certain height and then released to impact the specimen. The difference in the height of the pendulum drop before impact (initial height) and after impact (rebound height) is directly proportional to the energy absorbed by the specimen.

In a standard Charpy impact test, a rectangular V-notched specimen is simply supported on both ends and the impact load is applied directly on the opposite side of the notch. In an Izod impact test, a rectangular V-notched specimen is held as cantilever and the impact load is applied at the free edge of the cantilever. In both the standard Charpy and Izod tests, the specimen is broken in flexure by the single blow of the swinging pendulum.

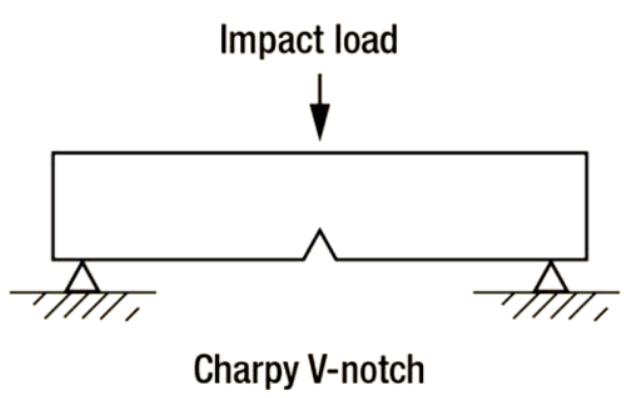

a)

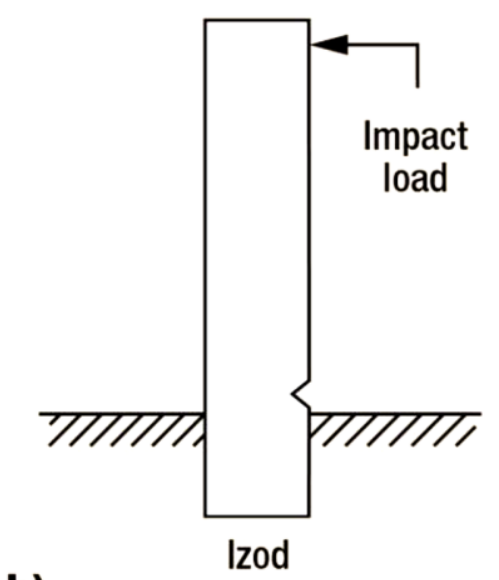

b)

Figure 25: Standard Charpy and Izod Impact Test Loading Mechanism

In this in-house designed impact apparatus, a 6 in. $\times 6$ in. composite specimen is clamped on all sides in a rigid support fixture, with a 5 in. $\times 5$ in. cut-out window in the in the support base. The cut-out window allows for the impactor tip to contact the specimen from one side and an optical view on the other side. The specimen is subjected to an out-of-plane concentrated impact 
loading at the centre of the specimen using a 4-kg steel impactor with a 16-mm diameter hemispherical striker tip. This testing effectively simulates the drop-weight impact test per ASTM D7136, except that the drop weight impact is achieved through a swinging pendulum mechanism. The energy absorbed the by composite specimen can be measured from the rebound height of the pendulum mass. To minimize friction and provide free rotation of the pendulum arm, a wellgreased ball bearing was used at the pendulum pivot.
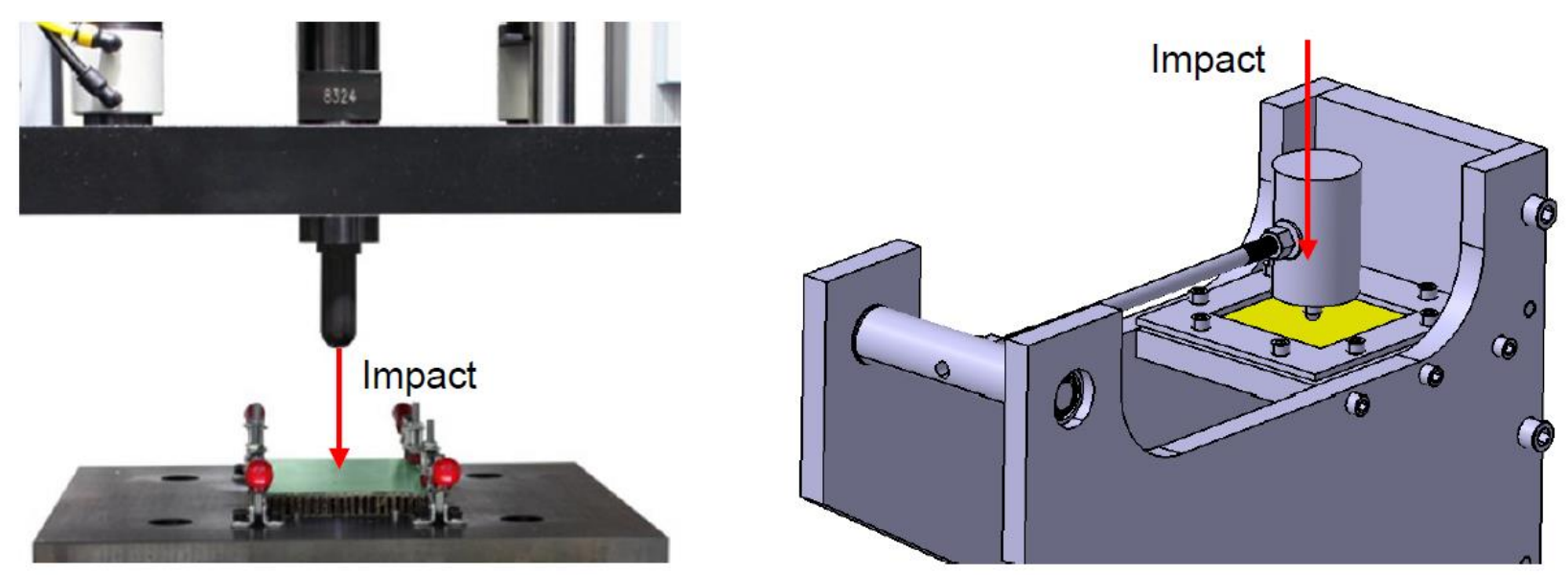

Figure 26: Drop Weight Impact Test vs. Modified Charpy Impact Test Loading Mechanism

To perform low velocity impact on the composite plate, the pendulum of mass $m$ is raised to a height $\mathrm{H}_{1}$ and then dropped. The height of the drop is selected based on the energy level required to impact the specimen. The initial height of the drop can be measured by either manually measuring the vertical travel the centre of mass of the pendulum, or by measuring the pendulum drop angle $(\alpha)$ and back-calculating the height $\mathrm{H}_{1}$.

$$
H_{1}=L \times(1-\cos \alpha)
$$

where $\mathrm{L}$ is the distance from the pivot to the centre of mass of the pendulum and arm assembly $\alpha$ is the pendulum drop angle measured from the initial arm position. 


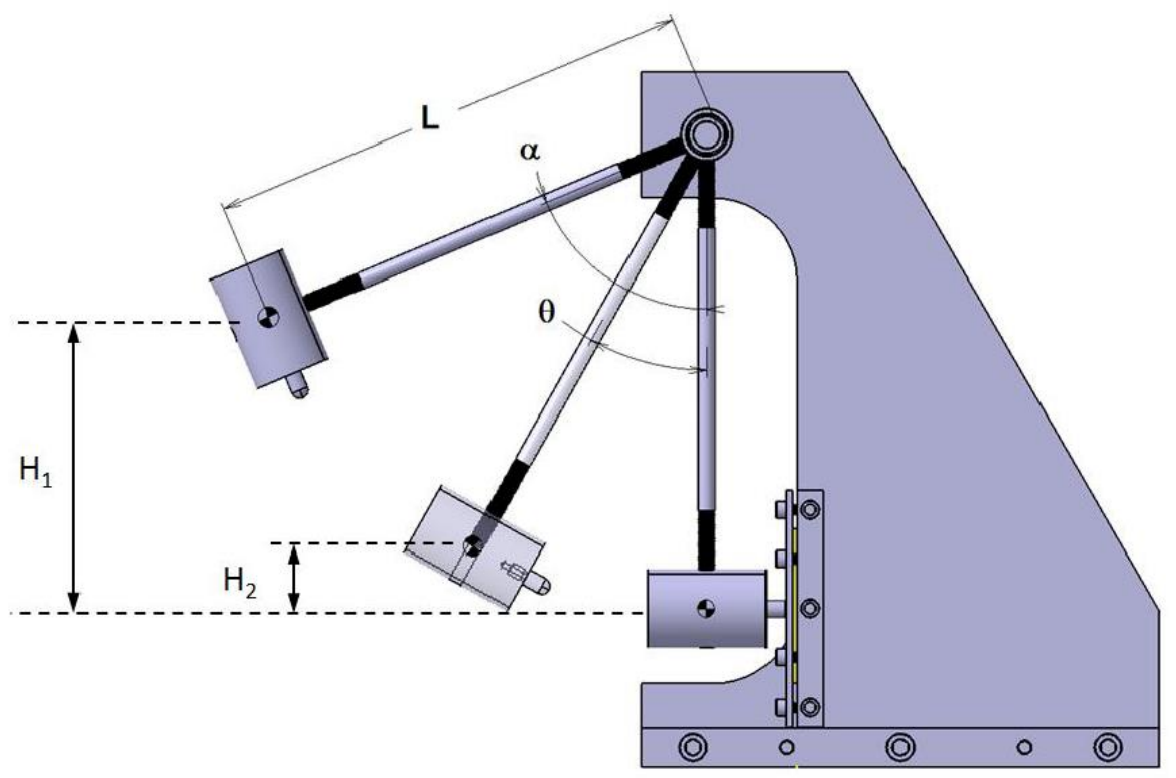

Figure 27: Modified Charpy Pendulum Impact Test Schematics

When the impactor strikes the composite plate, the pendulum will rebound to a lower height $\mathrm{H}_{2}$. The energy absorbed by the specimen is obtained by calculating the difference between the initial and final potential energies of the pendulum.

$$
E_{\text {absorbed }}=m \times g \times\left(H_{1}-H_{2}\right)
$$

where $\mathrm{m}$ includes the total mass of the pendulum and arm assembly $(4.4 \mathrm{~kg})$

$\mathrm{g}$ is the acceleration due to gravity $\left(9.81 \mathrm{~m} / \mathrm{s}^{2}\right)$

$\mathrm{H}_{2}=\mathrm{L} \times(1-\cos \theta)$

The velocity $\left(v_{i}\right)$ of the pendulum just before impact can be determined from the conservation of energy equation:

$$
\begin{aligned}
& m g H_{1}=\frac{1}{2} m v_{i}^{3} \\
& v_{1}=\sqrt{2 g H_{1}}
\end{aligned}
$$


A more accurate method of determining the incident and absorbed energy is by measuring the velocity just before impact and after the rebound using a high-speed camera. From the incident and rebound velocities, the impact and rebound energies can be calculated using the kinetic energy equation. The following table shows the design specifications for the impact test apparatus:

Table 12: Mechanical Properties of 16-layer Flax/Epoxy Composite in Compression [11]

\begin{tabular}{|c|c|}
\hline SPECIFICATION & VALUE / DESCRIPTION \\
\hline Pendulum Effective Mass ${ }^{1}$ & $4.4 \mathrm{~kg}$ \\
\hline Distance from Pivot to centreline of impactor & $18 "(457 \mathrm{~mm})$ \\
\hline Distance from Pivot to centre of mass of pendulum & $17.85 "(453 \mathrm{~mm})$ \\
\hline Impactor Tip Diameter $^{2}$ (per ASTM D7136) & $0.63 ”(16 \mathrm{~mm})$ \\
\hline Impactor Shape & Hemispherical \\
\hline Required Specimen Size & $6 "$ x 6" (152.4 mm x $152.4 \mathrm{~mm})$ \\
\hline Required Specimen Thickness ${ }^{3}$ & Up to $0.25 "$ thick $(6.35 \mathrm{~mm})$ \\
\hline Cut-out Window Size & 5" x 5" (127 mm x $127 \mathrm{~mm})$ \\
\hline Maximum pendulum drop angle & 179 degrees \\
\hline Maximum Impact Energy ${ }^{4}$ & up to 39 Joules \\
\hline Maximum Striking Velocity ${ }^{4}$ & up to $4.2 \mathrm{~m} / \mathrm{s}$ \\
\hline $\begin{array}{l}{ }^{1} \text { This includes the mass of the pendulum, arm, striker tip, lock nuts } \\
{ }^{2} \text { The impactor tip is removable and can be replaced with a differen } \\
{ }^{3} \text { The impactor tip is threaded and can be adjusted forward/aft to ac } \\
{ }^{4} \text { The maximum energy and velocity can be achieved at a maximum }\end{array}$ & $\begin{array}{l}\text { rs } \\
\text { geometry with an M12 thread attachment. } \\
\text { different specimen thicknesses. } \\
\text { drop angle of } 180 \text { degrees. }\end{array}$ \\
\hline
\end{tabular}




\subsection{IMPACT TEST SETUP}

The following figure shows the schematic of the impact test arrangement. The test arrangement consists of the impact test apparatus clamped onto a rigid and sturdy table, an infrared (IR) camera (FLIR Systems SC5000) positioned at the rear of the cut-out window, and a highspeed camera (MotionPro X3) positioned at the side of the impact apparatus directly in the line of sight of the pendulum pivot pin.

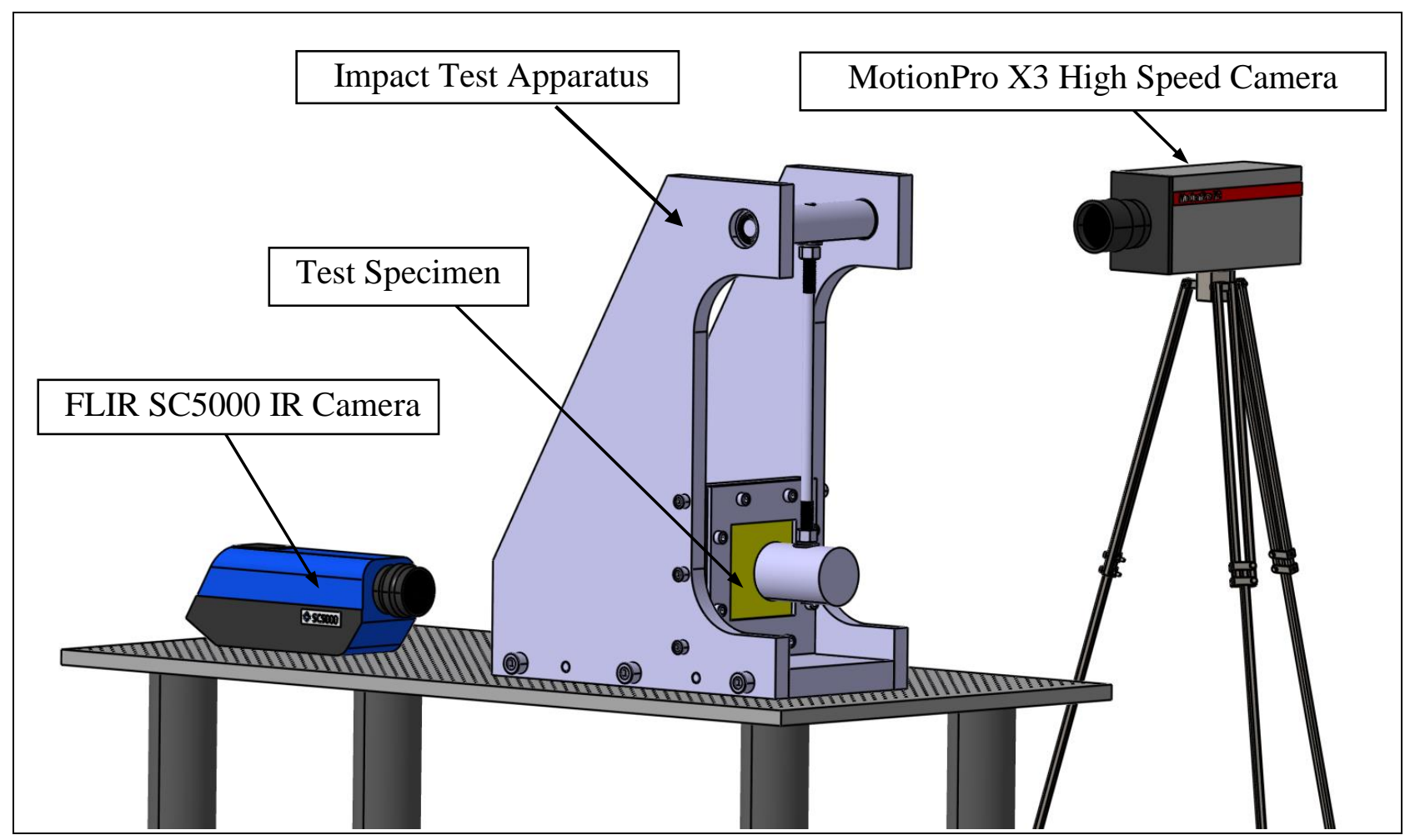

Figure 28. Low Velocity Pendulum Impact Test Setup

The purpose of the IR camera is to monitor the thermal response of the specimen during the impact event. IR thermography (IRT) allows one to create a temperature map of the visualized surface by exploiting the thermal energy radiated by the surface in the infrared band of the electromagnetic spectrum [61]. During an impact event, kinetic energy is transferred from the impactor tip to the target specimen, and that such energy is in part dissipated as heat [60]. Any form of damage such as delamination, matrix cracking or fibre breakage is accompanied by heat dissipation and is manifested in the IR camera as the appearance of hot spots over the material 
surface [60]. By examining the change in temperature $\Delta \mathrm{T}$ before, during and after the impact event, the progression of damage in the test specimen can be observed. Thus, the use of the IR camera can provide some insight on the failure modes that arise during the impact event. In addition, the use of IRT can allow for the measurement of the impact-induced damage areas especially in composites with barely visible impact damage (BVID) or internal damage, which cannot be detected with visual inspection.

The IR camera used in this test is the FLIR Systems SC5000 camera. The camera is equipped with a cooled Inidium antimonide detector that operates in the 2.5 to $5.1 \mu \mathrm{m}$ waveband [62]. It has a resolution of $320 \times 240$ pixels and a temperature sensitivity of $20 \mathrm{mK}$. The impact event was recorded at the maximum allowable frame rate of $173 \mathrm{fps}$. The FLIR Altair radiometric software was used to view and post-process all thermographic results.

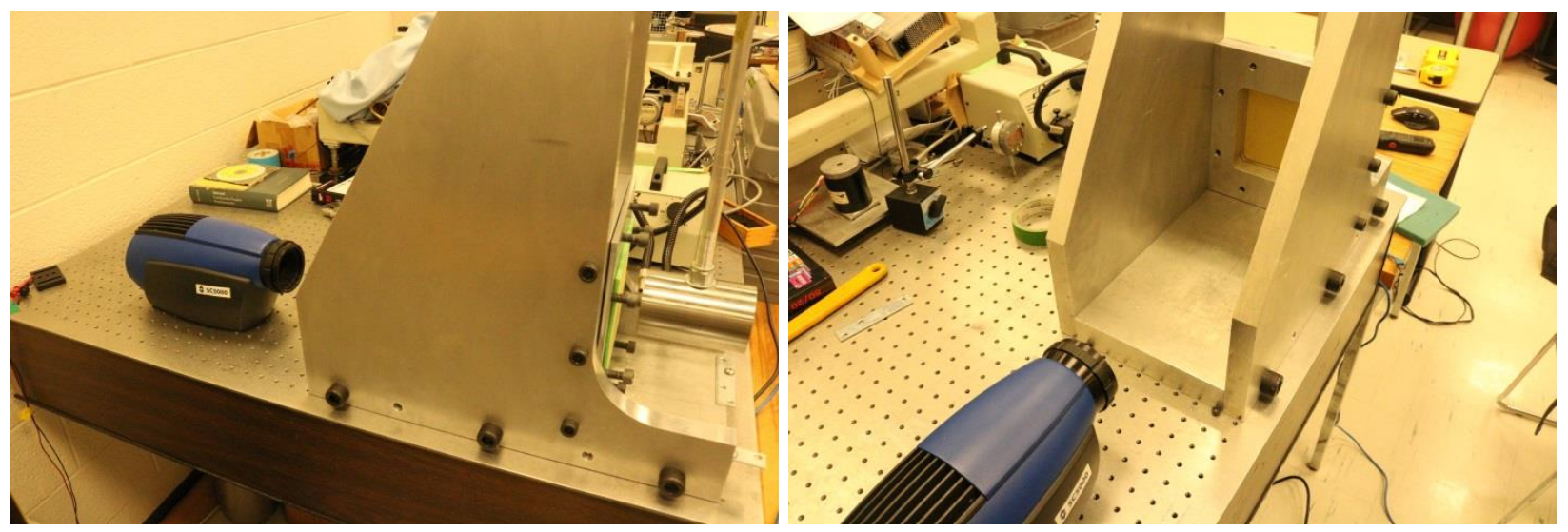

Figure 29. Position of FLIR SC5000 IR Camera

The high-speed camera was positioned at the side of the impact apparatus directly in the line of sight of the pendulum pivot pin. The purpose of the camera was to capture the motion of the pendulum arm, which then allowed for an indirect measurement of the pendulum angle before impact and during rebound. The camera used is the MotionPro X3. It records the video in in a series of monochromatic images. For the test, a video recording frequency of $300 \mathrm{~Hz}$ was selected because this provided the best image output with the amount of lighting available. This frequency is more than sufficient to capture the motion of the pendulum arm, considering that the impact is 
a low velocity event. The IDT MotionStudio x64 image acquisition and processing software was used to record and post-process the video recordings. To measure the pendulum arm angle before and after the impact event, the Iconico Screen Protractor software was used.

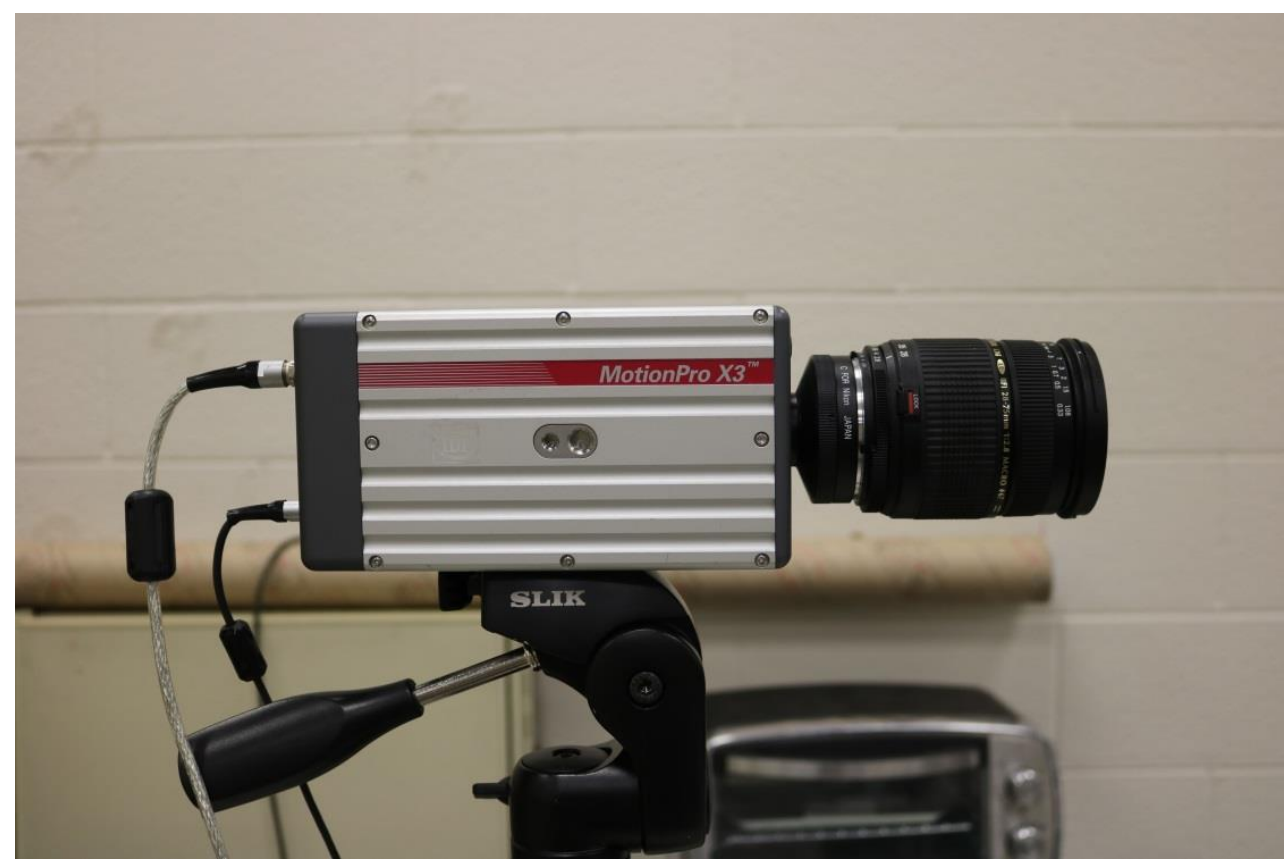

Figure 30. MotionPro X3 High Speed Camera Setup

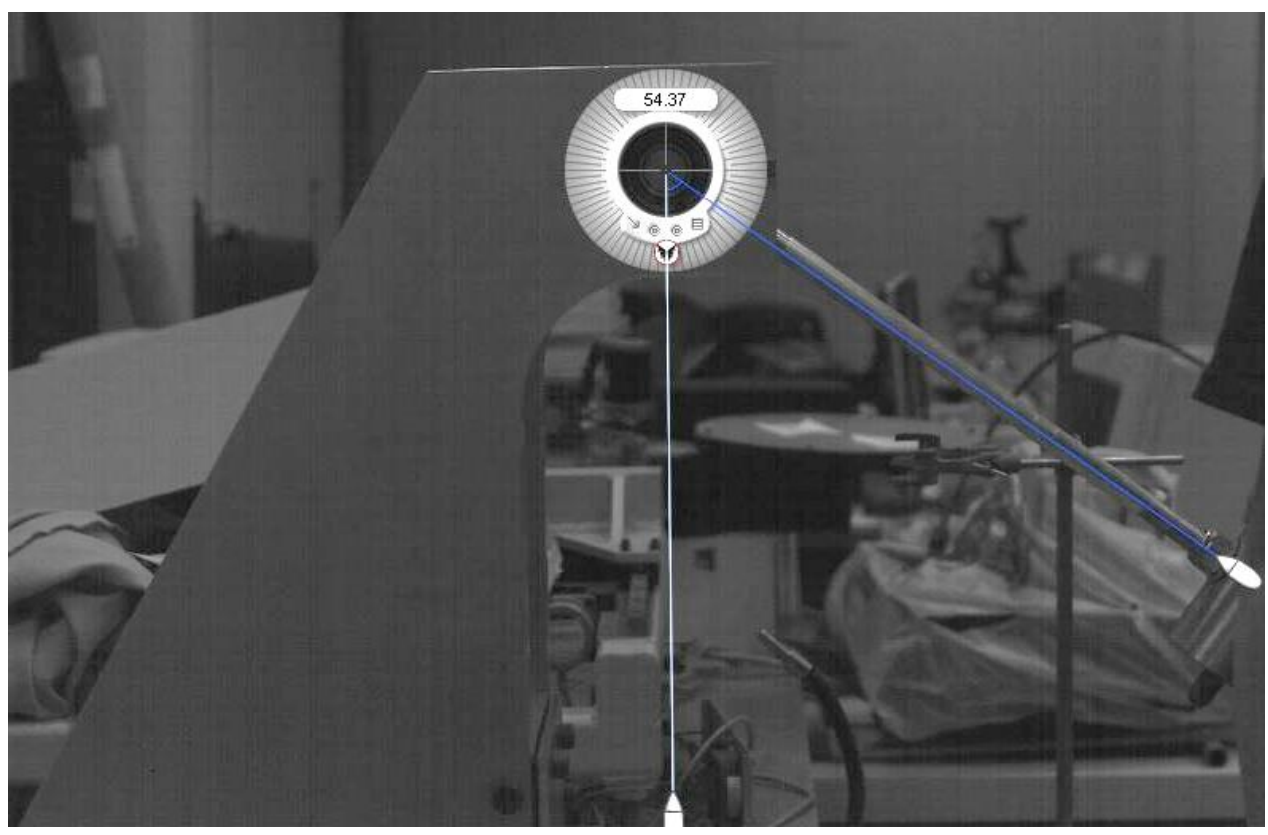

Figure 31. Angle Measurement using Iconico Screen Protractor Software 
Before the impact test, the fixture was first equipped with two light gates that were positioned along the path of the striker tip, such that as the striker approached the specimen, the striker tip blocked gate 1 first and then gate 2 just prior to impact. The purpose of this procedure was to measure the actual velocity just before impact and then compare it with the theoretical velocity calculated. The actual impact velocity was calculated using the measured times each light gate was obstructed by the striker tip, and the distance between the two light gates. From the calculated impact velocity, the incident impact energy was calculated. For this procedure, the impact event was recorded using the same high-speed camera at a frequency of $1000 \mathrm{fps}$.

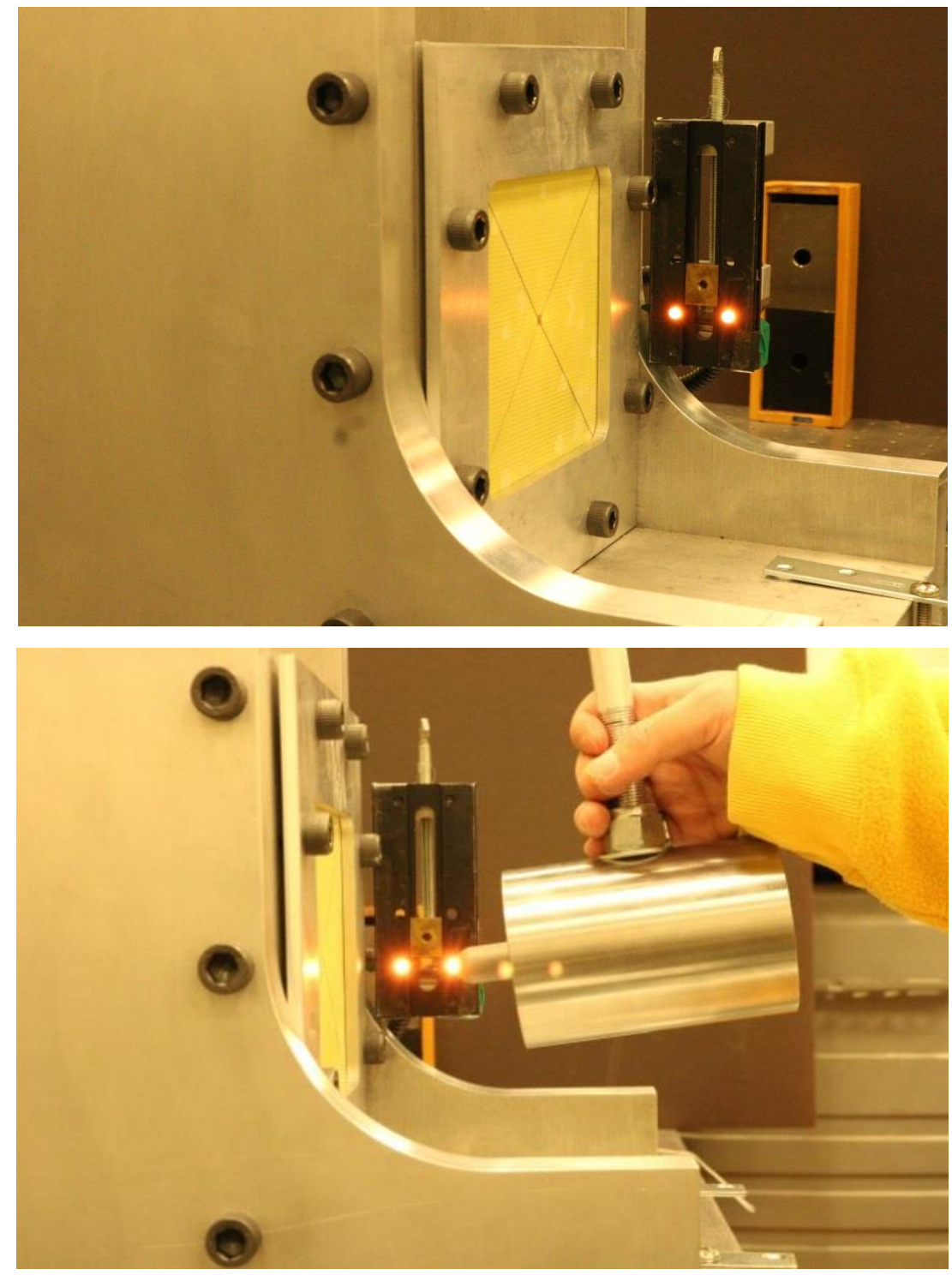

Figure 32. Light gate setup for impact velocity measurement 
The following graph compares the theoretical and actual impact velocities for the pendulum at different pendulum drop angles.

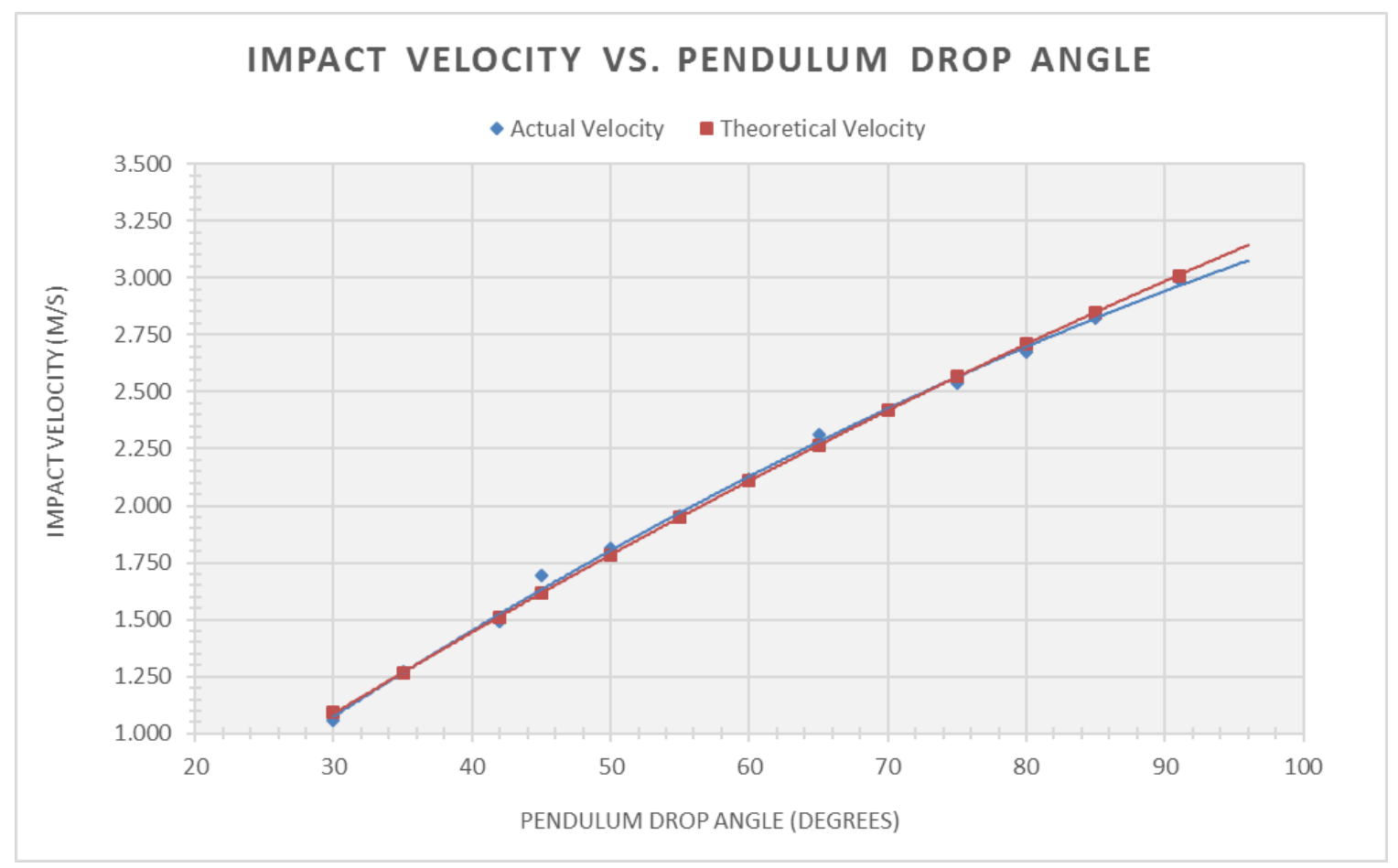

Figure 33. Theoretical vs. actual velocity of the impact test apparatus

As can be seen in the above graph, there is a good correlation between the measured and theoretical impact velocities. The losses due to air resistance and pivot joint friction are negligible and can therefore be ignored in the analysis. 


\subsection{Pre-Test Non-Destructive InsPection}

Thermographic techniques make use of the thermal conductivity of a material, considering that thermal conductivity of a material at a flaw location is different from that at the location without a flaw [12]. In thermography, the material surface is first heated uniformly using pulsating ash lamps such as the high-wattage tungsten halide lamp or halogen lamp, which can raise the surface temperature by as much as $10^{\circ} \mathrm{F}$ to $30^{\circ} \mathrm{F}$. As heat is conducted into the part, the surface temperature increases. If there is a defect such as void below the surface, the cooling rate of the surface above the defect will be different from the cooling rate above a defect-free surface. Using an infrared camera, the surface of the part can be monitored by collecting the radiation emitted from the surface. This data can be analyzed by an imaging software and then converted into a colored plot depicting the variation in the surface temperature [41]. Cooler regions in the an otherwise homogeneous temperature field would indicate a defect underneath the surface [12].

Prior to impacting the specimens, the latter were first non-destructively inspected using transient thermographic technique in reflection mode to search for obvious manufacturing defects. This was performed by briefly heating up the specimen for 20 seconds using two $500 \mathrm{~W}$ halogen lamps and then allowing the specimen to cool down. The heating and cooling down of the specimen were captured using the same IR camera positioned $500 \mathrm{~mm}$ in front of the specimen. The presence of defects (e.g. delamination) can be detected as distortion in the temperature field. This distortion is manifested by temperature differences on the material's surface.
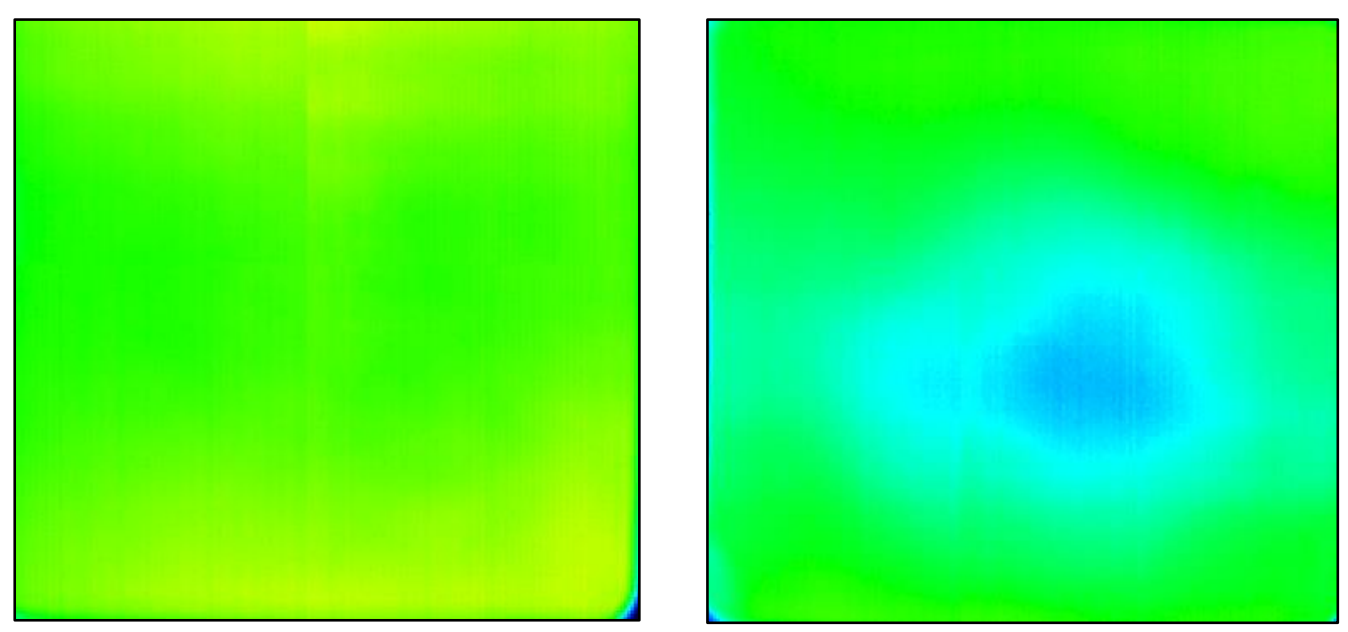

Figure 34. Defect-free vs. defective composite plate (with delamination damage) 
The following figures show the test setup for the non-destructive transient thermographic inspection performed on all the plates tested.

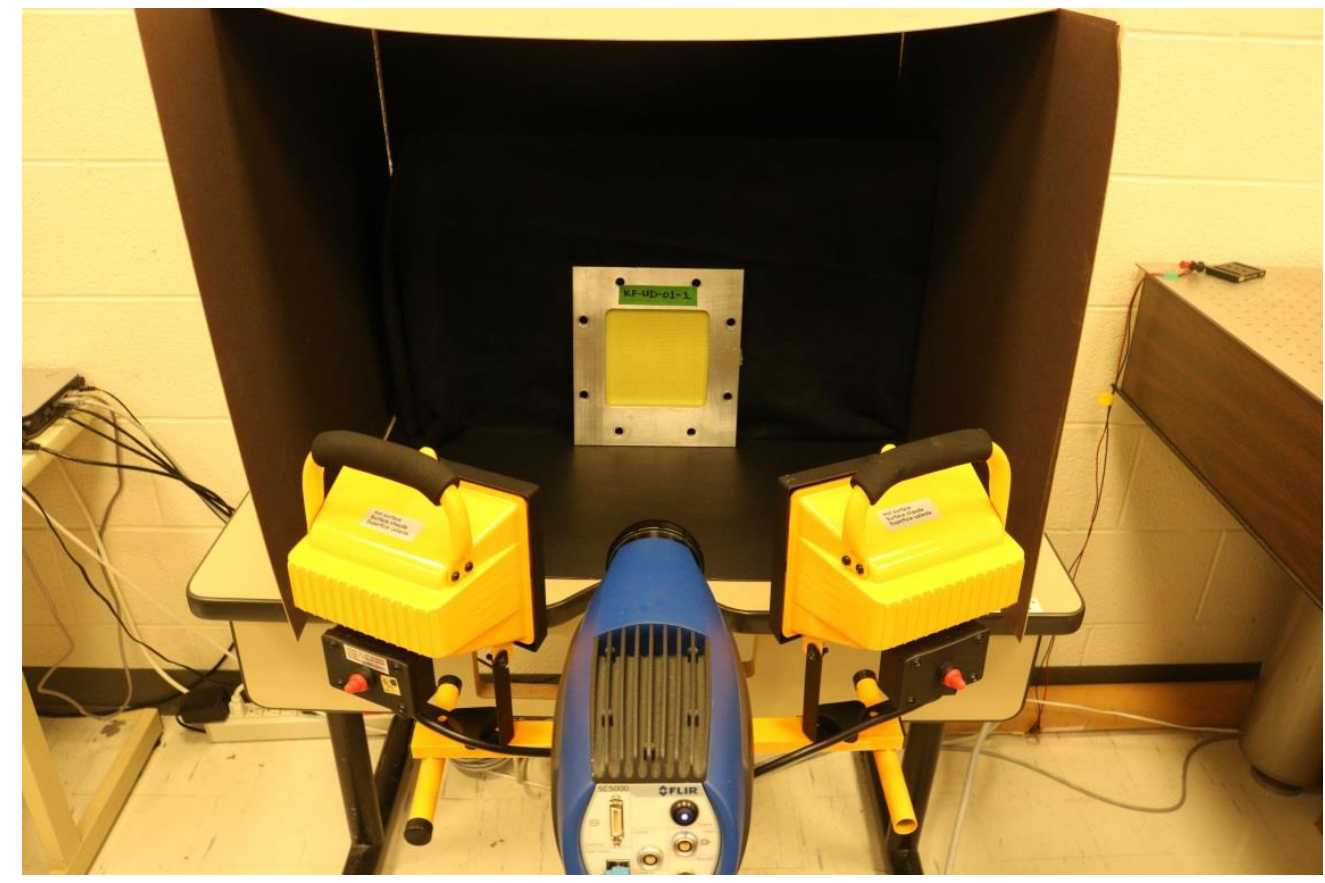

Figure 35. Transient thermographic NDT Setup

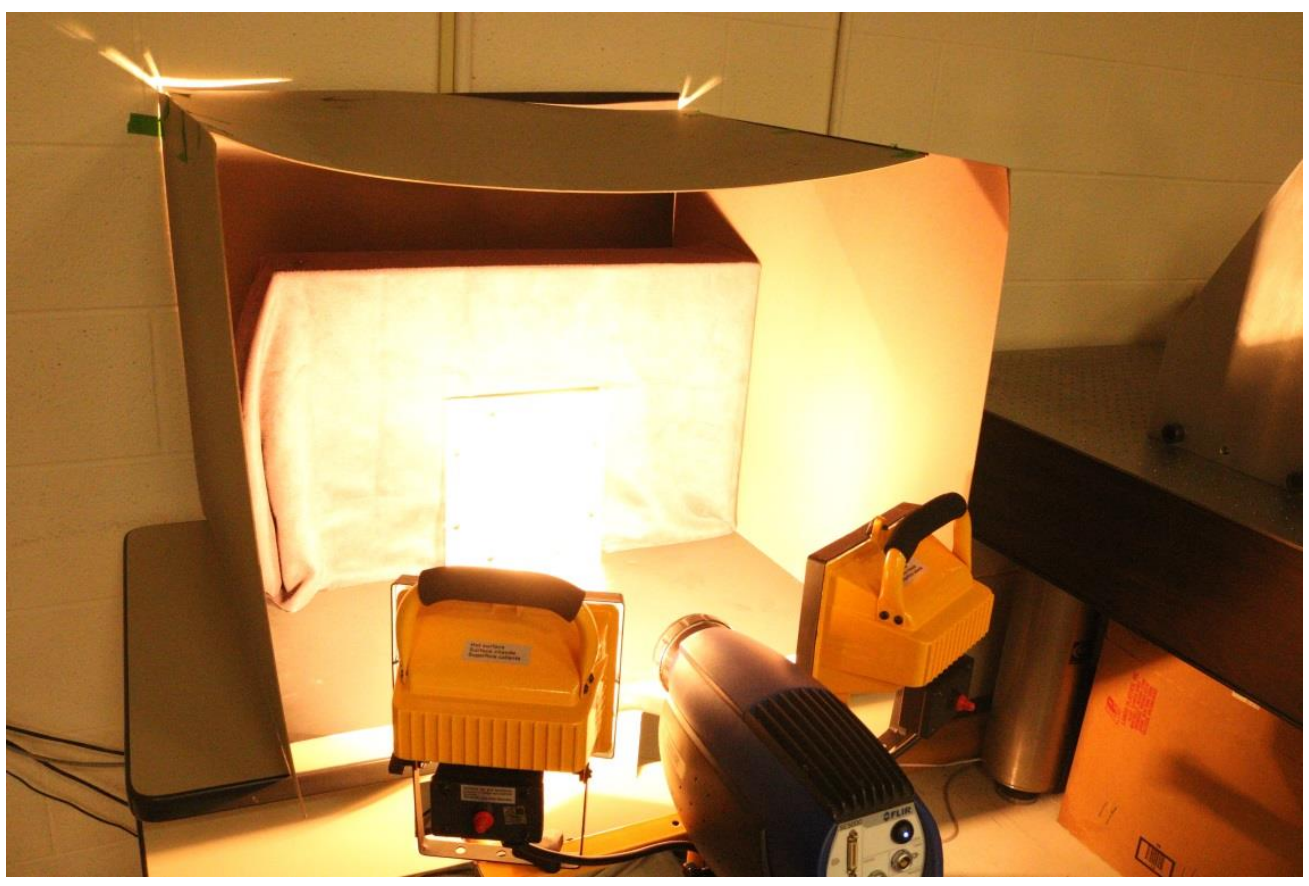

Figure 36. Heating up of the samples during the transient thermographic NDT 


\subsection{Impact Testing Procedure}

When a composite laminate is subjected to low velocity impact loading, the total impact energy can be classified into absorbed energy $\left(E_{\text {absorbed }}\right)$, and rebound energy $\left(E_{\text {rebound }}\right)$. The rebound energy comes from the elastic energy stored in the specimen, which gets transferred back to the impactor during rebound [63]. The absorbed energy on the other hand is the energy absorbed by the specimen [63] through deformation and the creation of new surfaces by different damage mechanisms [12]. The deformation energy includes the membrane energy $E_{m}$ and the bending energy $E_{b}$, while the damage energy $E_{d}$ comprises of the energy required to induce damage such as matrix cracking, delamination, fibre breakage and fibre pull-out.

$$
E_{\text {impact }}=E_{\text {rebound }}+E_{\text {absorbed }}
$$

where

$$
E_{\text {absorbed }}=E_{m}+E_{b}+E_{d}
$$

The amount of energy absorbed during impact is the difference between the impact energy and the rebound energy.

$$
E_{\text {absorbed }}=E_{\text {impact }}-E_{\text {rebound }}
$$

From the pendulum impact test, the rebound energy is determined by calculating the potential energy of the impactor at the recorded rebound height. The remaining energy is the energy absorbed by both the test specimen and the impact test system in the form of heat, vibration, and support reactions. It is assumed that the energy absorbed by the test system is rather small compared to the energy absorbed by specimen damage and is thus ignored.

In this study, the composite specimens were subjected to incident impact energies ranging from $5 \mathrm{~J}$ up to penetration energy, in increments of $5 \mathrm{~J}$ or less, depending on the material behaviour under impact. Two to four samples from each configuration were tested for each test condition, depending on the repeatability of the results. Each specimen was impacted only once. The required 
impact energy levels were achieved by adjusting the initial drop height of the pendulum. The elastic energy of the specimen was measured by first recording the maximum rebound angle of the pendulum arm with the high-speed camera. From the rebound angle, the rebound height and energy were calculated using the potential energy equation. The difference between the total impact energy and rebound energy is the energy absorbed by the specimen, assuming the energy absorbed by the impactor is negligible as assumed earlier.

The flax/epoxy composite laminates were tested first. The Kevlar-flax/epoxy composite laminates were tested afterwards to determine the effect of hybridization on the impact properties of the flax/epoxy composite. During the impact test, the impact response of the composite was characterized in terms of the energy absorbed during impact, damage size (area or crack length), dent depth, thermal response, damage evolution during the impact process and impact toughness. The dent depth was measured using a digital height indicator. 


\section{ReSUlts AND Discussion}

\subsection{FLAX/EPOXY COMPOSITE}

\subsubsection{GENERAL IMPACT RESPONSE}

Figure 37 below shows the absorbed energy versus impact energy plot for the flax/epoxy composites with stack-up sequences of $\left[0_{8 \mathrm{~F}}\right]_{\mathrm{S}}$ and $\left[(0 / 90)_{4 \mathrm{~F}}\right]_{\mathrm{S}}$, where the subscript $\mathrm{F}$ stands for flax and $\mathbf{S}$ for symmetry. The energy absorption results were plotted against the equal energy line to determine the penetration threshold of each composite laminate. The equal energy line is the diagonal line that indicates the equality between the impact energy and absorbed energy [64]. The absorbed energy cannot be higher than the impact energy. When the level of absorbed energy is equal to that of the impact energy, the composite is considered to be penetrated by the impactor [64]. The gap between the equal energy line indicates the unabsorbed (elastic) energy during impact. The magnitude of the gap determines the energy absorption efficiency of the composite material. The raw data for the graph below can be found in the Appendix of this report.

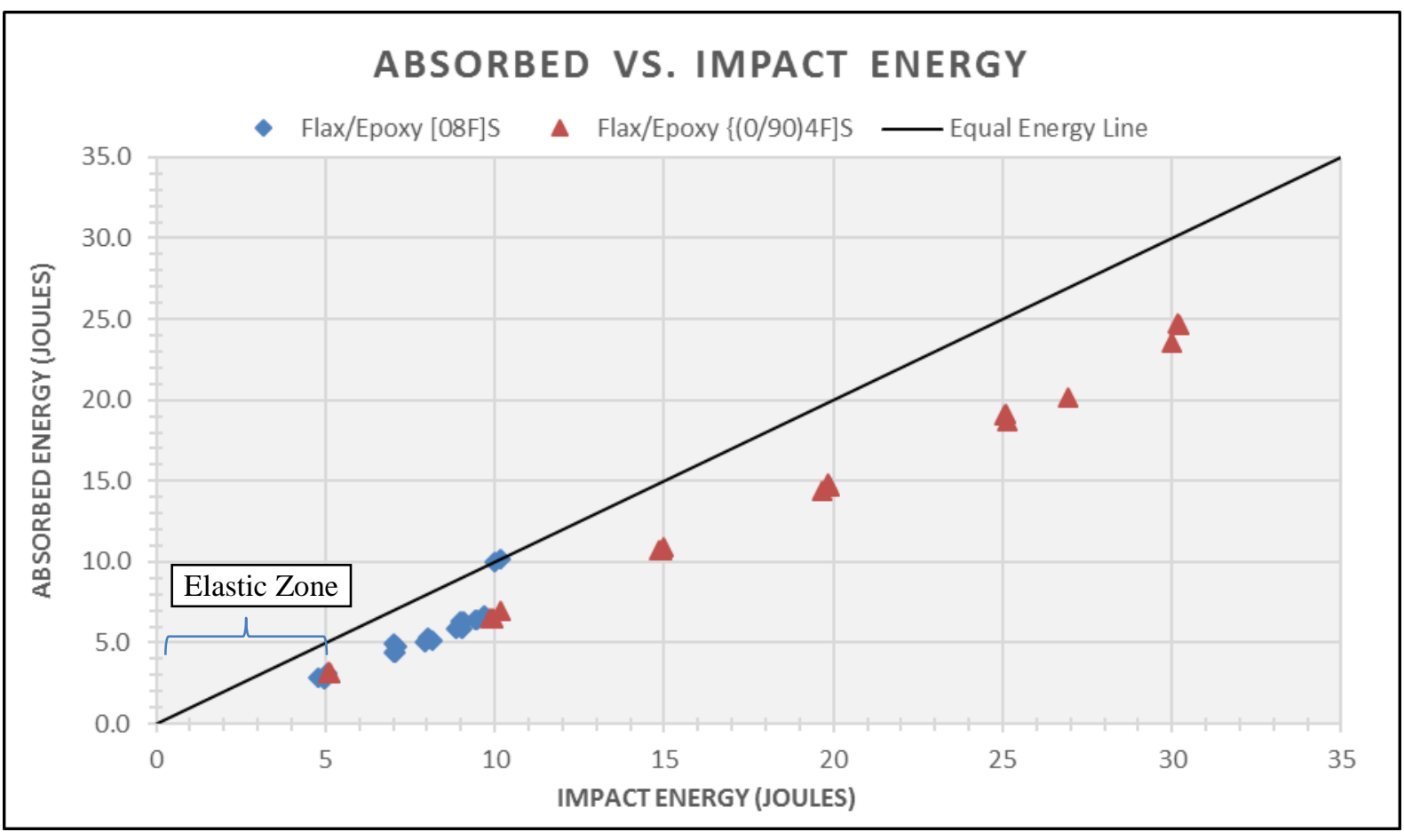

Figure 37. Absorbed energy versus impact energy for flax/epoxy composite 
For clarity, separate absorbed energy versus impact energy plots for the $\left[0_{8 \mathrm{~F}}\right]_{\mathrm{S}}$ and $\left[(0 / 90)_{4 \mathrm{~F}}\right]_{\mathrm{S}}$ composite configurations are shown in Figure 38 and Figure 39, respectively.

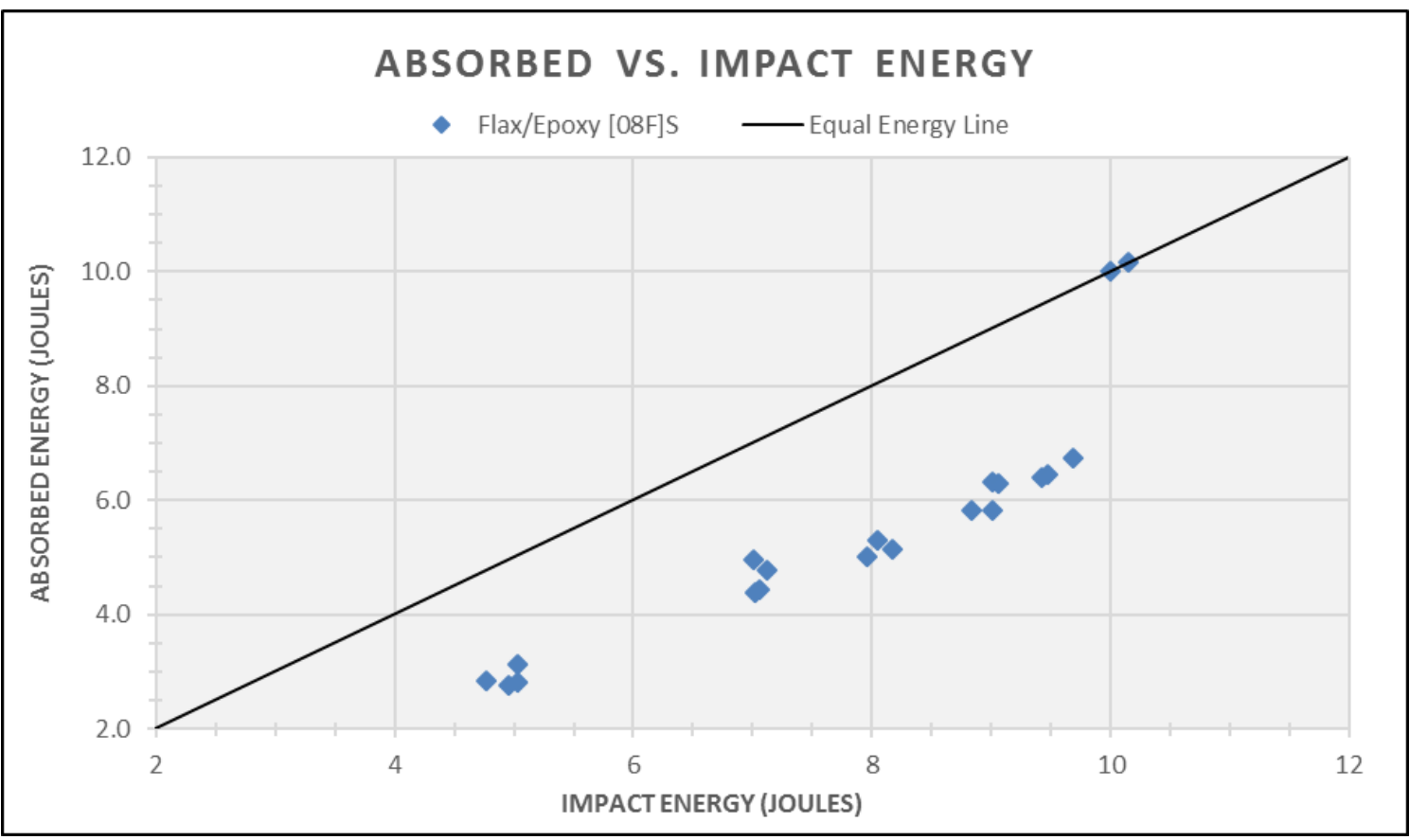

Figure 38. Absorbed energy versus impact energy for $\left[0_{8 \mathrm{~F}}\right]_{\mathrm{S}}$ flax/epoxy composite

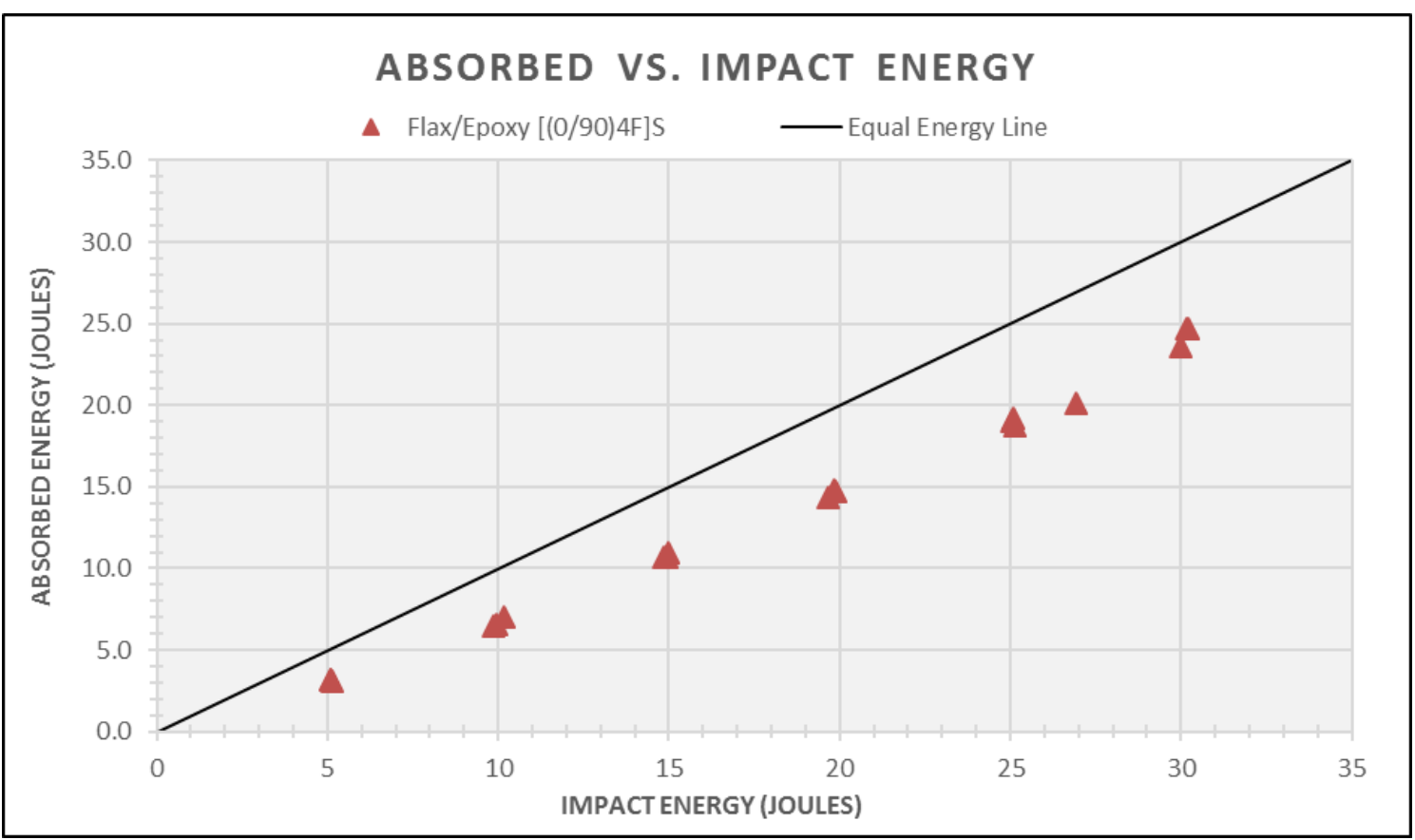

Figure 39. Absorbed energy versus impact energy for $\left[(0 / 90)_{4 \mathrm{~F}}\right]_{\mathrm{S}}$ flax/epoxy composite 
From the absorbed energy versus impact energy plots, it can be observed that the cross-ply flax/epoxy composite absorbed more energy than the unidirectional flax/epoxy composite prior to complete fracture of the plate. The cross-ply composite did not experience any penetration failure even at $30 \mathrm{~J}$ of impact energy. Its penetration threshold is expected to be greater than $30 \mathrm{~J}$, which is more than three times higher than that of the unidirectional composite.

The fact that the cross-ply composite configuration outperformed the unidirectional one in terms of the energy absorption capacity is a typical behaviour observed in fibre-reinforced composite materials. Few studies [45] [46] have investigated the effect of stacking sequence on the impact response of FRP composites and all have shown that the energy absorbed by cross-ply composites was consistently higher than that of the unidirectional ones. Since the mode of loading during impact is an out-of-plane transverse loading, the presence of the $90^{\circ}$ layers in the cross-ply configuration helped stop the matrix crack from propagating through the laminate thickness, thus allowed it to absorb more energy during impact.

For the unidirectional flax/epoxy composite laminate, the absorbed energy increased at a constant rate prior to penetration. Beyond $9.5 \mathrm{~J}$, the absorbed energy abruptly approached the equal energy line, which is indicative of a brittle fracture behaviour.

For the cross-ply flax/epoxy composite laminate, the absorbed energy also increased at a constant rate at impact energies below the penetration threshold. The cross-ply composite laminate was not completely penetrated at the maximum impact test energy of $30 \mathrm{~J}$; however, judging by the trend in the data points, a slight increase in the impact energy will likely result in penetration. The penetration threshold is estimated to be between $30 \mathrm{~J}$ to $35 \mathrm{~J}$.

Figure 40 and Figure 41 show the percent of the absorbed energy as function of the impact energy. Both plots show that the percentage of the impact energy absorbed by the laminates increased with increasing impact energy. Between $5 \mathrm{~J}$ and $9.5 \mathrm{~J}$, the unidirectional composite absorbed 60-70\% of the impact energy. The cross-ply composite on the other hand absorbed 60$80 \%$ of the impact energy between $5 \mathrm{~J}$ and $30 \mathrm{~J}$. For the unidirectional flax/epoxy composite, the percentage of the energy absorbed by the laminate abruptly increased to $100 \%$ as the impactor penetrated the laminate at $10 \mathrm{~J}$. 


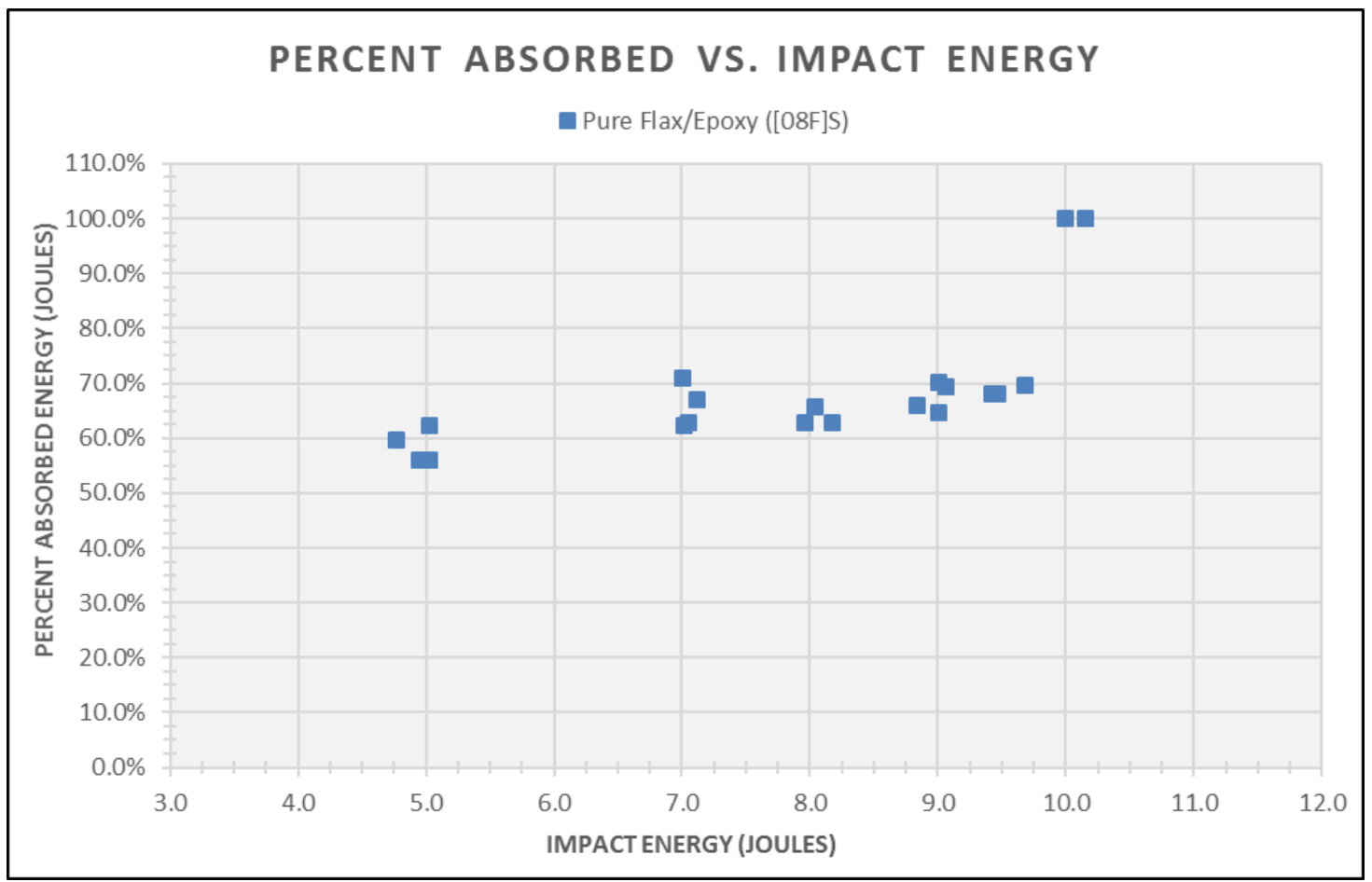

Figure 40. Percent absorbed energy versus impact energy for $\left[0_{8 \mathrm{~F}}\right]_{\mathrm{s}}$ laminate

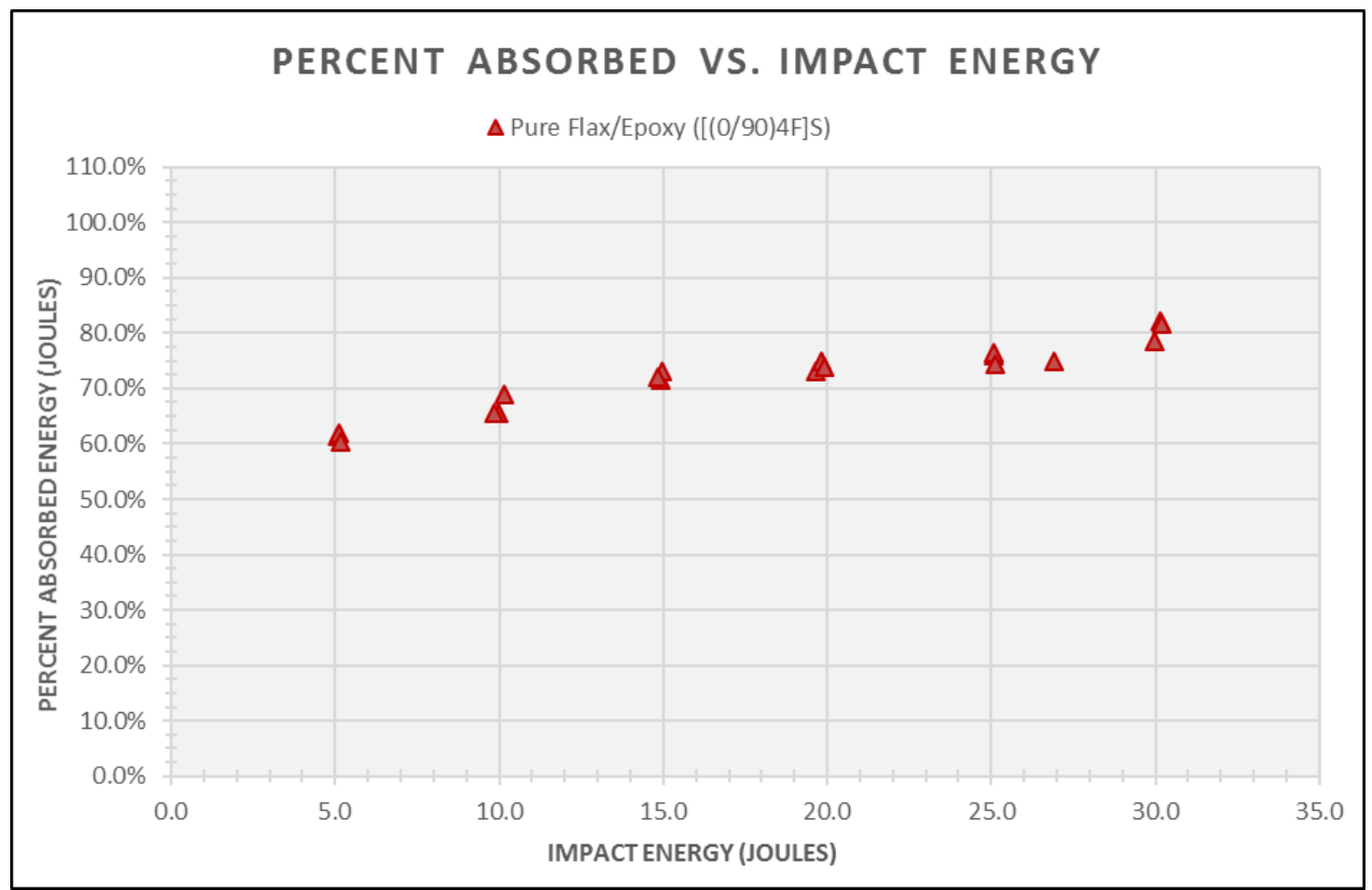

Figure 41. Percent absorbed energy versus impact energy for $\left[(0 / 90)_{4 \mathrm{~F}}\right]_{\mathrm{s}}$ laminate 


\subsubsection{Post-Impact Damage Characterization}

\subsubsection{UNIDIRECTIONAL F LAX/EPOXY COMPOSITE}

Post-impact damage assessment of the flax/epoxy composite was carried out through visual inspection of the front and back faces. High-resolution photographs of the front and back faces were taken to assess the damage extension at different impact energy levels. Consistent damage profiles have been observed for every test case and therefore only one sample per test case is shown. In the photographs below, the longitudinal direction $\left(0^{\circ}\right)$ of the composite is indicated by an arrow $(\uparrow)$ symbol on the lower left corner of the images.

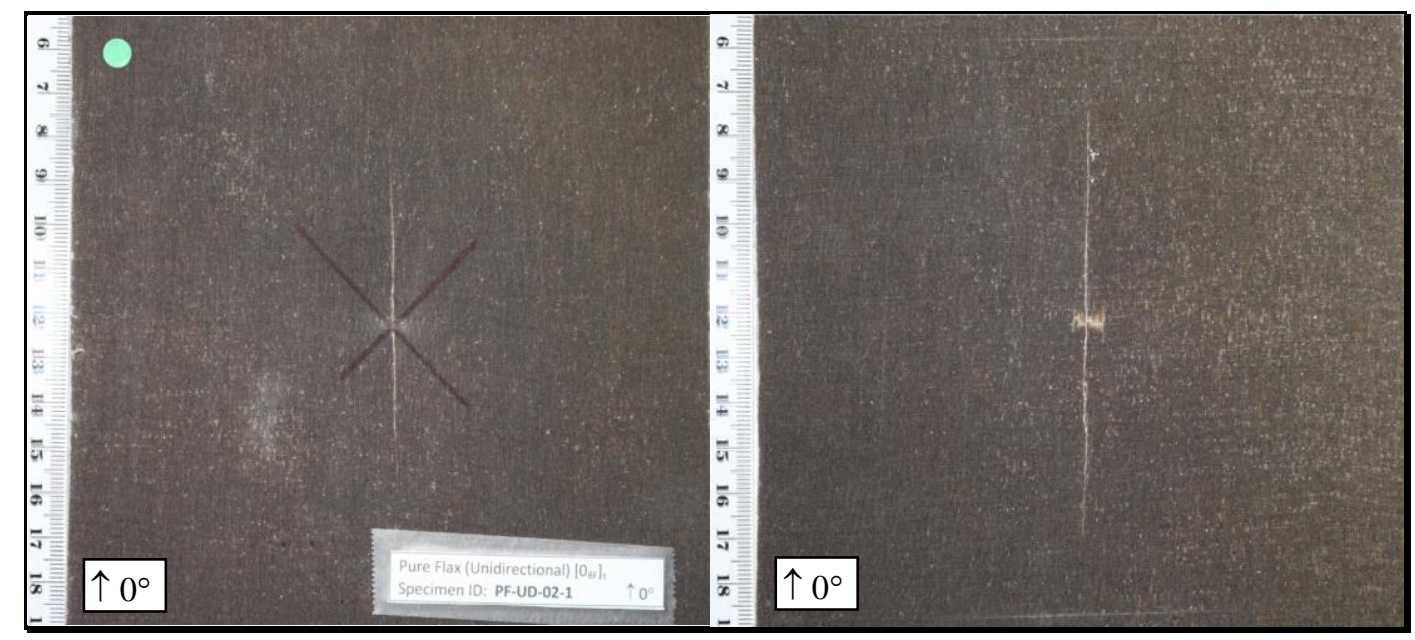

Figure 42: Front face (left); back face damage (right) for $\left[0_{8 \mathrm{~F}}\right]_{\mathrm{S}}$ at $\mathrm{E}=5 \mathrm{~J}$

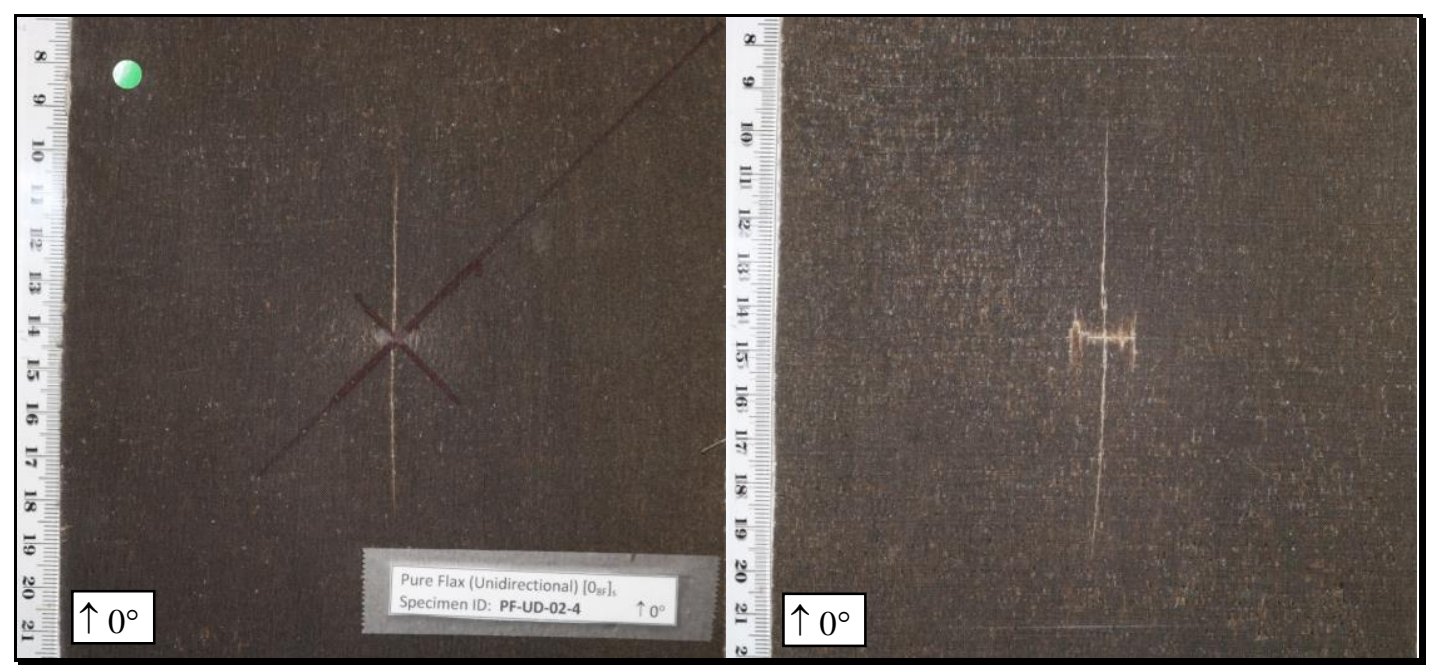

Figure 43: Front face (left); back face damage (right) for $\left[0_{8 \mathrm{~F}}\right]_{\mathrm{S}}$ at $\mathrm{E}=7 \mathrm{~J}$ 


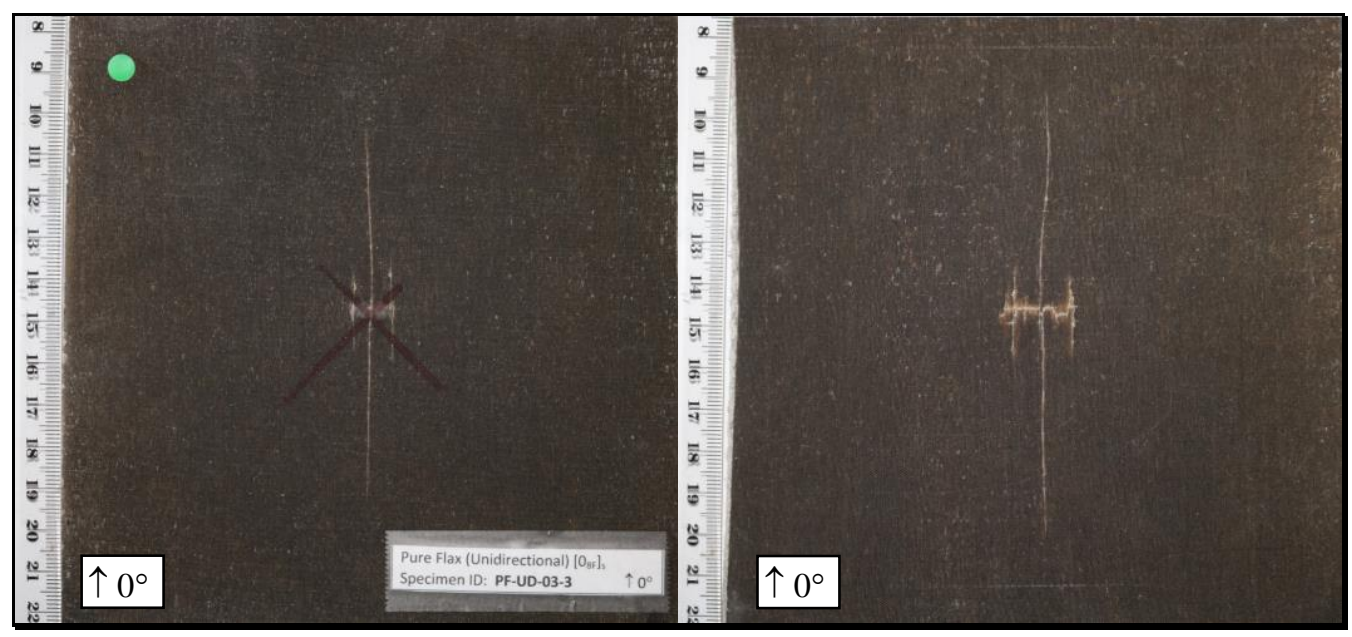

Figure 44: Front face (left); back face damage (right) for $\left[0_{8 \mathrm{~F}}\right]_{\mathrm{s}}$ at $\mathrm{E}=8 \mathrm{~J}$

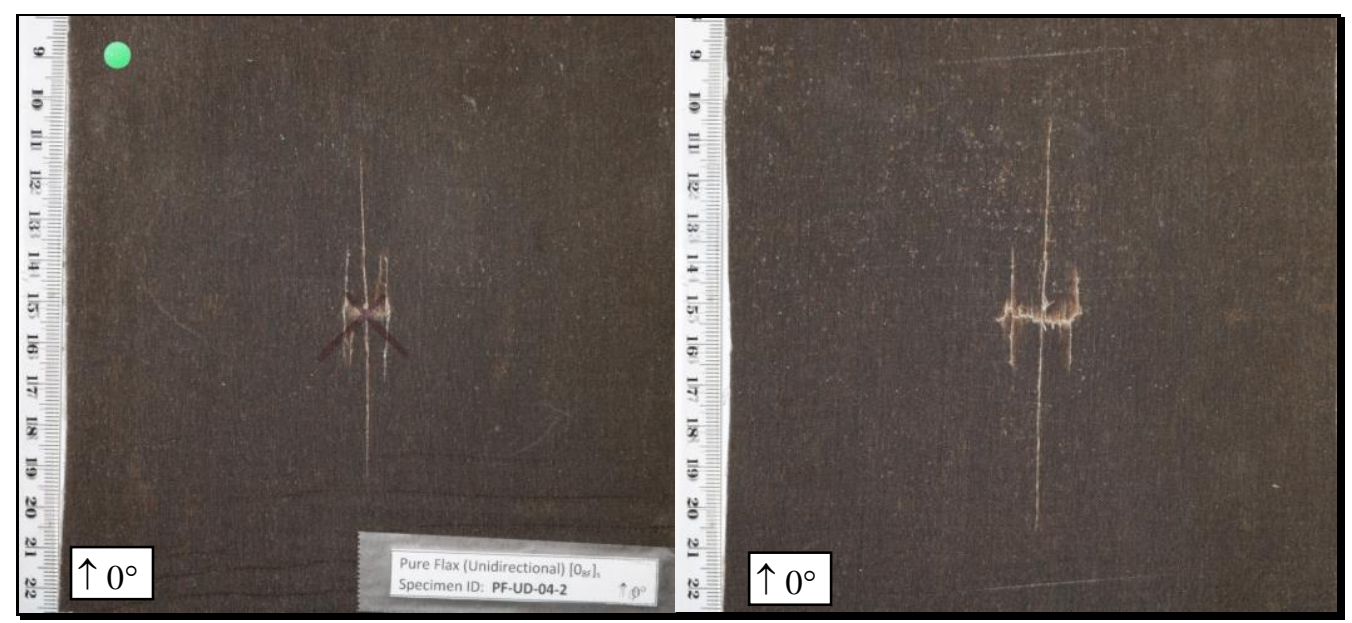

Figure 45: Front face (left); back face damage (right) for $\left[0_{8 \mathrm{~F}}\right]_{\mathrm{s}}$ at $\mathrm{E}=9 \mathrm{~J}$

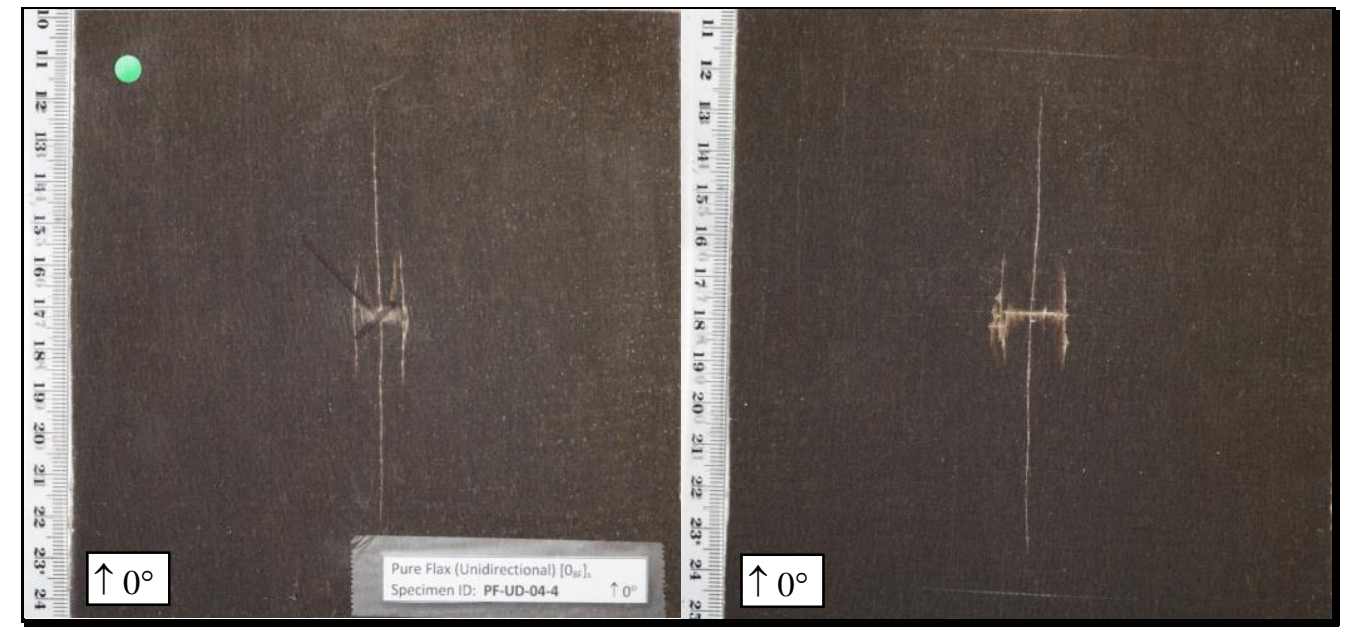

Figure 46: Front face (left); back face damage (right) for $\left[0_{8 \mathrm{~F}}\right]_{\mathrm{S}}$ at $\mathrm{E}=9.5 \mathrm{~J}$ 


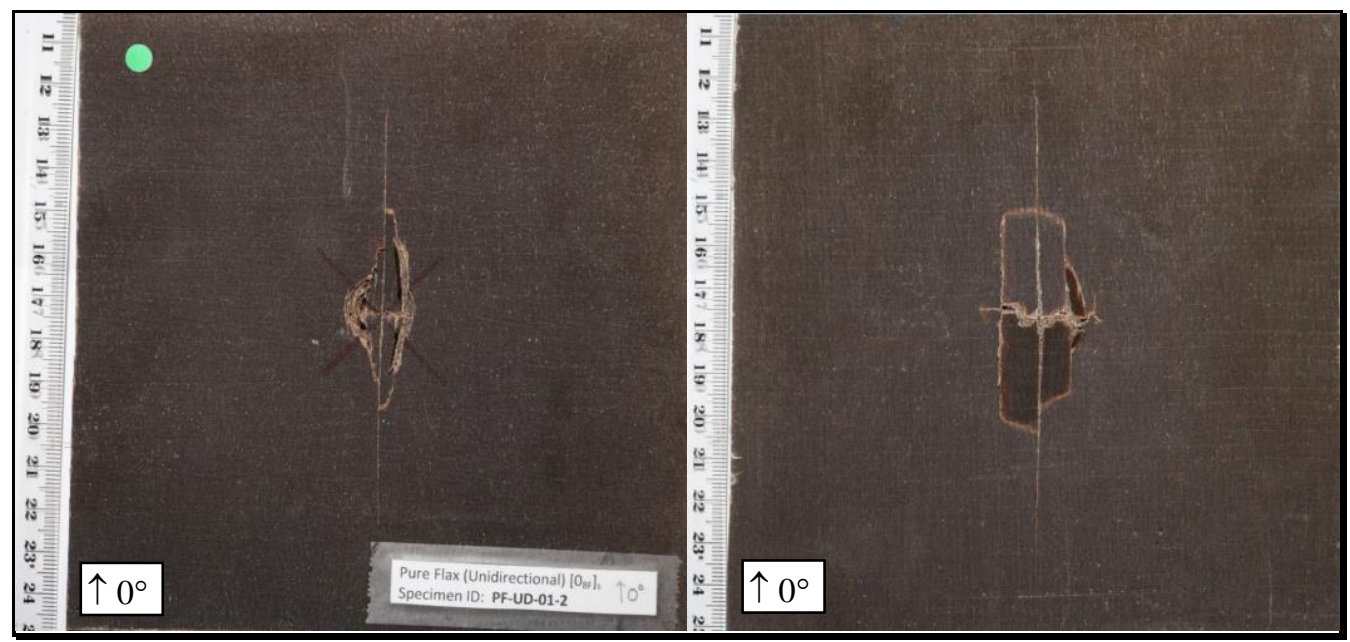

Figure 47: Front face (left); back face damage (right) for $\left[0_{8 \mathrm{~F}}\right]_{\mathrm{S}}$ at $\mathrm{E}=10 \mathrm{~J}$

The general schematics of the front and back face damage profiles of the unidirectional composite are depicted in the following figures:
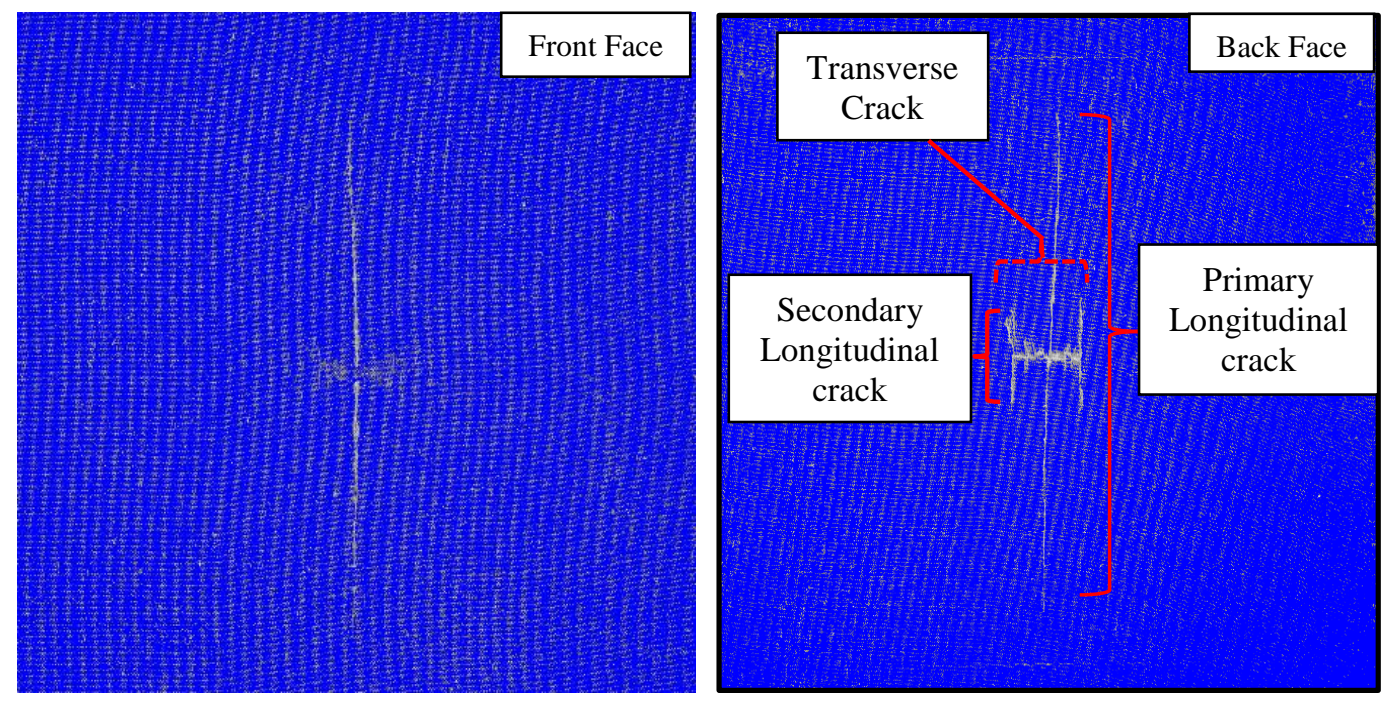

Figure 48: Typical front (left) and back (right) face damage to the $\left[0_{8 \mathrm{~F}}\right]_{\mathrm{s}}$ composite

Post-impact visual inspection showed that the typical damage on the unidirectional flax/epoxy composite consisted of a longitudinal crack originating from the center of plate, a transverse crack running across the longitudinal crack, and two short symmetric cracks at both ends of the transverse crack. The damage on the front face was similar to that of the back face, although less severe in terms of geometry. 
On the back face, the longitudinal crack lengths increased with increasing impact energy, while the transverse crack length remained constant at approximately $16 \mathrm{~mm}$, corresponding to the diameter of the impactor. The length of the central longitudinal crack plateaued as the penetration energy threshold was approached, which can be attributed to the boundary condition effect limiting the crack propagation to a maximum length.

The observed failure mode on the impacted laminate was primarily due to bending, with the matrix crack originating directly opposite to the point of impact where the tensile stress is the highest. As the impact energy reached the penetration threshold, the secondary crack length abruptly increased as the specimen fractured along the transverse crack. Figure 49 plots the primary and secondary longitudinal crack lengths as a function of the impact energy.

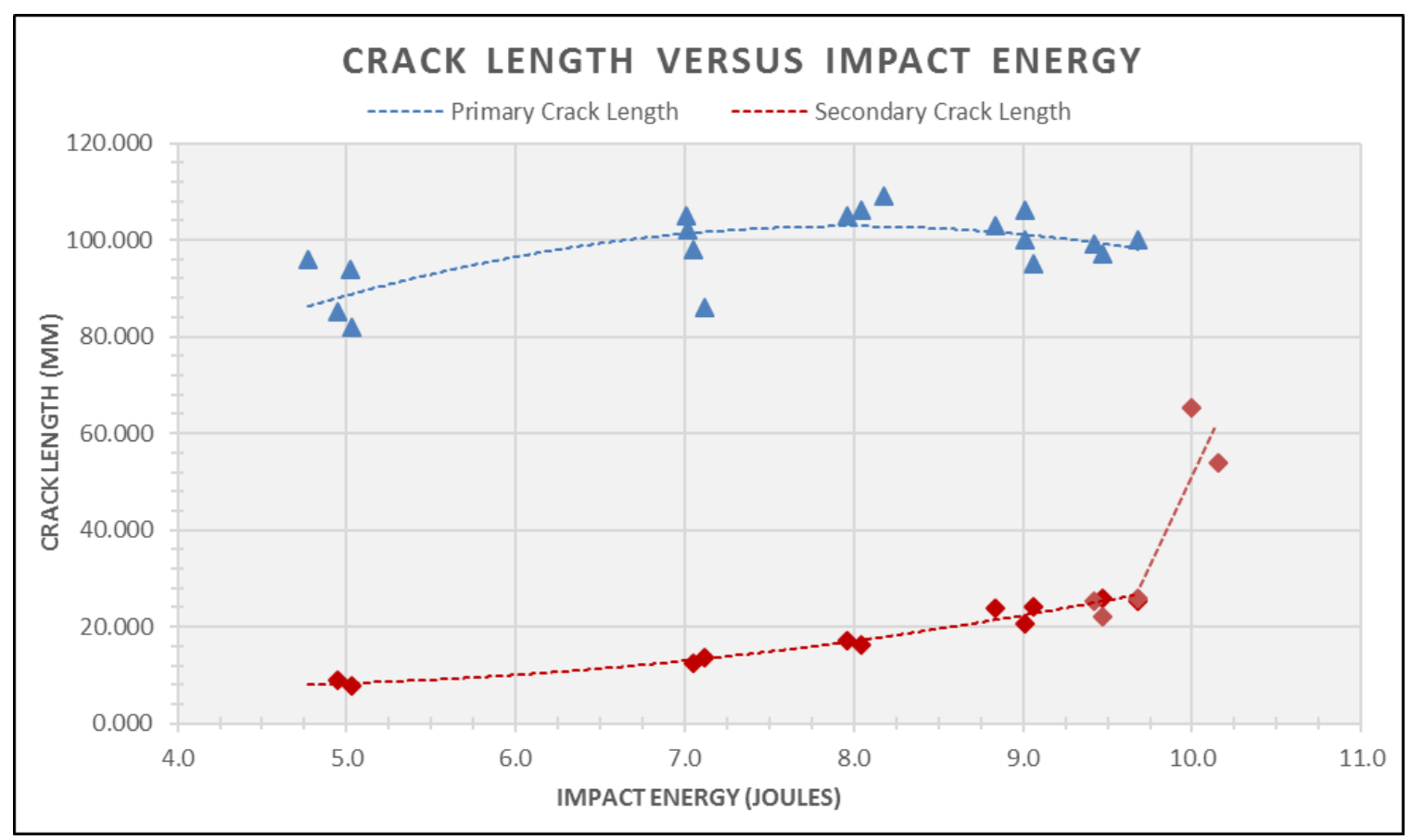

Figure 49. Longitudinal crack lengths versus impact energy for the $\left[0_{8 \mathrm{~F}}\right]_{\mathrm{S}}$ laminate

From the above graph, the primary crack length follows a parabolic profile, where the crack length plateaus as it approaches the penetration energy threshold. The secondary crack length on the other hand initially follows a quadratic function up to $\mathrm{E}=9.5 \mathrm{~J}$, but then abruptly increases in length as the impact energy approaches the penetration energy threshold at $10 \mathrm{~J}$. 


\subsubsection{CROSS-PLY FLAX/EPOXY COMPOSITE}

The next set of figures show the front and back face damages on the cross-ply flax/epoxy composites post-impact. Consistent damage profile has been obtained for all test cases, therefore, only one sample per test case is shown.

Post-impact visual inspection showed two different damage patterns on the front and back faces of the cross-ply flax/epoxy composite, respectively. The front face damage consisted of a central longitudinal crack with a symmetric "butterfly-shaped" delamination on the top layer(s) surrounding the impact location. This delamination zone did not manifest at low impact energies but only started to show at impact energies of $15 \mathrm{~J}$ and higher.
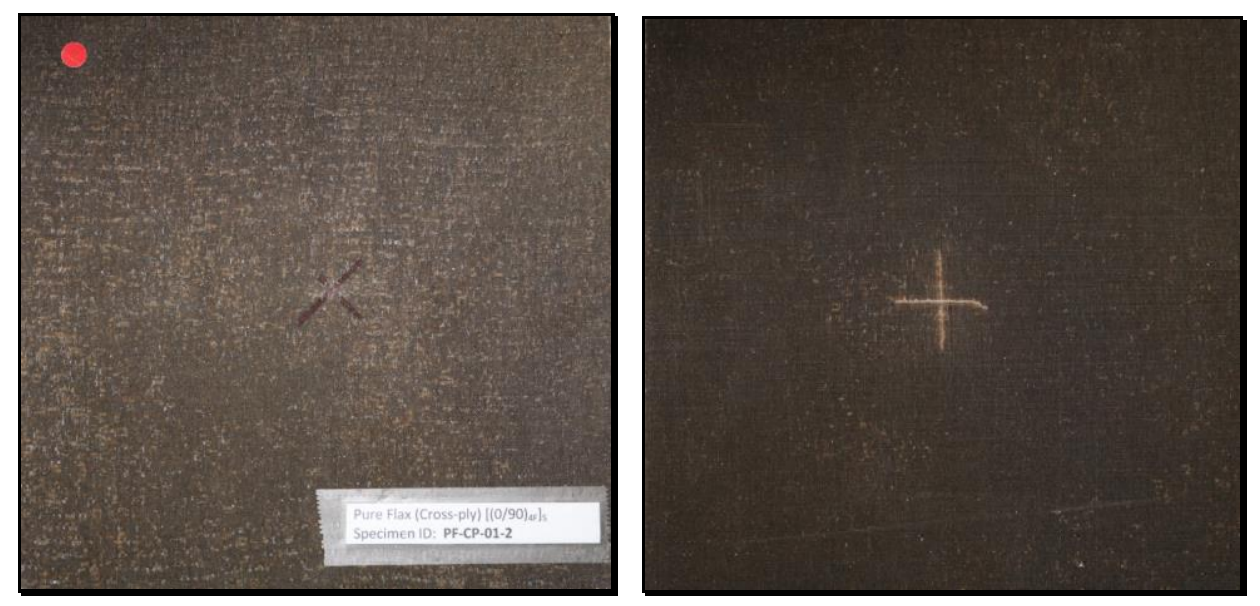

Figure 50: Front face (left); back face damage (right) for $\left[(0 / 90)_{4 \mathrm{~F}}\right]_{\mathrm{s}}$ at $\mathrm{E}=5 \mathrm{~J}$
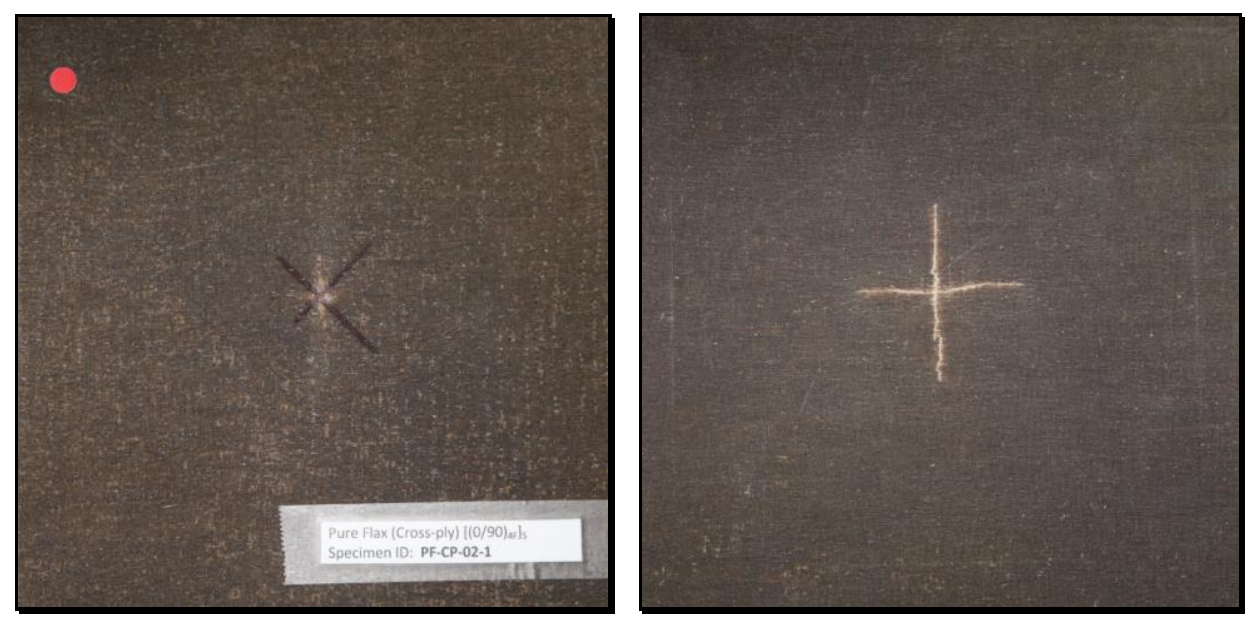

Figure 51: Front face (left); back face damage (right) for $\left[(0 / 90)_{4 \mathrm{~F}}\right]_{\mathrm{S}}$ at $\mathrm{E}=10 \mathrm{~J}$ 

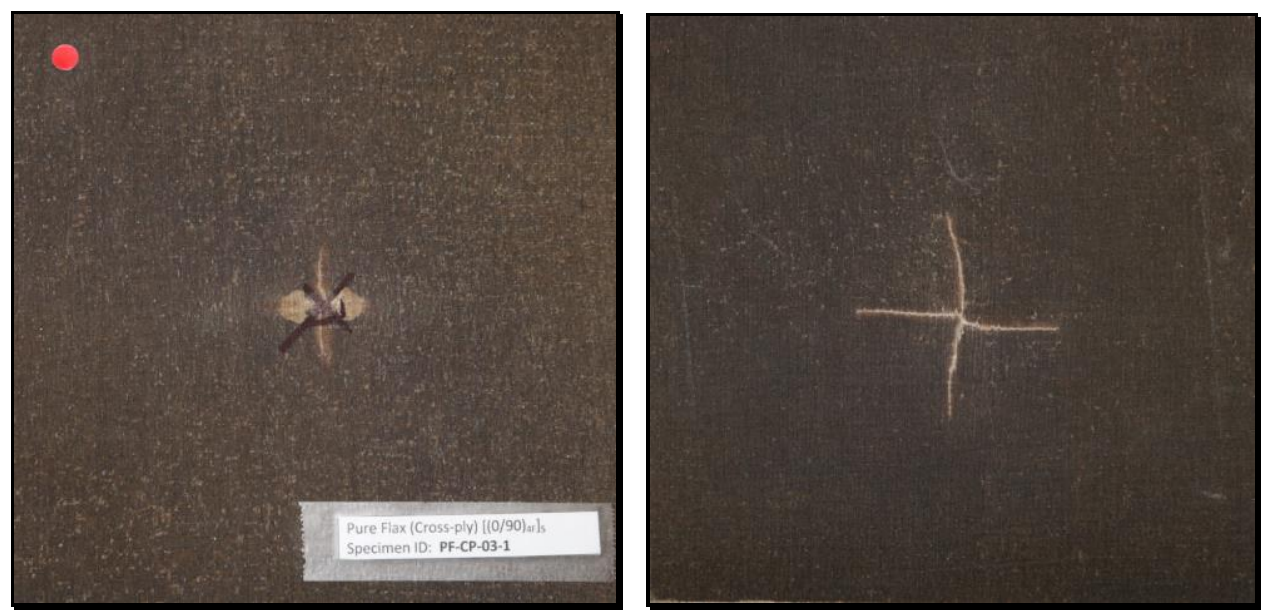

Figure 52: Front face (left); back face damage (right) for $\left[(0 / 90)_{4 \mathrm{~F}}\right]_{\mathrm{S}}$ at $\mathrm{E}=15 \mathrm{~J}$
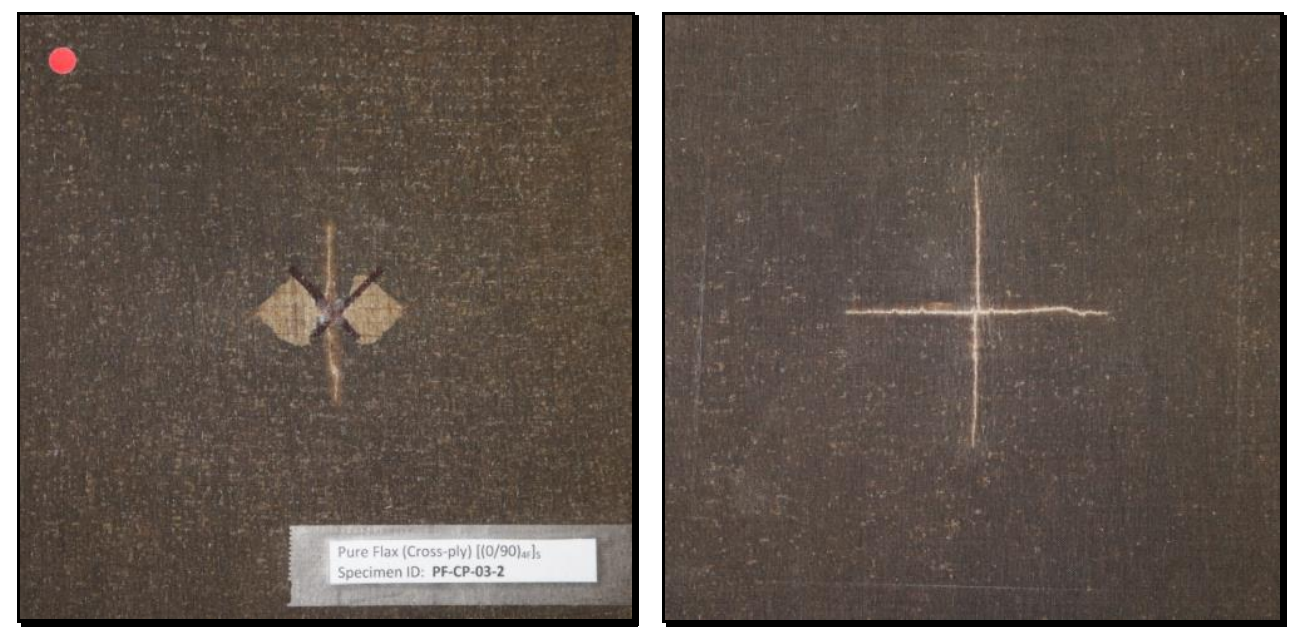

Figure 53: Front face (left); back face damage (right) for $\left[(0 / 90)_{4 \mathrm{~F}}\right]_{\mathrm{S}}$ at $\mathrm{E}=\mathbf{2 0} \mathrm{J}$
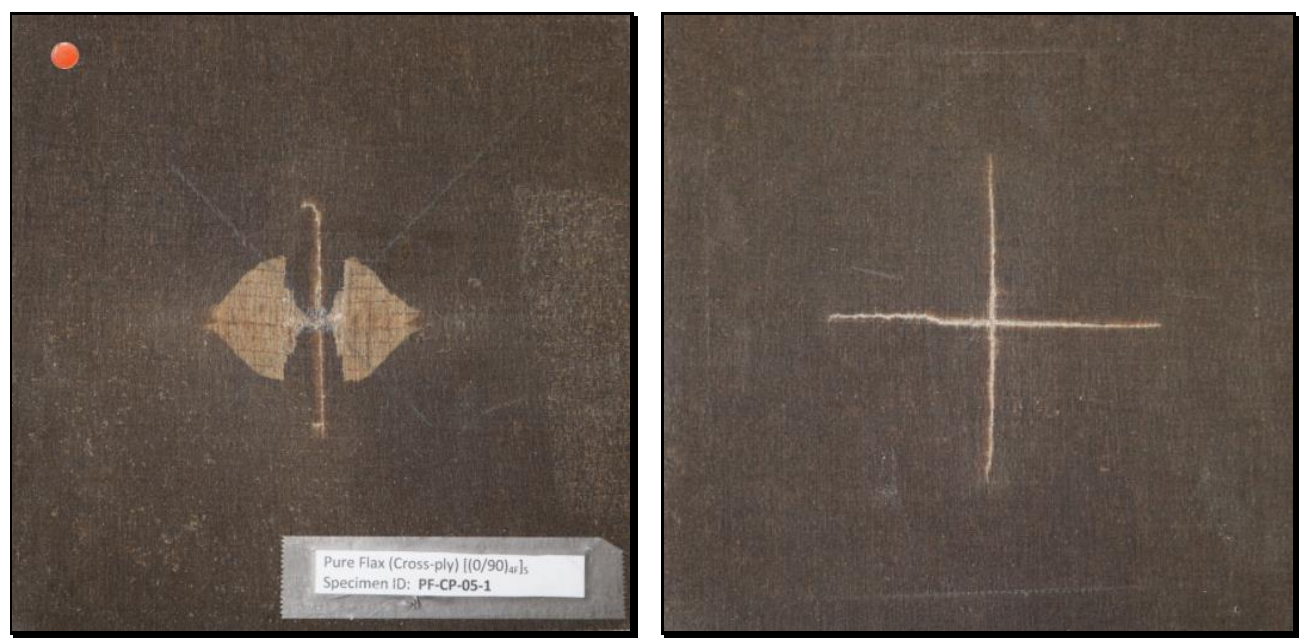

Figure 54: Front face (left); back face damage (right) for $\left[(0 / 90)_{4}\right]_{\mathrm{s}}$ at $\mathrm{E}=\mathbf{2 5} \mathrm{J}$ 

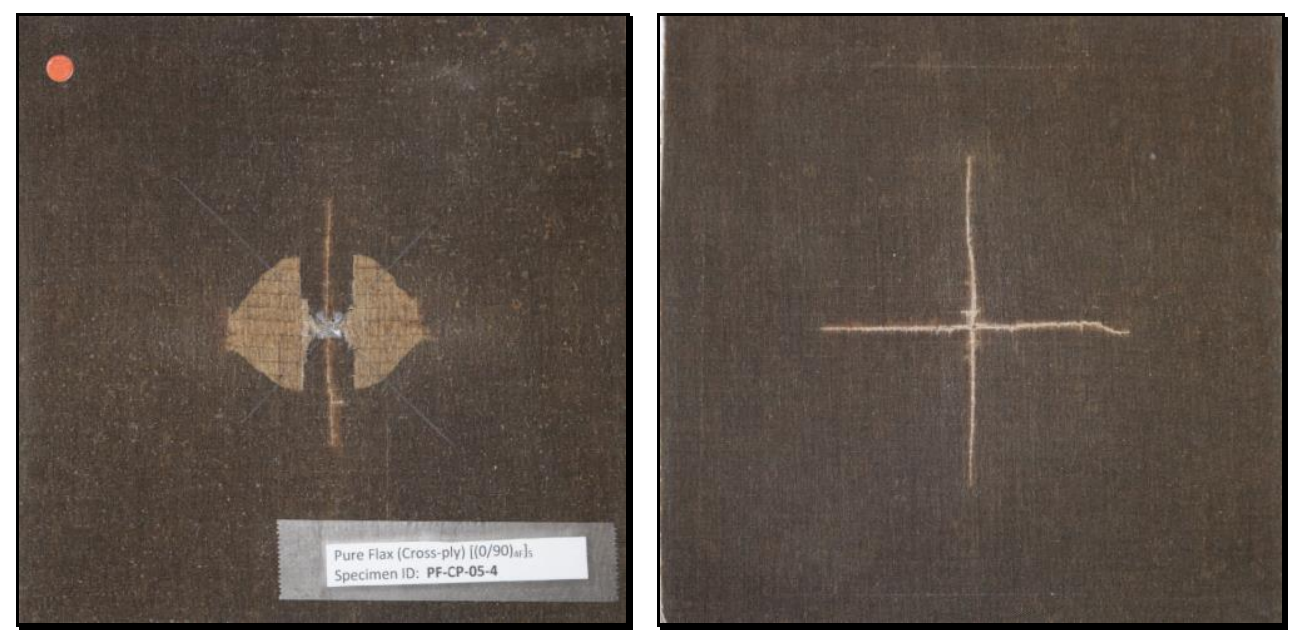

Figure 55: Front face (left); back face damage (right) for $\left[(0 / 90)_{4 \mathrm{~F}}\right]_{\mathrm{S}}$ at $\mathrm{E}=\mathbf{2 7} \mathrm{J}$
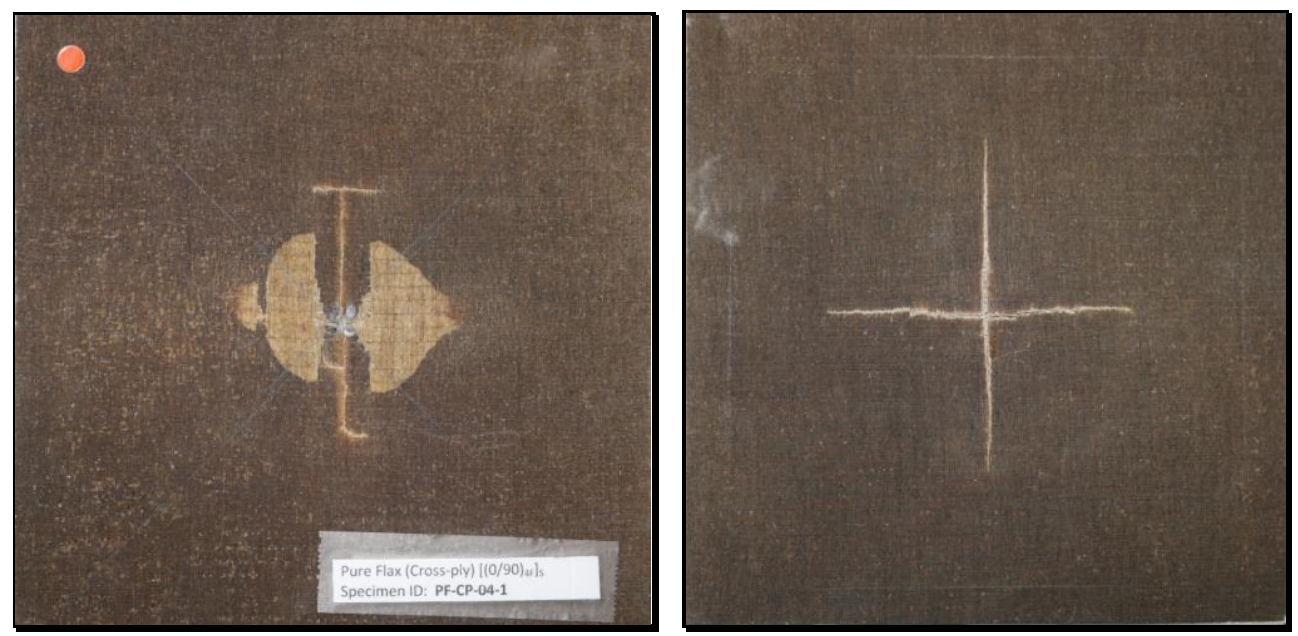

Figure 56: Front face (left); back face damage (right) for $\left[(0 / 90)_{4 \mathrm{~F}}\right]_{\mathrm{s}}$ at $\mathrm{E}=30 \mathrm{~J}$

The size of delamination zone also increased with increasing impact energy. The delamination zone emanated from the impact point and propagated conically in the transverse direction of the composite. Visually, it appeared that only the first ply had delaminated from the composite. This observation was later validated by microscopic images taken across the delamination zone.

The back-face damage on the other hand consisted of two intersecting matrix cracks of almost equal lengths in the longitudinal and transverse directions. Both the crack lengths and the crack width increased with increasing impact energy. The increasing crack width can be attributed 
to the increase in plate curvature as the impact energy increased. The crack lengths plateaued at approximately $30 \mathrm{~J}$ because of the fixed plate dimensions and boundary condition effects.

It can also be observed that the composite was not fully penetrated at the maximum impact test energy of $30 \mathrm{~J}$; however, given the trend in the damage and plate curvature, a slight increase in the impact energy will likely result in full penetration of the laminate.

The following figures show the general schematic of the damage pattern in the front and back faces of the cross-ply flax/epoxy composite laminate.
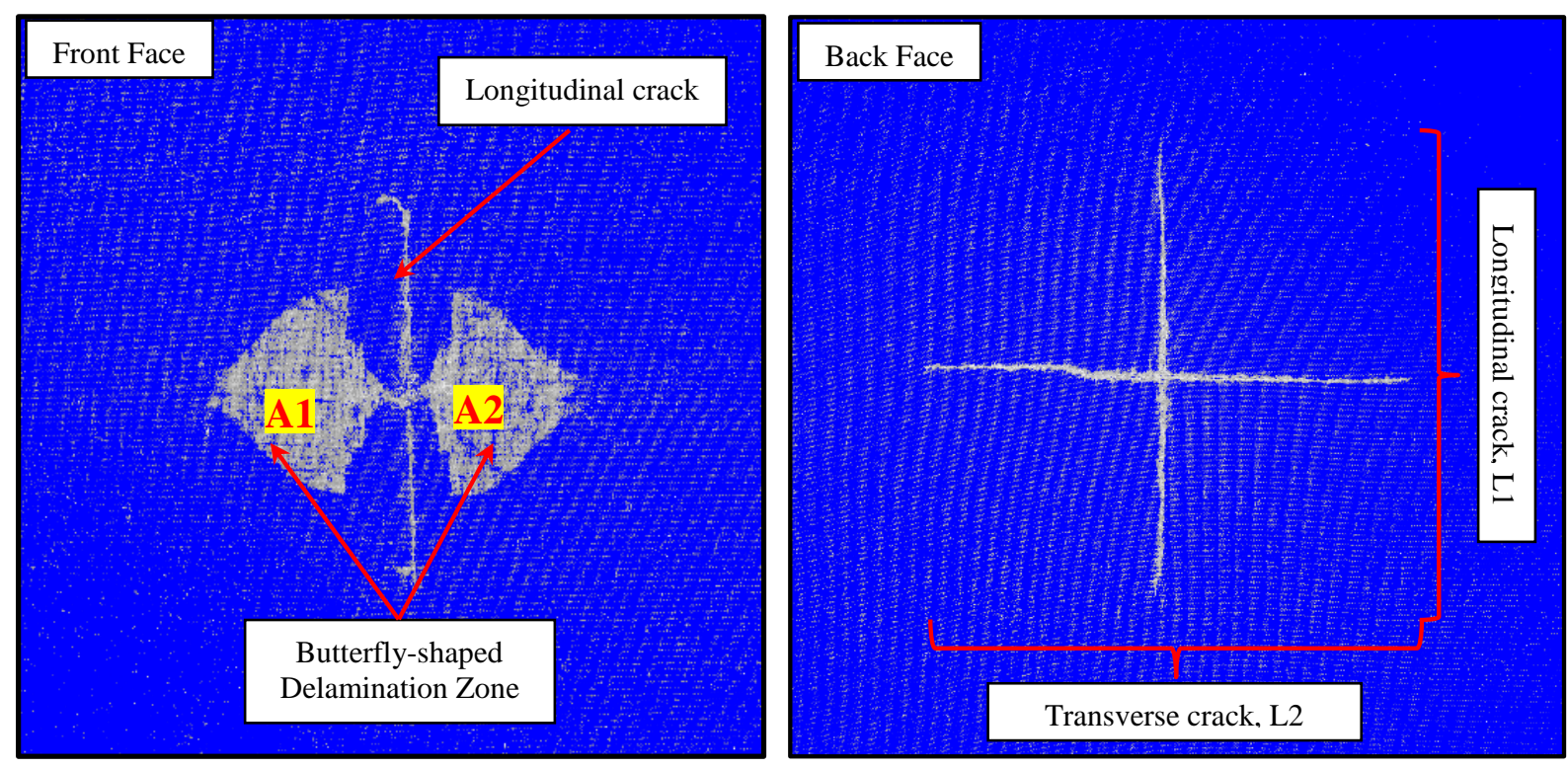

Figure 57: Typical front (left) and rear (left) face damage on a cross-ply flax/epoxy composite

Figure 58 and Figure 59 on the following page plot the front face delamination area (A1 + A2) and back face crack lengths (L1 and L2) as functions of impact energy. From these graphs, the relationship between the front face delamination area and impact energy can be fitted with a cubic function, with the delamination area increasing with increasing impact energy. On the other hand, the trend of the back-face crack lengths follows a negative quadratic function, with the maximum crack length occurring at $\mathrm{E}=30 \mathrm{~J}$. 


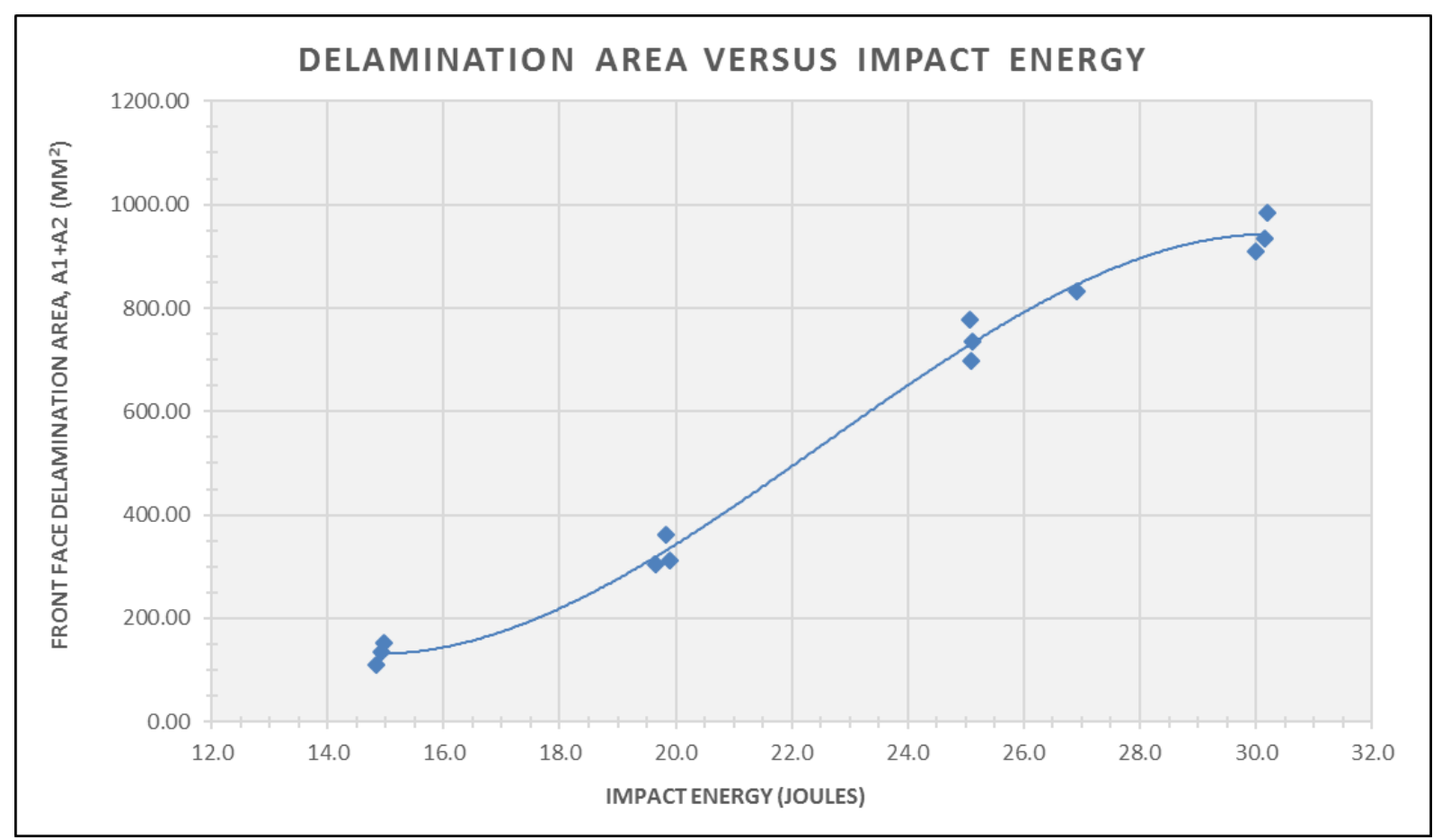

Figure 58: Front face delamination zone area versus impact energy for $\left[(0 / 90)_{4 \mathrm{~F}}\right]_{\mathrm{S}}$

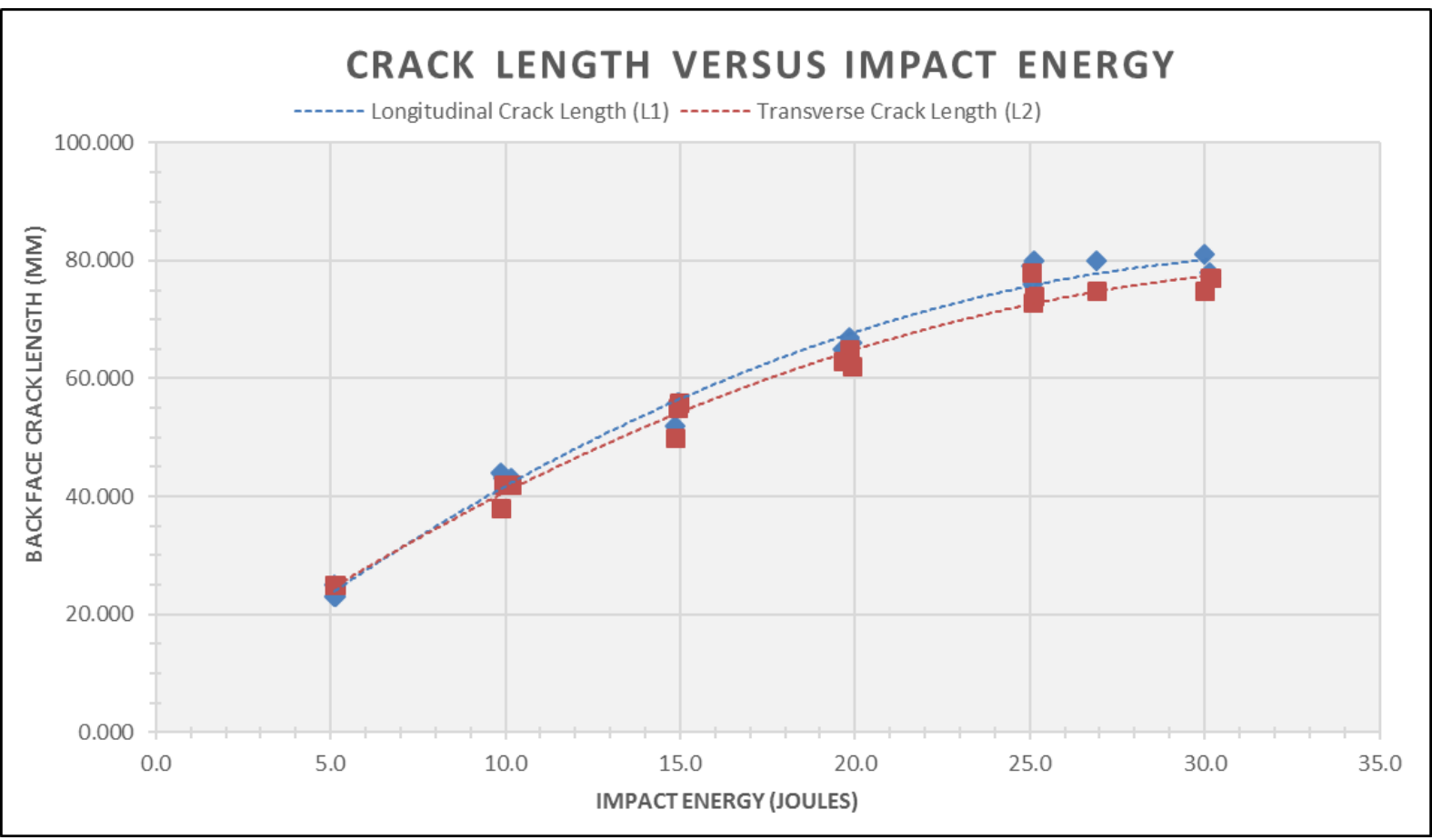

Figure 59: Longitudinal and transverse crack lengths versus impact energy for $\left[(0 / 90)_{4 \mathrm{~F}}\right]_{\mathrm{s}}$ 


\subsubsection{POST-IMPACT INDENTATION DEPTH}

When subjected to impact loading, the composite laminates undergo surface indentation at the point of impact. To investigate the relationship between the dent depth and impact energy, the indentation depth was measured using a digital height indicator (DHI). This was performed by measuring the vertical position of the impact point pre-impact and post-impact and then calculating the difference between the two measurements.
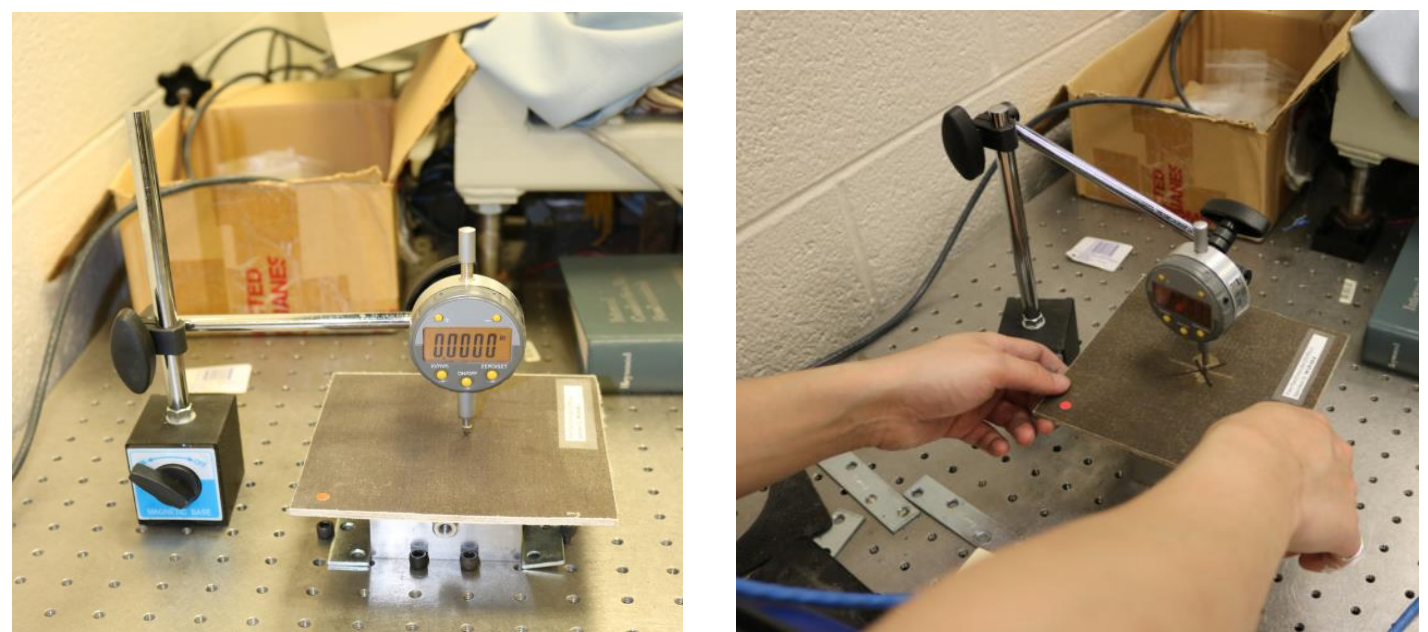

Figure 60: Indentation depth measurement using a digital height indicator

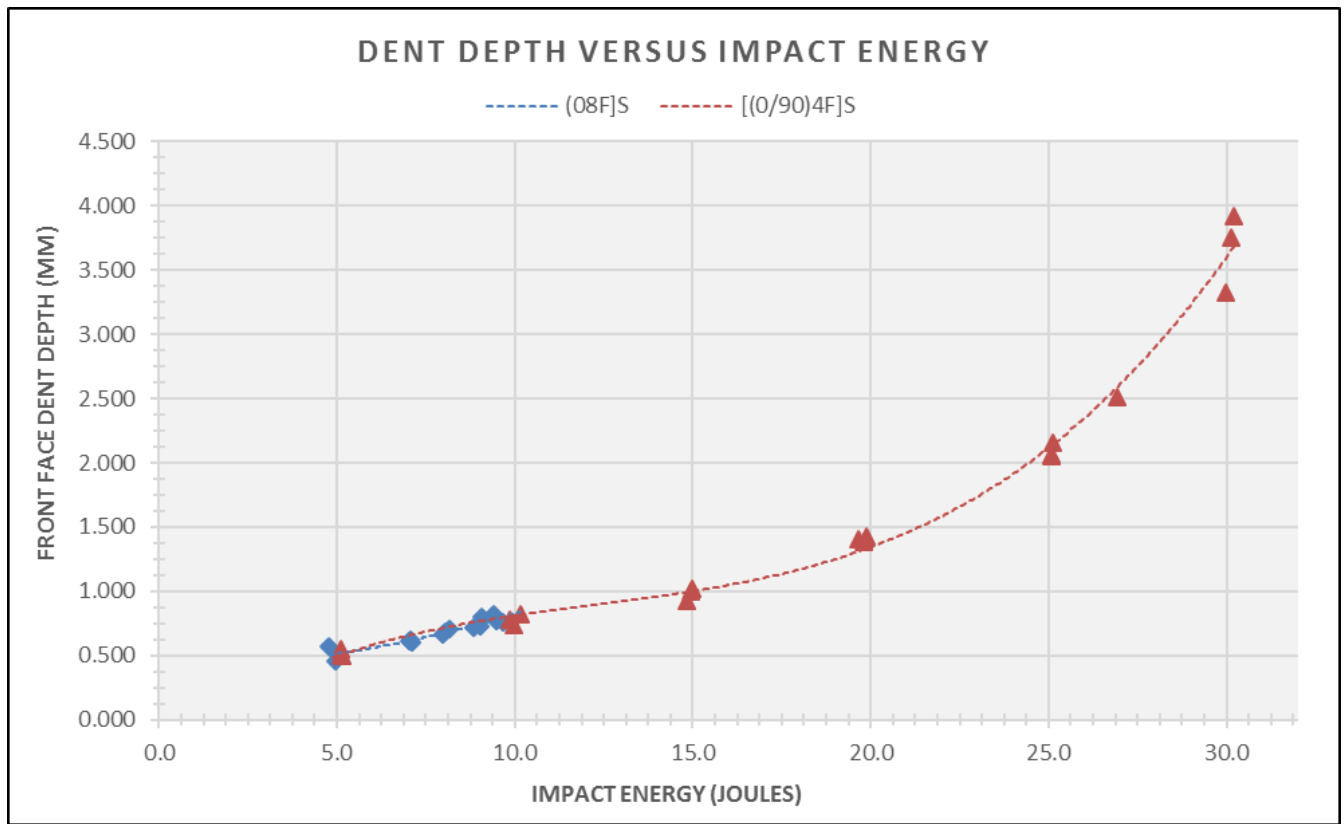

Figure 61: Front face indentation depth versus impact energy for the flax/epoxy composites 


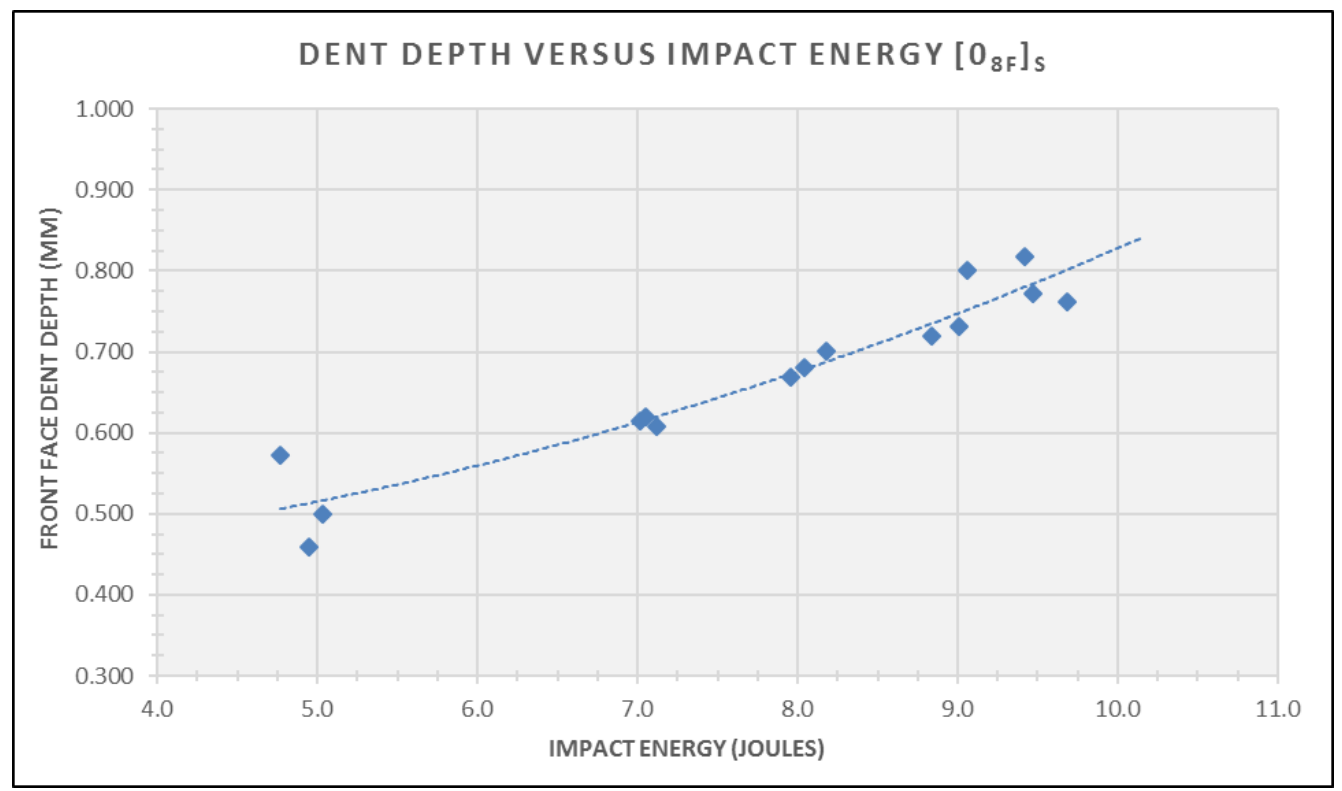

Figure 62: Front face indentation depth versus impact energy for $\left[0_{8 F}\right]_{s}$

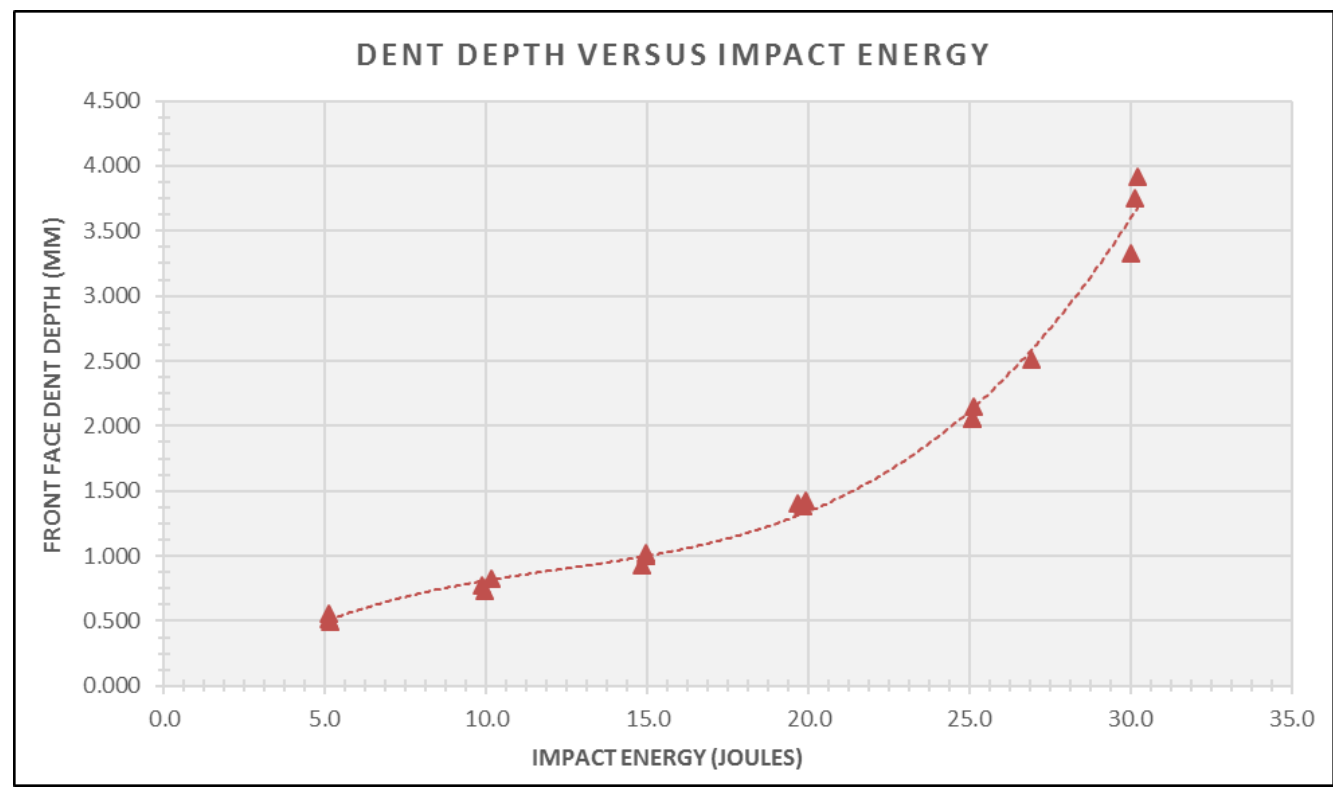

Figure 63: Front face indentation depth versus impact energy for $\left[(0 / 90)_{4 \mathrm{~F}}\right]_{\mathrm{S}}$

For the unidirectional flax/epoxy composite, the trend of the indentation depth versus impact energy follows a quadratic function up to the point prior to penetration. At penetration energy, the impact depth goes to infinity as the composite fractures. The cross-ply flax/epoxy composite on the other hand follows a cubic function, with an inflection point at approximately 15 J. The curve approaches infinity beyond $30 \mathrm{~J}$. 


\subsubsection{IMPACT DAMAGE ASSESSMENT}

In order to investigate the internal impact damage on the flax/epoxy composite, the impacted unidirectional laminates were cross-sectioned across the longitudinal cracks (A-A) at approximately $5 \mathrm{~mm}$ away from the point of impact. The cross-ply laminates on the other hand were cross-sectioned (B-B) across one side of the delamination zone up to the longitudinal crack at approximately $5 \mathrm{~mm}$ from the point of impact. Another section cut was created across one side of the delamination zone at section $\mathrm{C}-\mathrm{C}$.
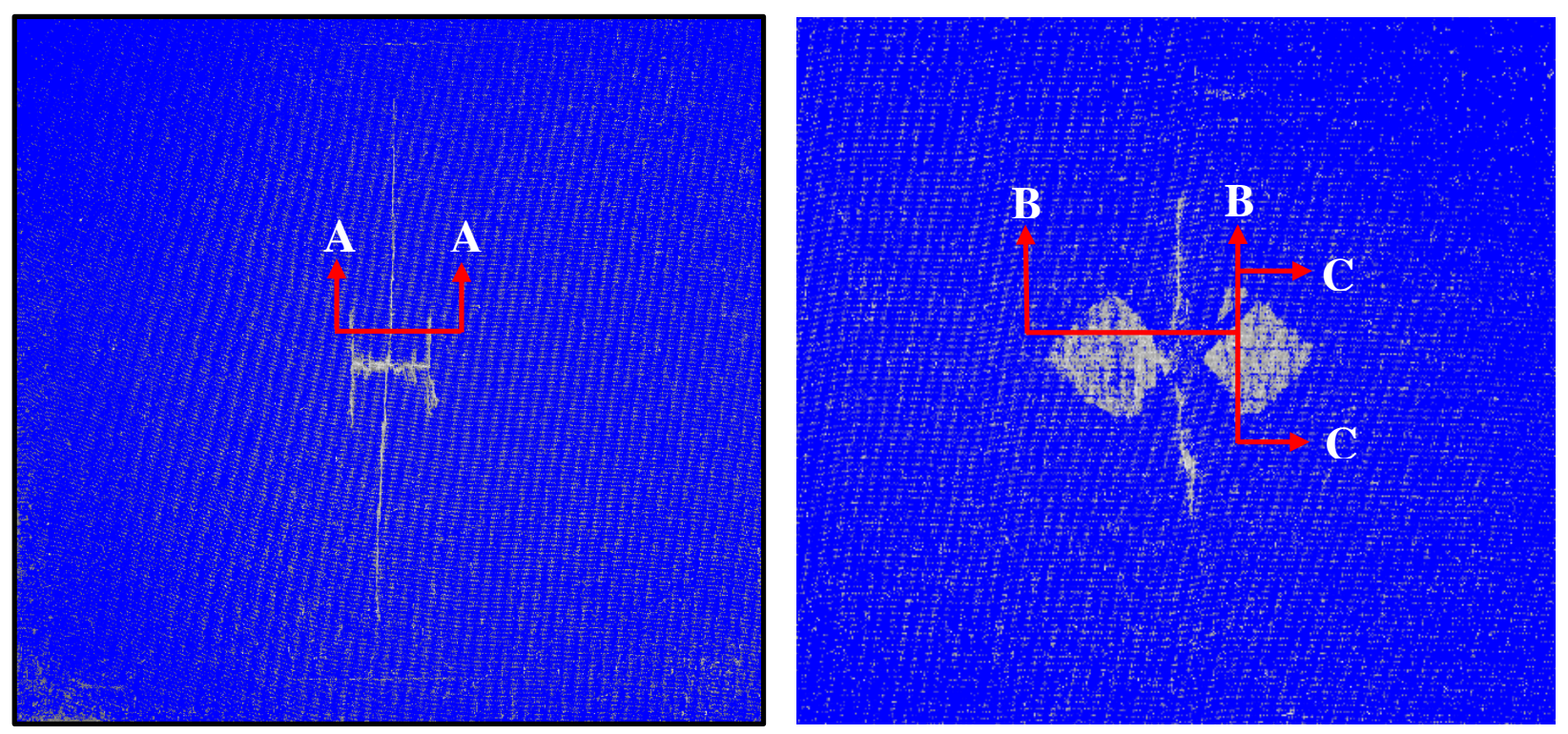

Figure 64: Section cuts on $\left[0_{8 \mathrm{~F}}\right]_{S}(\mathrm{~A}-\mathrm{A})$ and $\left[(0 / 90)_{4 \mathrm{~F}}\right]_{S}(\mathrm{~B}-\mathrm{B})$ flax/epoxy composites

The sectioned samples were then polished to obtain a clear view of the cross sectional damage. High-resolution photographs of the cross section were then taken using a DSLR camera fitted with a macro lens in order to macroscopically examine the damaged cross sections. In addition, the samples were also viewed under an optical microscope in order to investigate the damage mechanism present such as fibre breakage, matrix cracking, delamination, fibre debonding and fibre pull-out. 


\subsubsection{UNIDIRECTIONAL F LAX/EPOXY COMPOSITE}

The following figure shows the typical cross-section impact damage on the unidirectional flax/epoxy composite laminate.

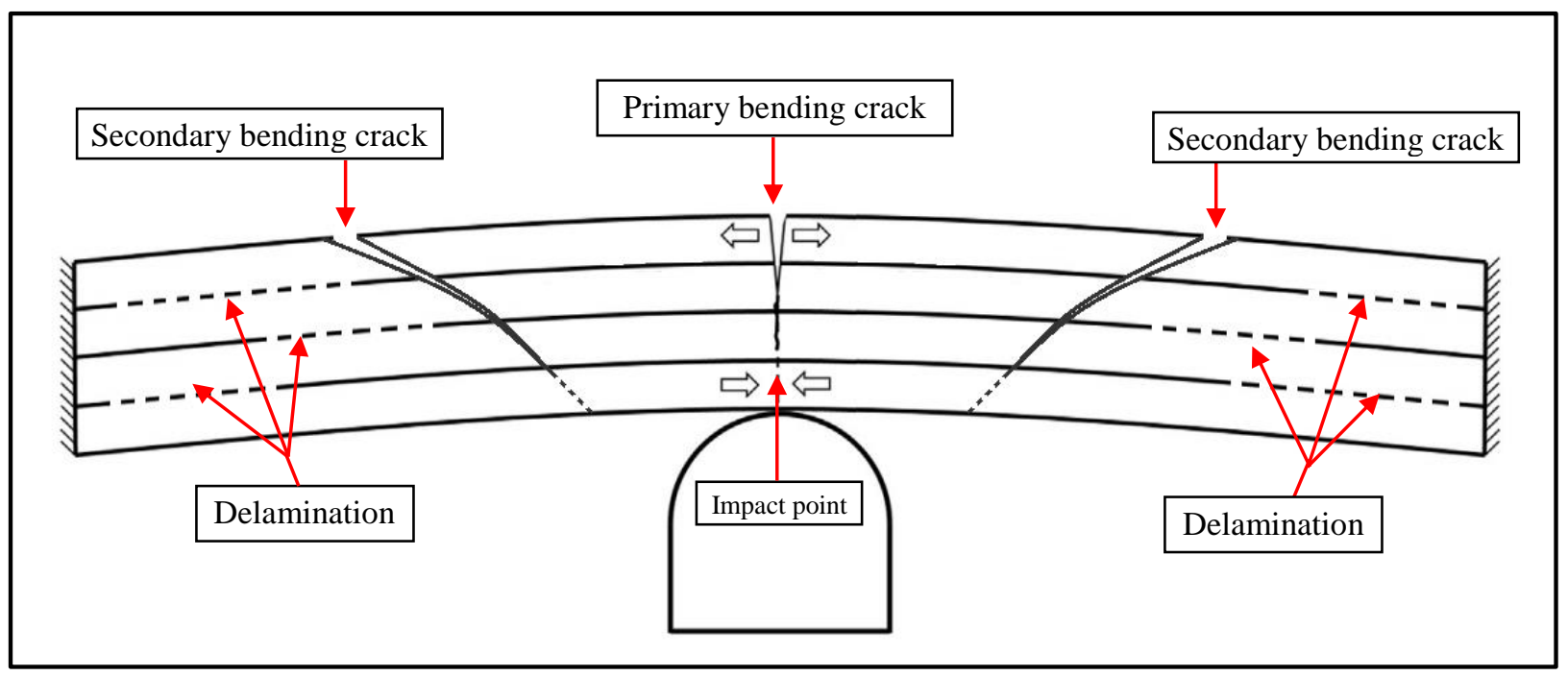

Figure 65: Schematic of typical cross section damage on unidirectional flax/epoxy

Moreover, the following figures show photographs of the cross sectioned unidirectional flax/epoxy composite samples under $5 \mathrm{~J}, 7 \mathrm{~J}, 8 \mathrm{~J}, 9 \mathrm{~J}$ and $9.5 \mathrm{~J}$, respectively.

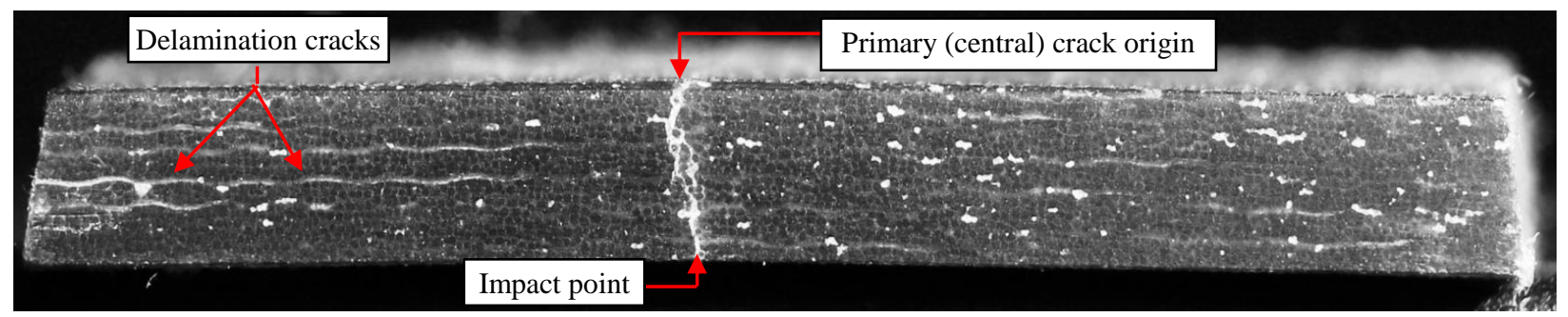

Figure 66: Cross-section A-A for $\left[0_{8 \mathrm{~F}}\right]_{\mathrm{s}}$ at $\mathrm{E}=5 \mathrm{~J}$

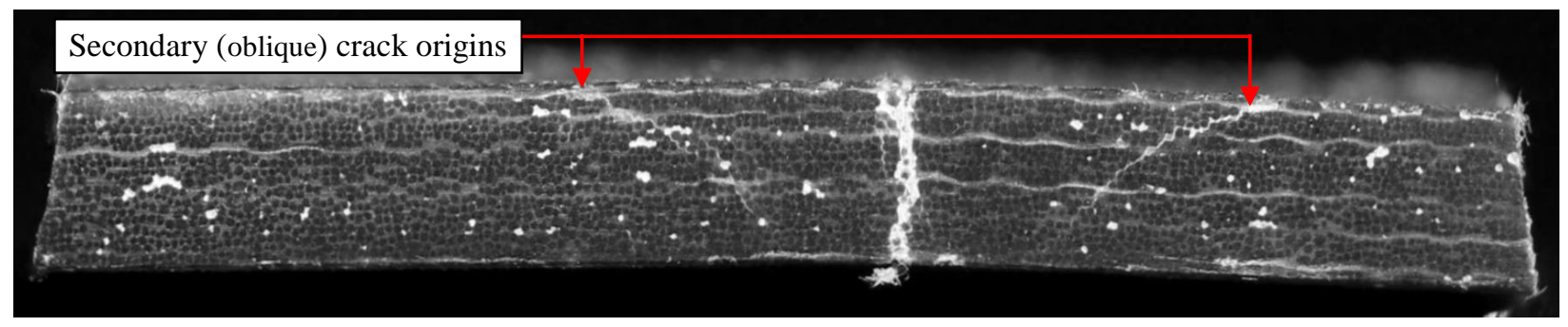

Figure 67: Cross-section A-A for $\left[0_{8 \mathrm{~F}}\right]_{\mathrm{s}}$ at $\mathrm{E}=7 \mathrm{~J}$ 


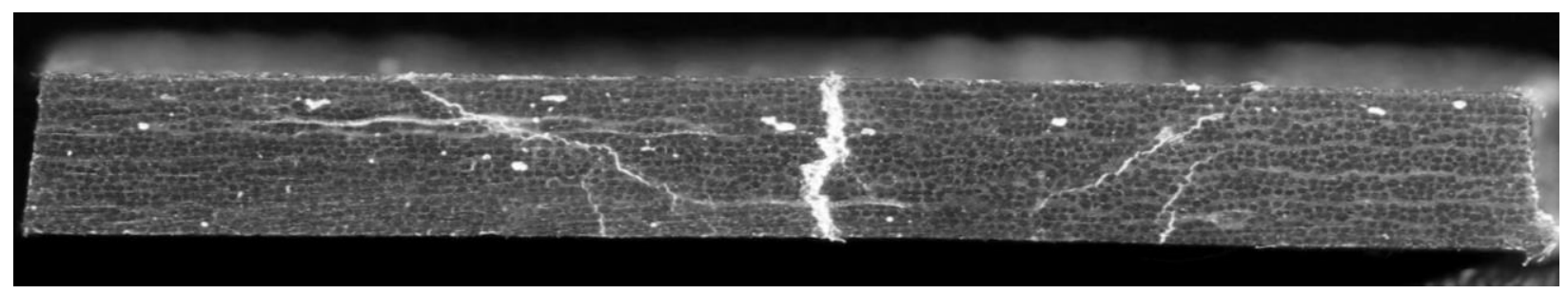

Figure 68: Cross-section A-A for $\left[0_{8 \mathrm{~F}}\right]_{\mathrm{S}}$ at $\mathrm{E}=8 \mathrm{~J}$

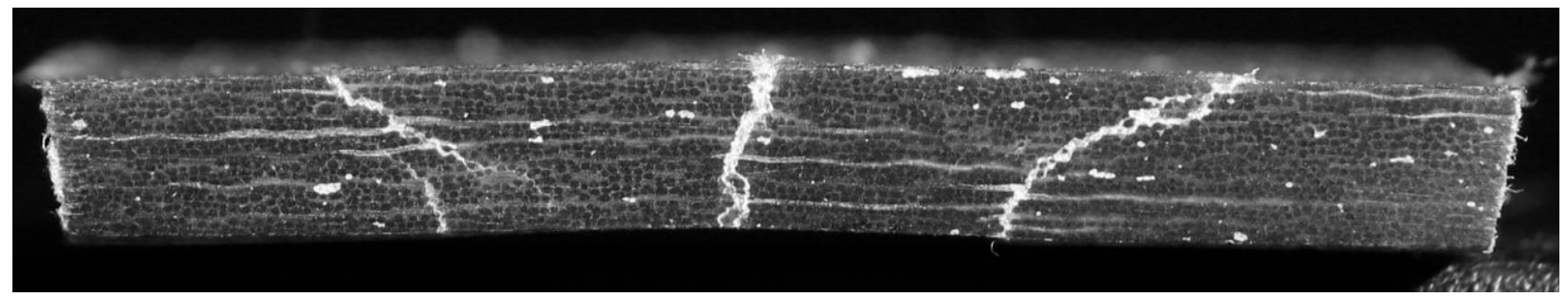

Figure 69: Cross-section A-A for $\left[0_{8 \mathrm{~F}}\right]_{\mathrm{S}}$ at $\mathrm{E}=9 \mathrm{~J}$

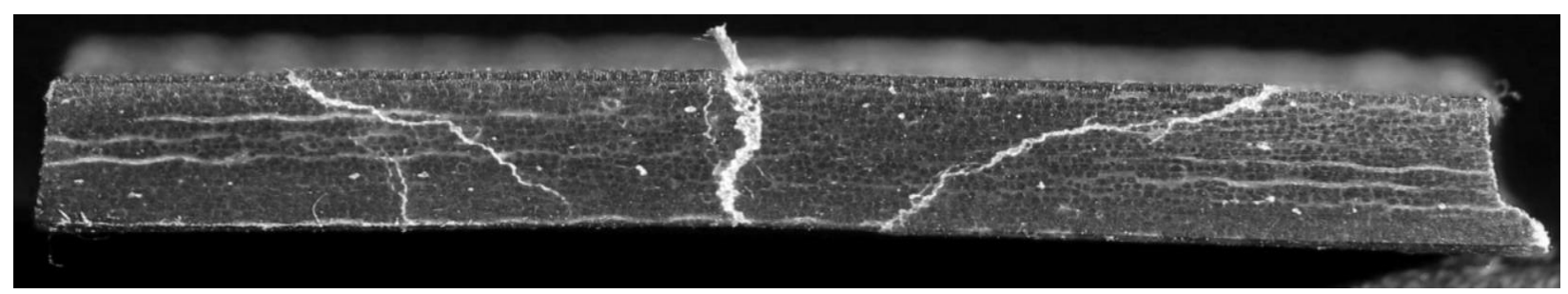

Figure 70: Cross-section A-A for $\left[0_{8 \mathrm{~F}}\right]_{\mathrm{S}}$ at $\mathrm{E}=9.5 \mathrm{~J}$

From a macroscopic level, the damage on the composite plate was due to flexure, with the bending crack originating from the back face opposite the point of impact. This is the location where the plate curvature and tensile stress are maximum. For all impact energies, the primary (central) crack propagated through the thickness of the plate. The crack width increased with increasing impact energy because of increasing plate curvature. In addition, two secondary (oblique) cracks also developed on both sides of the central crack. These secondary cracks were non-existent on the plates impacted at $5 \mathrm{~J}$, but can only be observed on composite plates impacted at energies of $7 \mathrm{~J}$ and higher. The cracks originated from the opposite side of the impacted face, and propagated conically through the thickness of the plate. The crack propagation rate also increased with increasing impact energy. At $7 \mathrm{~J}$ impact energy, the secondary cracks propagated to approximately $50 \%$ of the plate thickness. At $8 \mathrm{~J}$, it propagated to approximately $70-80 \%$. At 9 $\mathrm{J}$, it completely propagated through the thickness of the plate. In addition to the bending cracks, random inter-ply delamination cracks were also observed at all impact energy levels. 
Microscopic images taken at the crack origin showed matrix cracking, fibre breakage and fibre pull-out as the damage mechanisms involved. Impact-induced tensile stresses generated on the back face caused matrix cracking to occur first since thermosetting resins are brittle and can undergo only a limited deformation prior to fracture. This was followed by fibre breakage and fibre pull-out along the crack path as shown in the figures below.

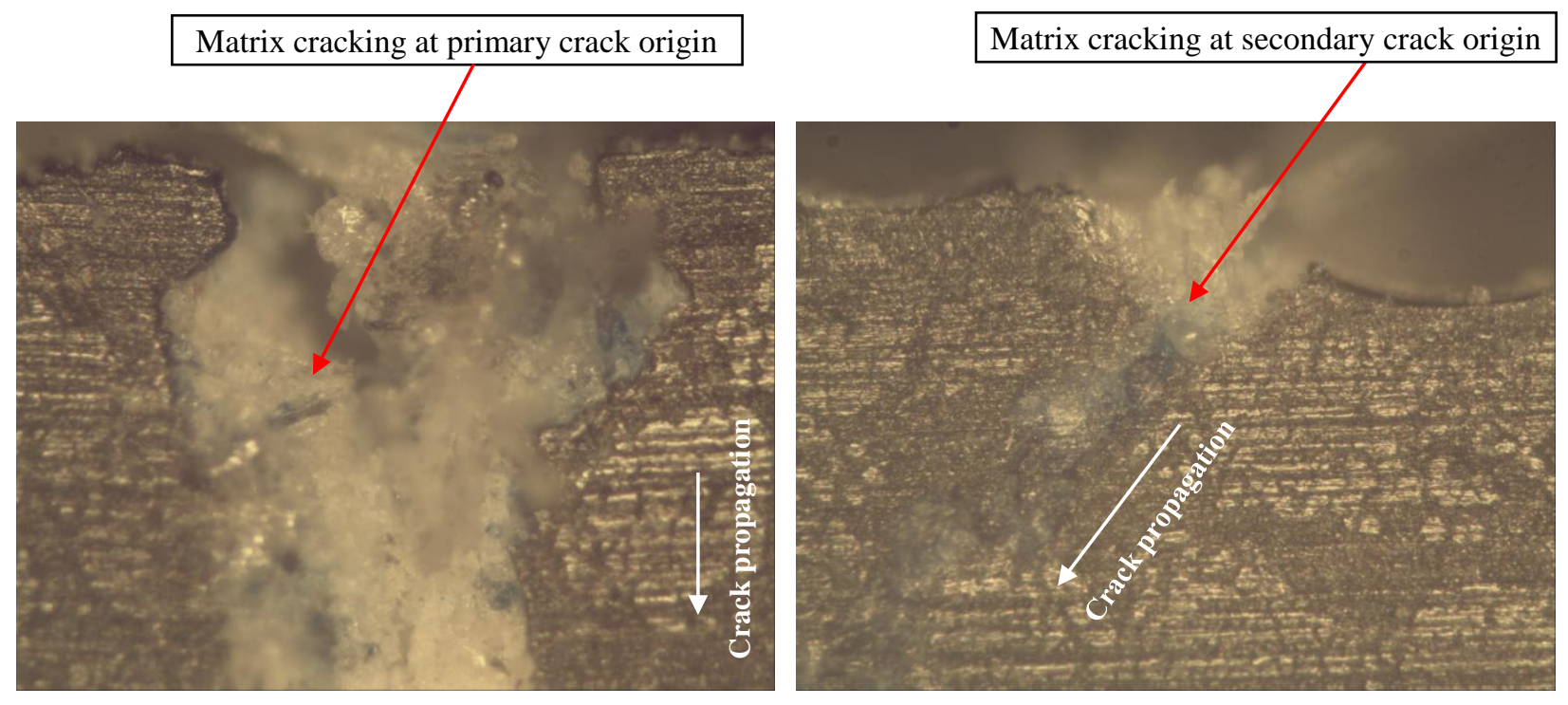

Figure 71: Matrix cracking at the primary (left) and secondary (right) crack origin

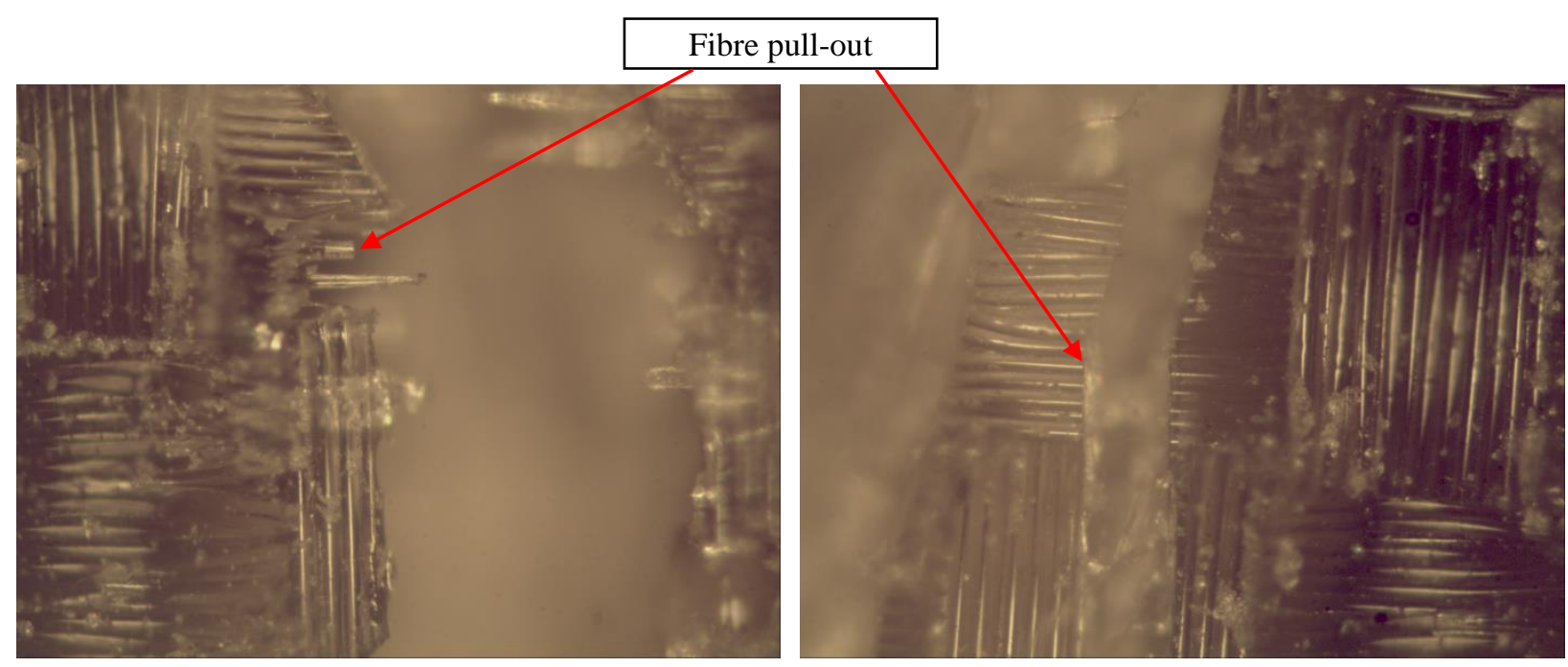

Figure 72: Fibre damage (pull-out and breakage) along the primary crack path 


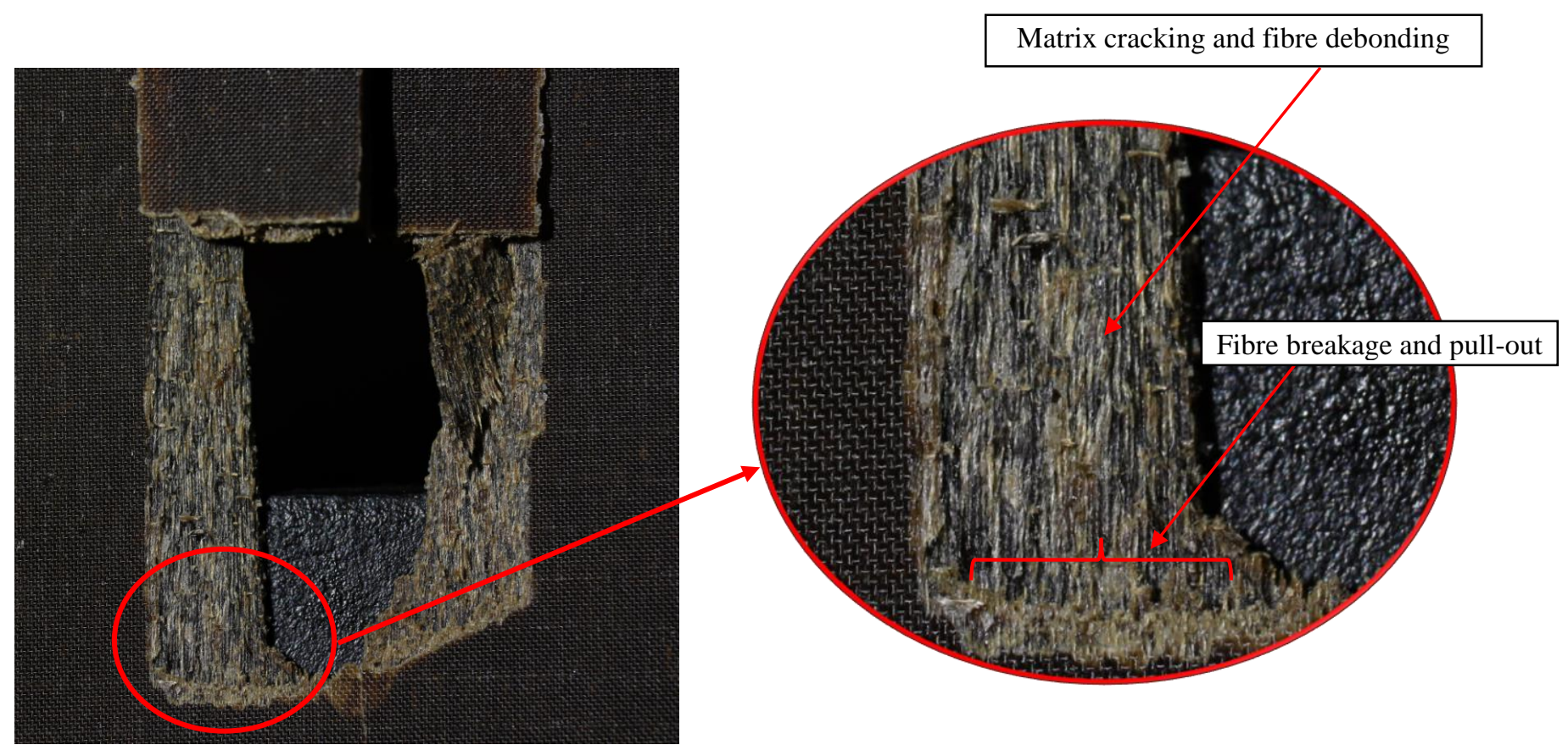

Figure 73: Fracture along the secondary crack paths $(E=10 \mathrm{~J})$

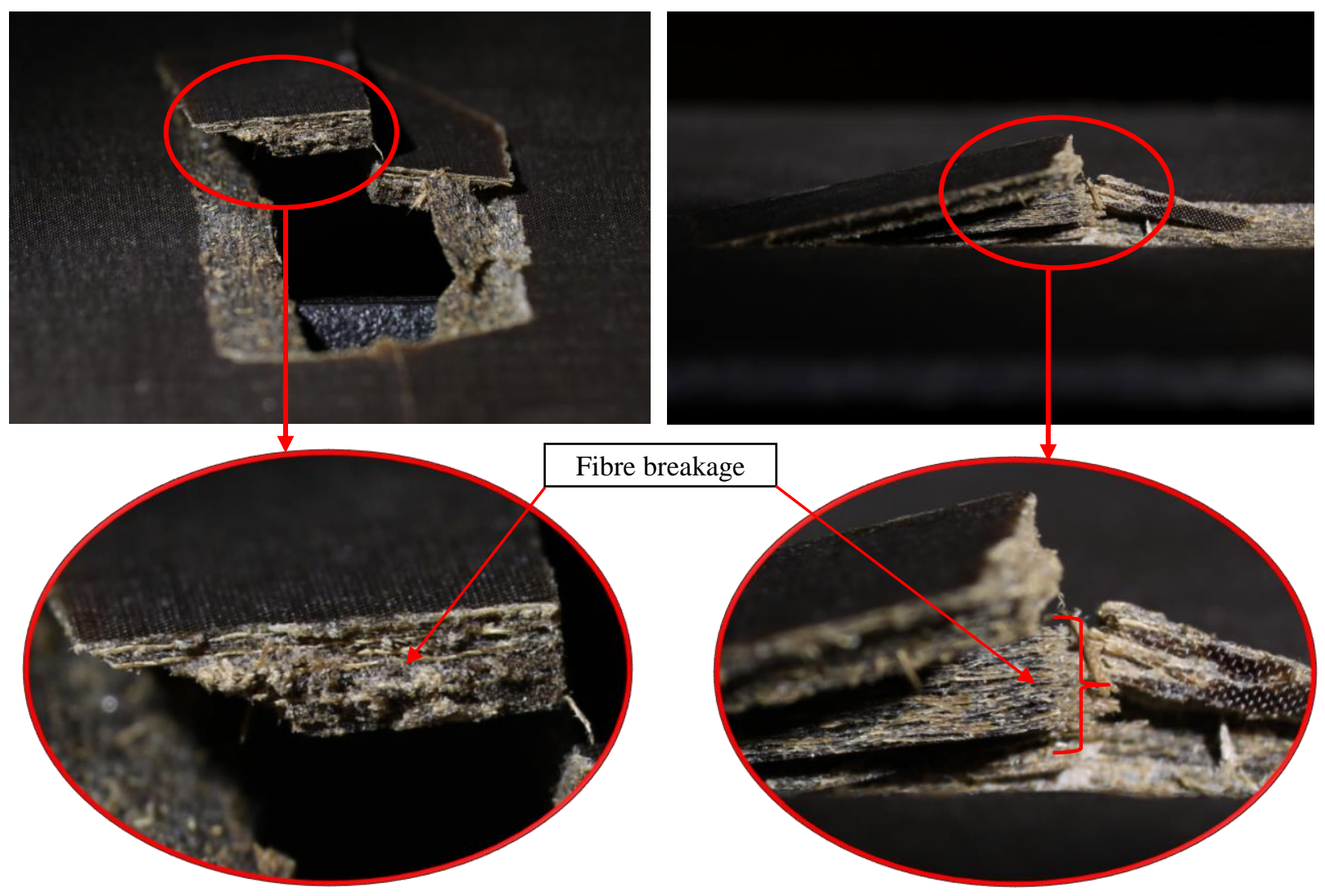

Figure 74: Fracture along the transverse crack path $(E=10 \mathrm{~J})$ 
At $\mathrm{E}=10 \mathrm{~J}$ impact energy, complete fracture of the unidirectional composite occurred. This damage is shown in Figure 73 and Figure 74. The composite fractured at the locations where the cracks propagated. Complete fracture of the matrix material occurred, combined with fibre breakage along the transverse crack path and fibre debonding along the primary and secondary crack paths. The composite fractured in a brittle manner.

\subsubsection{CROSS-PLY FLAX/EPOXY COMPOSITE}

The following figure illustrates the typical cross-section impact damage on the cross-ply flax/epoxy composite laminate.

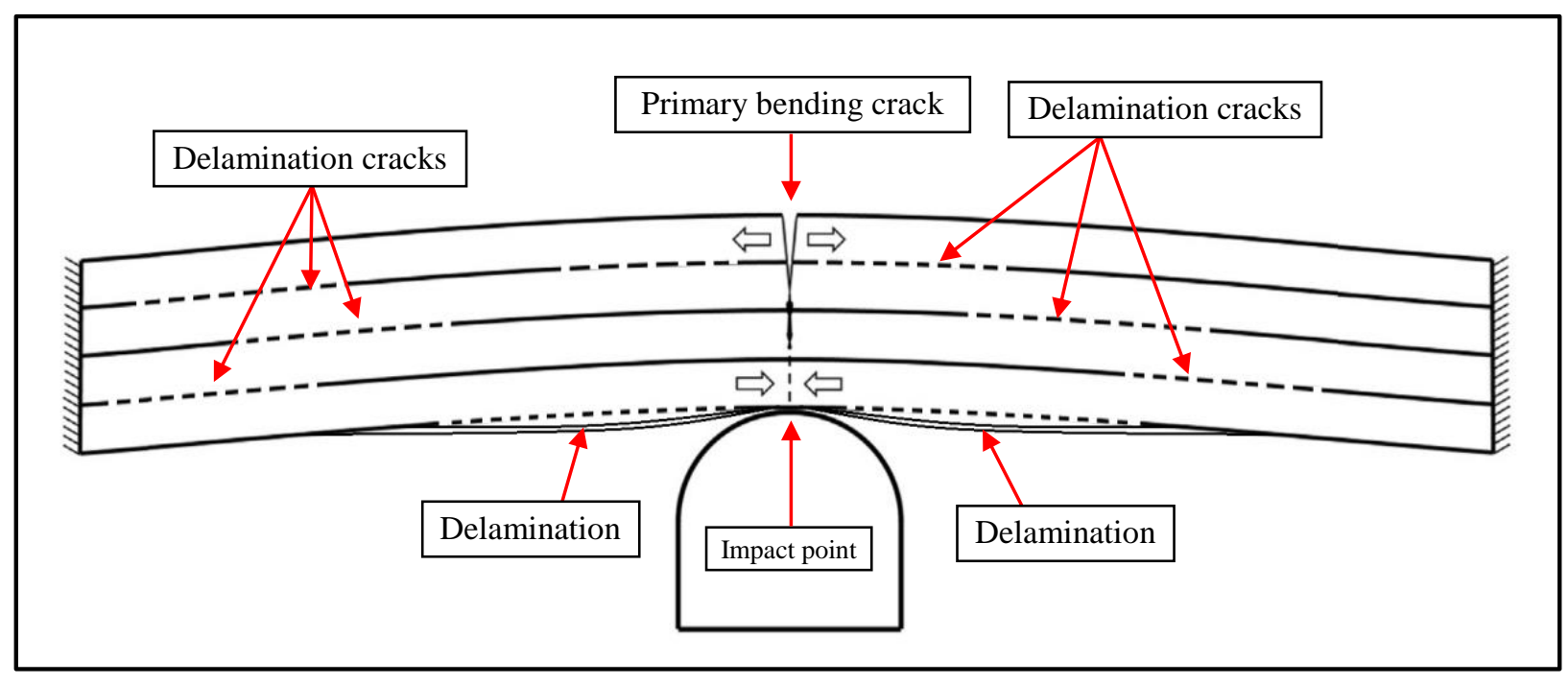

Figure 75: Schematic of typical cross section damage on cross-ply flax/epoxy

The damage on the cross-ply laminate consisted of longitudinal $\left(0^{\circ}\right)$ and transverse $\left(90^{\circ}\right)$ bending cracks, which originated from the side opposite to the point of impact. It also consisted of a "butterfly-shaped" delamination zone in the front face, adjacent to the point of impact. This delamination zone appeared only at $\mathrm{E}=15 \mathrm{~J}$ and higher, and increased in size with increasing impact energy. The delamination zone originated from the point of impact and propagated conically to the outer sides of the composite plate. In addition, randomly distributed delamination cracks can also be observed in between plies. 


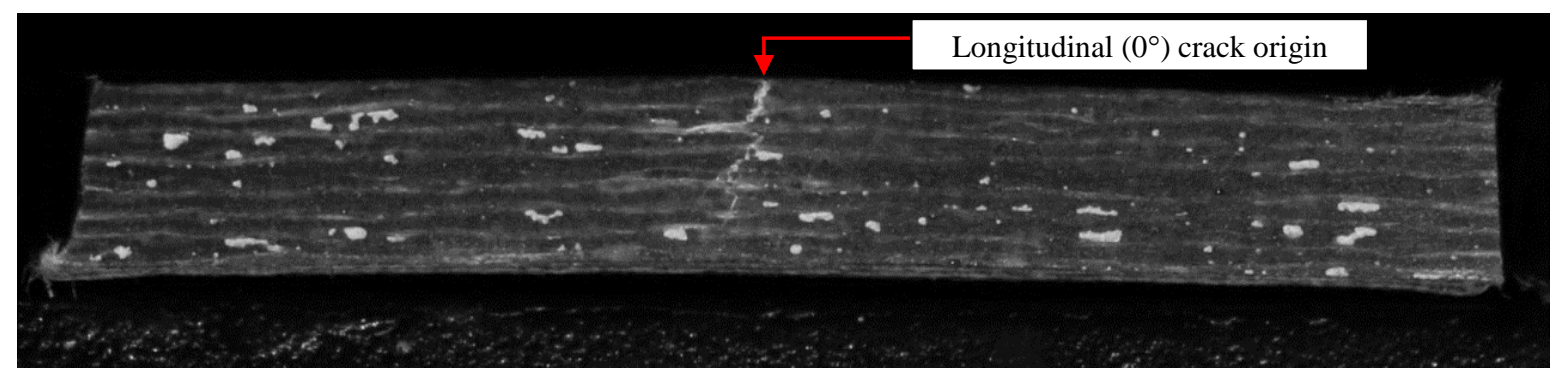

Figure 76: Cross-section B-B for $\left[(0 / 90)_{4 \mathrm{~F}}\right]_{\mathrm{S}}$ at $\mathrm{E}=5 \mathrm{~J}$

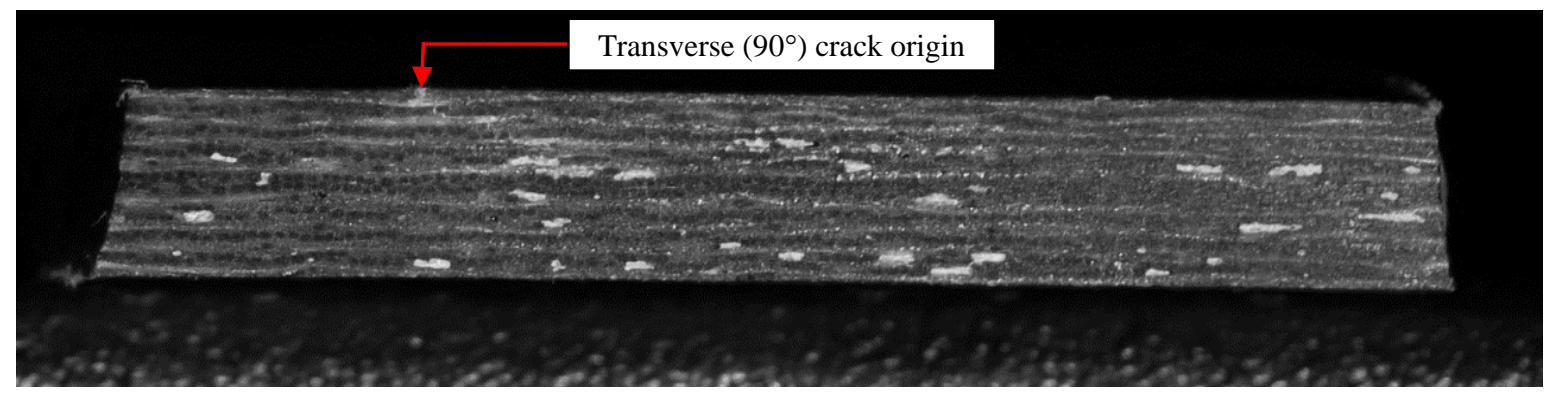

Figure 77: Cross-section C-C for $\left[(0 / 90)_{4 \mathrm{~F}}\right]_{\mathrm{s}}$ at $\mathrm{E}=\mathbf{5} \mathrm{J}$

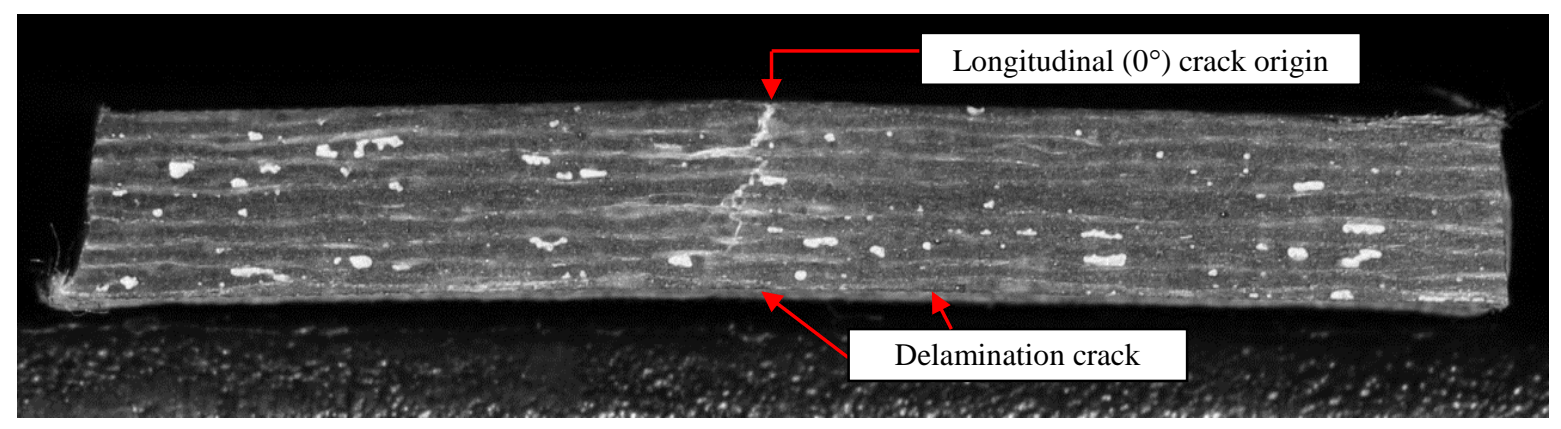

Figure 78: Cross-section B-B for $\left[(0 / 90)_{4 \mathrm{~F}}\right]_{\mathrm{S}}$ at $\mathrm{E}=\mathbf{1 0} \mathrm{J}$

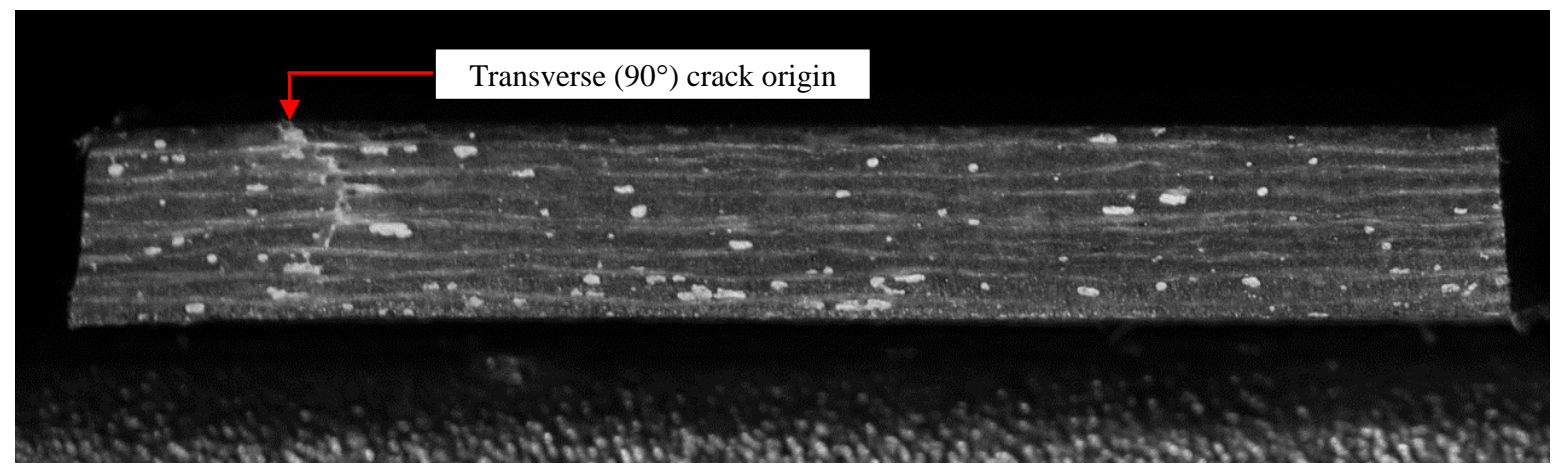

Figure 79: Cross-section C-C for $\left[(0 / 90)_{4 \mathrm{~F}}\right]_{\mathrm{S}}$ at $\mathrm{E}=\mathbf{1 0} \mathrm{J}$ 


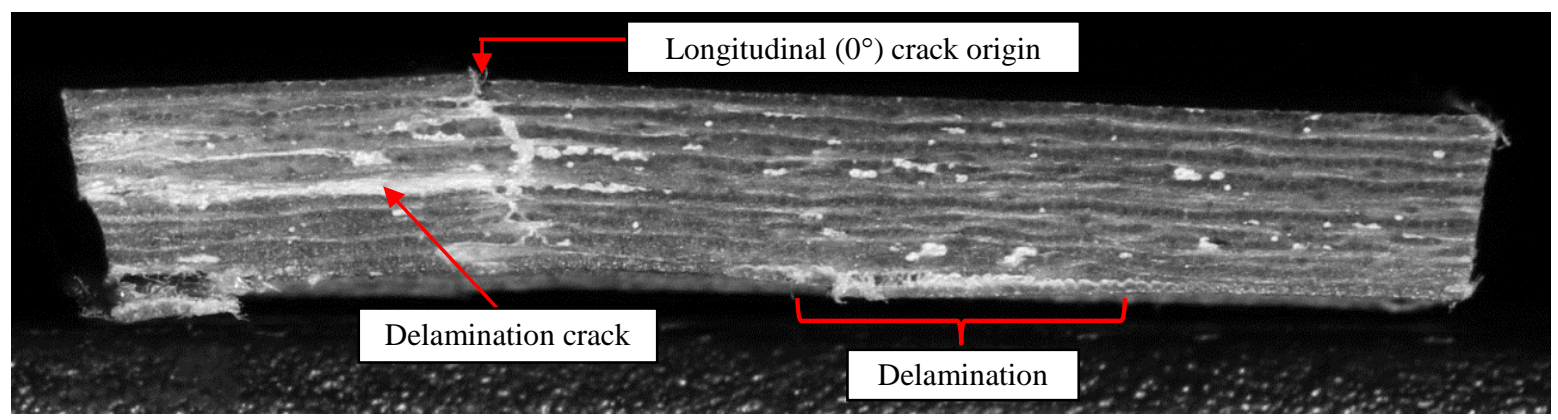

Figure 80: Cross-section B-B for $\left[(0 / 90)_{4 \mathrm{~F}}\right]_{\mathrm{S}}$ at $\mathrm{E}=15 \mathrm{~J}$

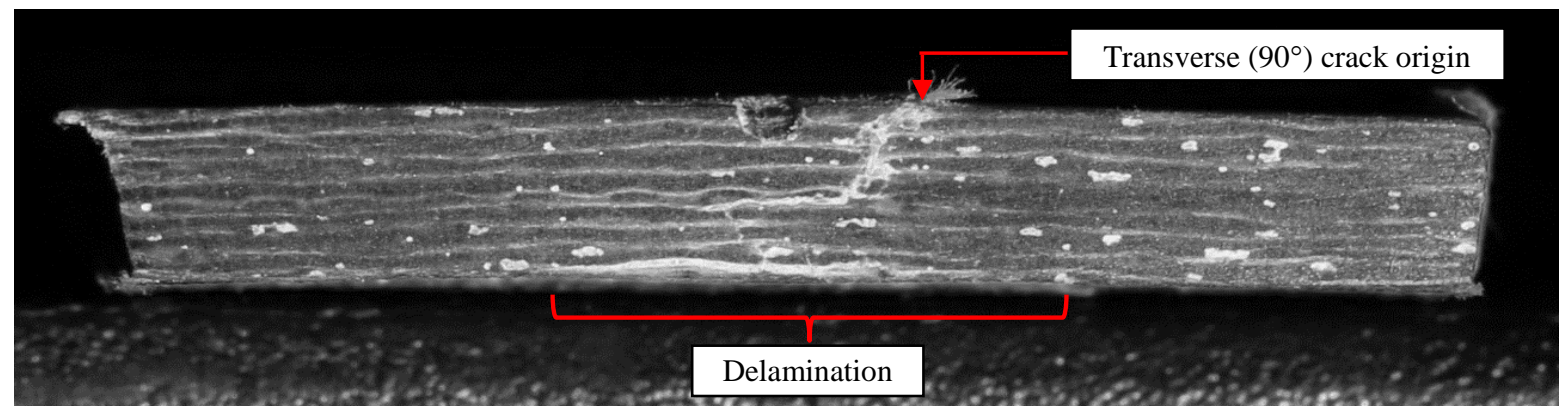

Figure 81: Cross-section C-C for $\left[(0 / 90)_{4 \mathrm{~F}}\right]_{\mathrm{S}}$ at $\mathrm{E}=15 \mathrm{~J}$

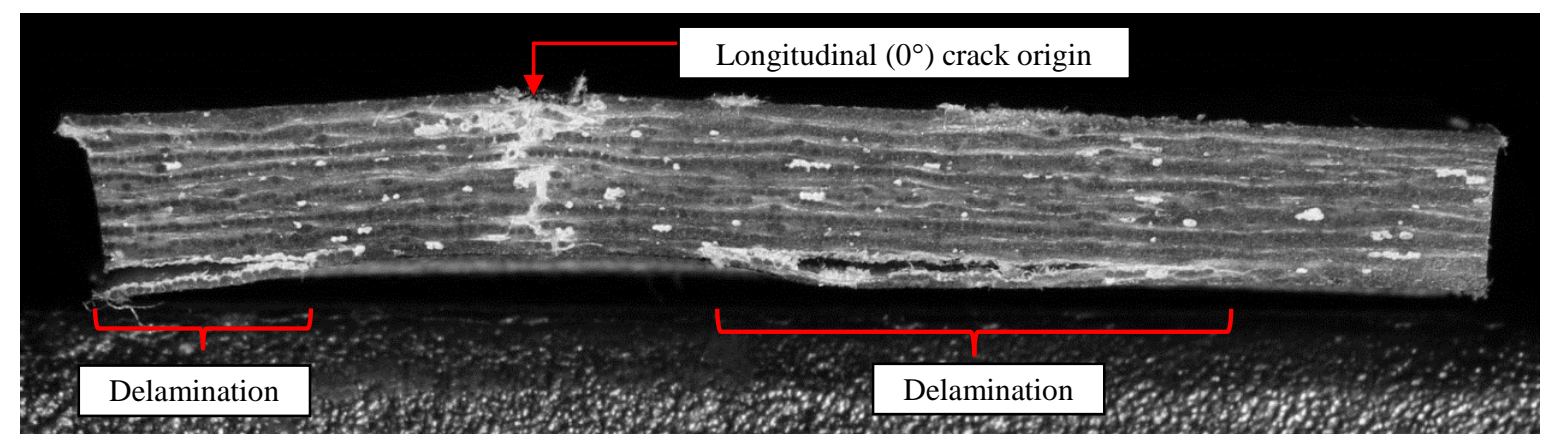

Figure 82: Cross-section B-B for $\left[(0 / 90)_{4 F}\right]_{S}$ at $E=20 \mathrm{~J}$

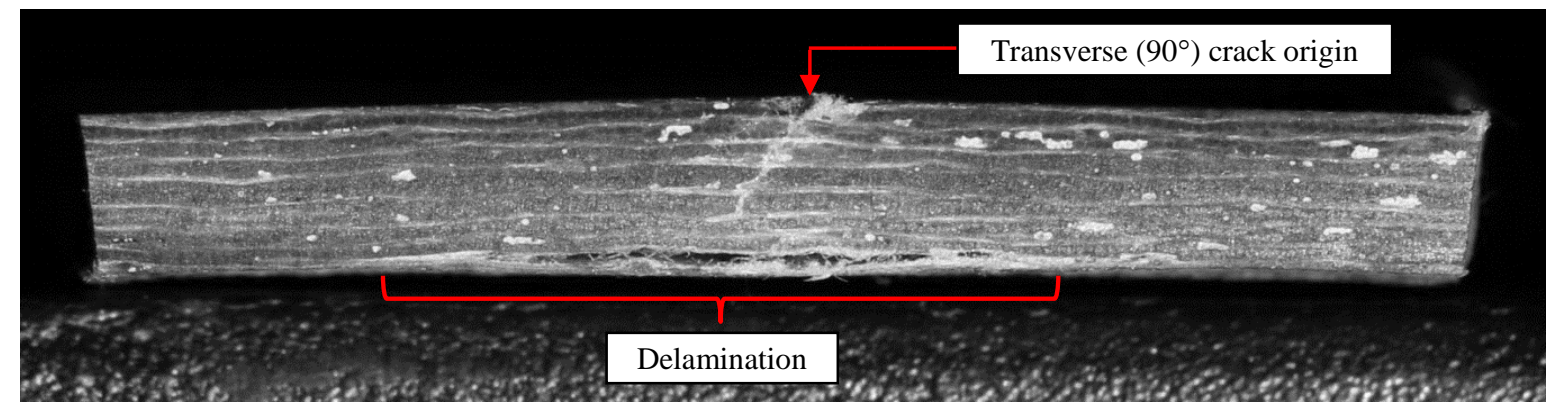

Figure 83: Cross-section C-C for $\left[(0 / 90)_{4 \mathrm{~F}}\right]_{\mathrm{S}}$ at $\mathrm{E}=\mathbf{2 0} \mathrm{J}$ 


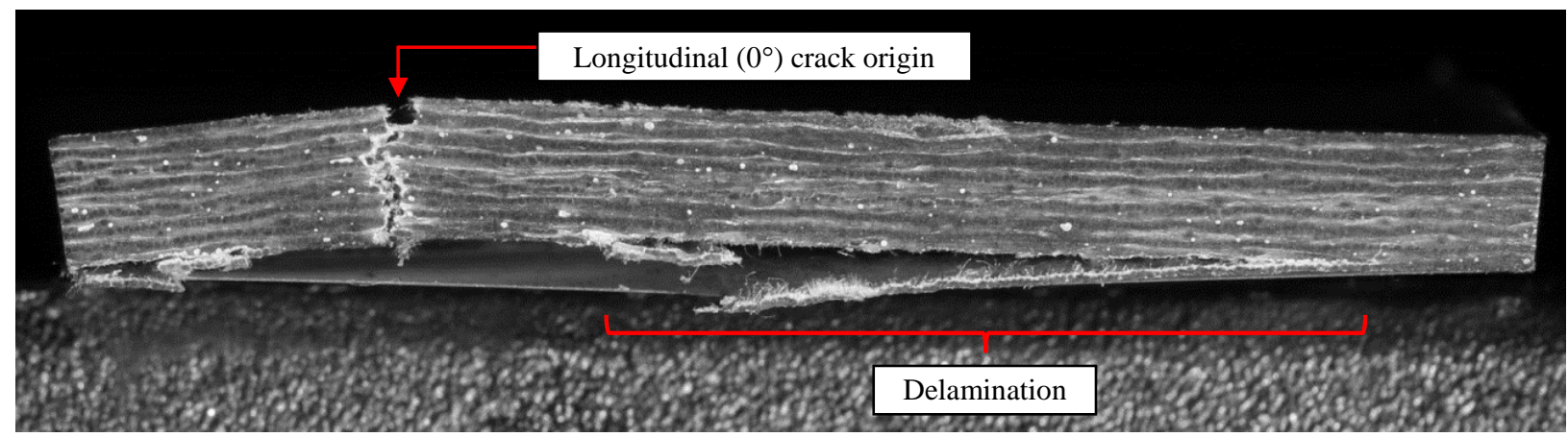

Figure 84: Cross-section B-B for $\left[(0 / 90)_{4 \mathrm{~F}}\right]_{\mathrm{S}}$ at $\mathrm{E}=\mathbf{2 5} \mathrm{J}$

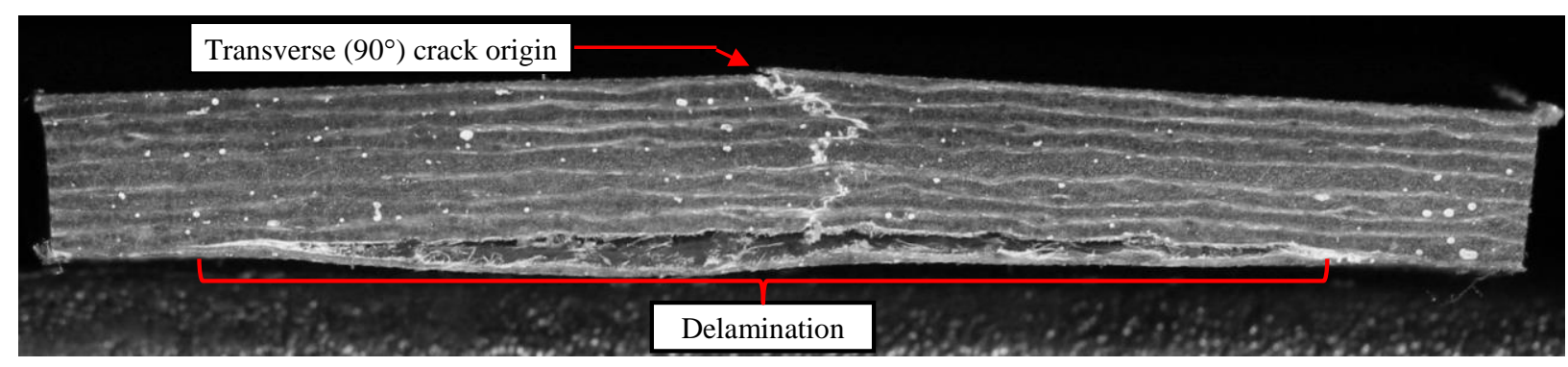

Figure 85: Cross-section C-C for $\left[(0 / 90)_{4 \mathrm{~F}}\right]_{\mathrm{S}}$ at $\mathrm{E}=\mathbf{2 5} \mathrm{J}$

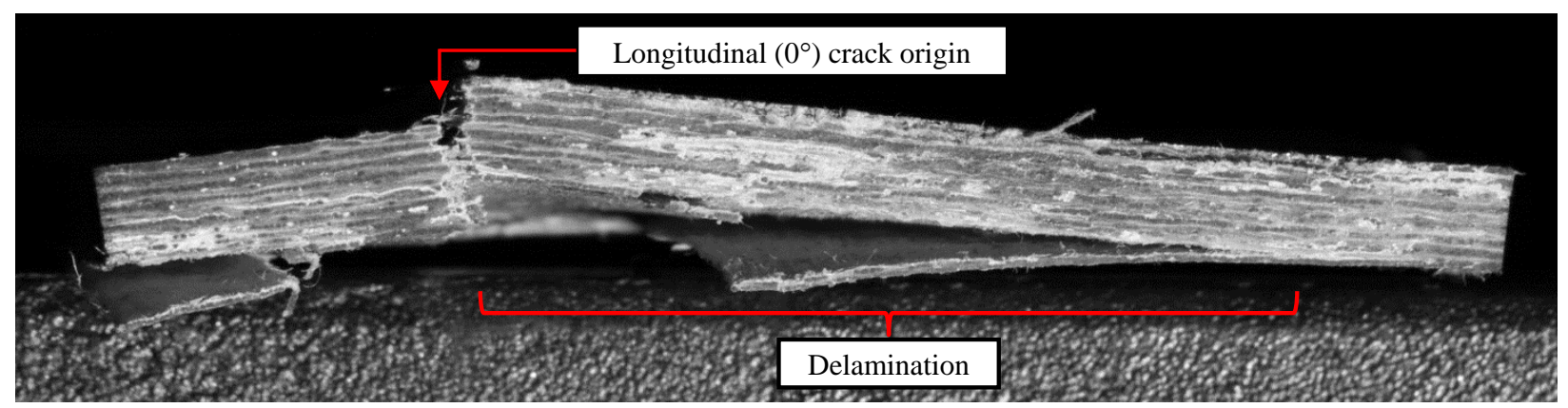

Figure 86: Cross-section B-B for $\left[(0 / 90)_{4 \mathrm{~F}}\right]_{\mathrm{S}}$ at $\mathrm{E}=\mathbf{3 0} \mathrm{J}$

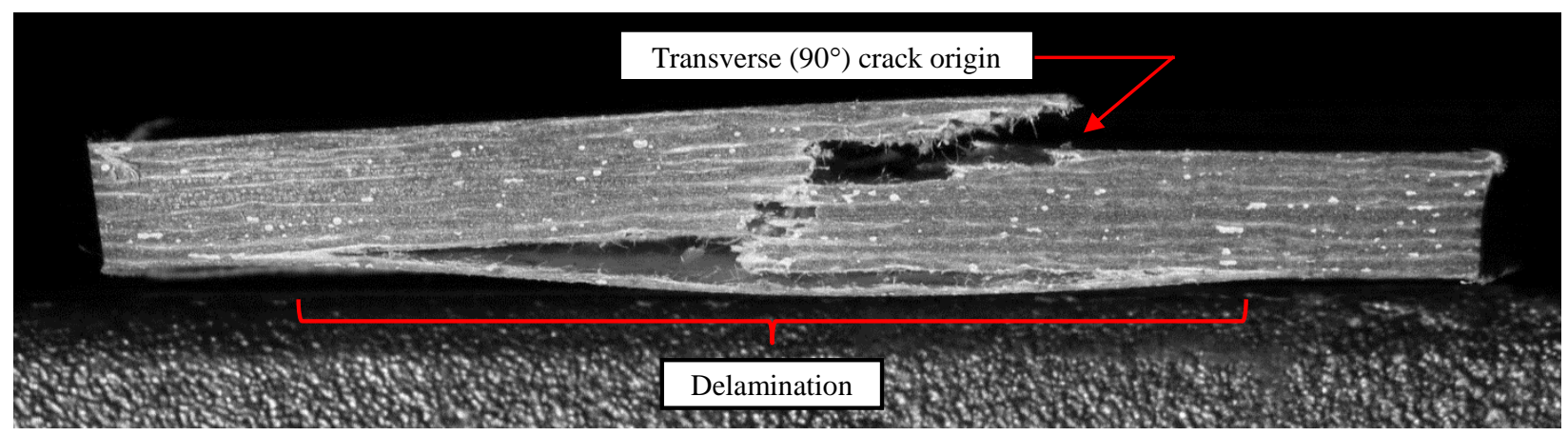

Figure 87: Cross-section B-B for $\left[(0 / 90)_{4 \mathrm{~F}}\right]_{\mathrm{S}}$ at $\mathrm{E}=\mathbf{3 0} \mathrm{J}$ 
At $\mathrm{E}=5 \mathrm{~J}$, two bending cracks originated at the back face of the composite in the longitudinal and transverse directions. From the cross-section cuts, the crack did not propagate completely through the thickness of the plate at this energy level. The crack only propagated to approximately $50 \%$ of the plate thickness. Microscopic images taken at the crack origin showed matrix cracking, fibre pullout and fibre debonding as the damage mechanisms present.

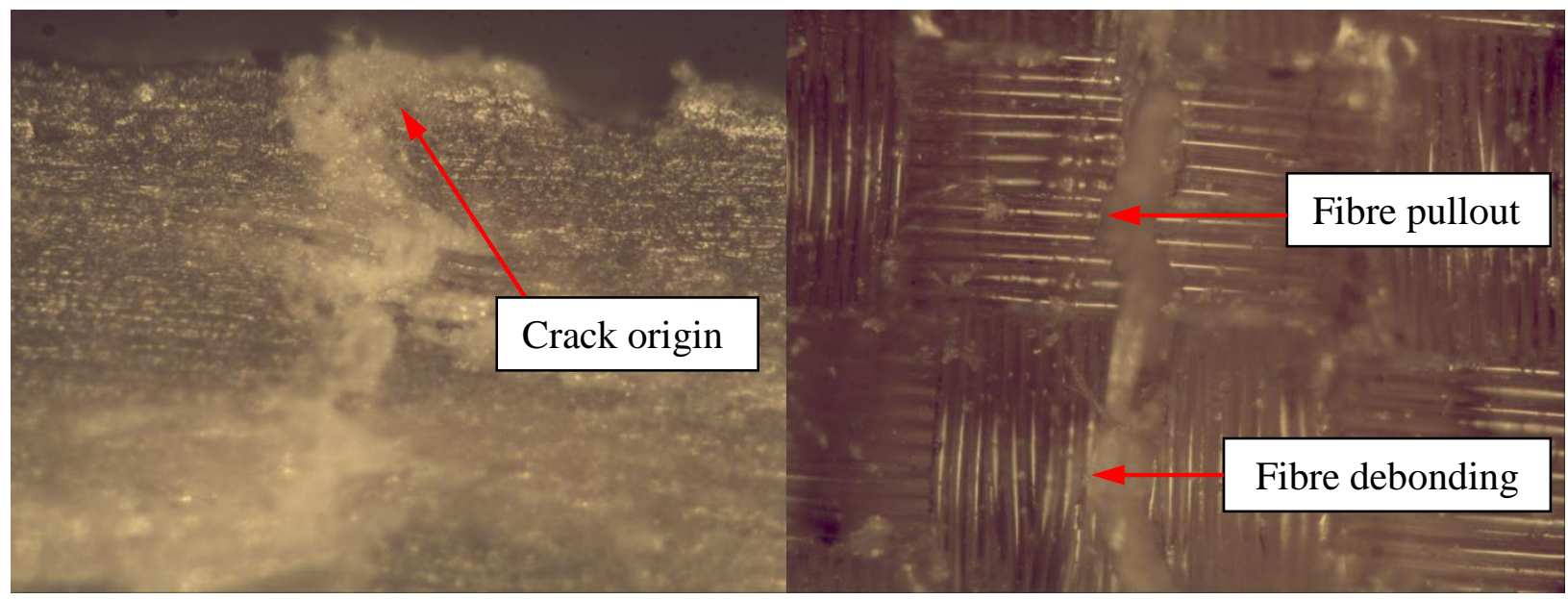

Figure 88: Microscopic images of the crack damage at $\mathrm{E}=5 \mathrm{~J}$ for $\left[(0 / 90)_{4 \mathrm{~F}}\right]_{\mathrm{S}}$

At $\mathrm{E}=10 \mathrm{~J}$, crack propagated to approximately $70 \%$ of the plate thickness. Moreover, a delamination crack can start to be observed underneath the first ply on the same side of the impacted face. This delamination crack cannot be observed without destructively cross-sectioning the plate along the delaminated area.

The first-ply delamination became visible at $\mathrm{E}=15 \mathrm{~J}$, with Figure 90 showing the microscopic images of the delaminated cross section. In addition, the longitudinal and transverse matrix cracks propagated to approximately $90 \%$ of the plate thickness. The crack width also increased in size because of the increase in plate curvature.

At $\mathrm{E}=20 \mathrm{~J}$, the delaminated area increased. The damage due to delamination, however, was still confined to the first ply. Microscopic images of the delaminated layer showed severe matrix cracking along the fibre-matrix interface of the delaminated ply (see Figure 95). 

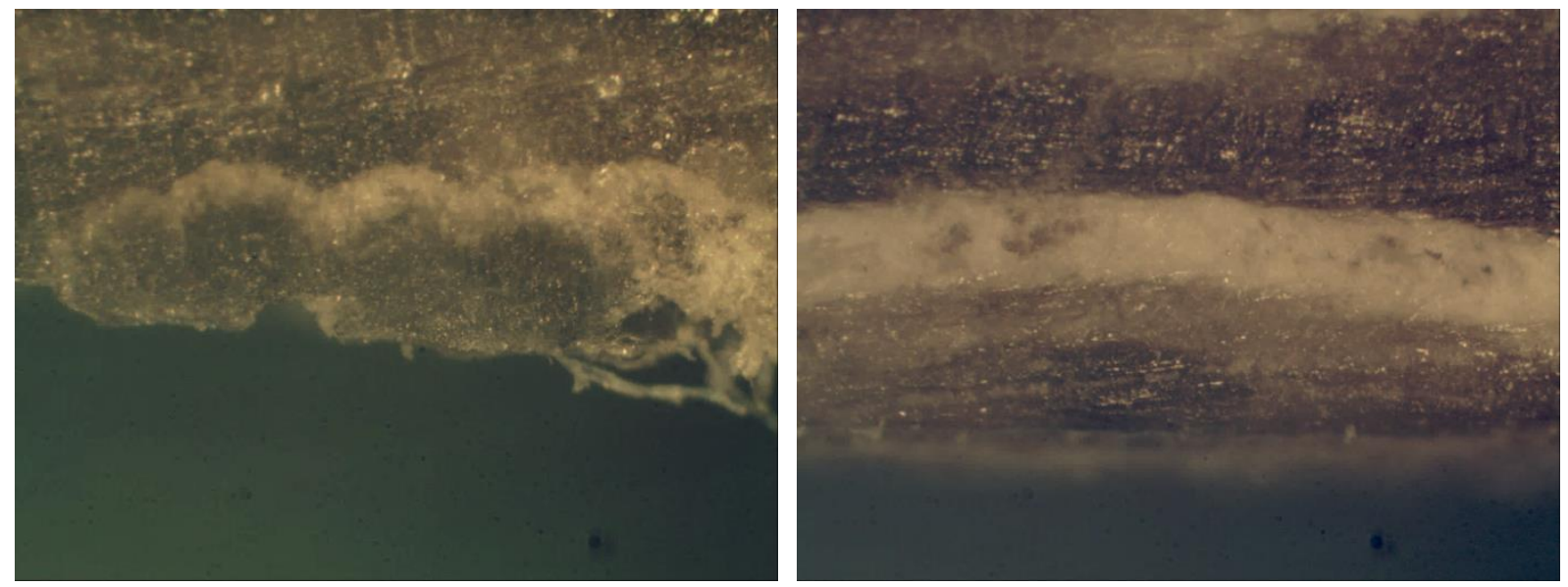

Figure 89: Microscopy of delamination zone near the crack tip of $\left[(0 / 90)_{4 F}\right]_{s}$ at $E=15 \mathrm{~J}$
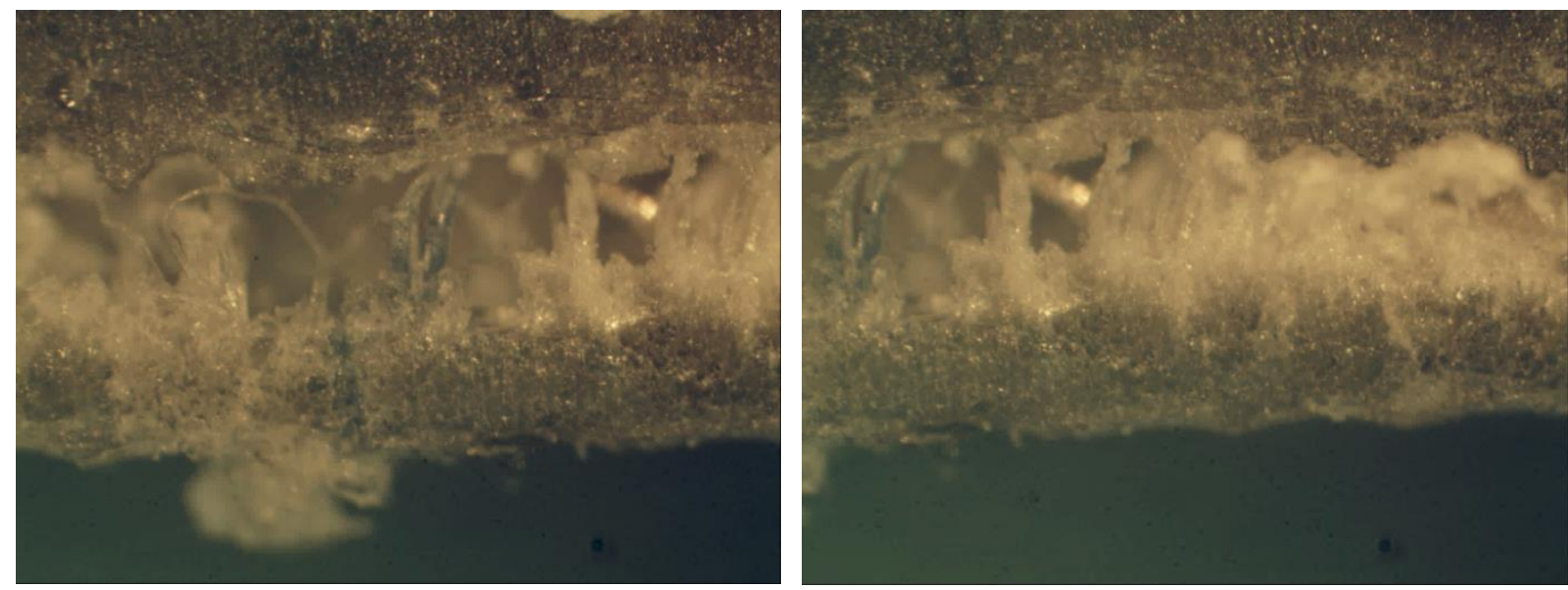

Figure 90: Microscopy of the middle delamination zone of $\left[(0 / 90)_{4 \mathrm{~F}}\right]_{\mathrm{s}}$ at $\mathrm{E}=15 \mathrm{~J}$
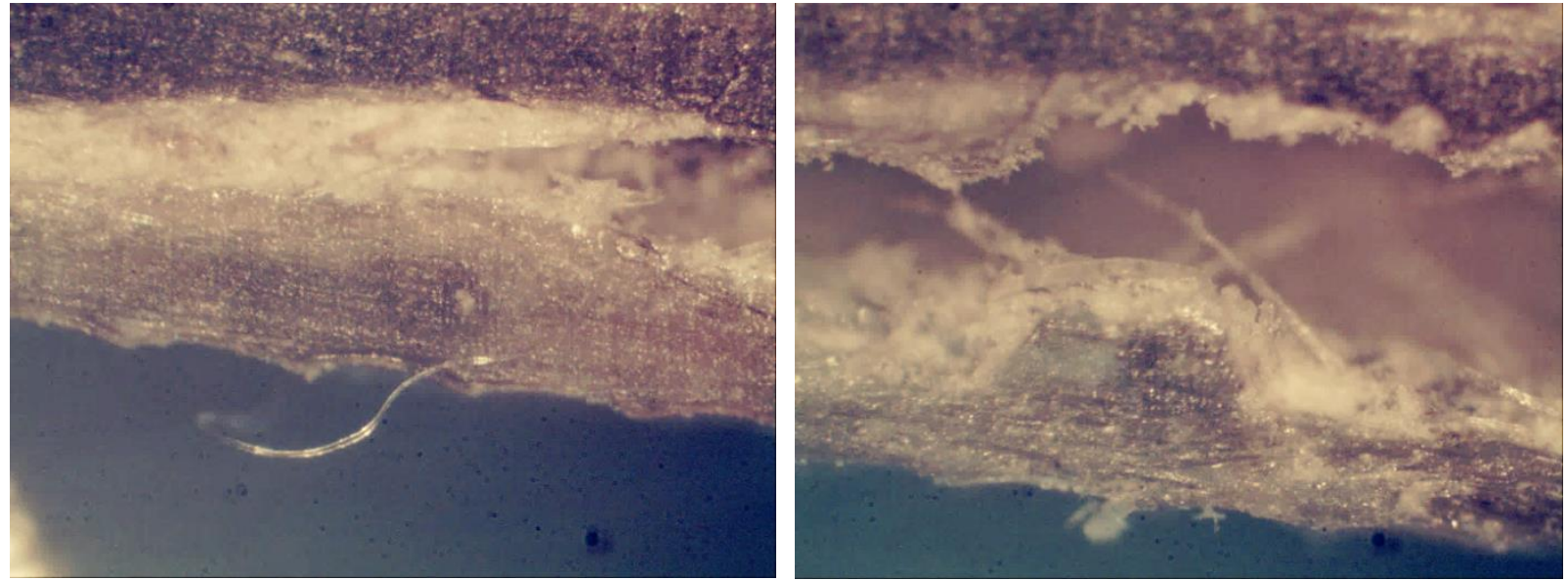

Figure 91: Microscopy of the delamination zone on $\left[(0 / 90)_{4 \mathrm{~F}}\right]_{\mathrm{S}}$ at $\mathrm{E}=\mathbf{2 0} \mathrm{J}$ 

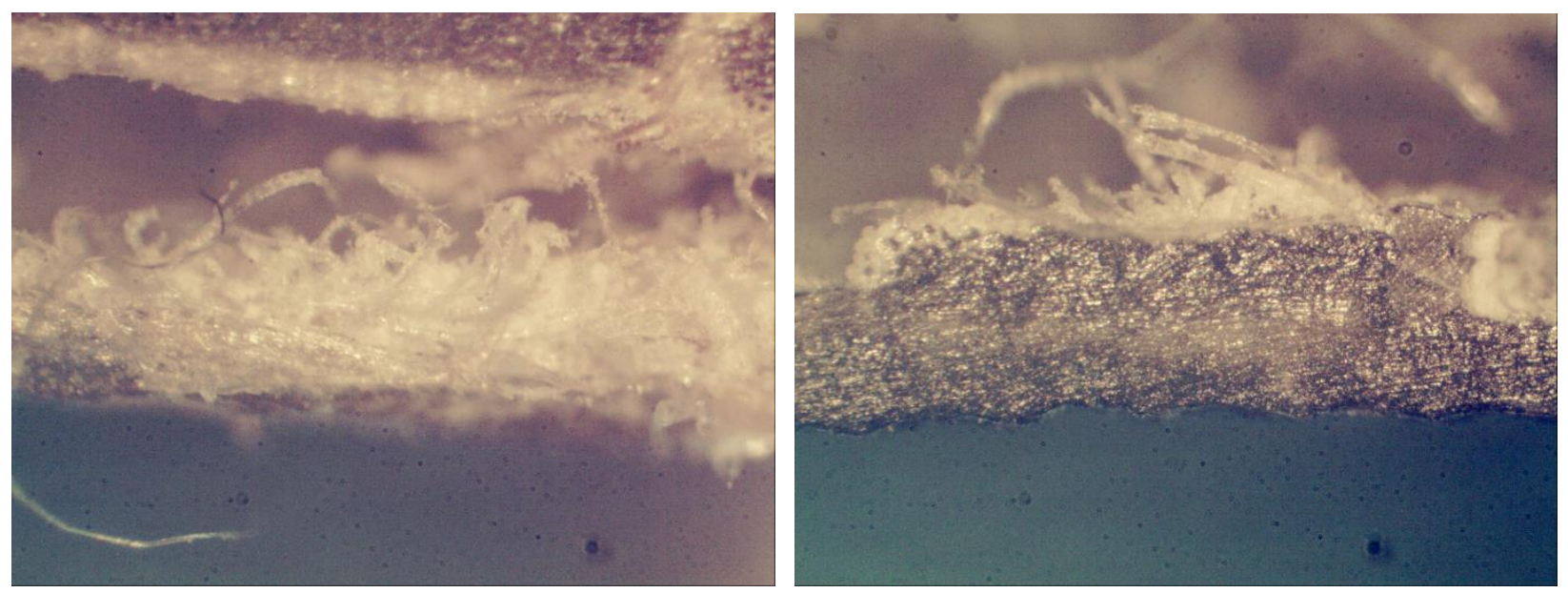

Figure 92: Matrix cracking at the delaminated layer of $\left[(0 / 90)_{4 \mathrm{~F}}\right]_{\mathrm{S}}$ at $\mathrm{E}=\mathbf{2 0} \mathrm{J}$

At $\mathrm{E}=25 \mathrm{~J}$, the longitudinal and transverse cracks have propagated completely through the thickness of the composite plate. Moreover, the crack width has also increased significantly due to severe flexural deformation. Microscopic images of the crack cross section showed the damage mechanism to be a combination of matrix cracking, fibre breakage and fibre-pullout. In addition, the delamination of the first ply was also observed. This delamination area has increased significantly compared to the previous energy levels tested. At E $=30 \mathrm{~J}$, complete throughthickness fracture of the composite has occurred, combined with a single ply delamination of the impacted face.
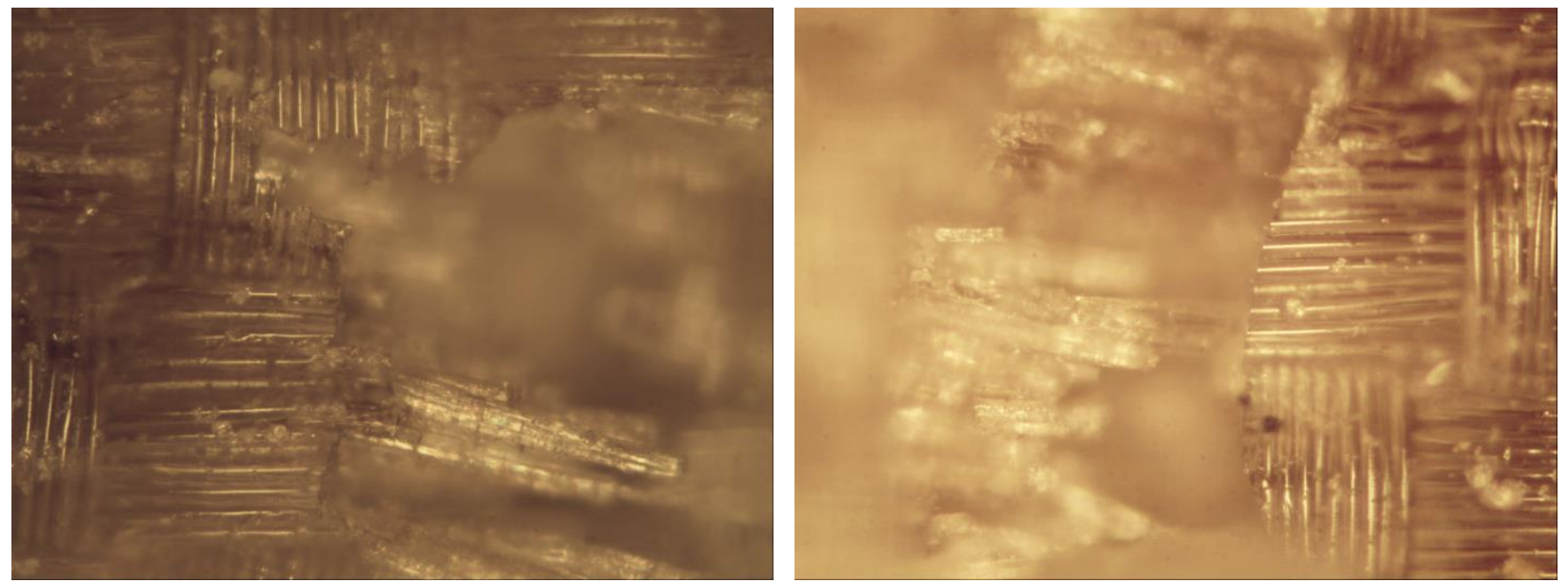

Figure 93: Fibre breakage and pull-out the crack path of the $\left[(0 / 90)_{4 \mathrm{~F}}\right]_{\mathrm{s}}$ at $\mathrm{E}=\mathbf{2 5} \mathrm{J}$ 

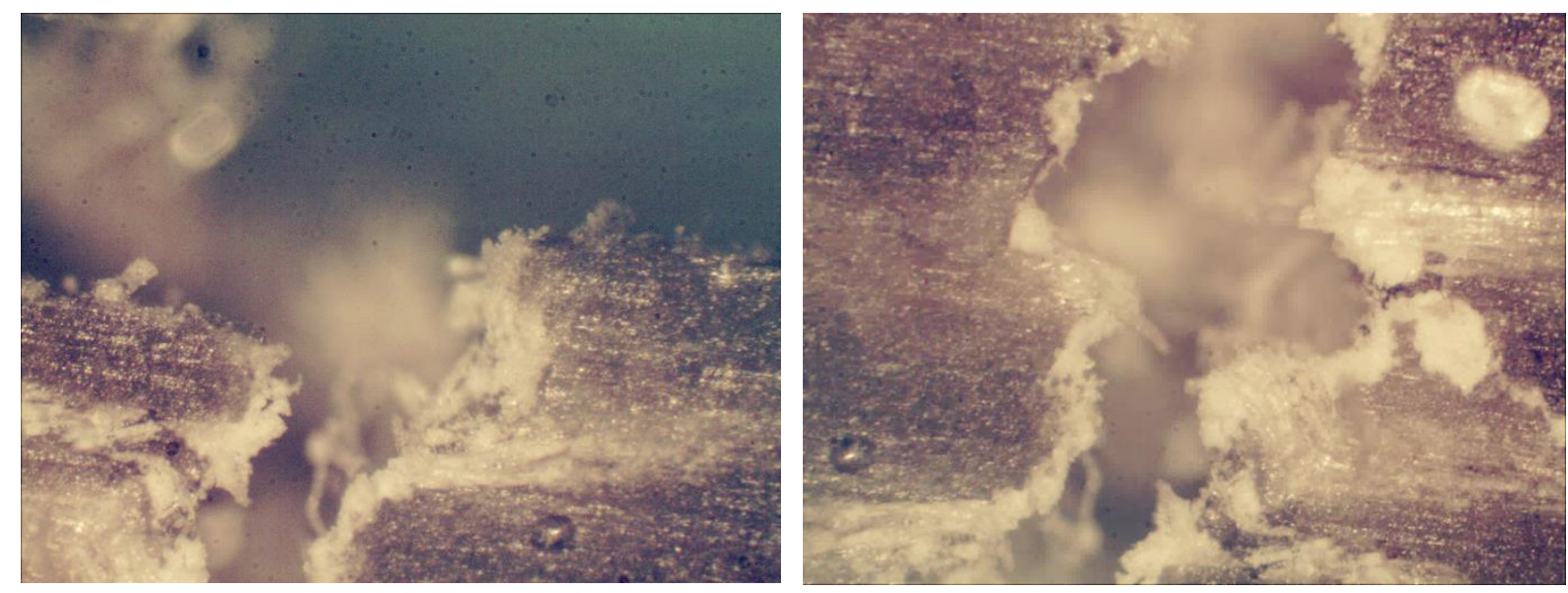

Figure 94: Matrix crack at the back face (left) and through-the-thickness (right) at $\mathrm{E}=25 \mathrm{~J}$
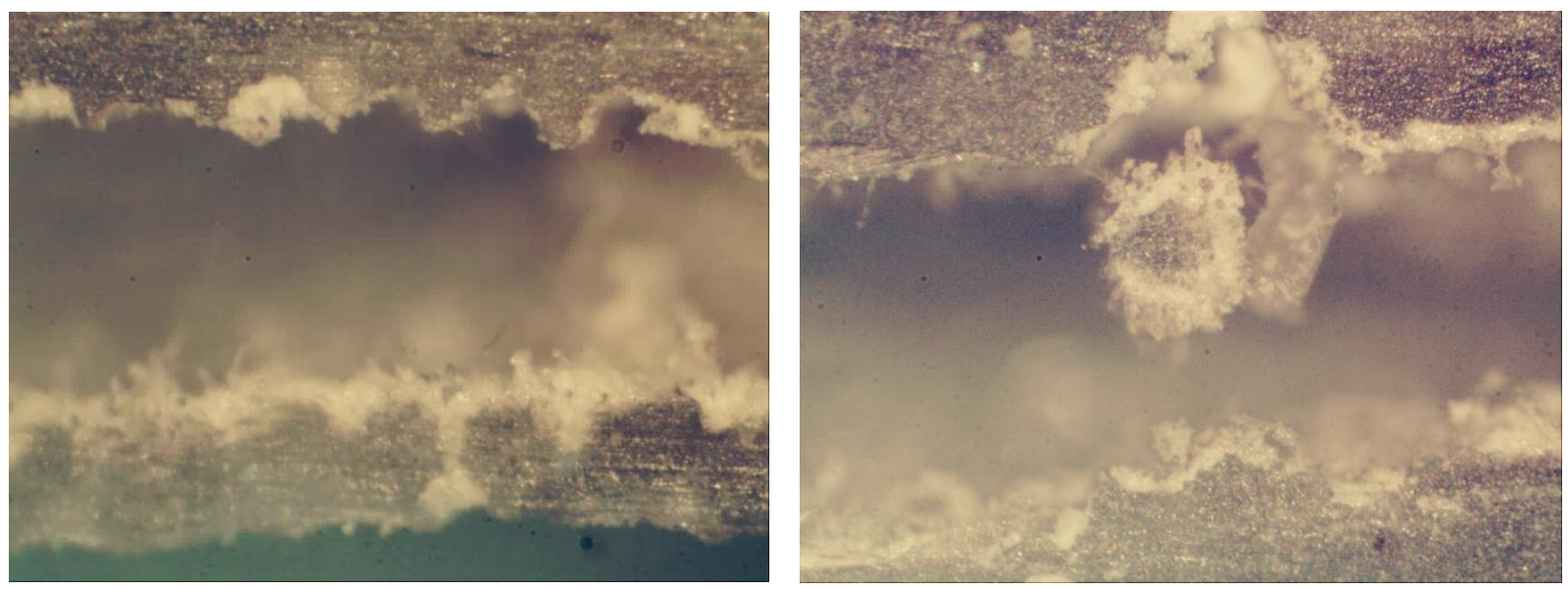

Figure 95: Microscopic image of the delamination interface of the $\left[(0 / 90)_{4 \mathrm{~F}}\right]_{\mathrm{S}}$ at $\mathrm{E}=\mathbf{2 5} \mathrm{J}$
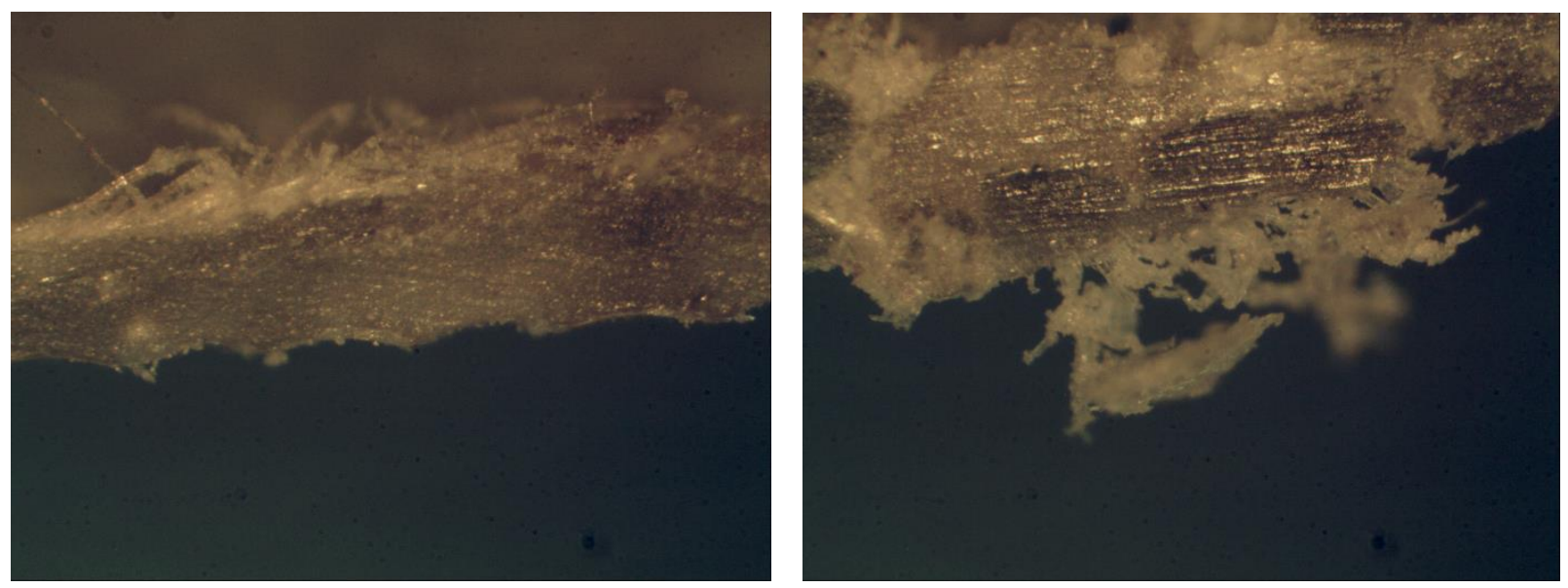

Figure 96: Microscopic image of the delamination interface of the $\left[(0 / 90)_{4 \mathrm{~F}}\right]_{\mathrm{S}}$ at $\mathrm{E}=30 \mathrm{~J}$ 


\subsubsection{IMPACT RESPONSE USING IR THERMOGRAPHY}

The use of IR thermography to evaluate the low velocity impact response of a composite laminate has been investigated in a few studies [59] [60] [61]. During an impact event, the kinetic energy passes from the impactor tip to the target specimen and that such an energy is in part dissipated as heat [60]. IR thermography (ITR) allows one to create a temperature map of the visualized surface by exploiting the thermal energy radiated by the surface in the infrared band of the electromagnetic spectrum [61].

Any form of impact damage such as delamination, matrix cracking or fibre breakage is accompanied by heat dissipation. Thus, it is manifested in the IR camera as the appearance of hot spots over the material surface [60]. By examining the change in temperature $\Delta \mathrm{T}$ before, during and after the impact event, the progression of damage in the test specimen can be analyzed.

During an impact event, a material first experiences an elastic phase in which the impact energy is dissipated without plastic deformation. This is followed by a plastic phase in which part of the impact energy is absorbed through creation of new surfaces by different damage mechanisms [59] [12].

In the elastic phase, impact energy is released and dissipated back into the impactor. As such, the surface temperature decreases. On the other hand, the energy is absorbed during the plastic phase and therefore the surface temperature of the composite increases. The elastic phase usually lasts only for a fraction of seconds and it is immediately followed by a sudden increase in temperature due to the formation of permanent damage [59]. This thermal phenomenon can be observed by looking at the temperature evolution during the impact event of the flax/epoxy composite.

The following figures show the temperature profile at the centre of impact for the flax/epoxy composite. Only selected cases are presented here for discussion purposes. 


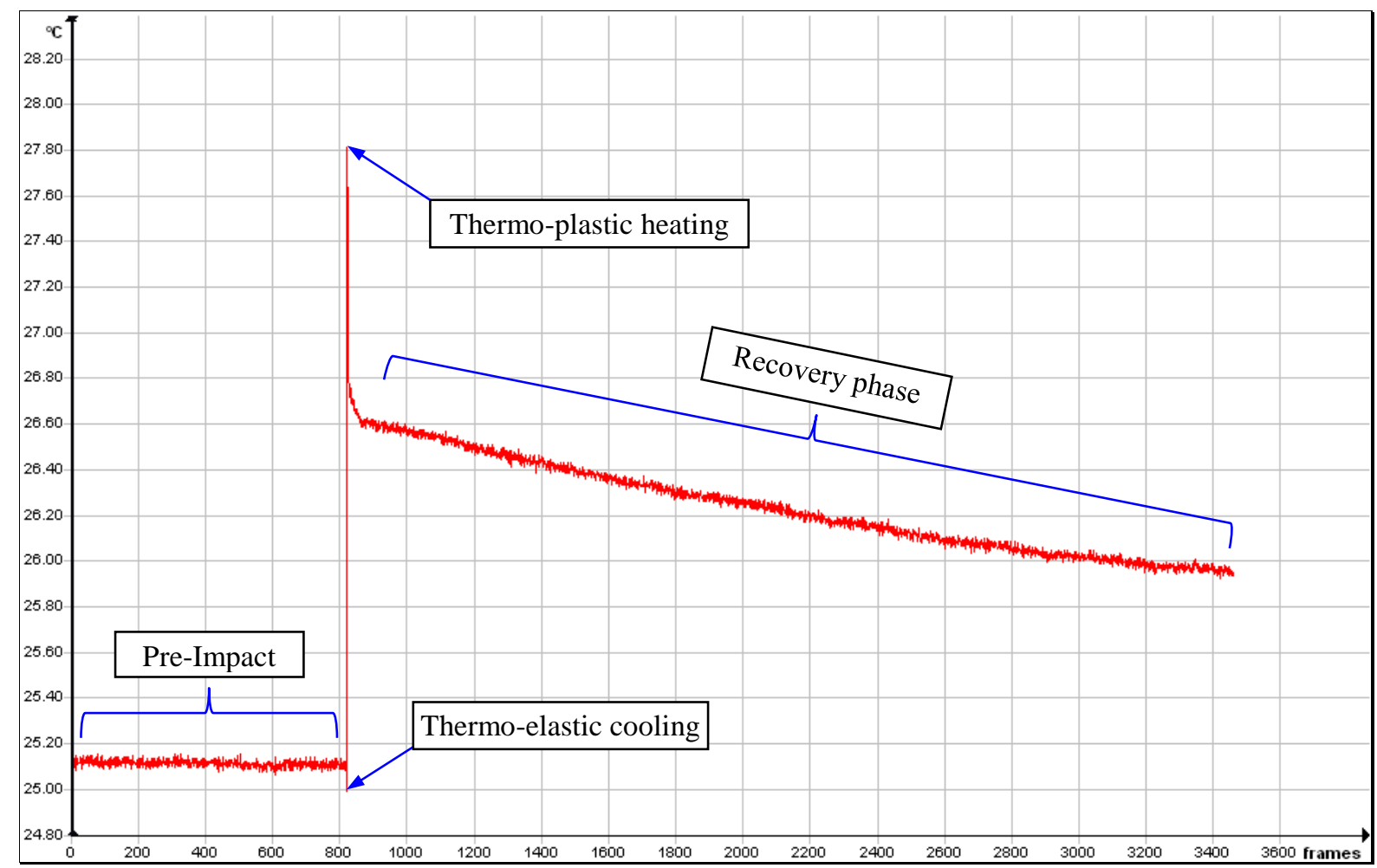

Figure 97: Temperature profile at impact loci for $\left[0_{8 \mathrm{~F}}\right]_{\mathrm{S}}$ at $\mathrm{E}=\mathbf{5} \mathrm{J}$

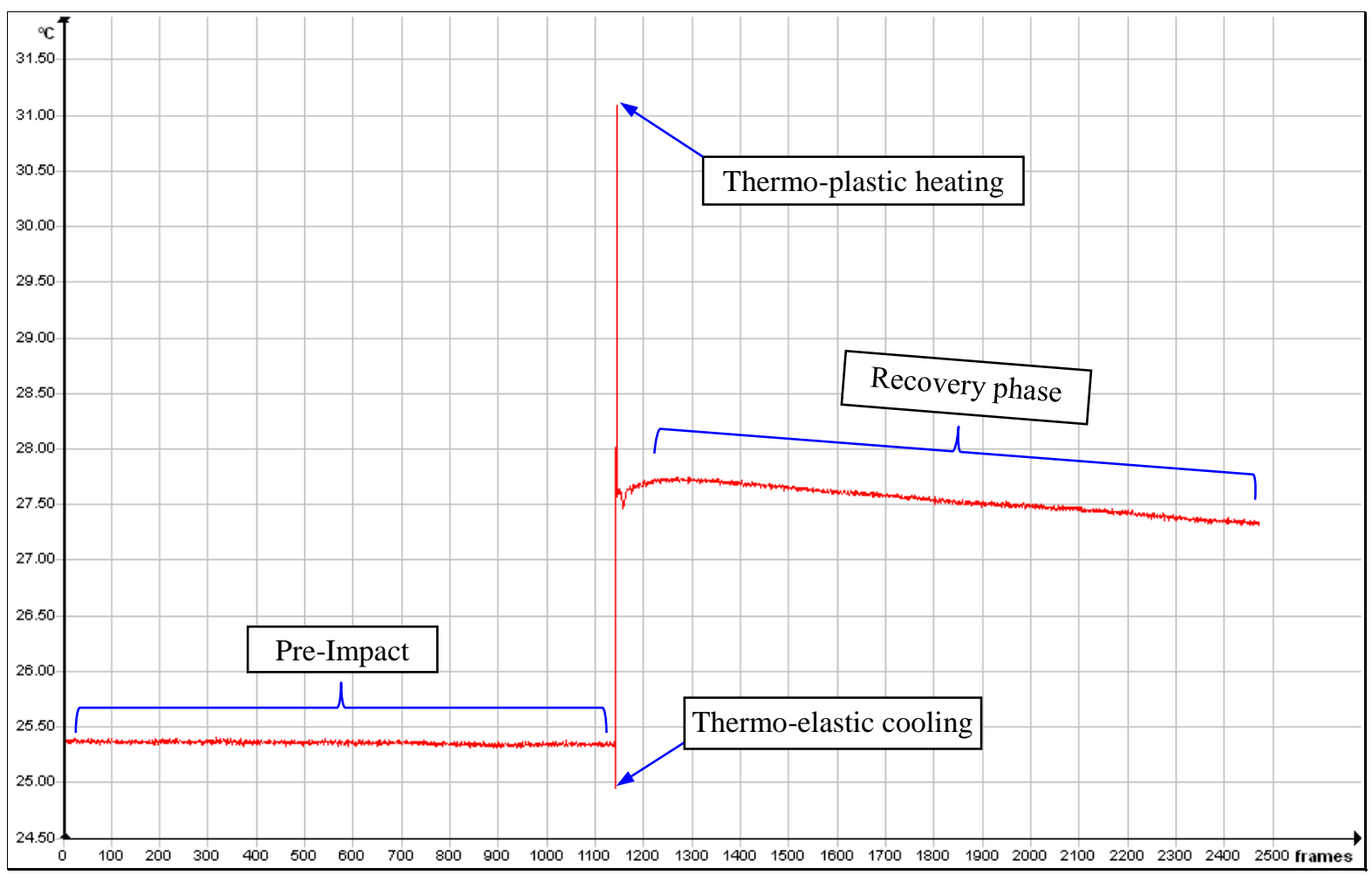

Figure 98: Temperature profile at impact loci for $\left[0_{8 \mathrm{FF}}\right]_{\mathrm{S}}$ at $\mathrm{E}=9.5 \mathrm{~J}$ 


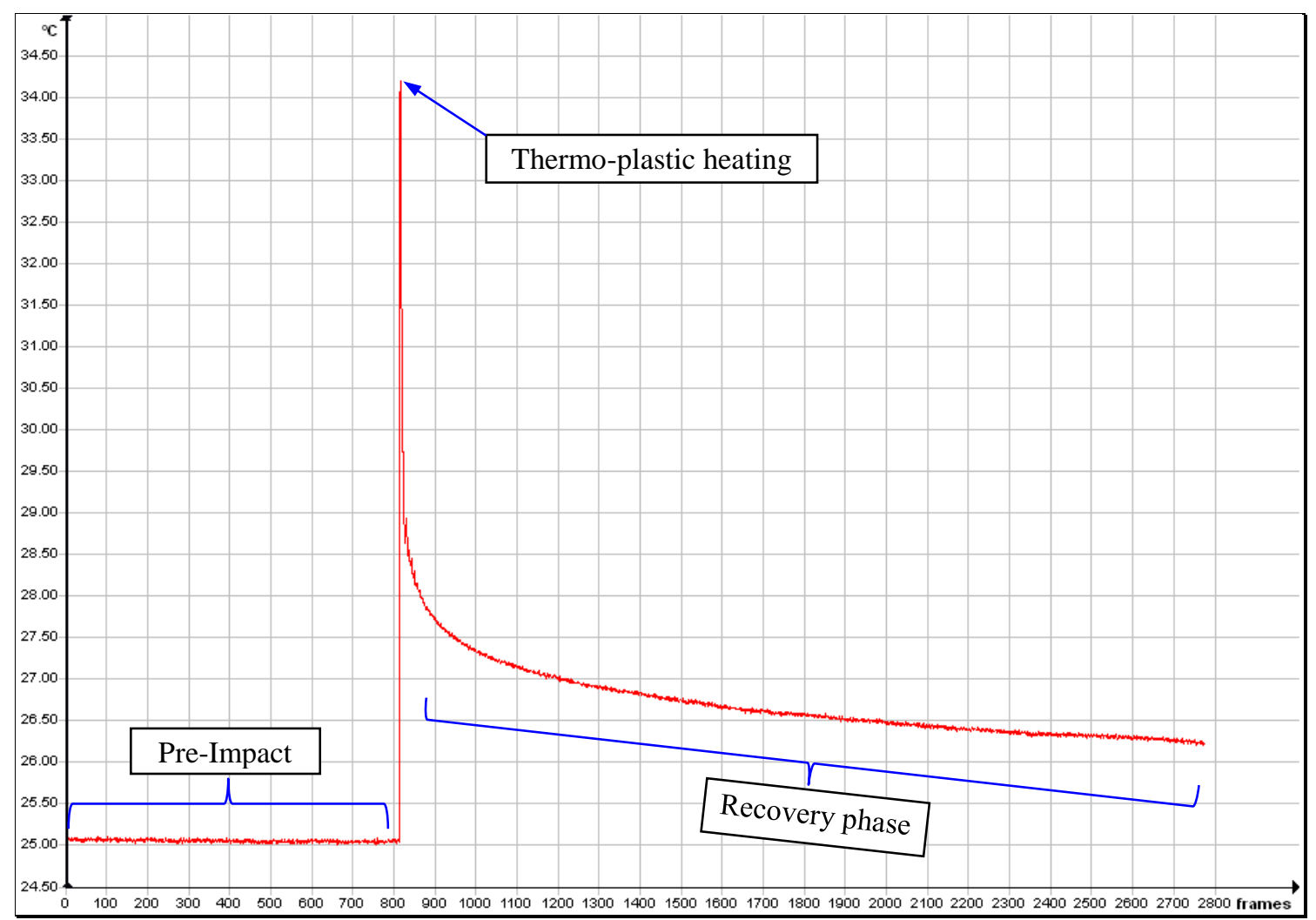

Figure 99: Temperature profile at impact loci for $\left[0_{8 \mathrm{~F}}\right]_{\mathrm{S}}$ at $\mathrm{E}=10 \mathrm{~J}$

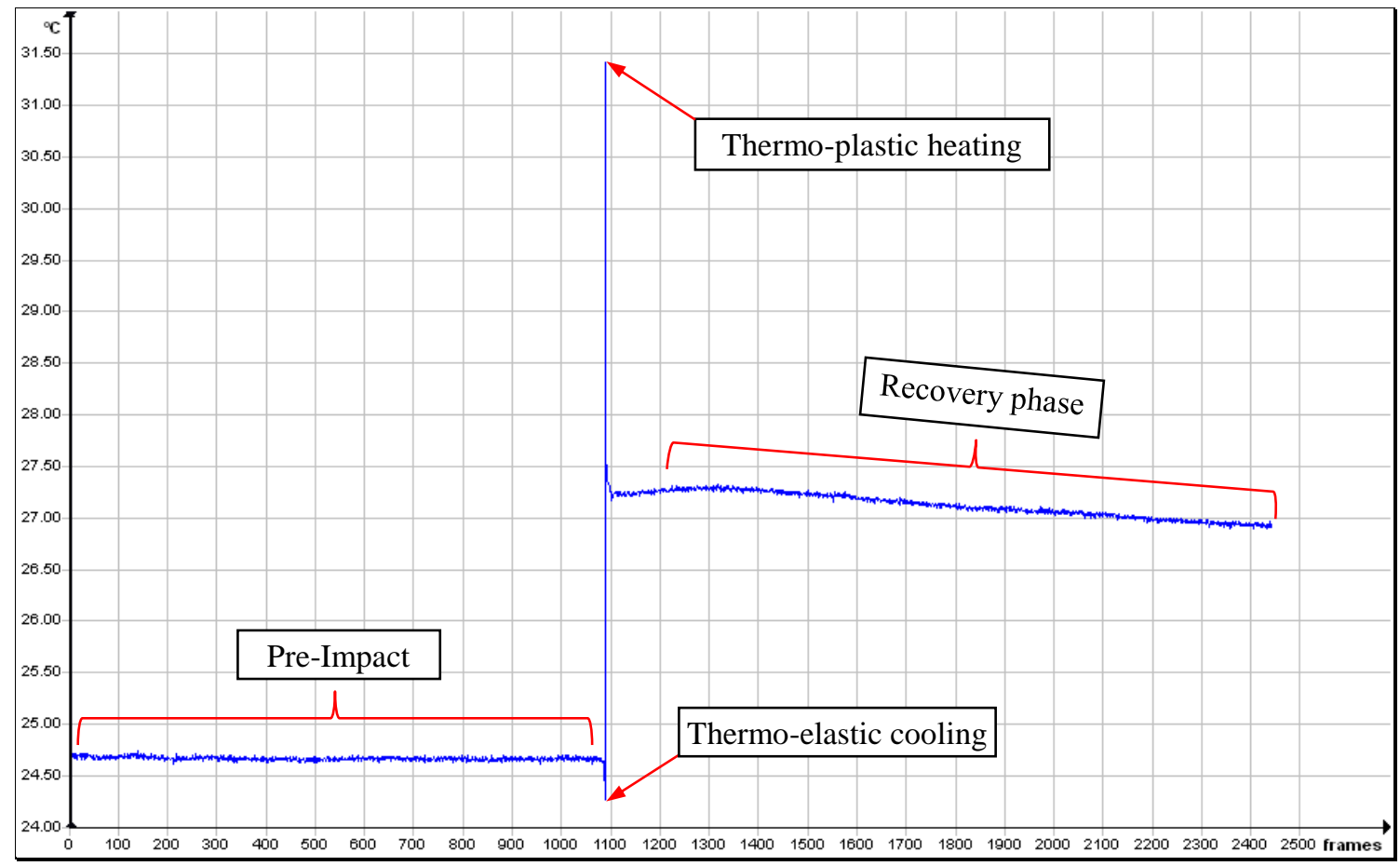

Figure 100: Temperature profile at impact loci for $\left[(0 / 90)_{4 \mathrm{~F}}\right]_{\mathrm{s}}$ at $\mathrm{E}=10 \mathrm{~J}$ 


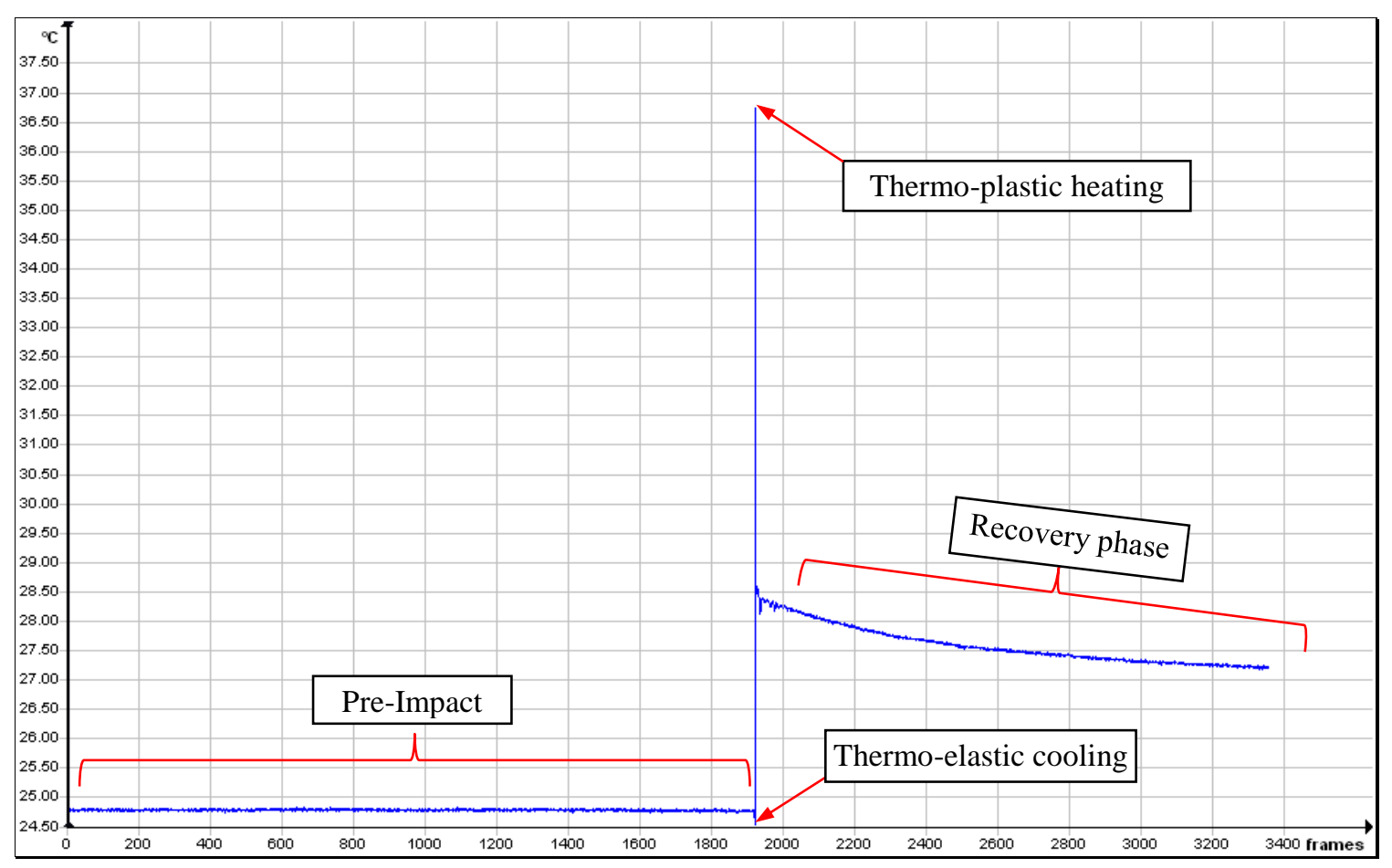

Figure 101: Temperature profile at impact loci for $\left[(0 / 90)_{4 \mathrm{~F}}\right]_{\mathrm{s}}$ at $\mathrm{E}=\mathbf{2 0} \mathrm{J}$

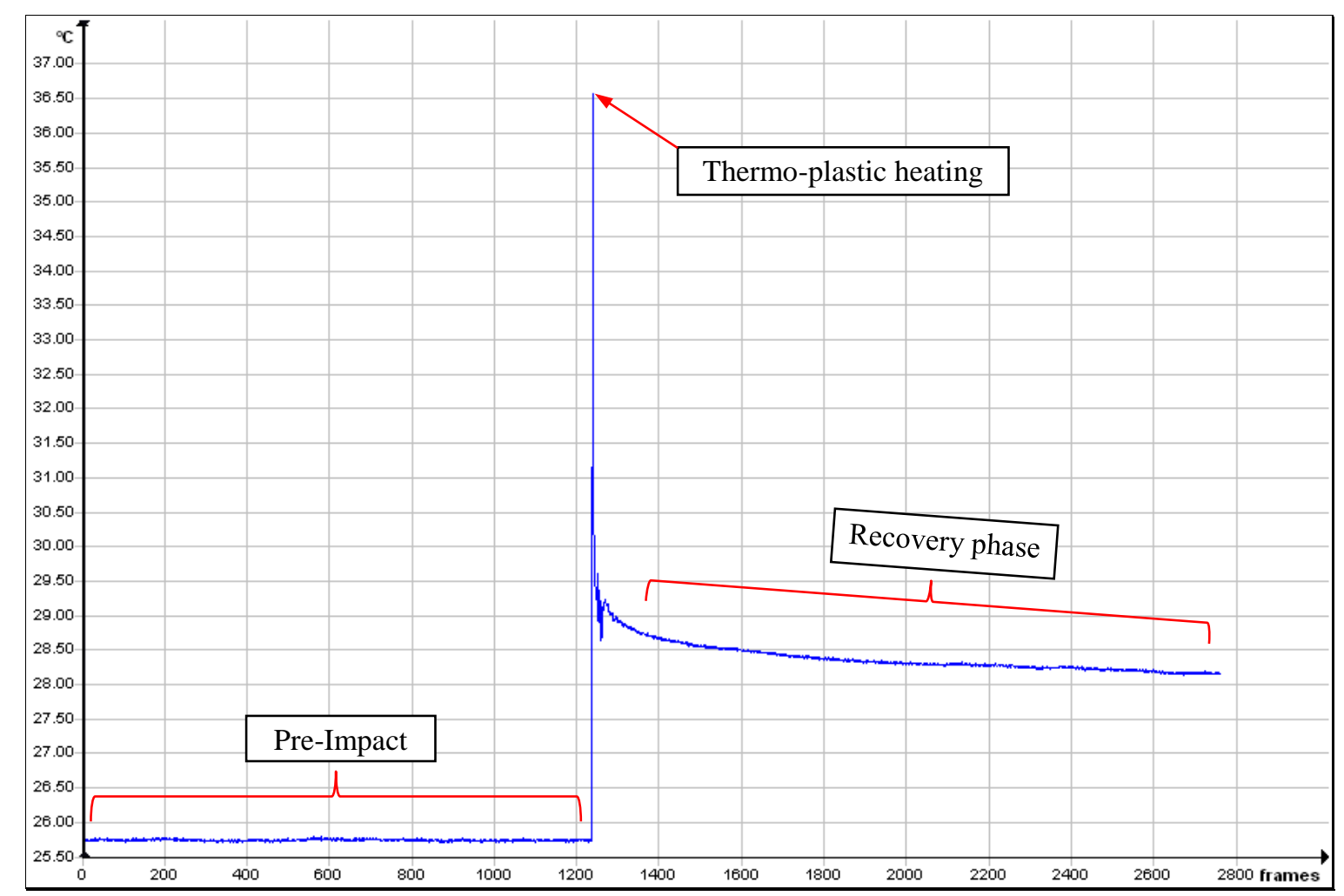

Figure 102: Temperature profile at impact loci for $\left[(0 / 90)_{4 \mathrm{~F}}\right]_{\mathrm{S}}$ at $\mathrm{E}=30 \mathrm{~J}$ 
From the preceding figures, it can be observed that the impact event started off with a sudden temperature drop (thermo-elastic effect), followed by an abrupt increase in temperature (thermos-plastic effect), then a second temperature drop, followed by a slow recovery phase to ambient temperature. The sudden temperature-drop at the beginning of impact accounts for the thermo-elastic response of the composite caused by the sudden elastic dilation at the instant the impactor contacted the specimen [59] [65]. This is a typical phenomenon observed in elastic materials during crack initiation under adiabatic conditions [66]. Such cooling down only lasts for a few fractions of seconds [59]. Thus, an IR camera with high recording frequency is required to always capture this event. The SC5000 IR camera used in this experiment has a frequency of 173 $\mathrm{Hz}(0.006 \mathrm{sec} /$ frame), just high enough to capture this thermos-elastic cooling effect. For impact events where contact duration is very short, a high frequency IR camera is almost always required.

Following the thermos-elastic phase is the thermo-plastic phase, where an abrupt increase in temperature occurred. During this phase, the thermo-elastic cooling was overwhelmed by the heating due to plastic deformation and damage initiation [66]. Since matrix cracking and damage propagation are always accompanied by a sudden release of strain energy and heat dissipation, an abrupt increase in surface temperature was observed. The thermo-plastic heating lasted only a fraction of seconds. It was then followed by a sudden temperature drop, corresponding to the end of the impact event. A gradual recovery phase to ambient condition followed.

From the thermographic images obtained using the IR camera, the progression of the damage in the composite material can also be observed. During the impact event, the damage process was initiated by matrix deformation and cracking followed by fracture. For the flax/epoxy composite, the onset of damage started at the impact point as evidenced by the circular hotspot where $\Delta \mathrm{T}$ is maximum. This is the spot where the matrix crack originated. As the damage progressed, this hotspot extended in the longitudinal and transverse directions, corresponding to the longitudinal and transverse cracks observed previously in Figure 42 to Figure 47. As time progressed, the intensity of the hot spot decreased as the surface temperature recovered gradually towards ambient temperature. The following figures show the thermographic images of the unidirectional flax/epoxy composite captured at various times during and after the impact event. 


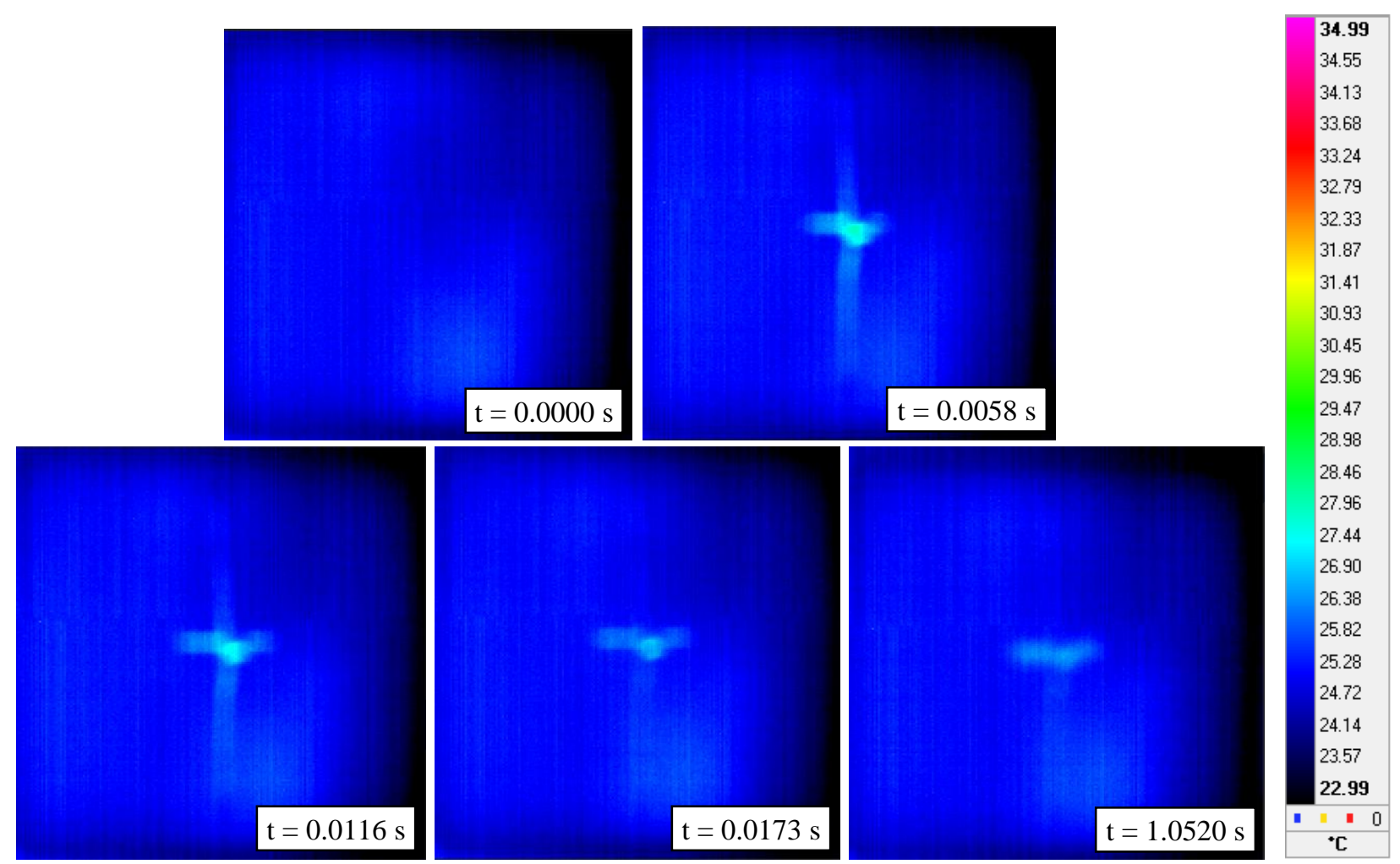

Figure 103: Thermographic images of the back face of $\left[0_{8 F}\right]_{\mathrm{s}}$ at $E=5 \mathrm{~J}$

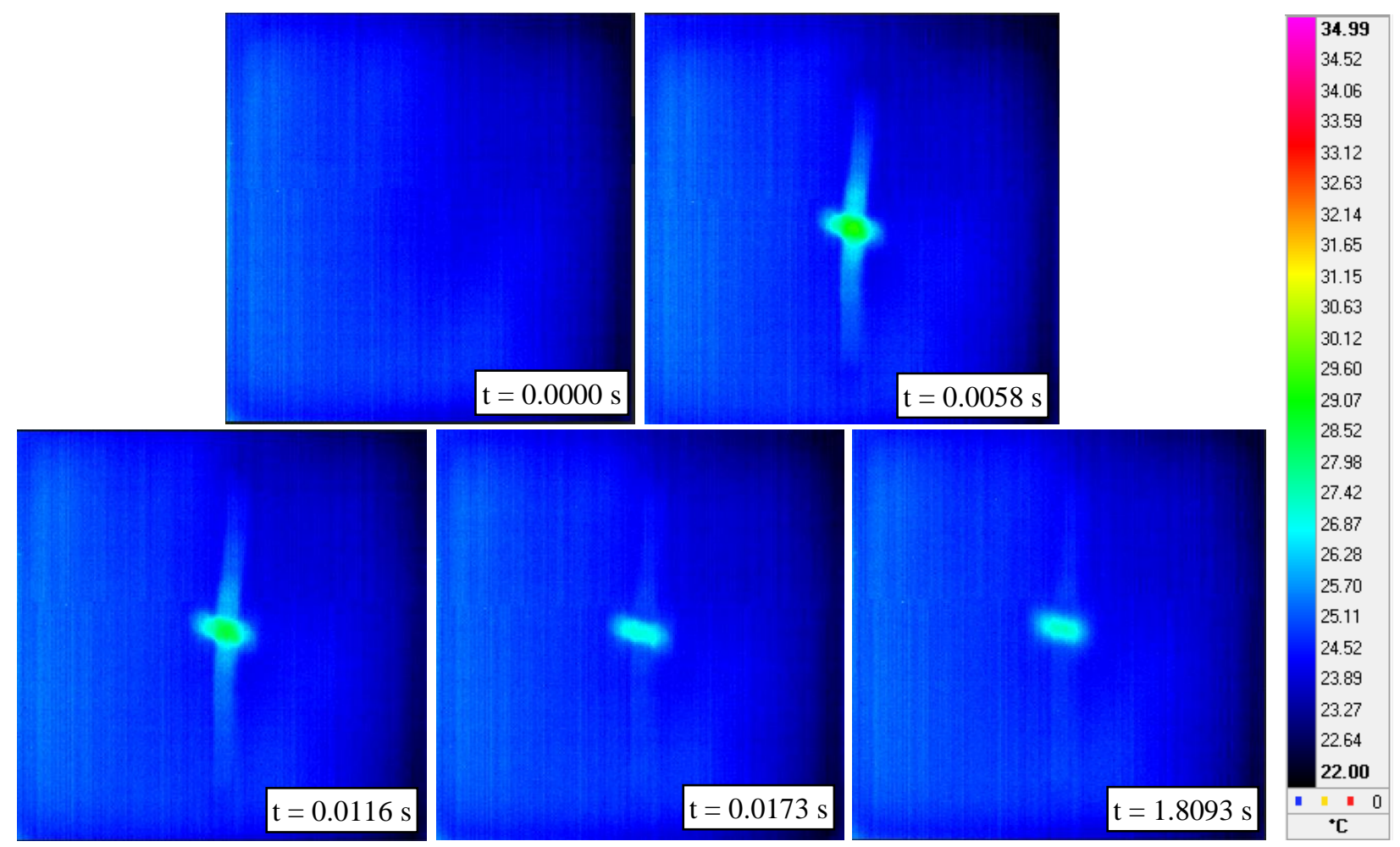

Figure 104: Thermographic images of the back face of $\left[0_{8 F}\right]_{S}$ at $E=7 \mathrm{~J}$ 


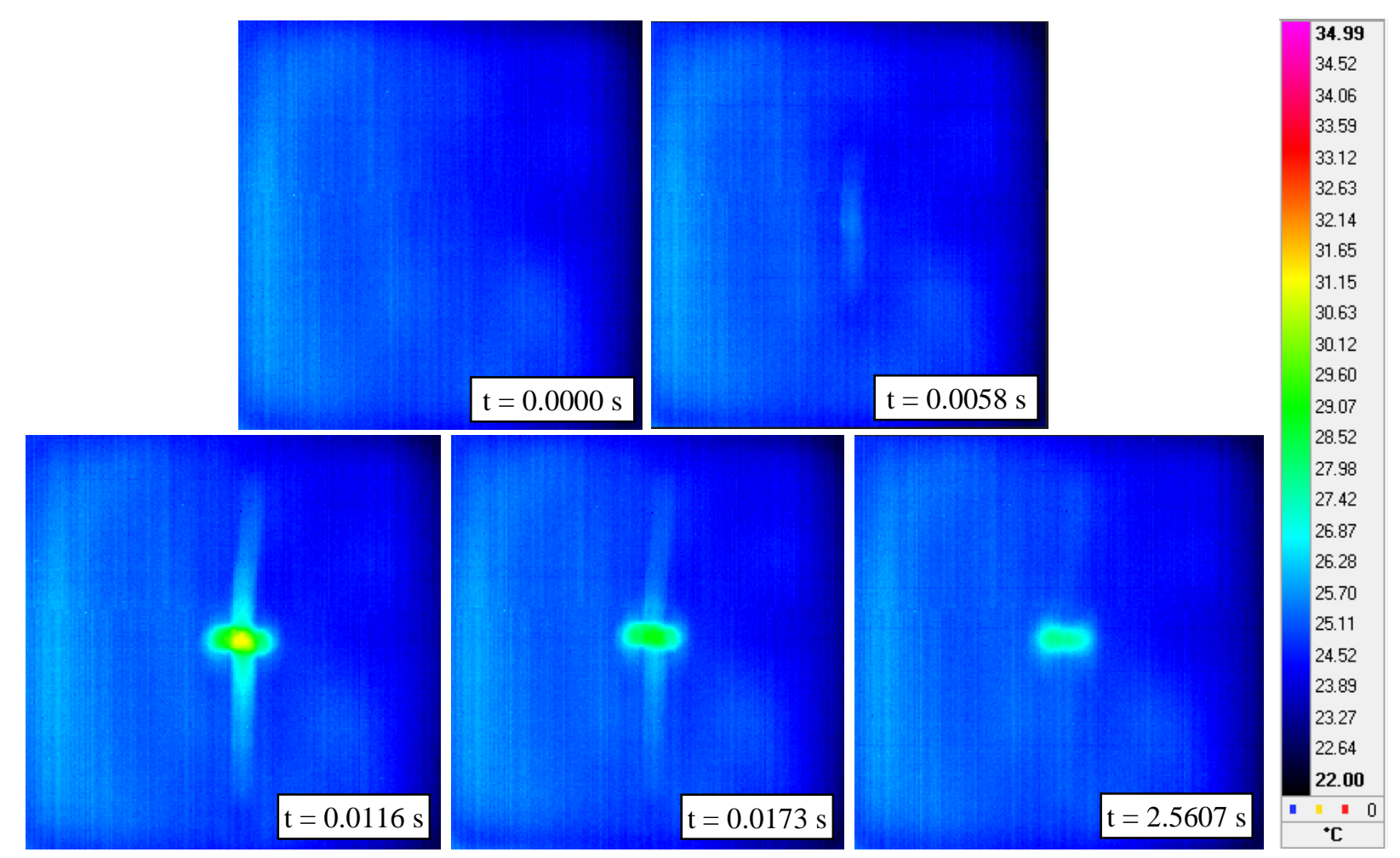

Figure 105: Thermographic images of the back face of $\left[0_{8 \mathrm{~F}}\right]_{\mathrm{s}}$ at $\mathrm{E}=8 \mathrm{~J}$

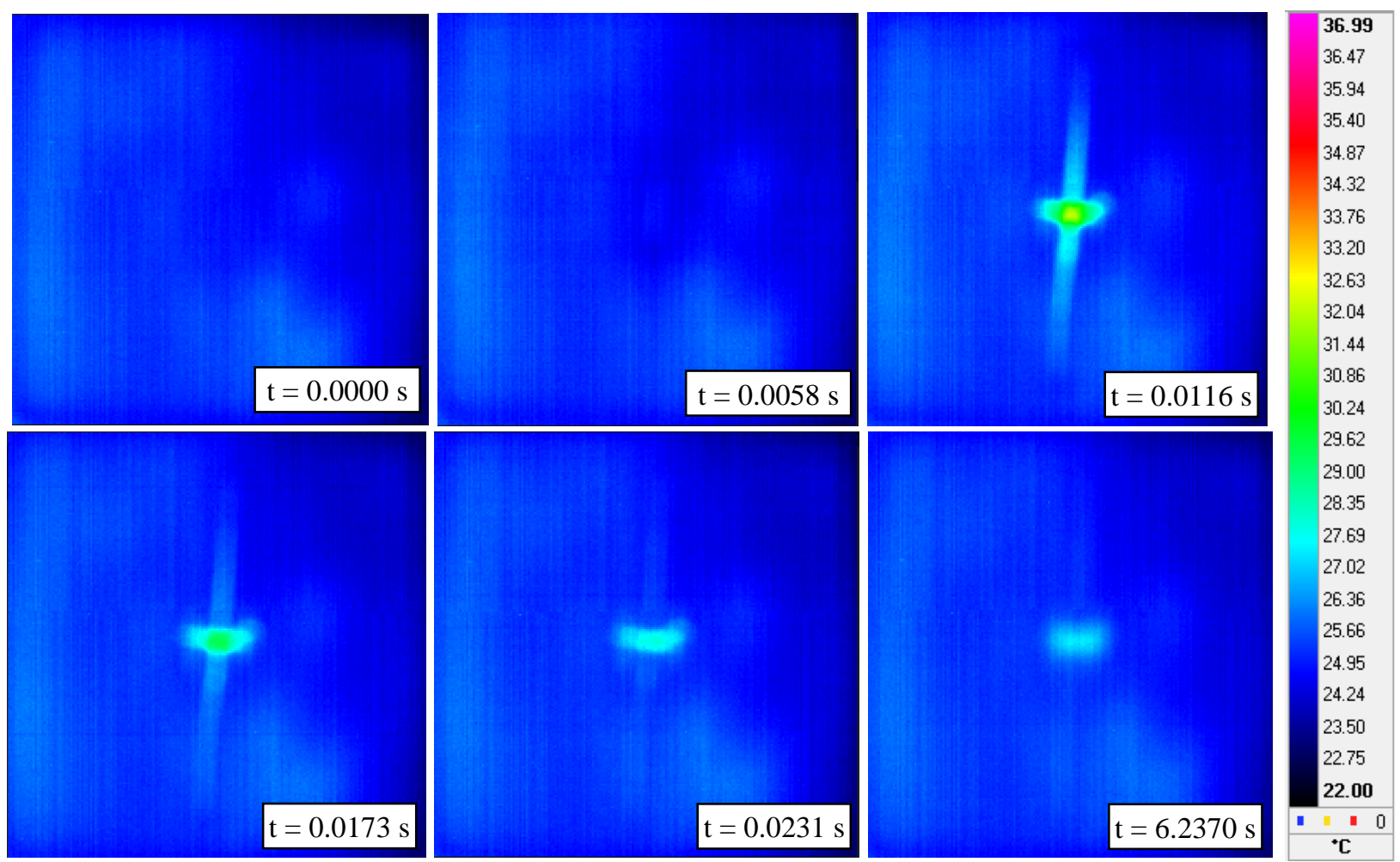

Figure 106: Thermographic images of the back face of $\left[0_{8 \mathrm{~F}}\right]_{\mathrm{s}}$ at $\mathrm{E}=9 \mathrm{~J}$ 


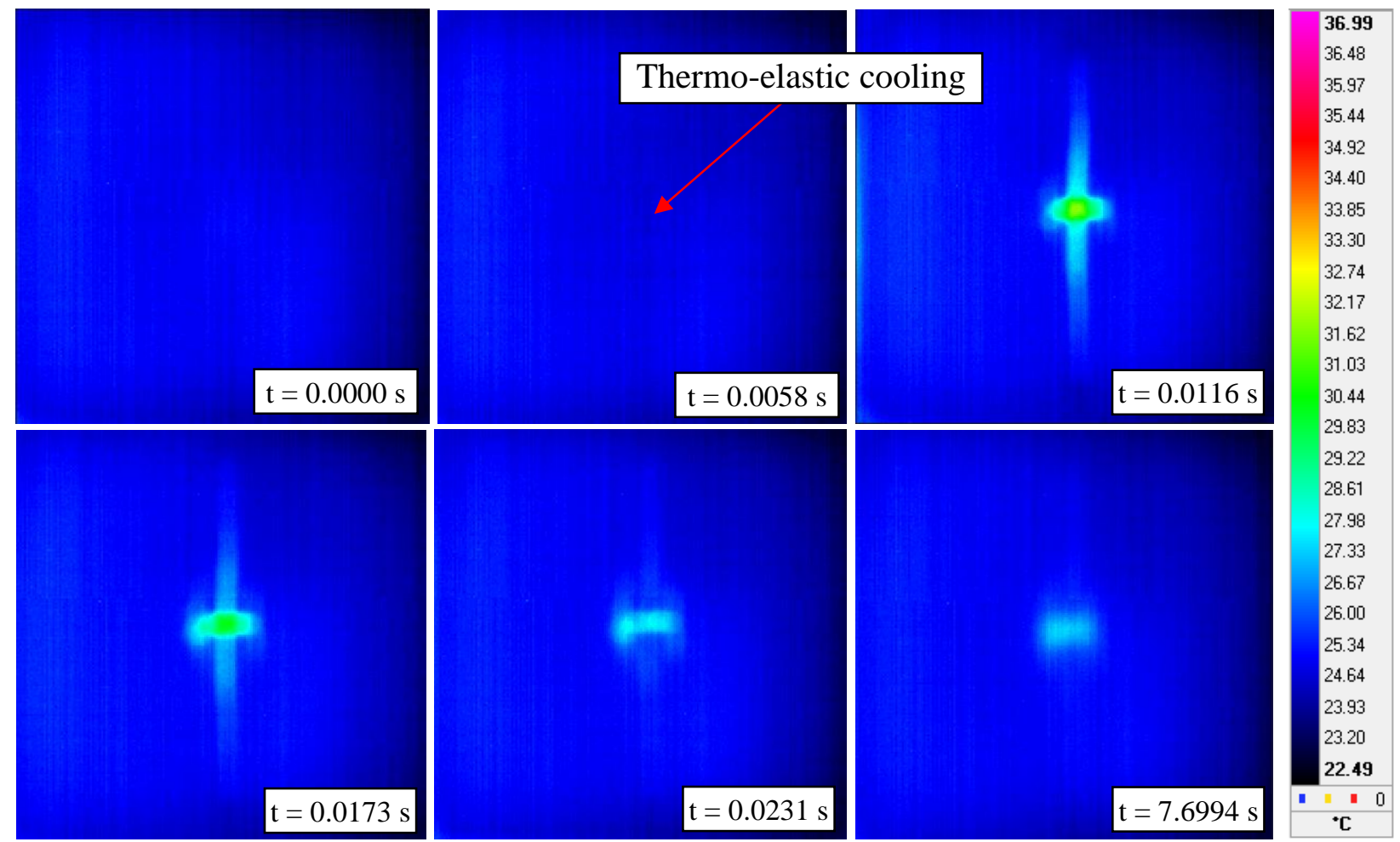

Figure 107: Thermographic images of the back face of $\left[0_{8 \mathrm{~F}}\right]_{\mathrm{S}}$ at $\mathrm{E}=9.5 \mathrm{~J}$
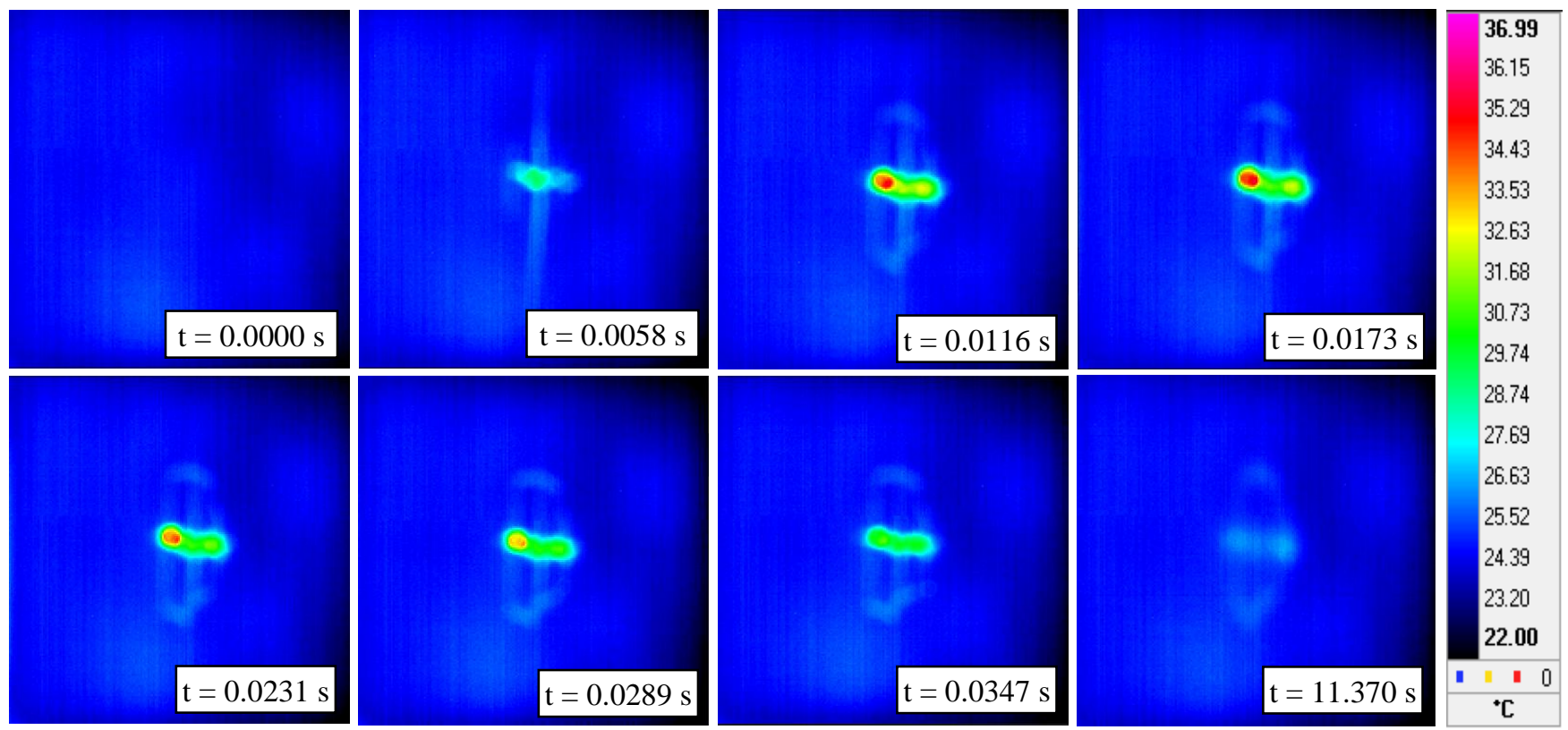

Figure 108: Thermographic images of the back face of $\left[0_{8 \mathrm{~F}}\right]_{\mathrm{S}}$ at $\mathrm{E}=10 \mathrm{~J}$ 


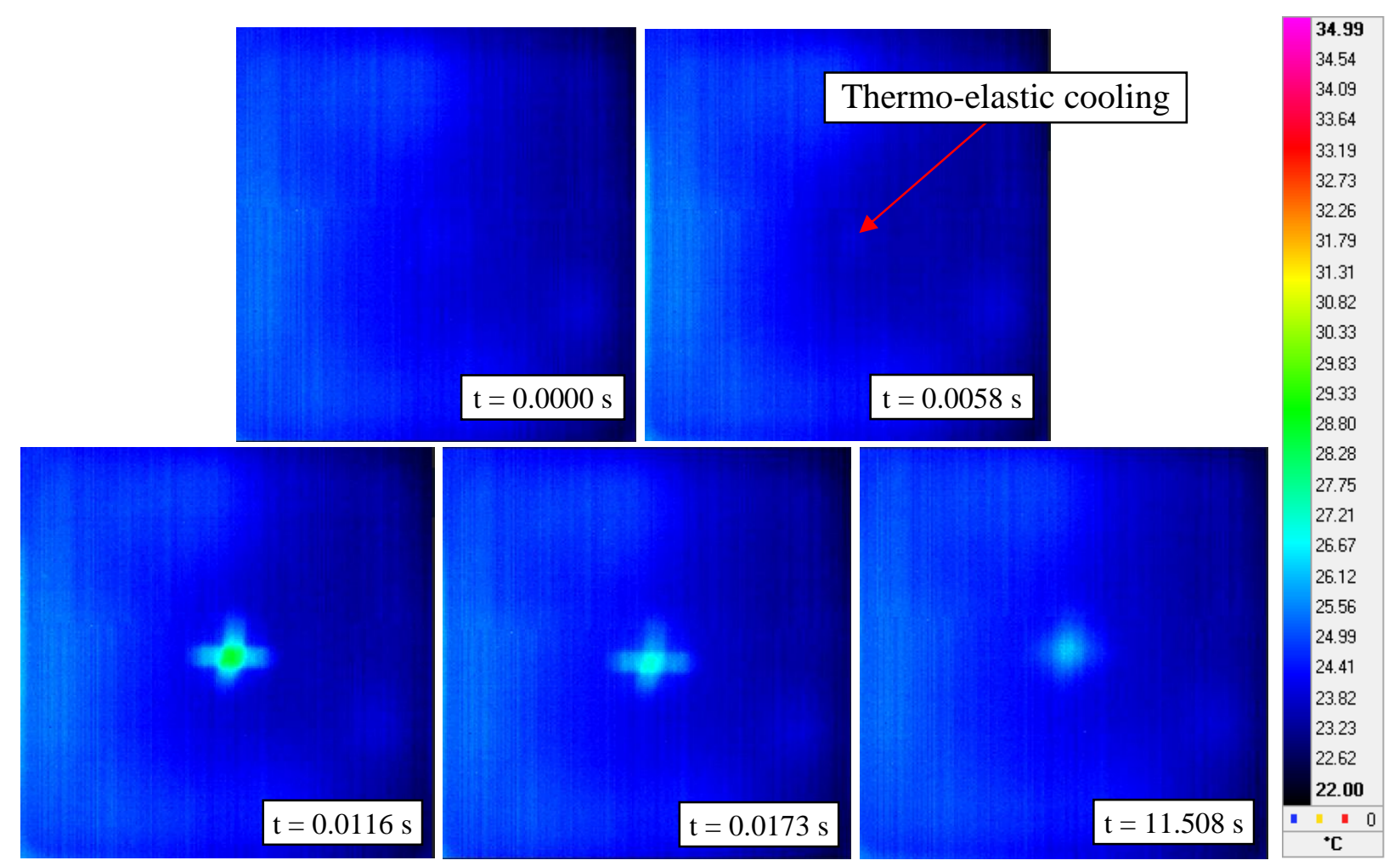

Figure 109: Thermographic images of the back face of $\left[(0 / 90)_{4 \mathrm{~F}}\right]_{\mathrm{S}}$ at $\mathrm{E}=5 \mathrm{~J}$

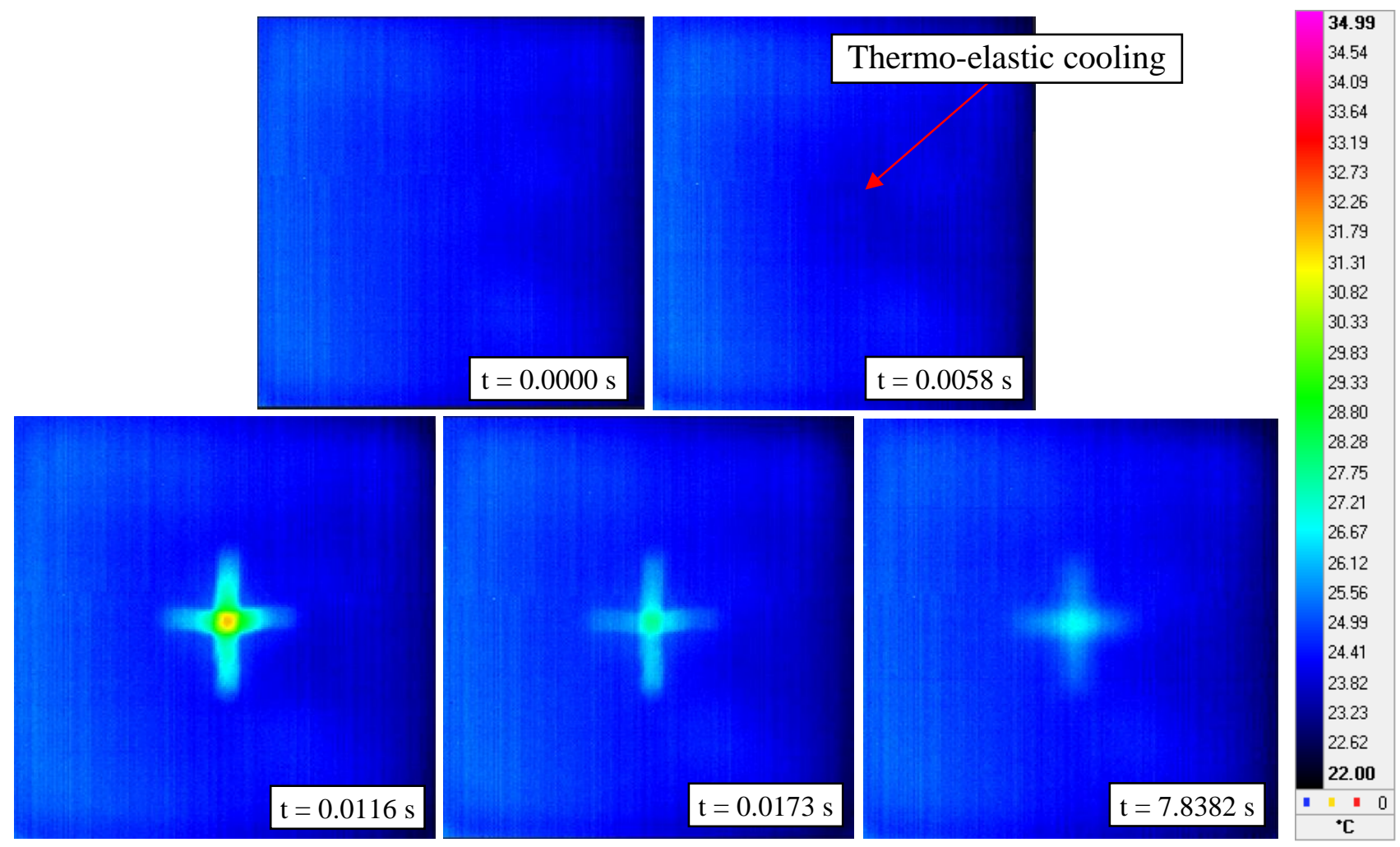

Figure 110: Thermographic images of the back face of $\left[(0 / 90)_{4 F}\right]_{s}$ at $E=10 \mathrm{~J}$ 


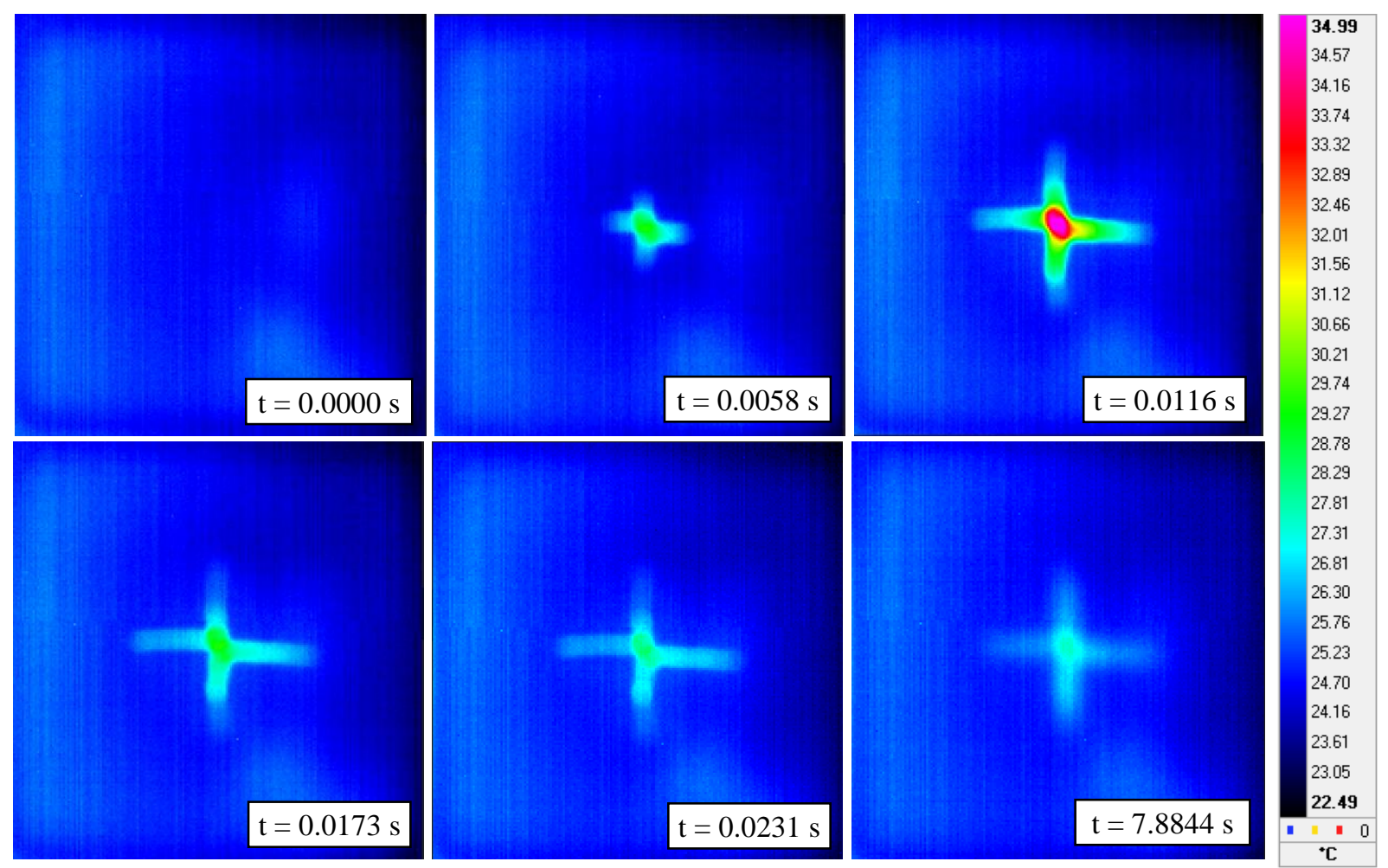

Figure 111: Thermographic images of the back face of $\left[(0 / 90)_{4 \mathrm{~F}}\right]_{\mathrm{S}}$ at $\mathrm{E}=15 \mathrm{~J}$

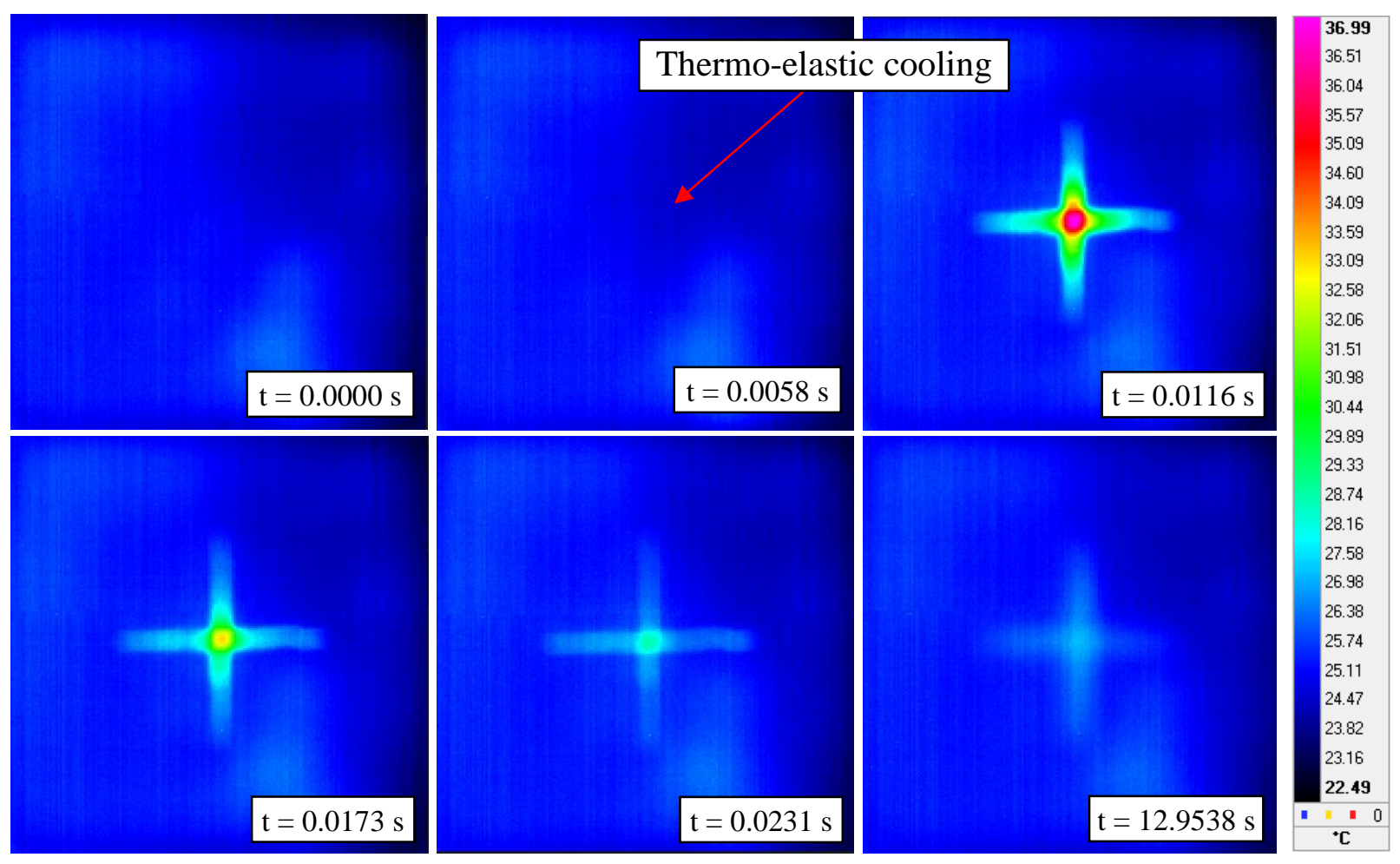

Figure 112: Thermographic images of the back face of $\left[(0 / 90)_{4 \mathrm{~F}}\right]_{\mathrm{S}}$ at $\mathrm{E}=\mathbf{2 0} \mathrm{J}$ 


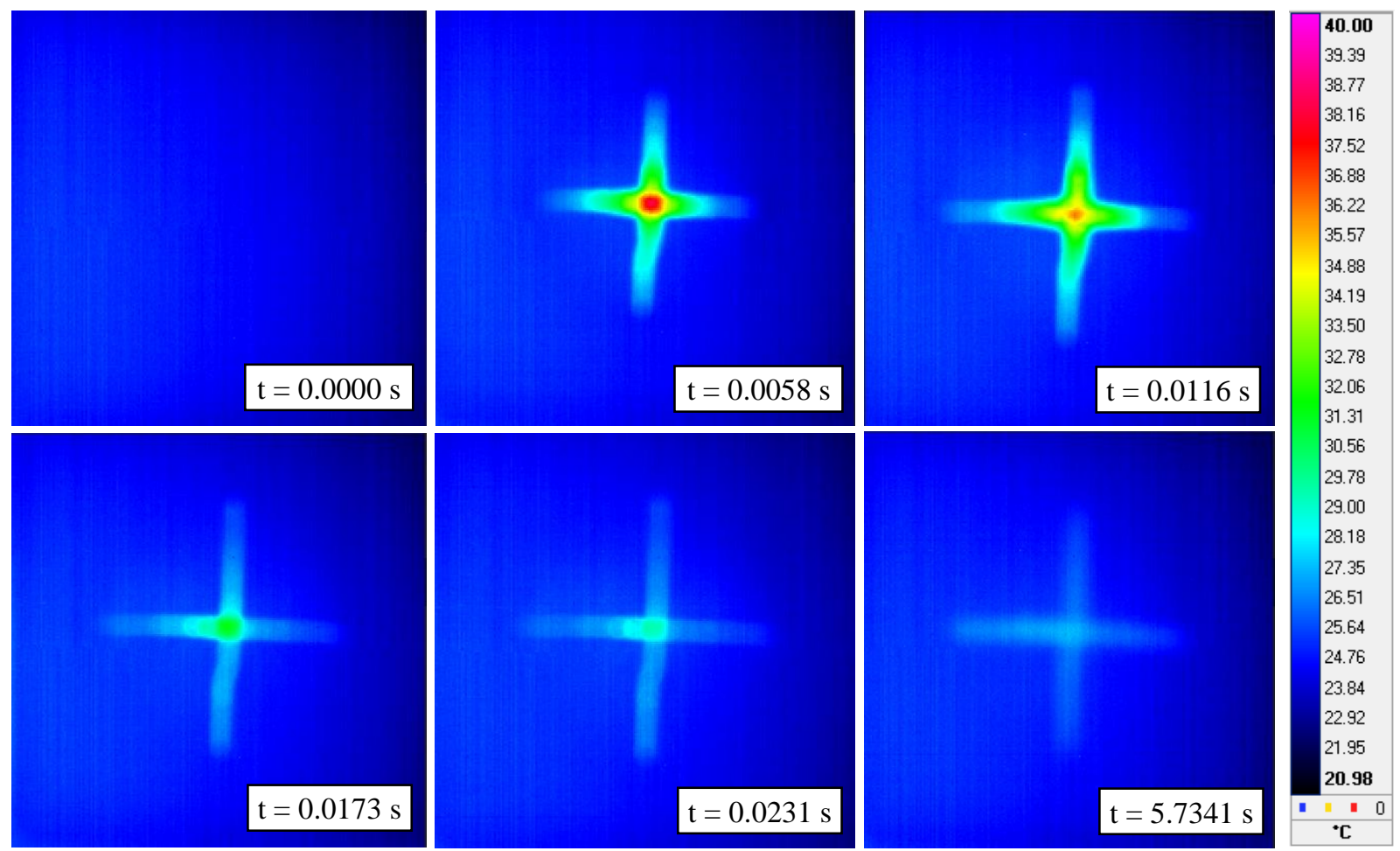

Figure 113: Thermographic images of the back face of $\left[(0 / 90)_{4 \mathrm{~F}}\right]_{S}$ at $E=25 \mathrm{~J}$

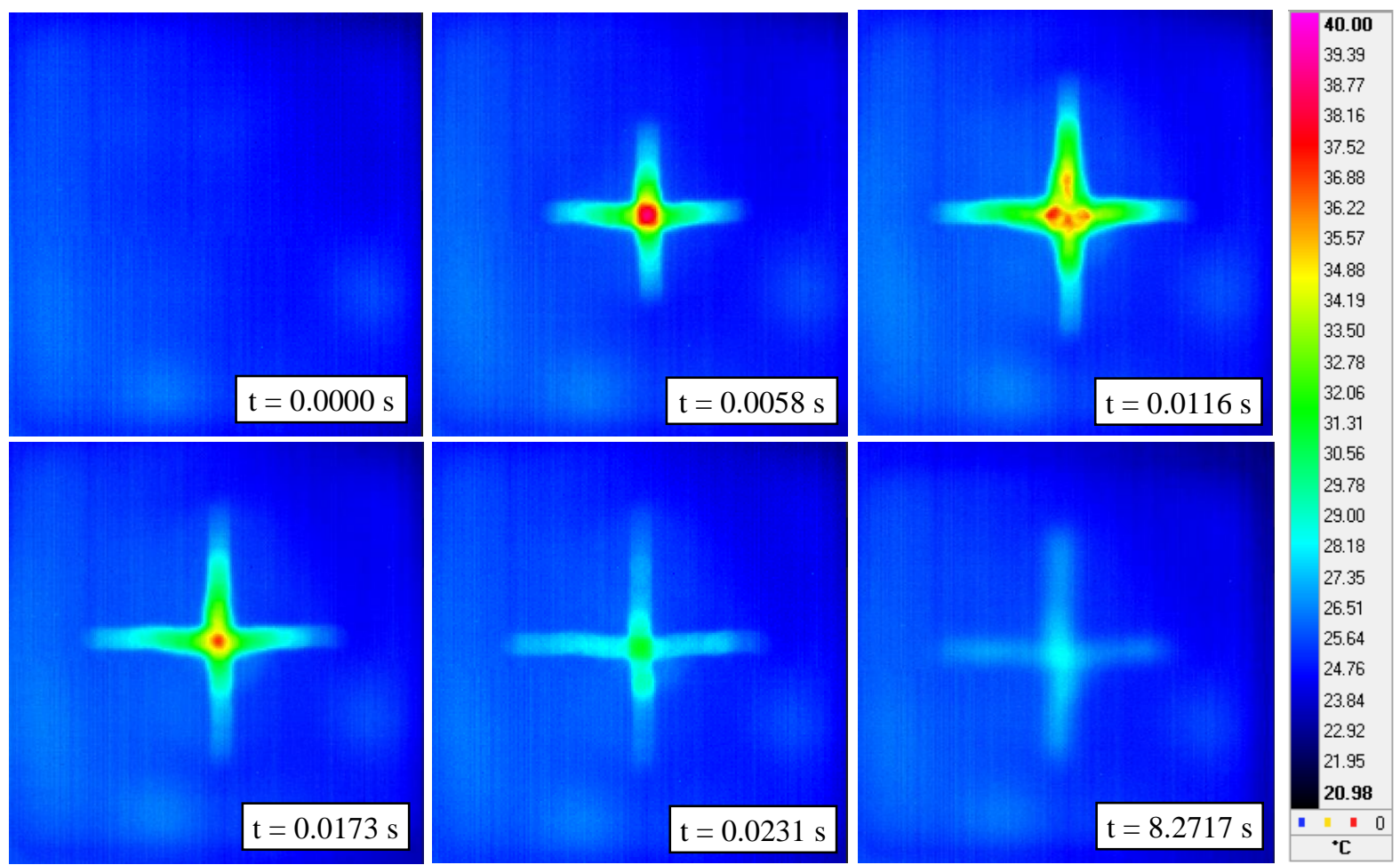

Figure 114: Thermographic images of the back face of $\left[(0 / 90)_{4 \mathrm{~F}}\right]_{\mathrm{S}}$ at $\mathrm{E}=30 \mathrm{~J}$ 
During impact, the kinetic energy from the impactor tip was transferred to the laminate. The impact energy was absorbed by the composite during the formation of matrix cracks, delamination and fibre damage. During the damage formation, heat was being dissipated and was manifested as a temperature rise in the IR camera. To get a better understanding of how this temperature change relates to the impact energy of the composite material, maximum $\Delta \mathrm{T}$ behind the point of impact was plotted against impact energy for all the test cases in Figure 115.

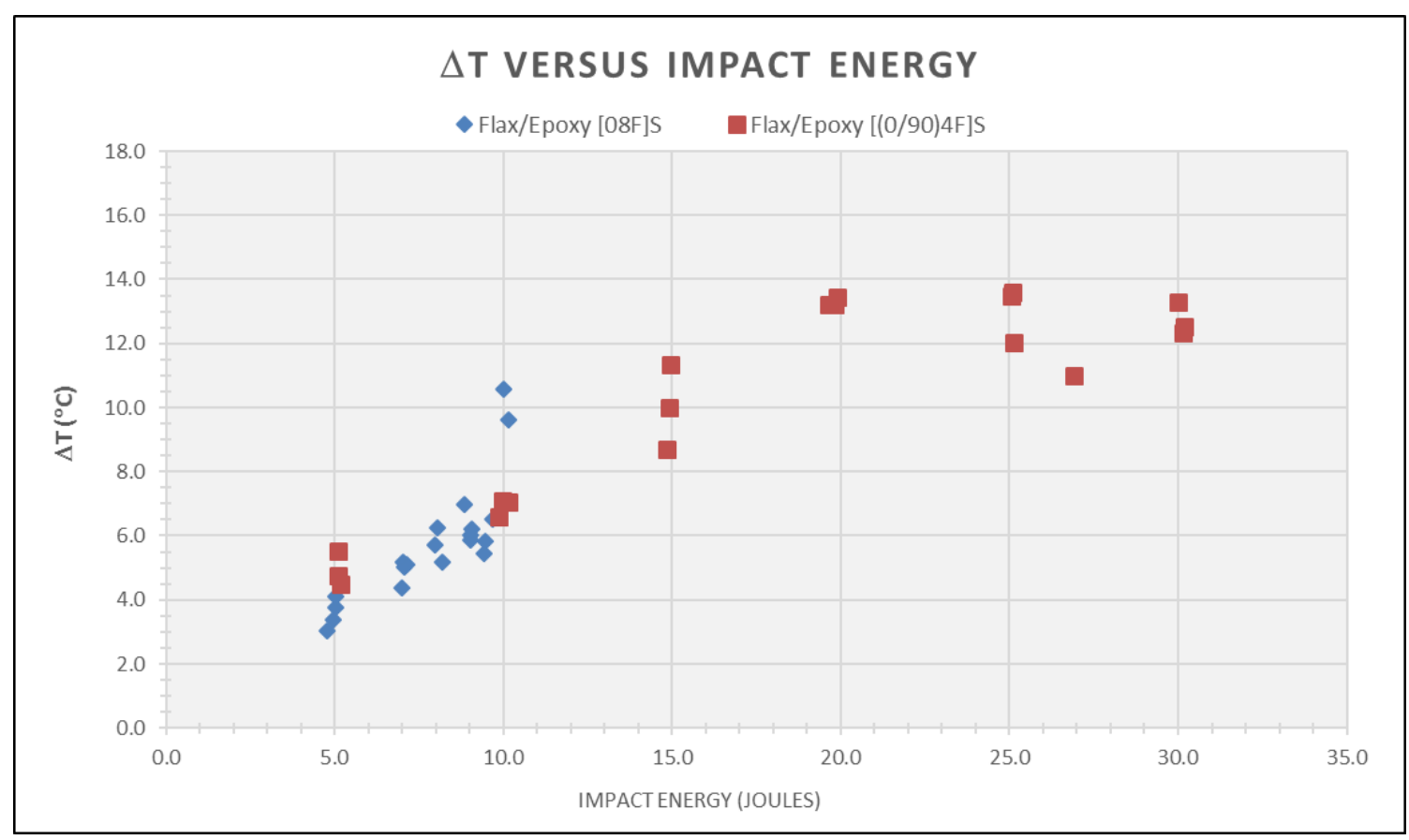

Figure 115: $\Delta \mathrm{T}$ versus impact energy for flax/epoxy composite

From the above graph, the maximum $\Delta \mathrm{T}$ increased with increasing impact energy. For the unidirectional flax/epoxy composite, the $\Delta \mathrm{T}$ increased steadily from $3^{\circ} \mathrm{C}$ to $7^{\circ} \mathrm{C}$ between $5 \mathrm{~J}$ and 9.5 J. The $\Delta \mathrm{T}$ then abruptly increased to an average value of $10^{\circ} \mathrm{C}$ as the composite fractured during penetration at $\mathrm{E}=10 \mathrm{~J}$. For the cross-ply flax/epoxy composite, the $\Delta \mathrm{T}$ also steadily increased from $5^{\circ} \mathrm{C}$ to $13^{\circ} \mathrm{C}$ between $5 \mathrm{~J}$ and $20 \mathrm{~J}$; however, between $20 \mathrm{~J}$ and $30 \mathrm{~J}$, the $\Delta \mathrm{T}$ plateaus at an average value of $13^{\circ} \mathrm{C}$. This is because beyond $20 \mathrm{~J}$, the damage to the composite at the centre of the plate (where $\Delta \mathrm{T}$ was being measured) already propagated through the thickness, although the laminate was not yet fully penetrated by the impactor. 
In addition, the absorbed energy was plotted against $\Delta \mathrm{T}$. As can be observed from Figure 116 , the absorbed energy increases with increasing $\Delta \mathrm{T}$. By properly correlating the absorbed energy with $\Delta \mathrm{T}$, this will allow for estimating numerically the absorbed energy using IRT technique.

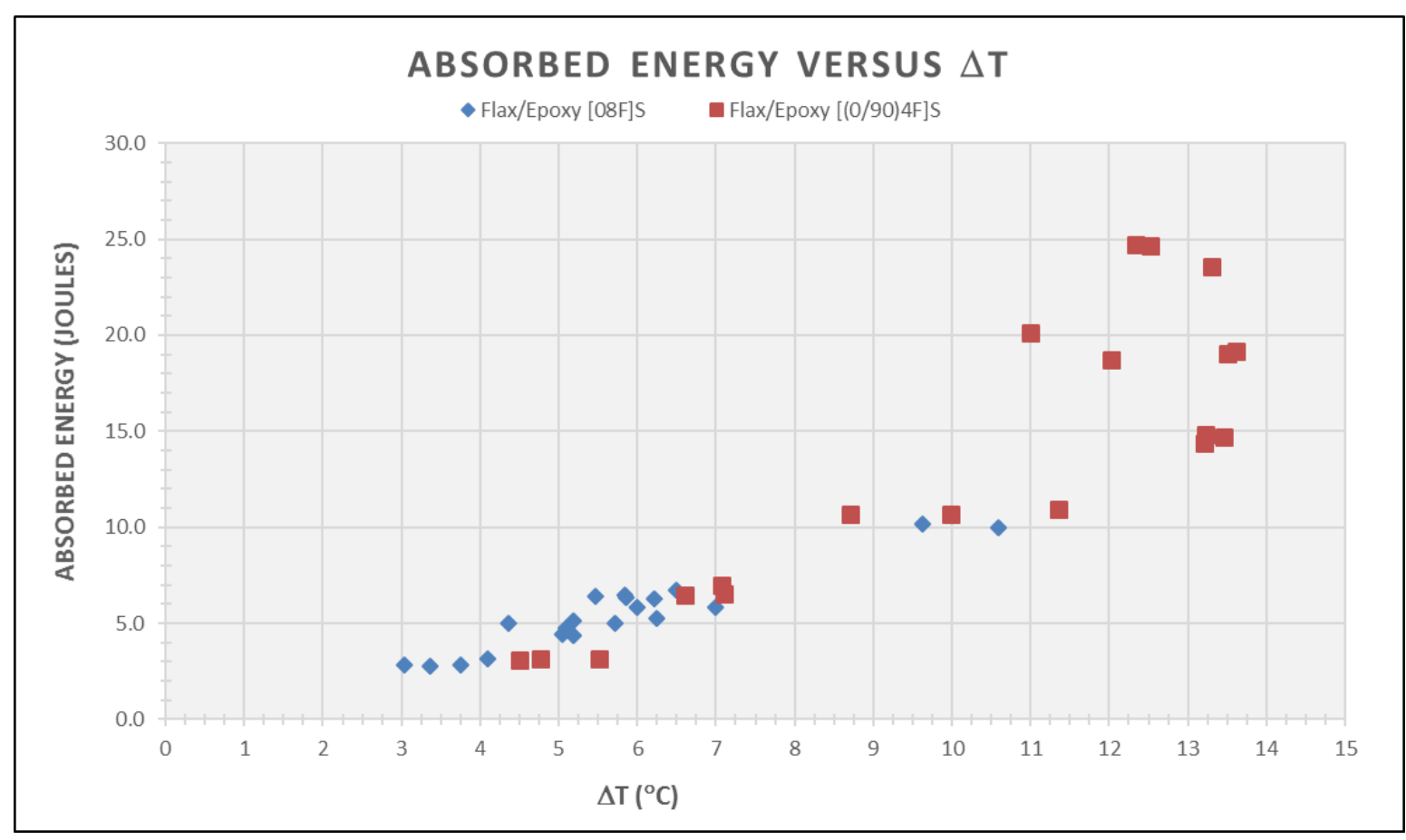

Figure 116: Absorbed energy versus $\Delta T$ for flax/epoxy composite 


\subsubsection{IMPACT DAMAge ChaRACTERIZATION USING IR TheRMOgRAPHY}

From the thermal images, by limiting the temperature value to a certain threshold, it is possible to gain insight on the extension of the warm areas, which coincides with the impact damage profile on the composite [60]. This information is valuable, especially for detecting BVID and internal damages on composites. For the flax/epoxy composite laminates, the impact damage is externally visible in the form of long matrix cracks. Hence, a side-by-side comparison of the physical damage and the thermographic contour can be made for correlation purposes.

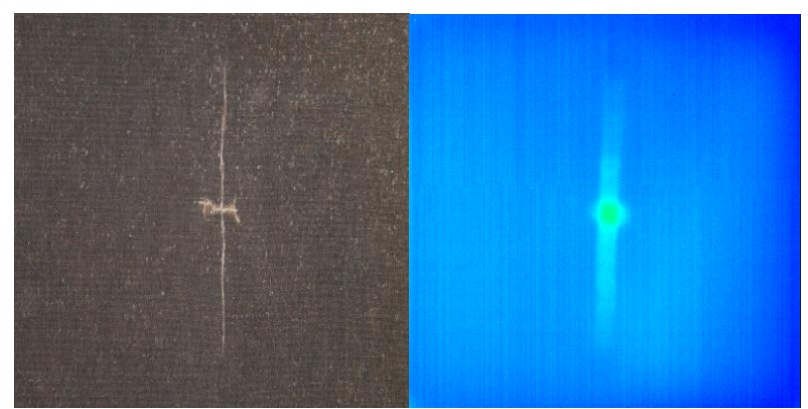

$$
\mathrm{E}=5 \mathrm{~J}
$$

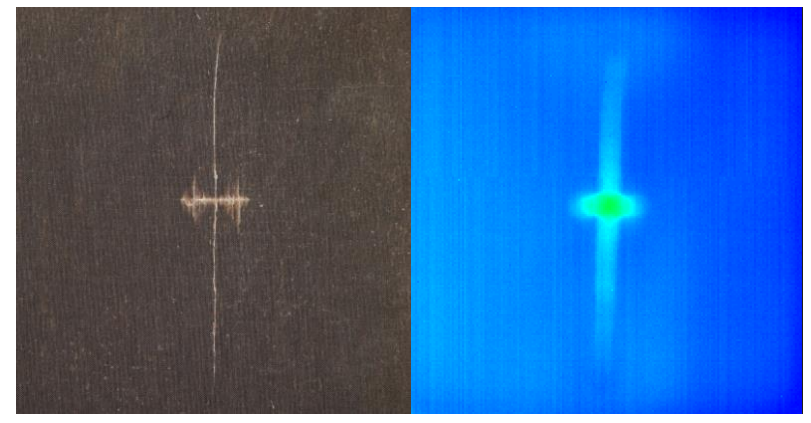

$\mathrm{E}=8 \mathrm{~J}$

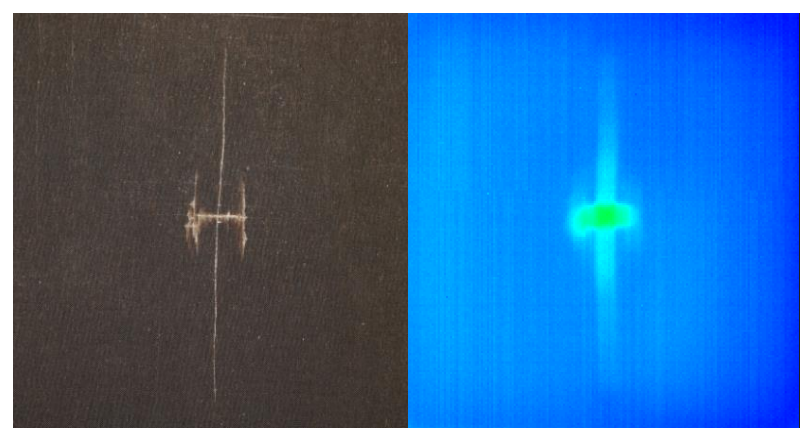

$$
\mathrm{E}=9.5 \mathrm{~J}
$$

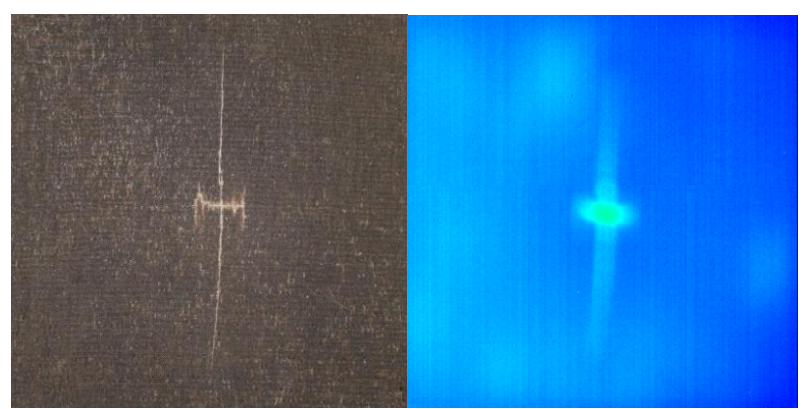

$\mathrm{E}=7 \mathrm{~J}$

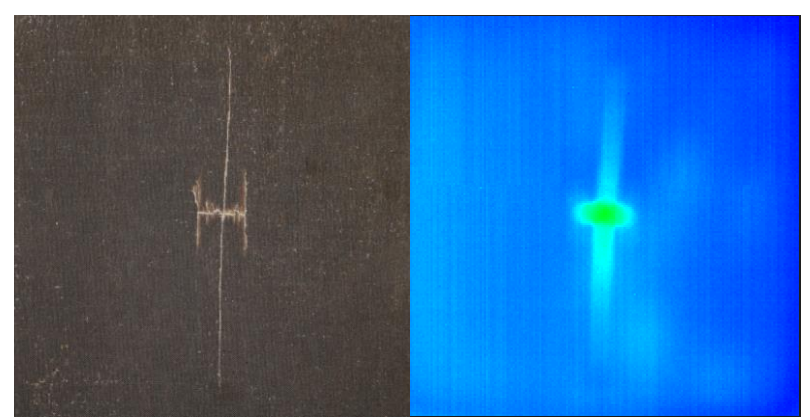

$\mathrm{E}=9 \mathrm{~J}$

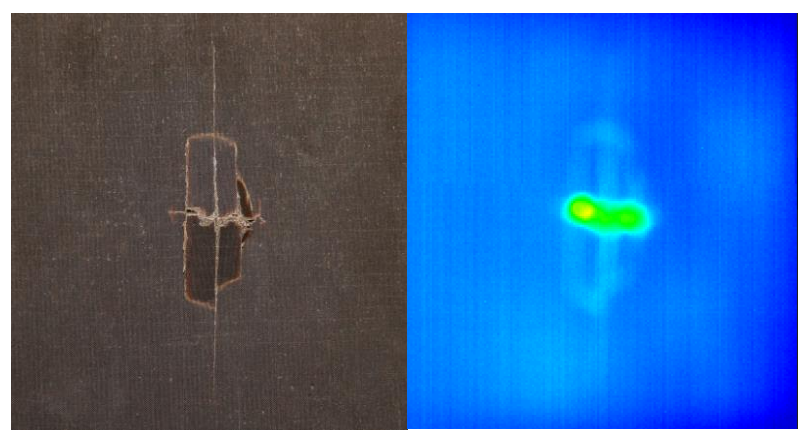

$\mathrm{E}=10 \mathrm{~J}$

Figure 117: Back face visible and thermal images of the $\left[0_{8 \mathrm{~F}}\right]_{\mathrm{s}}$ 


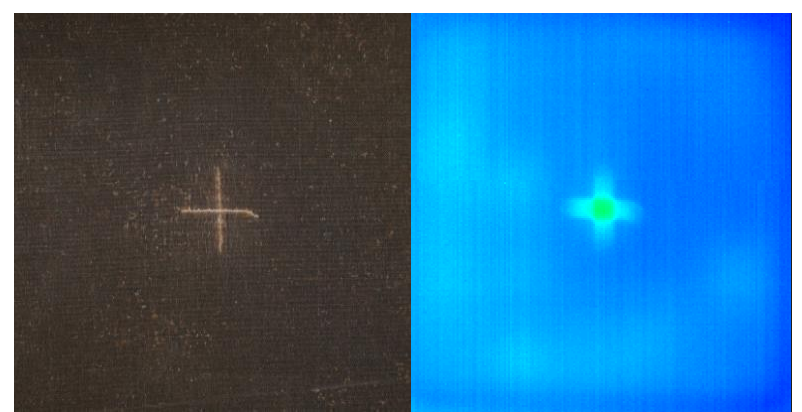

$\mathrm{E}=5 \mathrm{~J}$

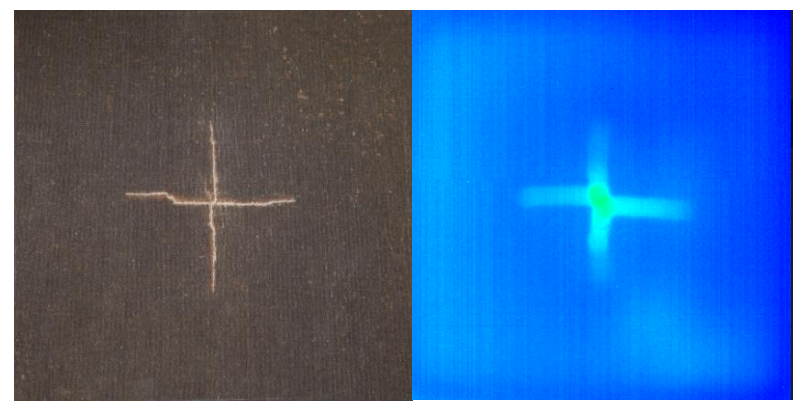

$\mathrm{E}=15 \mathrm{~J}$

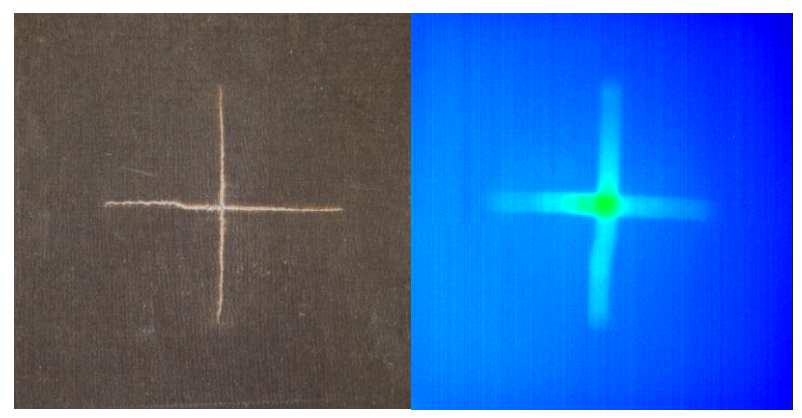

$\mathrm{E}=25 \mathrm{~J}$

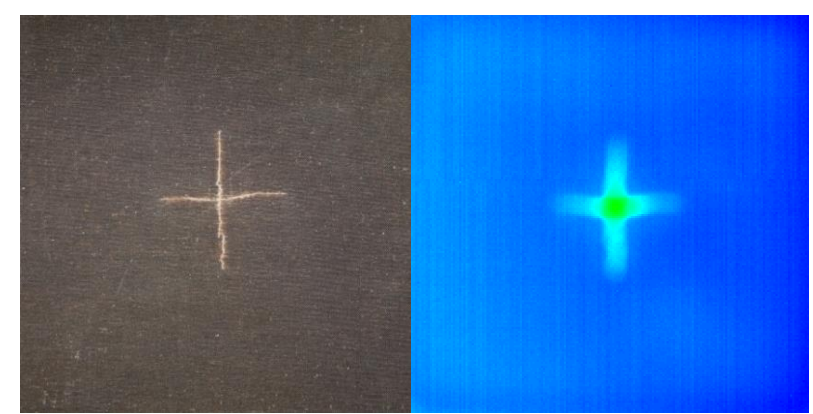

$\mathrm{E}=10 \mathrm{~J}$

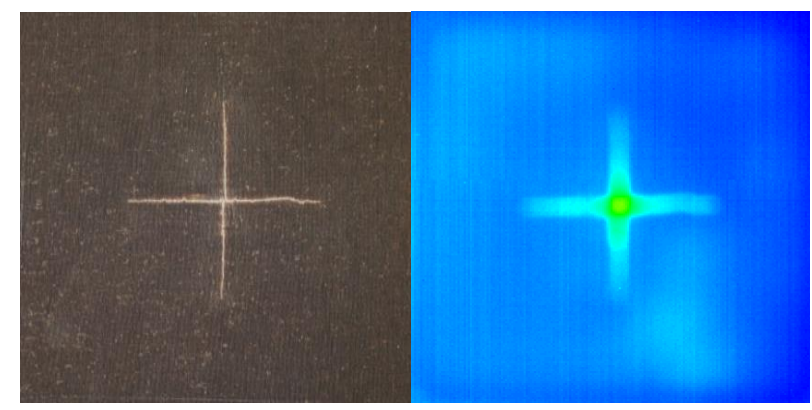

$\mathrm{E}=20 \mathrm{~J}$

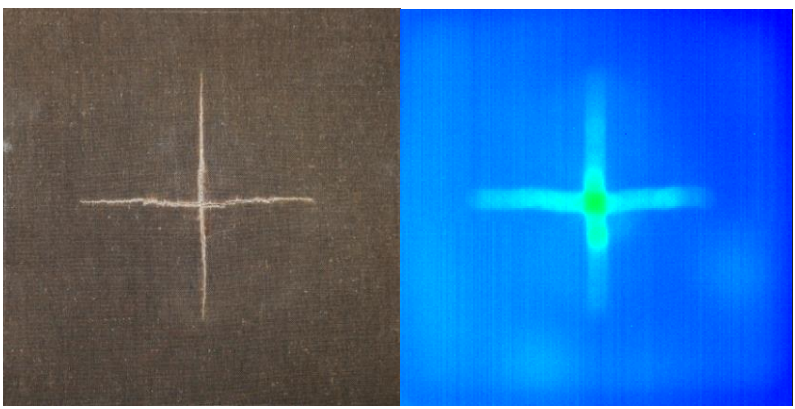

$\mathrm{E}=30 \mathrm{~J}$

Figure 118: Back face visible and thermal images of the $\left[(0 / 90)_{4 \mathrm{~F}}\right]_{\mathrm{S}}$

As can be seen from Figure 125 and Figure 126, there is a good correlation between the back face visible damage and the thermographic contour images. The matrix crack originated from the centre of the plate, hence the $\Delta \mathrm{T}$ at this location is the highest. This hot spot extends to approximately the same size as the crack propagation. Additionally, the thickness of the warm streak is larger than the actual crack width, suggesting the presence of localized matrix damage surrounding the crack, which is barely visible to the naked eye. All this information suggests the effectiveness of infrared thermography as a method of measuring the damage extension in a composite material. This method is helpful in cases where the material is not translucent or where the damage on the specimen is internal or barely visible (BVID). 


\subsubsection{SUMMARY OF LOW VELOCITY IMPACT RESPONSE}

When subjected to low velocity impact loading, composite laminates undergo elastic response until damage is initiated. For the flax/epoxy composites, this elastic response is indicated as the "elastic zone" in the absorbed energy versus impact energy plot of Figure 37 . Beyond the elastic zone, permanent damage ensues in the form of matrix cracking, fibre failure, interlayer damage (delamination) or a combination of both, depending on the magnitude of impact energy.

At the beginning of the damage process, surface indentation was created at the impact point, with the depth and width of the indentation increasing with increasing energy level. This surface indentation caused local fibre breakage at the center of impact, as shown by the presence of a transverse crack approximately the size of the impactor diameter. As the impact energy increased, the impactor moved deeper into the composite causing flexural deformation of the laminate. The bending of the plate generated high tensile stresses at the side opposite to the point of impact, resulting in the formation of bending cracks. In the case of the unidirectional flax/epoxy composite, the bending crack propagated along the fibre (longitudinal) direction. In the case of the cross-ply flax/epoxy composite, the bending cracks propagated in both longitudinal and transverse directions. For the unidirectional composite, two oblique cracks also formed adjacent to the primary central crack. The oblique cracks were caused by the high transverse shear stress due to the flexural deformation of the composite [67]. For both composite configurations, the crack lengths increased with increasing impact energy.

For the cross-ply composite laminate, delamination of top-most layer also developed starting at $\mathrm{E}=15 \mathrm{~J}$. Delamination damage is typical of laminates loaded in flexure [12]. The flexural deformation of the plate caused high interlaminar shear stresses at the compression side of the plate causing the ply to delaminate. This behaviour is especially common in cross-ply and angle ply composites, where the stiffnesses between adjacent plies are different. In the case of the cross-ply flax/epoxy composite, the combination of high compressive bending stress, interlaminar shear stress and the difference in stiffness between the first and second plies were what caused the delamination of the lamina. 
The delamination area increased with increasing impact energy. The increase in crack length and delamination area agreed with the trend in the absorbed energy vs. impact energy plot, up to the point prior to the penetration threshold energy. This implies that the dominant failure modes between low and penetration energy include matrix cracking, fibre failure and delamination, with the extent of damage increasing with increasing impact energy.

At the end of the bending failure stage, the absorbed energy versus impact energy plot abruptly changed slope as the curve approached the equal energy line. This indicates the approach to the penetration stage. A slight increase in the impact energy at this stage would be spent in pushing the impactor through the thickness of the composite resulting in full penetration. Once the impactor fully penetrates, the composite completely absorbs all the impact energy from the impactor.

For the unidirectional flax/epoxy, the penetration threshold is at $\mathrm{E}=10 \mathrm{~J}$, while for the cross-ply flax/epoxy, the penetration threshold is just slightly above $\mathrm{E}=30 \mathrm{~J}$. A close examination of the fractured unidirectional composite at $\mathrm{E}=10 \mathrm{~J}$ showed that the dominant modes of failure were matrix cracking, fibre breakage and pullout along the central crack, and fibre debonding along the oblique cracks. For the cross-ply composite, full penetration did not occur at $30 \mathrm{~J}$. At this energy level, the dominant failure modes in the composite were matrix cracking, fibre failure (pullout and breakage) and delamination. 


\subsection{EFFECT OF HYBRIDIZATION WITH KEVLAR 49}

The major benefits of natural fibres such as flax include sustainability, biodegradability, abundance, lower cost and lower specific gravity compared to conventional synthetic fibres [1] [3]. Although their strength is relatively lower than the latter, they have comparable specific strength and stiffness and acceptable mechanical properties such as elongation, flexural strength, impact resistance, non-abrasiveness, good damping and acoustic absorption [3] [4]. A major drawback which restricts their usage in several engineering applications is their high moisture absorption and low degradation temperature (typically below $200^{\circ} \mathrm{C}$ ), which makes them incompatible to high-temperature curing thermosets [3] [4] [5]. Moreover, flax fibres in general experience large variability and degradation in their mechanical properties when exposed to different environmental conditions and humidity [5] [6]. Treating flax fibres with suitable coupling agents such as silane and alkali will reduce their moisture absorption and enhance their mechanical properties. All these, however, are at the expense of a reduction in impact performance [6] [11].

Moreover, because of their lower tensile strength compared to synthetic fibres, flax/epoxy composites are limited to non-structural applications. Hybridization with synthetic fibres such as glass, carbon and aramid are commonly used to achieve the desired combination of mechanical properties for specific applications. The advantage of hybridization is that one fibre can compensate for the disadvantage of the other fibre. In this study, flax fibres were hybridized with aramid (Kevlar 49 fabric). Aramid fibres are known for their high tensile strength and stiffness, low density, ductility and impact toughness. The hybridization of both fibres could potentially create a material with excellent specific strength, stiffness and damping ability, while also offering improved impact strength and toughness. This will be beneficial in the aerospace, automotive and sports equipment applications, where such properties are desirable.

The basic mechanical properties of flax/epoxy and Kevlar-flax/epoxy composites can be found in \$4.3. This section of the report will mainly focus on the impact characterization of the unidirectional and cross-ply Kevlar-flax/epoxy hybrid composites, and compare their impact characteristics with those of flax/epoxy composite. The goal is to determine the effectiveness of this hybridization on the impact performance of the flax/epoxy composite laminate. 


\subsubsection{GENERAL IMPACT RESPONSE}

The following figure shows the absorbed energy versus impact energy plots for the Kevlarflax/epoxy composites with stack-up sequences of $\left[0_{2 K} / 0_{6 \mathrm{~F}}\right]_{\mathrm{S}}$ and $\left[0_{2 \mathrm{~K}} /(0 / 90)_{3 \mathrm{~F}}\right]_{\mathrm{S}}$, where subscript F stands for Flax, K for Kevlar and S for symmetry. The energy absorption results were plotted against the equal energy line to determine the penetration threshold for each composite laminate. The raw data for the graphs below can be found in the Appendix of this report.

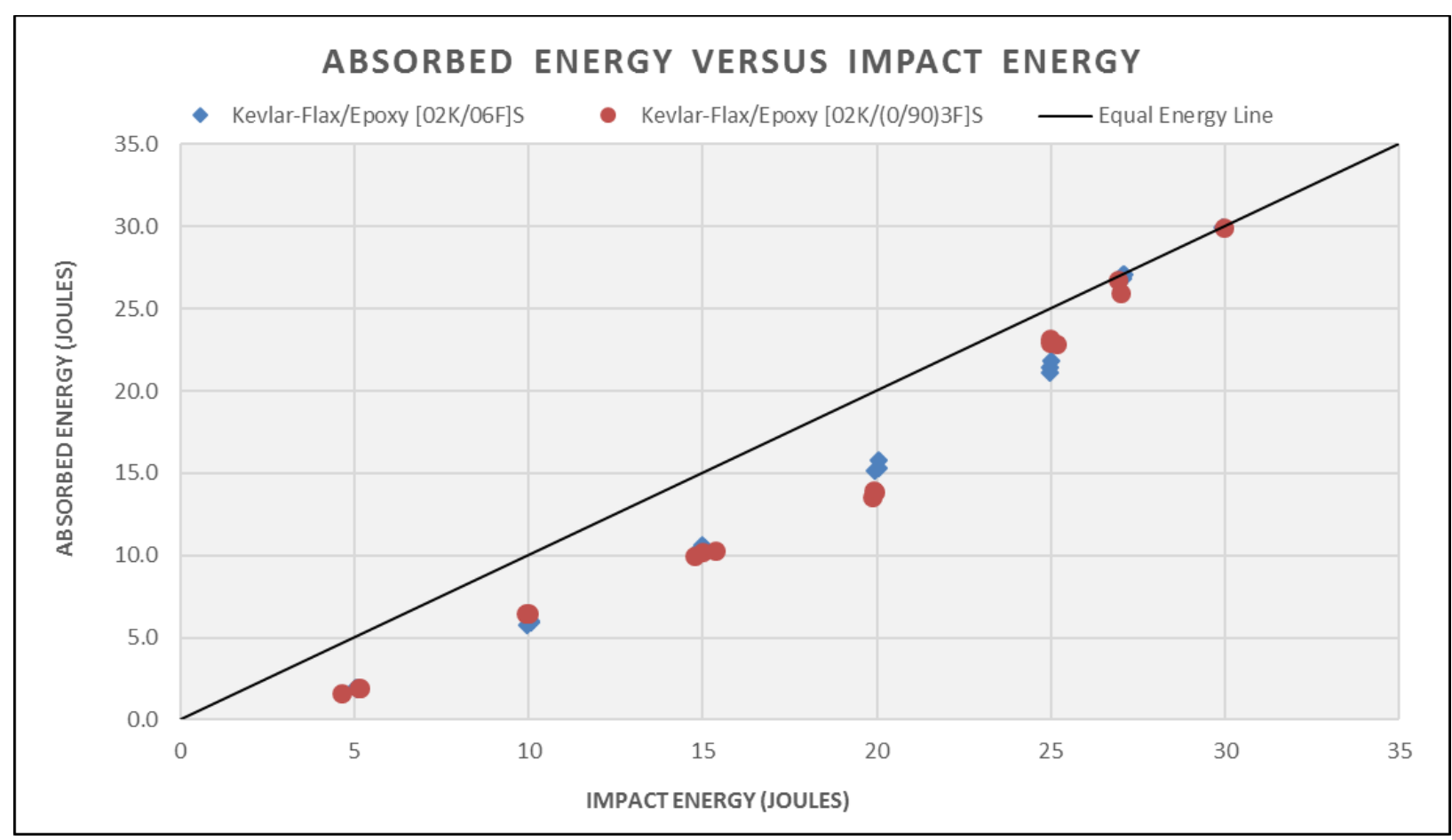

Figure 119: Absorbed energy versus impact energy for Kevlar-flax/Epoxy composite

From the above graphs, it can be observed that the energy absorption characteristic of the $\left[0_{2 \mathrm{~K}} / 0_{6 \mathrm{~F}}\right] \mathrm{s}$ and $\left[0_{2 \mathrm{~K}} /(0 / 90)_{3 \mathrm{~F}}\right]_{\mathrm{S}}$ composite are almost equivalent. Both the unidirectional and crossply Kevlar-flax/epoxy composites reached the energy penetration threshold at $E=27 \mathrm{~J}$. At $E=30$ $\mathrm{J}$, complete perforation of the composites had occurred.

For comparison purposes, the energy absorption results for the hybrid composite were also plotted against those of the pure flax/epoxy composite as shown in Figure 120. From the graph, it can be observed that hybridization with Kevlar 49 had a significant effect to the energy absorption 
capacity of the unidirectional flax/epoxy composite. The penetration energy threshold almost tripled because of hybridization. Moreover, the unidirectional Kevlar-flax did not experience an abrupt increase in absorbed energy as it approached penetration, unlike the pure flax/epoxy composite. This can be attributed to the ductile nature of the Kevlar fibres which allowed the hybrid composite to sustain higher impact load and deflection at a more gradual rate. Hybridization with aramid has a toughening effect on the unidirectional flax/epoxy composite.

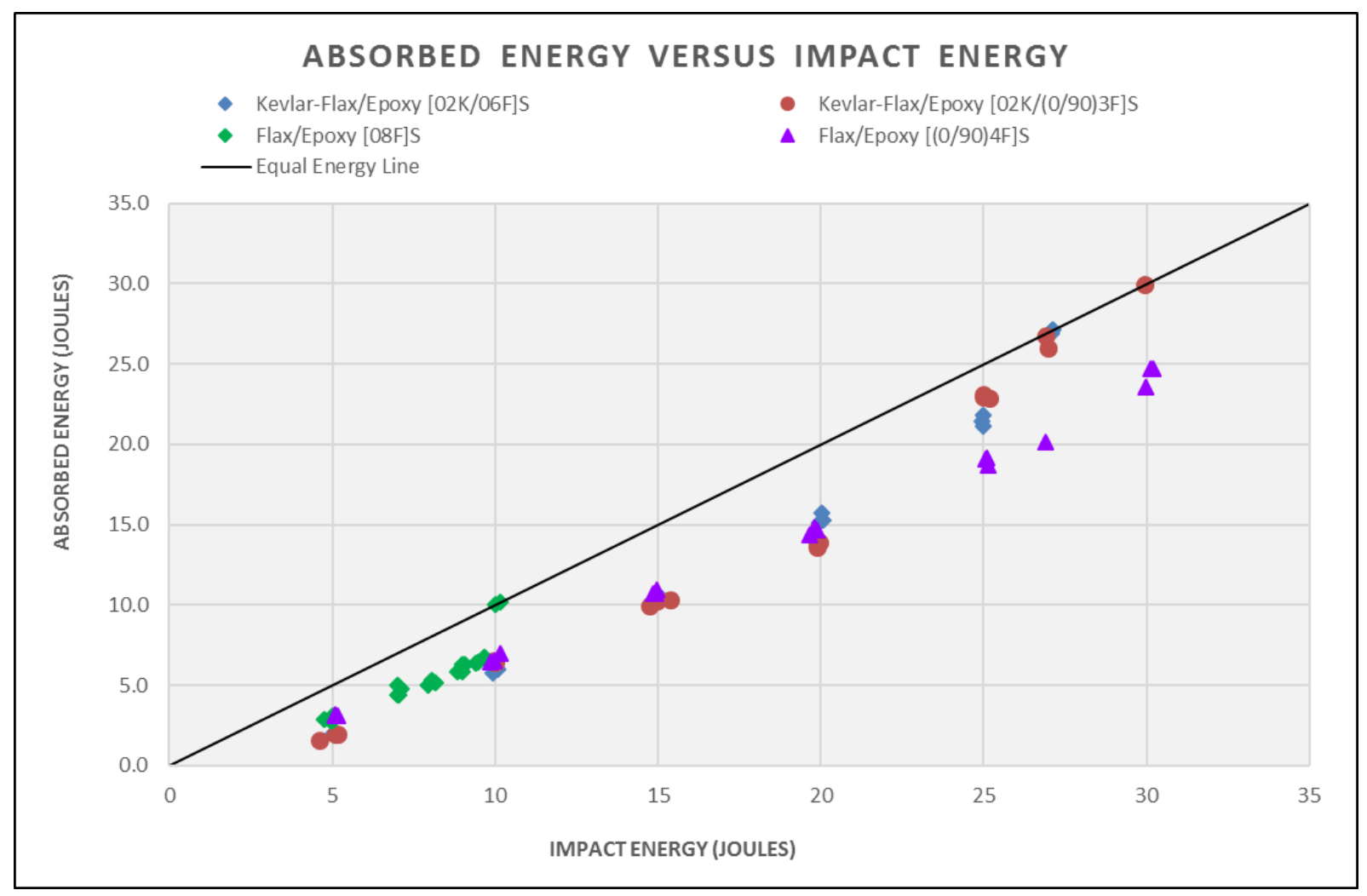

Figure 120: Absorbed vs. impact energy for flax/epoxy and Kevlar-flax/epoxy composite

On the other hand, the effect of hybridization on the cross-ply flax/epoxy composite appeared rather detrimental at first, reducing the penetration energy threshold from $30 \mathrm{~J}$ to $27 \mathrm{~J}$. However, a closer look at the slope of the graph showed the toughening effect of hybridization with Kevlar. The curve for the cross-ply Kevlar-flax composite followed a more gradual approach towards the equal energy penetration line while the curve for the cross-ply flax/epoxy composite appeared to deviate from the equal energy line, which implies the brittle-type behaviour of the 
composite during fracture. This trend is similar to that of the unidirectional flax/epoxy composite, where there was an abrupt increase in absorbed energy as the energy approaches the penetration threshold. This brittle behaviour is inherent to flax/epoxy composites, where the failure mode is fibre-dominant (i.e. quasi-linear, brittle) [11].

Based on these observations, it can be inferred that the impact energy absorption behaviour of the Kevlar-flax/epoxy composites is controlled by the elastic properties of Kevlar rather than those of the flax fibres. The Kevlar 49 fabric is tougher and more ductile than the flax fibres. It has higher strength and can sustain higher strain levels before failure. Furthermore, the woven nature of the Kevlar fabric provided additional strength in both longitudinal and transverse directions, which helped stop the propagation of the matrix cracks in the flax/epoxy layers.

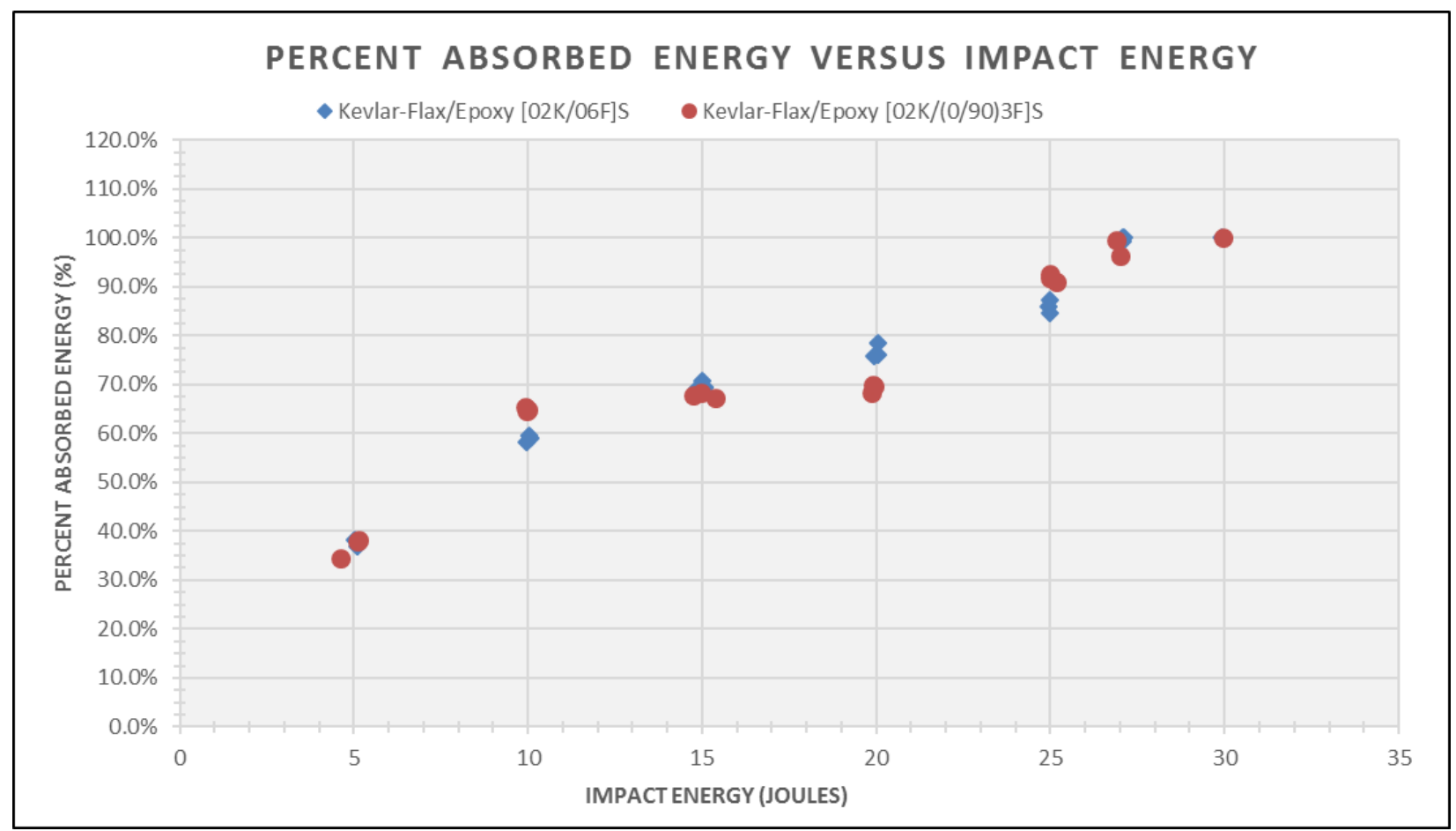

Figure 121: Percent absorbed energy versus impact energy for Kevlar-flax/Epoxy composite 


\subsubsection{Post-Impact Damage Characterization}

\subsubsection{UNIDIRECTIONAL KEVLAR-FLAX/EPOXY COMPOSITE}

Post-impact damage assessment of the Kevlar-flax/epoxy composite was carried out through visual inspection of the front and back face areas. High-resolution photographs of the front and back faces were taken to assess the damage extension at different impact energies. Consistent damage profiles have been observed for all test cases, therefore only one sample per test case is shown. In the images, the direction of the longitudinal (fibre) direction is indicated by an arrow $(\uparrow)$ symbol on the lower left corner of the images.
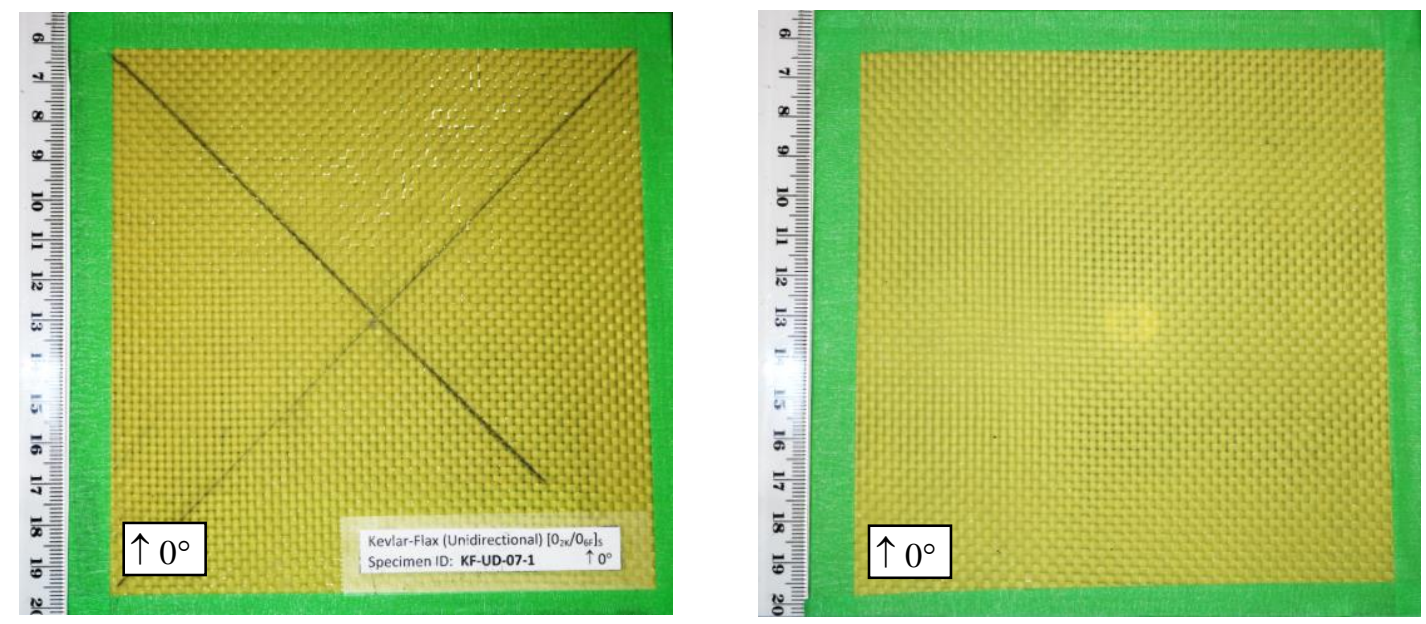

Figure 122: Front face (left); back face damage (right) for $\left[0_{2 \mathrm{~K}} / 0_{6 \mathrm{~F}}\right]_{\mathrm{S}}$ at $\mathrm{E}=\mathbf{5} \mathrm{J}$
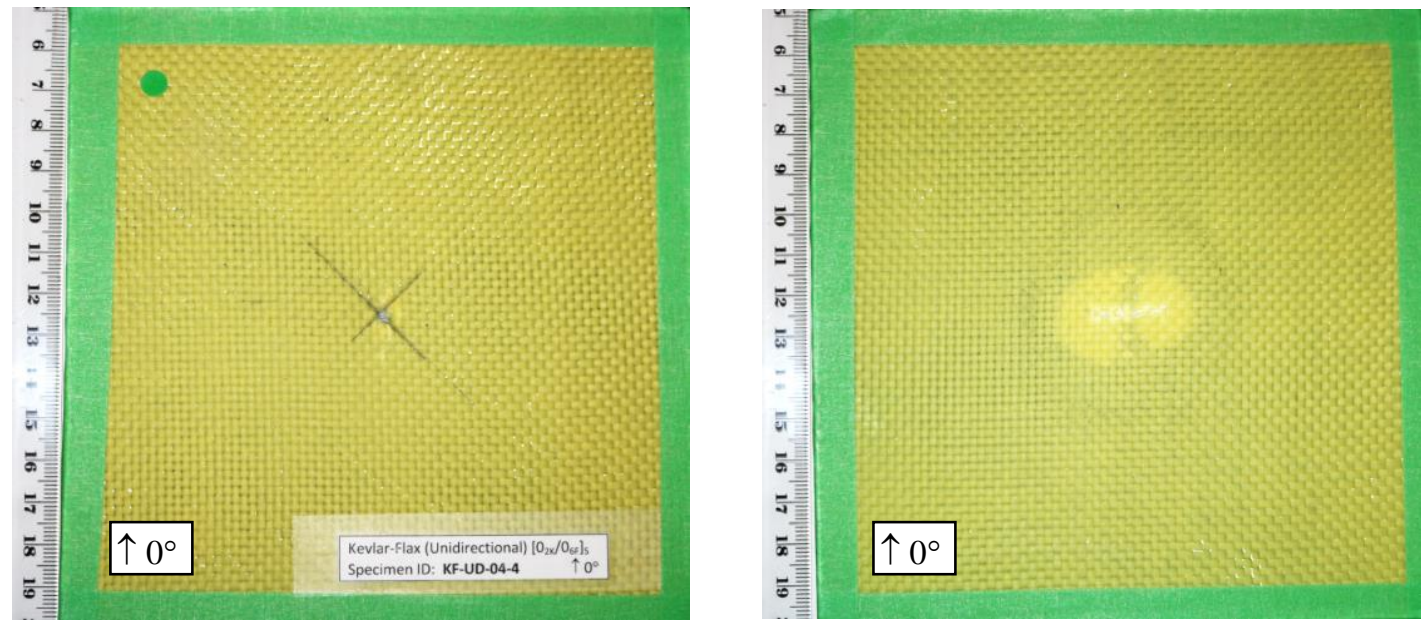

Figure 123: Front face (left); back face damage (right) for $\left[0_{2 \mathrm{~K}} / 0_{6 \mathrm{~F}}\right]_{\mathrm{S}}$ at $\mathrm{E}=10 \mathrm{~J}$ 

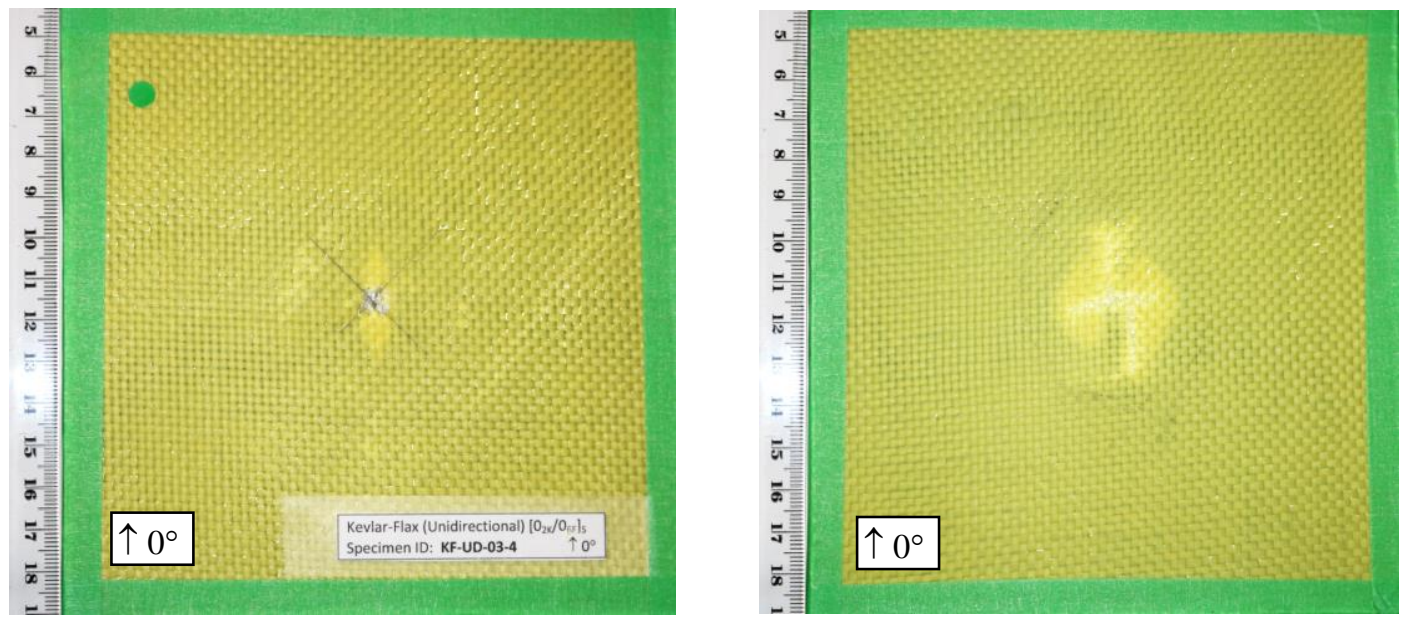

Figure 124: Front face (left); back face damage (right) for $\left[0_{2 \mathrm{~K}} / 0_{6 \mathrm{~F}}\right]_{\mathrm{s}}$ at $\mathrm{E}=15 \mathrm{~J}$
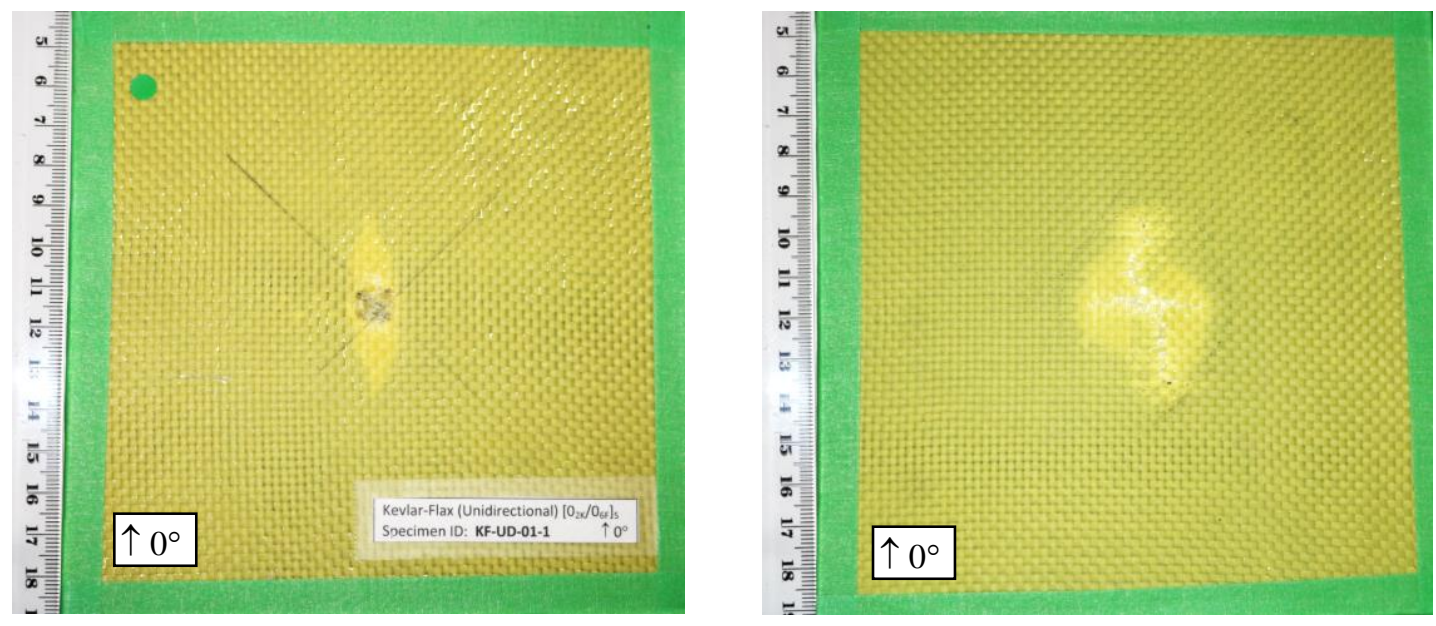

Figure 125: Front face (left); back face damage (right) for $\left[0_{2 \mathrm{~K}} / 0_{6 \mathrm{~F}}\right]_{\mathrm{S}}$ at $\mathrm{E}=\mathbf{2 0} \mathrm{J}$
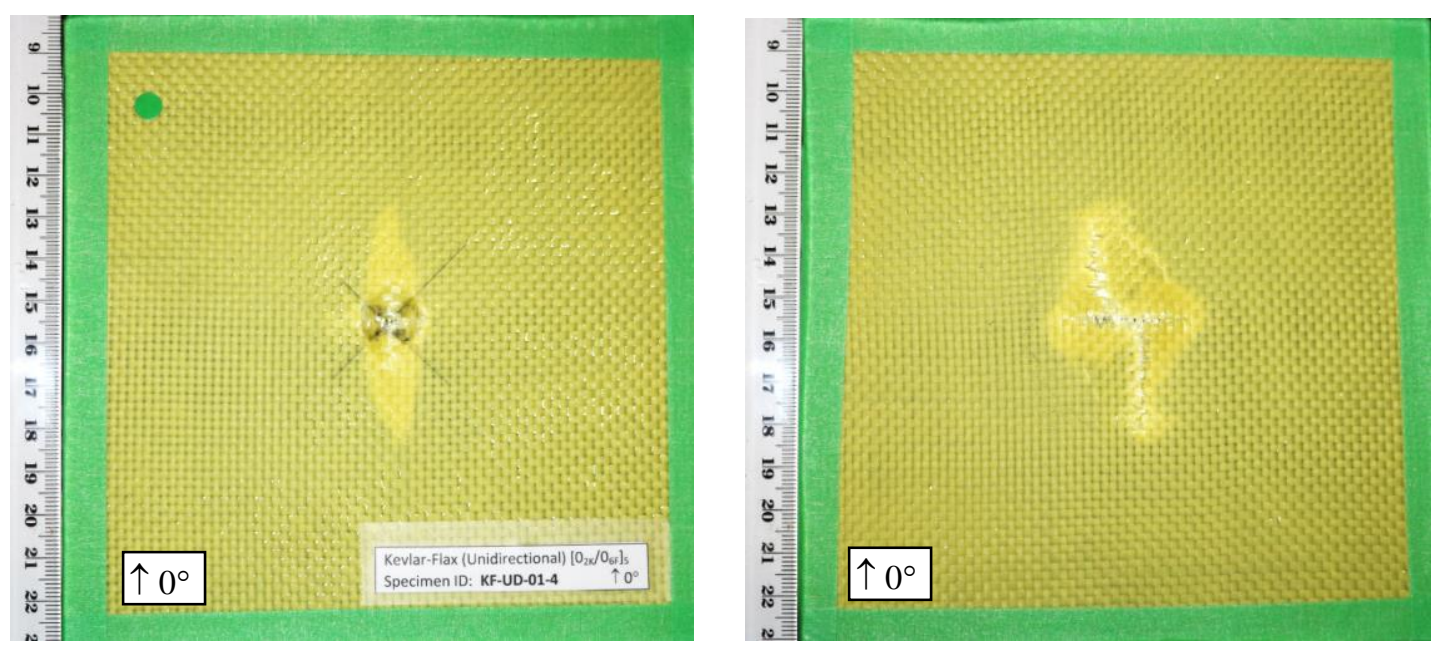

Figure 126: Front face (left); back face damage (right) for $\left[0_{2 \mathrm{~K}} / 0_{6 \mathrm{~F}}\right]_{\mathrm{S}}$ at $\mathrm{E}=\mathbf{2 5} \mathrm{J}$ 

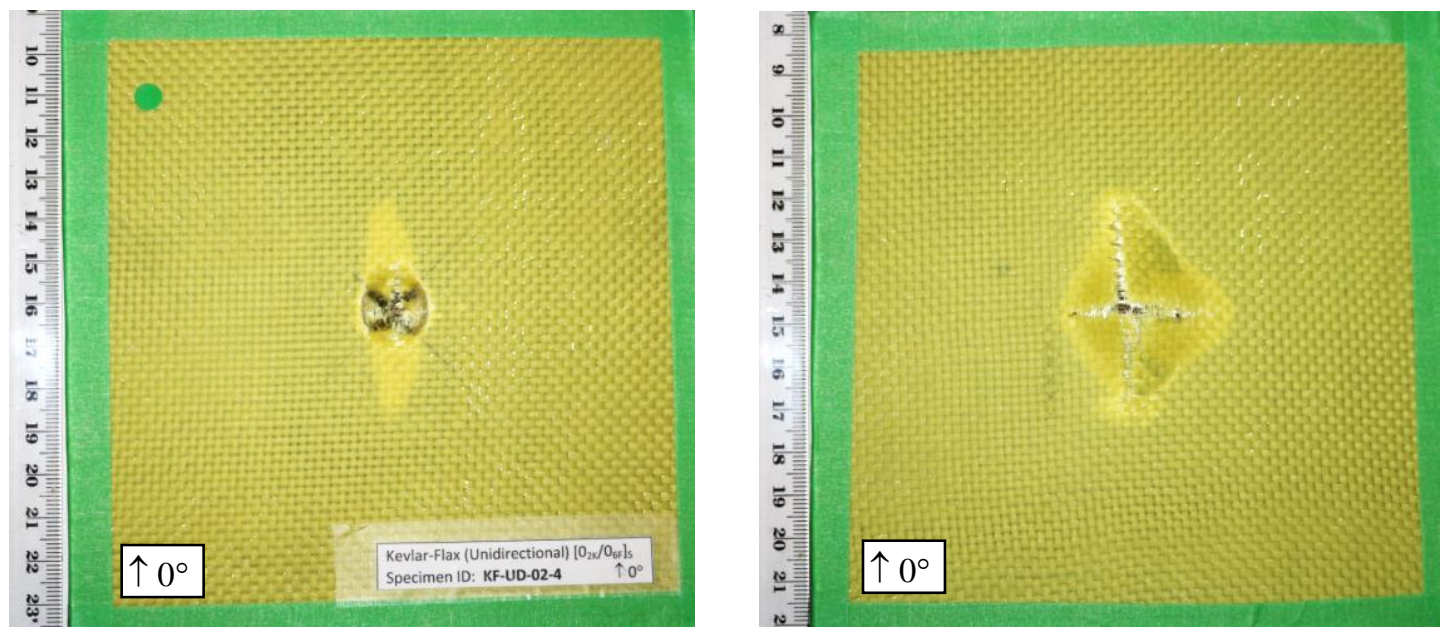

Figure 127: Front face (left); back face damage (right) for $\left[0_{2 \mathrm{~K}} / \mathbf{0}_{6 \mathrm{~F}}\right]_{\mathrm{S}}$ at $\mathrm{E}=\mathbf{2 7} \mathrm{J}$
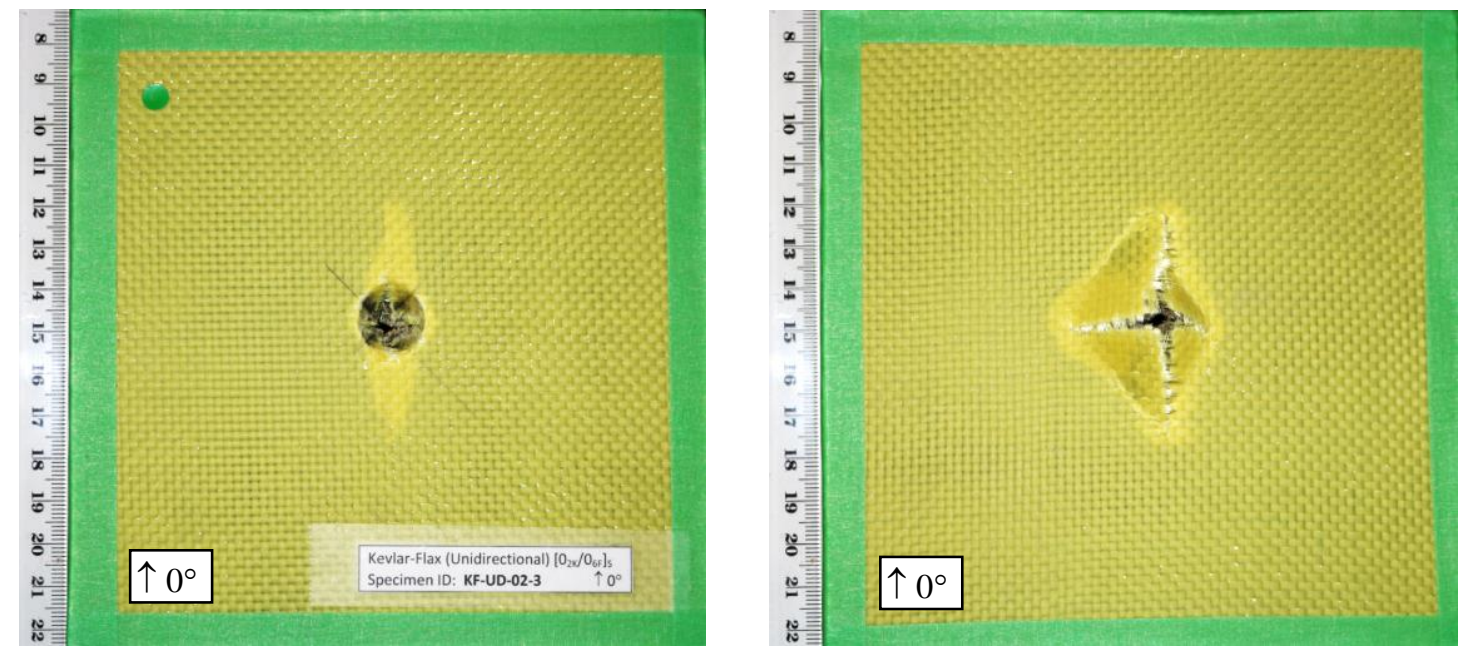

Figure 128: Front face (left); back face damage (right) for $\left[0_{2 K} / 0_{6 F}\right]_{s}$ at $E=30 \mathrm{~J}$

Post-impact visual inspection showed that the damage on the unidirectional Kevlarflax/epoxy composite consisted of delamination, fibre breakage and fibre pull-out. At $\mathrm{E}=5 \mathrm{~J}$, the damage on the back face can be observed as a small whitish elliptical spot of a few millimeters in diameter. No fibre failure was observed, indicating that the damage was most likely in the form of matrix deformation. This behaviour is consistent with brittle polymer matrices where the energy required for matrix deformation is small [12]. At $\mathrm{E}=10 \mathrm{~J}$, the size of the damage became more prominent in the form of an elliptical-shaped delamination area, with its major axis normal to the longitudinal direction of the composite. A central transverse crack was also observed in the outer Kevlar layer, which was caused by fibre breakage in the warp Kevlar yarns. 
At impact energies between $15 \mathrm{~J}$ and $25 \mathrm{~J}$, the delamination area expanded in the form of a rounded rhombus. An additional crack also emanated at the center of impact, which was caused by fibre breakage in the weft Kevlar yarns. At penetration, the composite fractured along the longitudinal and transverse cracks. The primary modes of failure in the Kevlar plies were fibre breakage and delamination. The delamination was caused by the high interlaminar shear stresses generated at the Kevlar-flax interface, due to the difference in the stiffness between the two materials.

On the front face, the damage consisted of indentation damage and delamination. Unlike the pure flax/epoxy composite, no matrix cracking was observed on the outer front plies. The impact energy was rather absorbed by the Kevlar plies in a more compliant manner through the formation of an indentation damage in the shape of the impactor tip.

\subsubsection{CROSS-PLY KEVLAR-FLAX/EPOXY COMPOSITE}

The next set of figures show the front face and back face damages to the cross-ply Kevlarflax/epoxy composites post-impact. Consistent damage profile has been observed for all test cases, therefore only one sample per test case is shown.
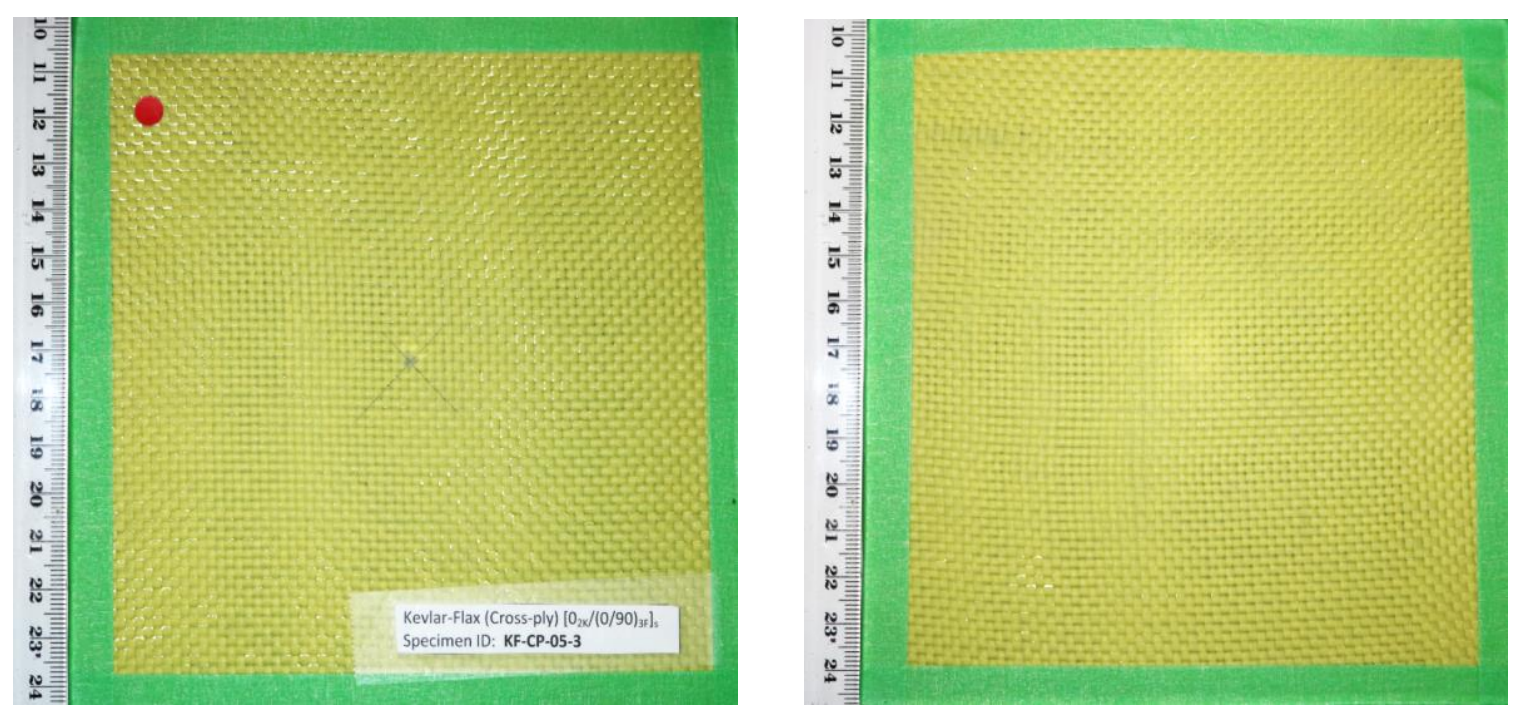

Figure 129: Front face (left); back face damage (right) for $\left[0_{2 K} /(0 / 90)_{3 F}\right]_{s}$ at $E=5 \mathrm{~J}$ 

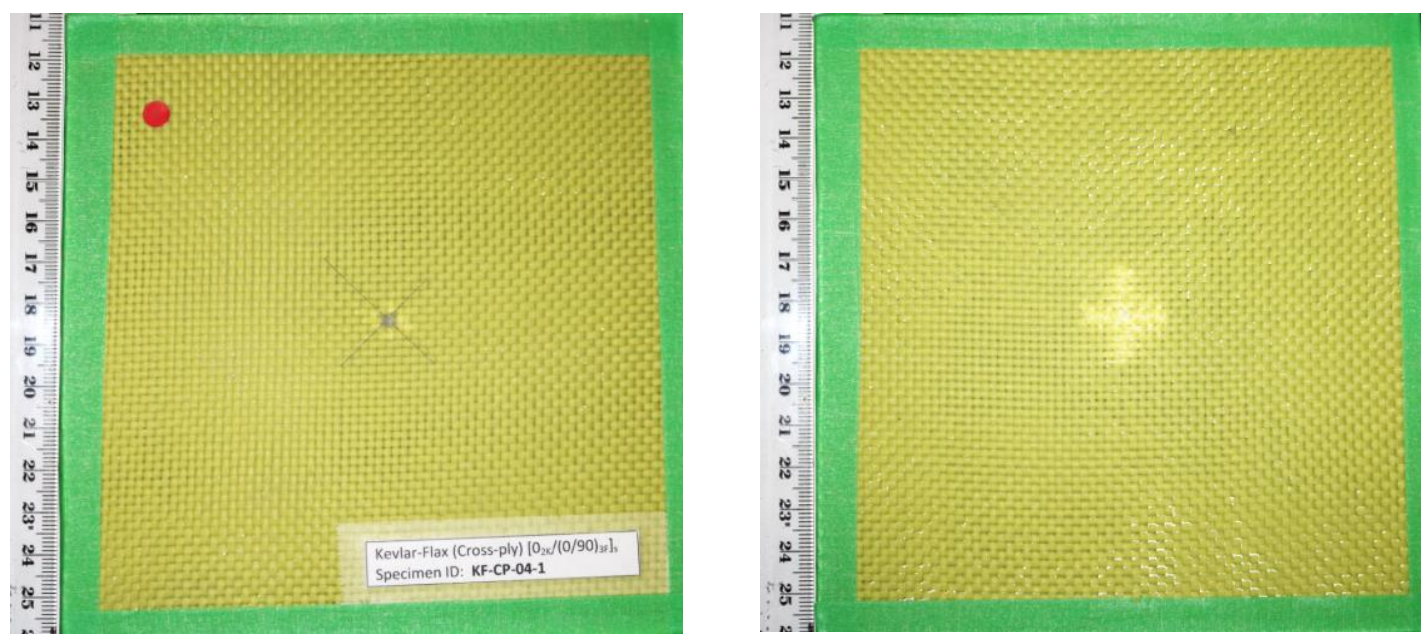

Figure 130: Front face (left); back face damage (right) for $\left[0_{2 \mathrm{~K}} /(0 / 90)_{3 \mathrm{~F}}\right]_{\mathrm{S}}$ at $\mathrm{E}=10 \mathrm{~J}$
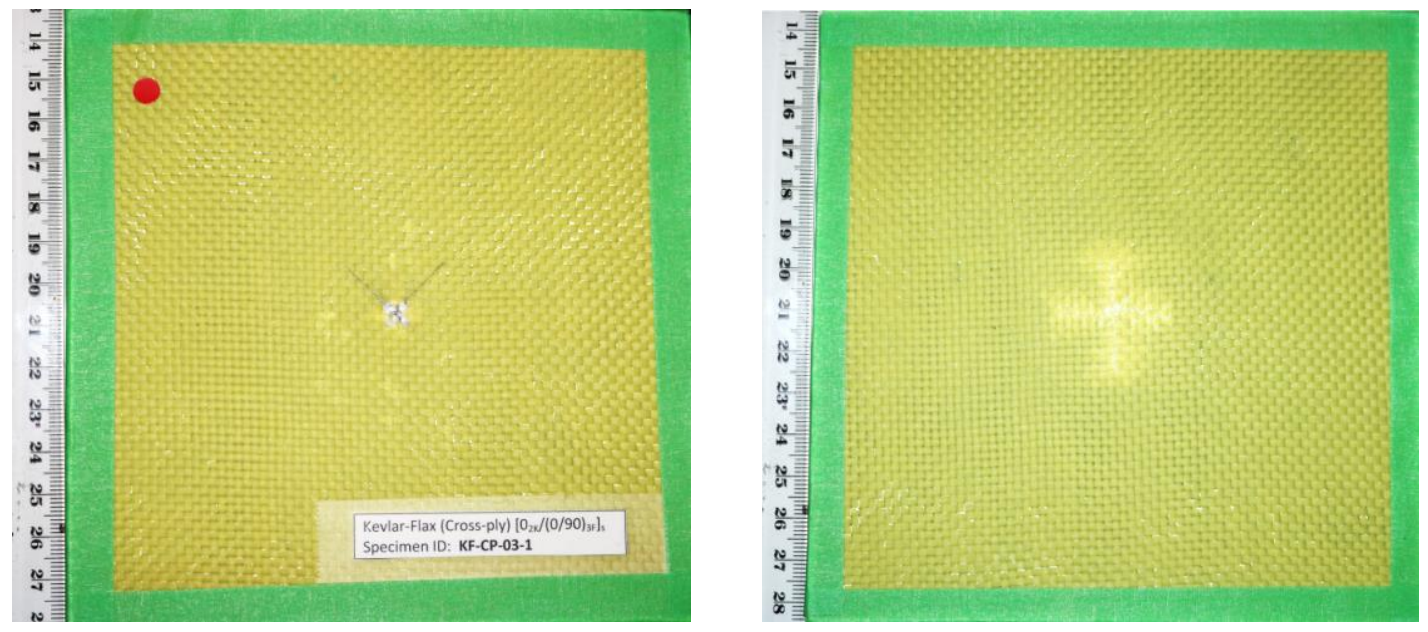

Figure 131: Front face (left); back face damage (right) for $\left[0_{2 \mathrm{~K}} /(0 / 90)_{3 \mathrm{~F}}\right]_{\mathrm{s}}$ at $\mathrm{E}=15 \mathrm{~J}$
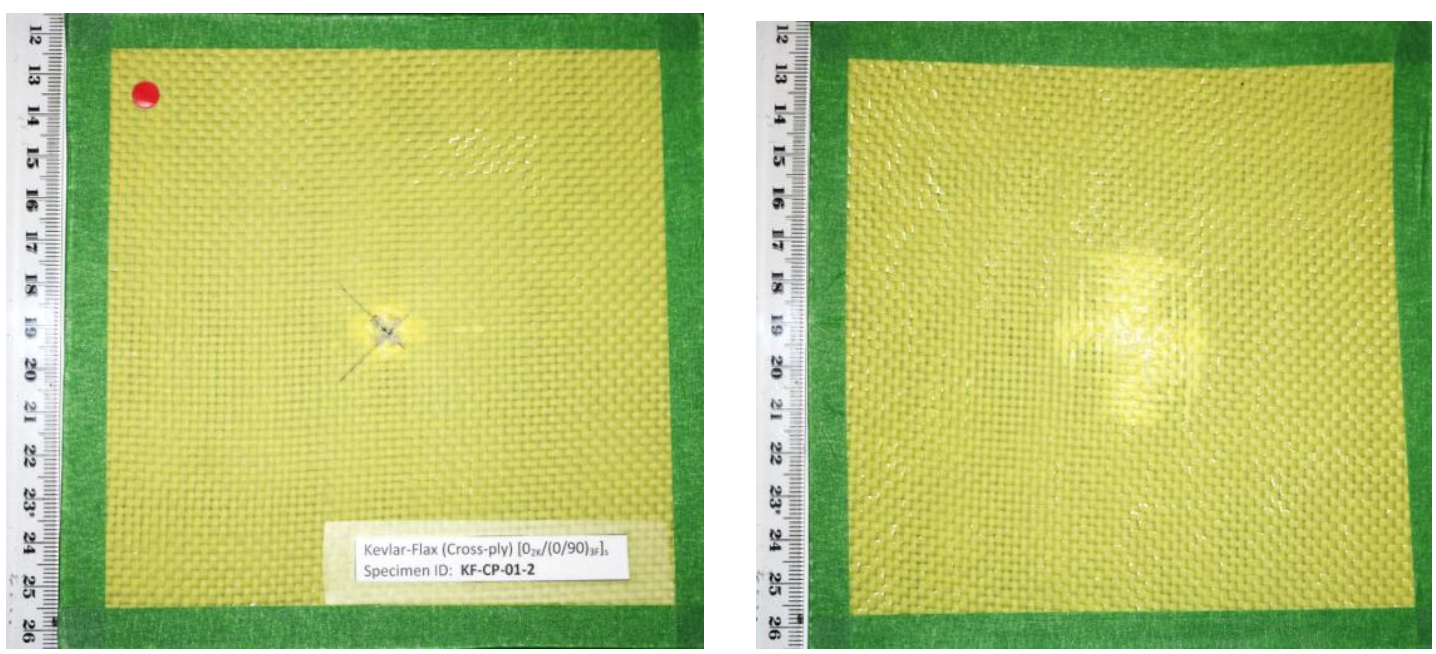

Figure 132: Front face (left); back face damage (right) for $\left[0_{2 \mathrm{~K}} /(0 / 90)_{3 \mathrm{~F}}\right]_{\mathrm{S}}$ at $\mathrm{E}=\mathbf{2 0} \mathrm{J}$ 

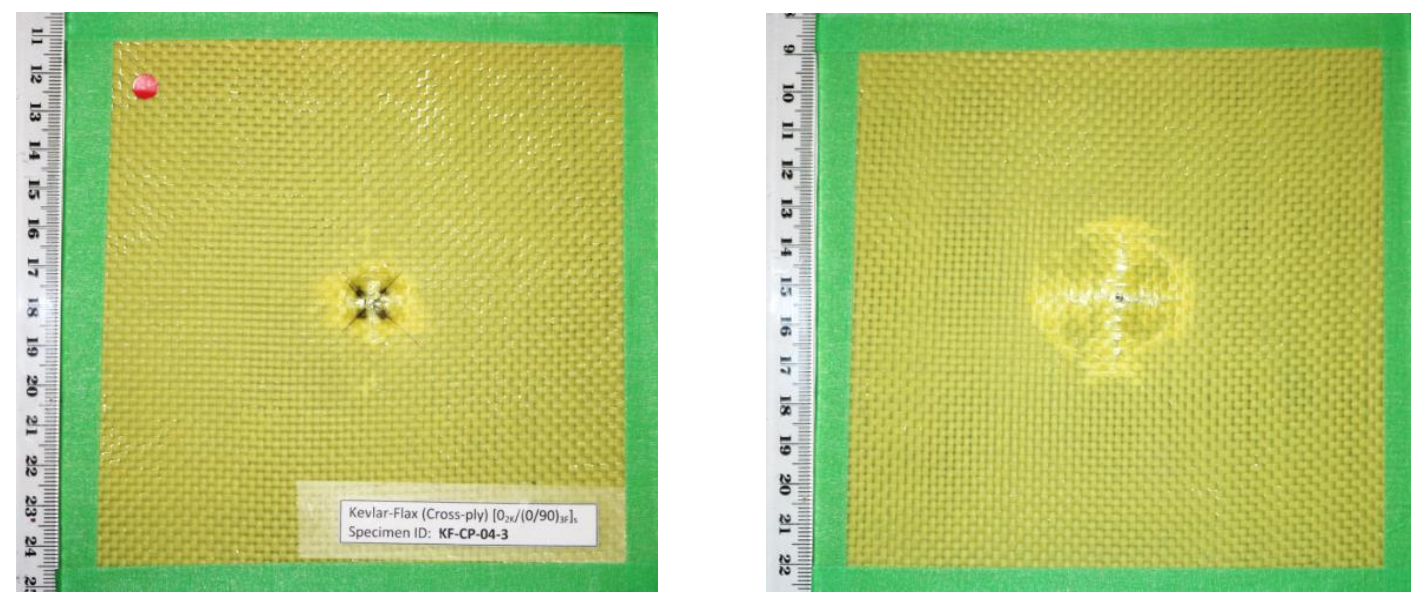

Figure 133: Front face (left); back face damage (right) for $\left[0_{2 \mathrm{~K}} /(0 / 90)_{3 \mathrm{~F}}\right]_{\mathrm{S}}$ at $\mathrm{E}=25 \mathrm{~J}$
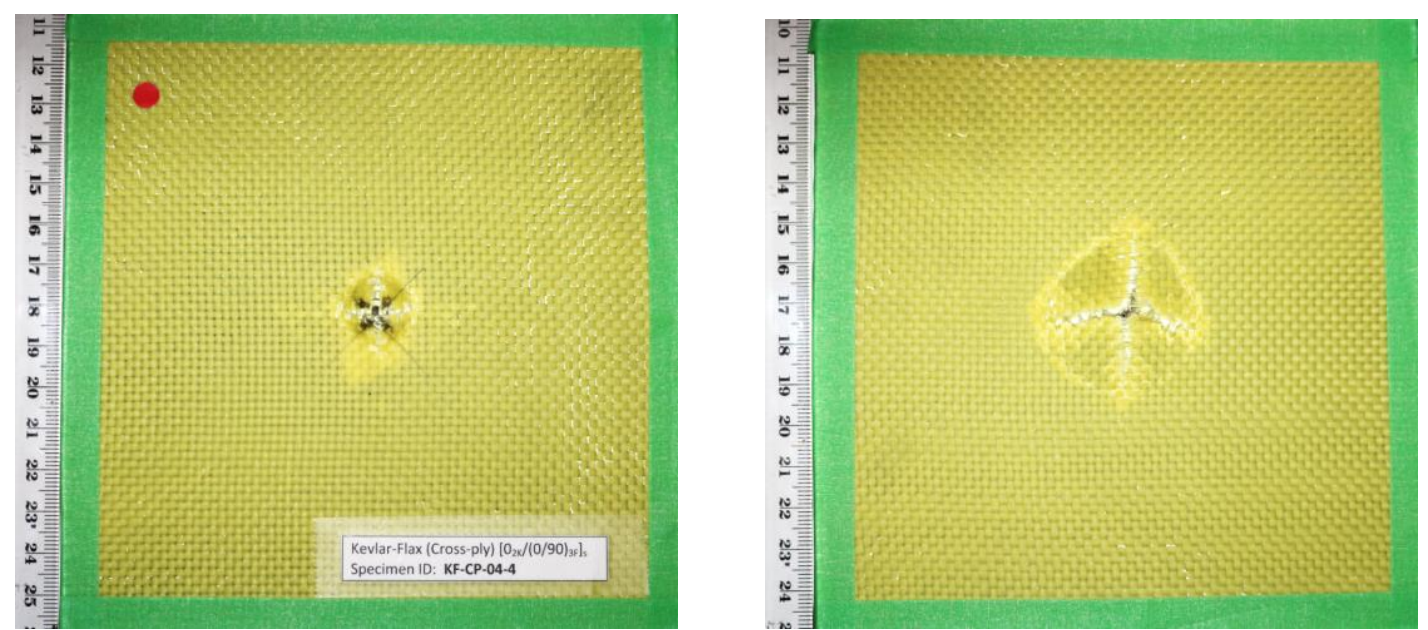

Figure 134: Front face (left); back face damage (right) for $\left[0_{2 \mathrm{~K}} /(0 / 90)_{3 \mathrm{~F}}\right]_{\mathrm{S}}$ at $\mathrm{E}=27 \mathrm{~J}$
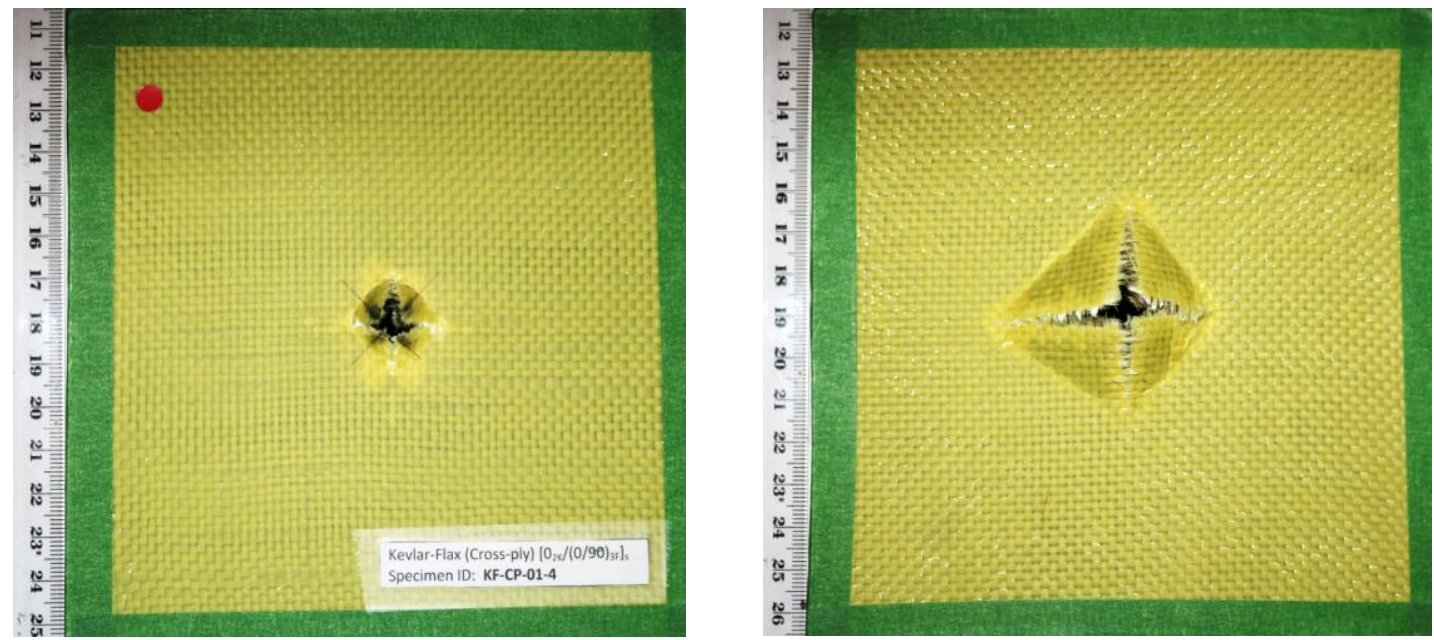

Figure 135: Front face (left); back face damage (right) for $\left[0_{2 \mathrm{~K}} /(0 / 90)_{3 \mathrm{~F}}\right]_{\mathrm{s}}$ at $\mathrm{E}=30 \mathrm{~J}$ 
Post-impact visual inspection showed that the damage on the cross-ply Kevlar-flax/epoxy composite consisted of delamination and fibre breakage. The damage is in the shape of a cross, similar to that of the cross-ply flax/epoxy composite. The main difference between the Kevlar-flax and flax/epoxy composites is that the crack length of the former is much shorter than the latter. It is also accompanied by a cross-shaped delamination zone due to the high interlaminar shear stresses developed in the Kevlar-flax interface.

At $\mathrm{E}=5 \mathrm{~J}$, the damage on the back face was small and barely visible to the naked eye. It can be observed as a small whish spot on the back face of the composite. At $\mathrm{E}=10 \mathrm{~J}$, damage became more visible in the form of a symmetrical cross. Evidence of fibre breakage in the Kevlar fibres can be observed, accompanied by delamination damage. At impact energies between $15 \mathrm{~J}$ to $25 \mathrm{~J}$, the delamination area expanded in the form of a rounded rhombus. The crack started to open in Mode I fracture due to the increasing plate curvature. At E = 27 J, the crack completely opened as the impactor penetrated the composite.

\subsubsection{BACK FACE IMPACT DAMAGE AREA MEASUREMENT}

A plot of the back-face damage area versus impact energy is shown in Figure 140. The back-face damage area was measured using ImageJ software. It is an open source image processing program designed for scientific multi-dimensional images [68]. The damage area was measured by first taking a high-resolution photograph of the back face, converting the images into an RGB stack format and adjusting the color threshold to isolate the damage area from the rest of the image.
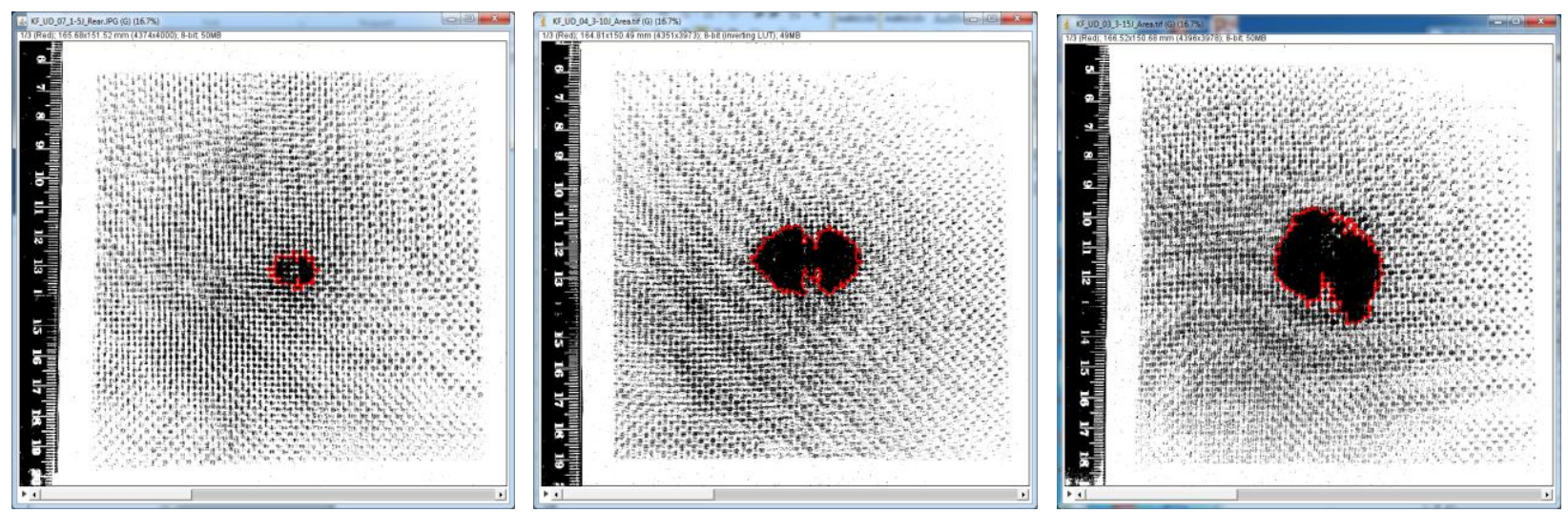

Figure 136: Image J thresholding for $\left[0_{2 \mathrm{~K}} / 0_{6 \mathrm{~F}}\right]_{\mathrm{S}}$ impacted at $\mathrm{E}=5 \mathrm{~J}, 10 \mathrm{~J}$ and $15 \mathrm{~J}$ 

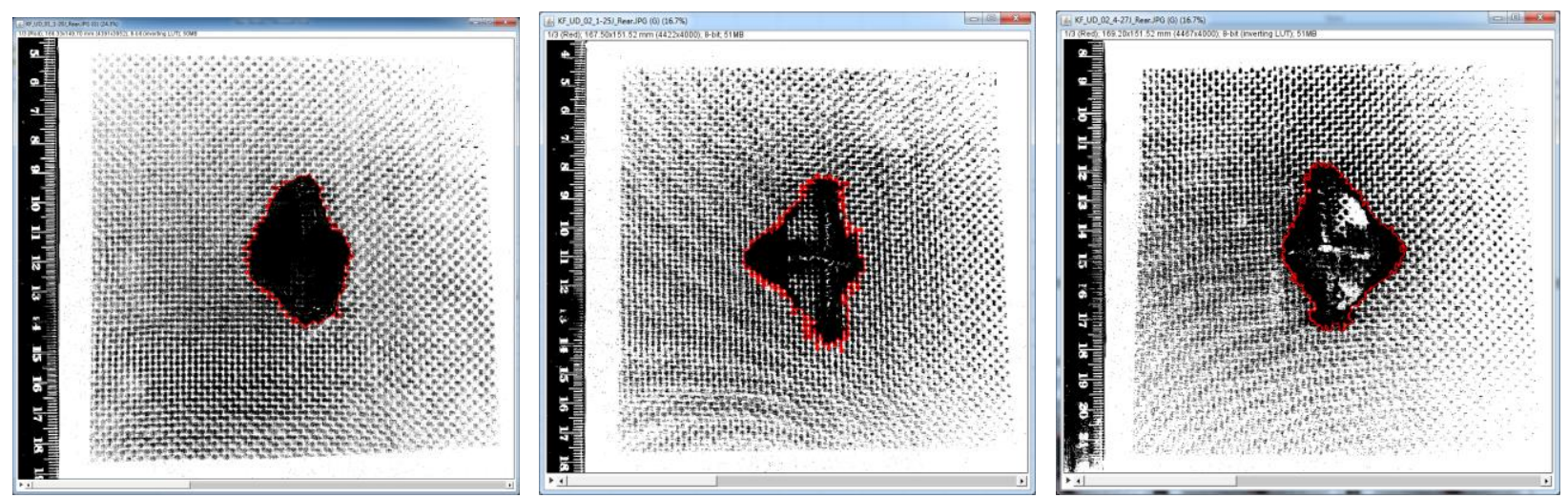

Figure 137: Image J thresholding for $\left[0_{2 \mathrm{~K}} / 0_{6 \mathrm{~F}}\right]_{\mathrm{S}}$ impacted at $\mathrm{E}=20 \mathrm{~J}, 25 \mathrm{~J}$ and $27 \mathrm{~J}$
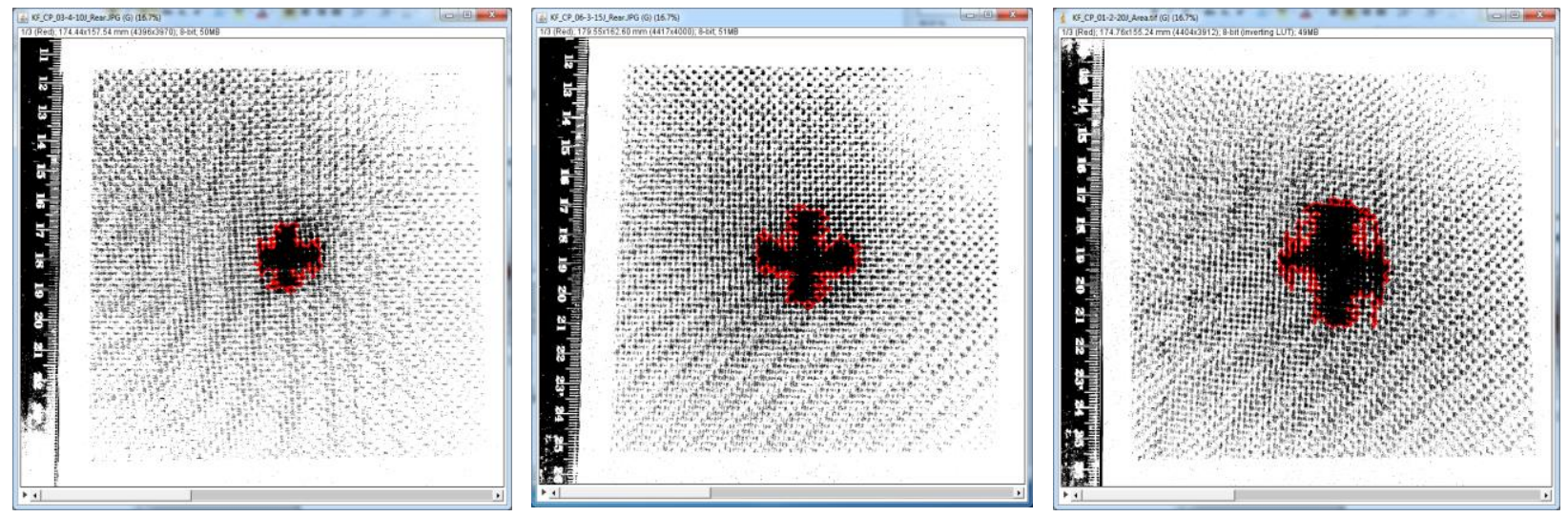

Figure 138: Image J thresholding for $\left[0_{2 \mathrm{~K}} /(0 / 90)_{3 \mathrm{~F}}\right]_{\mathrm{S}}$ impacted at $\mathrm{E}=10 \mathrm{~J}, 15 \mathrm{~J}$ and $20 \mathrm{~J}$
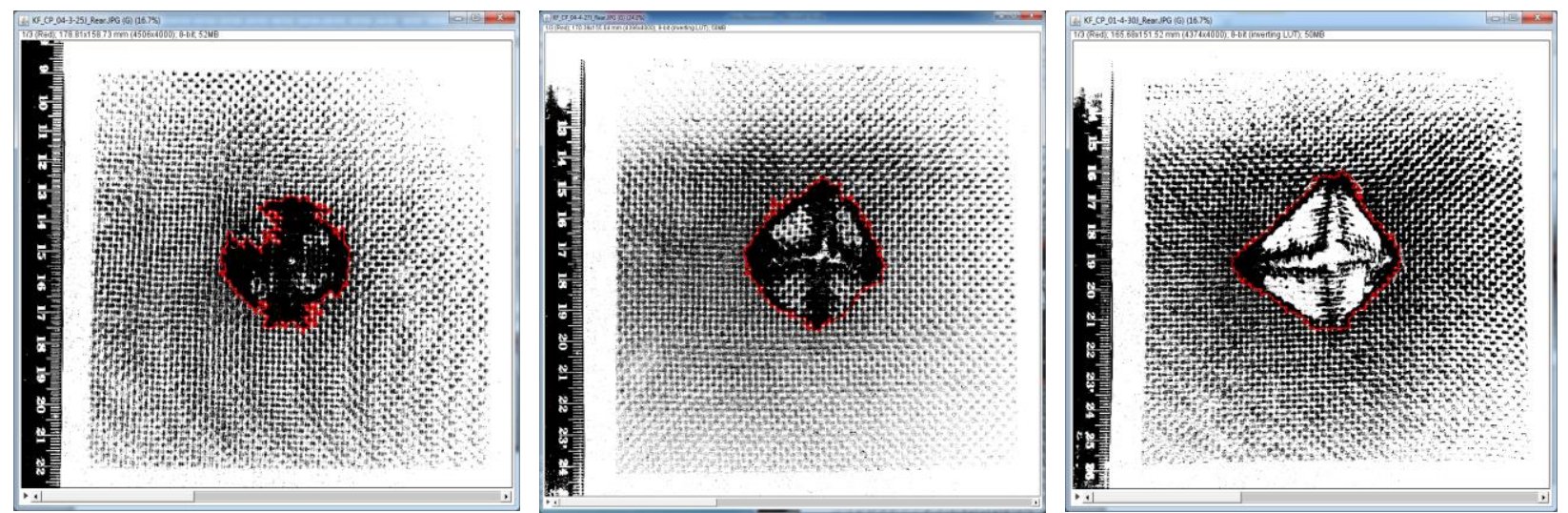

Figure 139: Image $\mathrm{J}$ thresholding for $\left[0_{2 \mathrm{~K}} /(0 / 90)_{3 \mathrm{~F}}\right]_{\mathrm{s}}$ impacted at $\mathrm{E}=25 \mathrm{~J}, 27 \mathrm{~J}$ and $30 \mathrm{~J}$

From the plot of the back-face damage area versus impact energy in Figure 140, it can be observed that the damage area on the unidirectional Kevlar-flax/epoxy composite is generally larger than that of the cross-ply Kevlar-flax/epoxy composite. As the impact energy approached 
the penetration threshold, the damage areas on both composites converged to the same value because the composites fractured in similar mode of failure.

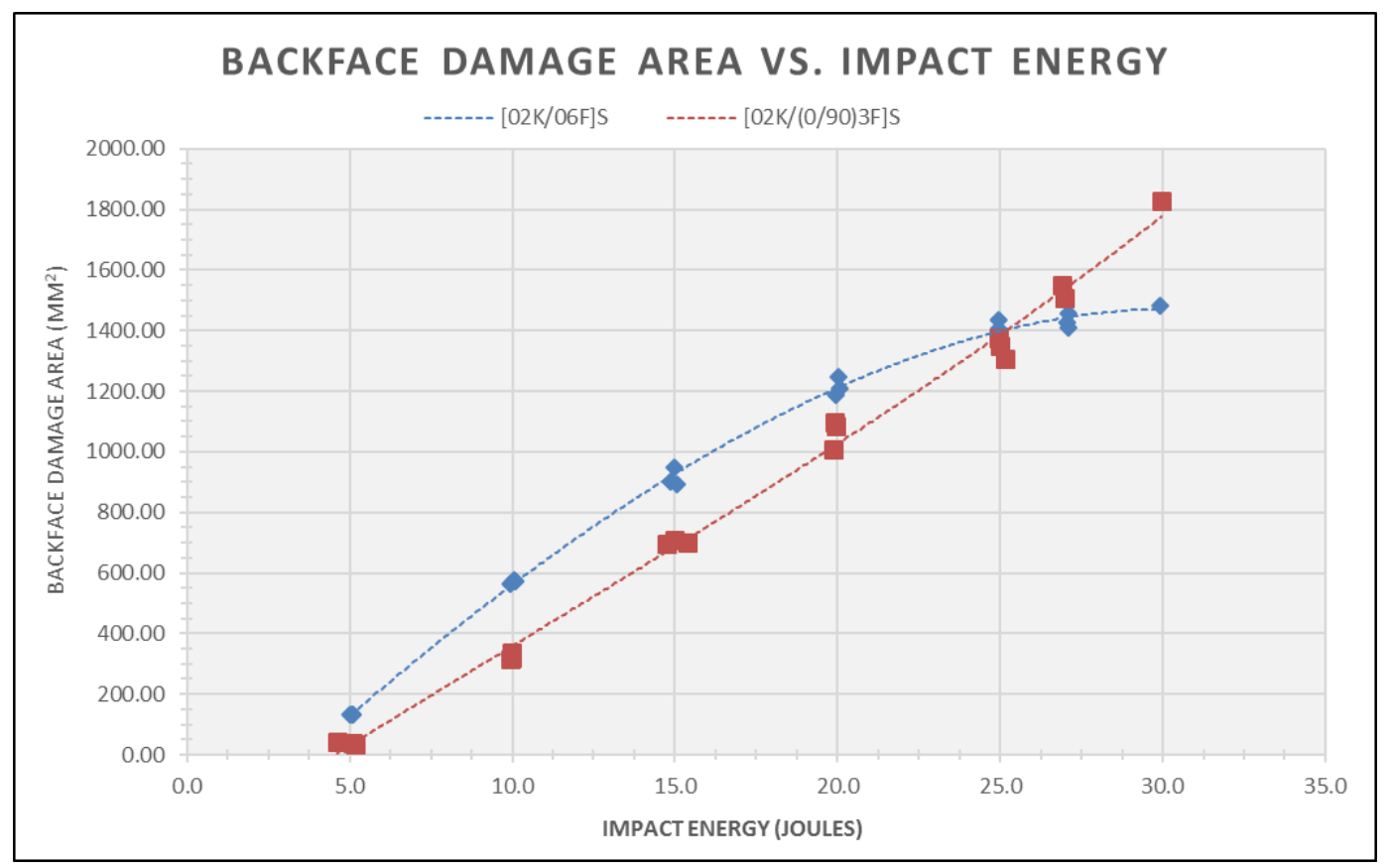

Figure 140: Back-face damage area vs. impact energy for the Kevlar-flax/epoxy composite

\subsubsection{DAMAGE COMPARISON BETWEEN FLAX/EPOXY AND KEVLAR-FLAX/EPOXY}

The following figure shows a comparison of the back-face damage profile between the flax and the Kevlar-flax/epoxy composite. Only selected test cases are shown for comparison purposes.
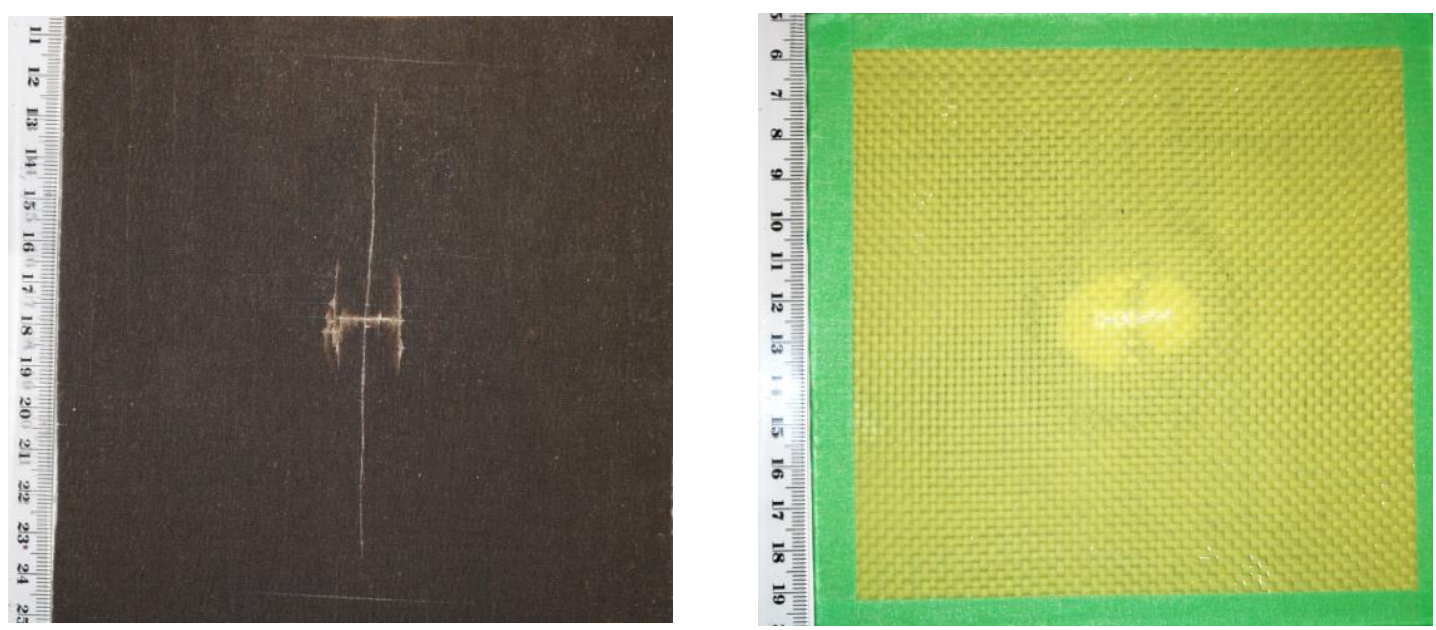

Figure 141: Back face damage to $\left[0_{8 \mathrm{~F}}\right]_{\mathrm{S}}$ at $\mathrm{E}=9.5 \mathrm{~J}$ and $\left[0_{2 \mathrm{~K}} / 0_{6 \mathrm{~F}}\right]_{\mathrm{S}}$ at $\mathrm{E}=10 \mathrm{~J}$ 

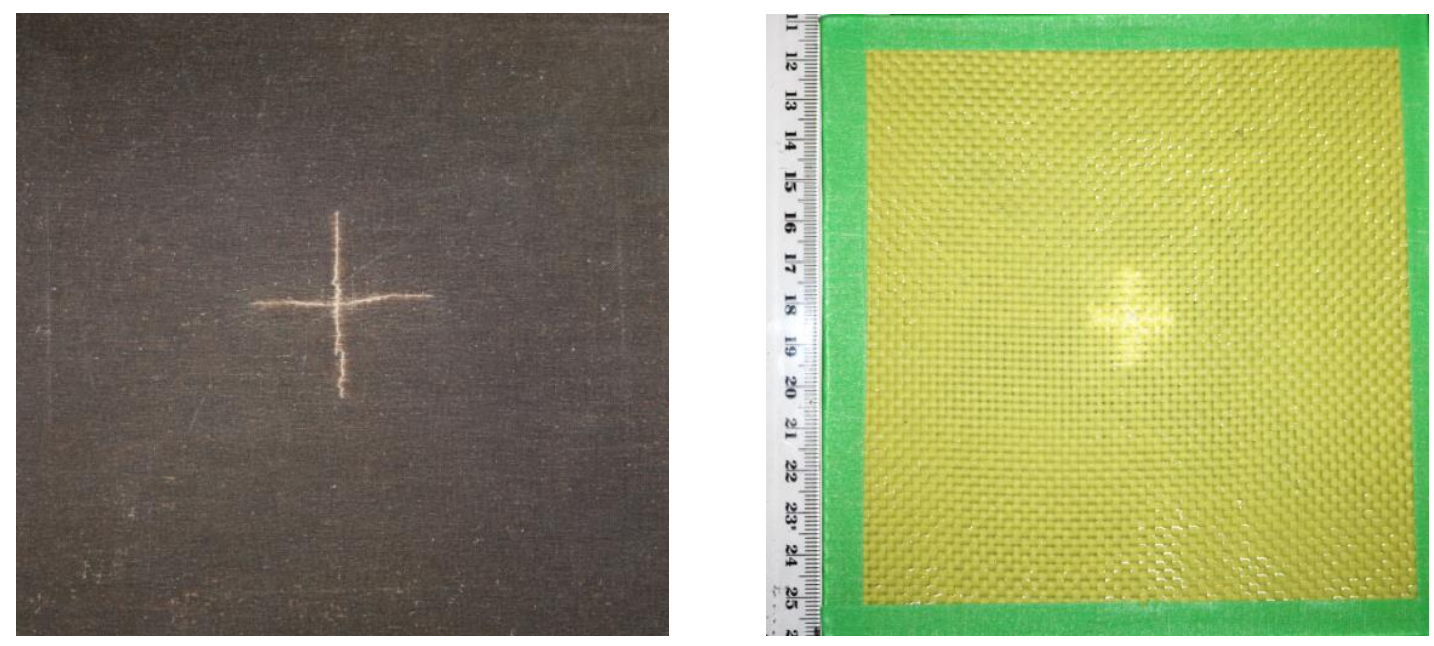

Figure 142: Back face damage to $\left[(0 / 90)_{4 F}\right]_{S}$ and $\left[0_{2 K} /(0 / 90)_{3 F}\right]_{S}$ at $E=10 \mathrm{~J}$
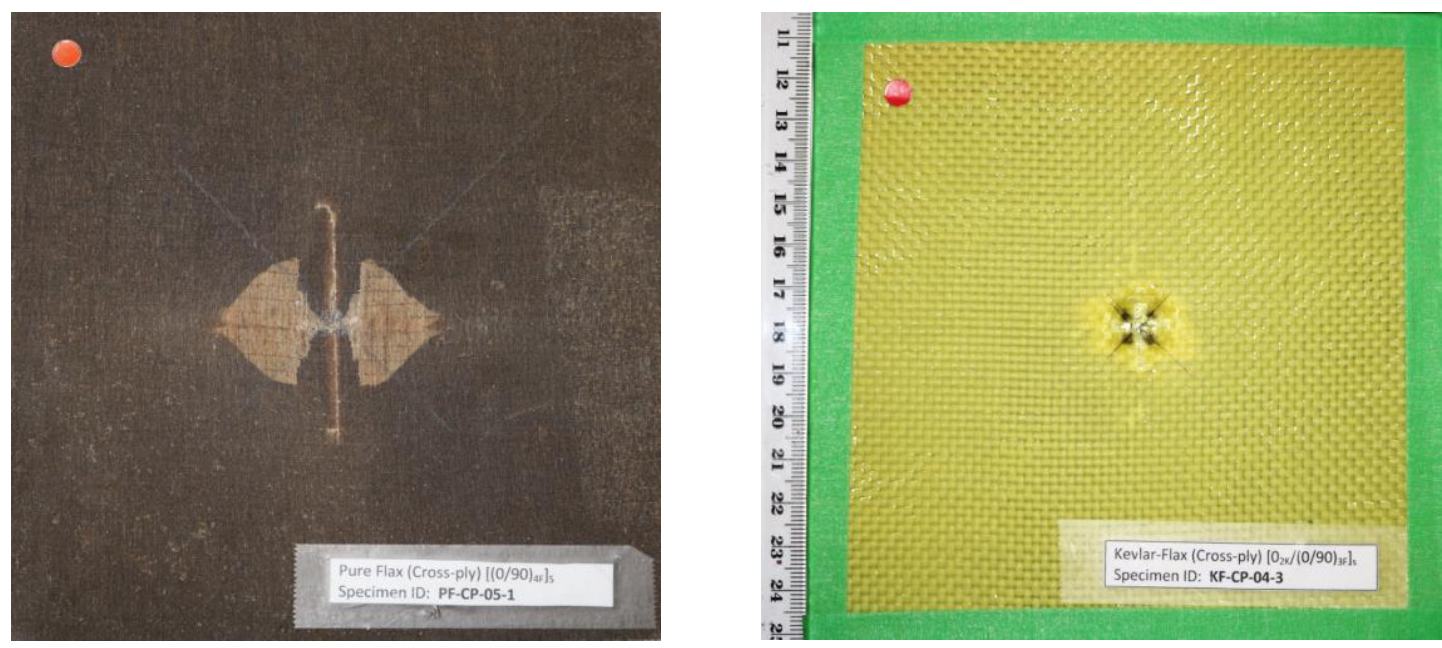

Figure 143: Front face damage to $\left[(0 / 90)_{4 \mathrm{~F}}\right]_{\mathrm{S}}$ and $\left[0_{2 \mathrm{~K}} /(0 / 90)_{3 \mathrm{~F}}\right]_{\mathrm{S}}$ at $\mathrm{E}=25 \mathrm{~J}$
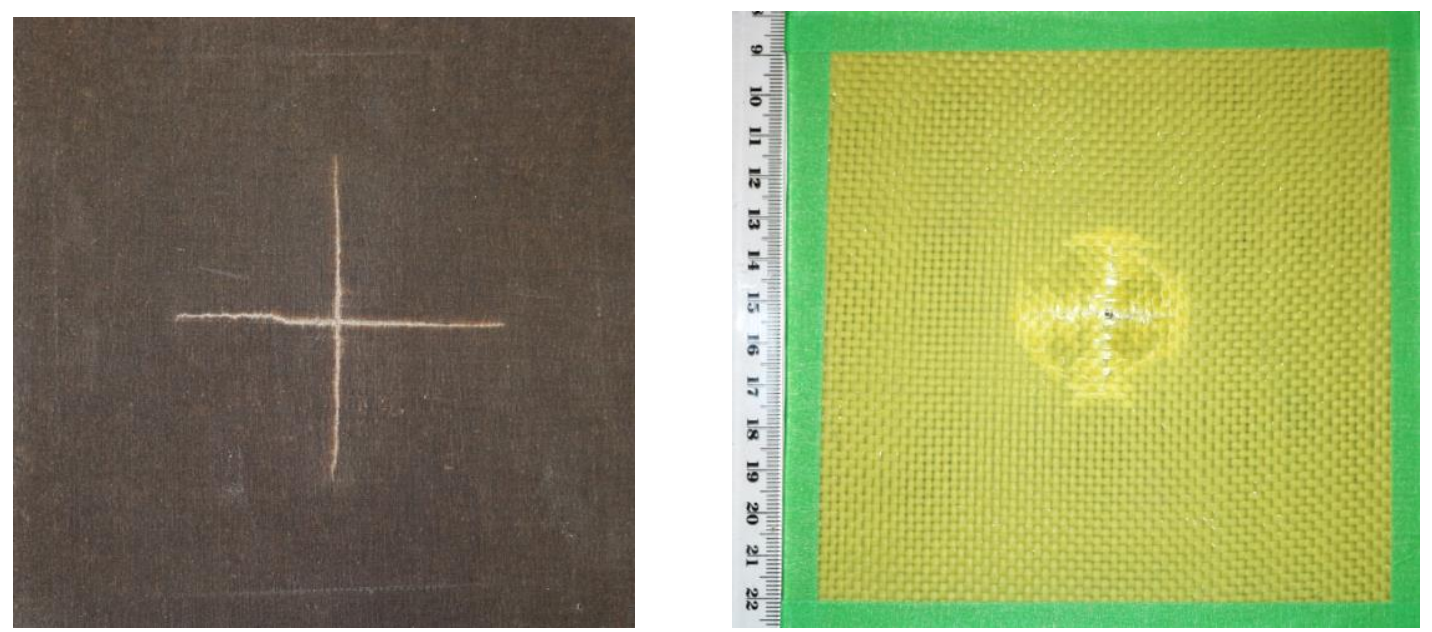

Figure 144: Front face damage to $\left[(0 / 90)_{4 \mathrm{~F}}\right]_{\mathrm{S}}$ and $\left[0_{2 \mathrm{~K}} /(0 / 90)_{3 \mathrm{~F}}\right]_{\mathrm{S}}$ at $\mathrm{E}=25 \mathrm{~J}$ 
It can be observed from the results that by hybridizing Kevlar fibres, we were able to improve the impact performance of the flax/epoxy composite. The presence of Kevlar layers mitigated propagation of the longitudinal matrix crack in the unidirectional flax/epoxy composite. Instead of matrix crack propagation, the absorbed energy was rather spent in the formation of delamination damage in the Kevlar-flax interface. For the cross-ply hybrid composite, the presence of Kevlar layers also mitigated the crack propagation in the longitudinal and transverse directions. Moreover, the Kevlar layers also stopped the formation of the "butterfly-shaped" delamination zone that was originally observed in the flax/epoxy composite. In lieu of the delamination damage, the energy absorbed was rather spent in the creation of a more pronounced indentation depth in the shape and size of the impactor tip.

In terms of indentation depth, the Kevlar-flax/epoxy composites exhibited a shallower dent compared to the flax/epoxy composites at impact energies less than $15 \mathrm{~J}$. At $\mathrm{E}=20 \mathrm{~J}$, the indentation depths for both composites were nearly equal. Above $20 \mathrm{~J}$, the indentation depths on the Kevlar-flax epoxy composites were significantly larger than those of the flax/epoxy composites. The ability of Kevlar-Flax composite to sustain larger indentation can be attributed to the compliant nature of aramids, allowing the hybrid composites to sustain higher strain levels before complete failure.

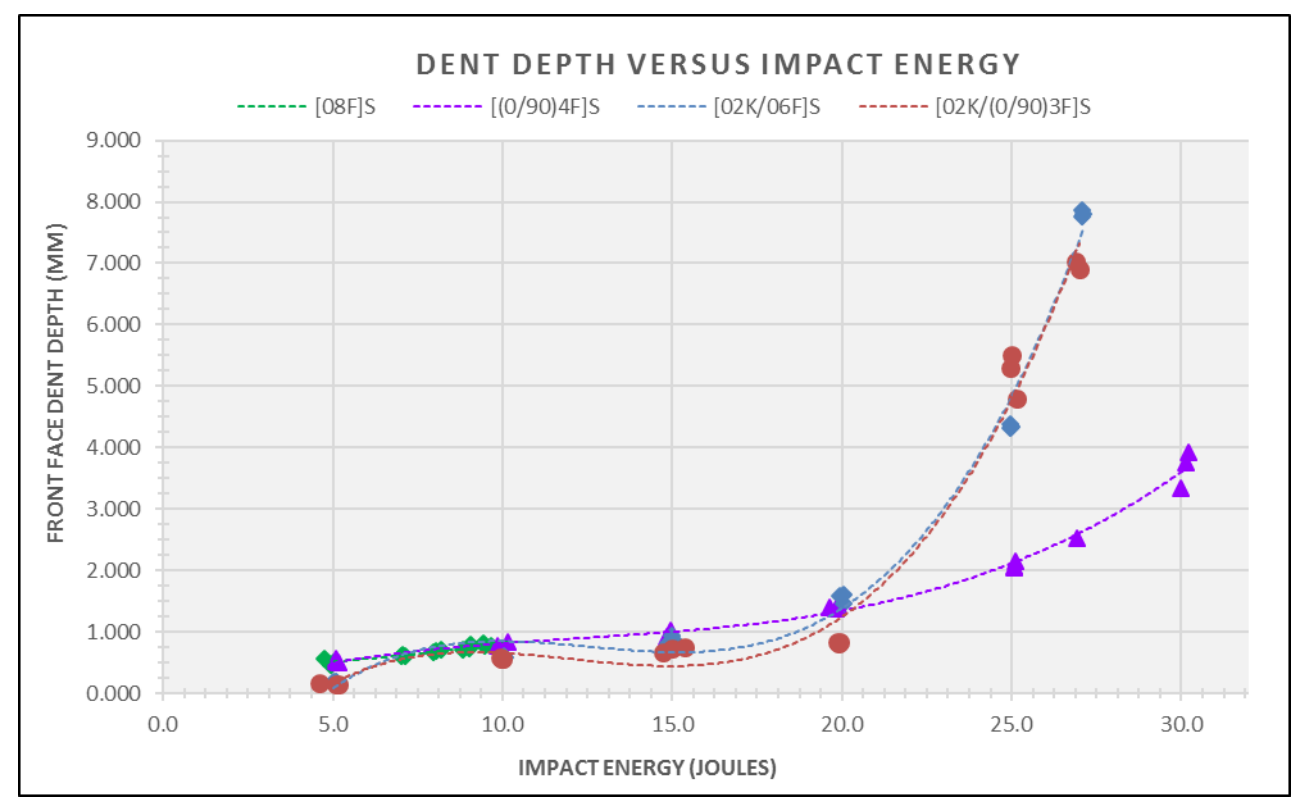

Figure 145: Dent Depth versus impact energy for the Flax/Epoxy and Kevlar-flax/epoxy 


\subsubsection{IMPACT DAMAGE ASSESSMENT USING IR THERMOGRAPHY}

The following figures show side-by-side comparison of the back face visible damage area and the IRT images for different impact energies. By comparing the images, it can be observed that there is a good correlation between the visible back face damage area and the back face thermographic images obtained using IRT.
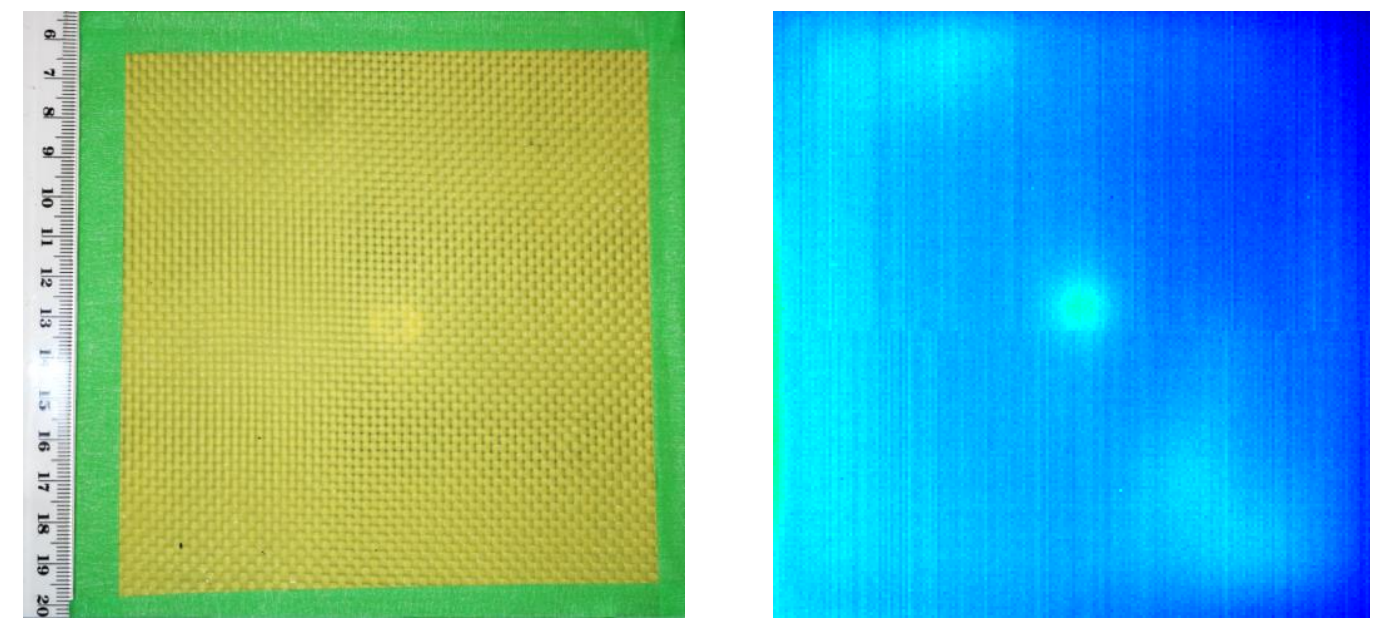

Figure 146: Visible back face damage (left) and IR image for $\left[0_{2 K} / 0_{6 F}\right]_{S}$ at $E=5 \mathrm{~J}$
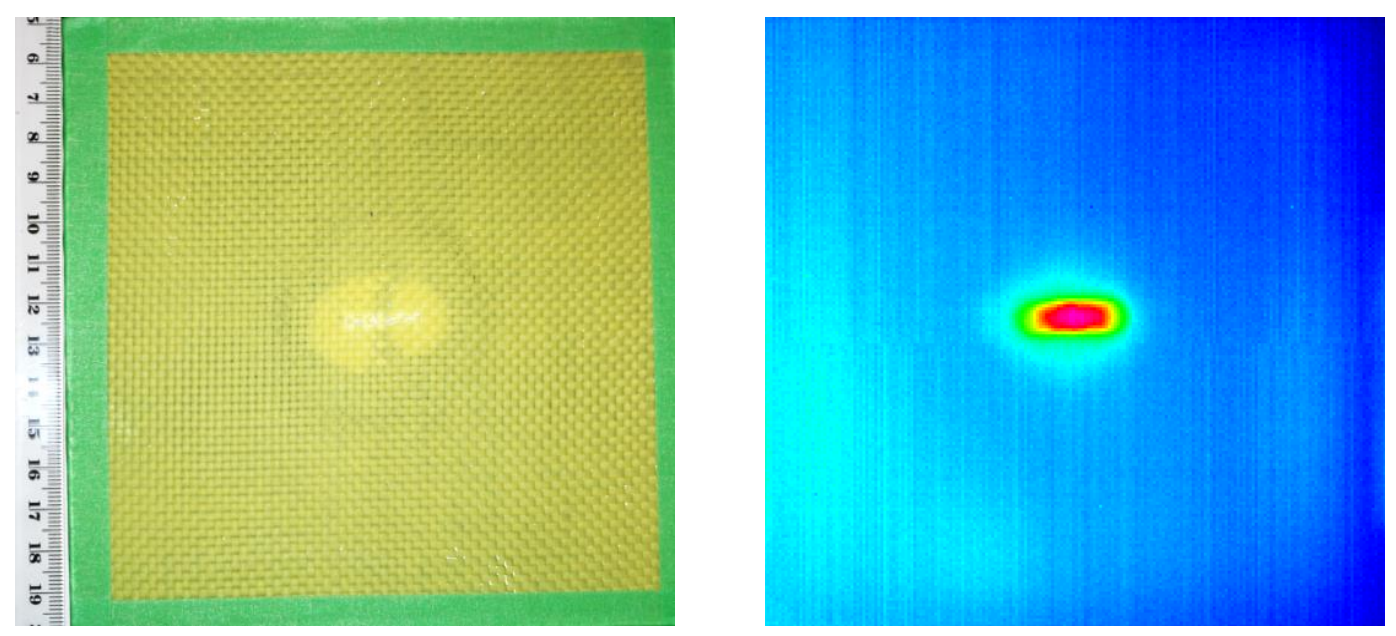

Figure 147: Visible back face damage (left) and IR image for $\left[0_{2 \mathrm{~K}} / 0_{6 \mathrm{~F}}\right]_{\mathrm{S}}$ at $\mathrm{E}=10 \mathrm{~J}$ 

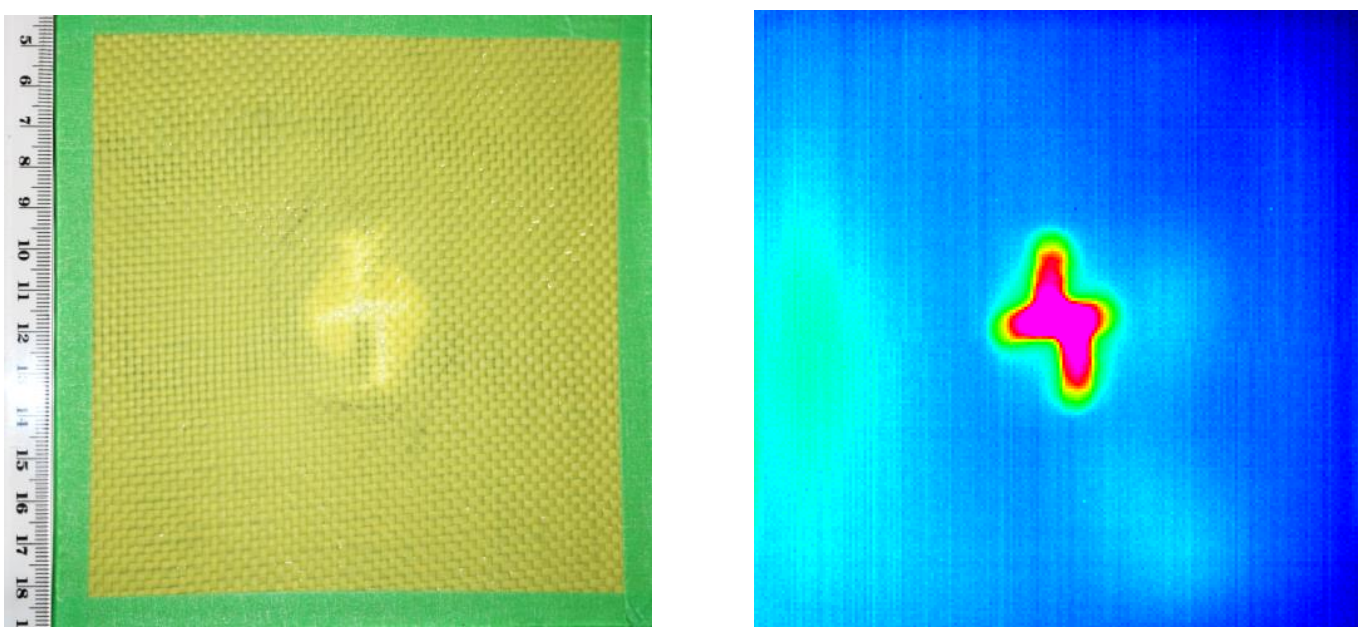

Figure 148: Visible back face damage (left) and IR image for $\left[0_{2 K} / 0_{6 F}\right]_{s}$ at $E=15 \mathrm{~J}$
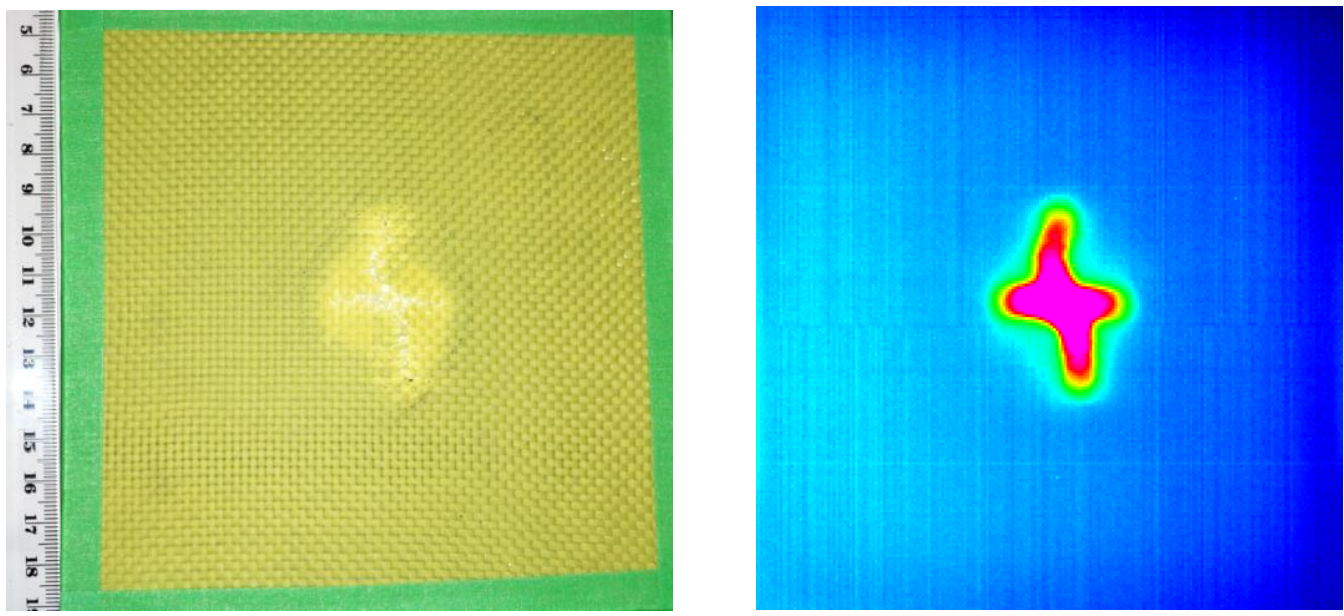

Figure 149: Visible back face damage (left) and IR image for $\left[0_{2 K} / 0_{6 F}\right]_{S}$ at $E=20 \mathrm{~J}$
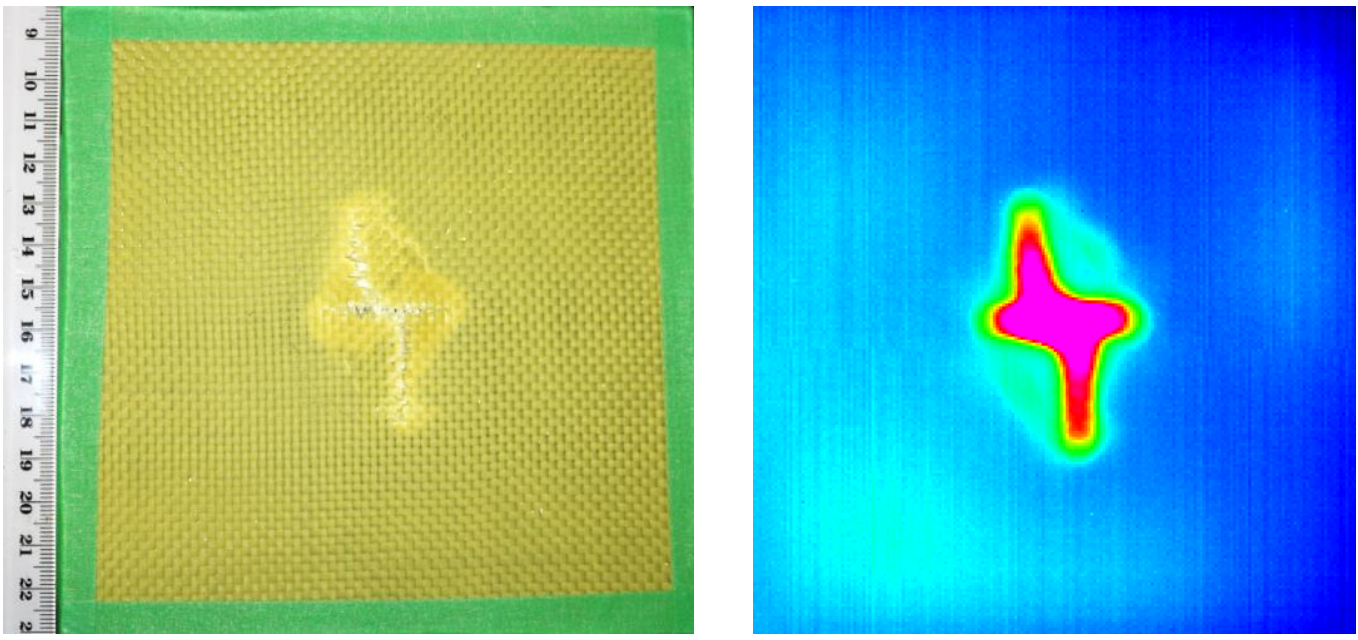

Figure 150: Visible back face damage (left) and IR image for $\left[0_{2 K} / 0_{6 F}\right]_{s}$ at $E=25 \mathrm{~J}$ 

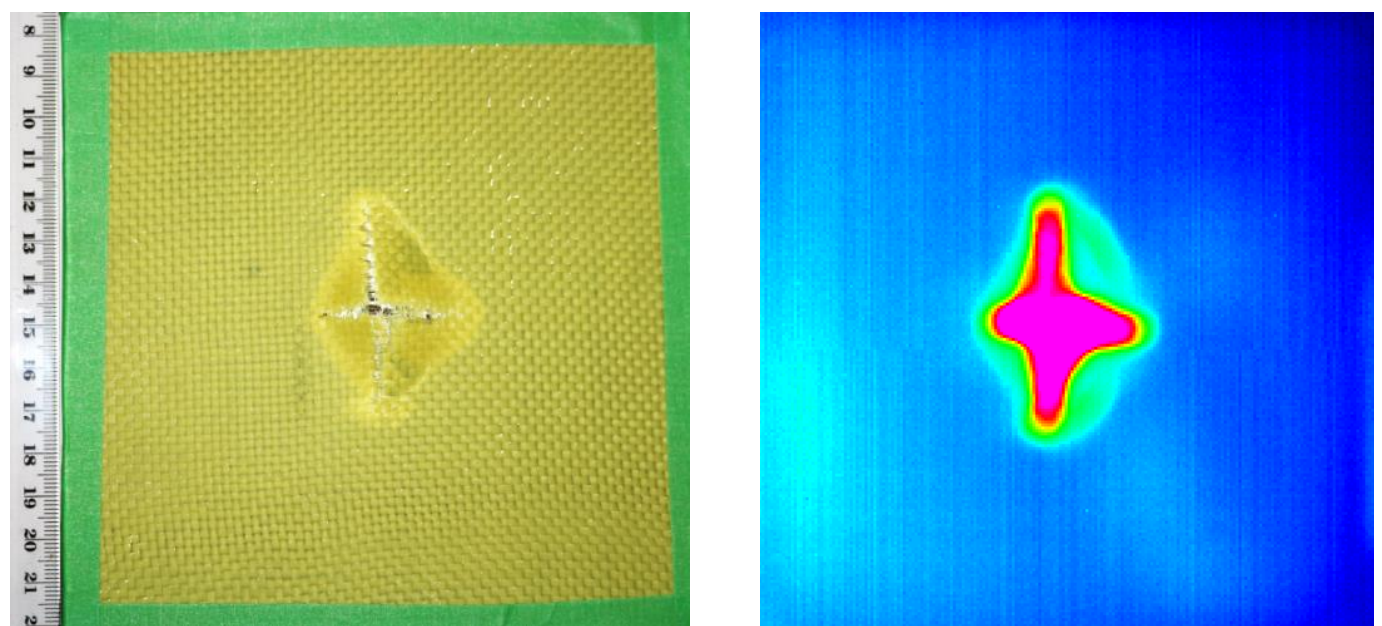

Figure 151: Visible back face damage (left) and IR image for $\left[0_{2 K} / 0_{6 F}\right]_{S}$ at $E=27 \mathrm{~J}$
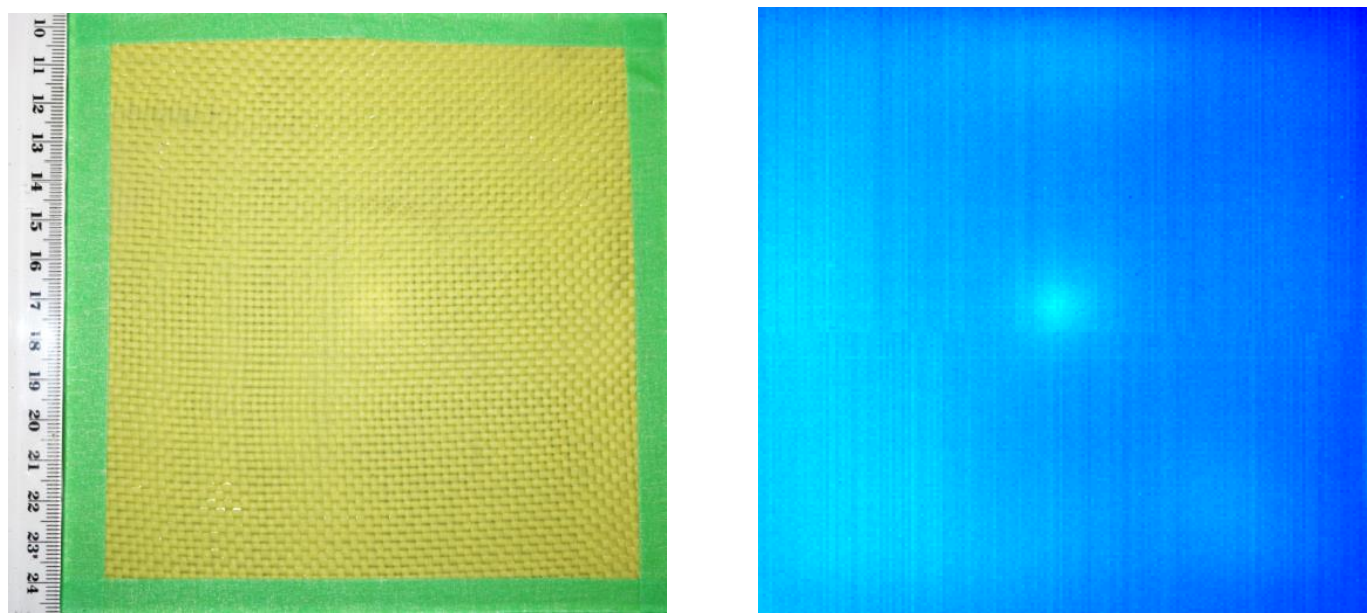

Figure 152: Visible back face damage (left) and IR image for $\left[0_{2 \mathrm{~K}} /(0 / 90)_{3 \mathrm{~F}}\right]_{\mathrm{S}}$ at $\mathrm{E}=5 \mathrm{~J}$
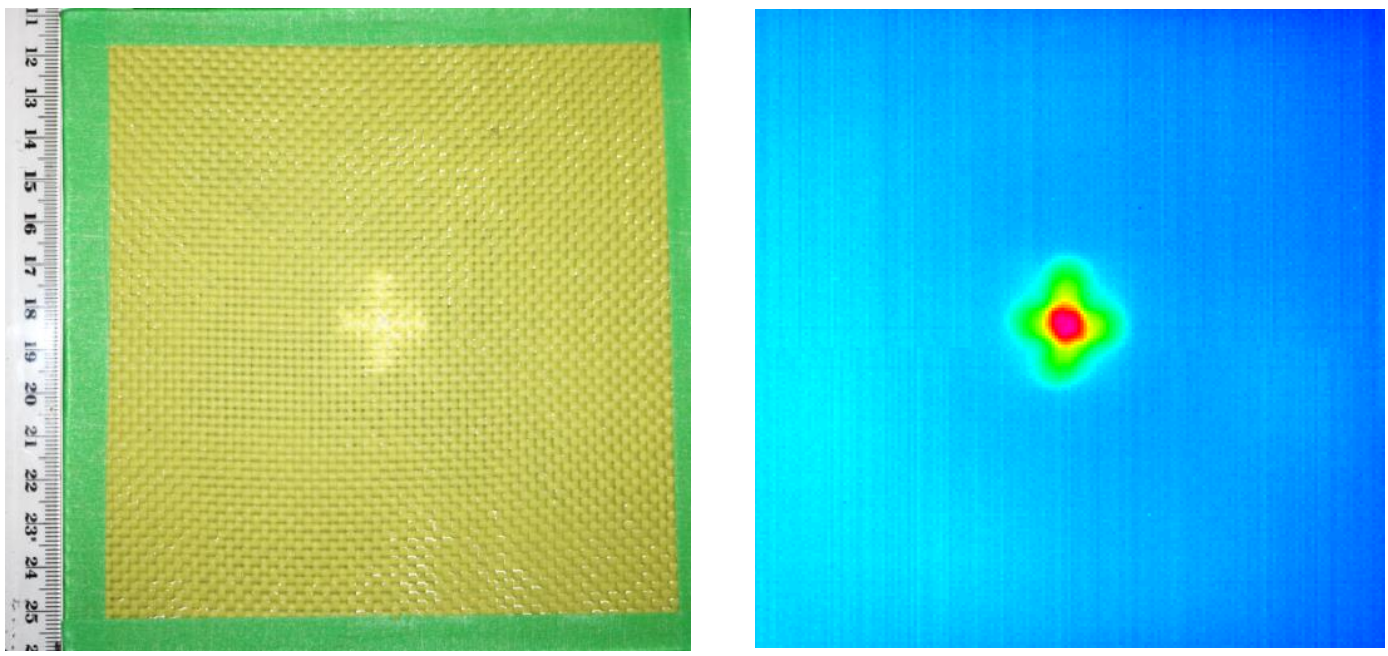

Figure 153: Visible back face damage (left) and IR image for $\left[0_{2 K} /(0 / 90)_{3 F}\right]_{s}$ at $E=10 \mathrm{~J}$ 

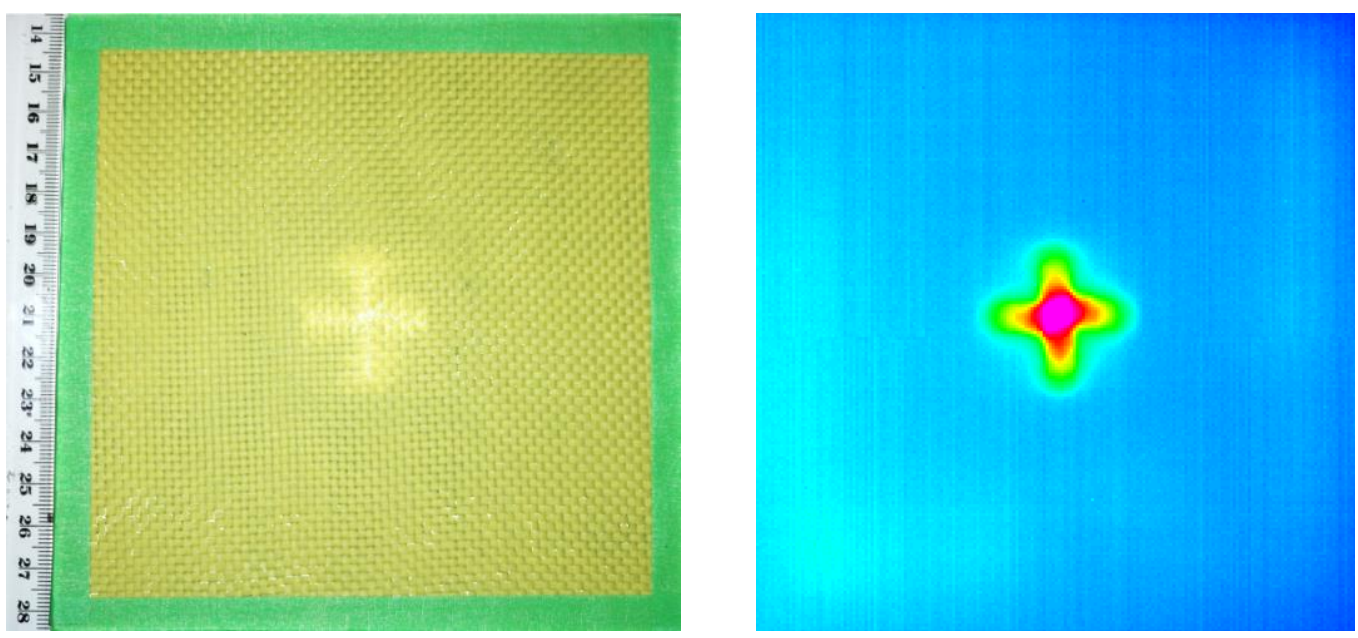

Figure 154: Visible back face damage (left) and IR image for $\left[0_{2 K} /(0 / 90)_{3 F}\right]_{s}$ at $E=15 \mathrm{~J}$
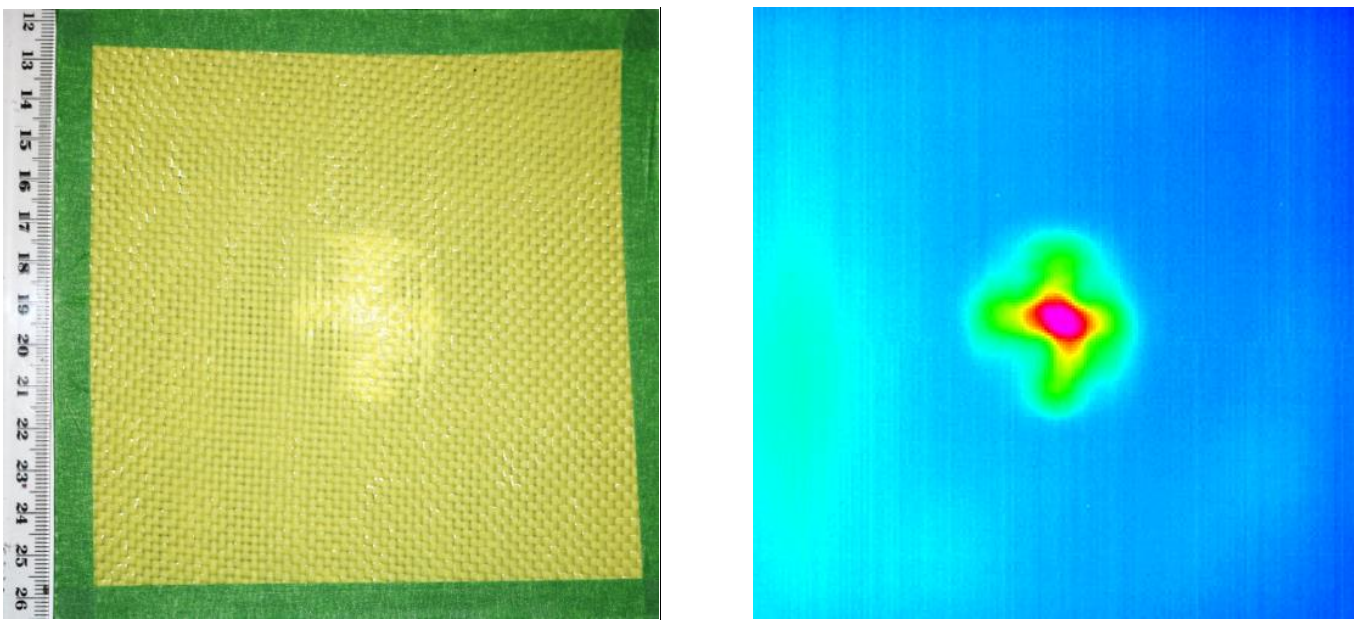

Figure 155: Visible back face damage (left) and IR image for $\left[0_{2 \mathrm{~K}} /(0 / 90)_{3 \mathrm{~F}}\right]_{\mathrm{S}}$ at $\mathrm{E}=\mathbf{2 0} \mathrm{J}$
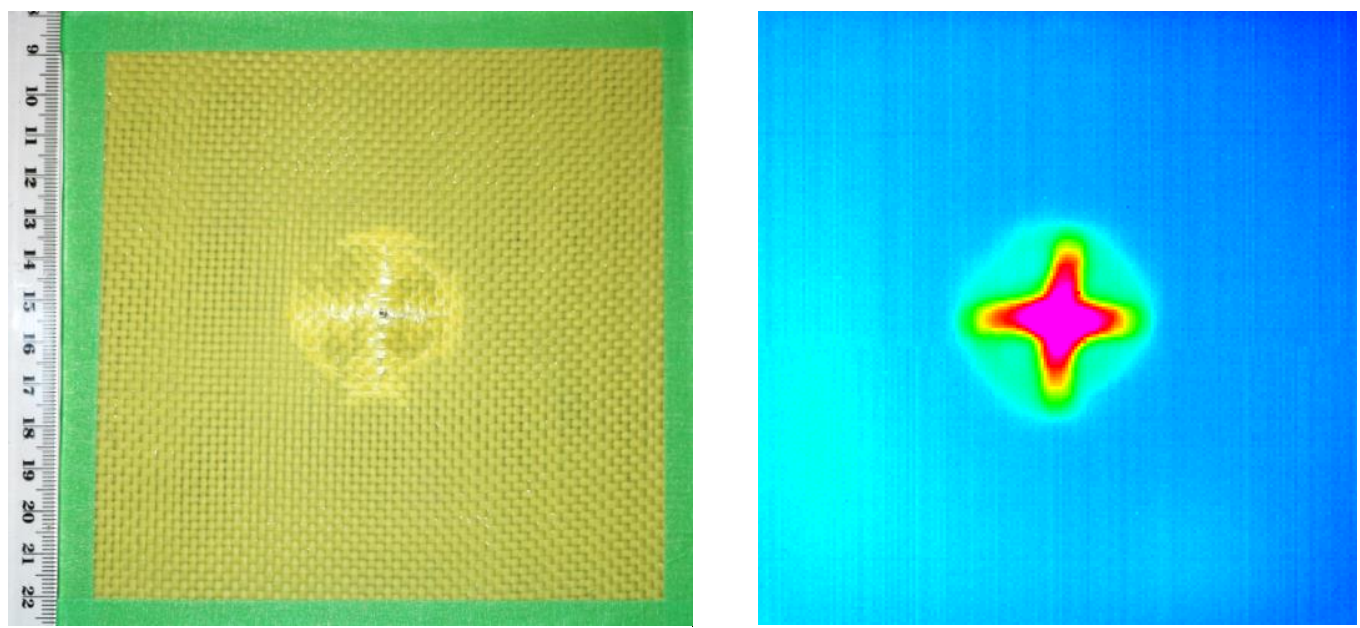

Figure 156: Visible back face damage (left) and IR image for $\left[0_{2 K} /(0 / 90)_{3 F}\right]_{S}$ at $E=25 \mathrm{~J}$ 

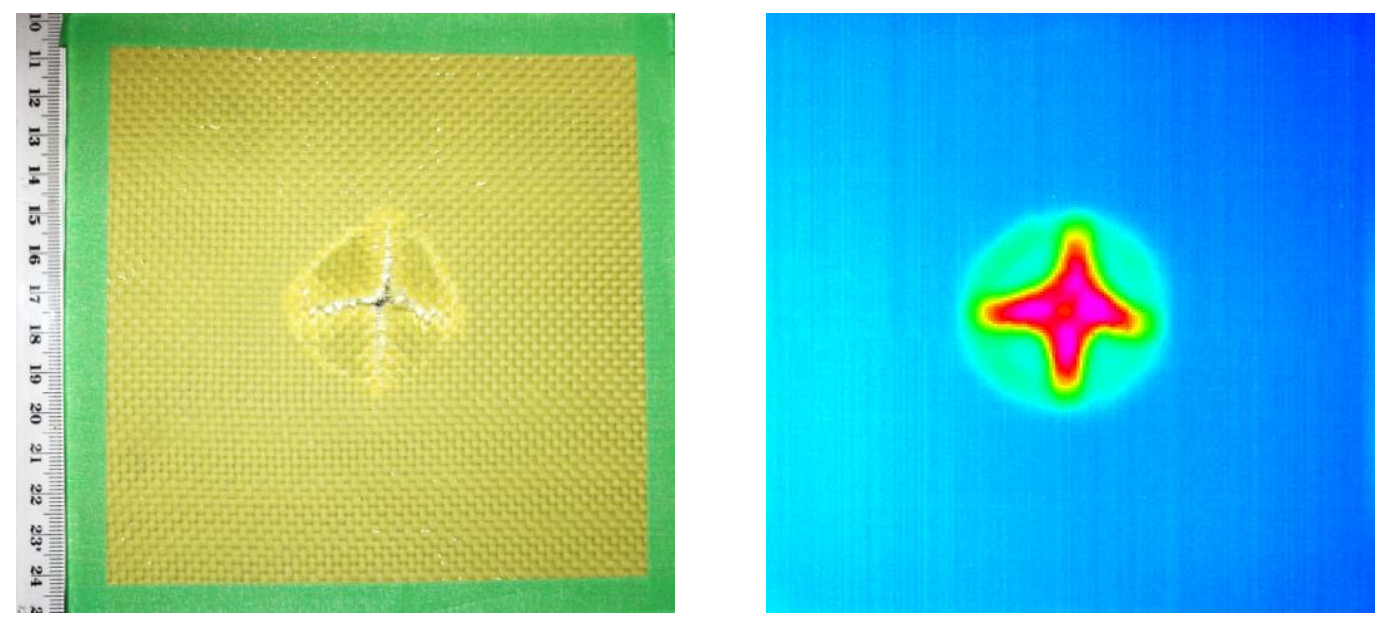

Figure 157: Visible back face damage (left) and IR image for $\left[0_{2 \mathrm{~K}} /(0 / 90)_{3 \mathrm{~F}}\right]_{\mathrm{S}}$ at $\mathrm{E}=\mathbf{2 7} \mathrm{J}$
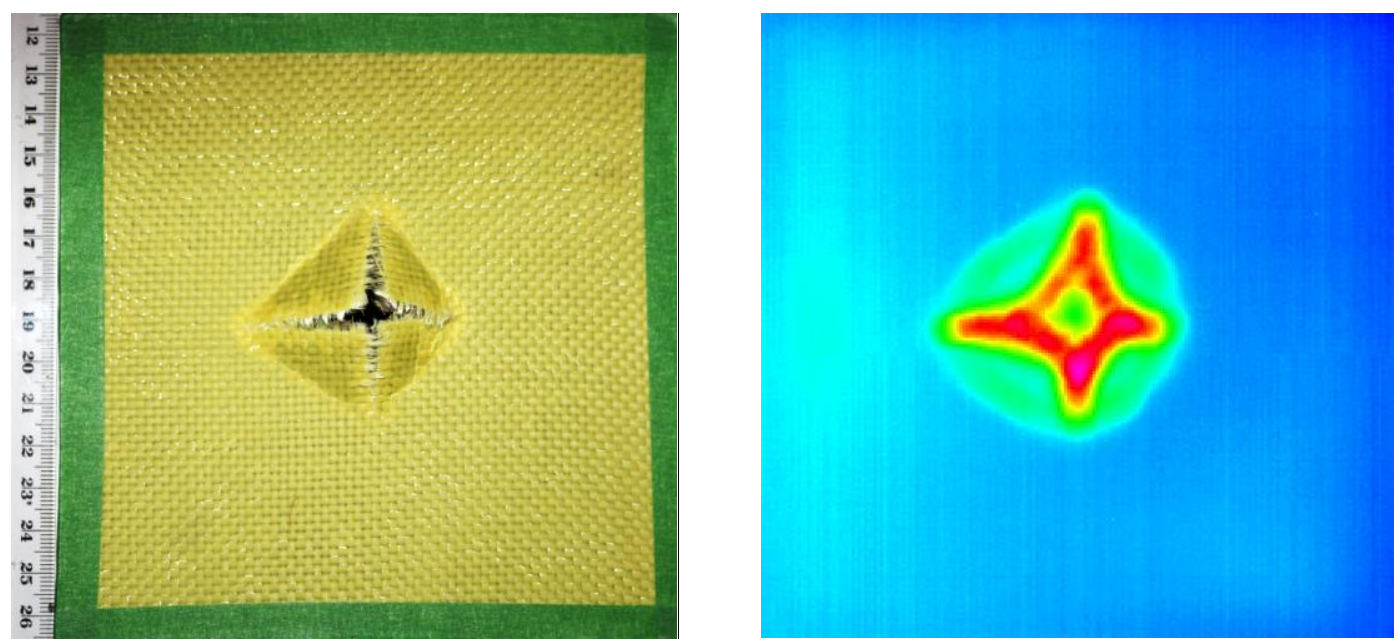

Figure 158: Visible back face damage (left) and IR image for $\left[0_{2 \mathrm{~K}} /(0 / 90)_{3 \mathrm{~F}}\right]_{\mathrm{S}}$ at $\mathrm{E}=30 \mathrm{~J}$

For the unidirectional Kevlar-flax/epoxy composite, the area obtained from the IRT images showed good correlation with the visible damage area. The IRT technique was able to capture both fibre breakage and delamination in the composite material. On the other hand, the IRT images for the cross-ply Kevlar-flax/epoxy composite showed slightly larger back face damage area than the actual visible damage area. Visual observation of the back face showed a cross-shape damage profile, while the IRT images showed a rhombical-shaped damage profile. The larger damage area depicted by the IRT could be an indication of a slightly larger internal delamination zone, which could not be perceived with visual inspection. Using IRT, the internal delamination can be detected because of the convection of the entrapped heat within the delaminated zone. 
A plot of $\Delta \mathrm{T}$ versus impact energy is shown in Figure 159. The trend of the data points can also provide insight on the damage mechanism involved during the impact event. From the plot, it can be observed that at low impact energy $(E=5 \mathrm{~J})$, the change in temperature at the centre of impact is very small $\left(\Delta \mathrm{T} \cong 1^{\circ} \mathrm{C}\right)$. This $\Delta \mathrm{T}$ is significantly lower than that of the flax/epoxy composite under the same impact energy. For the flax/epoxy composite, the $\Delta \mathrm{T}$ at $\mathrm{E}=5 \mathrm{~J}$ was between $3^{\circ} \mathrm{C}$ and $5^{\circ} \mathrm{C}$. Such difference can be attributed to the damage mechanism present at this impact energy. For the flax/epoxy composite, the damage consisted of matrix cracking in the longitudinal and transverse directions. On the other hand, the damage on the Kevlar-flax/epoxy composite was mainly in the form of matrix deformation. Since the energy required for matrix deformation is lower than the energy required for matrix cracking [12], the temperature rise due to matrix deformation is also lower than the temperature rise due to matrix cracking.

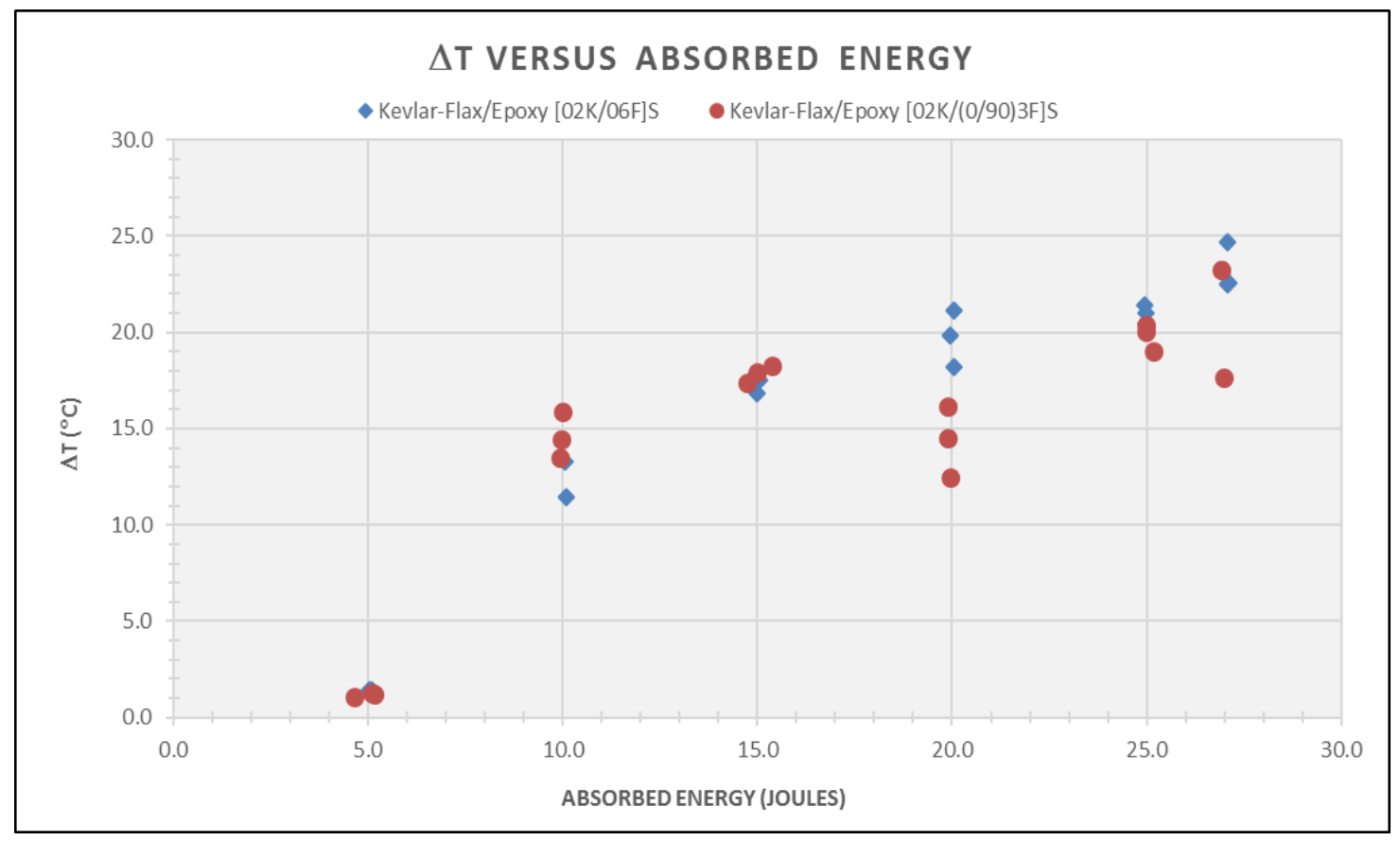

Figure 159: $\Delta \mathrm{T}$ versus impact energy for Kevlar/flax/epoxy composite

At $\mathrm{E}=10 \mathrm{~J}$, the $\Delta \mathrm{T}$ abruptly increased to an average of $15^{\circ} \mathrm{C}$ for the unidirectional Kevlarflax/epoxy composite and $13^{\circ} \mathrm{C}$ for the cross-ply Kevlar-flax/epoxy composite. This abrupt increase in temperature can be attributed to the development of delamination cracks in the Kevlarflax interface. The extent of delamination in the unidirectional Kevlar/flax composite was larger 
than that of the cross-ply Kevlar-flax/epoxy composite, therefore the $\Delta \mathrm{T}$ for the former was slightly higher than the latter. At $\mathrm{E}=15 \mathrm{~J}$, the $\Delta \mathrm{T}$ for both unidirectional and cross-ply Kevlar-flax/epoxy composites were nearly equal. At $\mathrm{E}=20 \mathrm{~J}$, however, the $\Delta \mathrm{T}$ for the unidirectional Kevlarflax/epoxy composite was lower. A lower $\Delta \mathrm{T}$ implies that the delamination damage for the unidirectional hybrid composite could be less severe than that of the cross-ply hybrid composite. At $\mathrm{E}>20 \mathrm{~J}$, the $\Delta \mathrm{T}$ for both hybrid composite configurations converged to the same value because composite failed in the same mode of failure.

Compared to the flax/epoxy composite, the $\Delta \mathrm{T}$ 's for Kevlar-flax/epoxy composite were generally higher for all energy levels, except at $5 \mathrm{~J}$. This was the result of the formation of delamination damage on the back face of the hybrid composites, which was not found in flax/epoxy composites. Delamination damage requires a large amount of fracture energy absorbed during impact [12], which is generally higher than the energy required to induce matrix cracking. Thus, the energy absorbed (being proportional to $\Delta \mathrm{T}$ ) for the Kevlar-flax/epoxy composite was generally higher. The same trend can be observed in the absorbed energy versus impact energy plot in Figure 120. The presence of the Kevlar layers improved the energy absorption capacity of flax/epoxy composite by allowing it to absorb energy in a more compliant manner.

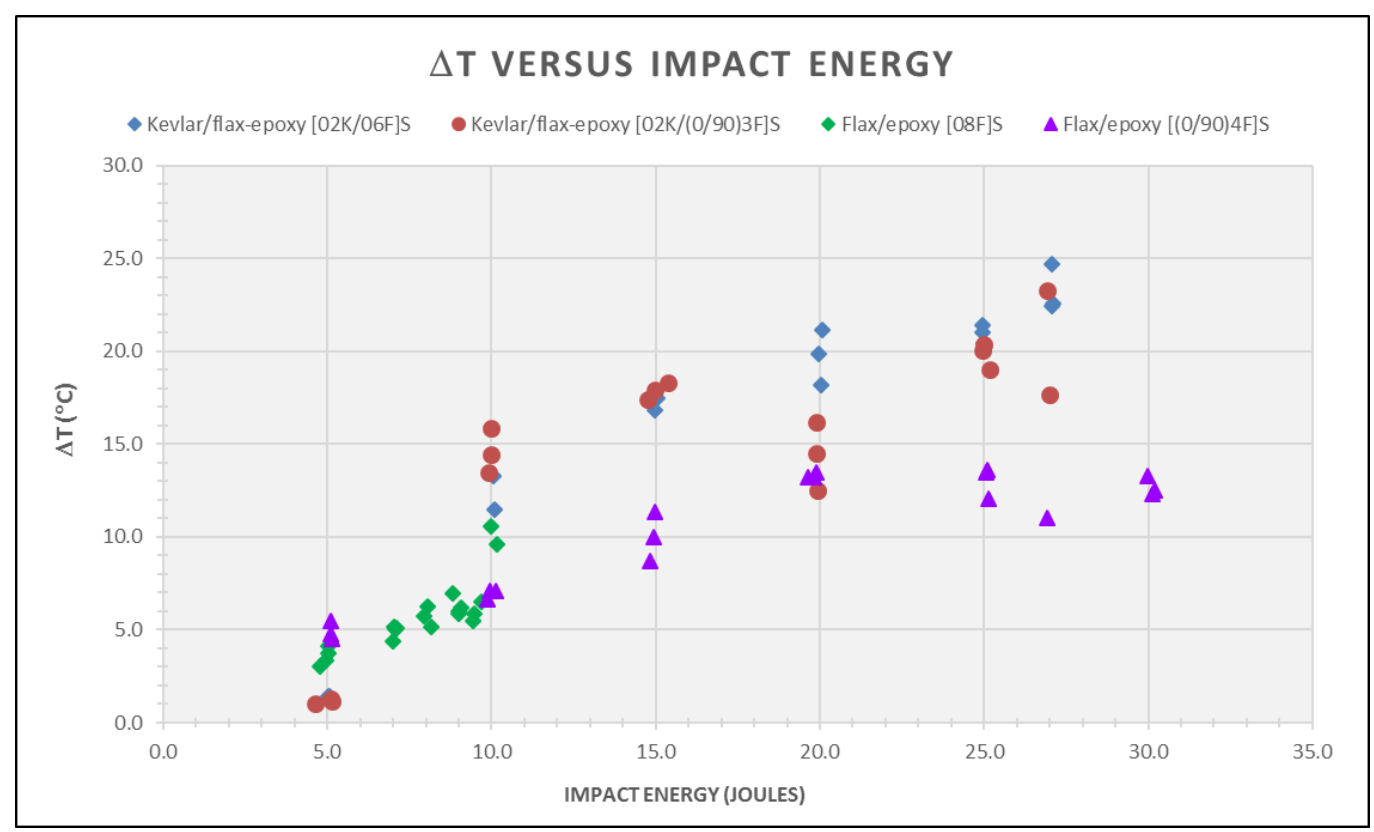

Figure 160: $\Delta T$ versus impact energy for flax/epoxy and Kevlar/flax/epoxy composite 


\subsection{IMPACT TOUGHNESS EVALUATION}

From the absorbed energy and fracture characteristics of the composite (i.e. crack length), the fracture toughness of a composite under impact can be estimated. Ravandi et. al. [69] proposed a simplified equation for estimating the impact toughness of a composite laminate under low velocity impact loading:

$$
G_{\text {impact }}=\frac{E_{\text {absorbed }}}{a \times t}
$$

where a is the average sum of transverse and longitudinal through-the-thickness cracks observed at back face of the specimens, and $t$ is the specimen thickness. Table 13 and Table 14 show the impact toughness calculation for the Flax/Epoxy and Kevlar-Flax/Epoxy laminates, respectively.

Table 13: Impact Toughness of Flax/Epoxy Composite

\begin{tabular}{|l|c|c|}
\hline \multicolumn{1}{|c|}{ Composite Parameters } & Unidirectional & Cross-Ply \\
\hline Longitudinal Crack Length, mm & 100 & 80 \\
\hline Transverse Crack Length, mm & 60 & 80 \\
\hline Average Crack Length $\boldsymbol{a}, \mathbf{m m}$ & 80 & 80 \\
\hline Laminate Thickness $\boldsymbol{t}, \mathbf{m m}$ & 3.7 & 3.7 \\
\hline Penetration Impact Energy $\boldsymbol{E}_{\text {impact }}, \mathbf{J}$ & 10 & $30\left(^{*}\right)$ \\
\hline Absorbed Energy $\boldsymbol{E}_{\text {absorbed }}, \mathbf{J}$ & 10 & $25\left(^{*}\right)$ \\
\hline Impact Toughness, J/mm & & 0.0845 \\
\hline Impact Toughness, $\mathbf{~ k J / \mathbf { m } ^ { 2 }}$ & 0.0338 & 84.5 \\
\hline
\end{tabular}

(*) Note that at $\mathrm{E}=30 \mathrm{~J}$, the cross-ply composite did not completely fracture; however, this energy is near the penetration threshold for the cross-ply flax/epoxy composite. Thus, a valid approximation of the impact toughness can be obtained using this test case. 
Table 14: Impact Toughness of Kevlar-Flax/Epoxy Composite

\begin{tabular}{|l|c|c|}
\hline \multicolumn{1}{|c|}{ Composite Parameters } & Unidirectional & Cross-Ply \\
\hline Longitudinal Crack Length, mm & 50 & 45 \\
\hline Transverse Crack Length, mm & 35 & 40 \\
\hline Average Crack Length $\boldsymbol{a}, \mathbf{m m}$ & 42.5 & 42.5 \\
\hline Laminate Thickness $\boldsymbol{t}, \mathbf{m m}$ & 3.4 & 3.4 \\
\hline Penetration Impact Energy $\boldsymbol{E}_{\text {impact }}, \mathbf{J}$ & 27 & 27 \\
\hline Absorbed Energy $\boldsymbol{E}_{\text {absorbed }}, \mathbf{J}$ & 27 & 27 \\
\hline Impact Toughness, $\mathbf{J} / \mathbf{m m}^{\mathbf{2}}$ & 0.187 & 0.187 \\
\hline Impact Toughness, $\mathbf{k J} / \mathbf{m}^{\mathbf{2}}$ & 187 & 187 \\
\hline
\end{tabular}

The impact toughness of unidirectional flax/epoxy composite is significantly lower compared to that of that of the cross-ply flax/epoxy composite. When compared to other composite materials, the impact toughness of unidirectional composite is relatively low, which means it is not effective under impact loading. The impact toughness of the cross-ply flax/epoxy on the other hand is comparable to that of Al 7075-T73, but still lower than conventional composite materials such as T-300 carbon/epoxy and glass/epoxy.

The hybridization with Kevlar 49 improved the impact toughness of the flax/epoxy composites. The calculated impact toughness is more than five times that of the unidirectional flax/epoxy composite and more than twice than that of the cross-ply flax/epoxy. It is lower than those of E-glass/epoxy and Kevlar/epoxy, but slightly better than those of aluminum alloys and T300 carbon/epoxy composite.

Figure 161 and Figure 162 show where the flax/epoxy and Kevlar-flax/epoxy composites fall with respect to other materials in terms of strength and impact toughness. 


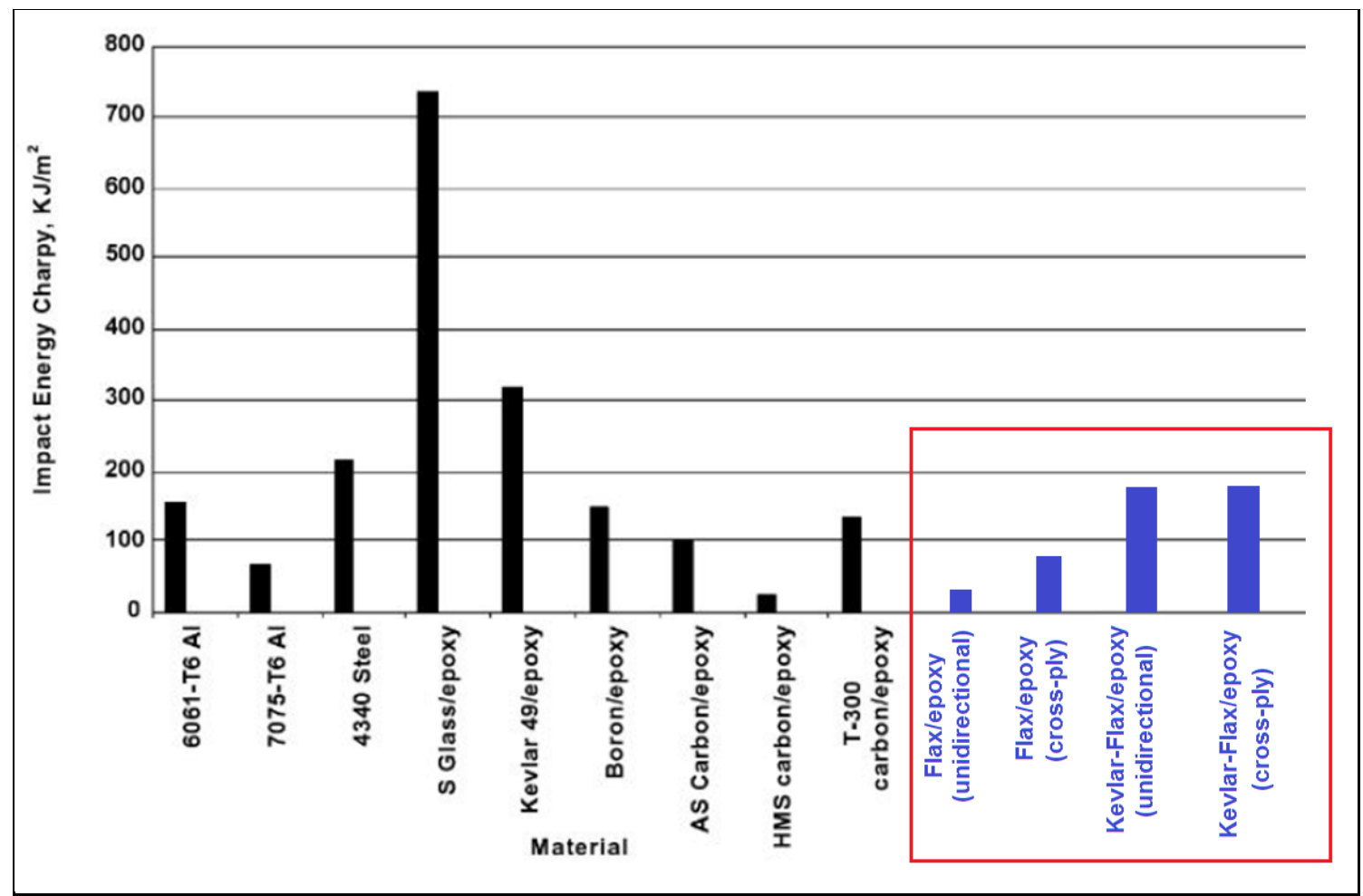

Figure 161: Impact properties of various composite and metallic materials [30] [43]

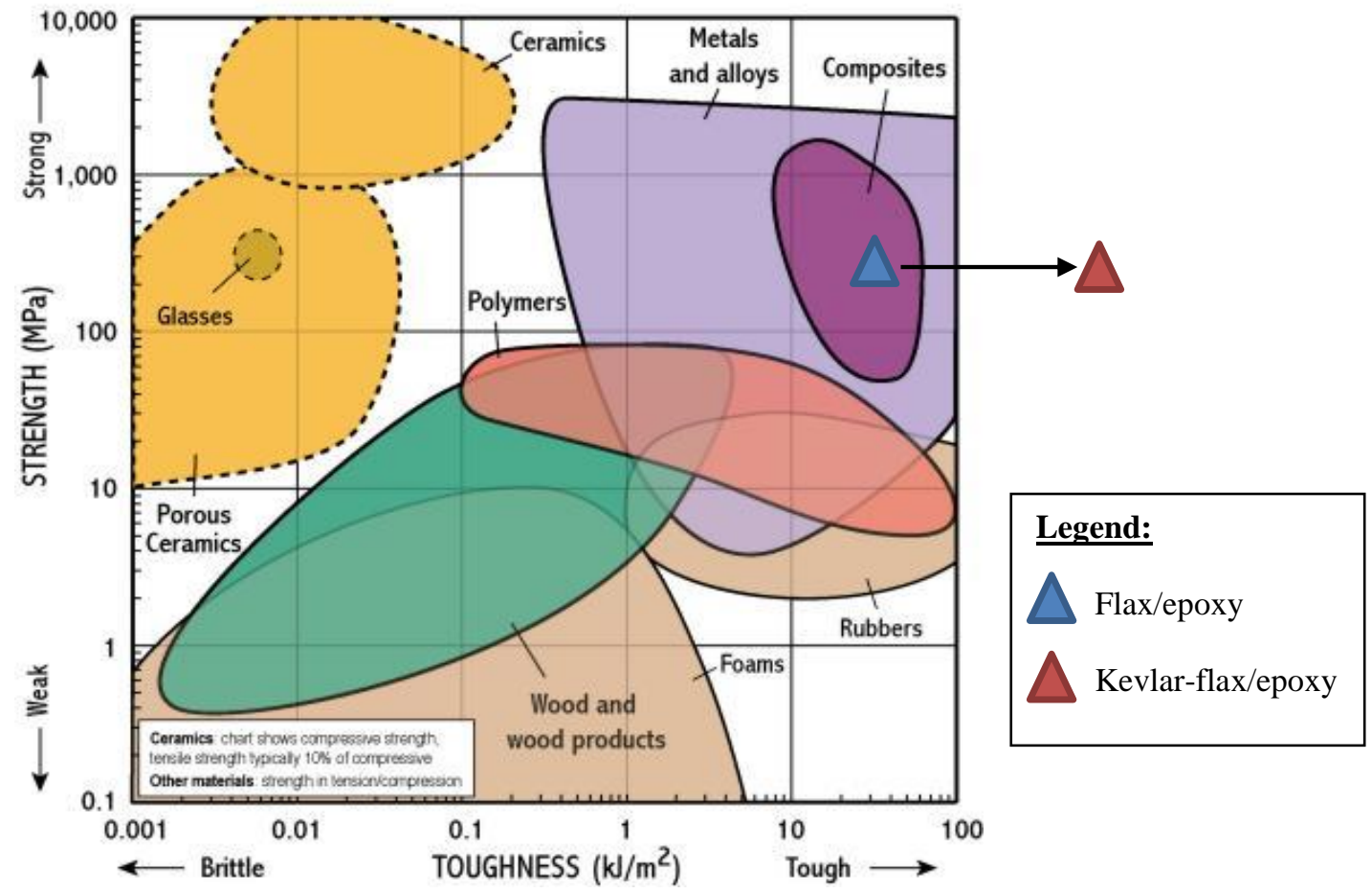

Figure 162: Strength versus impact toughness of various materials [70] 


\section{NUMERICAL ANALYSIS USING LS-Dyna}

Numerical (FEA) analysis was performed to correlate the experimental results with analysis. To perform the numerical simulation, LS-DYNA 3D numerical explicit finite element code was used. This FE software has many composite failure models to simulate the damage behaviour of composites [52]. The most common among these are the MAT_022 and MAT_05455 composite damage models. A brief description of each material models is provided as follows.

MAT_022 models an orthotropic material combined with Chang-Chang composite failure model [71]. This material model utilizes five material parameters namely $S_{l}$ (longitudinal tensile strength), $S_{2}$ (transverse tensile strength), $S_{12}$ (shear strength), $C_{2}$ (transverse compressive strength) and $\alpha$, which is a non-linear shear stress parameter defined by the material shear stress-strain measurements [72]. This material model has three failure criteria namely:

\section{Matrix Cracking Failure Criteria [72]}

$$
F_{\text {matrix }}=\left(\frac{\sigma_{2}}{S_{2}}\right)^{2}+\bar{\tau}
$$

where

$$
\bar{\tau}=\frac{\frac{\tau_{12}^{2}}{2 G_{12}}+\frac{3}{4} \alpha \tau_{12}^{4}}{\frac{S_{12}^{2}}{2 G_{12}}+\frac{3}{4} \alpha S_{12}^{4}}
$$

$\sigma_{2}$ is the stress in the transverse (matrix) direction, $\mathrm{G}_{12}$ is the composite shear modulus and $\tau_{12}$ is the in-plane shear stress. Failure of the matrix occurs whenever $F_{\text {matrix }}>1$.

\section{Compression Failure Criteria [72]}

$$
F_{\text {comp }}=\left(\frac{\sigma_{2}}{2 S_{12}}\right)^{2}+\left[\left(\frac{C_{2}}{2 S_{12}}\right)^{2}-1\right] \frac{\sigma_{2}}{C_{2}}+\bar{\tau}
$$

Failure in compression occurs whenever $F_{\text {comp }}>1$. 


\section{Fibre Breakage Failure Criteria [72]}

$$
F_{\text {fiber }}=\left(\frac{\sigma_{1}}{S_{1}}\right)^{2}+\bar{\tau}
$$

Fibre failure is assumed whenever $F_{\text {fibre }}>1$.

This material model is applicable to thin-shell element formulation, where laminated shell theory can be activated to properly model transverse shear deformation [71]. MAT_054-055 are enhanced versions of MAT_022, which uses the Chang/Chang (MAT_054) and Tsai-Wu (MAT_55) failure criteria to model composite failure. This material model is only valid for thin shell elements [52]. The Chang/Chang failure criteria are given as follows:

\section{Tensile Failure, Fibre Direction [52]}

$$
\left[\frac{\sigma_{11}}{X_{T}}\right]^{2}+\beta\left[\frac{\sigma_{12}}{S_{C}}\right]^{2}-1\left\{\begin{array}{l}
\geq 0 \text { failed } \\
<0 \text { elastic }
\end{array}\right.
$$

2. Compressive Failure, Fibre Direction [52]

$$
\left[\frac{\sigma_{11}}{X_{C}}\right]^{2}-1\left\{\begin{array}{l}
\geq 0 \text { failed } \\
<0 \text { elastic }
\end{array}\right.
$$

3. Tensile Failure, Matrix Direction $\left(\sigma_{22}>0\right)[72]$

$$
\left[\frac{\sigma_{22}}{Y_{T}}\right]^{2}+\left[\frac{\sigma_{12}}{S_{C}}\right]^{2}-1\left\{\begin{array}{l}
\geq 0 \text { failed } \\
<0 \text { elastic }
\end{array}\right.
$$

4. Compressive Failure, Matrix Direction $\left(\sigma_{22}<0\right)[72]$

$$
\left[\frac{\sigma_{22}}{2 S_{C}}\right]^{2}+\left[\left(\frac{Y_{C}}{2 S_{C}}\right)^{2}-1\right] \frac{\sigma_{22}}{Y_{C}}+\left[\frac{\sigma_{12}}{S_{C}}\right]^{2}-1\left\{\begin{array}{l}
\geq 0 \text { failed } \\
<0 \text { elastic }
\end{array}\right.
$$

where $\sigma_{11}$ is the stress in the fibre direction, $\sigma_{22}$ is the stress in matrix direction, $\sigma_{12}$ is the in-plane shear stress, $\mathrm{X}_{\mathrm{T}}$ is the longitudinal tensile strength, $\mathrm{X}_{\mathrm{C}}$ is the longitudinal compressive strength, $\mathrm{Y}_{\mathrm{T}}$ is the transverse tensile strength, $\mathrm{Y}_{\mathrm{C}}$ is the transverse compressive strength, $\mathrm{S}_{\mathrm{C}}$ is the in-plane shear strength and $\beta$ is the weighting factor for shear term in fibre mode [52]. 
For the Tsai/Wu failure criteria, the fibre tensile and compressive failure criteria are the same as Chang/Chang. The failure criteria for the tensile and compressive failure modes in the matrix direction is given by the following equation:

\section{Tensile and Compressive Failure, Matrix Direction [72]}

$$
\left[\frac{\sigma_{22}}{Y_{C} Y_{T}}\right]^{2}+\left[\frac{\sigma_{12}}{S_{C}}\right]^{2}+\left[\frac{\left(Y_{C}-Y_{t}\right) \sigma_{22}}{Y_{C} Y_{T}}\right]^{2}-1\left\{\begin{array}{l}
\geq 0 \text { failed } \\
<0 \text { elastic }
\end{array}\right.
$$

For the MAT 54/55 material model, the element is deleted when failure occurred in all the composite layers. This can occur in four different ways:

1. If DFAILT (tensile fail strain in fibre direction) $=0$, failure occurs if the Chang/Chang failure criterion is satisfied in tensile fibre mode

2. If DFAILT $>0$, failure occurs if the tensile fibre strain $>$ DFAILT or $<$ DFAILC (compressive fail strain in fibre direction)

3. If EFS (effective fail strain) $>0$, failure occurs if the effective strain $>$ EFS.

4. If TFAIL (time step criteria for element deletion) $>0$, failure occurs based on TFAIL criteria [72].

It must be noted that MAT 54/55 is only applicable to thin shell elements. Moreover, it uses fracture mechanics and energy-based approaches in the analysis and therefore cannot predict delamination failure or debonding [73]. Modelling of delamination requires the inclusion of cohesive elements modelled in between plies, which results in more expensive computational time. This approach is also more complicated and is outside the scope of this research work. Thus, for this numerical impact simulation, MAT 54/55 is considered appropriate.

The input parameters for this material model can be divided into two groups. The first group relates to the mechanical properties of the lamina related to strength, strain and stiffness. The relevant/required parameters pertaining to this group are as follows: 
Table 15: MAT54/55 Required Composite Mechanical Properties

\begin{tabular}{|cl|}
\hline Parameter & \multicolumn{1}{c|}{ Description } \\
\hline EA, EB & Longitudinal and transverse elastic modulus, respectively \\
\hline GAB & Poisson's ratio \\
\hline XT, YT & Tensile strength in longitudinal and transverse direction, respectively \\
\hline XC, YC & Compressive strength in longitudinal and transverse directions, respectively \\
\hline SC & In-Plane shear strength \\
\hline DFAILM & Maximum strain for matrix failure (DFAILM = YT/EB or YT/EB) \\
\hline DFAILS & Maximum in-plane shear strain (DFAILS = SC/GAB) \\
\hline DFAILT & Maximum strain for fibre tension (DFAILT = XT/EA) \\
\hline DFAILC & Maximum strain for fibre compression (DFAILC = XC/EA) \\
\hline
\end{tabular}

The second group of parameters (Table 16) relates to damage factors, which are the parameters used to degrade the pristine material strength after some damage have been introduced to composite constituents. These parameters cannot be acquired by implementing coupon tests, but can be found by trial and error [74]. To find the appropriate values for these parameters for impact analysis, the user should conduct an experimental impact test and try to match the simulation result with the experiment by changing these parameters [74].

Table 16: MAT54/55 Damage Factors Input

\begin{tabular}{|cl|}
\hline Parameter & \multicolumn{1}{c}{ Description } \\
\hline FBRT & Softening for fibre tensile strength after matrix compressive failure. \\
\hline YCFAC & Reduction factor for compressive fibre strength after matrix compressive failure. \\
\hline SOFT & Softening reduction factor for material strength in crash front elements \\
\hline ALPH & Shear stress parameter for nonlinear term in matrix stress equation \\
\hline BETA & Weighting factor for shear term in tensile fibre mode \\
\hline
\end{tabular}


If activated, the FBRT parameter defines the percentage of the original fibre tensile strength after a compressive matrix failure [71]. It is a strength reduction factor that degrades the pristine fiber strengths of a ply if compressive matrix failure takes place. In other words, it is a residual strength parameter implying that there still exists load carrying ability in the layup despite the existence of damage. This is in the range between 0 to 1 . A value of " 0 " would indicate no residual strength and the laminate has failed, where as a value greater than " 0 " indicates that the laminate has not completely failed and retains the ability to carry load albeit at a reduced capacity.

$$
X T(\text { after matrix failure })=F B R T \times X T(\text { original })
$$

The YCFAC parameter on the other hand defines the compressive fibre strength left after compressive matrix failure [71].

$$
X C(\text { after matrix failure })=Y C F A C \times Y C
$$

The SOFT parameter is the softening reduction factor for material strength in crash front elements. It reduces the strength of elements immediately ahead of the crash front. The strength degradation is applied to the four lamina strengths as follows: [75]

$$
[X T, X C, Y T, Y C]_{\text {reduced }}=S O F T \times[X T, X C, Y T, Y C]
$$

If failure occurs in the entire composite layers (i.e. failure occurs at all through-thickness integration points), the element is deleted and elements attached to the deleted elements become the crash-front elements [76].

The parameter ALPH refers to the non-linear shear stress parameter $\alpha$ in the equations defined in Equation 6.2 for the matrix failure criteria. Per LS-DYNA manual, the suggested value is between 0 to 0.5 . The BETA factor on the other hand refers to the weighting factor for the shear term in the Chang/Chang tensile fibre failure criteria equation. This value ranges between 0 and 1 . 


\subsection{COMPOSITE FE MODEL}

The composite laminate was modelled as layers of thin shells and meshed with shell elements. The impactor was modelled as a solid part and meshed with solid brick elements. The flax/epoxy composite used in the experiment is comprised of 16 layers of lamina with a total thickness of $3.7 \mathrm{~mm}$. Each layer is $0.23125 \mathrm{~mm}$ thick. Modelling all sixteen layers will increase the complexity and time required to run the analysis. Thus, a ply compaction approach was implemented. This involved consolidating several plies together into a single shell element, with $n$ number of integration points within the shell element representing each layer of lamina. In this case, all 16 layers were compacted into 4 shell layers. Each shell layer is $0.925 \mathrm{~mm}$. thick and has four integration points, with each integration point measuring $0.23125 \mathrm{~mm}$. thick.

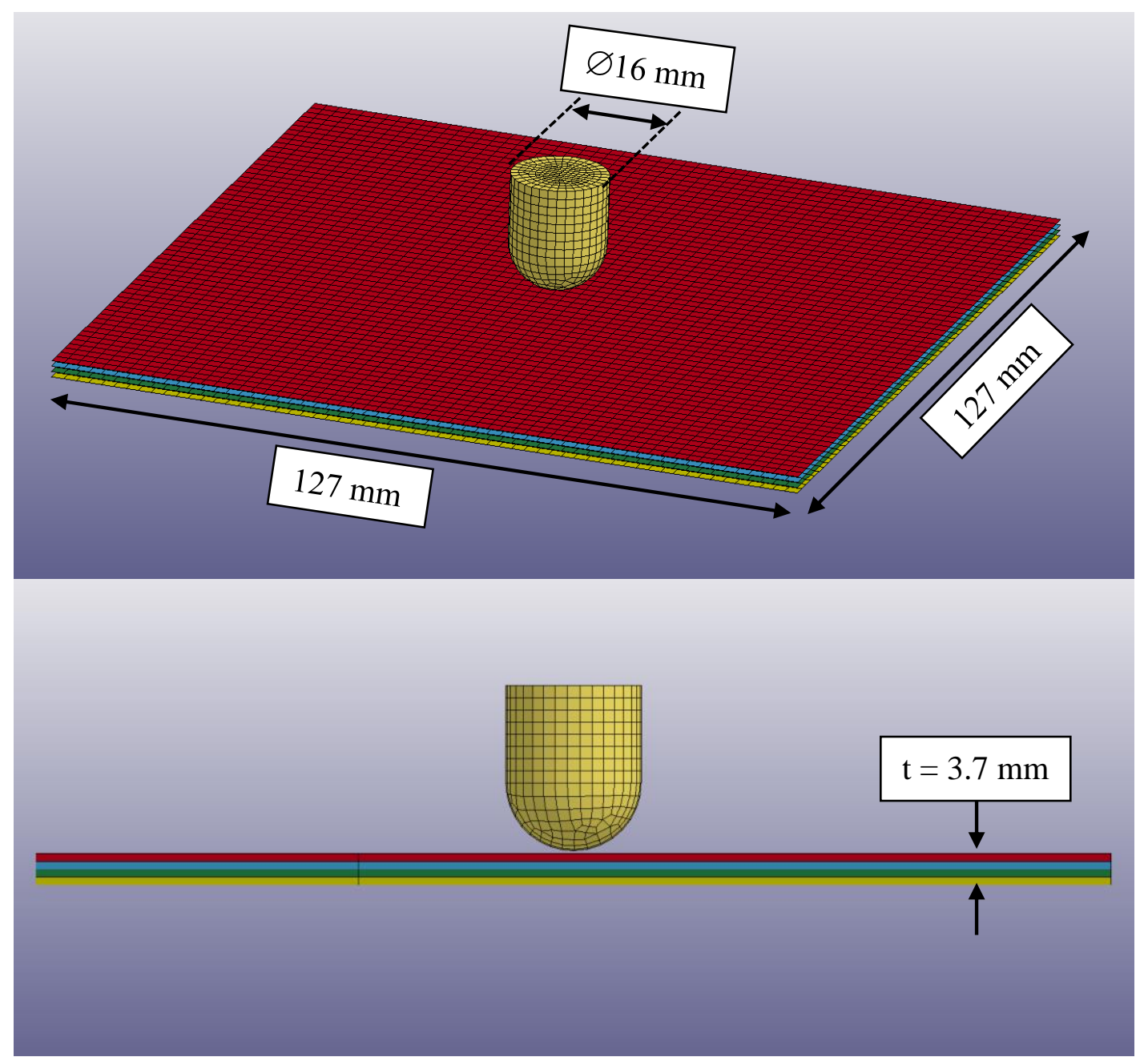

Figure 163: LS-DYNA Flax/Epoxy Composite Impact Assembly Model 


\begin{tabular}{|c|c|}
\hline $\mathrm{t}=0.23125 \mathrm{~mm}$ & $x \leftarrow$ INTEGRATION PT \\
\hline $\mathrm{t}=0.23125 \mathrm{~mm}$ & $x \leftarrow$ INTEGRATION PT \\
\hline $\mathrm{t}=0.23125 \mathrm{~mm}$ & $x \leftarrow$ INTEGRATION PT \\
\hline $\mathrm{t}=0.23125 \mathrm{~mm}$ & $x \leftarrow$ INTEGRATION PT \\
\hline
\end{tabular}

Figure 164: *PART_COMPOSITE shell layer of unidirectional flax/epoxy

\begin{tabular}{|c|c|}
\hline $\mathrm{t}=0.23125 \mathrm{~mm}$ & $x \leftarrow$ INTEGRATION PT \\
\hline $\mathrm{t}=0.23125 \mathrm{~mm}$ & $x \leftarrow$ INTEGRATION PT \\
\hline $\mathrm{t}=0.23125 \mathrm{~mm}$ & $x \leftarrow$ INTEGRATION PT \\
\hline $\mathrm{t}=0.23125 \mathrm{~mm}$ & $x \leftarrow$ INTEGRATION PT \\
\hline
\end{tabular}

Figure 165: PART_COMPOSITE shell layer of cross-ply flax/epoxy (above symmetry line)

\begin{tabular}{|c|c|}
\hline $\mathrm{t}=0.23125 \mathrm{~mm}$ & $x \leftarrow$ INTEGRATION PT \\
\hline $\mathrm{t}=0.23125 \mathrm{~mm}$ & $x \leftarrow$ INTEGRATION PT \\
\hline $\mathrm{t}=0.23125 \mathrm{~mm}$ & $x \leftarrow$ INTEGRATION PT \\
\hline $\mathrm{t}=0.23125 \mathrm{~mm}$ & $x \leftarrow$ INTEGRATION PT \\
\hline
\end{tabular}

Figure 166: PART_COMPOSITE shell layer of cross-ply flax/epoxy (below symmetry line)

\subsection{MESH DETAILS}

Each composite shell layer was meshed using 3600 ELFORM = 2 Belytschko-Tsay shell elements (element size $=2.1 \mathrm{~mm}$ ), which has four nodes and one in-plane reduced integration point. This element type is very fast and economical and is generally recommended for most applications. The impactor was meshed using 1552 selective reduced integrated brick elements (ELFORM = 2), which has eight nodes and one reduced integration point per element. 


\subsection{Contact Definition}

Contact interaction between the thin shell elements and the impactor was modelled using CONTACT_AUTOMATIC_NODES_TO_SURFACE formulation. This contact algorithm establishes contact when a contacting node penetrates a target surface. It also considers the true thickness of 2D shell elements [77]. It is a simple and fast contact algorithm and is very robust for problems where the contact area is relatively small and contact area known beforehand [78]. Per LS-DYNA contact guideline, convex surface and coarse mesh should be selected as the master surface, while fine meshes should be the slave surface. Thus, the impactor was selected as the master surface, and the shell elements as the slave surface. A static friction coefficient of $\mu=0.20$ was used between the impactor and the composite layers.

With composite materials, it is also important to model the interlaminar interaction (i.e. delamination) between composite plies. The choice of proper modelling technique to model delamination is important because delamination itself is an important energy absorption mechanism and it reduces the load bearing capacity of a structure in bending [76]. In LS DYNA, there are three different approaches to model the interlaminar interaction between composite layers: (1) Thick shell elements with cohesive interface MAT185 interlayer, (2) solid elements with cohesive zone element interface MAT185 interlayer, and (3) thin shell elements with delamination tiebreak contact [76]. The first two approaches make use of cohesive zone modelling (CZM) technique, which stems the concept of fracture as a gradual phenomenon in which separation takes place across an extended crack tip or "cohesive zone" and is resisted by cohesive tractions [76]. It is modelled using cohesive zone elements modelled in between plies. CZM is governed by the cohesive constitutive law:

$$
\sigma=\sigma_{\max } \mathrm{f}(\lambda)
$$

where $\sigma_{\max }$ is the cohesive strength of the element, $\lambda=\delta / \delta_{\mathrm{nc}}, \delta_{\mathrm{nc}}$ is the crack tip opening displacement and $f(\lambda)$ is a dimensionless function describing the shape of the cohesive law (e.g. bilinear, trilinear, parabolic or exponential) [76]. Cohesive traction stresses $\sigma$ are generated when these elements are pulled apart. When the maximum traction strength $\sigma_{\max }$ is reached, inter-ply separation occurs [76]. 
The third modelling approach, which is applicable to thin shell elements, is to use the contact card with stress-based delamination CONTACT_AUTOMATIC_ONE_WAY_SURFACE_TO_SURFACE_TIEBREAK. In LS-DYNA, tiebreak contact is used as adhesive to bond laminates together [76]. A normal and shear failure strength is entered into the contact card to check for bond failure. Tie break bond failure occurs when it satisfies the following equation:

$$
\left(\frac{\sigma_{n}}{N F L S}\right)^{2}+\left(\frac{\sigma_{s}}{S F L S}\right)^{2} \geq 1
$$

where NFLS is the tensile failure strength and SLFS is the shear failure strength of the adhesive. A study [76] have shown that with proper selection of tiebreak contact parameters, this method is effective and shows a good correlation with experimental results.

For the current FE model, the tiebreak contact approach was used because it is computationally less expensive and simple compared to the CZM approach. For the tiebreak bond failure criteria, NFLS = $56 \mathrm{MPa}$ and SFLS = 44 MPa were used. These values are typical properties for epoxy adhesives used in structural applications [76].

\subsection{MATERIAL DEFINITION}

MAT54/55 material model card was used to model the *PART_COMPOSITE shell elements. For the failure criteria, the MAT55 (Tsai-Wu) approach was selected. For the steel impactor, MAT20 (Rigid Solid) material was applied. The simplification of the impactor as a rigid body is acceptable because its stiffness is significantly larger than that of the composite material. In the material definition of the impactor, $\mathrm{E}=2.00 \mathrm{e}+5 \mathrm{MPa}$ and $v=0.32$ were used, which are typical values for steel. Moreover, since only the impactor tip was modelled in the assembly, the density of the impactor was artificially increased to $\rho=1.312 \mathrm{e}-6$ metric tonne $/ \mathrm{mm}^{3}$ to obtain the actual mass of the pendulum and arm assembly, which is $4.4 \mathrm{~kg}$. Defining the mass of the impactor assembly is important because it is used in the calculation of the kinetic energy of the impactor just before impact. 
Table 17: MAT55 Material properties for unidirectional Flax/Epoxy lamina [11]

\begin{tabular}{|ccc|}
\hline Parameter & Units & Value \\
\hline EA & $\mathrm{MPa}$ & 31420 \\
\hline PRBA & $\mathrm{MPa}$ & 5580 \\
\hline GAB & --- & 0.353 \\
\hline XT & $\mathrm{MPa}$ & 2070 \\
\hline XC & $\mathrm{MPa}$ & 287.7 \\
\hline YT & $\mathrm{MPa}$ & 127.1 \\
\hline YC & $\mathrm{MPa}$ & 33.86 \\
\hline SC & $\mathrm{MPa}$ & 79.94 \\
\hline DFAILM & $\mathrm{MPa}$ & 37.35 \\
\hline DFAILS & $\mathrm{mm} / \mathrm{mm}$ & 0.006 \\
\hline DFAILT & $\mathrm{mm} / \mathrm{mm}$ & 0.018 \\
\hline DFAILC & $\mathrm{mm} / \mathrm{mm}$ & 0.009 \\
\hline
\end{tabular}

The fail strains DFAILM, DFAILS, DFAILT and DFAILC are defined by linear functions in terms of the mechanical properties obtained experimentally from [11].

$$
\begin{aligned}
& \text { DFAILT }=X_{T} / E_{A} \\
& \text { DFAILC }=X_{C} / E_{A} \\
& \text { DFAILM }=Y_{T} / E_{B} \text { or } Y_{C} / E_{B} \\
& \text { DFAILS }=S_{C} / G_{A B}
\end{aligned}
$$

It is worth noting that the above equations assume the failure strains as linear functions of the tensile strength and elastic modulus. Under dynamic conditions, a degree of strain hardening occurs and this can be idealized as an elastic-plastic stress/strain curve. Also, flax fibres exhibit 
non-linearity in its tensile stress-strain behaviour. MAT54/55 material card in LS-DYNA currently does not provide this flexibility in defining the elastic-plastic stress strain curve of the material. This simplified method, however, should provide a reasonable result as a starting point. Material damage factors can later be adjusted to obtain reasonable correlation with the experimental impact test results. The following MAT54/55 damage factors were used in the FEM. These values were obtained iteratively to match the experimental results with some degree of accuracy. ALPH $=0$ and BETA $=0$ approaches are considered appropriate for materials showing brittle behaviour [52].

\section{Table 18: MAT54/55 Damage Factors Input for Flax/Epoxy Lamina}

\begin{tabular}{|cc|}
\hline Parameter & Value \\
\hline FBRT & 0.2 \\
\hline YCFAC & 1.5 \\
\hline SOFT & 0.2 \\
\hline ALPH & 0.0 \\
\hline BETA & 0.0 \\
\hline
\end{tabular}

\subsection{INITIAL IMPACT CONDITION}

For the unidirectional flax/epoxy composite $\left[0_{8 \mathrm{~F}}\right]_{\mathrm{S}}$, the low velocity impact simulations were conducted for impact energies of $\mathrm{E}=5 \mathrm{~J}, 7 \mathrm{~J}, 8 \mathrm{~J}, 9 \mathrm{~J}$ and $10 \mathrm{~J}$. For the cross-ply flax/epoxy composite $\left[(0 / 90)_{4 \mathrm{~F}}\right]_{\mathrm{S}}$, the simulations were conducted for impact energies between $5 \mathrm{~J}$ to $30 \mathrm{~J}$ inclusively, in increments of $5 \mathrm{~J}$. The impact energies were applied to the model as initial velocities on the impactor. Table 19 shows the relationship between impact energy and impact velocity, based on the conservation of energy equation:

$$
V_{\text {impact }}=\sqrt{2 g H_{1}}
$$

where $\mathrm{H}_{1}$ is the initial pendulum drop height and $\mathrm{g}$ is the acceleration due to gravity. 


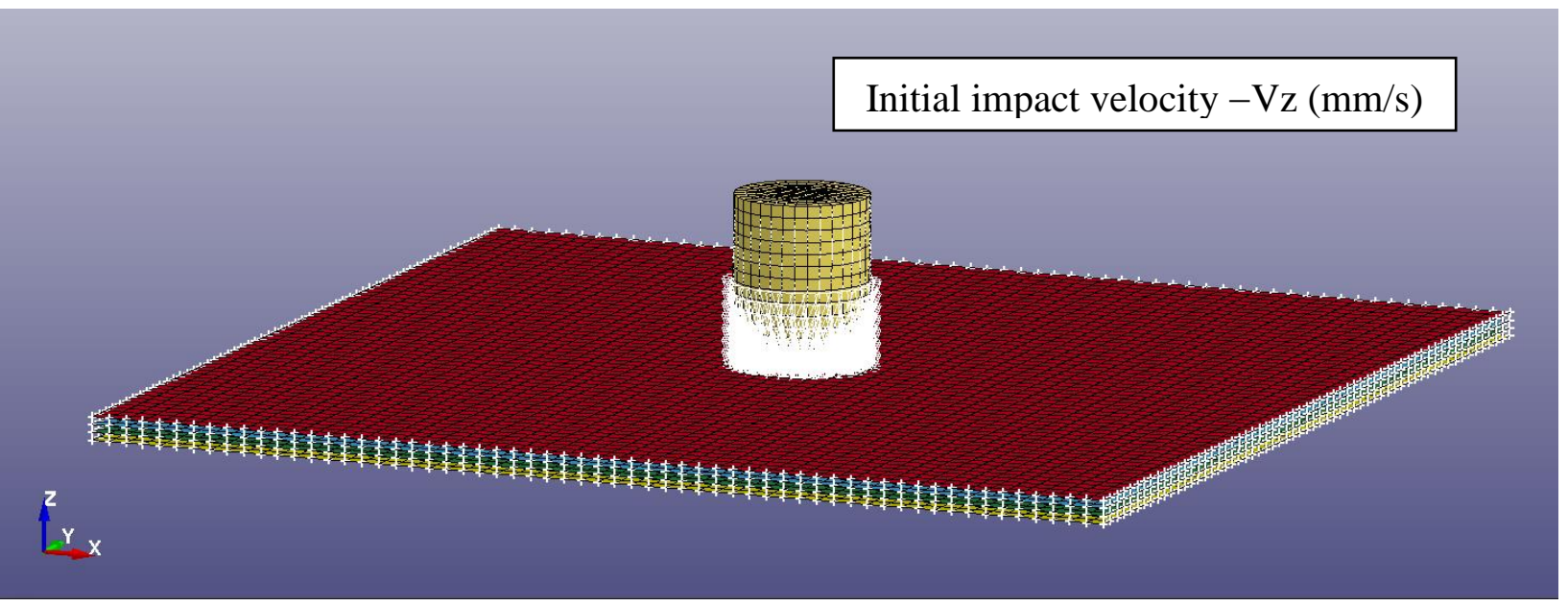

Figure 167: Initial velocity application

Table 19: Impact Velocity vs. Impact Energy for the Pendulum Impact Apparatus

\begin{tabular}{|cc|}
\hline Impact Energy & Impact Velocity \\
\hline $5 \mathrm{~J}$ & $1508 \mathrm{~mm} / \mathrm{s}$ \\
\hline $7 \mathrm{~J}$ & $1784 \mathrm{~mm} / \mathrm{s}$ \\
\hline $8 \mathrm{~J}$ & $1908 \mathrm{~mm} / \mathrm{s}$ \\
\hline $9 \mathrm{~J}$ & $2024 \mathrm{~mm} / \mathrm{s}$ \\
\hline $10 \mathrm{~J}$ & $2133 \mathrm{~mm} / \mathrm{s}$ \\
\hline $15 \mathrm{~J}$ & $2612 \mathrm{~mm} / \mathrm{s}$ \\
\hline $20 \mathrm{~J}$ & $3016 \mathrm{~mm} / \mathrm{s}$ \\
\hline $25 \mathrm{~J}$ & $3372 \mathrm{~mm} / \mathrm{s}$ \\
\hline $30 \mathrm{~J}$ & $3694 \mathrm{~mm} / \mathrm{s}$ \\
\hline
\end{tabular}

\subsection{BOUNDARY CONDITION}

During the impact test, the composite plate was clamped into the impact fixture on all four sides. To model the same setup in LS_DYNA, all edges of the composite were constrained in all degrees of freedom using an SPC (single-point constraint) boundary condition. 

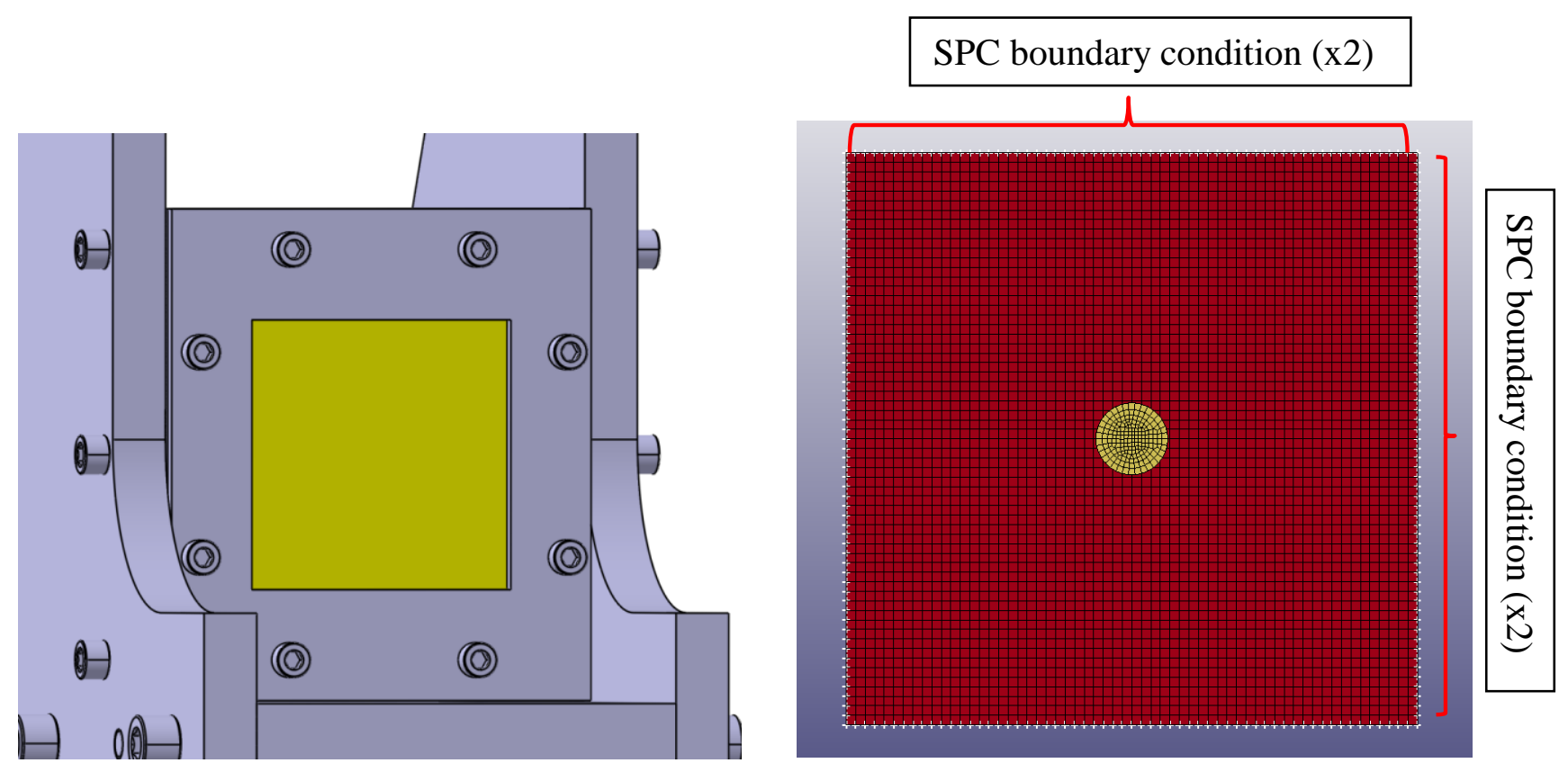

Figure 168: SPC boundary condition on the composite model

\subsection{TIME STEP AND TERMINATION TIME}

The time step for outputting the history data was set to $1.00 \mathrm{e}-5 \mathrm{~s}$, and the termination time was set to $0.015 \mathrm{~s}$. This small value of the time step allowed for a total for 1500 data increments and the termination time was long enough to capture the entire impact event up to the beginning of rebound.

\subsection{MeSh CONVERGENCE STUdY}

In finite element modelling, a finer mesh typically results in a more accurate solution. However, as the element size becomes smaller, the computation time also increases. The purpose of a mesh convergence study is to determine the optimum element/mesh size that will ensure that the results of the analysis are not affected by changing the size of the mesh. In this mesh sensitivity study, the number of elements across one side of the laminate were varied between 20 to 70 elements, in increments of 10. These correspond to element sizes of $6.35 \mathrm{~mm}, 4.23 \mathrm{~mm}, 3.18 \mathrm{~mm}$, $2.54 \mathrm{~mm}, 2.12 \mathrm{~mm}$ and $1.81 \mathrm{~mm}$, respectively. Table 20 summarizes the different mesh sizes considered in the study and Figure 169 shows the different mesh densities on the composite shell. 
Table 20: Element sizes considered for meshing

\begin{tabular}{|ccc|}
\hline Element Size & Number of Elements/Side & Total Elements per Shell \\
\hline $6.35 \mathrm{~mm}$ & 20 & 400 \\
\hline $4.23 \mathrm{~mm}$ & 30 & 900 \\
\hline $3.18 \mathrm{~mm}$ & 40 & 1600 \\
\hline $2.54 \mathrm{~mm}$ & 50 & 2500 \\
\hline $2.12 \mathrm{~mm}$ & 60 & 3600 \\
\hline $1.81 \mathrm{~mm}$ & 70 & 4900 \\
\hline
\end{tabular}

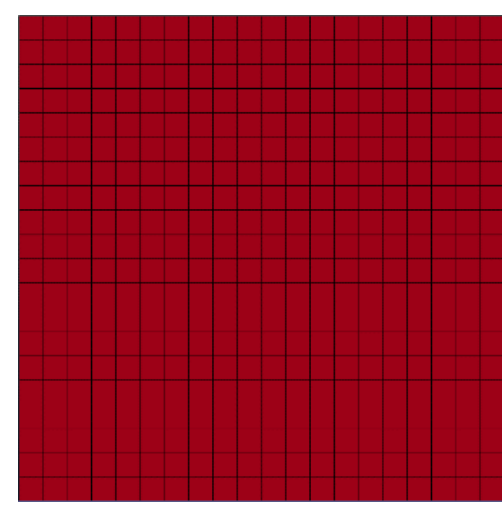

(a) $6.35 \mathrm{~mm}$

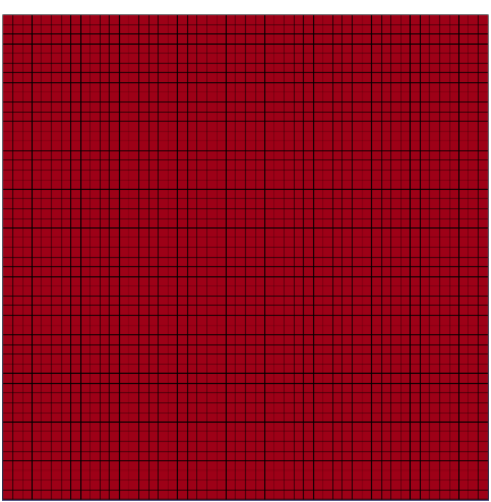

(a) $2.54 \mathrm{~mm}$

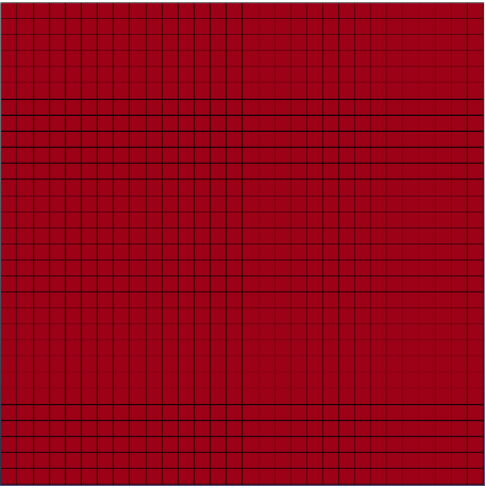

(b) $4.23 \mathrm{~mm}$

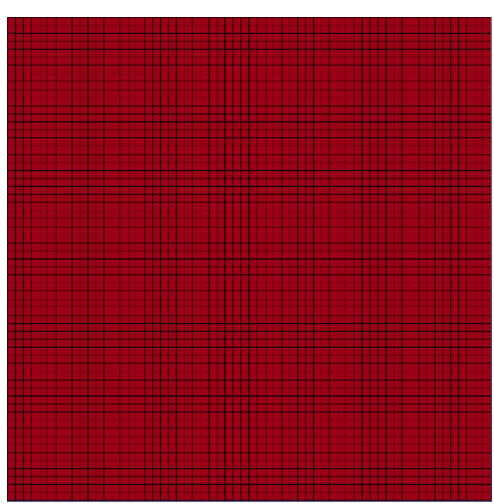

(b) $2.12 \mathrm{~mm}$

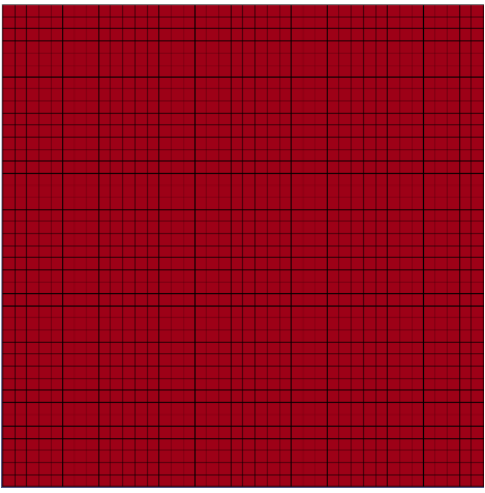

(c) $3.18 \mathrm{~mm}$

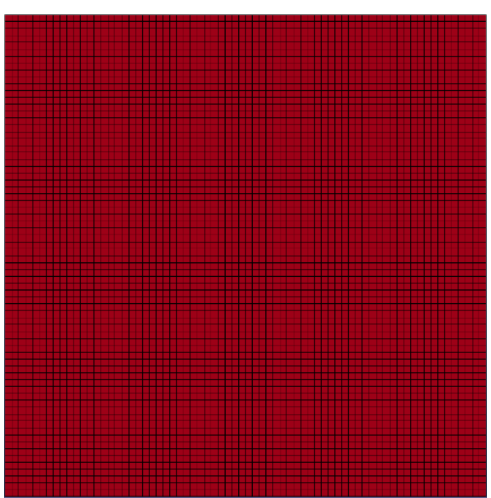

(c) $1.81 \mathrm{~mm}$

Figure 169: Element sizes considered in the mesh convergence study

Figure 170 shows the results of the mesh convergence study. Only three impact energy cases $(5 \mathrm{~J}, 7 \mathrm{~J}$ and $9 \mathrm{~J}$ ) for the unidirectional flax/epoxy laminate were analyzed for mesh convergence because these cases already provided consistent results on the optimum element size. 


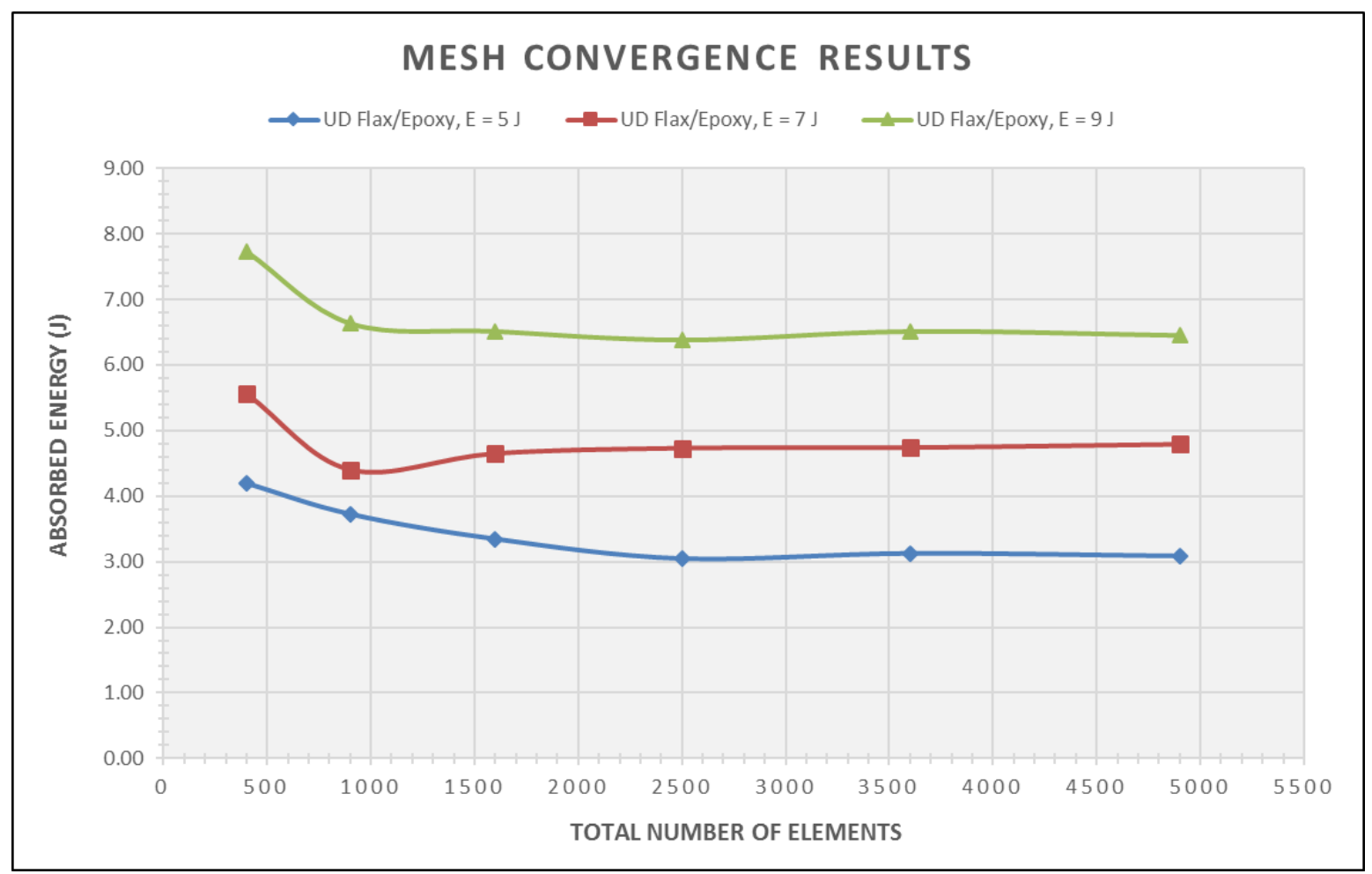

Figure 170: Mesh convergence study results

The above graphs show that mesh convergence was obtained using a minimum number of 2500 elements per shell or an element size of $2.54 \mathrm{~mm}$. Further reducing the element size did not change the values of the energy absorbed by the laminate. Thus, for the remaining analyses, a slightly finer element size of $2.12 \mathrm{~mm}$ will be used, resulting in 3600 elements per composite shell.

\subsection{LS-DYNA SIMULATION RESULTS}

The impact behaviour of a composite laminate under low velocity impact is typically characterized in terms of the force versus time, deflection versus time and force versus deflection. These plots provide information on how the material behaves during the impact process [49]. For instance, from the force vs. time curve, a load drop would indicate fracture initiation. From the contact force versus deflection curve, it is also possible to perceive whether the impact event is elastic (i.e. rebounding), or whether the impactor is penetrating or perforating into the composite material [52]. The representative graphs for these three cases are shown in Figure 171. 

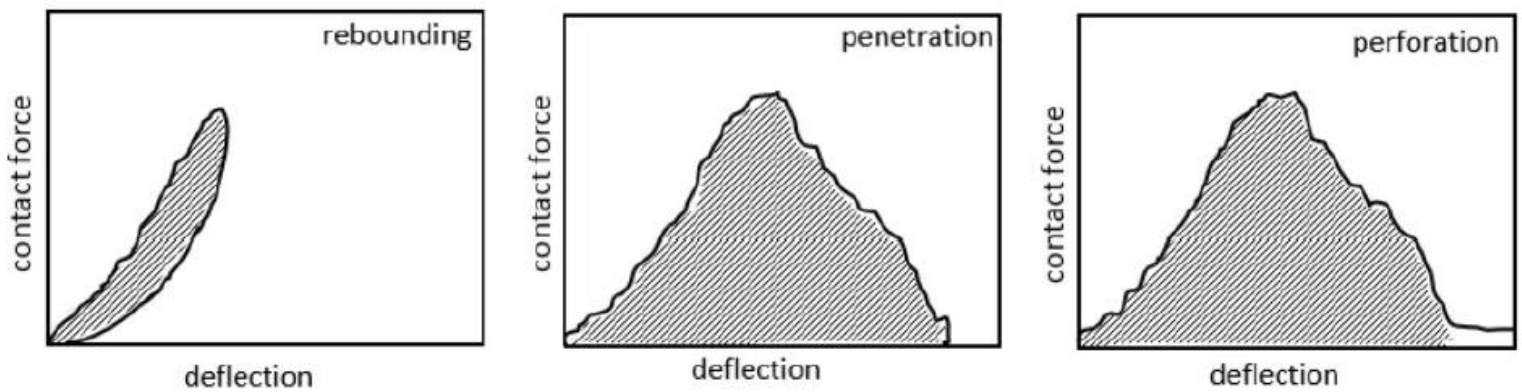

Figure 171: Force-deflection curves for composites subjected to low velocity impact [52]

From the above figures, rebounding occurs when the contact force increases with deflection. At the end of the impact event, both contact force and deflection decreases back to zero (perfectly elastic) or to some finite deflection less than the maximum deflection at maximum contact force. Penetration occurs when the deflection after impact continues to increase after the maximum contact force is reached. Perforation occurs when the curve remains parallel to the deflection axis after the maximum deflection have been achieved [52]. From the contact force versus deflection curve, the energy absorbed by the composite is obtained by calculating the area under the curve (i.e. by integrating the force vs. deflection curve).

Figure 172 to Figure 177 show the contact force vs. time, deflection vs. time and contact force vs. deflection curves for the flax/epoxy composites, respectively. From the contact forcetime graphs, it can be observed that peak force, deflection and contact duration increase with the impact energy. In the loading part of the curve, the contact force initially increased with very small amplitude oscillations. These oscillations were mainly due to the elastic wave response and vibration of the composite during impact loading [79]. This phase was then followed by a few minor load drops, indicative of minor stiffness change caused by damage initiation in the form of matrix cracks and inter-ply delamination. For all cases, the contact-force time histories did not show a sudden significant load drop that would indicate laminate level damage during the impact event. Some differences were observed between the unidirectional and cross-ply composite impact behaviour. The unidirectional composite had lower peak contact force, longer contact duration and larger load drops compared to the cross-ply composite for the same energy level. This indicates that the unidirectional composites are less efficient in sustaining impact load compared to the cross-ply composites. 


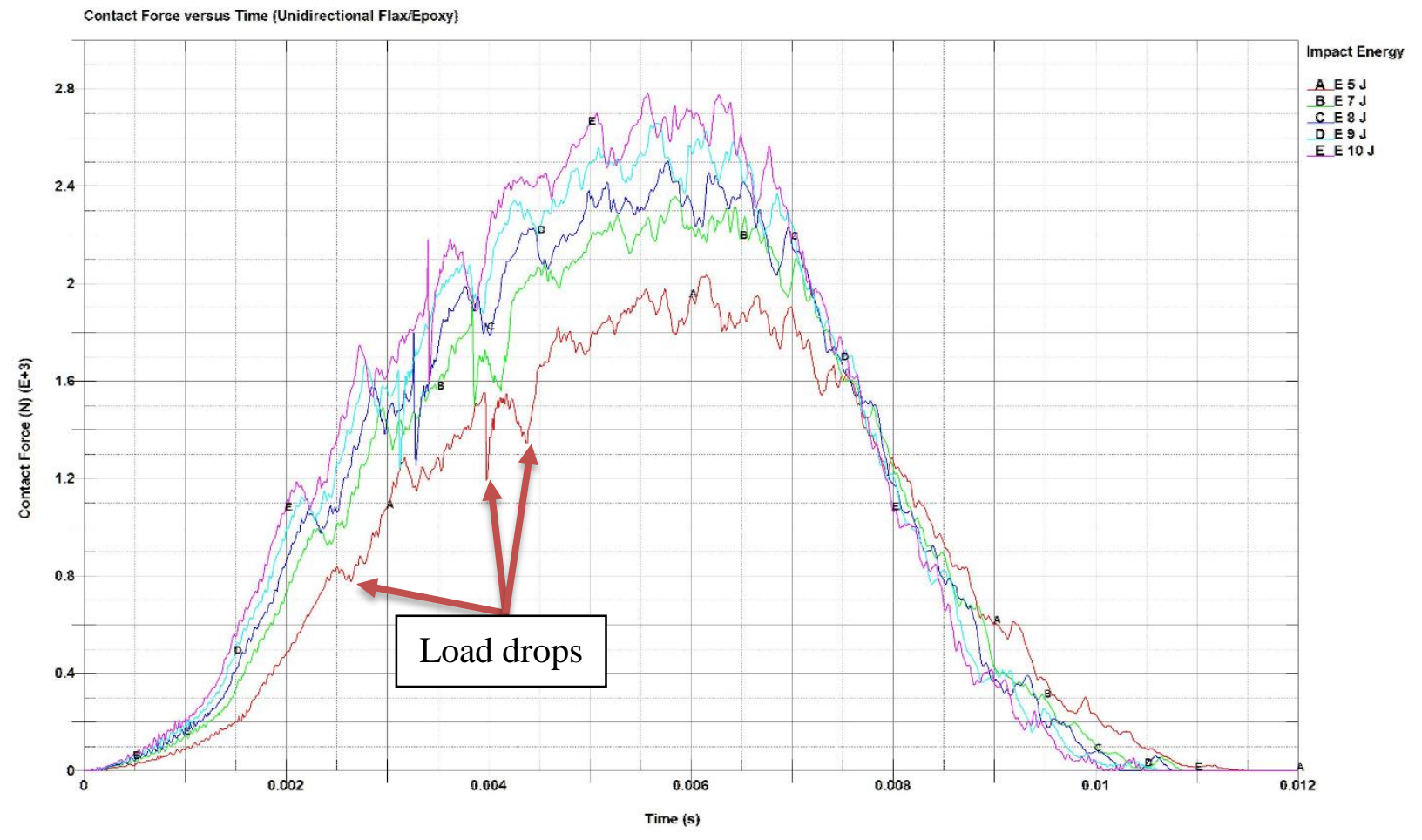

Figure 172: Contact force-time history plot for unidirectional flax/epoxy composite

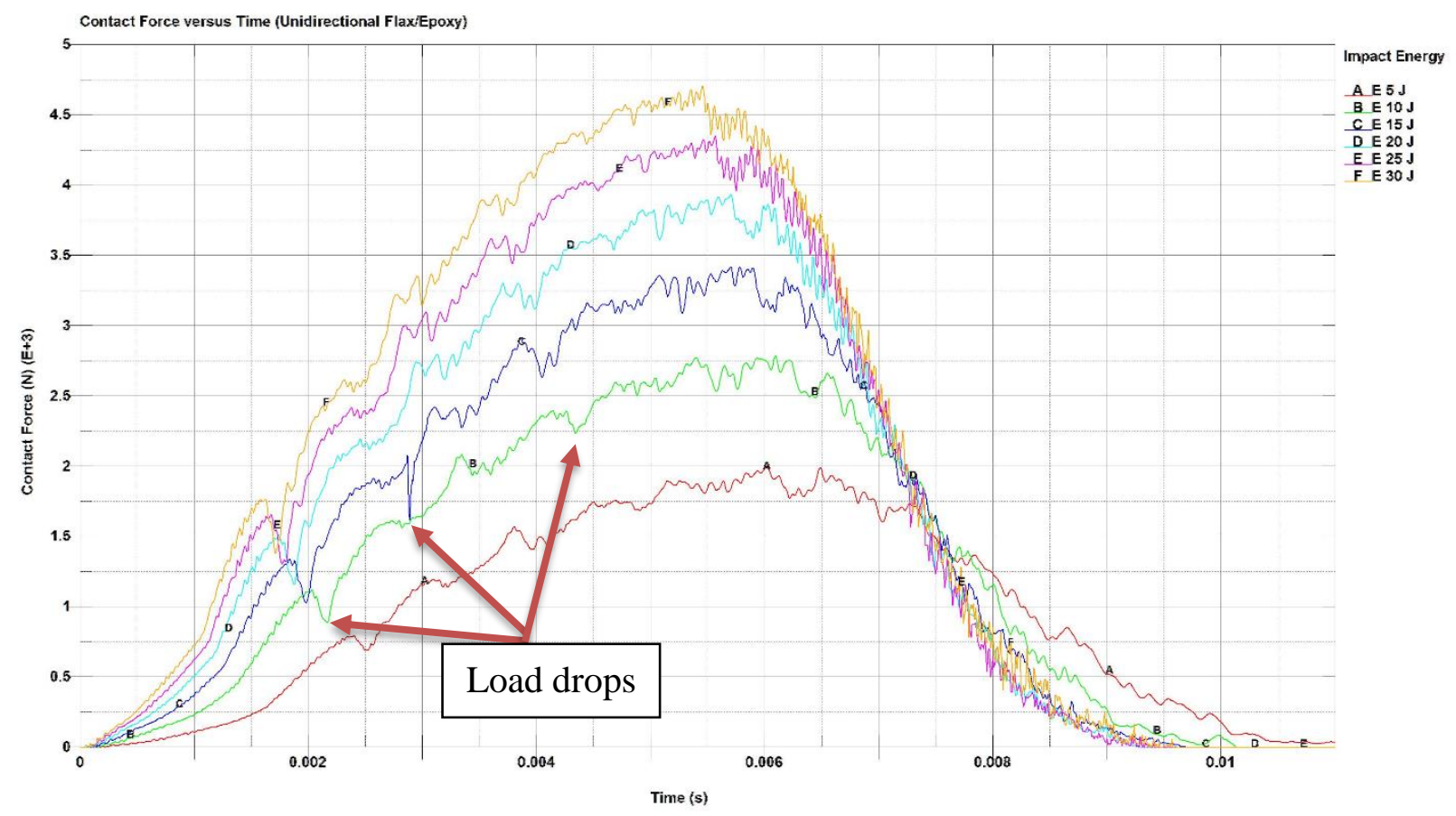

Figure 173: Contact force vs. time for cross-ply flax/epoxy composite 


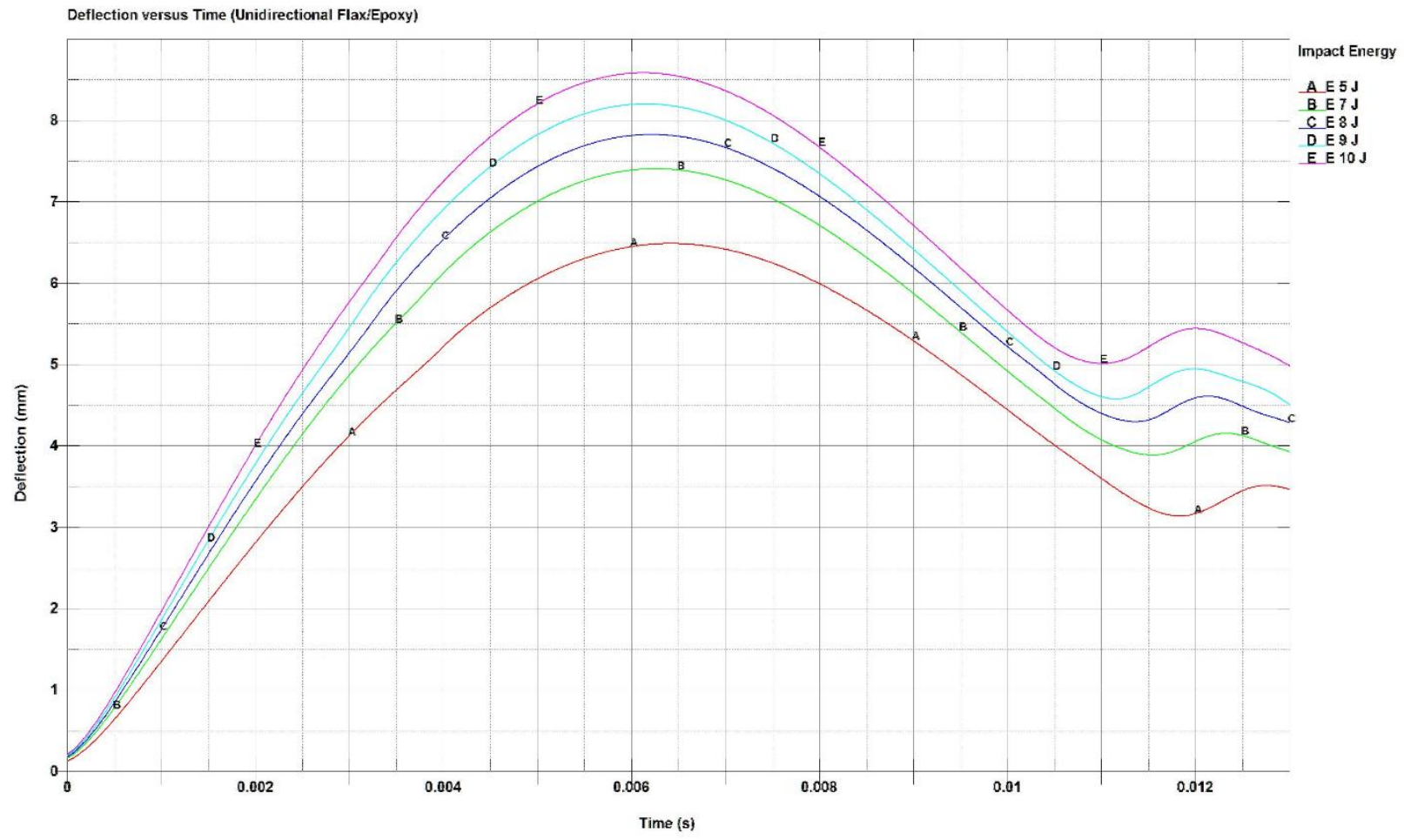

Figure 174: Deflection vs. time for unidirectional flax/epoxy composite

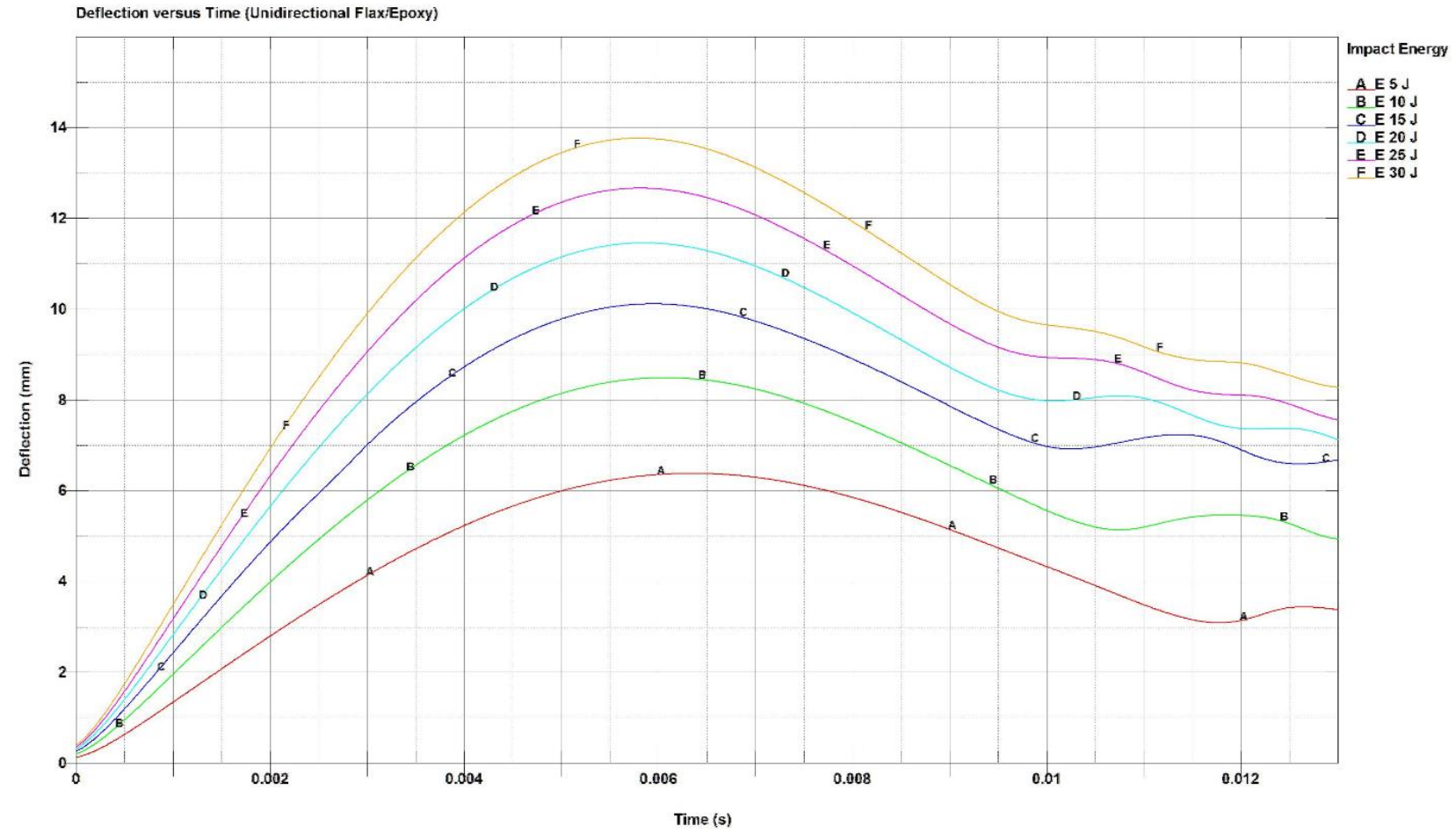

Figure 175: Deflection vs. time for cross-ply flax/epoxy composite 
The contact force versus displacement plots for the unidirectional and cross-ply flax/epoxy composites are shown in Figure 176 and Figure 177, respectively. In general, the forcedisplacement curves can be divided into three zones based on the different phases that occur during the impact event. Zone A indicates the elastic region during the loading stage. Within this region, the impact response of the composite is purely elastic. In zone B, force perturbations occur during loading because of damage initiation in the composite. This region extends up to the peak of the curve where the peak force and plate deflection are at maximum. The larger Zone B is, the larger the damage development within the laminate [69]. Zone $\mathrm{C}$ indicates the unloading region of the curve during rebound. The resulting deflection at the end of this zone indicates the residual permanent depression on the laminate [69].

From the force-deflection curves, it can be observed that all cases are rebounding. The unloading part of each curve was well separated from the loading part, indicating that the specimens absorbed a significant fraction of the impact energy. The energy absorbed, which is the area under the force-deflection curve, increased with increasing impact energy.

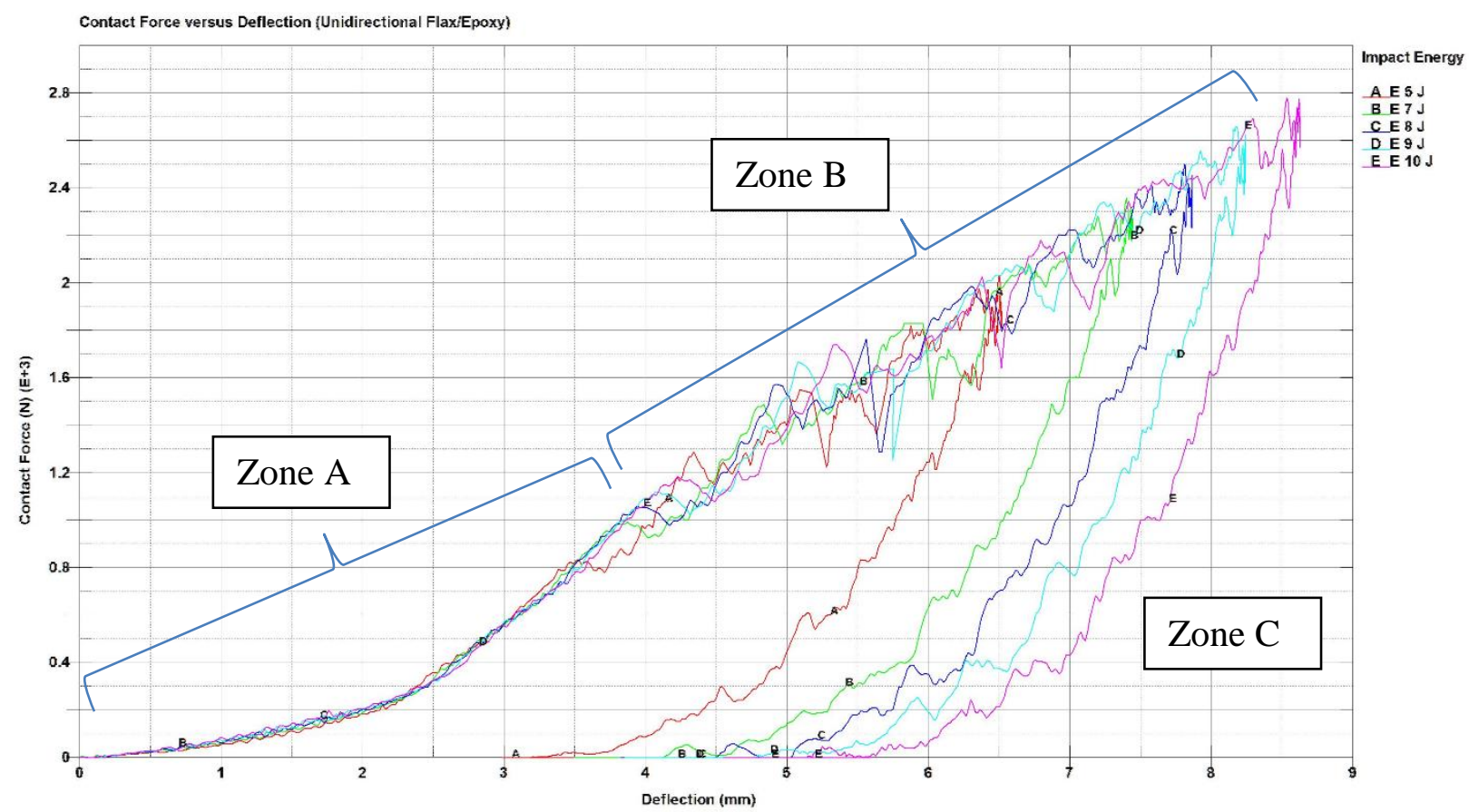

Figure 176: Contact force versus deflection for unidirectional flax/epoxy composite 


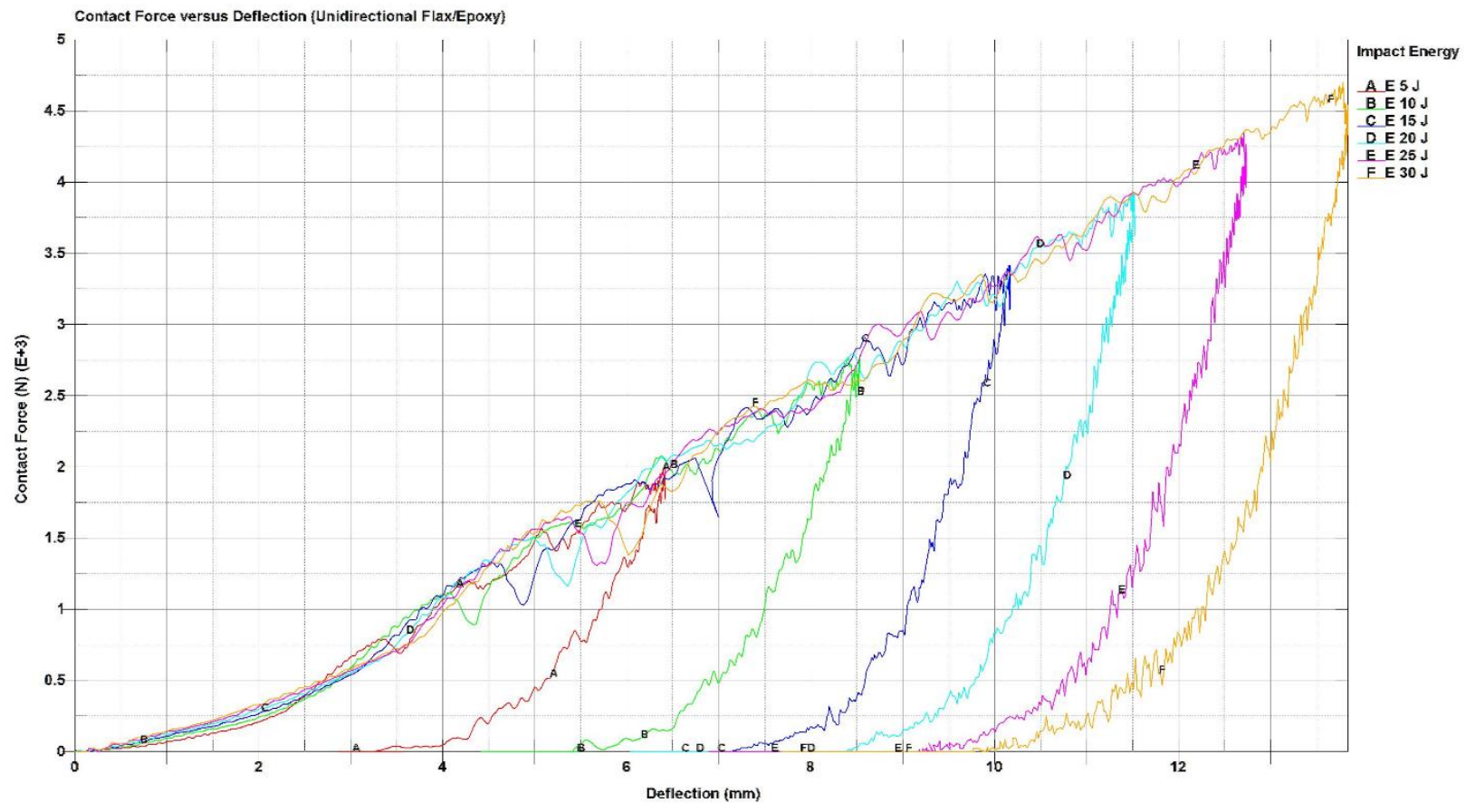

Figure 177: Contact force versus deflection for cross-ply flax/epoxy composite

The following table compares the energy absorbed between the numerical and experimental results. The energy absorbed is calculated by integrating the area under the forcedisplacement curves.

Table 21: Experimental vs. numerical results for absorbed energy for $\left[0_{8 \mathrm{~F}}\right]_{\mathrm{S}}$

\begin{tabular}{|cccc|}
\multirow{2}{*}{ Impact Energy (J) } & \multicolumn{2}{c}{ Absorbed Energy (J) } & Percentage Difference \\
\cline { 2 - 3 } & Experimental & Numerical & $7.96 \%$ \\
\hline $\mathbf{5}$ & 2.89 & 3.12 & $2.16 \%$ \\
\hline $\mathbf{7}$ & 4.64 & 4.74 & $10.31 \%$ \\
\hline $\mathbf{9}$ & 5.14 & 5.67 & $7.25 \%$ \\
\hline $\mathbf{1 0}$ & 6.07 & 6.51 & $25.9 \%$ \\
\hline
\end{tabular}


For the unidirectional flax/epoxy composite, there is a good correlation between the experimental and numerical results in terms of absorbed energy. For the rebounding cases $(\mathrm{E}<10$ $\mathrm{J})$, the percentage difference between the experimental and numerical results is $<10.3 \%$. At $\mathrm{E}=$ $10 \mathrm{~J}$, the percentage error is higher at $26 \%$.

The numerical model could predict the rebounding cases but could not accurately predict the sudden fracture at $\mathrm{E}=10 \mathrm{~J}$. This can be attributed to the brittle nature of the flax/epoxy composite and the large scatter in the mechanical properties of flax fibres. Moreover, few assumptions were made when defining the stress-strain behaviour of the material. In the analysis, the failure strains were assumed to be linear functions of the tensile strength and elastic modulus. Under dynamic conditions, a degree of strain hardening occurs, which can be idealized as an elastic-plastic stress/strain curve. Also, flax fibres exhibit non-linearity in its tensile stress-strain behaviour, which is not accurately captured in the model.

Table 22: Experimental vs. numerical results for absorbed energy for $\left[(0 / 90)_{4 \mathrm{~F}}\right]_{\mathrm{S}}$

\begin{tabular}{|cccc|}
\hline \multirow{2}{*}{ Impact Energy $(\mathbf{J})$} & \multicolumn{2}{c}{ Absorbed Energy $(\mathbf{J})$} & Percentage Difference \\
& Experimental & Numerical & \\
\hline $\mathbf{5}$ & 3.13 & 3.22 & $2.88 \%$ \\
\hline $\mathbf{1 0}$ & 6.67 & 7.49 & $12.29 \%$ \\
\hline $\mathbf{1 5}$ & 10.77 & 12.4 & $15.13 \%$ \\
\hline $\mathbf{2 0}$ & 14.63 & 16.4 & $12.10 \%$ \\
\hline $\mathbf{2 5}$ & 18.98 & 20.9 & $10.12 \%$ \\
\hline $\mathbf{3 0}$ & 24.3 & 25.3 & $4.12 \%$ \\
\hline
\end{tabular}

For the cross-ply flax/epoxy composite, the numerical results were slightly over-predicting the absorbed energy compared to those measured experimentally. The maximum percentage difference in the experimental and numerical results is $15.13 \%$.

Overall, the numerical approach provided a good starting point in numerically modelling the impact response of the flax/epoxy composite under impact loading. Considering the large variability in the mechanical properties of flax and the assumptions made in terms of its stress- 
strain behaviour, the model provides a reasonable prediction of the composite response under low velocity impact loading. The model can be improved by further refining the material properties and adjusting the damage factors to provide an even better correlation with the experimental results. Moreover, modelling each lamina as solid elements with cohesive elements modelled in between plies will provide better results as this includes proper modelling of delamination damage, which is an important energy absorption mechanism during an impact event. This modelling technique, however, is more complicated and required significant analysis run time.

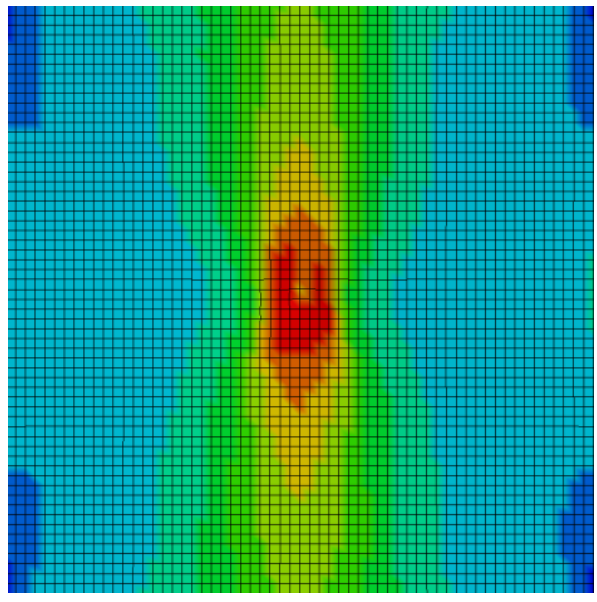

(Front Face)

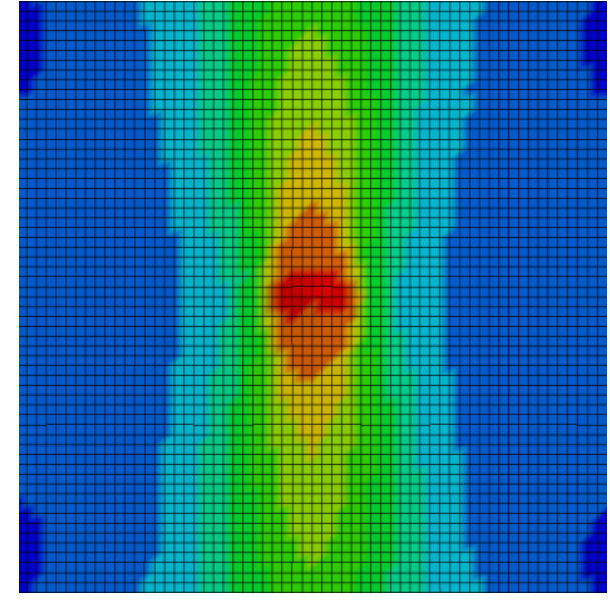

(Back Face)

Figure 178: Typical Von-Mises stress plot of the impacted unidirectional flax/epoxy

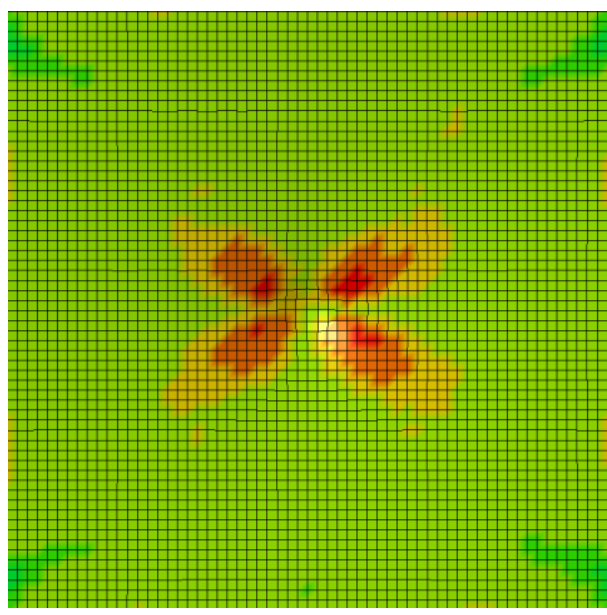

(Front Face)

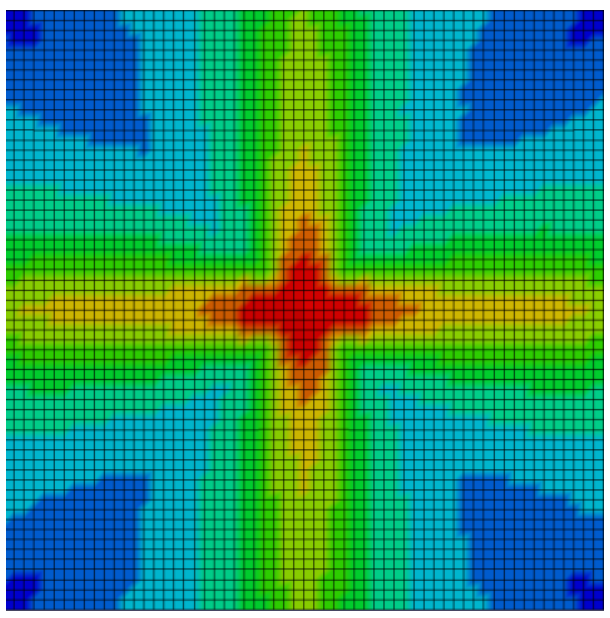

(Back Face)

Figure 179: Typical Von-Mises stress plot of the impacted cross-ply flax/epoxy 


\section{CONCLUSION AND FUtURE WORK}

The use of synthetic fibre-reinforced polymer composites in aerospace, automotive and sporting industries has increased significantly over the years. Composite materials have allowed different industries to produce advanced, light-weight and high-performance composite structural replacement for metallic materials. One of the downside of synthetic-fibre PMCs, however, is their recyclability. In addition, the production of carbon-based fibres also contributes to increased greenhouse gas emissions. Recent push for sustainability and recyclability have forced industries to find an alternative and eco-friendly materials to produce compatible composites. As a result, scientist and the industry alike have turned to plant-based natural fibres because they offer sustainability, biodegradability, abundance, cost savings and lower specific gravity when compared to synthetic fibres like glass and carbon. Although their strengths are relatively lower than synthetic fibres, they have comparable specific properties and acceptable mechanical properties, which makes them a good replacement to synthetic fibres.

In this research work, low velocity impact characterization of flax-based polymer composites was conducted. This study is part of a bigger research activity conducted in the Mechanical and Aerospace departments at Ryerson University on the material characterization of flax/epoxy composites and their hybrids for use in the aerospace and bio-medical applications. Specific to this research, experimental assessment of low velocity impact behaviour of flax/epoxy and Kevlar-flax/epoxy composites have been conducted using a pendulum-type impact apparatus, with IR thermography to monitor the material damage evolution during the impact event. Numerical impact analysis was also carried out using LS-Dyna to create a model that correlates with the experimental results. The objective of the numerical analysis is to establish the basic modelling parameters required to be able to reproduce the results of the experiment. The goal is to be able to analytically evaluate the impact performance of different lay-up configurations of flaxbased polymer composites without conducting further experiments.

The results of experiments conducted in this study showed that the unidirectional flax/epoxy composite exhibited poor impact behaviour under low velocity impact with an energy penetration threshold of only $10 \mathrm{~J}$ and an impact toughness of $34 \mathrm{~kJ} / \mathrm{m}^{2}$. The composite displayed brittle 
fracture at impact, with matrix cracking, fibre breakage, debonding and pull-out as the damage mechanisms involved during the composite fracture. The cross-ply flax/epoxy composite on the other hand performed significantly better than the unidirectional composite, achieving an energy penetration threshold of $30 \mathrm{~J}$ and an impact toughness of $85 \mathrm{~kJ} / \mathrm{m}^{2}$. The presence of the $90^{\circ}$ layers in the cross-ply configuration helped stop the matrix crack propagation through the laminate thickness, thus allowing it to absorb more energy during an impact event.

The hybridization with Kevlar had significantly improved the impact toughness of the unidirectional flax/epoxy composite, increasing the energy penetration threshold three times and the impact toughness five times. Hybridization with Kevlar on the other hand had reduced the energy penetration threshold of the cross-ply flax/epoxy composite from $30 \mathrm{~J}$ to $27 \mathrm{~J}$, but improved its impact toughness from $85 \mathrm{~kJ} / \mathrm{m}^{2}$ to $187 \mathrm{~kJ} / \mathrm{m}^{2}$. Kevlar is tougher and more ductile than flax. Hence, the presence of Kevlar layers allowed to the flax/epoxy composite to absorb energy effectively and in a more compliant manner. Both the hybrid composites have similar impact toughness of $187 \mathrm{~kJ} / \mathrm{m}^{2}$, which is comparable (or slightly better) to those of aluminum alloys and carbon/epoxy composites.

Unidirectional Kevlar-flax/epoxy composites are suitable in applications where the mode of loading is primarily axial, and both tensile strength, stiffness and impact resistance are required. For applications where both axial, shear and/or flexure loading are present, but also requires good damping and impact resistance, the use cross-ply or angle-ply flax/epoxy composite with Kevlarreinforcement is suitable. Examples of such applications are sporting equipment such as bicycle, helmets and tennis racquets.

One of the major drawbacks of use of flax-based polymer composites in structural applications is its hydrophilicity or high moisture absorption rate. This results in increased weight and mechanical property degradation over time, which are not favourable in such applications. Currently, silane and alkali treatments are performed on flax fibers to mitigate this problem; however, it is not as effective as desired. Flax fibres have good potential to replace glass and other synthetic fibres in structural applications across different industries. Therefore, future research should focus on improving its mechanical properties and moisture resistance to extend is usage 
across a range of industries including automotive, aerospace, construction, civil and sports industries. This will result in lower cost with improved sustainability which will benefit both the environment and the industries alike.

Other future work relevant to this research could include the following:

1. Perform low velocity impact tests other flax/epoxy configurations such as angle-ply and quasi-isotropic laminates.

2. Provide instrumentation to the impact apparatus to record the load-time, deflection-time and load-deflection histories during the impact event. Having this data will be valuable in performing correlation with the numerical analysis results.

3. Perform impact tests on other hybrid configurations such as glass/epoxy and carbon/epoxy to compare its impact performance with the Kevlar/flax-epoxy hybrid composite.

4. Adjust the different test parameters such as the laminate thickness and impactor tip shape and diameter to investigate their effects on the impact response and energy absorption capacity of the composite.

5. Improve the numerical model by adjusting the material and damage parameters to obtain a better correlation with the experimental results. Furthermore, the FE model can be improved by modelling each lamina with solid layers and inter-ply cohesive elements to properly model delamination. 


\section{APPENDIX}

\section{A1 RAW EXPERIMENTAL DATA}

Table 23: Experimental data and results for the $\left[0_{8 F}\right]_{s}$ composite

\begin{tabular}{|c|c|c|c|c|c|c|c|c|c|c|}
\hline Specimen ID & $\begin{array}{l}\theta_{1} \\
\left({ }^{\circ}\right)\end{array}$ & $\begin{array}{l}\theta_{2} \\
\left({ }^{\circ}\right)\end{array}$ & $\begin{array}{l}\Delta \theta \\
\left({ }^{\circ}\right)\end{array}$ & $\begin{array}{c}\mathbf{E} \\
(\mathbf{J})\end{array}$ & $\begin{array}{l}\text { Ereb } \\
(J)\end{array}$ & $\begin{array}{l}\text { Eabs } \\
(\mathbf{J})\end{array}$ & $\% \mathbf{E}_{a b s}$ & $\begin{array}{l}\mathbf{T}_{1} \\
\left({ }^{\circ} \mathbf{C}\right)\end{array}$ & $\begin{array}{c}\mathbf{T}_{2} \\
\left({ }^{\circ} \mathbf{C}\right)\end{array}$ & $\begin{array}{l}\Delta \mathrm{T} \\
\left({ }^{\circ} \mathbf{C}\right)\end{array}$ \\
\hline PF-UD-01-1 & 40.9 & 25.6 & 15.3 & 4.8 & 1.9 & 2.9 & $59.77 \%$ & 25.1 & 28.1 & 3.0 \\
\hline PF-UD-02-1 & 42.0 & 27.6 & 14.5 & 5.0 & 2.2 & 2.8 & $55.85 \%$ & 25.6 & 29.4 & 3.8 \\
\hline PF-UD-02-2 & 41.7 & 27.3 & 14.4 & 4.9 & 2.2 & 2.8 & $56.01 \%$ & 24.6 & 28.0 & 3.4 \\
\hline PF-UD-05-3 & 42.0 & 25.5 & 16.6 & 5.0 & 1.9 & 3.1 & $62.27 \%$ & 25.3 & 29.4 & 4.1 \\
\hline PF-UD-01-3 & 50.1 & 26.4 & 23.7 & 7.0 & 2.0 & 5.0 & $70.95 \%$ & 25.2 & 29.6 & 4.4 \\
\hline PF-UD-02-3 & 50.1 & 30.1 & 20.0 & 7.0 & 2.6 & 4.4 & $62.38 \%$ & 24.4 & 29.6 & 5.2 \\
\hline PF-UD-02-4 & 50.3 & 30.1 & 20.2 & 7.1 & 2.6 & 4.4 & $62.70 \%$ & 24.2 & 29.2 & 5.0 \\
\hline PF-UD-05-1 & 50.5 & 28.3 & 22.2 & 7.1 & 2.3 & 4.8 & $67.11 \%$ & 24.2 & 29.3 & 5.1 \\
\hline PF-UD-03-1 & 54.4 & 32.3 & 22.0 & 8.2 & 3.0 & 5.1 & $62.87 \%$ & 24.8 & 30.0 & 5.2 \\
\hline PF-UD-03-2 & 53.6 & 31.9 & 21.7 & 8.0 & 3.0 & 5.0 & $62.81 \%$ & 24.7 & 30.4 & 5.7 \\
\hline PF-UD-03-3 & 53.9 & 30.8 & 23.1 & 8.0 & 2.8 & 5.3 & $65.73 \%$ & 25.0 & 31.2 & 6.2 \\
\hline PF-UD-03-4 & 57.4 & 33.1 & 24.2 & 9.0 & 3.2 & 5.8 & $64.73 \%$ & 25.1 & 31.1 & 6.0 \\
\hline PF-UD-04-1 & 56.8 & 32.2 & 24.6 & 8.8 & 3.0 & 5.8 & $65.99 \%$ & 25.1 & 32.1 & 7.0 \\
\hline PF-UD-04-2 & 57.4 & 30.5 & 26.9 & 9.0 & 2.7 & 6.3 & $70.05 \%$ & 24.8 & 30.7 & 5.9 \\
\hline PF-UD-05-2 & 57.5 & 30.8 & 26.7 & 9.1 & 2.8 & 6.3 & $69.46 \%$ & 25.4 & 31.6 & 6.2 \\
\hline PF-UD-04-3 & 58.8 & 32.3 & 26.5 & 9.4 & 3.0 & 6.4 & $67.93 \%$ & 25.4 & 30.9 & 5.5 \\
\hline PF-UD-04-4 & 59.7 & 31.9 & 27.8 & 9.7 & 3.0 & 6.7 & $69.50 \%$ & 25.3 & 31.8 & 6.5 \\
\hline PF-UD-05-4 & 59.0 & 32.3 & 26.6 & 9.5 & 3.0 & 6.4 & $68.02 \%$ & 25.5 & 31.3 & 5.8 \\
\hline PF-UD-01-2 & 61.3 & 0.0 & 61.3 & 10.2 & 0.0 & 10.2 & $100.00 \%$ & 25.0 & 34.6 & 9.6 \\
\hline PF-UD-01-4 & 61.4 & 0.0 & 61.4 & 10.0 & 0.0 & 10.0 & $100.00 \%$ & 24.9 & 35.5 & 10.6 \\
\hline \multicolumn{11}{|l|}{ Legend: } \\
\hline$\theta_{1}$ & \multicolumn{10}{|c|}{ Initial Pendulum Drop Angle } \\
\hline$\theta_{2}$ & \multicolumn{4}{|c|}{ Final Pendulum Rebound Angle } & $E_{\text {reb }}$ & \multicolumn{5}{|c|}{ Rebound Energy } \\
\hline$\Delta \theta$ & \multirow{2}{*}{\multicolumn{4}{|c|}{$\begin{array}{l}\text { Difference between } \theta_{1} \text { and } \theta_{2} \\
\text { Initial Temperature at impact loci }\end{array}$}} & $E_{a b s}$ & \multicolumn{5}{|c|}{ Absorbed Energy } \\
\hline$T_{1}$ & & & & & $\Delta T$ & Cha & ge in temp & ature at & mpact & \\
\hline$T_{2}$ & \multicolumn{10}{|c|}{ Final Temperature at impact loci } \\
\hline
\end{tabular}


Table 24: Experimental data and results for the $\left[(0 / 90)_{4 F}\right]_{s}$ composite

\begin{tabular}{|c|c|c|c|c|c|c|c|c|c|c|}
\hline Specimen ID & $\begin{array}{l}\theta_{1} \\
\left(^{\circ}\right)\end{array}$ & $\begin{array}{l}\theta_{2} \\
\left({ }^{\circ}\right)\end{array}$ & $\begin{array}{l}\Delta \theta \\
\left(^{\circ}\right)\end{array}$ & $\begin{array}{c}\mathbf{E} \\
(\mathbf{J})\end{array}$ & $\begin{array}{l}\text { E }_{\text {reb }} \\
\text { (J) }\end{array}$ & $\begin{array}{c}\mathbf{E}_{\mathrm{abs}} \\
(\mathrm{J})\end{array}$ & $\% \mathbf{E}_{a b s}$ & $\begin{array}{c}\mathbf{T}_{1} \\
\left({ }^{\circ} \mathbf{C}\right)\end{array}$ & $\begin{array}{c}\mathrm{T}_{2} \\
\left({ }^{\circ} \mathrm{C}\right)\end{array}$ & $\begin{array}{c}\Delta \mathrm{T} \\
\left({ }^{\circ} \mathrm{C}\right)\end{array}$ \\
\hline PF-CP-01-1 & 42.3 & 25.9 & 16.4 & 5.1 & 2.0 & 3.1 & $61.36 \%$ & 24.4 & 29.9 & 5.5 \\
\hline PF-CP-01-2 & 42.3 & 25.7 & 16.6 & 5.1 & 1.9 & 3.2 & $62.05 \%$ & 25.3 & 30.1 & 4.8 \\
\hline PF-CP-01-3 & 42.6 & 26.5 & 16.1 & 5.2 & 2.0 & 3.1 & $60.25 \%$ & 25.1 & 29.6 & 4.5 \\
\hline PF-CP-01-4 & 61.2 & 32.9 & 28.3 & 10.1 & 3.1 & 7.0 & $69.01 \%$ & 24.7 & 31.8 & 7.1 \\
\hline PF-CP-02-1 & 60.6 & 34.4 & 26.2 & 10.0 & 3.4 & 6.5 & $65.67 \%$ & 24.6 & 31.7 & 7.1 \\
\hline PF-CP-02-2 & 60.3 & 34.3 & 26.0 & 9.9 & 3.4 & 6.5 & $65.58 \%$ & 24.4 & 31.0 & 6.6 \\
\hline PF-CP-02-3 & 76.3 & 38.5 & 37.9 & 14.9 & 4.2 & 10.7 & $71.59 \%$ & 24.9 & 34.9 & 10.0 \\
\hline PF-CP-02-4 & 76.3 & 37.4 & 38.9 & 14.9 & 4.0 & 10.9 & $73.06 \%$ & 24.8 & 36.2 & 11.4 \\
\hline PF-CP-03-1 & 76.0 & 38.0 & 38.0 & 14.8 & 4.2 & 10.7 & $72.00 \%$ & 24.8 & 33.5 & 8.7 \\
\hline PF-CP-03-2 & 90.3 & 43.2 & 47.1 & 19.7 & 5.3 & 14.4 & $73.04 \%$ & 25.1 & 38.3 & 13.2 \\
\hline PF-CP-03-3 & 90.8 & 41.8 & 48.9 & 19.8 & 5.0 & 14.8 & $74.85 \%$ & 24.9 & 38.1 & 13.2 \\
\hline PF-CP-03-4 & 91.0 & 42.8 & 48.2 & 19.9 & 5.2 & 14.7 & $73.80 \%$ & 24.8 & 38.3 & 13.5 \\
\hline PF-CP-05-1 & 106.3 & 46.2 & 60.1 & 25.1 & 6.0 & 19.0 & $75.96 \%$ & 24.9 & 38.4 & 13.5 \\
\hline PF-CP-05-2 & 106.4 & 45.7 & 60.7 & 25.1 & 5.9 & 19.2 & $76.46 \%$ & 25.1 & 38.7 & 13.6 \\
\hline PF-CP-05-3 & 106.5 & 47.8 & 58.7 & 25.1 & 6.4 & 18.7 & $74.45 \%$ & 25.4 & 37.4 & 12.0 \\
\hline PF-CP-05-4 & 112.1 & 49.1 & 62.9 & 26.9 & 6.8 & 20.2 & $74.89 \%$ & 25.4 & 36.4 & 11.0 \\
\hline PF-CP-04-1 & 122.2 & 47.8 & 74.4 & 30.0 & 6.4 & 23.6 & $78.60 \%$ & 25.4 & 38.7 & 13.3 \\
\hline PF-CP-04-3 & 122.7 & 43.7 & 79.1 & 30.1 & 5.4 & 24.7 & $82.06 \%$ & 25.7 & 38.0 & 12.3 \\
\hline PF-CP-04-4 & 122.9 & 44.1 & 78.8 & 30.2 & 5.5 & 24.7 & $81.72 \%$ & 25.9 & 38.4 & 12.5 \\
\hline \multicolumn{11}{|l|}{ Legend: } \\
\hline$\theta_{1}$ & \multicolumn{4}{|c|}{ Initial Pendulum Drop Angle } & $E_{\text {inc }}$ & \multicolumn{5}{|c|}{ Incident impact energy } \\
\hline$\theta_{2}$ & \multicolumn{4}{|c|}{ Final Pendulum Rebound Angle } & $E_{\text {reb }}$ & \multicolumn{5}{|c|}{ Rebound Energy } \\
\hline$\Delta \theta$ & \multicolumn{4}{|c|}{ Difference between $\theta_{1}$ and $\theta_{2}$} & $E_{a b s}$ & \multicolumn{5}{|c|}{ Absorbed Energy } \\
\hline$T_{1}$ & \multicolumn{4}{|c|}{ Initial Temperature at impact loci } & $\Delta T$ & \multicolumn{5}{|c|}{ Change in temperature at impact loci } \\
\hline$T_{2}$ & \multicolumn{10}{|c|}{ Final Temperature at impact loci } \\
\hline
\end{tabular}


Table 25: Experimental data and results for the $\left[0_{2 K} / 0_{6 F}\right]_{S}$ composite

\begin{tabular}{|c|c|c|c|c|c|c|c|c|c|c|}
\hline Specimen ID & $\begin{array}{l}\theta_{1} \\
\left({ }^{\circ}\right)\end{array}$ & $\begin{array}{l}\theta_{2} \\
\left({ }^{\circ}\right)\end{array}$ & $\begin{array}{l}\Delta \theta \\
\left({ }^{\circ}\right)\end{array}$ & $\begin{array}{l}\mathbf{E} \\
(\mathbf{J})\end{array}$ & $\begin{array}{c}\mathbf{E}_{\text {reb }} \\
(\mathbf{J})\end{array}$ & $\begin{array}{c}\mathbf{E}_{\text {abs }} \\
(\mathbf{J})\end{array}$ & $\% \mathrm{E}_{\mathrm{abs}}$ & $\begin{array}{c}\mathbf{T}_{1} \\
\left({ }^{\circ} \mathbf{C}\right)\end{array}$ & $\begin{array}{c}\mathbf{T}_{2} \\
\left({ }^{\circ} \mathbf{C}\right)\end{array}$ & $\begin{array}{c}\Delta \mathbf{T} \\
\left({ }^{\circ} \mathbf{C}\right)\end{array}$ \\
\hline KF-UD-05-1 & 42.3 & 33.1 & 9.2 & 5.1 & 3.2 & 1.9 & $37.60 \%$ & 25.6 & 26.9 & 1.3 \\
\hline KF-UD-05-4 & 42.0 & 32.8 & 9.3 & 5.0 & 3.1 & 1.9 & $38.20 \%$ & 25.5 & 26.9 & 1.4 \\
\hline KF-UD-07-1 & 42.3 & 33.3 & 9.0 & 5.1 & 3.2 & 1.9 & $36.90 \%$ & 25.5 & 26.9 & 1.4 \\
\hline KF-UD-04-3 & 61.0 & 37.9 & 23.1 & 10.1 & 4.1 & 6.0 & $59.08 \%$ & 25.5 & 37.0 & 11.5 \\
\hline KF-UD-04-4 & 60.6 & 38.1 & 22.5 & 9.9 & 4.2 & 5.8 & $58.12 \%$ & 25.3 & 38.7 & 13.4 \\
\hline KF-UD-06-2 & 60.9 & 37.6 & 23.3 & 10.0 & 4.1 & 6.0 & $59.56 \%$ & 25.6 & 38.9 & 13.3 \\
\hline KF-UD-03-3 & 76.5 & 39.1 & 37.3 & 15.0 & 4.4 & 10.6 & $70.71 \%$ & 26.0 & 42.8 & 16.8 \\
\hline KF-UD-03-4 & 76.7 & 40.1 & 36.6 & 15.1 & 4.6 & 10.5 & $69.45 \%$ & 25.6 & 43.1 & 17.5 \\
\hline KF-UD-04-1 & 76.1 & 40.1 & 36.0 & 14.9 & 4.6 & 10.3 & $69.04 \%$ & 25.3 & 42.8 & 17.6 \\
\hline KF-UD-01-1 & 91.1 & 41.1 & 50.1 & 20.0 & 4.8 & 15.1 & $75.89 \%$ & 25.4 & 45.2 & 19.8 \\
\hline KF-UD-01-2 & 91.4 & 38.7 & 52.7 & 20.0 & 4.3 & 15.7 & $78.58 \%$ & 25.3 & 43.5 & 18.2 \\
\hline KF-UD-01-3 & 91.5 & 41.0 & 50.5 & 20.1 & 4.8 & 15.3 & $76.14 \%$ & 25.2 & 46.3 & 21.1 \\
\hline KF-UD-01-4 & 106.0 & 34.8 & 71.2 & 25.0 & 3.5 & 21.5 & $86.00 \%$ & 25.4 & 46.8 & 21.4 \\
\hline KF-UD-02-1 & 106.1 & 33.1 & 73.0 & 25.0 & 3.2 & 21.8 & $87.28 \%$ & 25.3 & 45.7 & 20.4 \\
\hline KF-UD-02-2 & 106.1 & 36.4 & 69.6 & 25.0 & 3.8 & 21.2 & $84.71 \%$ & 25.6 & 46.6 & 21.0 \\
\hline KF-UD-02-4 & 112.6 & 8.1 & 104.5 & 27.1 & 0.2 & 26.9 & $99.27 \%$ & 25.7 & 50.4 & 24.7 \\
\hline KF-UD-03-1 & 112.7 & 0.0 & 112.7 & 27.1 & 0.0 & 27.1 & $100.00 \%$ & 25.7 & 48.3 & 22.6 \\
\hline KF-UD-03-2 & 112.6 & 0.0 & 112.6 & 27.1 & 0.0 & 27.1 & $100.00 \%$ & 25.7 & 48.1 & 22.5 \\
\hline KF-UD-02-3 & 122.0 & 0.0 & 122.0 & 29.9 & 0.0 & 29.9 & $100.00 \%$ & --- & --- & --- \\
\hline \multicolumn{11}{|l|}{ Legend: } \\
\hline$\theta_{1} \quad \mathrm{I}$ & \multicolumn{4}{|c|}{ Initial Pendulum Drop Angle } & $E_{\text {inc }}$ & \multicolumn{5}{|c|}{ Incident impact energy } \\
\hline$\theta_{2}$ & \multicolumn{4}{|c|}{ Final Pendulum Rebound Angle } & $E_{\text {reb }}$ & \multicolumn{5}{|c|}{ Rebound Energy } \\
\hline$\Delta \theta$ & \multirow{2}{*}{\multicolumn{4}{|c|}{$\begin{array}{l}\text { Difference between } \theta_{1} \text { and } \theta_{2} \\
\text { Initial Temperature at impact loci }\end{array}$}} & $E_{a b s}$ & \multicolumn{5}{|c|}{ Absorbed Energy } \\
\hline$T_{1}$ & & & & & $\Delta T$ & & ge in temp & tture a & mpact & \\
\hline$T_{2}$ & \\
\hline
\end{tabular}


Table 26: Experimental data and results for the $\left[0_{2 K} /(0 / 90)_{3 F}\right]_{s}$ composite

\begin{tabular}{|c|c|c|c|c|c|c|c|c|c|c|}
\hline Specimen ID & $\begin{array}{l}\theta_{1} \\
\left({ }^{\circ}\right)\end{array}$ & $\begin{array}{l}\theta_{2} \\
\left({ }^{\circ}\right)\end{array}$ & $\begin{array}{l}\Delta \theta \\
\left({ }^{\circ}\right)\end{array}$ & $\begin{array}{c}\mathbf{E} \\
(\mathbf{J})\end{array}$ & $\begin{array}{l}\text { E } \\
(J)\end{array}$ & $\begin{array}{l}\mathbf{E}_{\mathrm{abs}} \\
(\mathbf{J})\end{array}$ & $\% \mathbf{E}_{\text {abs }}$ & $\begin{array}{c}\mathbf{T}_{1} \\
\left({ }^{\circ} \mathbf{C}\right)\end{array}$ & $\begin{array}{c}\mathbf{T}_{2} \\
\left({ }^{\circ} \mathbf{C}\right)\end{array}$ & $\begin{array}{l}\Delta \mathrm{T} \\
\left({ }^{\circ} \mathrm{C}\right)\end{array}$ \\
\hline KF-CP-05-1 & 42.6 & 33.1 & 9.5 & 5.2 & 3.2 & 2.0 & $38.35 \%$ & 25.8 & 26.9 & 1.2 \\
\hline KF-CP-05-3 & 42.3 & 33.0 & 9.3 & 5.1 & 3.2 & 1.9 & $37.93 \%$ & 25.7 & 27.0 & 1.3 \\
\hline KF-CP-06-1 & 40.2 & 32.3 & 7.9 & 4.6 & 3.0 & 1.6 & $34.49 \%$ & 26.3 & 27.3 & 1.1 \\
\hline KF-CP-03-4 & 60.7 & 34.9 & 25.8 & 10.0 & 3.5 & 6.5 & $64.81 \%$ & 25.9 & 41.7 & 15.9 \\
\hline KF-CP-04-1 & 60.5 & 34.4 & 26.1 & 9.9 & 3.4 & 6.5 & $65.48 \%$ & 25.6 & 39.1 & 13.5 \\
\hline KF-CP-04-2 & 60.6 & 34.9 & 25.7 & 10.0 & 3.5 & 6.4 & $64.69 \%$ & 25.7 & 40.1 & 14.5 \\
\hline KF-CP-03-1 & 76.5 & 40.8 & 35.6 & 15.0 & 4.8 & 10.2 & $68.23 \%$ & 25.6 & 43.5 & 17.9 \\
\hline KF-CP-03-3 & 75.7 & 40.8 & 34.9 & 14.7 & 4.8 & 10.0 & $67.73 \%$ & 25.7 & 43.1 & 17.4 \\
\hline KF-CP-06-3 & 77.6 & 42.1 & 35.5 & 15.4 & 5.0 & 10.3 & $67.14 \%$ & 25.7 & 44.0 & 18.3 \\
\hline KF-CP-01-1 & 91.0 & 46.0 & 44.9 & 19.9 & 6.0 & 13.9 & $69.93 \%$ & 25.3 & 39.8 & 14.5 \\
\hline KF-CP-01-2 & 90.9 & 47.3 & 43.6 & 19.9 & 6.3 & 13.6 & $68.31 \%$ & 25.3 & 41.5 & 16.2 \\
\hline KF-CP-01-3 & 91.1 & 46.4 & 44.7 & 19.9 & 6.1 & 13.9 & $69.59 \%$ & 25.4 & 37.9 & 12.5 \\
\hline KF-CP-02-1 & 106.1 & 25.0 & 81.0 & 25.0 & 1.8 & 23.1 & $92.64 \%$ & 25.3 & 45.7 & 20.4 \\
\hline KF-CP-02-3 & 106.6 & 28.0 & 78.6 & 25.2 & 2.3 & 22.9 & $90.89 \%$ & 25.4 & 44.5 & 19.1 \\
\hline KF-CP-04-3 & 106.1 & 26.3 & 79.8 & 25.0 & 2.0 & 23.0 & $91.92 \%$ & 25.5 & 45.5 & 20.1 \\
\hline KF-CP-04-4 & 112.3 & 18.4 & 93.9 & 27.0 & 1.0 & 26.0 & $96.29 \%$ & 25.4 & 43.1 & 17.7 \\
\hline KF-CP-05-4 & 112.0 & 6.3 & 105.7 & 26.9 & 0.1 & 26.8 & $99.56 \%$ & 25.8 & 49.0 & 23.3 \\
\hline KF-CP-01-4 & 122.1 & 0.0 & 122.1 & 30.0 & 0.0 & 30.0 & $100.00 \%$ & --- & --- & --- \\
\hline \multicolumn{11}{|l|}{ Legend: } \\
\hline$\theta_{l}$ & \multicolumn{4}{|c|}{ Initial Pendulum Drop Angle } & $E_{\text {inc }}$ & \multicolumn{5}{|c|}{ Incident impact energy } \\
\hline$\theta_{2}$ & \multicolumn{4}{|c|}{ Final Pendulum Rebound Angle } & $E_{r e b}$ & \multicolumn{5}{|c|}{ Rebound Energy } \\
\hline$\Delta \theta$ & \multicolumn{4}{|c|}{ Difference between $\theta_{1}$ and $\theta_{2}$} & $E_{a b s}$ & \multicolumn{5}{|c|}{ Absorbed Energy } \\
\hline$T_{1}$ & \multicolumn{4}{|c|}{ Initial Temperature at impact loci } & $\Delta T$ & \multicolumn{5}{|c|}{ Change in temperature at impact loci } \\
\hline$T_{2}$ & \multicolumn{10}{|c|}{ Final Temperature at impact loci } \\
\hline
\end{tabular}




\section{A2 LS-DYNA INPUT FILES}

Note: The node and element numbering are not shown in any of the input file below.

\section{A2.1 Unidirectional FlaX/EPOXY COMPOSITE (E = 8 J CASE SHOWN)}

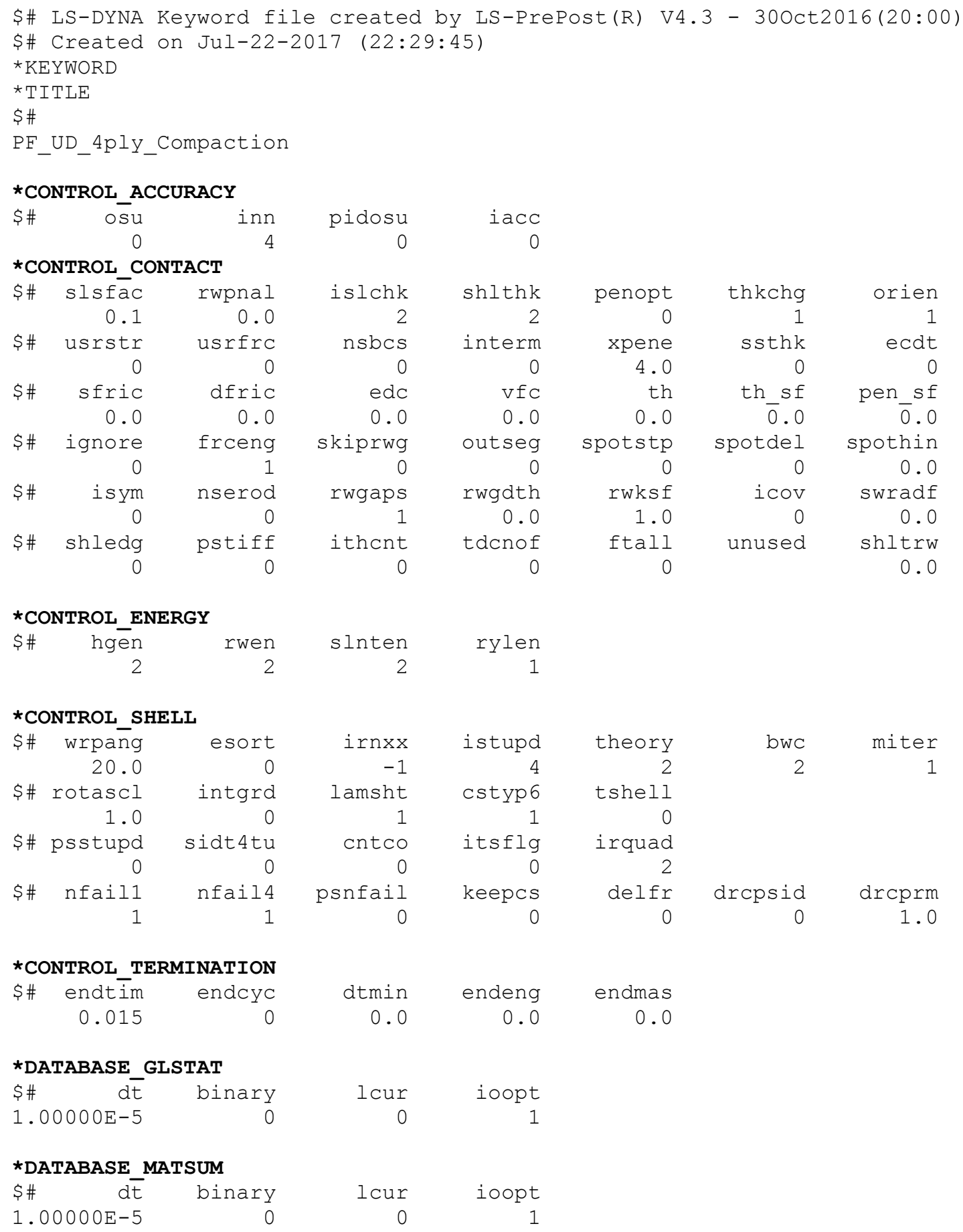




\begin{tabular}{|c|c|c|c|c|c|c|c|c|}
\hline \multicolumn{9}{|c|}{ *DATABASE NCFORC } \\
\hline \$\# & $d \bar{t}$ & binary & lcur & ioopt & & & & \\
\hline & $0000 E-5$ & 0 & 0 & 1 & & & & \\
\hline \multicolumn{9}{|c|}{ *DATABASE NODFOR } \\
\hline \$ & $d \bar{t}$ & binary & lcur & ioopt & & & & \\
\hline & $0000 \mathrm{E}-5$ & 0 & 0 & 1 & & & & \\
\hline \multicolumn{9}{|c|}{ *DATABASE NODOUT } \\
\hline \$\# & $d \bar{t}$ & binary & lcur & ioopt & option1 & option2 & & \\
\hline & $0000 \mathrm{E}-5$ & 0 & 0 & 1 & 0.0 & 0 & & \\
\hline \multicolumn{9}{|c|}{ *DATABASE RCFORC } \\
\hline \$ & $d \bar{t}$ & binary & lcur & ioopt & & & & \\
\hline & $0000 E-5$ & 0 & 0 & 1 & & & & \\
\hline \multicolumn{9}{|c|}{ *DATABASE_BINARY_D3PLOT } \\
\hline$\$ \#$ & $d \bar{t}$ & $\bar{l} c d t$ & beam & npltc & psetid & & & \\
\hline & $0000 \mathrm{E}-5$ & 0 & 0 & 0 & 0 & & & \\
\hline \multicolumn{9}{|c|}{ \$\# ioopt } \\
\hline \multicolumn{9}{|c|}{0} \\
\hline \multicolumn{9}{|c|}{ *DATABASE_NODAL_FORCE_GROUP } \\
\hline & $n s i \bar{d}$ & - cid & & & & & & \\
\hline & 3 & 0 & & & & & & \\
\hline \multicolumn{9}{|c|}{ *DATABASE HISTORY NODE } \\
\hline \multirow[t]{2}{*}{$\$ \#$} & $i d \overline{1}$ & $\bar{i} d 2$ & id3 & id 4 & id5 & id 6 & id 7 & id 8 \\
\hline & 33520 & 37241 & 40962 & 44683 & 0 & 0 & 0 & 0 \\
\hline \multicolumn{9}{|c|}{ *BOUNDARY_SPC_SET } \\
\hline \multirow[t]{2}{*}{ \$\# } & $n s i \bar{d}$ & $-\quad$ cid & dofx & dofy & dof z & dofrx & dofry & dofrz \\
\hline & 2 & 0 & 1 & 1 & 1 & 1 & 1 & 1 \\
\hline \multicolumn{9}{|c|}{ *CONTACT_AUTOMATIC_ONE_WAY_SURFACE_TO_SURFACE_TIEBREAK_ID } \\
\hline$\$$ & $\mathrm{c} \bar{i} \mathrm{~d}$ & Set1_Ply & & & & & & title \\
\hline \multirow[t]{2}{*}{$\$ \ddagger$} & ssid & msid & sstyp & mstyp & sboxid & mboxid & spr & $\operatorname{mpr}$ \\
\hline & 2 & 1 & 3 & 3 & 0 & 0 & 0 & 0 \\
\hline \multirow[t]{2}{*}{ \$\# } & fs & fd & $\mathrm{dc}$ & $\mathrm{VC}$ & vdc & penchk & bt & $d t$ \\
\hline & 0.2 & 0.0 & 0.0 & 0.0 & 20.0 & 0 & 0.0 & $00 E 20$ \\
\hline \multirow[t]{2}{*}{$\$ \#$} & sfs & $\mathrm{s} f \mathrm{~m}$ & sst & mst & sfst & sfmt & fsf & vsf \\
\hline & 1.0 & 1.0 & 0.0 & 0.0 & 1.0 & 1.0 & 1.0 & 1.0 \\
\hline \multirow[t]{2}{*}{ \$\# } & option & nfls & sfls & param & eraten & erates & ct $2 \mathrm{cn}$ & $\mathrm{cn}$ \\
\hline & 8 & 56.0 & 44.0 & 0.0 & 0.0 & 0.0 & 0.0 & 0.0 \\
\hline \multicolumn{9}{|c|}{ *CONTACT_AUTOMATIC_ONE_WAY_SURFACE_TO_SURFACE_TIEBREAK_ID } \\
\hline$\$$ & $\mathrm{c} \overline{\mathrm{i}} \mathrm{d}$ & Set2 Ply & & & & & & title \\
\hline \multirow[t]{2}{*}{$\$ \ddagger$} & ssid & $\mathrm{m} \overline{\mathrm{s}} \mathrm{id}$ & sstyp & mstyp & sboxid & mboxid & spr & mpr \\
\hline & 3 & 2 & 3 & 3 & 0 & 0 & 0 & 0 \\
\hline$\$ \neq$ & fS & fd & dc & $\mathrm{VC}$ & vdc & penchk & bt & $d t$ \\
\hline & 0.2 & 0.0 & 0.0 & 0.0 & 20.0 & 0 & 0.0 & $00 \mathrm{E} 20$ \\
\hline$\$ \neq$ & $s f s$ & $\mathrm{~s} f \mathrm{~m}$ & sst & mst & sfst & sfmt & fsf & vsf \\
\hline & 1.0 & 1.0 & 0.0 & 0.0 & 1.0 & 1.0 & 1.0 & 1.0 \\
\hline \$\# & option & nfls & sfls & param & eraten & erates & ct $2 \mathrm{cn}$ & cn \\
\hline & 8 & 56.0 & 44.0 & 0.0 & 0.0 & 0.0 & 0.0 & 0.0 \\
\hline
\end{tabular}




\begin{tabular}{|c|c|c|c|c|c|c|c|}
\hline \$\# & \multicolumn{3}{|c|}{ cìd } & \multirow[b]{2}{*}{ mstyp } & \multirow[b]{2}{*}{ sboxid } & \multirow[b]{2}{*}{ mboxid } & title \\
\hline \multirow[t]{2}{*}{ \$\# } & ssid & mśs & sstyp & & & & spr \\
\hline & 4 & 3 & 3 & 3 & 0 & 0 & 0 \\
\hline \multirow[t]{2}{*}{ \$\# } & fs & $\mathrm{fd}$ & $\mathrm{dc}$ & $\mathrm{VC}$ & vdc & penchk & $\mathrm{bt} \quad \mathrm{dt}$ \\
\hline & 0.2 & 0.0 & 0.0 & 0.0 & 20.0 & 0 & $0.01 .00000 \mathrm{E} 20$ \\
\hline \multirow[t]{2}{*}{ \$\# } & sfs & $\mathrm{s} f \mathrm{~m}$ & sst & mst & sfst & sfmt & fsf $\quad$ vsf \\
\hline & 1.0 & 1.0 & 0.0 & 0.0 & 1.0 & 1.0 & 1.0 \\
\hline \multirow[t]{2}{*}{ \$\# } & option & $n f l s$ & sfls & param & eraten & erates & ct $2 \mathrm{cn}$ \\
\hline & 8 & 56.0 & 44.0 & 0.0 & 0.0 & 0.0 & 0.0 \\
\hline \multicolumn{8}{|c|}{ *CONTACT AUTOMATIC NODES TO SURFACE ID } \\
\hline \$\# & $\mathrm{c} \overline{\mathrm{i}} \mathrm{d}$ & tor $\mathrm{Pl}$ & et 1 & & & & title \\
\hline \multirow[t]{2}{*}{ \$\# } & ssid & msīd & sstyp & mstyp & sboxid & mboxid & spr \\
\hline & 1 & 9 & 3 & 3 & 0 & 0 & 0 \\
\hline \multirow[t]{2}{*}{ \$\# } & fs & fd & $\mathrm{dc}$ & $\mathrm{VC}$ & vdC & penchk & bt $\quad d t$ \\
\hline & 0.2 & 0.0 & 0.0 & 0.0 & 20.0 & 0 & $0.01 .00000 \mathrm{E} 20$ \\
\hline \multirow[t]{2}{*}{ \$\# } & sfs & $\mathrm{sfm}$ & sst & mst & sfst & sfmt & fsf $\quad$ vsf \\
\hline & 1.0 & 1.0 & 0.0 & 0.0 & 1.0 & 1.0 & 1.0 \\
\hline \multicolumn{8}{|c|}{ *CONTACT_AUTOMATIC_NODES_TO_SURFACE_ID } \\
\hline & $\mathrm{c} \overline{\mathrm{i}} \mathrm{d}$ & tor $\mathrm{Pl}$ & et 2 & & & & title \\
\hline \multirow[t]{2}{*}{ \$\# } & ssid & msìd & sstyp & mstyp & sboxid & mboxid & spr \\
\hline & 2 & 9 & 3 & 3 & 0 & 0 & 0 \\
\hline \multirow[t]{2}{*}{ \$\# } & fs & $\mathrm{fd}$ & $\mathrm{dc}$ & $\mathrm{VC}$ & vdC & penchk & bt $\quad d t$ \\
\hline & 0.2 & 0.0 & 0.0 & 0.0 & 20.0 & 0 & $0.01 .00000 \mathrm{E} 20$ \\
\hline \multirow[t]{2}{*}{ \$\# } & sfs & $\mathrm{s}$ fm & sst & mst & sfst & sfmt & fsf $\quad$ vsf \\
\hline & 1.0 & 1.0 & 0.0 & 0.0 & 1.0 & 1.0 & 1.0 \\
\hline \multicolumn{8}{|c|}{ *CONTACT AUTOMATIC NODES TO SURFACE ID } \\
\hline \$\# & $\mathrm{c} \overline{\mathrm{i} d}$ & tor $\mathrm{Pl}$ & et 3 & & & & title \\
\hline \multirow[t]{2}{*}{ \$\# } & ssid & msid & sstyp & mstyp & sboxid & mboxid & spr \\
\hline & 3 & 9 & 3 & 3 & 0 & 0 & 0 \\
\hline \multirow[t]{2}{*}{ \$\# } & fs & $\mathrm{fd}$ & dc & $\mathrm{VC}$ & vdc & penchk & bt $\quad d t$ \\
\hline & 0.2 & 0.0 & 0.0 & 0.0 & 20.0 & 0 & $0.01 .00000 \mathrm{E} 20$ \\
\hline \multirow[t]{2}{*}{ \$\# } & $\operatorname{sfs}$ & $\mathrm{s} f \mathrm{~m}$ & sst & mst & sfst & sfmt & fsf $\quad \operatorname{vsf}$ \\
\hline & 1.0 & 1.0 & 0.0 & 0.0 & 1.0 & 1.0 & 1.0 \\
\hline & ТTACT AL & TIC NO & TO SUF & $E$ ID & & & \\
\hline \$\# & cīd & tor $\mathrm{Pl}$ & et 4 & & & & title \\
\hline \$\# & ssid & msīd & sstyp & mstyp & sboxid & mboxid & spr \\
\hline & 4 & 9 & 3 & 3 & 0 & 0 & 0 \\
\hline \$\# & fs & $\mathrm{fd}$ & $\mathrm{dc}$ & $\mathrm{VC}$ & $\mathrm{vdC}$ & penchk & bt $\quad d t$ \\
\hline & 0.2 & 0.0 & 0.0 & 0.0 & 20.0 & 0 & $0.01 .00000 \mathrm{E} 20$ \\
\hline \$\# & sfs & $\mathrm{s} f \mathrm{~m}$ & sst & mst & sfst & sfmt & fsf $\quad$ vsf \\
\hline & 1.0 & 1.0 & 0.0 & 0.0 & 1.0 & 1.0 & 1.0 \\
\hline
\end{tabular}




\section{*PART COMPOSITE}

\$\#

Ply Set 1

\begin{tabular}{|c|c|c|c|c|c|c|c|}
\hline$\$ \#$ pid & elform & $\operatorname{shrf}$ & nloc & marea & hgid & adpopt & ithelfrm \\
\hline 1 & 2 & 1.0 & 0.0 & 0.0 & 1 & 0 & 0 \\
\hline midl & thickl & b1 & tmidl & $\operatorname{mid} 2$ & thick2 & $\mathrm{b} 2$ & $\operatorname{tmid} 2$ \\
\hline 1 & 0.23125 & 0.0 & 0 & 1 & 0.23125 & 0.0 & \\
\hline 1 & 0.23125 & 0.0 & 0 & 1 & 0.23125 & 0.0 & \\
\hline
\end{tabular}

*PART COMPOSITE

\$\#

Ply_Set2

$\begin{array}{lrr}\text { \$\#_ } & \text { pid } & \text { elform } \\ & 2 & 2 \\ \text { \$\# } & \text { mid1 } & \text { thick1 } \\ & 1 & 0.23125 \\ & 1 & 0.23125\end{array}$

$\begin{array}{rr}\text { shrf } & \text { nloc } \\ 1.0 & 0.0 \\ \text { bl } & \text { tmidl } \\ 0.0 & 0 \\ 0.0 & 0\end{array}$
marea
0.0
mid2

1
1

hgid
1
thick 2
0.23125
0.23125

title

\section{*PART COMPOSITE}

$\$ \#$

Ply Set3

$\begin{array}{lrr}\text { \$\# } & \text { pid } & \text { elform } \\ & 3 & 2 \\ \text { \$\# } & \text { mid1 } & \text { thick1 } \\ & 1 & 0.23125 \\ & 1 & 0.23125\end{array}$

shrf

1.0

b1

0.0

0.0

*PART_COMPOSITE

$\$ \#$

Ply_Set 4

$\begin{array}{lrr}\text { \$\# } & \text { pid } & \text { elform } \\ \text { \$\# } & 4 & 2 \\ & \text { midl } & \text { thick1 } \\ & 1 & 0.23125 \\ 1 & 0.23125\end{array}$

* PART

$\$ \#$

Impactor

\$\# pid secid

*SECTION_SOLID_TITLE

Impactor

\$\# secid elform

shrf
1.0
$\mathrm{~b} 1$
0.0
0.0

$$
\begin{array}{r}
\text { nloc } \\
0.0 \\
\text { tmidl } \\
0 \\
0
\end{array}
$$

$$
\begin{array}{r}
\text { hgid } \\
1 \\
\text { thick2 } \\
0.23125 \\
0.23125
\end{array}
$$
marea
0.0
mid2
1
1
hgid
1

\begin{tabular}{|c|c|c|c|c|c|c|c|}
\hline$\$ \#$ & $\begin{array}{l}\operatorname{mid} \\
21\end{array}$ & $\begin{array}{r}r o \\
0 E-6\end{array}$ & $\begin{array}{r}e \\
200000.0\end{array}$ & $\begin{array}{r}\text { pr } \\
0.32\end{array}$ & $\begin{array}{r}n \\
0.0\end{array}$ & $\begin{array}{r}\text { couple } \\
0.0\end{array}$ & $\begin{array}{r}m \\
0.0\end{array}$ \\
\hline \$\# & $\begin{array}{l}\text { cmo } \\
0.0\end{array}$ & $\begin{array}{r}\text { con } 1 \\
0\end{array}$ & $\begin{array}{r}\text { con } 2 \\
0\end{array}$ & & & & \\
\hline$\$ \# 1 C O$ & $\begin{array}{c}\text { or a } 1 \\
0.0\end{array}$ & $\begin{array}{l}a^{2} \\
0.0\end{array}$ & $\begin{array}{l}a 3 \\
0.0\end{array}$ & $\begin{array}{l}\mathrm{v1} \\
0.0\end{array}$ & $\begin{array}{l}\mathrm{v} 2 \\
0.0\end{array}$ & $0.0^{v 3}$ & \\
\hline
\end{tabular}
0.23125
0.23125

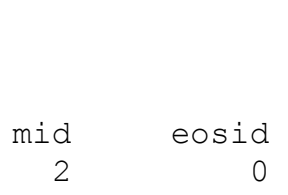

aet

0

*MAT_RIGID_TITLE

Rigi_d_Impactor 


\begin{tabular}{|c|c|c|c|c|c|c|c|c|}
\hline \multicolumn{9}{|c|}{$\begin{array}{l}\text { *HOURGLASS_TITLE } \\
\text { Hour Glass Control Solid }\end{array}$} \\
\hline \multirow[t]{2}{*}{ \$\# } & ${ }^{-}$hgid & $i \bar{h} q$ & qm & ibq & q1 & q2 & $\mathrm{qb} / \mathrm{vdc}$ & qW \\
\hline & 2 & 8 & 0.1 & 0 & 1.5 & 0.06 & 0.1 & 0.1 \\
\hline \multicolumn{9}{|c|}{ ^HOURGLASS_TITLE } \\
\hline \multicolumn{9}{|c|}{ Hour_Glass_Control Shell } \\
\hline \multirow[t]{2}{*}{$\$ \#$} & hgid & $i \bar{h} q$ & qm & ibq & q1 & q2 & $\mathrm{qu} / \mathrm{vdc}$ & qW \\
\hline & 1 & 8 & 0.1 & 0 & 1.5 & 0.06 & 0.1 & 0.1 \\
\hline \multicolumn{9}{|c|}{$\begin{array}{l}\text { *MAT_ENHANCED_COMPOSITE_DAMAGE_TITLE } \\
\text { UD FI }\end{array}$} \\
\hline \multirow[t]{2}{*}{$\$ \#-$} & mid & ro & ea & eb & $(e c)$ & prba & (prca) & (prcb) \\
\hline & 11 & $5000 E-9$ & 31420.0 & 5580.0 & 0.0 & 0.353 & 0.0 & 0.0 \\
\hline \multirow[t]{2}{*}{$\$ \#$} & gab & $g b c$ & gca & $(k f)$ & aopt & 2way & & \\
\hline & 2070.0 & 0.0 & 0.0 & 0.0 & 2.0 & 0.0 & & \\
\hline \multirow[t]{2}{*}{ \$\# } & $\mathrm{xp}$ & yp & $z p$ & a1 & a2 & a3 & mangle & \\
\hline & 0.0 & 0.0 & 0.0 & 0.0 & 1.0 & 0.0 & 0.0 & \\
\hline \multirow[t]{2}{*}{ \$\# } & V1 & v2 & v3 & d1 & $\mathrm{d} 2$ & d3 & dfailm & dfails \\
\hline & 0.0 & 0.0 & 0.0 & 0.0 & 0.0 & 0.0 & 0.006 & 0.018 \\
\hline$\$ \#$ & tfail & alph & soft & fbrt & ycfac & dfailt & dfailc & efs \\
\hline & $5300 E-9$ & 0.0 & 0.2 & 0.2 & 1.5 & 0.009 & -0.004 & 0.0 \\
\hline & $\mathrm{XC}$ & $x t$ & yc & $y t$ & SC & crit & beta & \\
\hline & 127.11 & 286.7 & 79.94 & 33.86 & 40.295 & 55.0 & 0.0 & \\
\hline \multirow[t]{2}{*}{ \$\# } & pel & epsf & epsr & tsmd & soft2 & & & \\
\hline & 0.0 & 0.0 & 0.0 & 0.0 & 0.2 & & & \\
\hline \multirow[t]{2}{*}{ \$\# } & slimt1 & slimcl & slimt2 & slimc2 & slims & ncyred & softg & \\
\hline & 0.0 & 0.0 & 0.0 & 0.0 & 0.0 & 0.0 & 0.2 & \\
\hline \multicolumn{9}{|c|}{ *INITIAL VELOCITY RIGID BODY } \\
\hline \multirow[t]{2}{*}{ \$\# } & pīd & $-\mathrm{vx}$ & - $\quad$ vy & $\mathrm{Vz}$ & $\operatorname{vxr}$ & vyr & vzr & icid \\
\hline & 9 & 0.0 & 0.0 & -1908.0 & 0.0 & 0.0 & 0.0 & 0 \\
\hline
\end{tabular}




\section{A2.2 Cross-Ply FlaX/EPoXy COMPOSite (E = 20 J CASE SHOWN)}

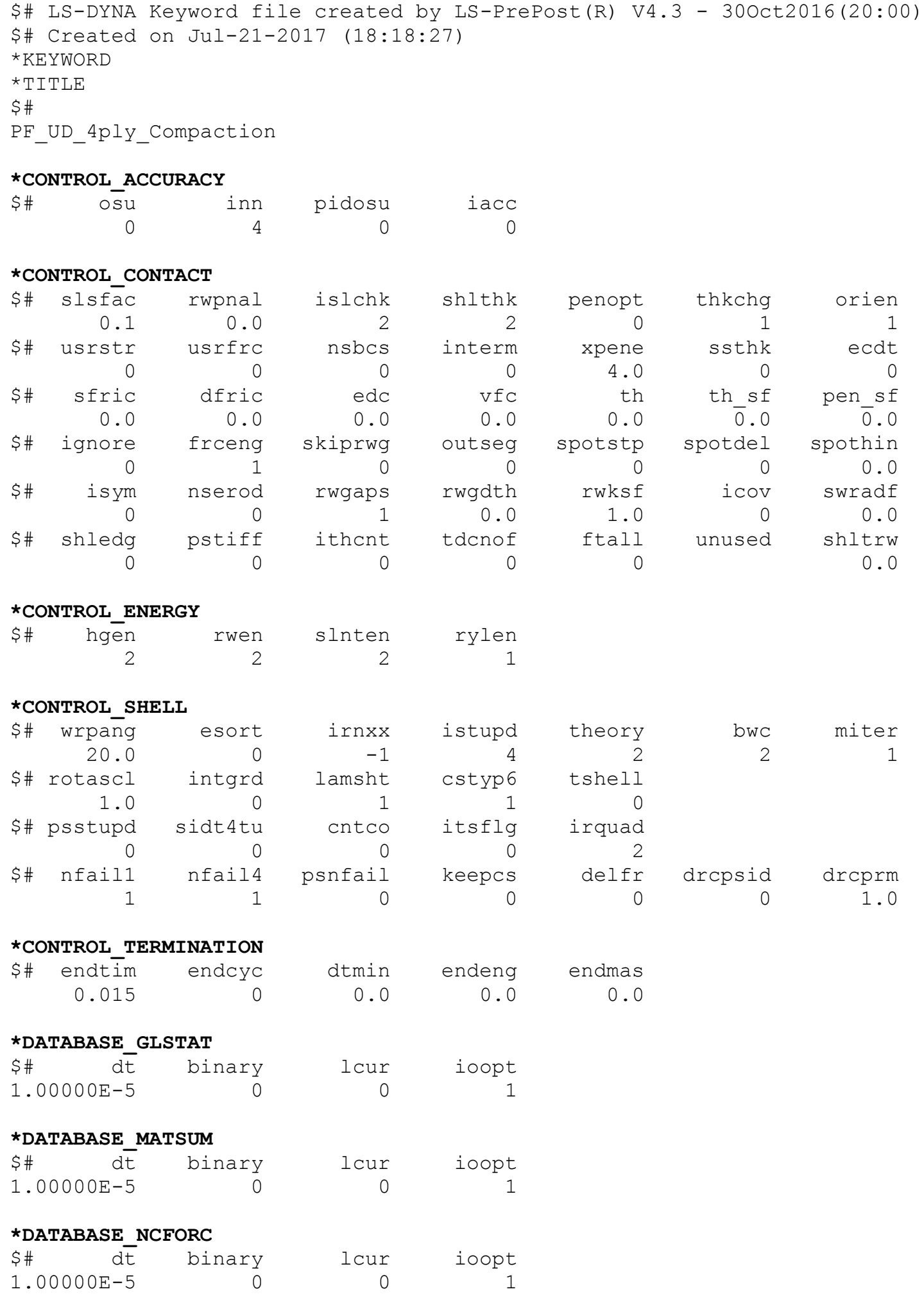




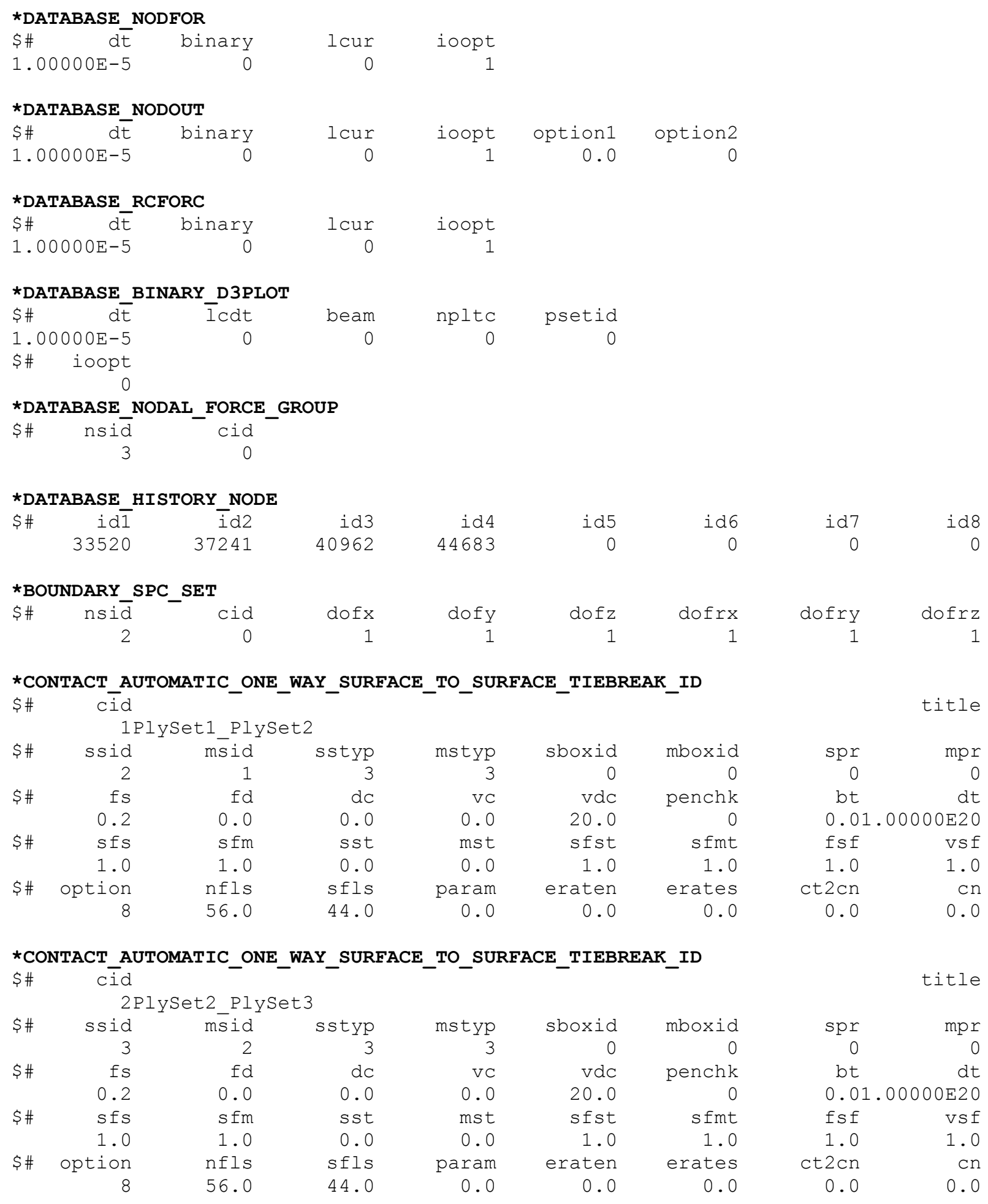




\begin{tabular}{|c|c|c|c|c|c|c|c|}
\hline$\$ \#$ & \multicolumn{3}{|c|}{$\begin{array}{l}\text { cìd } \\
\text { 3PlySet3_PlySet4 }\end{array}$} & \multirow[b]{2}{*}{ mstyp } & \multirow[b]{2}{*}{ sboxid } & \multirow[b]{2}{*}{ mboxid } & title \\
\hline \multirow[t]{2}{*}{ \$\# } & ssid & msid & sstyp & & & & spr \\
\hline & 4 & 3 & 3 & 3 & 0 & 0 & 0 \\
\hline \multirow[t]{2}{*}{ \$\# } & fs & $\mathrm{fd}$ & dc & $\mathrm{VC}$ & vdc & penchk & bt $\quad d t$ \\
\hline & 0.2 & 0.0 & 0.0 & 0.0 & 20.0 & 0 & $0.01 .00000 \mathrm{E} 20$ \\
\hline \multirow[t]{2}{*}{ \$\# } & sfs & sfm & sst & mst & sfst & sfmt & fsf $\quad \operatorname{vsf}$ \\
\hline & 1.0 & 1.0 & 0.0 & 0.0 & 1.0 & 1.0 & 1.0 \\
\hline \multirow[t]{2}{*}{ \$\# } & option & nfls & sfls & param & eraten & erates & ct $2 \mathrm{cn}$ \\
\hline & 8 & 56.0 & 44.0 & 0.0 & 0.0 & 0.0 & 0.0 \\
\hline \multicolumn{8}{|c|}{ *CONTACT_AUTOMATIC_NODES_TO_SURFACE_ID } \\
\hline & $\mathrm{c} \overline{\mathrm{i}} \mathrm{d}$ & tor_Pl & et 1 & & & & title \\
\hline \multirow[t]{2}{*}{ \$\# } & ssid & msid & sstyp & mstyp & sboxid & mboxid & spr \\
\hline & 1 & 9 & 3 & 3 & 0 & 0 & 0 \\
\hline \multirow[t]{2}{*}{ \$\# } & fs & fd & dc & $\mathrm{VC}$ & vdc & penchk & bt $\quad d t$ \\
\hline & 0.2 & 0.0 & 0.0 & 0.0 & 20.0 & 0 & $0.01 .00000 \mathrm{E} 20$ \\
\hline \multirow[t]{2}{*}{ \$\# } & sfs & sfm & sst & mst & sfst & sfmt & fsf $\quad v s f$ \\
\hline & 1.0 & 1.0 & 0.0 & 0.0 & 1.0 & 1.0 & 1.0 \\
\hline \multicolumn{8}{|c|}{ *CONTACT_AUTOMATIC_NODES_TO_SURFACE_ID } \\
\hline & $\mathrm{cid}$ & tor_Pl & t2 & & & & title \\
\hline \multirow[t]{2}{*}{ \$\# } & ssid & msid & sstyp & mstyp & sboxid & mboxid & spr \\
\hline & 2 & 9 & 3 & 3 & 0 & 0 & 0 \\
\hline \multirow[t]{2}{*}{ \$\# } & fs & $\mathrm{fd}$ & dc & $\mathrm{VC}$ & vdc & penchk & bt $\quad d t$ \\
\hline & 0.2 & 0.0 & 0.0 & 0.0 & 20.0 & 0 & $0.01 .00000 \mathrm{E} 20$ \\
\hline \multirow[t]{2}{*}{ \$\# } & sfs & sfm & sst & mst & sfst & sfmt & fsf $\quad$ vsf \\
\hline & 1.0 & 1.0 & 0.0 & 0.0 & 1.0 & 1.0 & 1.0 \\
\hline \multicolumn{8}{|c|}{ ^CONTACT_AUTOMATIC_NODES_TO_SURFACE_ID } \\
\hline \$\# & $\mathrm{ci \overline {d }}$ & tor_P] & t 3 & & & & title \\
\hline \multirow[t]{2}{*}{ \$\# } & ssid & msid & sstyp & mstyp & sboxid & mboxid & spr \\
\hline & 3 & 9 & 3 & 3 & 0 & 0 & 0 \\
\hline \multirow[t]{2}{*}{ \$\# } & fs & fd & dc & $\mathrm{VC}$ & vdC & penchk & bt $\quad d t$ \\
\hline & 0.2 & 0.0 & 0.0 & 0.0 & 20.0 & 0 & $0.01 .00000 \mathrm{E} 20$ \\
\hline \multirow[t]{2}{*}{ \$\# } & sfs & sfm & sst & mst & sfst & sfmt & fsf $\quad$ vsf \\
\hline & 1.0 & 1.0 & 0.0 & 0.0 & 1.0 & 1.0 & 1.0 \\
\hline *CC & ITACT_AC & IIC_NC & TO_SUF & E_ID & & & \\
\hline \$ & $\mathrm{c} \overline{\mathrm{i}} \mathrm{d}$ & tor_PI & 4 & & & & title \\
\hline \$\# & ssid & ms ìd & sstyp & mstyp & sboxid & mboxid & spr \\
\hline & 4 & 9 & 3 & 3 & 0 & 0 & 0 \\
\hline \$\# & fs & fd & dc & $\mathrm{VC}$ & vdc & penchk & bt $\quad d t$ \\
\hline & 0.2 & 0.0 & 0.0 & 0.0 & 20.0 & 0 & $0.01 .00000 \mathrm{E} 20$ \\
\hline \$\# & sfs & $\mathrm{sfm}$ & sst & mst & sfst & sfmt & fsf $\quad \operatorname{vsf}$ \\
\hline & 1.0 & 1.0 & 0.0 & 0.0 & 1.0 & 1.0 & 1.0 \\
\hline
\end{tabular}




\section{*PART COMPOSITE}

\$\#

Ply Set 1

\begin{tabular}{|c|c|c|c|c|c|c|c|}
\hline$\$ \#$ pid & elform & $\operatorname{shrf}$ & nloc & marea & hgid & adpopt & ithelfrm \\
\hline 1 & 2 & 1.0 & 0.0 & 0.0 & 1 & 0 & 0 \\
\hline midl & thickl & b1 & tmidl & $\operatorname{mid} 2$ & thick2 & $\mathrm{b} 2$ & $\operatorname{tmid} 2$ \\
\hline 1 & 0.23125 & 0.0 & 0 & 1 & 0.23125 & 90.0 & \\
\hline 1 & 0.23125 & 0.0 & 0 & 1 & 0.23125 & 90.0 & \\
\hline
\end{tabular}

*PART COMPOSITE

\$\#

Ply_Set2

$\begin{array}{lrr}\text { \$\# } & \text { pid } & \text { elform } \\ & 2 & 2 \\ \text { \$\# } & \text { mid1 } & \text { thick1 } \\ 1 & 0.23125 \\ 1 & 0.23125\end{array}$

$\begin{array}{rr}\text { shrf } & \text { nloc } \\ 1.0 & 0.0 \\ \text { bl } & \text { tmidl } \\ 0.0 & 0 \\ 0.0 & 0\end{array}$
marea
0.0
mid2

1
1

$$
\begin{array}{r}
\text { hgid } \\
1 \\
\text { thick } 2 \\
0.23125 \\
0.23125
\end{array}
$$

title

\section{*PART COMPOSITE}

$\$ \#$

Ply Set 3

$\begin{array}{rrr}\text { \$\# } & \text { pid } & \text { elform } \\ \text { \$\# } & 3 & 2 \\ & \text { mid1 } & \text { thick1 } \\ & 1 & 0.23125 \\ & 1 & 0.23125\end{array}$

shrf

1.0

b1

90.0

90.0

\section{*PART COMPOSITE}

\$\#

Ply_Set 4

$\begin{array}{lrr}\text { \$\# } & \text { pid } & \text { elform } \\ \text { \$\# } & 4 & 2 \\ & \text { midl } & \text { thick1 } \\ & 1 & 0.23125 \\ & 1 & 0.23125\end{array}$

*PART

$\$ \#$

Impactor

\$\# pid secid

*SECTION_SOLID_TITLE

Impactor

\$\# secid elform

$$
\begin{array}{r}
\text { shrf } \\
1.0 \\
\text { b1 } \\
90.0 \\
90.0
\end{array}
$$

$$
\begin{array}{r}
\text { nloc } \\
0.0 \\
\text { tmidl } \\
0 \\
0
\end{array}
$$

$$
\begin{array}{rr}
\text { marea } & \text { hgid } \\
0.0 & 1 \\
\text { mid2 } & \text { thick2 } \\
1 & 0.23125 \\
1 & 0.23125
\end{array}
$$

\begin{tabular}{|c|c|c|c|c|c|c|c|}
\hline \$\# & $\begin{array}{l}\operatorname{mid} \\
21\end{array}$ & $\begin{array}{r}r o \\
0 E-6\end{array}$ & $\begin{array}{r}e \\
200000.0\end{array}$ & $\begin{array}{r}\text { pr } \\
0.32\end{array}$ & $\begin{array}{r}n \\
0.0\end{array}$ & $\begin{array}{r}\text { couple } \\
0.0\end{array}$ & $\begin{array}{r}\mathrm{m} \\
0.0\end{array}$ \\
\hline \$\# & $\begin{array}{l}\text { cmo } \\
0.0\end{array}$ & $\begin{array}{r}\text { con } 1 \\
0\end{array}$ & $\begin{array}{r}\operatorname{con} 2 \\
0\end{array}$ & & & & \\
\hline \$\# l co & $\begin{array}{c}\text { or } a 1 \\
0.0\end{array}$ & $\begin{array}{l}a_{2} \\
0.0\end{array}$ & $\begin{array}{l}\text { a3 } \\
0.0\end{array}$ & $0.0^{v 1}$ & $\begin{array}{l}v^{2} \\
0.0\end{array}$ & $\begin{array}{l}\text { v3 } \\
0.0\end{array}$ & \\
\hline
\end{tabular}

marea
0.0
mid2
1
1

$$
\begin{array}{r}
\text { hgid } \\
1 \\
\text { thick } 2 \\
0.23125 \\
0.23125
\end{array}
$$
mid
2
eosid

hgid
2

$$
\begin{array}{r}
\text { grav } \\
0
\end{array}
$$

adpopt

title

tmid

aet

0

*MAT_RIGID_TITLE

Rigi_d_Impactor 


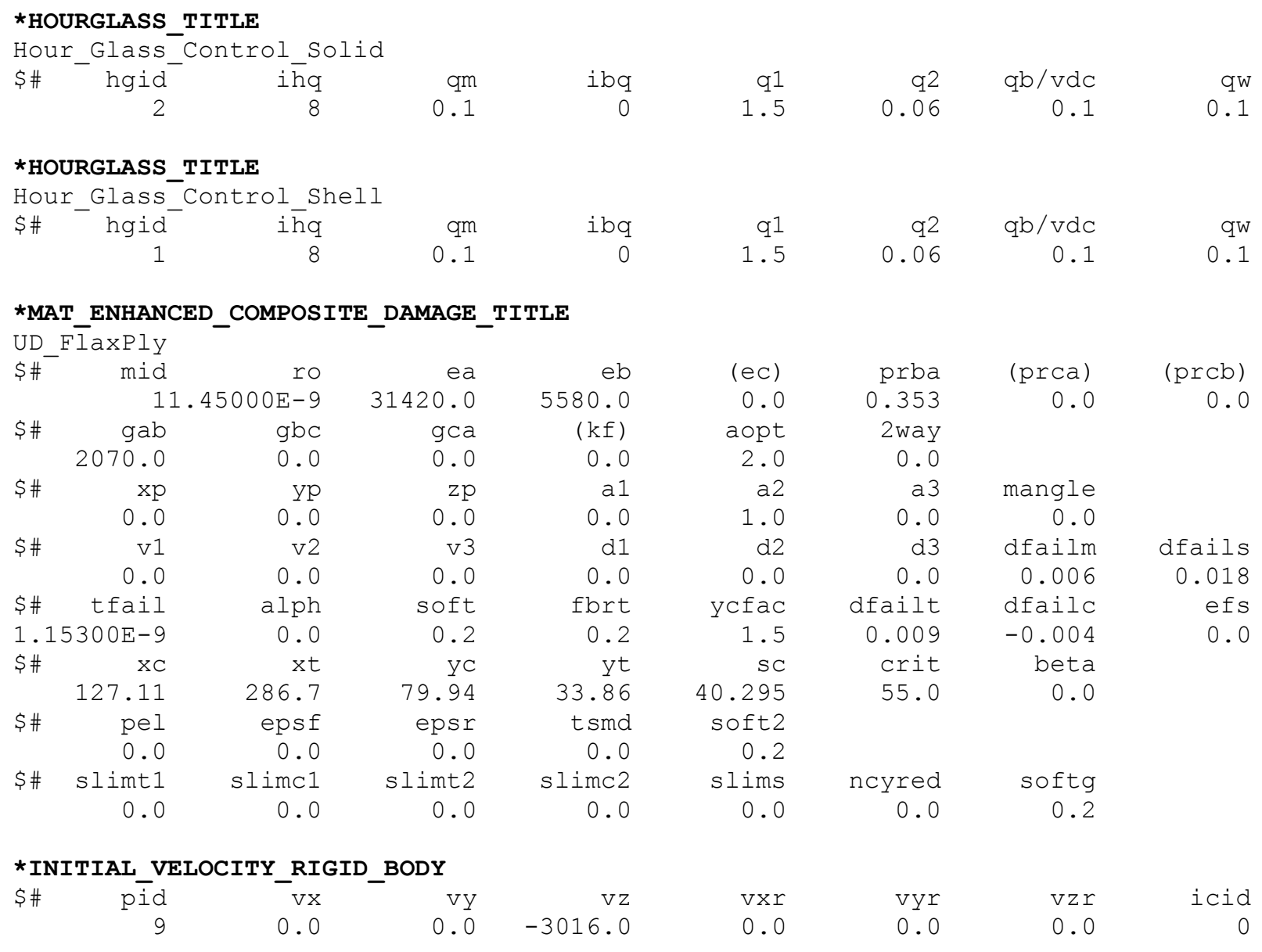




\section{REFERENCES}

[1] H. Hamada, J. Denault, A. K. Mohanty, Y. Li and M. S. Aly-Hassan, "Natural fiber composites," Advances in Mechanical Engineering, vol. 5, no. 569020, 2013.

[2] E. A. Elbadry, M. S. Aly-Hassan and H. Hamada, "Mechanical properties of natural jute/jute mat fiber reinforced polymer matrix hybrid composites," Advances in Mechanical Engineering, vol. 4, no. 354547, 2012.

[3] N. Sgriccia, M. C. Hawley and M. Misra, "Characterization of natural fiber surfaces and natural fiber composites," Composites Part A: Applied Science and Manufacturing, vol. 39, no. 10, pp. 1632-1637, 2008.

[4] F. Ahmad, H. S. Choi and M. K. Park, "A review: Natural fiber composites selection in view of mechanical, light weight, and economic properties," Macromolecular Materials and Engineering, vol. 300, no. 1, pp. 10-24, 2015.

[5] L. Yan, N. Chouw and K. Jayaraman, "Flax fibre and its composites - a review," Composites Part B: Engineering, vol. 56, pp. 296-317, 2014.

[6] D. B. Dittenber and H. GangRao, "Critical review of recent publications on use of natural composites in infrastructure," Composites Part A: Applied Science and Manufacturing, vol. 43, no. 8, pp. 1419-1429, 2012.

[7] M. Karus and M. Kaup, "Natural fibers in the European automotive industry," Journal of Industrial Hemp, vol. 7, no. 1, pp. 119-131, 2002.

[8] J. Summerscales, N. Dissanyake, A. S. Virk and W. Hall, "A review of bast fibres and their composites. Part 1 - fibres as reinforcements," Composites: Part A, vol. 41, pp. 1329-1355, 2010. 
[9] S. Kalia, B. S. Kaith and I. Kaur, Cellulose Fibers: Bio- and Nano-Polymer Composites, Springer, 2011.

[10] J. Flynn, A. Amiri and C. Ulven, "Hybridized carbon and flax fiber composites for tailored performance," Materials and Design, vol. 102, pp. 21-29, 2016.

[11] Z. Mahboob, I. E. Sawi, R. Zdero, Z. Fawaz and H. Bougherara, "Tensile and compressive damaged response in flax fibre reinforced epoxy composites," Composites: Part A, vol. 92, pp. 118-133, 2017.

[12] B. D. Agarwal, L. J. Broutman and K. Chandrashekhara, Analysis and performance of fiber composites, 3rd ed., Hoboken, New Jersey: John Wiley and Sons Inc., 1990.

[13] National Aeronautics and Space Administration (NASA), "Fiber-reinfirced polymer composite material selection (GD-ED-2210)," NASA, 1996.

[14] R. A. Witik, R. Teuscher, V. Michaud, C. Ludwig and J. E. Manson, "Carbon fibre reinforced composite waste: An environmental assessment of recycling, energy recovery and landfilling," Composites: Part A, vol. 49, pp. 89-99, 2013.

[15] V. K. Thakur, M. K. Thakur and R. K. Gupta, "Review: Raw natural fiber-based polymer composites," International Journal of Polymer Analysis and Characterization, vol. 19, no. 3, pp. 256-271, 2014.

[16] M. A. Fuqua, S. Huo and C. A. Ulven, "Natural fiber reinforced composites," Polymer Reviews, vol. 52, no. 3, pp. 259-320, 2012.

[17] D. D. Stokke, Q. Wu, G. Han and C. V. Stevens, Wood and natural fiber composites, Chichester, West Sussex: Wiley and Sons, Ltd., 2014. 
[18] T. P. Sathishkumar, P. Navaneethakrishnan, S. Shankar, R. Rajasekar and N. Rajini, "Characterization of natural fiber and composites, a review," Journal of Reinforced Plastics and Composites, vol. 32, no. 19, pp. 1457-1476, 2013.

[19] F. T. Wallenberger and N. Weston, Natiral fibers, plastics and composites, New York, NY: Springer Science+Business Media, 2004.

[20] M. Wrobel-Kwiatkowska, M. Czemplik, J. Kaczmar, L. Dyminska, J. Hanuza, M. Ptak and J. Szopa, "New biocomposites based on bioplastic flax fibers and biodegradable polymers," Biotechnology Progress, vol. 28, no. 5, pp. 1336-1346, 2012.

[21] A. Bourmaud, C. Morvan, A. Bouali, V. Placet, P. Perre and C. Baley, "Relationships between micro-fibrillar angle, mechanical properties and biochemical composition of flax fibers," Industrial Crops and Products, vol. 44, pp. 343-351, 2013.

[22] Flaxcomposites, "About Flax Fibers," 2014. [Online]. Available: http://flaxcomposites.com/?page_id=2. [Accessed 27 July 2017].

[23] R. Campilho, Natural fiber composites, Boca Raton, FL: CRC Press, 2016.

[24] M. J. John and S. Thomas, Natural Polymers Volume 1: Composites, Cambridge, UK: RSC Publishing, 2012.

[25] A. K. Kaw, Mechanics of composite materials, Boca Raton, FL: CRC Press, 1997.

[26] F. J. Campbell, Manufacturing process for advanced composites, New York: Elsvier, Ltd, 2004.

[27] F. Aird, Fiberglass and other composite materials: a guide to high performance non-metallic materials for race cars, street rods, body shops, boats and aircraft, New York: HP Books (Penguin Group), 2006. 
[28] M. E. Tuttle, Structural analysis of polymeric composite materials, New York: Marcel Dekker, Inc., 2004.

[29] L. A. Pilato and M. J. Michno, Advanced composite materials, Berlin, Heidelberg: SpringerVerlag, 1994.

[30] A. Baker, S. Dutton and D. Kelly, Composite materials for aircraft structures, 2nd ed., Blacksburg, VA: AIAA Inc., 2004.

[31] S. Lee, Handbook of composite reinforcements, Palo Alto, CA: Wiley-VCH, 1993.

[32] A. P. Mouritz, Introduction to aerospace materials, Cambridge: Woodhead Publishing Ltd, 2012.

[33] M. F. Ashby, P. J. Ferreira and D. L. Schodek, Nanomaterials, nanotechnologies and design, Jordan Hill, Oxford: Butterworth-Heinemann, 2009.

[34] T. Astrom, Manufacturing of polymer composites, Cheltenham: Nelson Thomas Ltd., 1997.

[35] S. Agrawal, K. K. Singh and P. K. Sarkar, "Impact damage on fiber-reinforced polymer matrix composite, a review," Journal of Composite Materials, vol. 48, no. 3, pp. 317-322, 2014.

[36] P. O. Sjoblom, J. T. Hartness and T. M. Cordell, "Low velocity impact testing of composite materials," Journal of Composite Materials, vol. 22, pp. 30-52, 1988.

[37] W. Cantwell and J. Morton, "The impact resistance of composite materials - a review," Composites, vol. 22, no. 5, pp. 347-362, 1991.

[38] S. Abrate, "Impact on laminated composite materials," Applied Mechanics Reviews, vol. 44, no. 4, pp. 155-190, 1990. 
[39] D. Liu, E. Lansing and L. E. Malvern, "Cracking in impacted glass/epoxy plates," Journal of Composite Materials, vol. 21, pp. 594-609, 1987.

[40] M. Quaresimin, M. Ricotta, L. Martello and S. Mian, "Energy absorption in composite laminates under impact loading," Composites Part B: Engineering, vol. 44, no. 1, pp. 133140, 2013.

[41] F. C. Campbell, Structural composite materials, Material Parks, OH: ASM International, 2010.

[42] NPTEL, "Textile Engineering: High performance and specialty fibers, Glass Fibers," [Online]. Available: http://nptel.ac.in/courses/116102006/9. [Accessed 2016].

[43] S. K. Mazumdar, Composite manufacturing: materials, products and process engineering, Boca Raton, FL: CRC Press Taylor and Francis Group, 2002.

[44] W. W. Stinchcomb and N. E. Ashbaugh, Composite materials: fatugue and fracture, fourth volume, Philadelphia, PA: American Society for Testing and Materials, 1993.

[45] A. S. Yaghoubi, Y. X. Liu and B. M. Liaw, "Drop weight impact studies of GLARE 5 fibermetal laminates," in Experimental and Applied Mechanics, Volume 6: Proceesings of the 2011 Annual Conference on Experimental and Applied Mechanics, Uncasville, Connecticut, 2011.

[46] F. Ahmad, J.-W. Hong, H. S. Choi, S.-J. Park and M. K. Park, "The effects of stacking sequence on the penetration-resistant behaviors of T800 carbon fiber composite plates under low-velocity impact loading," Carbon Letters, vol. 16, no. 2, pp. 107-115, 2015.

[47] B. R. Blackman and J. G. Williams, "Impact and high rate testing of composites," in NATO Advanced Study Institute on the Mechanics of Composite Materials and Structures, Troia, Portugal, 1998. 
[48] G. A. Davies and X. Zhang, "Impact damage predictions in carbon composite structures," International Journal of Impact Engineering, vol. 16, no. 1, pp. 149-170, 1995.

[49] J. M. Duelle, "Impact testing of advanced composites," in Advanced Topics in Characterization of Composites, Victoria, BC, M. Kessler, Ed., Trafford, 2004, pp. 97-112.

[50] Instron, "ASTM D7136/D7136M-05 Measuring Damage Resistance of Composite to Impact Event," [Online]. Available: http://www.instron.us/en-us/testing-solutions/by-testtype/impact/astm-d7136-d7136m-05. [Accessed 20 June 2017].

[51] ASTM International, "ASTM D7136/D7136M-15 Standard Test Method for Measuring the Damage Resistance of a Fiber-Reinforced Polymer Matrix Composite to a Drop-Weight Impact Event," [Online]. Available: https://compass-astmorg.ezproxy.lib.ryerson.ca/download/D7136D7136M.34716.pdf. [Accessed 21 June 2017].

[52] B. Berk, R. Karakuzu, B. M. Icten, V. Arikan, Y. Arman, C. Atas and A. Goren, "An experimental and numerical investigation on low velocity impact behavior of composite plates," Journal of Composite Materials, vol. 50, no. 25, pp. 3551-3559, 2016.

[53] Lineo, "Technical data sheet 2016: Flaxply UD 150," SANS LINEO, Saint Martin du Tilleul, 2016.

[54] Huntsman Corporation, "Araldite® LY 1564* / Aradur® 22962*," Huntsman Advanced Materials, Basel, Switzerland, 2012.

[55] BFG Industries, "Data Sheet for Kevlar 49 Style 5500," BFG Industries, Greensboro, NC.

[56] Dupont, "Technical Guide: Kevlar Aramid Fiber," Dubont Advanced Fibers Systems, Richmond, VA. 
[57] D. Zhu and B. Mobasher, "Characterization of mechanical behaviour of Kevlar 49 fabrics," Experimental and Applied Mechanics, vol. 6, pp. 377-384, 2011.

[58] S. Manteghi, Z. Mahboob, Z. Fawaz and H. Bougherara, "Investigation of the mechanical properties and failure modes of hybrid natural fiber composites for potential bone fracture fixation plates," Journal of Mechanical Behavior of Biomedical Materials, vol. 65, pp. 306316, 2017.

[59] C. Meola and G. Carlomagno, "Impact damage in GFRP: New insights with infrared thermography," Composites: Part A, vol. 41, pp. 1839-1847, 2010.

[60] C. Meola and G. Carlomagno, "Infrared thermography to evaluate impact damage in glass/epoxy with manufacturing defects," International Journal of Impact Engineering, vol. 67, pp. 1-11, 2014.

[61] S. Boccardi, G. M. Carlomagno, G. Simeoli, P. Russo and C. Meola, "Evaluation of impactaffected areas pf glass fibre thermoplastic composites from thermographic images," Measurement Science and Technology, vol. 27, pp. 1-12, 2016.

[62] FLIR, "FLIR SC5000 Series," FLIR, 2017. [Online]. Available: http://www.flir.co.uk/cs/display/?id=42577. [Accessed 23 June 2017].

[63] T. J. Kang and C. Kim, "Impact energy absorption mechanism of largely deformable composites with different reinforcing structures," Fibers and Polymers, vol. 1, no. 1, pp. 4554, 2000.

[64] D. Liu and B. B. Raju, "Load-Displacement Curves of Glass/Epoxy Laminates Subjected to Low-Velocity Impact," in The Seventeenth Annual Technical Conference of the American Society for Composites, Lafayette, Indiana, 2002.

[65] K. B. Broberg, Cracks and Fracture, San Diego, CA: Academic Press, 1999. 
[66] H. D. Bui, Fracture Mechanics: Inverse Problems and Solutions, Netherlands: Springer, 2006.

[67] G. Perillo, N. P. Vedvik and A. T. Echtermeyer, "Numerical analyses of low velocity impacts on composite. Advanced modelling techniques," in SIMULIA Community Conference, 2012.

[68] "ImageJ," [Online]. Available: https://imagej.net/ImageJ. [Accessed 22 July 2017].

[69] M. Ravandi, W. S. Teo, L. Q. Tran, M. S. Yong and T. E. Tay, "Low velocity impact performance of stitched-flax/epoxy composite laminates," Composites Part B, vol. 117, pp. 89-100, 2017.

[70] University of Cambridge, Department of Engineering, "Material selection and processing," 25 February 2002. [Online]. Available: http://wwwmaterials.eng.cam.ac.uk/mpsite/interactive_charts/strength-toughness/NS6Chart.html. [Accessed 7 August 2017].

[71] Livermore Software Technology Corporation (LSTC), "LS-DYNA Keyword User's Manual, Volume II: Material Models," LSTC, Livermore, California, 2012.

[72] J. O. Hallquist, "LS Dyna Theory Manual," LSTC, Livermore, California, 2006.

[73] K. E. Jackson, J. D. Littel and E. L. Fasanella, "Simulating the impact response of composite airframe components," in 13th International LS-DYNA Users Conference, Dearborn, MI, 2014.

[74] M. Kiani and K. Motoyama, "Using experimental data to improve crash modelling for composite materials," Composite Materials and Joining Technologies for Composites, vol. 7, pp. 215-226, 2013. 
[75] M. Osborne, "Single-Element Characterization of LS-DYNA MAT54 Material Model: A thesis in partial fulfillment of the requirements for the degree of master of Science," University of Washington, 2012.

[76] F. Dogan, H. Hadavinia, T. Donchev and P. Bhonge, "Delamination of impacted composite structures by cohesive zone interface elements and tiebreak contact," Central European Journal of Engineering, vol. 2, no. 4, pp. 612-626, 2012.

[77] Livermore Software Technology Corporation (LSTC), "LS-DYNA Keyword User's Manual Volume I," LSTC, Livermore, California, 2007.

[78] M. Suman, "Contacts in LS-Dyna," in M.S. Ramaiah School of Advanced Studies, Bengaluru.

[79] S. Liang, L. Guillaumat and P.-B. Gning, "Impact behaviour of flax/epoxy composite plates," International Journal of Impact Engineering, vol. 80, pp. 56-64, 2015.

[80] J. Flynn, A. Amiri and C. Ulven, "Hybridized carbon and flax fiber composites for tailored performance," Materials and Design, vol. 102, pp. 21-29, 2016.

[81] K. Roy, "Numerical modelling of impact damage on carbon fiber reinforced polymer laminates: A thesis presented to Ryerson University in partial fulfillment of the requirements for the degree in Master of Applied Science," Ryerson University, Toronto, Canada, 2012.

[82] F. Sarasini, J. Tirillo, S. D'Altilia, T. Valente, C. Santulli, F. Touchard, L. Chocinski-Arnault, D. Mellier, L. Lampani and P. Guadenzi, "Damage tolerance of carbon/flax hybrid composites subject to low velocity impact," Composites Part B, vol. 91, pp. 144-153, 2016.

[83] Baker, A, S. Dutton and D. Kelly, Composite materials for aircraft structures, Reston, VA: American Institute of Aeronautics and Astronautics, 2004. 